\title{
Numerical analysis of the fire resistance of circular and elliptical slender concrete filled tubular columns
}

ANA ESPINÓS CAPILLA 



\section{UNIVERSITAT POLITÈCNICA DE VALÈNCIA}
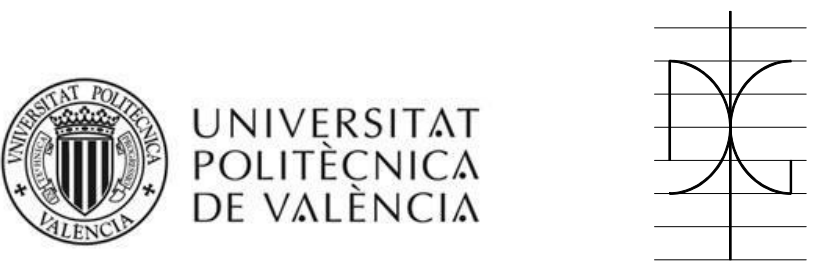

\section{DEPARTMENT OF CONSTRUCTION ENGINEERING AND CIVIL ENGINEERING PROJECTS}

\section{Numerical analysis of the fire resistance of circular and elliptical slender concrete filled tubular columns}

Thesis submitted in partial fulfillment of the requirements for the degree of Doctor of Philosophy

by

\section{Ana Espinós Capilla}

Advisors:

Dr. Manuel L. Romero García

Dr. Antonio Hospitaler Pérez

Valencia (Spain), October 2012 
First Edition, 2013

\section{(c) Ana Espinós Capilla}

(c) of the present edition:

Editorial Universitat Politècnica de València

www.editorial. upv.es

ISBN: 978-84-9048-073-1 (printed version)

Any unauthorized copying, distribution, marketing, editing, and in general any other exploitation, for whatever reason, of this piece of work or any part thereof, is strictly prohibited without the authors' expressed and written permission. 


\section{Acknowledgements}

In first place, I would like to express my sincere gratitude to my supervisors Dr. Manuel L. Romero and Dr. Antonio Hospitaler for guiding me throughout my doctoral period and for their expert opinions, which have made the consecution of this thesis possible.

I also wish to thank my colleagues from Universitat Politècnica de València for making this constant work easier: Ana, Andrés, Carmen and Toni, thanks for creating a good atmosphere at the office. This gratitude is also extensive to the people from the Department of Construction Engineering and Civil Engineering Projects and ICITECH.

Particular thanks are owed to Cesar Lacuesta for his wise advice during my first incursions in the finite element modelling. I would also like to give special thanks to our laboratory technician Enrique Serra for his hard work during the fire testing programme, which has been partially used in this thesis to support the development of the numerical model.

I would also like to extend this acknowledgement to the people from AIDICO for their much appreciated efforts, especially to Vicente Moliner, for taking care of the good progress of the fire testing programme.

Another big thank you goes to Dr. Leroy Gardner for inviting me to join a leading institution as Imperial College London during part of my doctoral period and for his guidance during my stay there, where I had the pleasure to collaborate with one of the world's biggest experts in the field of steel structures. I take this opportunity to thank also my colleagues from that period in the Department of Civil and Environmental Engineering at Imperial College London.

Last but not least, I would like to give special thanks to my family and friends for their continuous support and understanding, this thesis is in part yours.

Ana Espinós Capilla

Valencia, October 2012 



\section{Abstract}

Concrete filled tubular (CFT) columns have become increasingly used in recent decades, due to their excellent structural performance, which takes advantage of the combined effect of steel and concrete working together. This association provides a series of advantages which make CFT columns an interesting solution: high load-bearing capacity or efficient construction technology can be cited amongst their widely known benefits, which are completed with a high fire resistance without the need of external protection.

Circular, square and rectangular hollow sections have been traditionally used to form these composite columns. Additionally, elliptical shapes have been recently introduced to the range of commercially available steel hollow sections. Their aesthetic appeal and reduced visual intrusion, combined with their structural advantages associated with sections of differing major and minor axis properties, make elliptical sections of great interest for designers. In this thesis, both circular and elliptical CFT columns are studied.

Although the behaviour of CFT columns at room temperature has been well established in the last years, in the fire situation the degradation of the material properties gives rise to an extremely nonlinear behaviour of these composite columns, which makes it difficult to predict their failure. The state of the research in the field of the fire behaviour of CFT columns is reviewed in this thesis, showing that further investigation is needed for a complete understanding of the performance of such columns in the fire situation. In the case of the elliptical sections, this work constitutes a novel investigation.

The fire behaviour of CFT columns is studied in this thesis by means of a realistic three-dimensional finite element model. The adopted values of the parameters of the model are a result of an extensive sensitivity analysis. The accuracy of the numerical model is verified against experimental results and, by means of the validated model, parametric studies are carried out in order to assess the influence of the main factors affecting their fire behaviour and to develop a simple calculation model for predicting the buckling resistance of CFT columns in the fire situation. The proposed simple calculation model is based on the general rules of Eurocode 4 Part 1.2 and has proved to provide a good estimation of the fire resistance of CFT columns as compared with real fire tests, as well as against the existing calculation methods which can be found in the design codes.

The scope of this thesis is restricted to unprotected CFT columns filled with normal strength concrete and subjected to concentric axial loads. 



\section{Resumen}

El empleo de pilares tubulares de acero rellenos de hormigón (CFT) ha crecido en las últimas décadas, debido a su excelente comportamiento estructural, que aprovecha el efecto combinado del acero y hormigón trabajando juntos. Esta asociación ofrece una serie de ventajas que hacen de las columnas CFT una solución interesante: su alta capacidad portante o su eficiente tecnología constructiva pueden citarse entre sus beneficios ampliamente conocidos, que se completan con una elevada resistencia al fuego sin necesidad de protección externa.

Tradicionalmente, se han venido utilizando secciones huecas circulares, cuadradas y rectangulares para formar estas columnas compuestas. Adicionalmente, la sección elíptica ha sido recientemente introducida dentro de la gama de secciones de acero huecas disponibles comercialmente. Su atractivo estético y su reducida intrusión visual, junto con sus ventajas estructurales asociadas a secciones con diferentes propiedades en sus ejes fuerte y débil, hacen a las secciones elípticas de gran interés para los diseñadores. En esta tesis se estudian pilares CFT de sección tanto circular como elíptica.

Pese a que el comportamiento de los pilares CFT a temperatura ambiente ha quedado bien establecido en los últimos años, en situación de incendio la degradación de las propiedades del material da lugar a un comportamiento extremadamente no lineal de estas columnas compuestas, lo que hace difícil predecir su fallo. El estado del arte en el campo del comportamiento frente al fuego de columnas CFT se revisa en esta tesis, mostrando que es necesario profundizar en su investigación para una comprensión completa del funcionamiento de tales columnas en situación de incendio. En el caso de las secciones elípticas, este trabajo constituye una investigación novedosa.

El comportamiento frente al fuego de los pilares CFT se estudia en esta tesis por medio de un modelo realista tridimensional de elementos finitos. Los valores adoptados de los parámetros del modelo son el resultado de un extenso análisis de sensibilidad. La precisión del modelo numérico se verifica con resultados experimentales $\mathrm{y}$, mediante el modelo validado, se llevan a cabo estudios paramétricos con el fin de evaluar la influencia de los principales factores que afectan a su comportamiento frente al fuego y para desarrollar un modelo simplificado de cálculo que permita predecir la resistencia a pandeo de pilares CFT en situación de incendio. El modelo propuesto se basa en los principios generales del Eurocódigo 4 Parte 1.2 y ha demostrado proporcionar una buena estimación de la resistencia al fuego de pilares CFT, en comparación con ensayos de fuego reales, así como frente a los actuales métodos de cálculo que se pueden encontrar en los diferentes códigos de diseño.

El alcance de esta tesis queda limitado a pilares CFT sin protección externa, rellenos de hormigón de resistencia normal y sometidos a carga axial centrada. 



\section{Resum}

L'ús de pilars tubulars d'acer omplerts de formigó (CFT) ha crescut en les últimes dècades, a causa del seu excel-lent comportament estructural, que aprofita l'efecte combinat de l'acer i formigó treballant junts. Aquesta associació ofereix una sèrie d'avantatges que fan de les columnes CFT una solució interessant: la seva alta capacitat portant o la seva eficient tecnologia constructiva poden citar-se entre els seus beneficis àmpliament coneguts, que es completen amb una elevada resistència al foc sense necessitat de protecció externa.

Tradicionalment, s'han utilitzat seccions buides circulars, quadrades i rectangulars per formar aquestes columnes compostes. Addicionalment, la secció el·líptica ha estat recentment introduïda dins de la gamma de seccions d'acer buides disponibles comercialment. El seu atractiu estètic i la seva reduïda intrusió visual, juntament amb els seus avantatges estructurals associats a seccions amb diferents propietats en els seus eixos fort i feble, fan a les seccions el-líptiques de gran interès per als dissenyadors. En aquesta tesi s'estudien pilars CFT de secció tant circular com el-líptica.

Tot i que el comportament dels pilars CFT a temperatura ambient ha quedat ben establert en els últims anys, en situació d'incendi la degradació de les propietats del material dóna lloc a un comportament extremadament no lineal d'aquestes columnes compostes, el que fa difícil predir el seu col-lapse. L'estat de l'art en el camp del comportament enfront al foc de columnes CFT es revisa en aquesta tesi, mostrant que cal aprofundir en la seva investigació per a una comprensió completa del funcionament d'aquestes columnes en situació d'incendi. En el cas de les seccions el-líptiques, aquest treball constitueix una recerca novedosa.

El comportament davant del foc dels pilars CFT s'estudia en aquesta tesi per mitjà d'un model realista tridimensional d'elements finits. Els valors adoptats dels paràmetres del model són el resultat d'una extensa anàlisi de sensibilitat. La precisió del model numèric es verifica amb resultats experimentals $i$, per mitjà del model validat, estudis paramètrics es duen a terme per tal d'avaluar la influència dels principals factors que afecten al seu comportament davant del foc i per desenvolupar un model simplificat de càlcul el qual permeta predir la resistència a vinclament de pilars CFT en situació d'incendi. El model proposat es basa en els principis generals de l'Eurocodi 4 Part 1.2 i ha demostrat proporcionar una bona estimació de la resistència al foc de pilars CFT, en comparació amb assajos de foc reals, així com davant els actuals mètodes de càlcul que es poden trobar en els diferents codis de disseny.

L'abast d'aquesta tesi queda limitat a pilars CFT sense protecció externa, omplerts de formigó de resistència normal i sotmesos a càrrega axial centrada. 



\section{MOTIVATION AND OUTLINE OF THIS THESIS}

This thesis falls within the framework of the research line on the fire behaviour of composite structures set up by Dr. Hospitaler and Dr. Romero at the Universitat Politècnica de València. At the same time, this work constitutes a continuation of the investigations of other $\mathrm{PhD}$ students from the same research group, who have studied the behaviour of concrete filled tubular (CFT) columns at room temperature.

Although this work was initially devoted to the study of the fire response of CFT columns of circular section, giving as a result the publication of the first article which forms part of this thesis, it was later on decided to include in this investigation the more innovative elliptical hollow sections.

The idea came motivated by the stay of the author of this thesis at Imperial College London (UK) during the doctoral period, where it was found interesting to join the acquired knowledge of the author on fire modelling of composite structures with that from the group leaded by Dr. Gardner, who had previously investigated the structural behaviour of elliptical hollow sections at room temperature. The work of the second article included in this thesis on the fire behaviour of concrete filled elliptical steel columns is the result from that collaboration.

Once the fire behaviour of CFT columns of circular and elliptical section had been well established through numerical modelling, it was decided to conduct further research on the proposal of design guidance, as an intend to contribute to the work of the Ad-hoc group for the development of the new EN 1994-1-2 Annex H from CEN/TC250/SC4 in which Dr. Romero is involved. In that line came the publication of the third article integrated in this thesis, which presents a simple calculation model for evaluating the fire resistance of unreinforced CFT columns of circular section, and which has been afterwards extended in complementary work included in this thesis to be valid for elliptical sections and columns with reinforcement.

This thesis is structured as a compendium of publications, being organized around three articles which have been published in scientific journals throughout the doctoral period of the author and which compose the core of this work. Although due to the nature of the document, which is a compendium rather than a monograph, this thesis may appear fragmented, its structure is a proof of the scientific productivity of the work included on it and, in any case, it has been tried to make it more intelligible to the reader by means of adding all the supplementary work which was found necessary for its completeness. 
The document starts with an introductory part in Chapters 1, 2 and 3. In Chapter 1, a comprehensive description of the theoretical background needed for the characterization of the fire behaviour of concrete filled tubular columns is given. Chapter 2 reviews the current state of the research in this field, covering analytical, numerical and experimental investigations, as well as the available design guidance. In Chapter 3, the aim and scope of this thesis is established.

Chapters 4, 5 and 6 make up the main part of this thesis and include the work published in the three articles, extended with more recent advances and complementary work.

Chapter 4 describes in detail the characteristics of the finite element model for predicting the fire behaviour of concrete filled circular hollow section (CFCHS) columns developed by the author, as well as the process for its validation and the sensitivity analysis performed for the selection of the appropriate values of the different parameters involved in the model.

Chapter 5 presents a work on the fire behaviour of concrete filled elliptical hollow section (CFEHS) columns, where the numerical model initially developed for circular columns is extended to the elliptical sections, in order to cover the current lack of knowledge in the fire performance of this novel shapes and to compare the relative effectiveness of both geometries in the fire situation.

Chapter 6 presents the currently available design methods and studies their accuracy. By means of the validated numerical model, parametric studies are carried out and, through the analysis and processing of their results, a new proposal is developed for the calculation of the fire resistance of CFT columns subjected to concentric axial load, based on the general rules in Eurocode 4 Part 1.2.

Finally, Chapter 7 presents the major conclusions drawn from this work and gives some suggestions on future research lines.

The three articles published in relation to this thesis are included in Annex I "Compendium of publications" at the end of the document, in their pre-print version (due to copyright restrictions). In addition, Annex II "Material constitutive modelling" includes the formulation of the different material models at elevated temperatures which are used throughout this thesis.

The details of the three articles which compose this compendium of publications are the following: 
Article 1

"Advanced model for predicting the fire response of concrete filled tubular columns"

Ana Espinos, Manuel L. Romero, Antonio Hospitaler

Journal of Constructional Steel Research 66 (2010) 1030-1046

Article 2

"Fire behaviour of concrete filled elliptical steel columns"

Ana Espinos, Leroy Gardner, Manuel L. Romero, Antonio Hospitaler

Thin-Walled Structures 49 (2011) 239-255

Article 3

"Simple calculation model for evaluating the fire resistance of unreinforced concrete filled tubular columns"

Ana Espinos, Manuel L. Romero, Antonio Hospitaler

Engineering Structures 42 (2012) 231-244 



\section{TABLE OF CONTENTS}

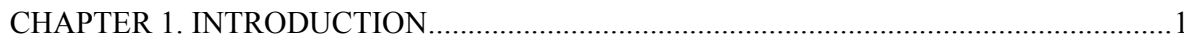

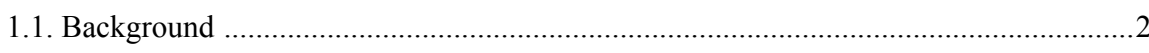

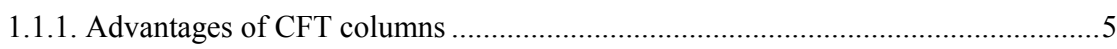

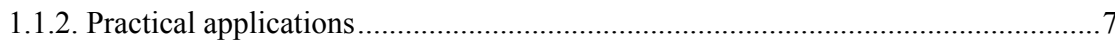

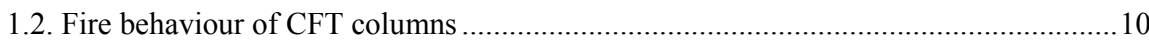

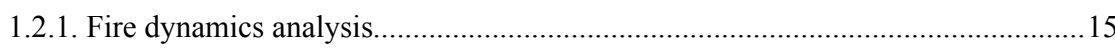

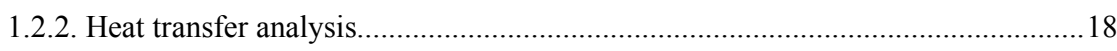

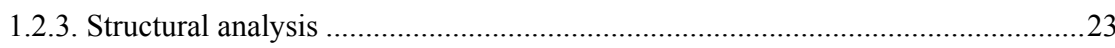

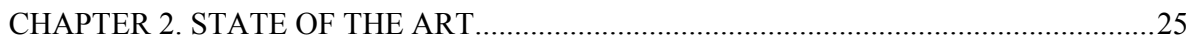

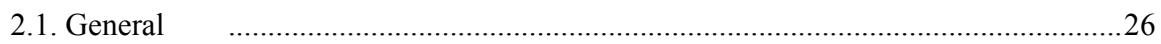

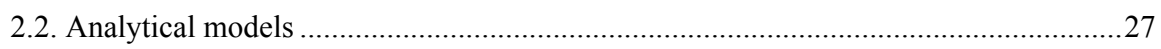

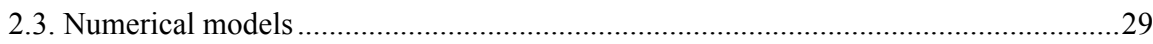

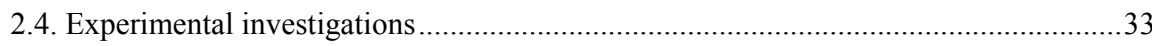

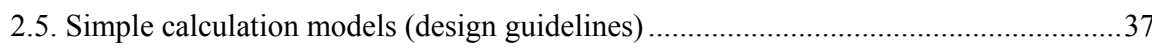

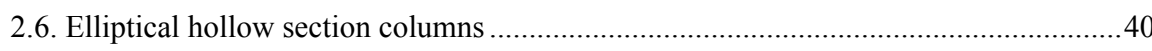

CHAPTER 3. AIM AND SCOPE OF THIS THESIS ............................................................... 43

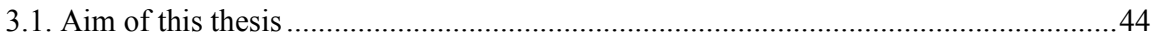

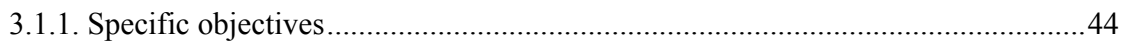

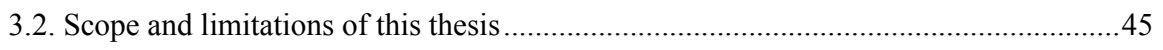

CHAPTER 4. DEVELOPMENT OF THE NUMERICAL MODEL .......................................47

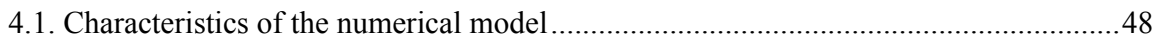

4.1.1. Geometry and finite element mesh of the model ...............................................48

4.1.2. Material properties at elevated temperatures .................................................50

4.1.2.1. Thermal properties at elevated temperatures ............................................50

4.1.2.2. Concrete material model at elevated temperatures ........................................51

4.1.2.3. Steel material model at elevated temperatures .............................................57 
4.1.3. Initial geometric imperfection of the column ................................................... 59

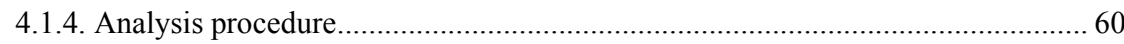

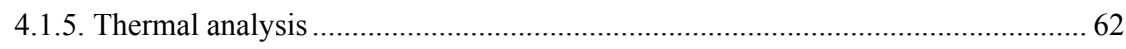

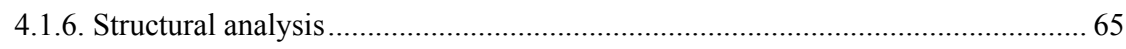

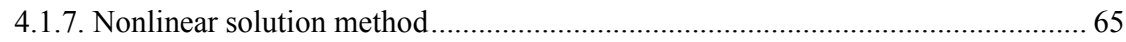

4.1.8. Thermal and mechanical contact at the steel-concrete interface ......................... 66

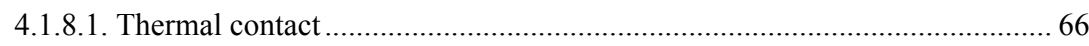

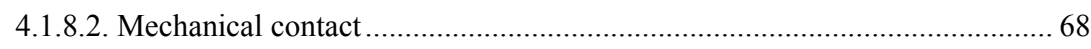

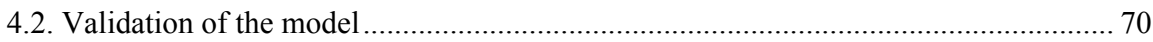

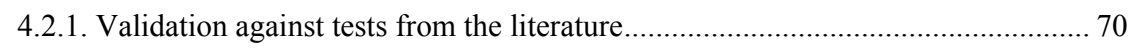

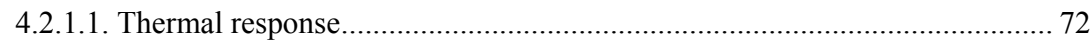

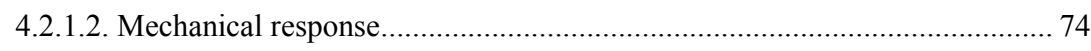

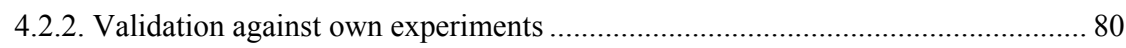

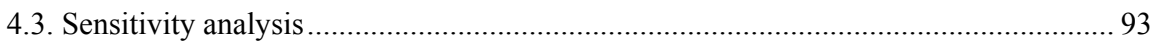

4.3.1. Steel-concrete interface friction model ........................................................... 93

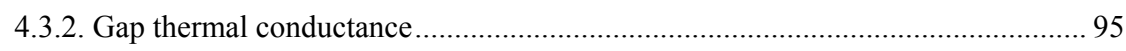

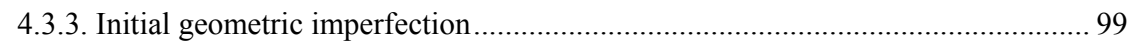

4.3.4. Material mechanical models at elevated temperatures ........................................ 99

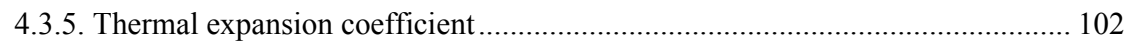

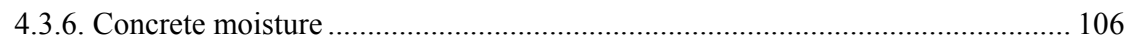

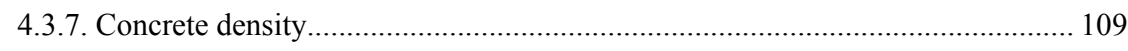

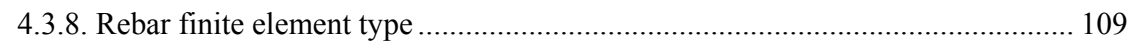

CHAPTER 5. CONCRETE FILLED ELLIPTICAL STEEL COLUMNS .......................... 111

5.1. Concrete filled elliptical hollow section columns at room temperature..................... 112

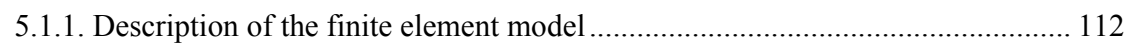

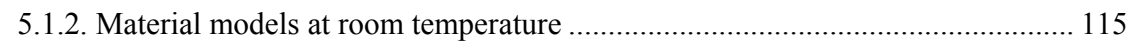

5.1.3. Comparison between numerical and experimental results ............................... 116 
5.1.4. Findings from the finite element modelling .118

5.2. Concrete filled elliptical hollow section columns exposed to fire 119

5.2.1. Description of the finite element model 119

5.2.2. Material models at elevated temperatures. 121

5.2.3. Analysis procedure 122

5.2.3.1. Thermal analysis 122

5.2.3.2. Structural analysis 122

5.2.4. Validation of the model for CFEHS columns at elevated temperatures 123

5.3. Parametric studies 125

5.3.1. Analysis cases. 125

5.3.2. Effect of column slenderness. 130

5.3.3. Effect of load level 131

5.3.4. Effect of cross-section slenderness 131

5.3.5. Effect of section size 133

5.4. Comparison between elliptical and circular CFT columns in fire 134

CHAPTER 6. DEVELOPMENT OF A SIMPLE CALCULATION MODEL 139

6.1. Review of existing design guidance. 140

6.1.1. Simple calculation model in Annex H of EN 1994-1-2 . 140

6.1.2. General method for composite columns in Clause 4.3.5.1 of EN 1994-1-2........142

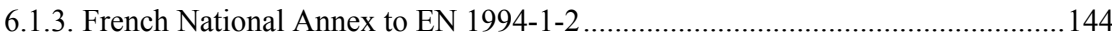

6.1.4. Simplified design equation proposed by Kodur................................................. 145

6.1.5. Strength index formulation proposed by Han et al. ........................................... 146

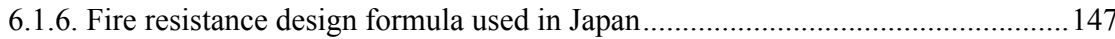

6.2. Evaluation of the current calculation methods in Eurocode 4 ................................... 148

6.3. Development of a new simple calculation model for axially loaded CFT columns ...152

6.3.1. Parametric studies 152

6.3.1.1. Analysis of results 155 


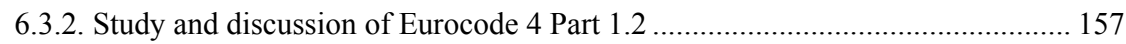

6.3.3. Simplified cross-sectional temperature field ................................................. 160

6.3.4. Flexural stiffness reduction coefficients.................................................... 167

6.3.5. Comparison of the proposed method with experiments ................................. 178

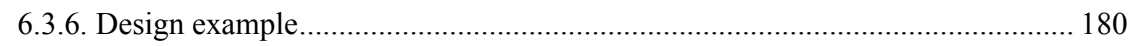

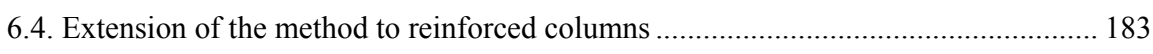

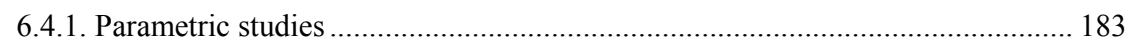

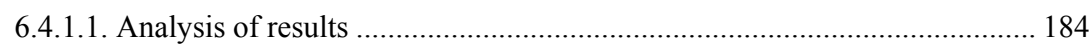

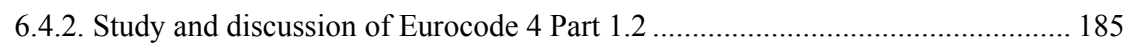

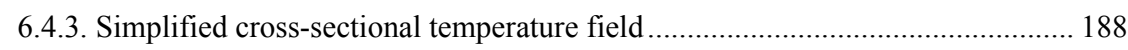

6.4.4. Flexural stiffness reduction coefficients.......................................................... 191

6.4.5. Comparison of the proposed method with experiments .................................. 194

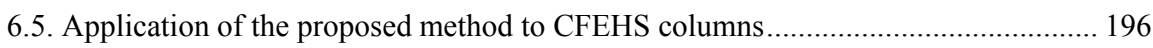

6.5.1. Simplified cross-sectional temperature field ................................................... 197

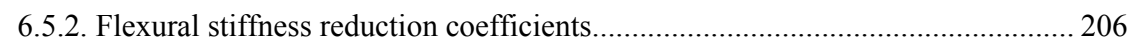

6.5.3. Comparison of the proposed method with experiments .................................. 211

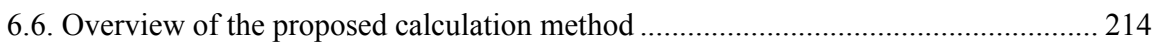

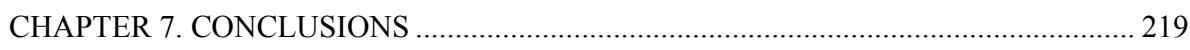

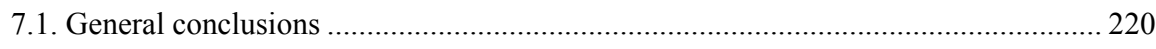

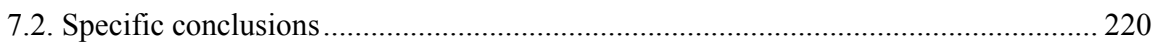

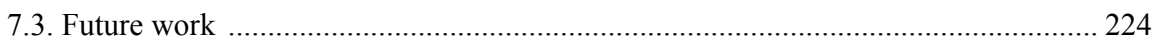

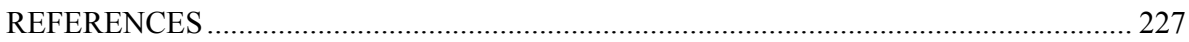

ANNEX I. COMPENDIUM OF PUBLICATIONS

ANNEX II. MATERIAL CONSTITUTIVE MODELLING 


\section{LIST OF FIGURES}

Figure 1.1. Typical CFT sections. 3

Figure 1.2. Elliptical hollow sections used in T4 terminal of Barajas Airport (Madrid, Spain).4

Figure 1.3. Enhancement achieved by filling steel hollow section columns with concrete: a) compressive capacity, b) fire resistance (Zhao et al. 2010). 6

Figure 1.4. Some examples of construction with CFT columns.............................................

Figure 1.5. Typical behaviour of a CFT column subjected to elevated temperatures. 11

Figure 1.6. Effect of using different types of concrete filling on the fire resistance of CFT columns (Kodur \& MacKinnon 2000, Kodur 2007)

Figure 1.7. Evolution of the strength of the different components of a CFT column. .13

Figure 1.8. Different stages in the evolution of a fire .15

Figure 1.9. Different types of fire curve. .17

Figure 1.10. Arrangement of layers in the cross-section (Lie 1994). .22

Figure 1.11. Example of the application of Lie's method to obtain the temperature distribution in a $141 \times 6.5 \mathrm{~mm}$ circular CFT column. .22

Figure 1.12. Schematic view of the load-deflection analysis (Lie 1994)................................23

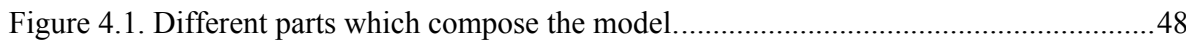

Figure 4.2. Details of the assembly of the different parts of the model...................................49

Figure 4.3. Different types of finite elements used in the model (ABAQUS 2010)...............49

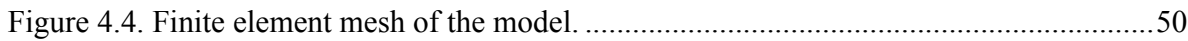

Figure 4.5. Yield surfaces in the meridional plane: a) linear model, b) hyperbolic model, c)

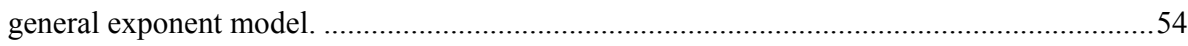

Figure 4.6. Typical yield/flow surfaces in the deviatoric plane..............................................55

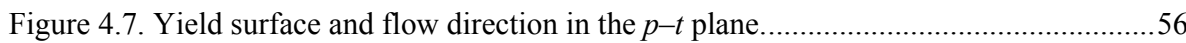

Figure 4.8. Stress-strain curves at elevated temperatures for a $30 \mathrm{MPa}$ concrete, obtained from

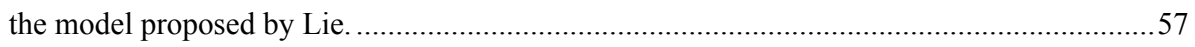

Figure 4.9. Von Mises yield criterion in the three-dimensional principal stress space.............58

Figure 4.10. Stress-strain curves at elevated temperatures for a S275 steel, obtained from the EC3 model. 
Figure 4.11. Shape of the initial imperfection applied to the columns. 60

Figure 4.12. Scheme of the analysis procedure. 61

Figure 4.13. Specific heat and latent heat definition. 63

Figure 4.14. Gap conductance as a function of clearance or contact pressure. 68

Figure 4.15. Pressure-overclosure relationship. 69

Figure 4.16. Slip regions for the Coulomb friction model. 70

Figure 4.17. Deformed shape after exposure to standard fire, for column C-04 (compared with Lie \& Chabot 1992). 72

Figure 4.18. Comparison between measured and predicted temperatures for column C-02... 73

Figure 4.19. Axial displacement and axial force ratio versus time, for column C-11. .75

Figure 4.20. Comparison of measured and predicted axial displacement. .76

Figure 4.21. Comparison of measured and predicted axial displacement with different supporting conditions, for column C-06. .77

Figure 4.22. Comparison of fire resistance rating between the numerical predictions and the test results from NRCC 79

Figure 4.23. Comparison of maximum axial displacement between the numerical predictions and the test results from NRCC. 80

Figure 4.24. Deformed shape after exposure to standard fire, for column C159-6-3-30-0-20 (compared with Romero et al. 2011)..... 82

Figure 4.25. Axial displacement versus time curve, C159-6-3-30-0-20. 83

Figure 4.26. Comparison of fire resistance rating between calculated and test results, own tests filled with normal strength concrete. 84

Figure 4.27. Comparison of maximum axial displacement between calculated and test results, own tests filled with normal strength concrete. . 85

Figure 4.28. Force and stress distribution in the failure section, C159-6-3-30-0-20 .............. 86

Figure 4.29. Force and stress distribution in the failure section, C159-6-3-30-0-60. .87

Figure 4.30. Stress distribution in the concrete core, C159-6-3-30-0-20. 89

Figure 4.31. Stress distribution in the concrete core, C159-6-3-30-0-60. 89

Figure 4.32. Distribution of longitudinal stresses, column C159-6-3-30-0-20. 90 
Figure 4.33. Distribution of longitudinal stresses in the column upper section, column C1596-3-30-0-20.

Figure 4.34. Comparison of measured and predicted axial displacement with different friction models. . .94

Figure 4.35. Comparison of measured and predicted axial displacement with different friction coefficients, for column C-05. .95

Figure 4.36. Comparison between measured and predicted temperatures with different gap conductance values, for column C-02.

Figure 4.37. Comparison of measured and predicted axial displacement with different gap conductance values. . .98

Figure 4.38. Comparison of measured and predicted axial displacement with different initial imperfections. .100

Figure 4.39. Comparison of measured and predicted axial displacement with different steel models. 101

Figure 4.40. Comparison of measured and predicted axial displacement with different concrete models. 103

Figure 4.41. Comparison of measured and predicted axial displacement with different steel expansion models. 104

Figure 4.42. Comparison of measured and predicted axial displacement with different concrete expansion models. 105

Figure 4.43. Comparison between measured and predicted temperatures with different moisture values, for column C-02. 106

Figure 4.44. Comparison of measured and predicted axial displacement with different moisture values.

Figure 4.45. Comparison between measured and predicted temperatures with different moisture values, for column C-31. .108

Figure 4.46. Comparison of measured and predicted axial displacement with different concrete density models.

Figure 4.47. Comparison of measured and predicted axial displacement with different rebar element types, for column C-48. 110

Figure 5.1. Three-dimensional finite element model for CFEHS stub columns. 112 
Figure 5.2. Comparison of experimental and numerical results with different steel tube meshes, $150 \times 75 \times 4$ C 30 . 113

Figure 5.3. Comparison of experimental and numerical results with different friction coefficients, $150 \times 75 \times 4$ _C 30 ... 114

Figure 5.4. Comparison of experimental and numerical results, for $150 \times 75 \times 4 \mathrm{~mm}$ columns.

Figure 5.5. Different failure modes obtained from the FEA of the stub columns. 119

Figure 5.6. Typical finite element mesh of the model for slender CFEHS columns in fire. . 121

Figure 5.7. Comparison of measured and predicted axial displacement, column E220-110-123-30-50-20. 124

Figure 5.8. Deformed shape after fire exposure, $300 \times 150 \times 12.5 \mathrm{~mm}, L=2 \mathrm{~m}, \mu=0.2 \ldots \ldots . .126$

Figure 5.9. Axial displacement versus time curves

Figure 5.10. Effect of the relative slenderness on the fire resistance rating of the columns. 130

Figure 5.11. Effect of the load level on the fire resistance rating of the columns. 131

Figure 5.12. Effect of the cross-sectional slenderness on the fire resistance rating of the columns.

Figure 5.13. Effect of the section factor on the fire resistance rating of the columns. 133

Figure 5.14. Comparison of the cross-sectional temperature field between CFCHS $219.95 \times 10$ $\mathrm{mm}$ and CFEHS $300 \times 150 \times 10 \mathrm{~mm}$, after 90 minutes of fire exposure.

Figure 5.15. Comparison of the cross-sectional temperature evolution between circular and elliptical columns for different exposure times. 136

Figure 5.16. Comparison between elliptical and circular columns for different lengths and load levels. 138

Figure 6.1. Procedure for obtaining the fire buckling resistance of the column with the method in Annex H (Wang 2005). 141

Figure 6.2. Comparison of the Eurocode 4 predictions with the tests. 151

Figure 6.3. Process for obtaining the buckling resistance of the columns at the different standard fire periods. 154

Figure 6.4. Evolution of the buckling coefficient with the relative slenderness at elevated temperature (neglecting the flexural stiffness reduction coefficients). 155 
Figure 6.5. Evolution of the buckling coefficient with the relative slenderness at elevated temperature (with French coefficients). . .156

Figure 6.6. Comparison between the different approaches studied in terms of the normalised buckling resistance: a) EC4(1), b) EC4(2), c) EC4(H), d) EC4(NF). .158

Figure 6.7. Evolution of the prediction errors with the relative slenderness of the columns, for the different approaches studied: a) EC4(1), b) EC4(2), c) EC4(H), d) EC4(NF).

Figure 6.8. Evolution of the equivalent temperature of the concrete core with the section factor, for the standard fire resistance classes.

Figure 6.9. Comparison between predicted and simulated equivalent temperatures for the concrete core. 164

Figure 6.10. Evolution of the equivalent temperature of the steel tube with the section factor, for the standard fire resistance classes. 165

Figure 6.11. Comparison between predicted and simulated equivalent temperatures for the steel tube. 166

Figure 6.12. Comparison between the proposed method (design equation) and numerical simulations: a) Normalised buckling load, b) Relative error. 171

Figure 6.13. Evolution of the buckling coefficient with the relative slenderness at elevated temperature, calculated with the proposed method (design equation).

Figure 6.14. Frequency histogram for the prediction error obtained with the proposed method (design equation). .173

Figure 6.15. Comparison between the proposed method (tabulated data) and numerical simulations: a) Normalised buckling load, b) Relative error.

Figure 6.16. Evolution of the buckling coefficient with the relative slenderness at elevated temperature, calculated with the proposed method (tabulated data). 176

Figure 6.17. Frequency histogram for the prediction error obtained with the proposed method (tabulated data) .177

Figure 6.18. Comparison of ultimate loads between the proposed method and tests. 179

Figure 6.19. Comparison of ultimate loads between the proposed method, other methods and tests. 180

Figure 6.20. Evolution of the buckling coefficient with the relative slenderness at elevated temperature, for different reinforcement ratios. 185 
Figure 6.21. Comparison between the different approaches studied in terms of the normalised buckling resistance: a) EC4(1), b) EC4(2), c) EC4(H), d) EC4(NF). Reinforced columns with $2.5 \%$ reinforcement ratio. 186

Figure 6.22. Evolution of the prediction errors with the relative slenderness of the columns, for the different approaches studied: a) $\mathrm{EC} 4(1)$, b) $\mathrm{EC} 4(2)$, c) $\mathrm{EC} 4(\mathrm{H})$, d) $\mathrm{EC} 4(\mathrm{NF})$. Reinforced columns with $2.5 \%$ reinforcement ratio. 187

Figure 6.23. Evolution of the equivalent temperature of the reinforcing bars with the section factor, for the standard fire resistance classes. 189

Figure 6.24. Comparison between predicted and simulated equivalent temperatures for the reinforcing bars. 190

Figure 6.25. Comparison between the predictions and numerical simulations for reinforced columns, in terms of normalised buckling load. Tabulated data, $2.5 \%$ reinforcement ratio. 193 Figure 6.26. Evolution of the buckling coefficient with the relative slenderness at elevated temperature, for reinforced columns. Tabulated data, $2.5 \%$ reinforcement ratio. 194

Figure 6.27. Comparison of ultimate loads between the proposed method for reinforced columns and tests. 195

Figure 6.28. Comparison of ultimate loads between the proposed method for reinforced columns, Kodur formula and tests. 196

Figure 6.29. Evolution of the equivalent temperature of the concrete core with the section factor, for the standard fire resistance classes. 198

Figure 6.30. Evolution of the equivalent temperature of the steel tube with the section factor, for the standard fire resistance classes. 198

Figure 6.31. Evolution of the equivalent temperature of the reinforcing bars with the section factor, for the standard fire resistance classes. 203

Figure 6.32. Comparison between the predictions and numerical simulations for CFEHS columns, in terms of normalised buckling load.

Figure 6.33. Evolution of the buckling coefficient with the relative slenderness at elevated temperature, for CFEHS columns. 211

Figure 6.34. Comparison of ultimate loads between the proposed method and tests, for CFEHS columns. 213 


\section{LIST OF TABLES}

Table 4.1. List of CFT columns analysed from the literature (Chabot \& Lie 1992, Lie \& Chabot 1992).

Table 4.2. Predicted and measured FRR and maximum axial displacement, Canadian tests ..78

Table 4.3. List of CFT columns analysed, own tests, NSC (Romero et al. 2011) .81

Table 4.4. Predicted and measured FRR and maximum axial displacement, own tests (normal strength concrete) .83

Table 5.1. List of room temperature CFEHS stub columns analysed from Yang et al. (2008)

Table 5.2. Measured and predicted maximum axial loads 118

Table 5.3. List of CFEHS columns tested at elevated temperatures 124

Table 5.4. Predicted and measured FRR, tests for CFEHS columns 125

Table 5.5. List of CFEHS columns exposed to fire analysed in the parametric studies 127

Table 5.6. List of CFCHS columns equivalent to the previously analyzed CFEHS columns 134

Table 6.1. Comparison of the buckling resistance at the time of failure between Eurocode 4 and experiments, Canadian tests

Table 6.2. Comparison of the buckling resistance at the time of failure between Eurocode 4 and experiments, own tests (Romero et al. 2011). 150

Table 6.3. Summary of the analysis cases in the parametric studies 153

Table 6.4. Values of the equivalent temperatures for concrete $\left(\theta_{c, e q}\right)$ and steel $\left(\theta_{a, e q}\right)$ in function of the section factor 164

Table 6.5. Values of the partial reduction coefficient for steel $\varphi_{a, \theta 1}$ to include in the design equation for stocky columns $\left(\ell_{\theta} / D \leq 12\right)$ 170

Table 6.6. Values of the reduction coefficient for steel $\varphi_{a, \theta}$ (tabulated method) 174

Table 6.7. Summary of the analysis cases in the parametric studies, reinforced columns.....184 Table 6.8. Values of the equivalent temperatures for the reinforcing bars $\left(\theta_{s, e q}\right)$ in function of the section factor 189

Table 6.9. Summary of the errors in the prediction of the buckling resistance for reinforced columns 192 
Table 6.10. Summary of the proposed buckling curve and reduction coefficient of the reinforcing bars. 193

Table 6.11. Values of the equivalent temperatures for concrete $\left(\theta_{c, e q}\right)$ and steel $\left(\theta_{a, e q}\right)$ in function of the section factor, for CFEHS columns.... 199

Table 6.12. Prediction errors obtained for the equivalent temperature of concrete. 200

Table 6.13. Prediction errors obtained for the equivalent temperature of steel 202

Table 6.14. Values of the equivalent temperatures for the reinforcing bars $\left(\theta_{s, e q}\right)$ in function of the section factor, for CFEHS columns 204

Table 6.15. Prediction errors obtained for the equivalent temperature of the reinforcing bars 205

Table 6.16. Summary of the errors in the prediction of the buckling resistance for CFEHS columns 207

Table 6.17. Values of the reduction coefficient for steel $\varphi_{a, \theta}$ (tabulated method) 208

Table 6.18. Summary of the errors in the prediction of the buckling resistance for CFEHS columns

Table 6.19. Summary of the results in the prediction of the fire buckling load, for column E220-110-12-3-30-00-20 212

Table 6.20. Values of the equivalent temperatures for concrete $\left(\theta_{c, e q}\right)$ and steel $\left(\theta_{a, e q}\right)$ in function of the section factor, for CFCHS columns..... 215

Table 6.21. Values of the equivalent temperatures for the reinforcing bars $\left(\theta_{s, e q}\right)$ in function of the section factor, for CFCHS columns 215

Table 6.22. Values of the equivalent temperatures for concrete $\left(\theta_{c, e q}\right)$ and steel $\left(\theta_{a, e q}\right)$ in function of the section factor, for CFEHS columns..... 216

Table 6.23. Values of the equivalent temperatures for the reinforcing bars $\left(\theta_{s, e q}\right)$ in function of the section factor, for CFEHS columns 216

Table 6.24. Values of the partial reduction coefficient for steel $\varphi_{a, \theta 1}\left(\ell_{\theta} / D \leq 12\right)$. 217

Table 6.25. Values of the reduction coefficient for steel $\varphi_{a, \theta}$ 217

Table 6.26. Buckling curve and reduction coefficient of the reinforcing bars 217 


\section{NOTATION}

\section{Latin upper case letters}

$A_{a, \theta} \quad$ Cross-sectional area of the steel profile at the temperature $\theta$

$A_{c, \theta} \quad$ Cross-sectional area of the concrete at the temperature $\theta$

$A_{m} / V \quad$ Section factor

$B$

Outer dimension of a square section

$D$

Outer diameter of a circular section

$D_{e}$

Equivalent diameter for an elliptical section

$E_{a, \theta}$

Modulus of elasticity of steel at the temperature $\theta$

$E_{c, \theta}$

Tangent modulus of concrete at the temperature $\theta$

$E_{c, s e c, \theta}$

Secant modulus of concrete at the temperature $\theta$

$(E I)_{f i, e f f}$

Effective flexural stiffness in the fire situation

$I_{a, \theta}$

Second moment of area of the steel profile at the temperature $\theta$

$I_{c, \theta}$

Second moment of area of the concrete at the temperature $\theta$

$L$

Length of the column

N

Applied axial load

$N_{f i, c r}$

Elastic critical load in the fire situation

$N_{f i, p l, R d}$

Design cross-sectional plastic resistance to axial compression in fire

$N_{f i, R d}$

Design axial buckling load of the column in the fire situation

$N_{R d}$

Resistance of the column in axial compression at room temperature

$N_{u}$

Ultimate resistance of the column at room temperature

$P$

Perimeter of the section

$Q$

Internal heat generation rate per unit of volume

$R$

Standard fire resistance

\section{Latin lower case letters}

$a$

$b$

$c_{i}$

$e$

$f_{c}$
Half larger outer dimension of an elliptical section

Half smaller outer dimension of an elliptical section

Specific heat

Loading eccentricity

Compressive cylinder strength of concrete at room temperature (test date) 


$\begin{array}{ll}f_{c k} & \text { Characteristic compressive cylinder strength of concrete at } 28 \text { days } \\ f_{c k, c u b e} & \text { Characteristic compressive cube strength of concrete at } 28 \text { days } \\ f_{c k, t} & \text { Characteristic tensile strength of concrete } \\ f_{s} & \text { Yield strength of reinforcing steel at room temperature } \\ f_{y} & \text { Yield strength of structural steel at room temperature } \\ h_{j} & \text { Thermal gap conductance } \\ \dot{h}_{n e t} & \text { Net heat flux } \\ k_{i, \theta} & \text { Reduction factor for a material property at elevated temperature } \\ \ell_{\theta} & \text { Buckling length of the column in the fire situation } \\ q & \text { Heat flux vector per unit surface } \\ t & \text { Thickness of the steel tube } \\ u_{s} & \text { Concrete cover }\end{array}$

\section{Greek upper case letters}
$(\Delta l / l)_{\mathrm{i}}$
Thermal elongation
$\Phi$
Configuration factor

\section{Greek lower case letters}

$\begin{array}{ll}\alpha & \text { Imperfection factor for the buckling curves } \\ \alpha_{c} & \text { Coefficient of heat transfer by convection } \\ \alpha_{i} & \text { Thermal expansion coefficient } \\ \beta & \text { Friction angle } \\ \chi & \text { Member slenderness reduction factor }\left(\chi=N_{f i, R d} / N_{f i, p l, R d}\right) \\ \delta_{\text {max }} & \text { Maximum axial displacement } \\ \varepsilon & \text { Strain } \\ \varepsilon_{f} & \text { Emissivity of the fire } \\ \varepsilon_{m} & \text { Emissivity of the exposed surface } \\ \gamma_{M, f i} & \text { Partial factor for a material property in the fire situation } \\ \varphi_{i, \theta} & \text { Reduction coefficient to make allowance for the effect of thermal stresses } \\ \mu & \text { Axial load level }\left(\mu=N / N_{R d}\right) / \text { Friction coefficient } \\ \lambda_{i} & \text { Thermal conductivity } \\ \bar{\lambda} & \text { Relative slenderness of the column at room temperature }\end{array}$




$\begin{array}{ll}\bar{\lambda}_{\theta} & \text { Relative slenderness of the column in the fire situation } \\ \theta & \text { Temperature } \\ \rho & \text { Percentage of reinforcement } \\ \rho_{i} & \text { Density } \\ \sigma & \text { Normal stress } \\ \tau & \text { Shear stress } \\ \xi & \text { Relative error } \\ \psi & \text { Dilation angle }\end{array}$

\section{Abbreviations}

Concrete with calcareous aggregates

CFCHS

Concrete filled circular hollow section

CFD

Computational fluid dynamics

CFEHS

Concrete filled elliptical hollow section

CFRHS

Concrete filled rectangular hollow section

CFSHS

Concrete filled square hollow section

CFST

Concrete filled steel tube

CFT

Concrete filled tube

CHS

Circular hollow section

EC1

Eurocode 1 Part 1-2 (EN 1991-1-2)

EC2

Eurocode 2 Part 1-2 (EN 1992-1-2)

EC3

Eurocode 3 Part 1-2 (EN 1993-1-2)

EC4

Eurocode 4 Part 1-2 (EN 1994-1-2)

EHS

Elliptical hollow section

FC

Fiber reinforced concrete

FEA

Finite element analysis

FEM

Finite element modelling

F-F

Fixed-fixed supporting conditions

FRR

Fire resistance rating

HSC

High strength concrete

NF

French National Annex to Eurocode 4 Part 1-2

NS

Numerical simulation 
NSC Normal strength concrete

PC Plain concrete

P-P Pinned-pinned supporting conditions

RC Bar-reinforced concrete

RHS Rectangular hollow section

SHS Square hollow section / Steel hollow section

SI Strength index

(sil) Concrete with siliceous aggregates 


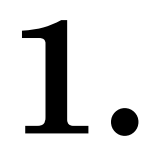

\section{INTRODUCTION}

This chapter presents an introductory overview on concrete filled steel tubular columns and the characterization of their fire resistance. The main advantages and applications of this type of composite columns are presented. The fundamentals of the fire performance of concrete filled tubular columns are explained here in the form of three different sub-problems: the fire dynamics, heat transfer and structural analyses. 


\subsection{BACKGROUND}

The use of concrete filled steel tubular (CFST) columns has increased in recent decades due to their excellent structural performance, which takes advantage of the combined effect of steel and concrete working together - the steel tube provides confinement to the concrete core, resulting in increased compressive strength, while the concrete core restricts inward deformation of the steel tube thus enhancing local buckling resistance and enabling the use of thinner cross-sections -.

The advantages of filling steel hollow sections (SHS) with concrete were early recognised, indeed the first known patent related to the concrete filling of circular hollow sections dates from 1898 (Hicks \& Newman 2002). Nevertheless, the use of concrete filled steel hollow sections did not really begin until the mid $20^{\text {th }}$ Century, when advances in the investigation of the structural performance of these composite types had been achieved and a wider range of structural hollow sections were available.

This type of composite sections provides a series of advantages which make them an interesting option for designers and structural engineers: high load-bearing capacity, high seismic resistance, attractive appearance, reduced cross-section, fast construction technology and high fire resistance without external protection. Due to the heat sink effect of the concrete infill, which delays the rise of temperatures in the cross-section, and the shield effect of the steel tube protecting the concrete core from direct exposure and retaining its integrity, concrete filled tubular (CFT) columns can reach high fire resistance times without external fire protection (Twilt et al. 1996).

In the fire situation, the degradation of the material properties gives rise to an extremely nonlinear behaviour of these composite columns, which makes it difficult to predict their failure. In fact, the analytical methods which can be found in the literature (Lie 1984, Han 2001) provide only approximations to the solution but not a realistic representation of the fire response of CFT columns, reason why it is common to resort to numerical models. Up until now, a large number of numerical models have been developed worldwide (Zha 2003, Renaud et al. 2003, Ding \& Wang 2008, Hong \& Varma 2009, Schaumann et al. 2009), which have helped to gain insight into the fire behaviour of this type of composite columns. Nevertheless, a number of key factors which are sometimes omitted or treated on a simplified manner need to be taken into account in the numerical models in order to obtain a more realistic representation of the fire behaviour of these types of composite columns. 
From the point of view of the designer, even though the structural efficiency of CFT columns has been widely proved, there is still a lack of knowledge on the constructional technology in this field and also some uncertainty in the design stage, particularly concerning the fire design, as only a few design guidelines and calculation methods have been developed up to now. In Europe, the current design rules for CFT columns at elevated temperatures are under review and the calculation methods available in the codes result tedious and unpractical, reason why in some cases it is common to resort to other traditionally used structural solutions. Therefore, further investigation on the technology and design of CFT columns is needed to promote their usage and make designers more familiar with the available constructional techniques and calculation methods.

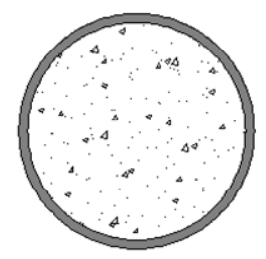

CFCHS

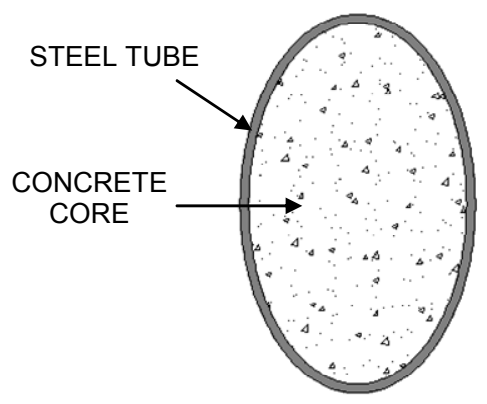

CFEHS

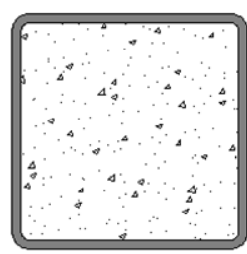

CFSHS

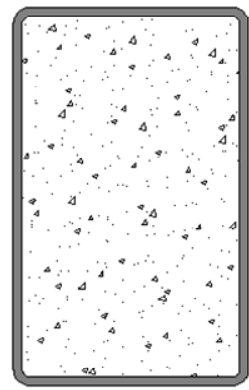

CFRHS

Figure 1.1. Typical CFT sections.

Circular, square and rectangular steel tubes have been traditionally used to form these composite columns (see Figure 1.1). Parallel to this, a new shape of tubular section (CEN 2006) has now been introduced to the construction industry (Corus 2007): the elliptical hollow section (EHS). Their aesthetic appeal and reduced visual intrusion, combined with their structural advantages associated with 
sections of differing major and minor axis properties, make elliptical sections of great interest for designers (Gardner \& Ministro 2005, Packer 2008). An example of the use of elliptical hollow sections can be seen in Figure 1.2.

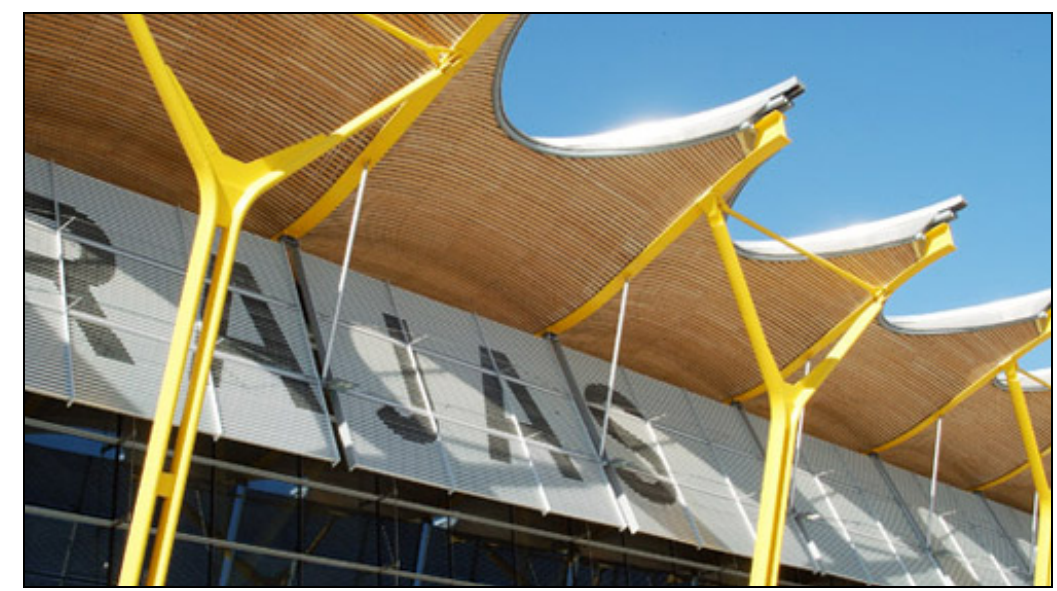

Figure 1.2. Elliptical hollow sections used in T4 terminal of Barajas Airport (Madrid, Spain).

The structural behaviour of elliptical hollow sections has been deeply studied in recent years (Gardner \& Chan 2007, Gardner et al. 2008, Chan \& Gardner 2008a,b, Ruiz-Teran \& Gardner 2008, Silvestre 2008, Gardner et al. 2011, Law \& Gardner 2012). The effect of filling these sections with concrete over their loadbearing capacity at room temperature has also been examined by Yang et al. (2008) and Zhao \& Packer (2009), and more recently by Dai \& Lam (2010). Nevertheless, the fire behaviour of elliptical hollow sections filled with concrete has not yet been established - only a numerical study on concrete filled stub columns which includes elliptical sections (Dai \& Lam 2012) has been presented recently, coinciding chronologically with the redaction of this thesis -.

This dissertation focuses on concrete filled hollow section columns of circular shape, although EHS columns will also be included, in order to contribute to a better understanding of the fire performance of this novel shape. In this aspect, all the findings from the numerical investigations and the design guidelines developed from their results, will be verified for both circular and elliptical shapes. 


\subsubsection{Advantages of CFT columns}

Concrete filled tubular hollow section columns present a series of advantages from the architectural, structural and economic point of view, which are highly appreciated by designers nowadays (Twilt et al. 1996, Zhao et al. 2010). Some of the aspects preferred by construction professionals and which give this typology a competitive advantage in front of other solutions are the following:

- The concrete infill provides a higher rigidity and load-bearing capacity to the tubular steel profile, thus aesthetic slender columns can sustain higher loads without the need of increasing the external dimensions. This result can be intensified by means of using reinforcing bars. In addition, the concrete infill prevents the steel tube from inward local buckling.

- The external steel tube provides a passive confinement to the concrete core, increasing its load-bearing capacity. Furthermore, the concrete core remains always protected by the steel profile, which prevents it from disaggregating even though its maximum strength is reached.

- Concrete filled tubular columns present a higher ductility and energy absorption during earthquakes compared to unfilled steel tubes.

- The net usable floor area results higher, thanks to the reduced dimensions of the columns for a certain design load.

- The external steel section offers the possibility of an architectural design with different finishing. Painting and corrosion protection coating costs are low due to the reduced exposed surface of the columns.

- The steel tube serves at the same time as formwork and external reinforcement for the concrete core. Additional formwork for concrete pouring is not needed. The concrete filling of the tubular hollow column does not require special equipment different from that used in normal concrete casting.

- The time needed for assembling is reduced and waiting times are minimized.

- Problems with joints seldom occur, due to the advanced assembly techniques which are currently being used in structural engineering. This permits the prefabrication and subsequent assembling on site.

- The steel tube can support a considerably high construction load prior to the pumping of concrete, resulting in an efficient construction. 
- The concrete infill increases the fire resistance of the tubular columns. Using the appropriate amount of reinforcement, CFT columns can resist the fire exposure during a long period of time without the need of external protection.

The last aspect is the one of interest in this dissertation. As can be seen in Figure 1.3, apart from an increase in the load-bearing capacity of the column as compared with that of unfilled hollow sections (Figure 1.3a), a noticeable benefit on the fire resistance of the column can be achieved through concrete filling (Figure $1.3 \mathrm{~b}$ ), which can be optimized by using the appropriate type of reinforcement.

a)

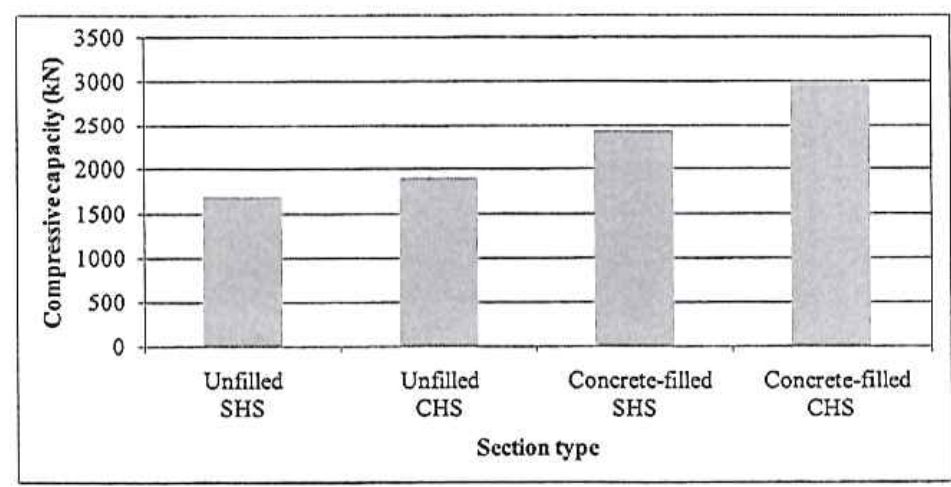

b)

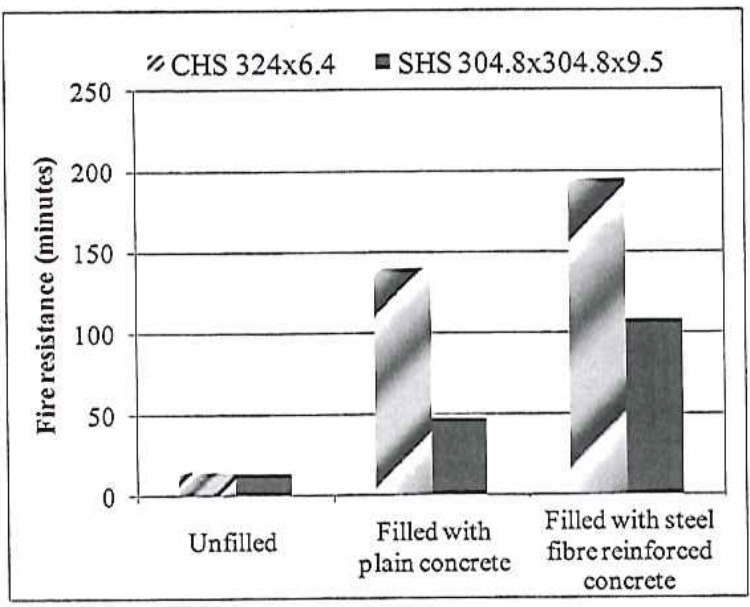

Figure 1.3. Enhancement achieved by filling steel hollow section columns with concrete: a) compressive capacity, b) fire resistance (Zhao et al. 2010). 


\subsubsection{Practical applications}

The use of concrete filled steel tubes has increased in recent decades, finding and important demand in the construction of high-rise buildings and bridges. Other applications are industrial buildings, electricity transmitting poles, subways or office blocks (Zhao et al. 2010).

Good examples of high-rise buildings using CFT columns can be found in China (Zhao et al. 2010). The SEG Plaza in Shenzhen, which is the tallest building in China using this type of composite columns, is a 76-storey office block with a four-level basement and a total height of $361 \mathrm{~m}$. It employs CFT columns of circular shape with diameters ranging from 900 to $1600 \mathrm{~mm}$. In the construction of the building, up to two-and-a-half storeys were erected per week, which demonstrates the efficiency of this technology. Another example is the Wuhan International Securities Building (WISB), which uses CFT columns of square and rectangular sections, reaching $249.2 \mathrm{~m}$ high.

Also the use of CFT sections is becoming popular in the construction of bridges as Zhao et al. (2010) reported. More than 100 bridges using this type of composite sections have been constructed up to now in China. An important advantage that concrete filled steel tubes offer in this application is that during the erection, the hollow tubes can serve as the formwork for casting the concrete, thus reducing the construction cost. Furthermore, the arch can be erected without the need of building an auxiliary bridge, given the excellent stability of the tubular sections.

A great number of applications can be also found in Japan, were CFT columns have been widely used in buildings recently, as Ikeda \& Ohmiya (2009) reported. Some design examples using CFT columns without external fire protection are listed in the referred publication, being built in Japan from 1993 to 2004.

Twilt et al. (1996) give also some examples of buildings erected in Japan using CFT columns: the Mitsui Soko Hakozaki Building (Tokio), the Nakanoshima Intes Building (Osaka) and the ENICOM Computer Centre (Tokio). The first example is a high-rise residential building (19-storeys) composed of square shaped CFT columns of $600 \times 600 \mathrm{~mm}$ using additional external fire protection. The second example is an office building with 22 storeys above ground using circular and square concrete filled tubular columns of width or diameter between 600 and 850 $\mathrm{mm}$. In the ENICOM building, the thickness of the required external fire protection was reduced by filling the square hollow section columns with concrete in combination with fire resistant steel. 
Examples of construction with concrete filled tubular members can also be found in the United States and Canada (Kodur \& MacKinnon 2000). In the Museum of Flight at King County Airport (Seattle, Washington) bar-reinforced concrete filled hollow sections were used for the columns supporting the roof of the exhibit hall, which permitted to achieve the required fire resistance without the need of sprayed fire protection, thus providing an aesthetic finishing, at the same time that minimizing the use of space and allowing for a clean entrance of natural light. Another application can be found in the St. Thomas Elementary School (Hamilton, Ontario), where concrete filled circular hollow section (CHS) columns with different concrete strengths were used, obtaining slender members with the required one hour fire resistance rating.

In Europe, the recent advances in the knowledge of these structural solutions and their technology have derived in a growth in the use of concrete filled tubular columns in new buildings. Good examples of practical applications can be found in London (Hicks \& Newman 2002). Amongst them, the following works must be cited: Fleet Place House, the Montevetro apartment block, the Peckham Library and Queensberry House. Fleet Place House (Figure 1.4a) is an eight-storey office block using circular CFT columns of $323.9 \mathrm{~mm}$ external diameter filled with concrete of grades $\mathrm{C} 40$ to $\mathrm{C} 60$. The columns are arranged on each longitudinal external face of the building, which has clear spans on the inside. In the Montevetro apartment block (Figure 1.4d), concrete filled CHS columns have been used on the facade, with sections of $244.5 \mathrm{~mm}$ and $355.6 \mathrm{~mm}$ external diameter. The Peckham Library is supported at its front by concrete filled CHS columns of diameter $323.9 \mathrm{~mm}$, angled to form an irregular facade. Finally, the Queensberry House consists on a six-storey office and commercial block using concrete filled CHS columns with a tube-in-tube system $(457 \times 10 \mathrm{~mm}$ outer tube and $323.9 \times 6.3$ inner tube in a typical case).

The Darlington Memorial Hospital and Rochdale Bus Station (Twilt et al. 1996) are also examples of constructions with concrete filled members in the United Kingdom, in these cases using RHS columns.

In the Tecnocent Building (Oulu, Finland), circular and square bar-reinforced concrete filled hollow section columns were used. In the Netherlands, the Amsterdam Mees Lease Building can be mentioned, which is a four-storey office building using $323 \mathrm{~mm}$ CHS columns filled with concrete in combination with concrete encased HEA beams (Twilt et al. 1996). In the Microsoft Head Office of Villebon-sur-Yvette (France), a variety of tubular columns filled with concrete were used. 


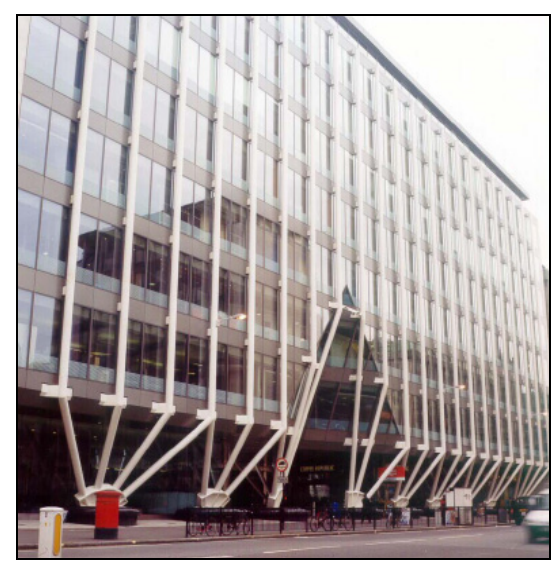

a) Fleet Place House (London, UK)

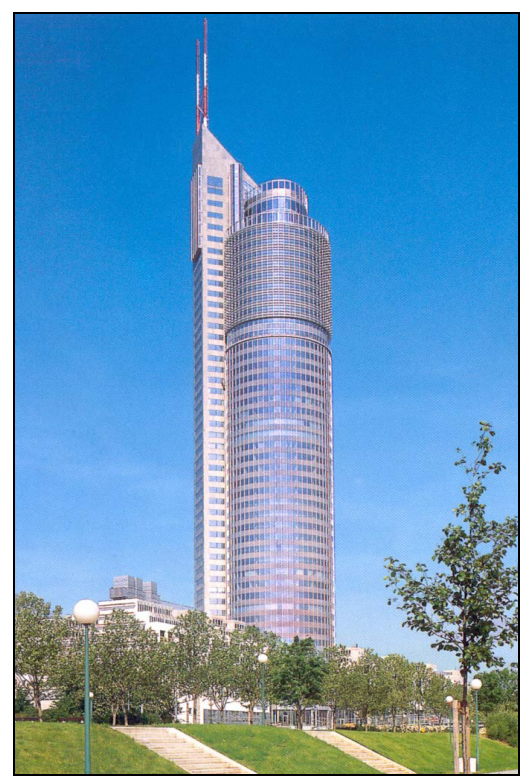

c) Millennium Tower (Wien, Austria)

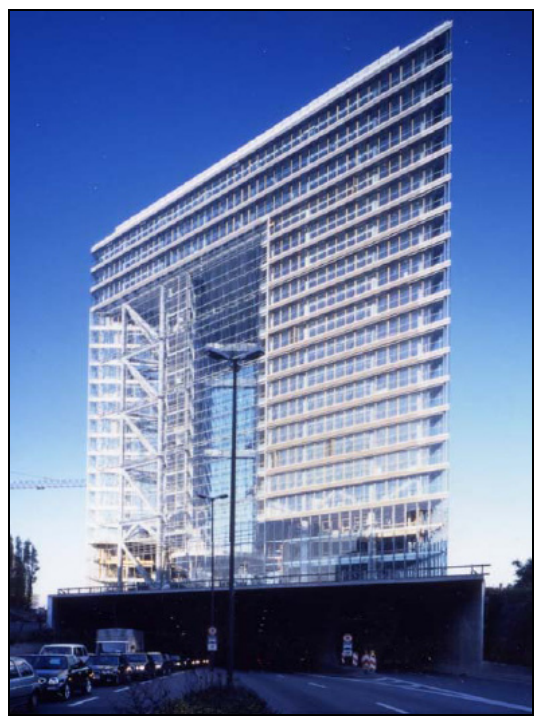

b) City Gate (Düsseldorf, Germany)

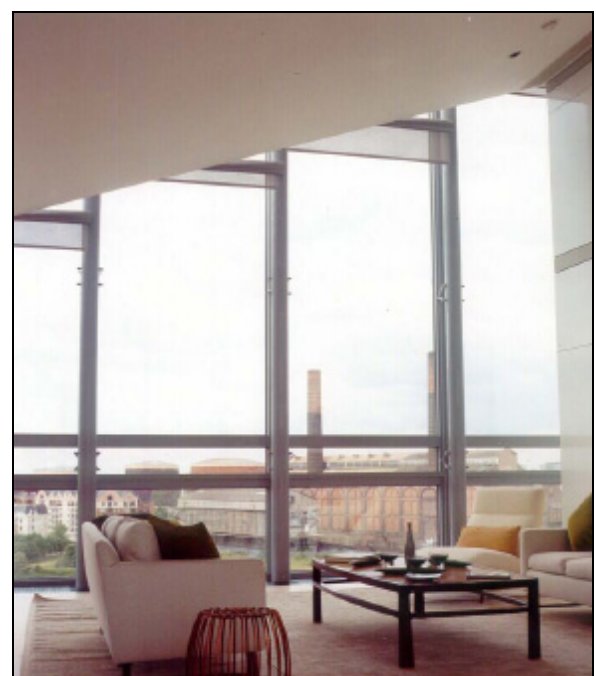

d) Montevetro apartment block (London, UK)

Figure 1.4. Some examples of construction with CFT columns. 
The Millennium Tower in Wien (Figure 1.4c), a high-rise 55 storey building, and the DEZ car park in Innsbruck, both in Austria, are examples of efficient construction using concrete filled tubular columns in combination with other composite elements.

The City Gate (Figure 1.4b) in Düsseldorf (Germany) is a high-rise building composed of two 16-storey towers connected by a 3-storey attic to a portal. Concrete filled hollow sections columns with diameters of $40 \mathrm{~cm}, 55 \mathrm{~cm}$ and $90 \mathrm{~cm}$ were used, in combination with concrete partially encased beams.

In Australia, the Riverside Office Building can be cited (Twilt et al. 1996), using concrete filled bar-reinforced CHS columns of $600 \mathrm{~mm}$ diameter which were required to fulfil a 120 minutes resistance to fire, in addition to a bracing system to resist lateral forces from earthquake and wind, with CHS diagonals of $406 \mathrm{~mm}$ diameter.

\subsection{FIRE BEHAVIOUR OF CFT COLUMNS}

Filling steel hollow sections with concrete provides the columns a high inherent fire resistance without the need of additional protection (Twilt et al. 1996). This is due, on the one hand, to the heat sink effect that concrete produces in the composite section by having a lower thermal conductivity, and on the other hand to the mechanical contribution of the concrete core, which not only helps to sustain the applied load, but also prevents the steel tube from inward local buckling.

During the first stages of the fire exposure, the steel tube expands faster than the concrete core, in such a way that the steel section carries a higher amount of the applied load. The heat flux is gradually transferred from the steel tube wall to the concrete infill, where due to the lower and much favorable thermal properties of concrete (which presents a low thermal conductivity), the temperature rise is relatively slow. After a certain period of fire exposure (between 20 and 30 minutes), the strength of steel starts to decrease fast due to its elevated temperature, therefore the load is progressively transferred to the concrete infill. As the temperature advances through the concrete core, its strength decreases until eventually the failure occurs, either due to global buckling or compression. This evolution can be seen in Figure 1.5 in terms of the axial displacement measured at the top end of the column. 


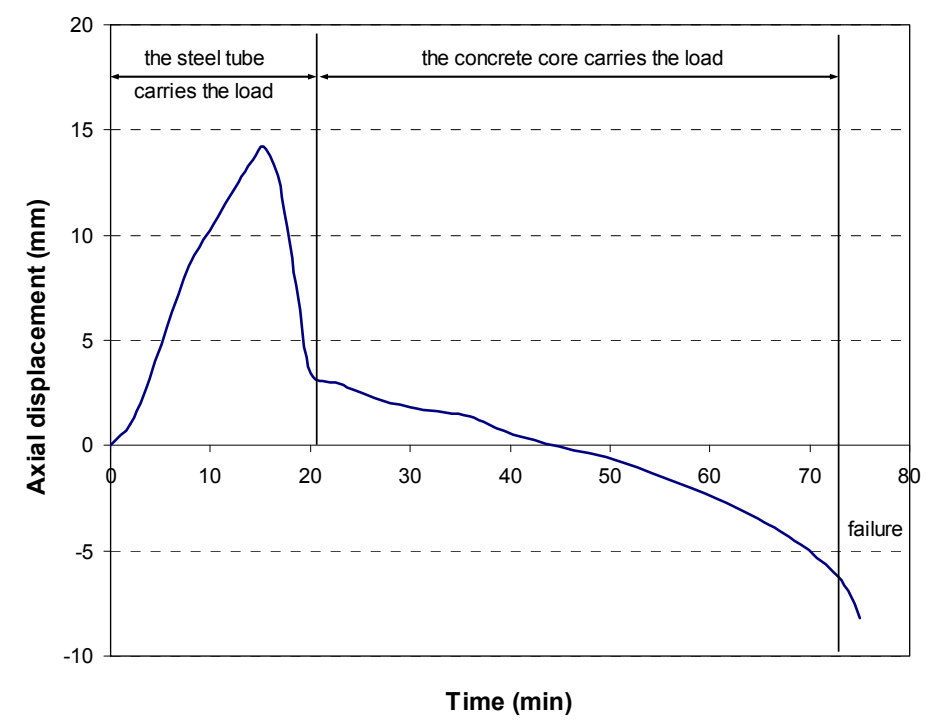

Figure 1.5. Typical behaviour of a CFT column subjected to elevated temperatures.

The reduction of the mechanical properties of concrete in CFT columns is slower than in other type of composite columns as it is the case of the concrete encased steel sections, since the external steel tube protects the concrete core from direct exposure to the heat source, therefore preventing progressive spalling (Kodur \& MacKinnon 2000).

It is important to note that at elevated temperatures, the moisture contained in the concrete core is liberated in form of water vapor, and in order to avoid problems caused by an excess of internal pressure, it is necessary to facilitate its release (Twilt et al. 1996, Kodur \& MacKinnon 2000). For this reason, vent holes of at least 20 $\mathrm{mm}$ diameter in the top and bottom ends of the columns are recommended, in every floor of the building.

The heating behaviour of CFT columns is significantly different than that of empty steel hollow sections (where the temperature is almost uniform). The combination of materials with very different thermal conductivities - as steel and concrete - produces an extreme transient heating behaviour characterized by high temperature differentials across the section (Twilt et al. 1996). Taking advantage of these temperature differentials, CFT columns can be designed to achieve a fire 
resistance of up to 120 minutes or even higher (if the proper internal reinforcement is used) without external protection. This is shown in Figure 1.6, where the effect of using different types of concrete filling can be seen. Steel fibers (FC in Figure 1.6) and reinforcing bars (RC) have been found to delay the degradation of the concrete core by providing additional tensile strength, reaching fire resistance times up to 3 hours as compared with a maximum of 2 hours for plain concrete (PC) filling (Kodur \& MacKinnon 2000).

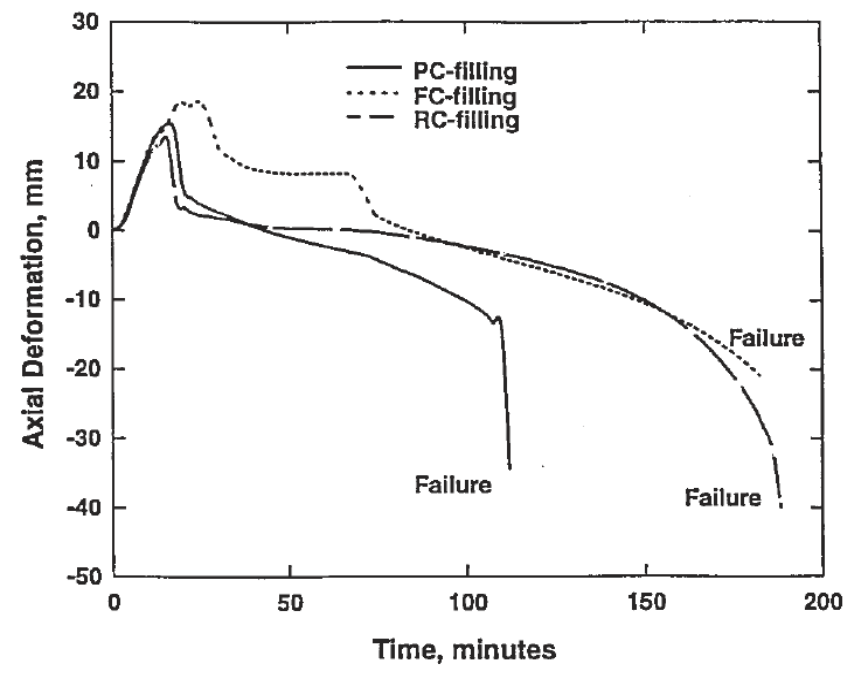

Figure 1.6. Effect of using different types of concrete filling on the fire resistance of CFT columns (Kodur \& MacKinnon 2000, Kodur 2007).

Due to the more complex evolution of the temperature field in composite steel-concrete sections, simple calculation models based on the section factor $A_{m} / V$ cannot be used for the design of CFT columns in the fire situation. Advanced calculation tools which take into account the time dependent thermal properties of the materials and the resulting thermal transients are needed instead.

Depending on their particular location within the cross-section, the different components of a CFT column present different strength reduction rates along the fire exposure time (Twilt et al. 1996). The steel tube, directly exposed to the fire, heats up faster and therefore its resistance results significantly reduced after a short period of time. In turn, the concrete core, with its high massivity and low thermal conductivity, retains for a longer time a higher proportion of its room temperature strength, mainly in the areas close to the center of the section. If reinforcing bars are 
used, they will be normally located close to the external surface of the section, but protected by a certain thickness of concrete cover and the external steel tube. Therefore, a slow reduction of their strength will occur. Figure 1.7 shows this behaviour characterized by the degradation of the strength of the different components of the composite section. This figure easily describes how the fire behaviour of a CFT column can be seen as the consequence of the evolution of each of its components.

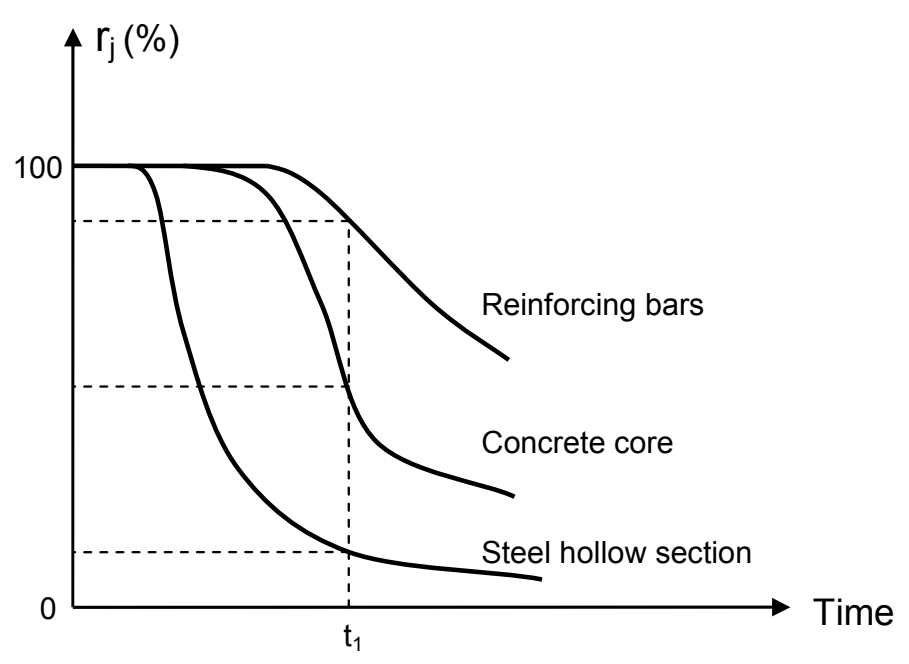

Figure 1.7. Evolution of the strength of the different components of a CFT column.

The load-bearing capacity $R$ of the column cross-section can be expressed as the sum of the capacities of its components $r_{j}$ (Twilt et al. 1996). In the fire situation, the capacities of the different components depend on the fire exposure time $t$.

$$
R(t)=\Sigma r_{j}(t)
$$

At room temperature, the steel tube is likely to be the dominant component of the section, due to the higher strength of steel and its location within the crosssection. Nevertheless, after a certain period of time $t_{1}$, only a small percentage of the original capacity of the steel tube remains. This means that, in the fire situation, the amount of load initially sustained by the steel tube will be redistributed to the concrete core, which loses its strength and stiffness at a slower rate. 
In the room temperature design, high resisting capacities can easily be obtained with reduced cross-sectional dimensions. But reduced dimensions normally limit the fire resistance of the structural element. As the strength reduction of the different sectional components is directly affected by their relative heating, a minimum dimension of the column cross-section is needed to fulfill the required fire resistance (Twilt et al. 1996).

When the temperature is increased, the strength and stiffness of the materials decrease, and thus the load-bearing capacity of the structural element becomes lower at the same time that its deformation increases. Therefore, in the fire design, account must be taken of the slenderness of the column.

The great number of investigations carried out to date to characterize the fire behaviour of CFT columns have made possible to establish the different parameters which are involved in their failure at elevated temperatures, e.g.:

- Width to thickness $(B / t)$ or diameter to thickness $(D / t)$ ratio

- Steel yield strength $\left(f_{y}\right)$

- Concrete strength in compression $\left(f_{c k}\right)$ and in tension $\left(f_{c k, t}\right)$

- Percentage and arrangement of reinforcement (if present)

- Member slenderness $\left(\bar{\lambda}=\sqrt{N_{p l, R d} / N_{c r}}\right)$

- Load level $\left(\mu=N / N_{p l, R d}\right)$

- Eccentricity of the load (e)

- Type of aggregates (calcareous or siliceous)

- Section factor $\left(A_{m} / V\right)$

Determninig the fire resistance of a structural element requires the use of three different models: a fire dynamics model, a heat transfer model and a structural model. Each of these models represents one of the stages in which the problem can be sub-divided: the fire dynamics analysis, the heat transfer analysis and the stress analysis, where the mechanical response at elevated temperature can be finally obtained. In the following sections, the theoretical background of each of the analysis stages which must be solved for predicting the fire resistance of a CFT column will be explained. 


\subsubsection{Fire dynamics analysis}

The fire dynamics model permits to obtain the temperature evolution along the time which develops in the compartment where the structural element is located, depending on the fire load, ventilation and insulation conditions.

A real fire in a building grows and decreases according to the mass and energy balance within the compartment where it is originated. The amount of energy released depends on the quantity and type of combustible materials and the existing ventilation conditions in the compartment.

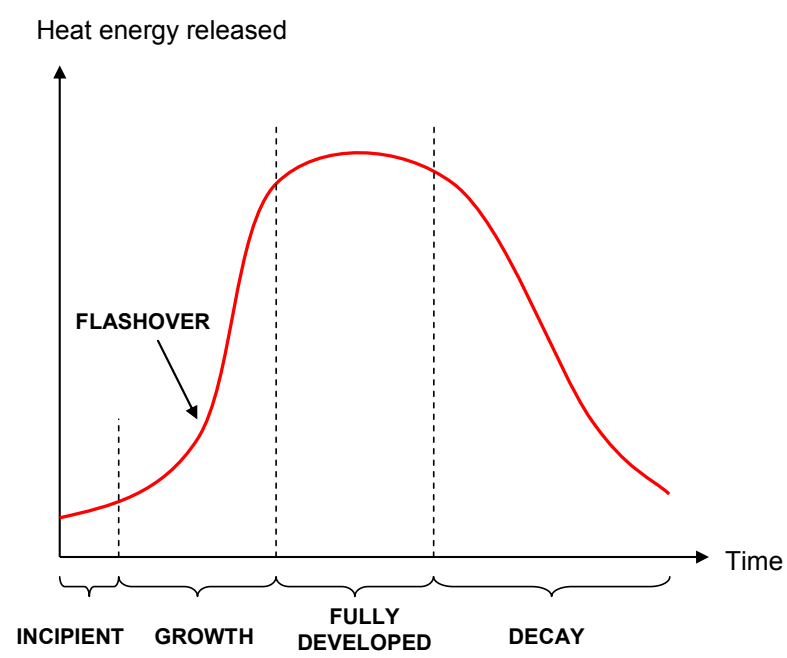

Figure 1.8. Different stages in the evolution of a fire.

The evolution of a fire can be divided into four stages: incipient, growth, fully developed and decay or cooling stage (Figure 1.8). The fastest temperature rise occurs after the so-called flashover or point of sudden generalized ignition, which is the point where most of the combustible material within the compartment is spontaneously burnt out.

Eurocode 1 Part 1.2 (CEN 2002) includes in its Section 3.3 different natural fire models: simplified models for compartment fires or localized fires and advanced fire models, which are described in more detail in the Annexes of the referred code.

Since the conditions are different in every fire and, in order to be able to compare the effectiveness of the different structural solutions and classify or verify 
their fire resistance, a standard fire model is commonly used, which is defined through a temperature curve which increases along the fire exposure time, regardless of the compartment conditions and the amount of fire load.

In many building codes, the fire resistance of a structural element is based on its performance when subjected to a fire pattern which follows an internationally agreed temperature-time curve, which is defined in the ISO 834 standard (ISO 1980) and does not represent a realistic fire. It is characterized by a gas temperature which grows continuously along the time, but at a reduced rate. This curve has become a standard pattern which is used in the laboratories for testing the resistance of structural elements to fire. The fire resistance time obtained through this test does not represent the real time that the structural element can resist until its final collapse, but it only provides a relative comparison and acts as an indicator of the severity of the fire that the member can resist.

The nominal fire curves described in Section 3.2 of EN 1991-1-2 (CEN 2002) are conventionally agreed curves which are used to classify or verify the fire resistance of a structural element. Amongst them, one can find the standard temperature-time curve (ISO 834 curve), the external fire curve and the hydrocarbon curve.

The standard ISO 834 curve is described in Section 3.2.1 of Eurocode 1 Part 1-2 (CEN 2002) and its formulation is as follows:

$$
\theta_{g}=20+345 \cdot \log _{10}(8 \cdot t+1)\left({ }^{\circ} \mathrm{C}\right)
$$

where:

- $\theta_{g}$ is the gas temperature in the fire compartment $\left[{ }^{\circ} \mathrm{C}\right]$

- $t$ is the time [min]

A coefficient of heat transfer by convection $\alpha_{c}=25 \mathrm{~W} / \mathrm{m}^{2} \mathrm{~K}$ is used.

When the structural element under study is located outside the building (i.e. external member), it may be exposed to fire through openings in the building enclosure. In those cases, the temperature of the gas affecting the member tends to be lower for a certain amount of time and the so-called external fire curve can be used. 
In those cases where the storage of materials with a high calorific value can cause very severe fires (e.g. in petrochemical plants), the hydrocarbon fire curve must be then used.

The three nominal temperature-time curves are shown in Figure 1.9 and described in Section 3.2 of Eurocode 1 Part 1-2 (CEN 2002).

Finally, Annex A in EC1 Part 1.2 (CEN 2002) presents the parametric temperature-time curves, which are obtained from realistic fire models, with heating and cooling phases and considering specific physical parameters which define the conditions in the fire compartment, as the fire load density, the area of openings and the thermal properties of the compartment itself.

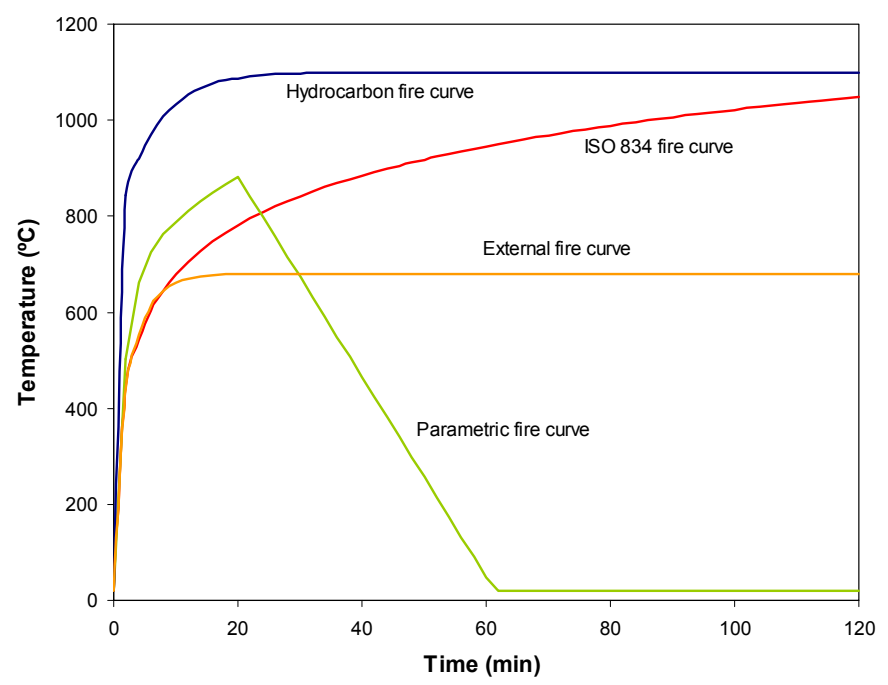

Figure 1.9. Different types of fire curve.

Eurocode 1 Part 1.2 (CEN 2002) also allows in its Section 3.3 for the use of natural fire models, based on specific physical parameters of the problem. They can be either simplified fire models, which consider at least the fire load density and the ventilation conditions, or advanced fire models taking into account other parameters such as the gas properties, the mass exchange and the energy exchange. Amongst the second category, three types of models can be found: one-zone models, two-zone models and computational fluid dynamics (CFD) models. One-zone models assume a uniform, time-dependent temperature distribution in the compartment. Two-zone models consider an upper and lower layer with time dependent thickness and time 
dependent uniform temperature. Finally, CFD models give the temperature evolution in the compartment in a completely time and space dependent manner.

\subsubsection{Heat transfer analysis}

The heat transfer model aims to obtain the temperature distribution at a certain time at which the fire resistance of the member wants to be verified. It should be noted that the thermal properties of the materials are not independent of temperature, and therefore the problem results highly nonlinear.

In order to predict the evolution of the temperature field with the time of fire exposure, numerical modelling software is frequently used (based either on finite differences or finite elements), otherwise the differential heat transfer equation must be analytically solved, which can result a tedious and difficult task.

The thermal analysis of a structural member can be divided into two parts: the heat transfer from the fire to the exposed surface, which is a combination of the convective and radiative heat transfer mechanisms, and the conductive heat transfer within the structural element itself, which is evaluated through the Fourier differential equation for heat conduction.

Conduction is the transfer of heat from one point to another through a solid or fluid due to the temperature difference. The heat transfer occurs here at the molecular level, without associated net mass movement of the material. The equation which describes this type of heat transfer is the Fourier's law of conduction, which is expressed as follows:

$$
q=-\lambda \nabla \theta
$$

where $q$ is the heat flux vector per unit surface, $\lambda$ is the thermal conductivity tensor and $\theta$ is the temperature.

The conservation of energy equation states:

$$
\rho c \frac{\partial \theta}{\partial t}=-\nabla \cdot q+Q
$$

where $\rho$ is the density, $c$ the specific heat, $t$ the time and $Q$ the internal heat generation rate per unit of volume. 
The specific heat of the material can be dependent of temperature, which introduces a non-linearity in this equation. Replacing equation (1.3) in equation (1.4), results:

$$
\rho c \frac{\partial \theta}{\partial t}=\nabla \cdot(\lambda \nabla \theta)+Q
$$

Equation (1.5) is the conductive heat transfer equation, which can be solved by setting up an initial condition and the corresponding boundary conditions. The initial condition consists on specifying the temperature at the initial time. The boundary condition in the fire exposed surface is given by the application of the thermal loads described hereafter, through a net heat flux applied to the surface.

The boundary condition on the exposed surface is a Neumann type, which specifies the normal derivative of the temperature, i.e.:

$$
\lambda \frac{\partial \theta_{m}}{\partial n}=\dot{h}_{n e t}
$$

where $n$ is the normal to the surface and $\dot{h}_{n e t}$ the net heat flux per unit surface.

Note that both equation (1.5) and the boundary condition on the exposed surface, equation (1.6), are nonlinear. The first one due to the variation of the thermal conductivity and specific heat with the temperature, and the second one due to the radiation component, which implies a nonlinear term of the temperature. This explains why numerical methods are normally used to solve this type of heat transfer problems.

\section{Thermal boundary conditions}

Eurocode 1 Part 1.2 (CEN 2002) describes in its Section 3 the different thermal loads which must be taken into account when conducting the heat transfer analysis.

On the fire exposed surfaces, the net heat flux $\left(\dot{h}_{n e t}\right)$ can be determined by considering two different heat transfer modes: convection $\left(\dot{h}_{n e t, c}\right)$ and radiation $\left(\dot{h}_{n e t, r}\right)$.

$$
\dot{h}_{n e t}=\dot{h}_{n e t, c}+\dot{h}_{n e t, r}\left(\mathrm{~W} / \mathrm{m}^{2}\right)
$$


Convective heat transfer, often referred to simply as convection, is the transfer of heat from one place to another by the movement of fluids, a process that is essentially transfer of heat via mass transfer. In free or natural convection, fluid motion is caused by buoyancy forces that result from density variations due to variations of temperature in the fluid.

The net convective heat flux component per unit surface is given by the following expression:

$$
\dot{h}_{n e t, c}=\alpha_{c} \cdot\left(\theta_{g}-\theta_{m}\right)\left(\mathrm{W} / \mathrm{m}^{2}\right)
$$

where:

- $\alpha_{c}$ is the coefficient of heat transfer by convection $\left[\mathrm{W} / \mathrm{m}^{2} \mathrm{~K}\right]$

- $\theta_{g}$ is the gas temperature in the vicinity of the fire exposed member $\left[{ }^{\circ} \mathrm{C}\right]$

- $\theta_{m}$ is the surface temperature of the member $\left[{ }^{\circ} \mathrm{C}\right]$

The coefficient of heat transfer by convection is equal to $25 \mathrm{~W} / \mathrm{m}^{2} \mathrm{~K}$ when the standard or external temperature-time curve is used, $35 \mathrm{~W} / \mathrm{m}^{2} \mathrm{~K}$ when a parametric fire curve is considered and $50 \mathrm{~W} / \mathrm{m}^{2} \mathrm{~K}$ when the hydrocarbon temperature-time curve is adopted.

On the unexposed side of separating members, the net heat flux should be determined by using $\alpha_{c}=4 \mathrm{~W} / \mathrm{m}^{2} \mathrm{~K}$. The coefficient of heat transfer by convection should be taken as $\alpha_{c}=9 \mathrm{~W} / \mathrm{m}^{2} \mathrm{~K}$, when assuming it contains the effects of heat transfer by radiation.

Radiation is the transfer of energy to or from a body by means of the emission or absorption of electromagnetic radiation. Thermal radiation propagates without the presence of matter through the vacuum of space. The net radiative heat flux component per unit surface is given by the following expression:

$$
\left.\dot{h}_{n e t, r}=\Phi \cdot \varepsilon_{m} \cdot \varepsilon_{f} \cdot \sigma \cdot \mid\left(\theta_{r}+273\right)^{4}-\left(\theta_{m}+273\right)^{4}\right\rfloor\left(\mathrm{W} / \mathrm{m}^{2}\right)
$$

where:

- $\Phi$ is the configuration factor

- $\varepsilon_{m}$ is the surface emissivity of the member

- $\varepsilon_{f}$ is the emissivity of the fire 
- $\sigma$ is the Stephan-Boltzmann constant, equal to $5.67 \times 10^{-8} \mathrm{~W} / \mathrm{m}^{2} \mathrm{~K}^{4}$

- $\theta_{r}$ is the effective radiation temperature of the fire environment $\left[{ }^{\circ} \mathrm{C}\right]$

- $\theta_{m}$ is the surface temperature of the member $\left[{ }^{\circ} \mathrm{C}\right]$

The configuration factor should be taken as unity according to EN 1991-1-2 3.1(7). A lower value may be chosen to take account of so called position and shadow effects. For the calculation of the configuration factor a method is given in Annex G of EN 1991-1-2.

Unless given in the material related fire design parts of the different Eurocodes, $\varepsilon_{m}=0.8$ may be used, according to Clause 3.1(6) of EN 1991-1-2. EN 1994-1-2 in Section 2.2(2) states that the emissivity coefficient for steel and concrete related to the surface of the member should be $\varepsilon_{m}=0.7$. The emissivity of the fire is taken in general as $\varepsilon_{f}=1.0$.

In case of fully fire engulfed members, the radiation temperature can be assimilated to the gas temperature around the member, according to EN 1991-1-2 3.1(8) (CEN 2002). The gas temperatures may be given by the previously described nominal temperature-time curves or by fire models.

\section{Solving the heat transfer problem}

The heat transfer analysis problem described above can be solved by means of numerical methods, using for instance advanced software tools as SAFIR (Franssen 2003), or general purpose finite element analysis (FEA) programs (such as ABAQUS, 2010). Another option, if the problem under study can be reduced to a two-dimensional (sectional) heat transfer problem, is to solve it analytically.

Lie $(1984,1990)$ developed an analytical model which allows for the prediction of the cross-sectional temperature field in circular concrete filled hollow section columns exposed to fire, by means of the application of the finite differences method, based on previous work from Dusinberre (1961). The work was later completed (Lie 1994) to account for the presence of reinforcing bars in concrete filled columns of circular section. A model for rectangular concrete filled tubular columns was also developed (Lie \& Irwin 1995).

The method developed by Lie allows obtain the temperature evolution in the cross-section of a CFT column, by means of an iterative process through the repeated application of the temperature equations proposed by the author for the different concentric layers in which the column cross-section can be subdivided. Figure 1.10 illustrates the subdivision of the cross-section used in Lie's method. 


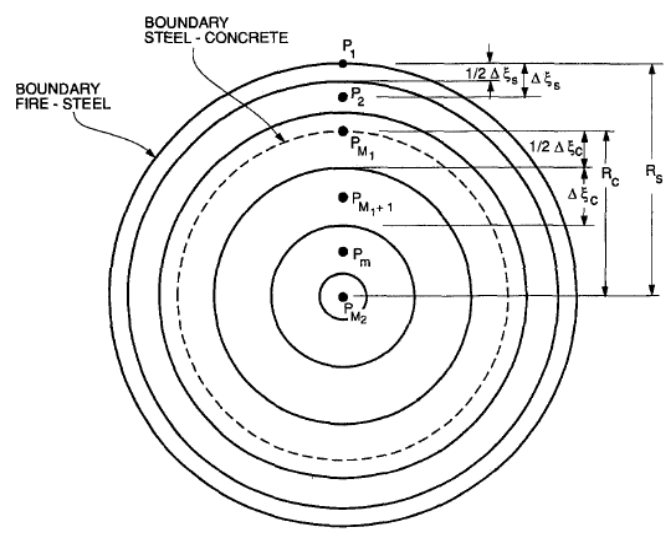

Figure 1.10. Arrangement of layers in the cross-section (Lie 1994).

As an example, Figure 1.11 shows the result of applying Lie's method for obtaining the temperature distribution in the cross-section of a column of $141 \mathrm{~mm}$ external diameter and a steel tube wall thickness of $6.5 \mathrm{~mm}$, exposed to an ISO 834 standard fire. The section was divided into 5 concentric layers, 1 for the steel tube and 4 for the concrete core.

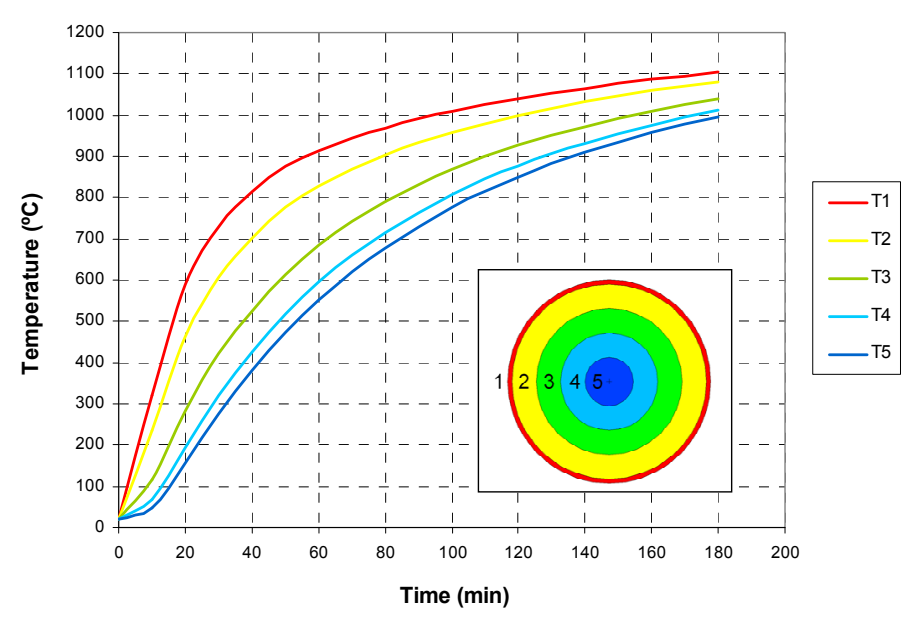

Figure 1.11. Example of the application of Lie's method to obtain the temperature distribution in a $141 \times 6.5 \mathrm{~mm}$ circular CFT column. 


\subsubsection{Structural analysis}

The structural analysis required for the determination of the fire resistance of the column takes as a starting point the previously calculated temperature distributions along the fire exposure time. From the previously known evolution of temperature and through the use of the constitutive equations for steel and concrete at elevated temperatures, the stress and strain solution can be obtained for every time step, and eventually the time at which the collapse of the column occurs, under a certain applied load.

Several methods have been proposed for the resolution of the structural problem at elevated temperatures. Lie $(1984,1990)$ proposed a theoretical method for the determination of the fire resistance of circular CFT columns based on a loaddeflection or stability analysis (Figure 1.12), as a continuation of the previously described thermal method. The model was afterwards completed (Lie 1994) to account for the effect of the addition of reinforcing bars, and extended to other sectional geometries (Lie \& Irwin 1995).

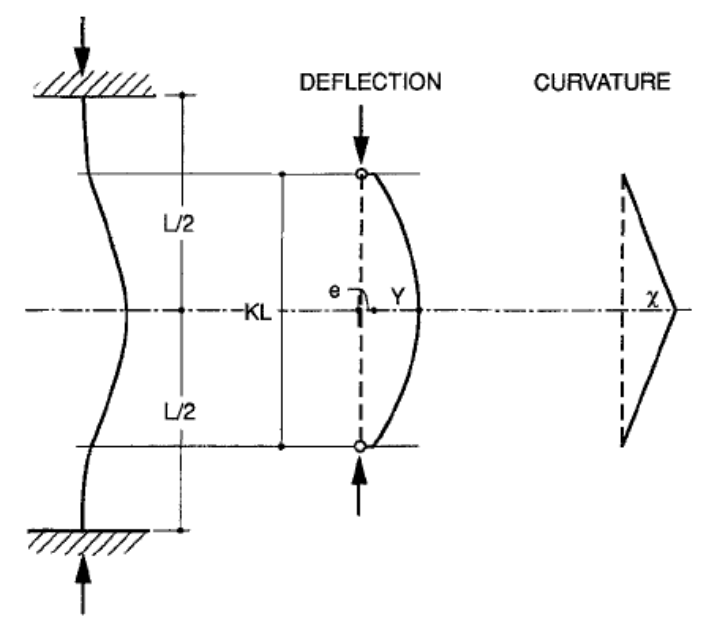

Figure 1.12. Schematic view of the load-deflection analysis (Lie 1994). 



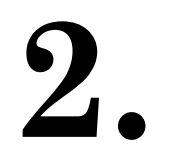

\section{STATE OF THE ART}

In this chapter, the current state of the research in the field of the fire behaviour of concrete filled tubular columns is reviewed, covering from the more simplistic models to the complex advanced numerical models which have brought light to the evaluation of the fire resistance of CFT columns, not forgetting the experimental investigations which have contributed to achieve a better understanding of the problem, all of which has helped to promote the use of this technology and disseminate its developments nowadays. 


\subsection{GENERAL}

The resolution of the transient heat transfer problem is a previous step to the structural analysis. The time-dependent cross-sectional temperature field can be obtained by means of theoretical-analytical methods (Lie 1984, Tan \& Tang 2004, Wang \& Tan 2006) or advanced numerical models which make use of finite element analysis (Zha 2003, Ding \& Wang 2008, Hong \& Varma 2009). Even though a number of software tools based on numerical methods exist (Iding et al. 1977, Sterner \& Wickström 1990, Franssen 2003), analytical solutions have been proposed by authors as Wang \& Tan (2006), who presented a solution for the transient heat conduction in concrete filled steel circular hollow sections based on Green's functions. Importance must be given to the publications from Lie and co-workers (Lie 1984, Lie \& Chabot 1990, Lie 1994, Lie \& Irwin 1995), who derived equations for the temperature of the concrete core and steel tube taking as a starting point the work from Dusinberre (1961) on heat transfer calculations by finite differences.

Artificial intelligence has even been used to solve the problem of the fire behaviour of CFT columns, as it was the case of Al-Khaleefi et al. (2002), who developed a model based on the use of neuronal networks generated from the experimental results obtained by other authors.

In the field of the constitutive equations of the materials - steel and concrete - at elevated temperatures, various authors have reviewed the different models which are available in the literature. It is worth mentioning the work from Li \& Purkiss (2005), who reviewed the state of the art on the concrete material constitutive models and developed a new proposal, comparing their results with the models from Anderberg \& Thelandersson (1976), Schneider (1986, 1988), Diederichs (1987) and Khoury \& Terro (Terro 1998). Youssef \& Moftah (2007) also reviewed the available constitutive models for concrete at elevated temperatures.

In the specific field of CFT columns, Han (2001) obtained experimental constitutive equations for concrete at elevated temperatures, accounting for the additional lateral confinement effect. The same author developed constitutive equations for normal strength concrete after exposure to a standard fire. In turn, Lie (1984) proposed high temperature constitutive equations for steel and concrete, which were proved accurate for CFT columns. Youssef \& Moftah (2007) proposed two analytical models for confined concrete at elevated temperatures based on the models from Mander \& Scott at room temperature. 
Also complex coupled thermo-hygro-mechanical models have been developed to solve problems of the behaviour of porous materials - such as concrete - at elevated temperatures, which account for the movement of the water vapour inside the material with the temperature evolution. A good example is the model developed by Bianco et al. (2003) at Pádova University.

In the following lines, a detailed revision of the state of the art on CFT columns subjected to fire is presented. The main models which can be found in the literature are described, covering both analytical models and numerical models. A review of the fire testing programs which have been carried out worldwide by the different research groups is also included, as well as the available simple calculation models and design guidelines. The state of the research on elliptical hollow section columns is finally presented.

\subsection{ANALYTICAL MODELS}

The first work which can be found in the literature on the analytical resolution of the transient heat conduction in concrete filled steel hollow sections exposed to fire is that from Lie (1984), who not only derived a mathematical solution for this particular heat transfer problem, but also proposed a theoretical structural model which permits to calculate the deformations and the fire resistance of the columns. Based on the finite differences method (Dusinberre 1961), Lie derived expressions which allow to calculate the temperature of the concrete core and steel tube by subdividing the cross-sectional area of the column in a number of layers for CHS columns (Lie 1984, Lie \& Chabot 1990, Lie 1994) or elements in the case of RHS columns (Lie \& Irwin 1995). Once the cross-sectional temperature field is known for every step time, the strength of the column can be calculated by a method based on a load-deflection or stability analysis. The model from Lie was validated against experimental results, and employed specific formulations for the constitutive laws of steel and concrete at elevated temperatures.

A theoretical structural model was also proposed by Han (2001), capable of predicting the fire resistance of CFT columns and beam-columns with circular or square sections. The model took into account the physical and geometrical nonlinearities. Han employed a specific formulation of the stress-strain relations of concrete at elevated temperatures, making allowance of the confinement effect. This theoretical model was used to calculate the fire resistance of CFT columns used in actual buildings, as the SEG Plaza in Shenzhen (China) described in Section 1.1.2. 
Despite the different theoretical models proposed to solve the transient heat transfer problem in CFT columns permitted to gain an insight in the solution of the problem, simplified considerations had been assumed on the boundary conditions at the steel-concrete interface, where the resistance to heat flow had traditionally been ignored. It is not until the work from Ghojel (2004), that expressions for estimating the value of the interface thermal conductance in these composite sections are available. Ghojel developed expressions for estimating the steel-concrete interfacial contact conductance of loaded and unloaded circular steel tubes filled with plain concrete, as a function of the steel tube temperature.

Tan \& Tang (2004) extended the Rankine method to the analyses of plain and reinforced concrete filled tubular columns at elevated temperatures. In their model, the fire resistance of a CFT column is expressed in terms of its plastic squash load and elastic buckling capacity at ambient temperature. This approach had initially been used to analyze steel columns and frames at elevated temperature by Toh et al. (2000), and years later had been extended by Tan \& Tang to reinforced concrete columns in fire conditions with satisfactory results.

Wang \& Tan (2006) presented a theoretical approach for the heat transfer analysis of concrete filled steel circular hollow sections subjected to fire based on an analytical Green's function solution. This approach can be used to predict the temperature field inside the composite domain and the heat flux at the fire and steelconcrete interfaces.

Yin et al. (2006) developed an analytical nonlinear model which uses the constitutive high temperature equations presented in Li \& Purkiss (2005) for normal strength concrete and the steel constitutive model from Lie (1994). Temperatures were calculated by solving the corresponding heat transfer equations, and the strains and stresses were obtained by assuming that the columns were perfectly straight and the axial load applied in such a way that makes the column fail in compression without any bending. These authors evaluated and compared the fire performance of circular and square sections, showing that for columns with the same steel and concrete cross-sectional areas, the circular column presented a slightly higher fire resistance. 


\subsection{NUMERICAL MODELS}

A great number of finite element computer codes are available nowadays, which can be employed to solve the nonlinear heat transfer problem. Some of the most widely used are FIRES-T3 (Iding et al. 1977), developed at the University of Berkeley (California, USA), TASEF (Sterner \& Wickström 1990), from Lund Institute of Technology (Sweden) and SAFIR (Franssen 2003) from Liège University (Belgium). Apart from these codes, specifically developed for the fire analysis of structural members, general purpose finite element programs exist such as ABAQUS, ANSYS or DIANA, among others, which can also be used for solving the thermo-mechanical problem under study.

In what refers to CFT columns, several numerical studies have been carried out worldwide. Two categories must be distinguished: global structural models and member models. The main numerical investigations which can be found in the literature are hereafter reviewed.

Among the global structural models which can be found in the literature, the work from Wang (1999) and Bailey (2000) must be highlighted.

Wang (1999) presented a global model which permitted to evaluate the effects of structural continuity on the fire resistance of composite columns of concrete filled steel tubes. Finite element analysis was used for obtaining the crosssectional temperature distributions and the structural response at elevated temperatures. For the thermal analysis, one-dimensional two-noded finite elements were used, with each element representing a circular slice of the cross-section. The structural response was obtained by means of a FEA computer program developed by the own author for steel and composite frames under fire conditions. The model from Wang made use of the thermal properties of the materials and stress-strain relationships from EN 1994-1-2 (CEN 2005c) and neglected the thermal resistance at the steel-concrete interface, as the composite cross-section was treated as a continuous medium with varying thermal properties.

Bailey (2000) also presented a global structural model which helped to investigate the effective lengths of CFT columns at the fire limit state. A purposewritten computer model based on the finite element method was extended to incorporate the structural behaviour of square CFT columns at ambient and elevated temperatures. The square concrete filled steel hollow sections were represented as one-dimensional two-noded finite elements with 7 degrees of freedom at each node. The cross-section was subdivided into a number of square or rectangular segments. 
The material constitutive models at elevated temperatures were taken as recommended by EN 1994-1-2 (CEN 2005c), and a concrete tensile strength equal to a $10 \%$ of its compressive strength for each temperature was used. The temperature distribution through the cross-section was previously obtained by means of the two-dimensional thermal computer package TFIRE. Since one-dimensional finite elements were used, local buckling could not be represented.

In the field of member analysis, one-dimensional, sectional and threedimensional models can be found in the literature. The two structural models presented before, make use of one-dimensional member submodels, being the more efficient from the computational point of view, but at the cost of adopting some simplified assumptions. Nevertheless, the most commonly found are the sectional (two-dimensional) and three-dimensional models. Amongst them, the following work must be highlighted, presented here in chronological order.

Renaud et al. (2003) presented a novel section fiber model based on displacement finite element methods with an Updated Lagrangian formulation to simulate the fire response of CFT columns, taking into account the interaction between the steel tube and the concrete core through an additional nodal degree of freedom. The composite column was modeled as an assemblage of three specific finite elements: a first beam-column element for a certain length of the steel hollow section, with two nodes and three degrees of freedom at each node (two translations and one rotation), a second beam-column element for the concrete core with the same characteristics and a connection element with two nodes and only one degree of freedom per node, corresponding to the discretisation of the distributed shear connection between the steel and concrete beam-column elements. The model accounted for both geometrical and material non-linearities as well as the crosssectional temperature distribution, which was previously obtained by solving a twodimensional transient heat transfer problem. Thermal and mechanical material properties from EN 1994-1-2 (CEN 2005c) were used, and an initial out-ofstraightness of the columns equal to $L / 500$ was considered.

Zha (2003) developed a finite element three-dimensional model for concrete filled circular hollow section columns. As a first step, the cross-sectional temperature field was obtained by means of a sectional model developed with the program FIRES-T (Iding et al. 1977). Once the temperature distribution was known, a time-dependent thermal-stress analysis was performed using DYNA3D, a threedimensional nonlinear finite element code for solid and structural mechanics. The model used eight-noded solid elements. Because of the symmetry of the problem, only one quarter section of the column was analysed. An initial imperfection equal 
to a $2 / 1000^{\text {th }}$ part of the length of the column was considered. For steel, the high temperature model from Witteveen et al. (1977) was used, and for concrete the stress-strain relations from Schneider (1988) were implemented.

Chung et al. (2008, 2009) developed a numerical model for predicting the fire resistance of concrete filled square steel tube columns subjected to concentric and eccentric loads. A simplified fiber based model with the cross-section discretized into square elements was designed, and an uncoupled thermal-stress analysis procedure was used. The temperature of the elements was obtained by means of the finite differences method. A subsequent load-displacement analysis was performed for obtaining the fire resistance of the columns. These authors assumed a series of simplifications in their model, as neglecting the local buckling of the steel tube and the interaction between the steel tube and the concrete core.

Yang et al. (2008a) presented a finite element model developed using Visual Fortran, where the column was divided into a small number of two-noded finite elements along its length and each cross-section was subdivided into a large number of blocks which represented the concrete or steel elements. The model was used to analyze the behaviour of CFT columns during the entire stage of fire exposure including loading at ambient temperature, heating, cooling to the ambient temperature and post-fire loading to failure. A series of simplifications were done, such as assuming that no slip occurs at the steel-concrete interface, eliminating the possible local buckling of the steel tube wall or neglecting the tensile strength of concrete.

Ding \& Wang (2008) presented an advanced three-dimensional model for circular and square CFT columns in fire. They included some important features which had often been neglected by other researchers (i.e. the thermal resistance at the steel-concrete interface) and obtained satisfactory results in terms of the fire resistance time. The model was developed by means of the commercial finite element analysis package ANSYS. A sectional model was first used to solve the transient heat transfer problem, and the resulting nodal temperatures were afterwards introduced as an input to a subsequent three-dimensional mechanical model. For the heat transfer analysis, 2-D solid thermal elements were used, whereas for the structural analysis eight-noded 3-D solid elements were considered. The effect of slip between the steel tube and the concrete core was simulated by a surface-tosurface contact, and an air gap thermal resistance was also used at the steel-concrete interface. The material properties at elevated temperatures were those recommended in EN 1994-1-2 (CEN 2005c), taking into account the moisture content. A user 
defined material subroutine was implemented in order represent the tensile behaviour of concrete.

Hong \& Varma (2009) developed few time later another three-dimensional model, in this case using the FEA software ABAQUS, for predicting the standard fire behaviour of square CFT columns. Nevertheless, these authors assumed no heat flux resistance at the steel-concrete boundary, aspect that might have produced important deviations in their numerical predictions. Their model consisted on a three-step sequentially coupled approach, were numerical models for each step of the analysis were developed: fire dynamics analysis, heat transfer analysis and stress analysis. The fire dynamics analysis was carried out by means of the program FDS (Fire Dynamics Simulator), developed by researchers from the NIST Building and Fire Research Laboratory. From this analysis, a temperature-time curve was obtained, which was subsequently applied to the columns as a thermal load in the heat transfer analysis step. For the heat transfer and stress analysis, threedimensional numerical models developed in ABAQUS were used, with eight-noded solid elements for the concrete core and four-noded shell elements for the steel tube. The longitudinal steel reinforcement was modeled using two-noded truss elements. From the different constitutive material models at elevated temperatures which were compared, the stress-strain curves from Poh (2001) for steel and Lie \& Irwin (1995) for concrete were finally adopted.

Schaumann et al. (2009) used a sectional numerical model to predict the fire behaviour of high strength CFT columns. The model was developed by means of the own authors' computer code BoFIRE, capable of predicting the thermal and structural behaviour of steel and composite structures exposed to fire. The procedure for calculating the load-bearing capacity of the columns was based on an incremental procedure coupling the thermal and mechanical response at each time step. Nonlinear material behaviour and temperature distribution were taken into account, and calculations were based on the Bernoulli hypothesis for plain state of strains. Four-noded isoparametric elements were used. A moisture content of $10 \%$ in concrete was considered, and an initial imperfection equal to $L / 1000$ was used. Due to the sectional nature of the model, it was not able to represent the complex local effects (local buckling and concrete cracking) that take place in a real fire situation, which explains the divergence between the calculated and test results.

$\mathrm{Lu}$ et al. (2009) presented a finite element model for investigating the fire behaviour of high strength self-consolidating concrete filled steel tubular stub columns of square section, complementary to an experimental program carried out by the same authors. The commercial FEA program ABAQUS was used in the 
analysis. A sequentially coupled thermal-stress analysis procedure was designed. Specific thermal properties for high strength concrete proposed by Kodur (2007) were used. The thermal expansion models for steel and concrete were those proposed by Lie (1994). For steel, uni-axial stress-strain relationships at elevated temperatures from Lie (1994) were also used. For concrete, the compressive uniaxial stress-strain relation proposed by Han et al. (2003b) was used, with a concrete damaged plasticity model. A heat contact conductance parameter of $100 \mathrm{~W} / \mathrm{m}^{2} \mathrm{~K}$ was used to describe the thermal resistance at the steel-concrete interface. The model was meshed with linear three-dimensional eight-noded solid elements for the concrete core, and linear four-noded shell elements for the steel hollow section. The model presented by these authors provided insight into the failure mechanism of CFT columns under fire exposure.

Recently, the group headed by professor Han at Tsinghua University (Beijing, China) (Song et al. 2010) developed a realistic finite element threedimensional model in ABAQUS to simulate a set of experiments of concrete filled steel tube stub columns under various thermal and mechanical loading conditions, as previously done in a more simplistic way in Yang et al. (2008a). The sequentially coupled thermal-stress analysis module in ABAQUS was used. Different stressstrain relationships at ambient, heating, cooling and post-fire conditions were used, as described in Yang et al. (2008a). The model was meshed by means of four-noded shell elements for the steel tube and eight-noded brick elements for the concrete core. A surface-based interaction with a contact pressure model in the normal direction and a Coulomb friction model in the tangential direction was used at the steel-concrete interface.

\subsection{EXPERIMENTAL INVESTIGATIONS}

At the level of experimental investigations, a number of fire testing programs have been carried out worldwide on CFT columns since the early 80 's. The first research reports were devoted to plain or bar-reinforced concrete filled columns of circular and square section, normally subjected to concentric axial loads except for some isolated cases. After a time, tests under eccentric loads appeared and more interest was paid on using other types of infill as steel fiber reinforced concrete or high strength concrete for increasing the fire resistance of the columns. Nowadays, other type of materials and section shapes are being investigated (i.e concrete filled double skin steel tubular columns), and the post-fire behaviour of CFT columns is also being studied. Also an increased interest is focused on large scale testing. 
The first reference to fire tests on CFT columns can be found in a publication dating back to 1917 (AFMFIC 1917), where amongst other types of building columns, concrete filled steel tubes were reported. Nevertheless, specific fire testing programs devoted to CFT columns do not appear until long time after.

The fire behaviour of composite hollow section columns was investigated for the first time in a research work sponsored by CIDECT (Comite International pour le Développement et l'Etude de la Construction Tubulaire). Between the years 1974 and 1982, several experimental programs were carried out (COMETUBE 1976, Grandjean et al. 1980, Kordina \& Klingsch 1983) in the framework of this research.

The CIDECT research project 15A (COMETUBE 1976) consisted of 75 tests on square concrete filled steel tubular columns, with the exception of one test carried out on a circular hollow section column. 50 columns were filled with ordinary concrete, 19 with reinforced concrete and 6 columns were tested as empty. The tests were carried out at Maizières-les-Metz and Champs-sur-Marne (France). Some columns were tested with external protection of different types. The sectional dimensions of the columns varied from $140 \mathrm{~mm}$ to $225 \mathrm{~mm}$ and the length of the columns was $3600 \mathrm{~mm}$.

In the CIDECT research project 15 B (Grandjean et al. 1980), circular and square CFT columns were tested. The sectional dimensions of the columns varied from $140 \mathrm{~mm}$ to $350 \mathrm{~mm}$ for the square columns and $406.3 \mathrm{~mm}$ for the circular columns. The length of the columns was $3600 \mathrm{~mm}$. Plain, bar-reinforced and steelfiber reinforced concrete columns were tested. The effect of the eccentricity was also investigated. In total, 86 fire tests were performed

The CIDECT research project 15 C (Kordina \& Klingsch 1983) presented tests on composite columns of different types, such as concrete filled steel hollow section columns, hot rolled open section columns embedded fully in concrete, cold formed $\mathrm{C}$ type section columns filled up with concrete and conventional solid steel columns. In total, 74 fire tests were carried out. Regarding CFT columns, 26 fire tests were performed in the facilities from Brunswick University (Germany), mainly on bar-reinforced square section columns, under eccentric loads and with column lengths between 3700 and $5700 \mathrm{~mm}$.

Fire resistance tests on hollow section columns filled with concrete were also carried out in Borehamwood (UK) in 1991 (Wainman \& Toner 1992). Three different sizes of circular hollow sections filled with concrete were tested, with diameters from $244.5 \mathrm{~mm}$ to $355.6 \mathrm{~mm}$. The columns were filled with plain concrete 
with a minimum 28 day cube strength of $40 \mathrm{MPa}$. The length of the columns was $3400 \mathrm{~mm}$, with an exposed length of $3100 \mathrm{~mm}$.

Fire tests on hollow section composite columns with high strength concrete (HSC) filling were reported in the CIDECT research project 15P (Hass et al. 2000). The purpose of this experimental program was to obtain the first fundamentals on the effect of using high strength concrete. Five small scale fire tests were carried out in order to study local effects at high temperatures (e.g. spalling) and one large scale fire test was performed in order to investigate the buckling behaviour of such columns. The tests were carried out in Brunswick (Germany).

More recently, a testing program on eccentrically loaded concrete filled tubular columns was carried out in France (Centre Technique Industriel de la Construction Métallique, CTICM), in the framework of the CIDECT research project 15R (Renaud \& Kruppa 2004), in order to validate the work on the development of a simplified calculation method for eccentrically loaded columns undertaken within the CIDECT project 15Q (Renaud et al. 2004). Four columns were tested under eccentric load, two of them of circular section and another two of square shape. All columns were filled with bar-reinforced normal strength concrete and had a length of $3450 \mathrm{~mm}$, although only $3100 \mathrm{~mm}$ were allocated inside the furnace. The eccentricities used were 0.75 and 1.5 times the sectional dimension.

Researchers from the Institute for Research in Construction at the National Research Council of Canada (NRCC) carried out several experimental programs between the years 1982 and 1994 (Lie \& Chabot 1992, Chabot \& Lie 1992, Kodur \& Lie 1995), testing CFT columns of circular and square sections filled with plain, bar-reinforced and steel-fiber reinforced concrete. The tested columns had sectional dimensions ranging from 141.3 to $406.4 \mathrm{~mm}$, steel tube wall thicknesses varying from $4.78 \mathrm{~mm}$ to $12.70 \mathrm{~mm}$, and a constant length equal to $3810 \mathrm{~mm}$. The columns were generally tested under fixed end conditions and subjected to concentric axial load, except for two of the tests, where the effect of the eccentricity was studied. Concrete mixes with 28-day cylinder compressive strength between $23 \mathrm{MPa}$ and 43 $\mathrm{MPa}$ were normally used, although in some concrete mixes higher strengths were achieved. The bar-reinforced specimens used a percentage of reinforcement around a $2.3 \%$, while for the steel-fiber reinforced columns, the percentage of steel fibers in the concrete mix was $1.76 \%$ by mass. The reinforced specimens, with either reinforcing bars or steel fibers, achieved in some cases fire resistances above 180 minutes. 
Some tests on high strength concrete filled tubular columns were carried out after a time in the NRCC facilities (Kodur \& Latour 2005). Six circular and two square CFT columns filled with high strength concrete were tested. The diameters of the circular columns varied from $219.1 \mathrm{~mm}$ to $406.4 \mathrm{~mm}$, while the width of the square sections was fixed to $203.2 \mathrm{~mm}$. The concrete strength at the age of 28 days varied from 68.4 to $90.50 \mathrm{MPa}$. The length of the column specimens was $3810 \mathrm{~mm}$ as in previous tests. Some of the specimens were reinforced by means of reinforcing bars or steel fibers, in order to improve the fire performance of high strength concrete.

In the last years, a great number of fire tests have been carried out in Fuzhou University (China) by the research group headed by professor Han (Han \& Huo 2003, Han et al. 2003 a,b, Han \& Lin 2004, Han et al. 2005). This research group obtained results of residual strength of concrete filled steel hollow section columns of circular and square shape under monotonic or cyclic load after exposure to a standard fire. Results are available on stub columns of $400 \mathrm{~mm}$ length (three times the diameter) and $D / t$ ratio equal to 27.7 , after 90 minutes of fire exposure. These columns were tested in Tianjin (China).

Some tests were also carried out by the same research group on slender columns (Han et al. 2003a). In this program, 13 slender CFT columns of circular section were tested, 5 of them externally protected. The parameters investigated were the diameter of the cross-section $(150-478 \mathrm{~mm})$, the steel tube wall thickness (4.6-8 $\mathrm{mm})$, the fire protection coat thickness $(0-25 \mathrm{~mm})$ and the load eccentricity ratio (0-0.6). All of the columns had a length of $3810 \mathrm{~mm}$. Two different concrete mixtures were used, with 39.6 and $68.8 \mathrm{MPa}$ average compression cube strength.

The research group from the University of Seoul (Korea) (Kim et al. 2005, Park et al. 2007, 2008) have recently carried out tests on concrete filled square steel tube columns under standard fire conditions, subjected to both concentric and eccentric axial loads. In a first research (Kim et al. 2005), seven concrete filled square columns of $300 \times 9$ and $350 \times 9 \mathrm{~mm}$ section and $3500 \mathrm{~mm}$ long were tested under concentric load and different effective heating lengths. Later on (Park et al. 2008) another 12 square CFT columns were tested under concentric load, all of them of $300 \times 9 \mathrm{~mm}$ section and filled with normal strength concrete.

Lu et al. (2009) carried out a series of fire tests on high strength selfconsolidating concrete filled steel tubular stub columns. Six columns of square section and $760 \mathrm{~mm}$ length with varying cross-section size, load case (concentric or eccentric load) and load level were tested. The cylinder compressive strength of 
concrete at 28 days was $90 \mathrm{MPa}$. Specimens were tested in the Civil Engineering Laboratory at Monash University (Clayton, Australia).

Recently, Romero et al. (2011) presented the results of an experimental program on slender axially loaded CFT columns subjected to fire, carried out in the testing facilities of AIDICO in Valencia (Spain). The aim of the testing program was to investigate the effects of three main parameters on the fire behavior of these columns: concrete strength $\left(f_{c}\right)$, type of concrete infilling (plain, bar-reinforced and steel fiber reinforced) and the load level $(\mu)$. Normal (NSC) and high strength concrete (HSC) mixtures were employed. In total, sixteen fire tests were carried out on axially loaded columns. All the tested columns were $3180 \mathrm{~mm}$ long and had a circular cross-section of $159 \times 6 \mathrm{~mm}$. Tests on eccentrically loaded columns have also been conducted by the same authors, and the results are ready to be published.

Also some experimental results on the post-fire bond between the steel tube and concrete core in CFT columns have been published recently (Tao et al. 2011). Push-out tests were carried out on 64 columns which had been exposed to ISO 834 standard fire for 90 or 180 minutes. 12 unheated specimens were also tested. The tests results showed that fire exposure had a significant effect on the bond between the steel tube and the concrete core. Both circular and square sections were used, and it was found that circular columns generally had much higher bond strength than square columns.

\subsection{SIMPLE CALCULATION MODELS (DESIGN GUIDELINES)}

The interest in the use and development of simple methods for calculating the fire resistance of concrete filled tubular columns is growing, due to the increased usage of this structural typology. Calculation tools are sought by designers in order to obtain an estimation of the fire resistance of the structural member, or conversely to be able to determine the minimum dimensions which fulfil the required fire resistance.

A number of design guides on the calculation of the fire resistance of CFT columns have been developed, amongst which one can find the Corus Tubes guide (Hicks \& Newman 2002) and the CIDECT guide (Twilt et al. 1996). In the latter of these guides, practitioners can find a number of design charts valid for the more commonly used cross-sectional dimensions, where the load-bearing capacity of the column for a certain fire exposure time is given as a function of its buckling length, cross-sectional dimensions and percentage of reinforcement. 
Authors as Zhao et al. (2010) or Rush et al. (2011) have reviewed the current methods that exist for calculating the fire resistance of CFT columns. Amongst these models, the following must be mentioned.

Kodur (1999) and co-workers developed a design equation for obtaining the fire resistance of CFT columns based on the results of the extensive experimental program carried out at the National Research Council of Canada. The proposed design equation is valid for CFT columns of circular and square shapes, filled with normal or high strength concrete and using different types of reinforcement: longitudinal bars or steel fibers.

Wang (2000) proposed an approximated method for obtaining the reduced squash load and rigidity of concrete filled circular hollow steel section columns at elevated temperatures, based on Eurocode 4 Part 1.2 (CEN 2005c). The method was developed through the analysis of the results of an extensive parametric study where numerical modelling procedures were used. The simple method proposed by Wang was valid for both unprotected and protected columns.

Han et al. (2003a,b) presented an empirical design equation based on the results from an experimental program carried out in China, where the influence of the main design variables that affect the fire behaviour of CFT columns was investigated. Expressions for circular and square geometries were adjusted, which provided the strength index of the columns at elevated temperatures, as referred to their maximum axial capacity at room temperature. Also a simple equation for obtaining the residual strength of CFT columns after fire exposure was developed by Han and co-workers (Han \& Huo 2003, Han \& Lin 2004).

Several design codes are also in use nowadays, which are a result of the numerical and experimental investigations carried out by the main groups working in this field of research.

The expressions proposed by Han et al. $(2003 \mathrm{a}, \mathrm{b})$ have been incorporated in the Chinese Code DBJ13-51 (2003), which establishes an equation to calculate the thickness of the external fire protection required to achieve a certain fire resistance, as well as a method for calculating the strength index of unprotected columns in the fire situation.

In turn, the preferred method in Japan (Harada 2004) is the simple formula given in the design guide manual for CFT columns published by the Association of New Urban Housing Technology (ANUHT 2004). 
In Korea, an empirical formula was suggested by Park et al. $(2007,2008)$ for square CFT columns subjected to axial loading, using regression analysis based on a previously established relationship between the fire resistance and the parameters width of the column, concrete strength and applied axial load ratio.

The approach from Kodur and co-workers (Kodur 1999, 2007, Kodur \& MacKinnon 2000) is in use in North America after having been incorporated into the National Building Code of Canada (NRCC, 2005), ASCE/SFPE 29-99 (ASCE 1999), ACI 216 (ACI 2007) and AISC Steel Design Guide 19 (Ruddy et al. 2003). This approach consists of a single design equation which includes the main parameters affecting the fire resistance of CFT columns.

In Europe, the most extended methods for calculating the fire resistance of CFT columns are those included in EN 1994-1-2 (CEN 2005c). Three levels of design are allowed: a) tabulated data, b) simple calculation models and c) advanced calculation models. Option a) is available in Clause 4.2.3.4 in the form of a selection table which provides the minimum cross-sectional dimensions and reinforcement that a CFT column must have in order to achieve a rated standard fire resistance under a certain load level. This approach is the most simplistic and results highly conservative as pointed out by Rush et al. (2011). Option b), simple calculation models, are the most widespread, and amongst them a full method is presented for calculating the fire resistance of composite columns in Clause 4.3.5.1 based on the elastic buckling theory. A specific method for columns composed of unprotected concrete filled hollow sections is also given in Annex $\mathrm{H}$ of the same code. Finally, advanced calculation models (option c) allow the use of finite element models capable to simulate the realistic fire behaviour of the element based on the modelling of the actual thermo-mechanical problem. This last approach can provide a more accurate approximation of the behaviour, but is generally out of reach of practitioners and often due to limited time or resources it is only applied to very specific design situations.

Authors as Wang (1997, 2000, 2008), Aribert et al. (2008), Ribeiro et al. (2008) or Leskela (2009) have focused on the study of the simple calculation model in EN 1994-1-2 (option b). Because of the complexity of the specific method in Annex $\mathrm{H}$ and after having been proved that it produces unsafe results for slender columns (Wang \& Orton 2008, Aribert et al. 2008), authors are more inclined to follow the general principles in Clause 4.3.5.1, which cover all types of composite columns. However, only a few studies have been carried out so far to investigate the applicability of the general method in Clause 4.3.5.1 to CFT columns, as it is the case of the CTICM group in France (Renaud et al. 2004, Aribert et al. 2008), whose 
work has led to the rules published in the French National Annex to EN 1994-1-2 (AFNOR 2007).

\subsection{ELLIPTICAL HOLLOW SECTION COLUMNS}

The structural behaviour of the elliptical sections has been deeply studied in recent years by Gardner and Chan (Gardner \& Chan 2007, Gardner et al. 2008, Chan \& Gardner 2008a,b), covering cross-section classification and the evaluation of compressive, shear and bending resistances. Furthermore, the elastic buckling response of elliptical hollow sections in compression has been studied by RuizTeran \& Gardner (2008) and Silvestre (2008). A review article was published by Gardner et al. (2010) on the structural design of elliptical hollow sections, which compiles the previous developments. In a more recent work, Gardner et al. (2011) studied the structural behaviour of elliptical hollow sections under combined compression and uniaxial bending. Law \& Gardner (2012) have also studied the lateral instability of elliptical hollow section members in bending.

The effect of filling EHS columns with concrete has been examined by Yang et al. (2008) and Zhao \& Packer (2009), through testing stub columns under compressive axial load at room temperature. Also concrete filled stainless steel elliptical stub columns have been experimentally investigated recently (Lam et al. 2010).

Yang et al. (2008) carried out an experimental programme consisting of 21 test specimens filled with three different concrete grades (C30, C60 and C100), 15 of which were compositely loaded, the rest being core-loaded. They found out that higher tube thickness improved the load-bearing capacity and ductility of the columns, while higher concrete strength resulted in higher load-bearing capacity but reduced ductility. The confinement provided to the concrete core by the elliptical steel tubes was also assessed, finding that the strength and ductility of the concrete was greatly improved. Through comparing their experimental results with existing code provisions for concrete filled hollow sections, Yang et al. (2008) confirmed that the behaviour of concrete filled elliptical hollow section (CFEHS) columns lies between that of concrete filled circular and square/rectangular hollow sections. According to the authors, the EN 1994-1-1 (CEN 2004b) design expression for SHS and RHS provides an accurate and safe prediction of the compressive response of CFEHS.

Zhao \& Packer (2009) performed a series of tests on normal and selfconsolidating concrete filled elliptical hollow section stub columns with different 
loading methods (compositely loaded, core-loaded and tube-loaded). The experimental load-carrying capacity of the tested specimens was compared with different code provisions. The authors proposed several design formulae, through three approaches: simple superposition of steel and concrete strengths, CFCHS approach and CFRHS approach, concluding that the existing design rules for circular and rectangular hollow section tubes are applicable to CFEHS stub columns, provided that appropriate equivalent section properties are used.

Dai \& Lam (2010) recently developed a numerical model to represent the axial compressive behaviour of short concrete filled elliptical steel columns. They studied the differences in concrete confinement between circular and elliptical hollow sections, finding that the circular hollow sections provided higher confinement than the elliptical ones. Unlike the uniform contact stress distribution around the perimeter of circular sections, the contact forces along the perimeter of elliptical sections were non-uniform, with higher stresses at the sharper corners. Based on this study, Dai \& Lam developed a stress-strain model for concrete confined by elliptical steel hollow sections.

Despite the room temperature behaviour of EHS columns being widely studied in the last few years, with some incursions on the effect of filling these sections with concrete, the performance of CFEHS columns in the fire situation has not yet been investigated. Some recent work on unfilled EHS columns subjected to fire carried out by Scullion et al. (2011a, 2011b, 2012) can be found in the literature, but no experimental studies have been carried out so far on concrete filled EHS columns exposed to fire. The only work related to the matter is that from Dai \& Lam (2012), coinciding in time with the redaction of this thesis. The authors studied through numerical simulation the effect of the sectional shape on the behaviour of axially loaded CFT stub columns, showing that circular sections possess the best structural fire behaviour, followed by columns with elliptical, square and rectangular sections. It is worth noting that no study on slender concrete filled elliptical hollow section columns at elevated temperatures has been presented yet, nor any design method for the calculation of the fire resistance of CFEHS columns has been verified or developed. 



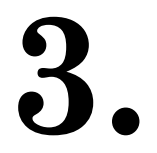

\section{AIM AND SCOPE OF THIS THESIS}

This chapter presents the general aim of this research work, as well as the specific objectives which are established throughout this thesis for its consecution. The scope and limitations of this investigation are also established. 


\subsection{AIM OF THIS THESIS}

The general aim of this thesis is to investigate the fire behaviour of axially loaded concrete filled steel hollow section columns of circular and elliptical crosssection. For that purpose, a three-dimensional nonlinear finite element model will be developed. The numerical model will be validated against experimental fire tests and, once the model is validated, it will be used to analyze the influence of the main parameters that affect the fire behaviour of concrete filled tubular columns.

By means of the validated model, the provisions of the different design codes, focusing especially in Eurocode 4, will be discussed. Parametric studies will be carried out with the aim of generating design recommendations and to develop a simple calculation method which will serve as a reference to designers in the future.

As it has been previously mentioned in the state of the art review, despite the room temperature behaviour of concrete filled elliptical hollow section columns being widely studied in the last few years, the performance of these columns in the fire situation has not yet been investigated. It will be therefore the aim of this thesis to provide a realistic representation of the fire behaviour of CFEHS columns, and to establish the difference in fire performance with the circular shapes, as well as to provide a method for the calculation of the fire resistance of this novel shapes.

\subsubsection{Specific objectives}

For the consecution of the final aim of this thesis, the following specific objectives must be previously solved:

- Review of the current models available in the literature for characterizing the behaviour of the materials involved in the composite section at elevated temperatures, and for solving the fire dynamics, heat transfer and structural analysis problems.

- Development of a three-dimensional nonlinear finite element model for CFT columns in the fire situation which includes the most realistic considerations, in such a way that the whole response of the columns during the fire exposure is obtained with precision.

- Determination of the appropriate values of the different parameters of the model through an extensive sensitivity analysis. 
- Validation of the numerical model against experimental fire tests available in the literature, as well as by means of own tests from the author's research group. Detailed analysis of those aspects which cannot be investigated through fire testing.

- Conduction of parametric studies, which cover the range of values commonly found in practice for the different variables of the problem, and which permit to draw conclusions on their influence.

- Study of the provisions of the available design guidance and verification of their accuracy through the results of numerical simulations.

- Development of a simple calculation model which will serve as a reference to designers in the future, improving the accuracy of the current methods in Eurocode 4 Part 1.2 and extending its current field of application.

- Comparison of the relative effectiveness in fire performance between the circular and elliptical shapes, and development of calculation tools for the determination of the fire resistance of CFEHS columns, which has not been studied up to now.

\subsection{SCOPE AND LIMITATIONS OF THIS THESIS}

The scope of this thesis is restricted to unprotected CFT columns of circular and elliptical shape, filled with normal strength concrete and subjected to concentric loads. Plain and bar-reinforced concrete fillings will be studied and included in the proposed simple calculation method.

The field of application of this thesis is limited to columns subjected to concentric loads, although some columns tested under eccentric load have been used in the validation process. Nevertheless, due to the extension of this work, the particularities on the fire behaviour and all what refers to the calculation methods of columns subjected to eccentric loads will be left out for future work.

This thesis will focus mainly on slender columns, which are likely to fail due to overall buckling, as the final aim is to develop a method for predicting the buckling loads at elevated temperatures, therefore stub columns will not be included in this work. 



\section{4.}

\section{DEVELOPMENT OF THE} NUMERICAL MODEL

This chapter presents a complete description of the finite element model developed for the investigation of the fire performance of CFT columns and its validation process. The main characteristics of the model are described in detail, and based on a comprehensive sensitivity analysis, the values of the relevant parameters of the model are selected. The numerical model is validated against fire tests available in the literature, as well as with own tests carried out in a parallel investigation. 


\subsection{CHARACTERISTICS OF THE NUMERICAL MODEL}

\subsubsection{Geometry and finite element mesh of the model}

A three-dimensional numerical model for simulating the fire behaviour of concrete filled circular steel hollow section columns was developed with the aid of the general purpose nonlinear finite element analysis package ABAQUS (2010). The main parameters of the model were the column length $(L)$, the external diameter $(D)$, the steel tube thickness $(t)$, the end conditions, the axial load level $(\mu)$, the percentage of reinforcement $(\rho)$ and the material properties. It consisted of three parts: the concrete core, the steel tube and the loading plate (Figure 4.1). Owing to symmetry on both the geometry and the boundary conditions, only a quarter of the column was modelled, for those specimens with pinned-pinned or fixed-fixed end conditions. For the pinned-fixed columns, the whole length was required due to the loss of symmetry on the boundary conditions, and therefore the columns were modelled with their whole length and half section.

The loading plate was modelled as a perfectly elastic part and through this element the applied axial load was transmitted to both the concrete core and the steel tube.

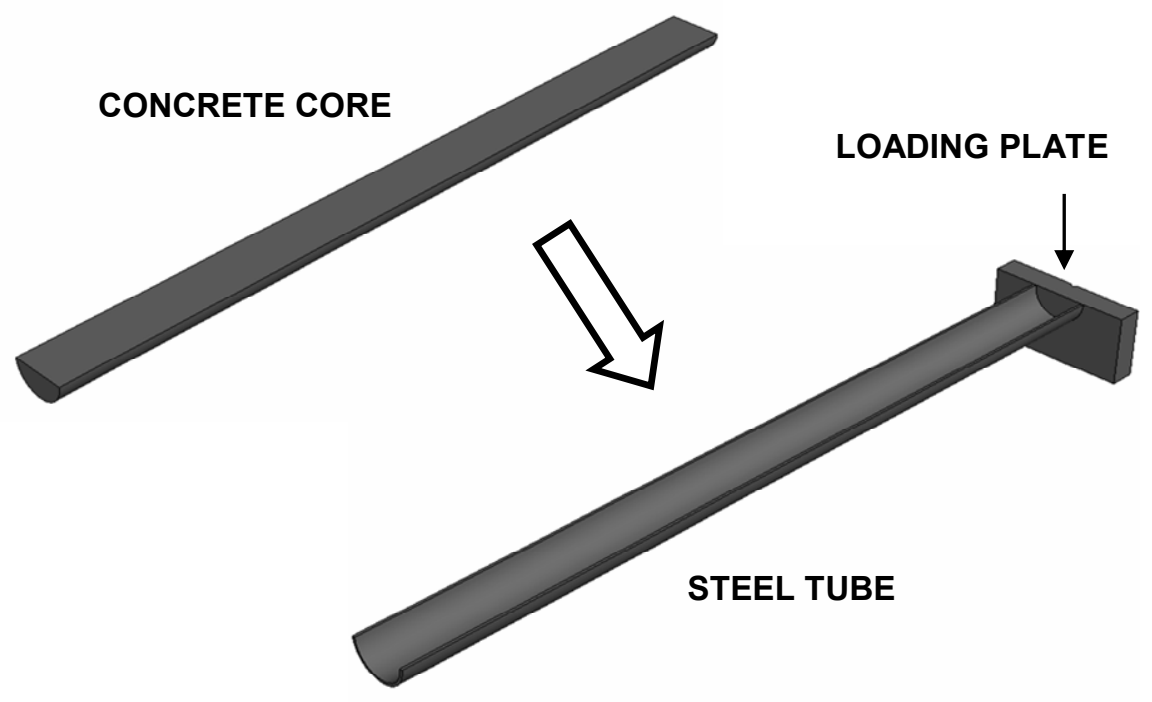

Figure 4.1. Different parts which compose the model. 
The different parts of the model were assembled, defining the appropriate thermal and mechanical interaction properties between them, which will be described with more detail in Section 4.1.8. Once assembled, the model presents the appearance shown in Figure 4.2.

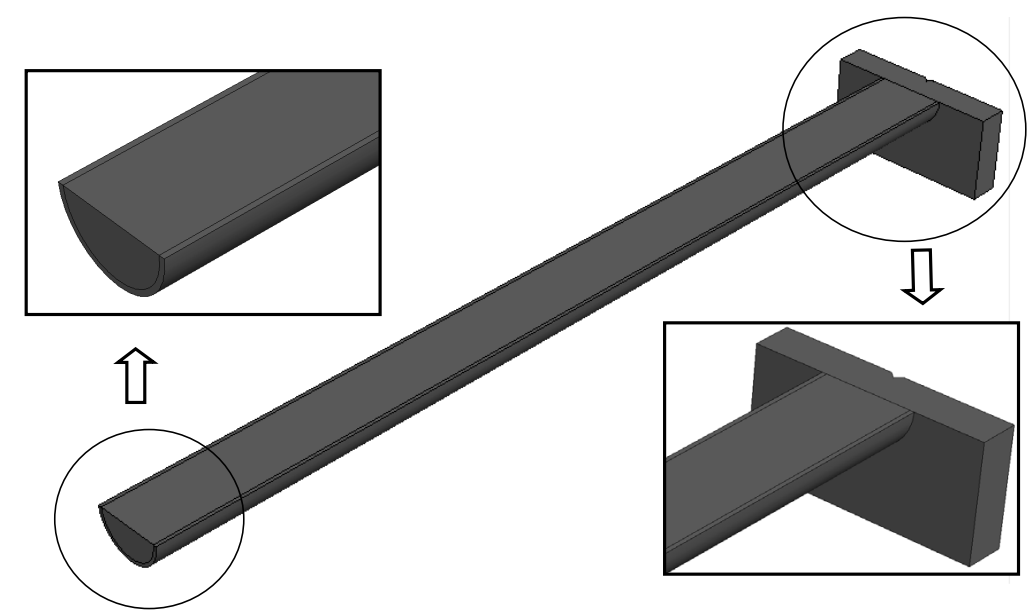

Figure 4.2. Details of the assembly of the different parts of the model.

The model was meshed with three-dimensional eight-noded solid elements for both the steel tube and the concrete core, and two-noded truss elements for the reinforcing bars. The loading plate was meshed by means of four-noded solid elements (Figure 4.3). The degrees of freedom which were active in the model were different in the case of the thermal and mechanical models, as it will be pointed out later.

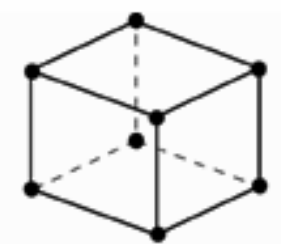

a) 8 node linear brick

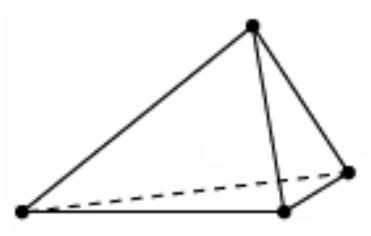

b) 4 node linear tetrahedron

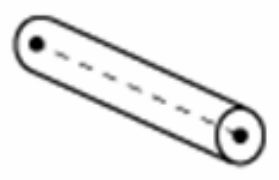

c) 2 node truss

Figure 4.3. Different types of finite elements used in the model (ABAQUS 2010). 
The mesh density was controlled to have a maximum element size of $2 \mathrm{~cm}$, which proved to be sufficient to predict with enough accuracy the thermal and mechanical behaviour of the CFT columns under fire. Figure 4.4 shows the finite element mesh for one of the CFT column specimens analysed.
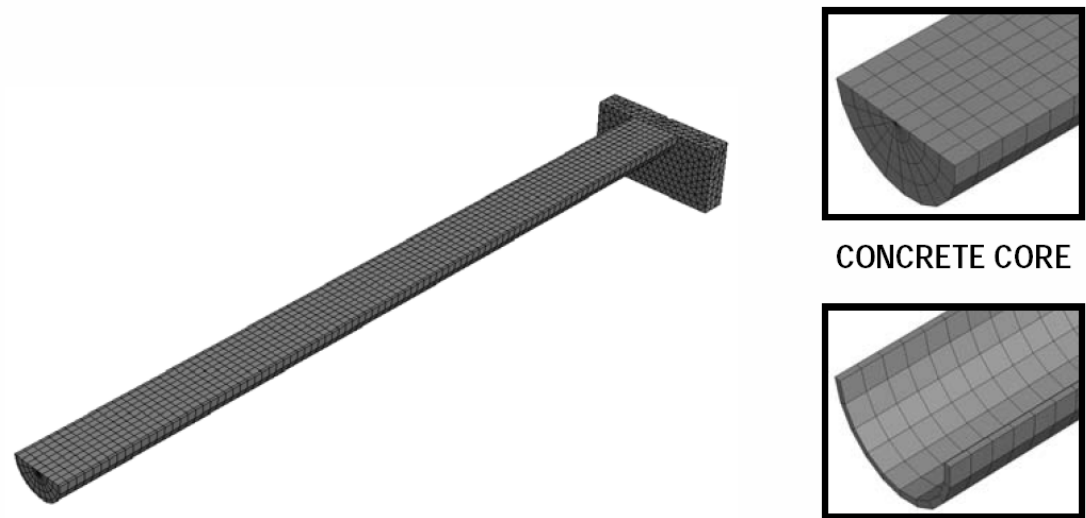

CONCRETE CORE

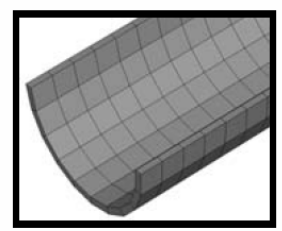

STEEL TUBE

Figure 4.4. Finite element mesh of the model.

\subsubsection{Material properties at elevated temperatures}

The numerical model took into account the temperature dependent thermal and mechanical properties of the materials. All the selected values that are presented here will be further discussed in the sensitivity analysis section.

\subsubsection{Thermal properties at elevated temperatures}

The thermal properties for concrete at elevated temperatures were extracted from EN 1992-1-2 (CEN 2004a).

The moisture content of the concrete infill was taken into account through a peak value in the specific heat, representing the latent heat of water vaporisation. EN 1994-1-2 (CEN 2005c) recommends a peak value of $2020 \mathrm{~J} / \mathrm{kgK}$ for a moisture content of $3 \%$ in concrete weight, and $5600 \mathrm{~J} / \mathrm{kgK}$ for a moisture content of $10 \%$. The peak value was selected for each case specimen analysed in function of its moisture content, if known. 
For structural steel, the temperature dependent thermal properties recommended in EN 1993-1-2 (CEN 2005b) were adopted. For the reinforcing steel, the thermal properties were the same that those used for the structural steel, as indicated in EN 1994-1-2 (CEN 2005c).

The value of the thermal expansion coefficient for concrete recommended by Hong \& Varma (2009) was employed: $\alpha_{c}=6 \times 10^{-6}{ }^{\circ} \mathrm{C}^{-1}$. For steel, the temperature dependent values of the thermal expansion coefficient from EN 1993-1-2 (CEN 2005b) were adopted.

\subsubsection{Concrete material model at elevated temperatures}

For characterizing the behaviour of brittle materials as concrete, ABAQUS (2010) offers several models available. Amongst the different options, the DruckerPrager model was selected. This model represented with the required precision the mechanical response of concrete at elevated temperatures in the simulations, at the same time that minimizing the convergence problems associated with concrete in tension. A robust and sufficiently accurate model was designed.

Drucker \& Prager (1952) extended the von Mises yield criterion to include the effect of hydrostatic pressure on the shearing resistance of the material (Chen 1982). This model is commonly used to represent materials in which the compressive yield strength is greater than the tensile yield strength (as concrete) and is intended to simulate material response under essentially monotonic loading, as it is the case of the problem object of this thesis. The theoretical fundamentals of the Drucker-Prager model are presented next.

\section{Stress invariants}

For the stress tensor $\sigma_{i j}$, the invariants are defined as follows:

$$
\begin{aligned}
& I_{1}=\operatorname{trace}\left(\sigma_{i j}\right) \\
& I_{2}=\left(\sigma_{11} \cdot \sigma_{22}+\sigma_{11} \cdot \sigma_{33}+\sigma_{22} \cdot \sigma_{33}\right)-\tau_{12}{ }^{2}-\tau_{13}{ }^{2}-\tau_{23}{ }^{2} \\
& I_{3}=\operatorname{det}\left(\sigma_{i j}\right)
\end{aligned}
$$

Any combination of the stress invariants will also be an invariant.

Due to the symmetry of the stress tensor, it can be separated into two symmetric tensors: one representing pure shear states of stress, called deviatoric stress tensor $S_{i j}$, and the other representing hydrostatic states of stress, called spherical stress tensor $P_{i j}$. 
The spherical stress tensor is defined as:

$$
P_{i j}=\frac{I_{1}}{3} \delta_{i j}
$$

where $\delta_{i j}$ is the Kronecker delta, which is defined as being equal to 1 if $i$ and $j$ are the same numbers and 0 otherwise.

The deviatoric stress tensor is obtained as the difference between the stress tensor and the spherical tensor:

$$
S_{i j}=\sigma_{i j}-\frac{I_{1}}{3} \delta_{i j}
$$

Once the deviatoric stress tensor $S_{i j}$ is obtained, the previously defined invariants can be applied to this new tensor, being:

$$
\begin{aligned}
& J_{1}=\operatorname{trace}\left(S_{i j}\right) \\
& J_{2}=\left(S_{11} \cdot S_{22}+S_{11} \cdot S_{33}+S_{22} \cdot S_{33}\right)-S_{12}{ }^{2}-S_{13}{ }^{2}-S_{23}{ }^{2} \\
& J_{3}=\operatorname{det}\left(S_{i j}\right)
\end{aligned}
$$

The value of $J_{1}$ is 0 , since it represents the mean stress and this tensor only includes the deviatoric component of the stress state.

Once the invariants $I_{1}, I_{2}, I_{3}, J_{1}, J_{2}, J_{3}$ have been presented, the Drucker-Prager yield stress surface can be now defined.

The yield stress surface makes use of two invariants, which are a combination of those previously presented, and are defined as the equivalent pressure stress,

$$
p=-\frac{1}{3} \operatorname{trace}\left(\sigma_{i j}\right)=-\frac{1}{3} I_{1}
$$

and the Mises equivalent stress,

$$
q=\sqrt{3 J_{2}}
$$

The equivalent pressure stress $p$ is defined as the mean, octahedral, spherical or hydrostatic stress, being normal to the octahedral plane, which forms the same angle with the three principal stress axes. 
The Mises equivalent stress $q$ is defined as the effective or uniaxial equivalent stress value, and represents the radius vector of the curve which defines the fluency dominium in the octahedral plane.

In addition, the linear model also uses the third invariant of deviatoric stress, through the parameter $r=\left[\frac{9}{2}\left(S_{11}^{3}+S_{22}^{3}+S_{33}^{3}\right)\right]^{1 / 3}$.

This parameter, together with $p$ and $q$, permits to locate a certain stress state in an octahedral plane; as the first invariant of the stress tensor defines the position of the octahedral plane and the second invariant of the deviatoric stress tensor fixes the limits of the plane. The third invariant of the deviatoric stress tensor defines the third and last component of the Haigh-Westergaard cylindrical coordinate system.

\section{Drucker-Prager yield criterion}

The yield criteria for this class of models are based on the shape of the yield surface in the meridional plane. The yield surface can have a linear form, a hyperbolic form, or a general exponent form, options which can be seen in Figure 4.5 .

The linear model (Figure 4.5a) provides for a possibly noncircular yield surface in the deviatoric plane (П-plane) to match different yield values in triaxial tension and compression, associated inelastic flow in the deviatoric plane, and separate dilation and friction angles. Input data parameters define the shape of the yield and flow surfaces in the meridional and deviatoric planes, as well as other characteristics of inelastic behavior.

The hyperbolic (Figure 4.5b) and general exponent (Figure 4.5c) models use a von Mises (circular) section in the deviatoric stress plane. In the meridional plane, a hyperbolic flow potential is used for both models, which, in general, means nonassociated flow.

The linear model is intended primarily for applications where the stresses are for the most part compressive. If tensile stresses are significant, the hyperbolic model should be used. In this investigation, the linear model was used, and therefore it is described in more detail next. 
a)

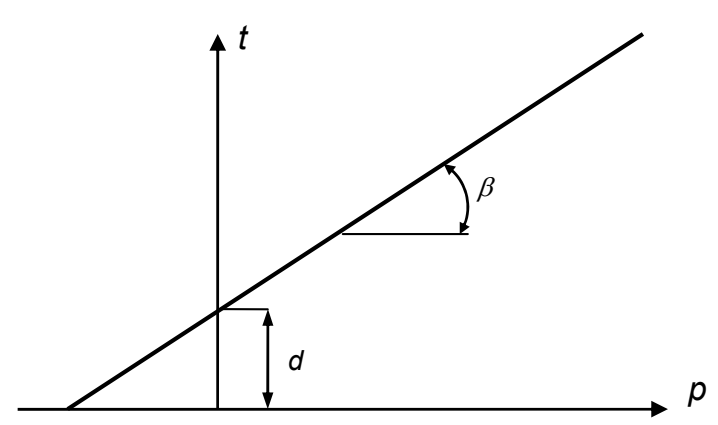

b)

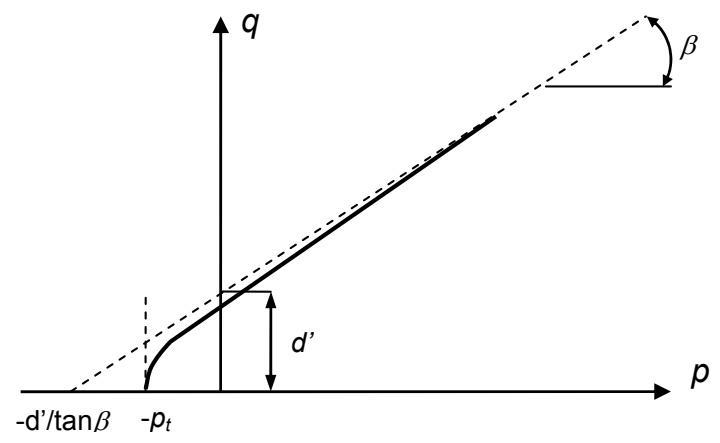

c)

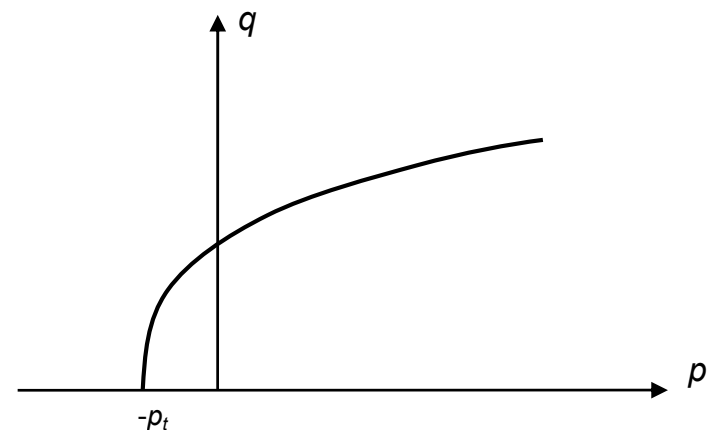

Figure 4.5. Yield surfaces in the meridional plane: a) linear model, b) hyperbolic model, c) general exponent model. 


\section{Linear Drucker-Prager model}

The yield criterion makes use of the previously defined stress invariants $p, q$ and $r$ and is written as:

$$
F=t-p \tan \beta-d=0
$$

where:

- $t=\frac{1}{2} q\left[1+\frac{1}{K}-\left(1-\frac{1}{K}\right)\left(\frac{r}{q}\right)^{3}\right]$

- $\beta$ is the slope of the linear yield surface in the $p-t$ stress plane and is commonly referred to as the friction angle of the material;

- $d$ is the cohesion of the material, which is related to the concrete compressive strength: $d=\left[1-\frac{\tan \beta}{3}\right] f_{c}$; and

- $K$ is the ratio of the yield stress in triaxial tension to the yield stress in triaxial compression and, thus, controls the dependence of the yield surface on the value of the intermediate principal stress.

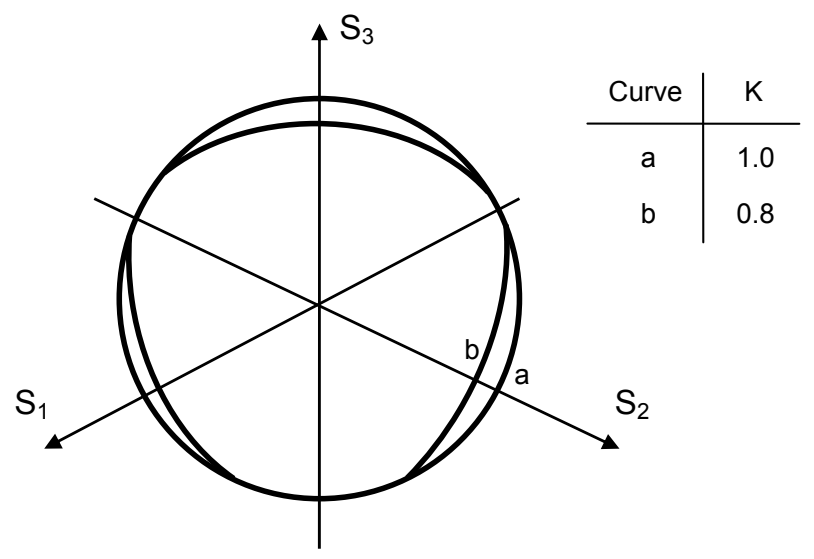

Figure 4.6. Typical yield/flow surfaces in the deviatoric plane. 
When $K=1, t=q$, which implies that the yield surface is the von Mises circle in the deviatoric principal stress plane (the П-plane), in which case the yield stresses in triaxial tension and compression are the same. To ensure that the yield surface remains convex requires values of $K$ between 0.778 and 1 .

\section{Plastic flow}

$G$ is the flow potential, chosen in this model as:

$$
G=t-p \tan \psi
$$

where $\psi$ is the dilation angle in the $p$ - $t$ plane. A geometric interpretation of $\psi$ is shown in the $p-t$ diagram of Figure 4.7.

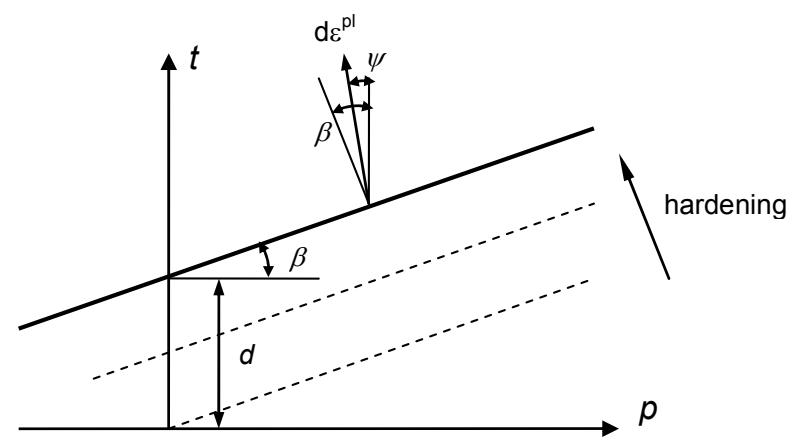

Figure 4.7. Yield surface and flow direction in the $p-t$ plane.

If $\psi=0$, the inelastic deformation is incompressible; if $\psi \geq 0$, the material dilates. Hence, $\psi$ is referred to as the dilation angle. Associated flow results from setting $\psi=\beta$. In the case of nonassociated flow, it is assumed that the flow is normal to the yield surface in the $\Pi$-plane but at an angle $\psi$ to the $t$-axis in the $p-t$ plane, where usually $\psi<\beta$, as illustrated in Figure 4.7. For granular materials, the linear model is normally used with nonassociated flow in the $p-t$ plane.

The stress-strain curves for concrete in uniaxial compression are built up with points of yield stress values versus equivalent plastic strain for a certain temperature. As the problem under study is temperature-dependent, different stress-strain curves must be defined for the different expected temperatures, therefore a constitutive model for concrete at elevated temperatures is needed. 
The stress-strain relations for concrete under compression proposed by Lie (1984) were employed, showing the more realistic response as will be demonstrated later on in the sensitivity analysis section. The accuracy of this constitutive model for representing the behaviour of the concrete infill in CFT columns at elevated temperatures has also been proved by other authors (Hong \& Varma 2009).

The initial elastic behaviour was defined at each temperature by means of the elastic modulus and Poisson's ratio. The Poisson's ratio was assumed to be independent of the temperature, and equal to 0.2 .

Figure 4.8 shows the elevated temperature stress-strain curves obtained with the concrete model used, for a $30 \mathrm{MPa}$ compressive strength concrete.

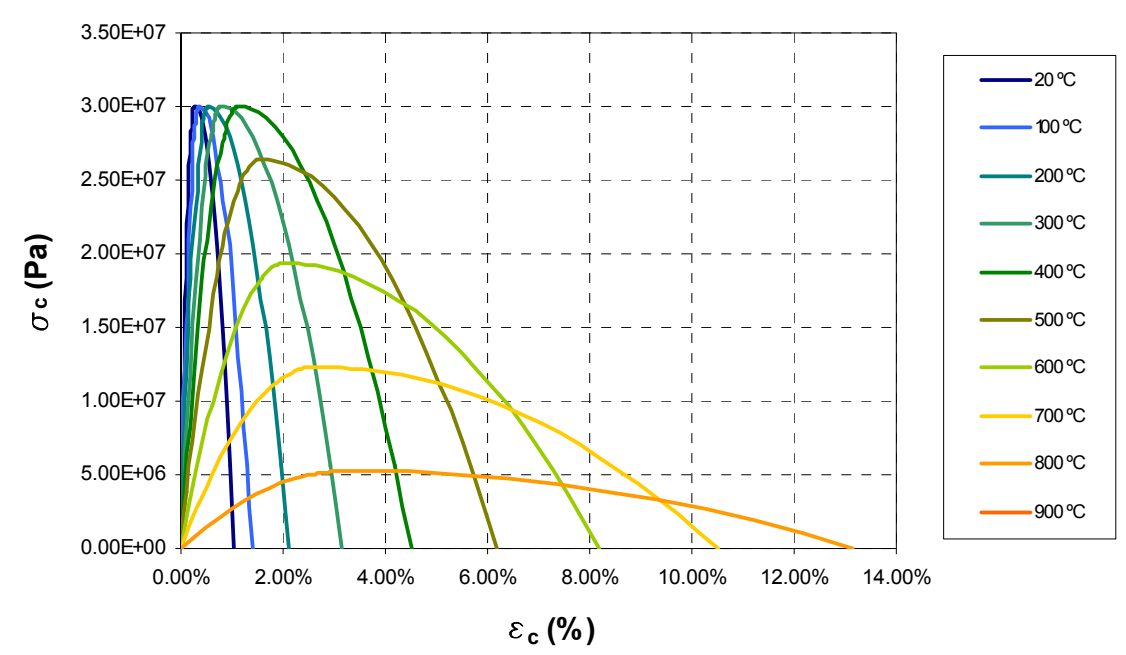

Figure 4.8. Stress-strain curves at elevated temperatures for a $30 \mathrm{MPa}$ concrete, obtained from the model proposed by Lie.

\subsubsection{Steel material model at elevated temperatures}

For representing the mechanical behaviour of steel, an isotropic elasto-plastic model in ABAQUS (2010) was chosen. The model makes use of the von Mises yield criterion, which is independent of the hydrostatic pressure, as it is confirmed experimentally for most metals. The model is defined through a uniaxial stress-strain curve as that obtained from the tensile strength test. 
The von Mises yield criterion suggests that the yielding of materials begins when the second deviatoric stress invariant $J_{2}$ reaches a critical value. The von Mises yield criterion can be also formulated in terms of the Mises equivalent stress, $\sigma_{v}$, a scalar stress value that can be computed from the stress tensor. In this case, a material is said to start yielding when its Mises equivalent stress, defined through equation (4.9), reaches the yield strength, $f_{y}$.

$$
\sigma_{v}=\sqrt{3 J_{2}}=\sqrt{\frac{1}{2}\left[\left(\sigma_{1}-\sigma_{2}\right)^{2}+\left(\sigma_{2}-\sigma_{3}\right)^{2}+\left(\sigma_{1}-\sigma_{3}\right)^{2}\right]}
$$

The von Mises yield surface in the three-dimensional space of principal stresses is a circular cylinder of infinite length with its axis inclined at equal angles to the three principal stresses, Figure 4.9.

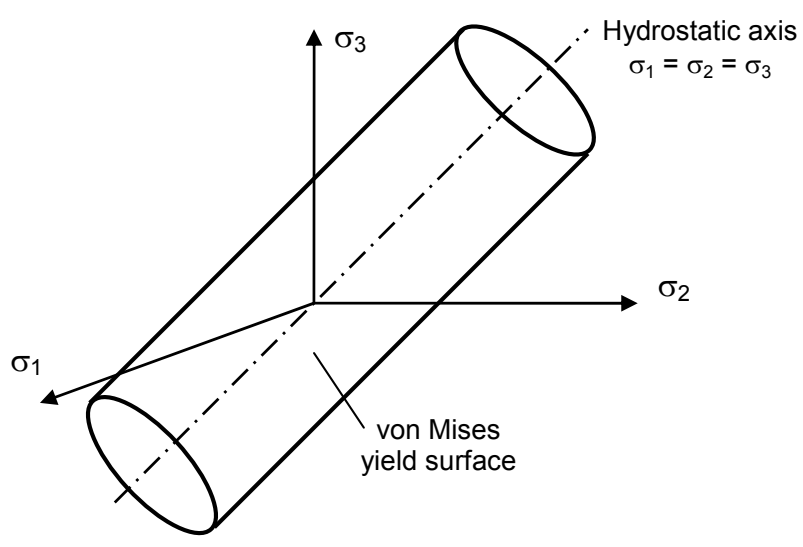

Figure 4.9. Von Mises yield criterion in the three-dimensional principal stress space.

The model uses an associated plastic flow rule, which means that there is no volumetric plastic strain, i.e., the plastic strains, once the stresses have met the yield criterion, have the direction normal to the yield surface. This assumption is valid for most metals.

The points of the uniaxial stress-strain curve for steel are defined as pairs of yield stress values versus equivalent plastic strain for a certain temperature. For the elastic part, the elastic modulus and Poisson's ratio were defined. The constitutive model selected for representing the uniaxial behaviour of steel at elevated temperatures was that from EN 1993-1-2 (CEN 2005b). The Poisson's ratio was assumed to be independent of the temperature, and equal to 0.3 . The strength and elastic modulus of steel at elevated temperatures were obtained by applying the 
reduction coefficients in EN 1993-1-2 (CEN 2005b) to their corresponding room temperature values.

For the reinforcing steel, the strength and deformation properties were obtained by means of the same mathematical model as that of the structural steel, but with the reduction factors recommended in EN 1992-1-2 (CEN 2004a).

Figure 4.10 shows the elevated temperature stress-strain curves obtained with the steel model used, for a tensile strength of $275 \mathrm{MPa}$.

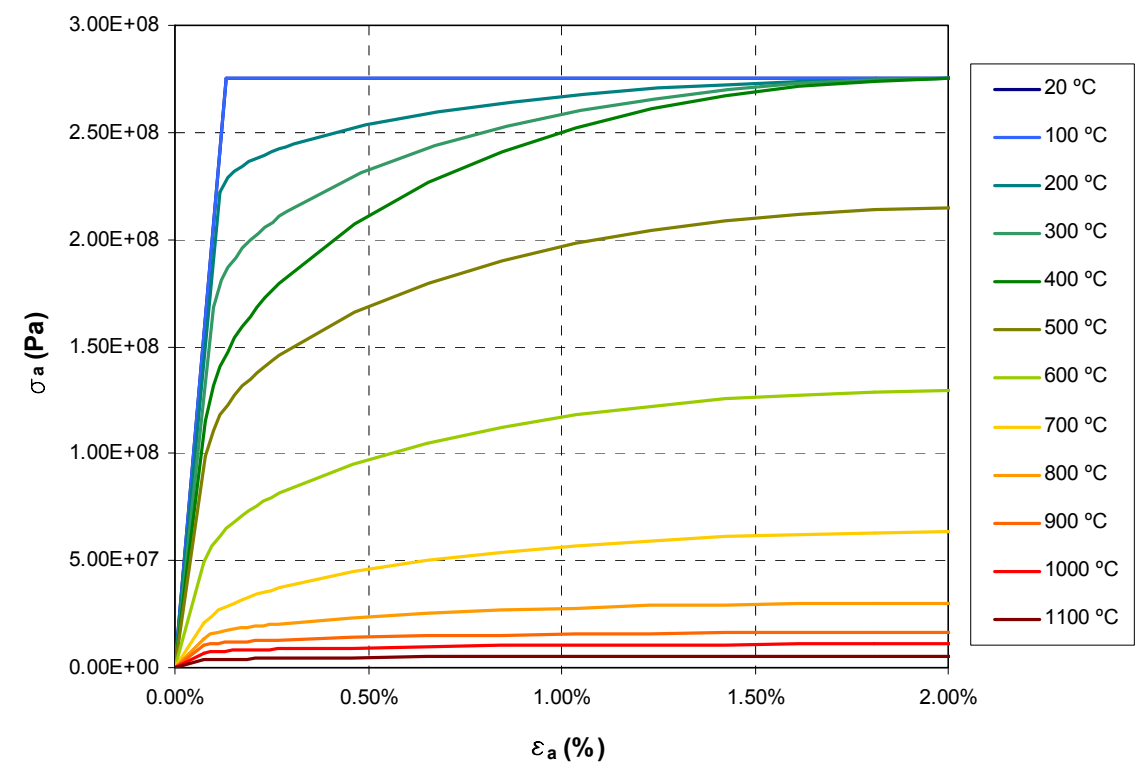

Figure 4.10. Stress-strain curves at elevated temperatures for a S275 steel, obtained from the EC3 model.

\subsubsection{Initial geometric imperfection of the column}

The numerical model took into account the possible out-of-straightness of the column specimens. This initial geometric imperfection of the column specimens was simulated in the model as the first buckling mode shape of the hinged column multiplied by an amplification factor. For this purpose, a previous eigenvalue analysis of the model was conducted over a pinned-pinned column subjected to axial loading. Once the initial shape of the column was obtained, it was imported to the mechanical model as the starting geometry from which to run the analysis. An 
amplification factor equal to the maximum imperfection along the length of the column was then applied. The value of $L / 1000$ employed by the majority of researchers for the amplification factor was used (Ding \& Wang 2008). The selection of this value will be later on discussed in the sensitivity analysis section.

The deformed shape obtained for each of the column specimens by means of this procedure was employed as the initial geometry for conducting the thermomechanical analysis.

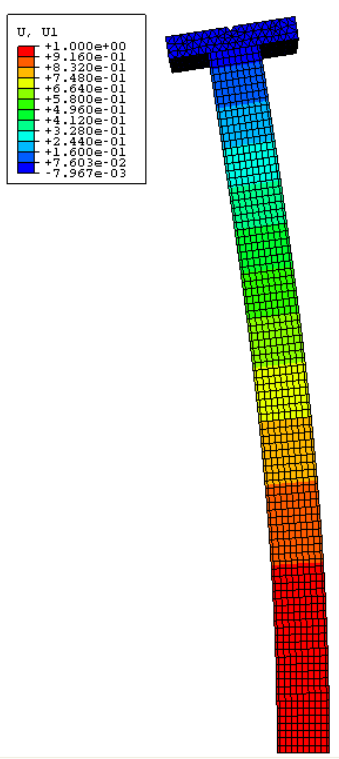

Figure 4.11. Shape of the initial imperfection applied to the columns.

\subsubsection{Analysis procedure}

Two different approaches can be considered when conducting the thermomechanical analysis of the model. The first one, more simplistic and less timeconsuming is to perform a sequentially coupled thermal-stress analysis. In this type of analysis, the stress/displacement solution is dependent on the temperature field but there is no inverse dependency. This type of analysis can be run as long as the thermal resistance at the steel-concrete boundary is considered to be independent from the gap clearance.

The second approach, more realistic but highly nonlinear and thus more computationally costly, is to perform a fully coupled thermal-stress analysis, 
assuming that the thermal resistance at the steel-concrete boundary is a function of the gap clearance. The gap conductance will decrease as the two contacting surfaces progressively separate from each other due to the thermal expansion differentials. In that case, the thermal and mechanical solutions affect each other strongly and the stress/displacement and temperature fields must be solved simultaneously.

Because of the high computing time requirements of the second approach, a sequentially coupled thermal-stress analysis was designed. Therefore, two different models were needed: a heat transfer model and a mechanical model. The analysis was performed by first conducting a pure heat transfer analysis for computing the temperature field and afterwards a stress/deformation analysis for calculating the structural response. Nodal temperatures were stored as a function of time in the heat transfer analysis results and then read into the stress analysis as a predefined field. Figure 4.12 presents a schematic representation of the analysis procedure.

Having obtained accurate enough results through a simple sequentially coupled thermal-stress analysis, as it will be demonstrated later on in the validation section, it can be concluded that there is no need to perform a fully coupled analysis, which is highly time-consuming and in most occasions leads to convergence problems.

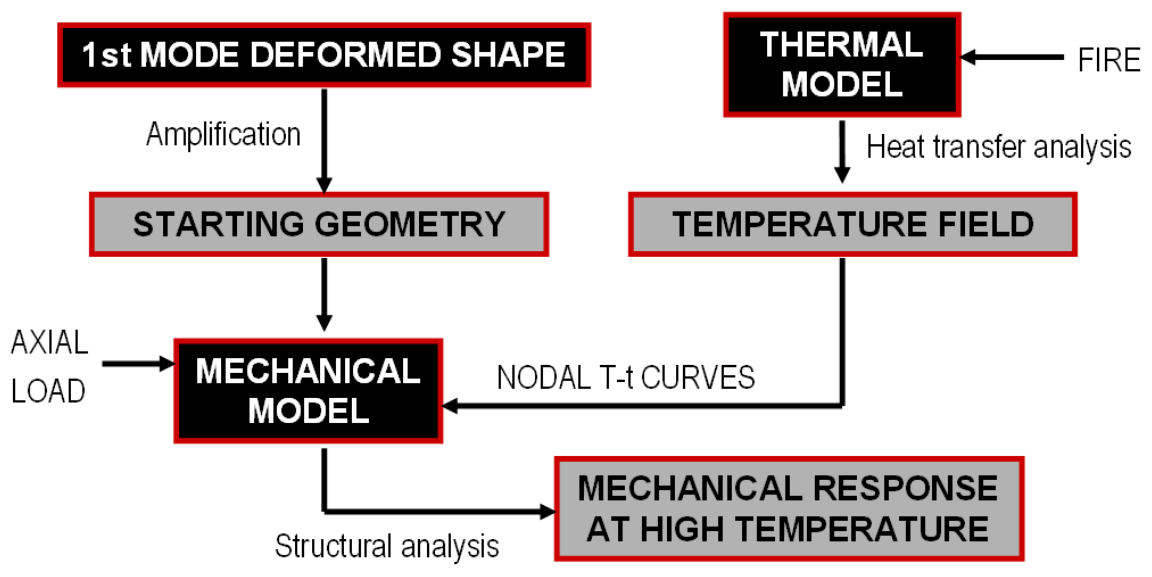

Figure 4.12. Scheme of the analysis procedure. 


\subsubsection{Thermal analysis}

A nonlinear heat transfer analysis was conducted as a previous step for each of the column specimens under study. A finite element formulation of the basic energy balance equation together with the Fourier law, which governs the heat conduction, was employed.

The basic energy balance is:

$$
\int_{V} \rho \dot{U} d V=\int_{S} q d S+\int_{V} r d V
$$

where $V$ is a volume of solid material, with surface area $S ; \rho$ is the density of the material; $\dot{U}$ is the material time rate of the internal energy; $q$ is the heat flux per unit area of the body; and $r$ is the heat supplied externally into the body per unit volume.

It is assumed that the thermal and mechanical problems are uncoupled in the sense that $U=U(\theta)$ only, where $\theta$ is the temperature of the material, and $q$ and $r$ do not depend on the strains or displacements of the body.

The constitutive definition is usually written in terms of a specific heat, neglecting coupling between mechanical and thermal problems:

$$
c(\theta)=\frac{d U}{d \theta}
$$

except for latent heat effects at phase changes, which are given separately in terms of solidus and liquidus temperatures and the total internal energy associated with the phase change, called the latent heat. When latent heat is given, it is assumed to be in addition to the specific heat effect. It can be assumed that the phase change occurs within a known temperature range. In this thesis, the latent heat of water vaporisation in concrete was modelled implicitly in the specific heat formulation of concrete and not added explicitly in terms of its associated internal energy, as explained in Section 4.1.2.1. 

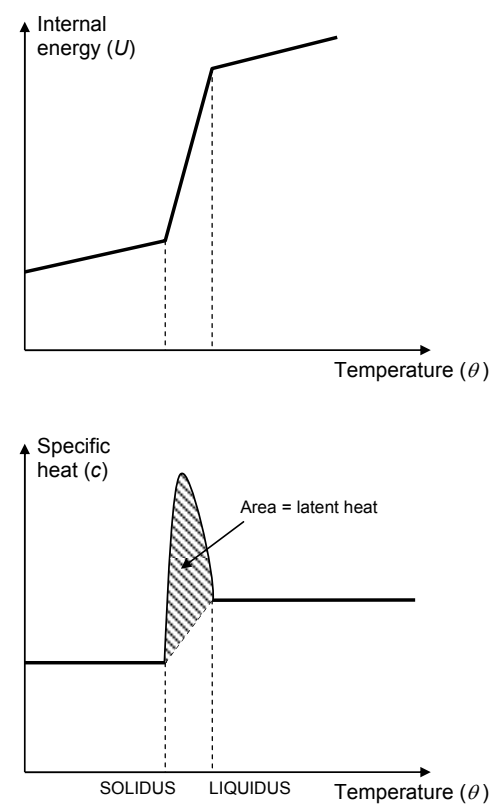

Figure 4.13. Specific heat and latent heat definition.

Heat conduction is assumed to be governed by the Fourier law,

$$
q=-\lambda \frac{\partial \theta}{\partial x}
$$

where $\lambda$ is the thermal conductivity tensor, $\lambda=\lambda(\theta) ; q$ is the heat flux vector per unit surface; and $x$ is the position.

Boundary conditions can be specified as prescribed temperature, $\theta=\theta(x, t)$; prescribed surface heat flux, $q=q(x, t)$ per area; prescribed volumetric heat flux, $q=$ $r(x, t)$ per volume; surface convection and radiation. In this problem, convection and radiation boundary conditions were only applied, which are defined as follows.

The convection boundary condition is given by:

$$
q=h\left(\theta-\theta^{0}\right)
$$

where $h=h(x, t)$ is the film coefficient and $\theta^{0}=\theta^{0}(x, t)$ is the sink temperature. 
In turn, the radiation boundary condition is defined with:

$$
q=A\left(\left(\theta-\theta^{Z}\right)^{4}-\left(\theta^{0}-\theta^{Z}\right)^{4}\right)
$$

where $A$ is the radiation constant (emissivity times the Stefan-Boltzmann constant) and $\theta^{\mathrm{Z}}$ is the absolute zero on the temperature scale used.

For conducting the thermal analysis, the standard ISO 834 (ISO 1980) or ASTM-E119 (ASTM 1990) fire curve, depending on the specimen studied, was applied to the exposed surface of the CFT column specimens through the convection and radiation heat transfer mechanisms presented above. In those cases where the fire curve applied at the test deviated from the reference, the real furnace temperature-time curve was used, since this can be an important source of error when validating the model.

The values recommended in EN 1991-1-2 (CEN 2002) were adopted for the governing parameters of the heat transfer problem:

- Film coefficient at the exposed surface: $h=25 \mathrm{~W} / \mathrm{m}^{2} \mathrm{~K}$

- Configuration factor for radiation at the exposed surface: $\Phi=1$

- Stephan-Boltzmann constant: $\sigma=5.67 \cdot 10^{-8} \mathrm{~W} / \mathrm{m}^{2} \mathrm{~K}^{4}$

- Emissivity of the exposed surface: $\varepsilon_{m}=0.7$

- Emissivity of the fire: $\varepsilon_{f}=1$

- Initial temperature: $T_{0}=20^{\circ} \mathrm{C}$

The three-dimensional eight-noded heat transfer solid element with nodal temperature degree of freedom (DC3D8) was used to mesh the thermal model. The longitudinal steel reinforcing bars for the reinforced specimens were modelled by means of two-noded heat transfer links (DC1D2). The loading plate was considered to be adiabatic, as it remains outside of the furnace and is not subjected to the heating conditions, therefore it was not taken into account in the thermal model.

The results from the nonlinear heat transfer analysis consisted of the temperature-time curves for all the nodes within the three-dimensional model, which were subsequently applied as a thermal loading to the mechanical model. 


\subsubsection{Structural analysis}

A nonlinear stress analysis was afterwards conducted using the same FEM package (ABAQUS 2010), accounting for the nodal temperature-time curves previously calculated in the thermal model. The finite element meshes and the node numbering were exactly the same as those used in the thermal analysis model.

The three-dimensional eight-noded solid element with reduced integration (C3D8R) was used to mesh the concrete infill and the steel tube. The longitudinal steel bars for the reinforced specimens were modelled by means of two-noded truss elements (T3D2) with both nodes tied to their corresponding concrete nodes. The loading plate was meshed by means of four-noded solid elements (C3D4).

The choice of the relevant properties of the mechanical model, such as the constitutive laws at elevated temperatures, the values of the thermal expansion coefficient for both concrete and steel, the initial imperfection of the column specimens or the frictional contact at the steel-concrete interface will be discussed in depth in the sensitivity analysis section (Section 4.3).

\subsubsection{Nonlinear solution method}

It has become clear from the previous sections that the finite element model developed in this work is nonlinear and involves a great number of variables. In terms of the variables of the model, the equilibrium equations obtained by discretizing the virtual work equation can be written symbolically as:

$$
F^{N}\left(u^{M}\right)=0
$$

where $F^{N}$ is the force component conjugate to the $N^{\text {th }}$ variable in the problem and $u^{M}$ is the value of the $M^{\text {th }}$ variable. The basic problem is to solve this equation for $u^{M}$ throughout the history of interest.

The problem under study is history-dependent, so the solution must be developed by a series of "small" increments.

The nonlinear solution method used in the simulations with ABAQUS (2010) was the Newton's method. The motivation for this choice was the convergence rate obtained by using Newton's method compared to the convergence rates exhibited by alternate methods (such as modified Newton or quasi-Newton methods).

The formulation of Newton's method is presented next. 
Assume that, after an iteration $i$, an approximation $u_{i}^{M}$ to the solution has been obtained. Let $c_{i+1}^{M}$ be the difference between this solution and the exact solution to the discrete equilibrium equation. This means that:

$$
F^{N}\left(u_{i}^{M}+c_{i+1}^{M}\right)=0
$$

Expanding the left-hand side of this equation in a Taylor series about the approximate solution $u_{i}^{M}$ then gives:

$$
F^{N}\left(u_{i}^{M}\right)+\frac{\partial F^{N}}{\partial u^{P}}\left(u_{i}^{M}\right) c_{i+1}^{P}+\frac{\partial^{2} F^{N}}{\partial u^{P} \partial u^{Q}}\left(u_{i}^{M}\right) c_{i+1}^{P} c_{i+1}^{Q}+\ldots=0
$$

If $u_{i}^{M}$ is a close approximation to the solution, the magnitude of each $c_{i+1}^{M}$ will be small, and so all but the first two terms above can be neglected giving a linear system of equations:

$$
K_{i}^{N P} c_{i+1}^{P}=-F_{i}^{N}
$$

where $K_{i}^{N P}=\frac{\partial F^{N}}{\partial u^{P}}\left(u_{i}^{M}\right)$ is the Jacobian matrix and $F_{i}^{N}=F^{N}\left(u_{i}^{M}\right)$.

The next approximation to the solution is then $u_{i+1}^{M}=u_{i}^{M}+c_{i+1}^{M}$ and the iteration continues until the solution is found.

\subsubsection{Thermal and mechanical contact at the steel-concrete interface}

\subsubsection{Thermal contact}

The thermal resistance at the boundary between the steel tube and the concrete core was taken into account in the numerical model. This is one of the aspects which have traditionally been ignored or neglected (Hong \& Varma 2009) and that will be deeply studied later on in the sensitivity analysis section.

ABAQUS (2010) allows heat flow across an interface via conduction or radiation. Generally, both modes of heat transfer are present to some degree. This is the case of the contact surface between the steel tube and the concrete core in a CFT column. Regardless of the mode, heat transfer across the interface is assumed to occur only in the normal direction. The radiation component resulted to be of minor importance in the problem under study, as compared with the effect of the conductive heat transfer, which is described next. 
Heat conduction across the interface is assumed to be defined by:

$$
q=k\left(\theta_{A}-\theta_{B}\right)
$$

where $q$ is the heat flux per unit area crossing the interface from point $A$ on one surface to point $B$ on the other, $\theta_{A}$ and $\theta_{B}$ are the temperatures of the points on the surfaces, and $k$ is the gap conductance. The gap conductance is defined as:

$$
k=k\left(\bar{\theta}, d, p, \bar{f}_{\gamma}, \overline{|\dot{m}|}\right)
$$

where:

- $\bar{\theta}=\frac{1}{2}\left(\theta_{A}+\theta_{B}\right)$ is the average of the surface temperatures at $A$ and $B$,

- $d$ is the clearance between $A$ and $B$,

- $p$ is the contact pressure transmitted across the interface between $A$ and $B$,

- $\bar{f}_{\gamma}=\frac{1}{2}\left(f_{\gamma}^{A}+f_{\gamma}^{B}\right)$ is the average of any predefined field variables at $A$ and $B$, and

- $\overline{|\dot{m}|}=\frac{1}{2}\left(\overline{|\dot{m}|_{A}}+\overline{|\dot{m}|_{B}}\right)$ is the average of the magnitudes of the mass flow rates per unit area of the contact surfaces at $A$ and $B$.

The gap conductance $k$ can be defined as a function of the clearance $d$. It must be introduced in form of tabulated data, starting with the value of $k$ for a zero clearance (closed gap) and varying $k$ as $d$ increases. At least two pairs of points must be given to define $k$ as a function of the clearance. Alternatively, the gap conductance can be defined as a function of the contact pressure, $p$. Figure 4.14 shows the form of introducing the gap conductance as a function of the clearance or contact pressure in ABAQUS (2010).

The option of making the gap conductance at the steel-concrete interface variable with the clearance was considered in initial studies, requiring a fully coupled thermal-stress analysis, since the temperature field then depends on the evolution of the relative transversal displacement between the steel tube and concrete core. These preliminary studies showed that the accuracy of the result was similar to that obtained by means of a sequentially-coupled thermal-stress analysis assuming a constant value for the gap conductance along the fire exposure time, 
where the thermal and mechanical responses can be evaluated separately and the required computational time is notably lower.

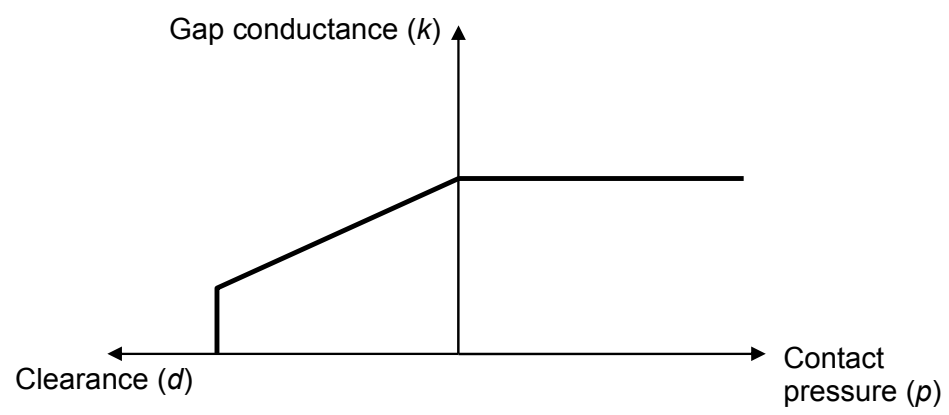

Figure 4.14. Gap conductance as a function of clearance or contact pressure.

Through the results of a sensitivity analysis, which will be presented later on in Section 4.3, it was decided to assume a constant value of $200 \mathrm{~W} / \mathrm{m}^{2} \mathrm{~K}$ for the gap conductance at the boundary between the steel tube and the concrete core.

\subsubsection{Mechanical contact}

The mechanical interaction between the steel tube and concrete infill contacting surfaces was modelled as follows. The normal behaviour employed a "hard" contact formulation, which allows any pressure value when the surfaces are in contact and transmits no pressure when the surfaces do not contact. The tangent behaviour made use of the Coulomb friction model with a constant friction coefficient of 0.3 , which had been used with successful results by Lacuesta et al. (2006) for room temperature simulations. In any case, the value of the friction coefficient is not relevant in the fire situation as will be demonstrated in the sensitivity analysis section. Both contact models are described next.

\section{Normal contact}

The contact pressure-overclosure relationship used in the numerical model is shown in Figure 4.15. It is defined as the "hard" contact relationship in ABAQUS (2010). When surfaces are in contact, any contact pressure can be transmitted between them. The surfaces separate if the contact pressure reduces to zero. Separated surfaces come into contact when the clearance between them reduces to zero. 


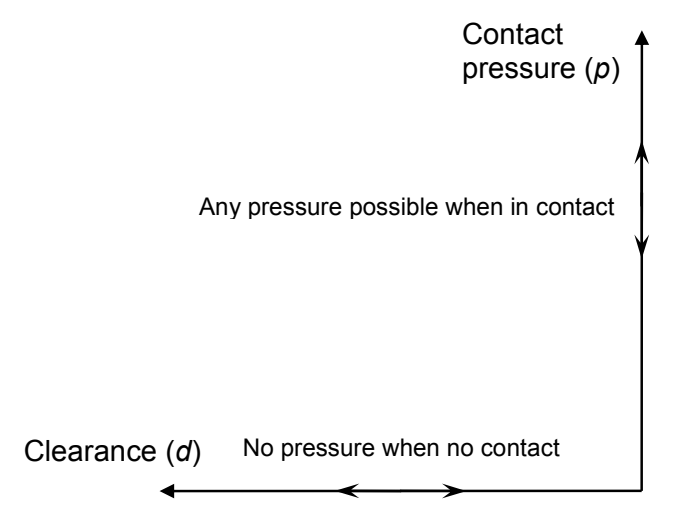

Figure 4.15. Pressure-overclosure relationship.

\section{Tangential contact}

The basic concept of the Coulomb friction model is to relate the maximum allowable frictional (shear) stress across an interface to the contact pressure between the contacting bodies. In the basic form of the Coulomb friction model, two contacting surfaces can carry shear stresses up to a certain magnitude across their interface before they start sliding relative to one another; this state is known as sticking. The Coulomb friction model defines this critical shear stress, $\tau_{c r i t}$, at which sliding of the surfaces starts as a fraction of the contact pressure, $p$, between the surfaces $\left(\tau_{c r i t}=\mu p\right)$. The stick/slip calculations determine when a point transitions from sticking to slipping or from slipping to sticking. The fraction, $\mu$, is known as the coefficient of friction.

The basic friction model assumes that the coefficient of friction $\mu$ is the same in all directions (isotropic friction). For a three-dimensional simulation there are two orthogonal components of shear stress, $\tau_{1}$ and $\tau_{2}$, along the interface between the two bodies. ABAQUS (2010) combines the two shear stress components into an "equivalent shear stress" $\bar{\tau}$, for the stick/slip calculations, where:

$$
\bar{\tau}=\sqrt{\tau_{1}^{2}+\tau_{2}^{2}}
$$

The stick/slip calculations define a surface (see Figure 4.16) in the contact pressure-shear stress space along which a point transitions from sticking to slipping. 


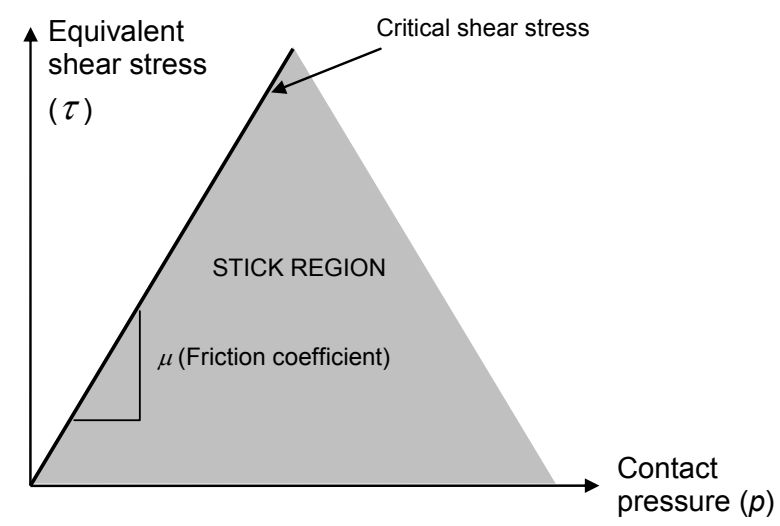

Figure 4.16. Slip regions for the Coulomb friction model.

\subsection{VALIDATION OF THE MODEL}

\subsubsection{Validation against tests from the literature}

The three-dimensional numerical model was on a first stage validated by comparing its results with experimental fire resistance tests of circular CFT columns available in the literature. The column specimens used in this validation stage were tested at the National Research Council of Canada, in two experimental programs (Chabot \& Lie 1992, Lie \& Chabot 1992).

In Lie \& Chabot (1992), the results of a series of tests on circular and square tubular columns filled with plain concrete were reported. These specimens were filled with either siliceous or calcareous aggregate concrete and subjected to concentric axial load, apart from test C-16 which was eccentrically loaded. All the columns were tested fixed at both ends, except for three of them, tested as pinnedpinned. The total length of the columns was $3810 \mathrm{~mm}$, although only the central $3048 \mathrm{~mm}$ were directly exposed to fire. From this experimental investigation, only those columns which were reported to have failed by overall buckling were chosen, corresponding to slender columns. The selected columns were filled with normal strength concrete, with cylinder compressive strengths at the test date under $50 \mathrm{MPa}$.

In Chabot \& Lie (1992), a series of hollow steel columns filled with barreinforced concrete were tested. From this experimental program, only two columns with circular shape were reported and used for the validation of the model. The 
characteristics of the columns were the same as in Lie \& Chabot (1992), but in this case filled with calcareous aggregate concrete and using a $2.3 \%$ percentage of reinforcement. The reinforcement consisted of 4 longitudinal bars of $19.5 \mathrm{~mm}$ diameter using $400 \mathrm{MPa}$ steel. The selected columns had a cylinder compressive strength at the test date under $50 \mathrm{MPa}$.

Table 4.1 lists the column specimens used for validating the numerical model, with their main characteristics.

Table 4.1. List of CFT columns analysed from the literature (Chabot \& Lie 1992, Lie \& Chabot 1992)

\begin{tabular}{|c|c|c|c|c|c|c|c|c|c|}
\hline $\begin{array}{c}\text { Column } \\
\text { No. }\end{array}$ & $\begin{array}{c}D \\
(\mathbf{m m})\end{array}$ & $\begin{array}{c}t \\
(\mathbf{m m})\end{array}$ & $\begin{array}{c}f_{y} \\
\left(\mathrm{~N} / \mathbf{m m}^{2}\right)\end{array}$ & $\begin{array}{c}f_{c} \\
\left(\mathbf{N} / \mathbf{m m}^{2}\right)\end{array}$ & $\begin{array}{c}\text { End } \\
\text { Cond. }\end{array}$ & $\begin{array}{c}e \\
(\mathbf{m m})\end{array}$ & $\begin{array}{c}N \\
(\mathrm{kN})\end{array}$ & $\mu$ & $\begin{array}{l}\text { FRR } \\
\text { (min) }\end{array}$ \\
\hline C-02 & 141.3 & 6.55 & 350 & 33.1 (sil) & F-F & 0 & 110 & 0.12 & 55 \\
\hline C-04 & 141.3 & 6.55 & 350 & 31.0 (sil) & F-F & 0 & 131 & 0.14 & 57 \\
\hline C-05 & 168.3 & 4.78 & 350 & 32.7 (sil) & F-F & 0 & 150 & 0.16 & 76 \\
\hline C-06 & 168.3 & 4.78 & 350 & 32.7 (sil) & P-P & 0 & 150 & 0.19 & 60 \\
\hline C-08 & 168.3 & 4.78 & 350 & 35.5 (sil) & F-F & 0 & 218 & 0.23 & 56 \\
\hline C-09 & 168.3 & 6.35 & 350 & 35.4 (sil) & F-F & 0 & 150 & 0.13 & 81 \\
\hline C-11 & 219.1 & 4.78 & 350 & 31.0 (sil) & F-F & 0 & 492 & 0.35 & 80 \\
\hline C-13 & 219.1 & 4.78 & 350 & 32.3 (sil) & F-F & 0 & 384 & 0.27 & 102 \\
\hline C-15 & 219.1 & 8.18 & 350 & 31.9 (sil) & P-P & 0 & 525 & 0.28 & 73 \\
\hline C-16 & 219.1 & 8.18 & 350 & 31.9 (sil) & P-P & 34 & 525 & 0.47 & 33 \\
\hline C-17 & 219.1 & 8.18 & 350 & 31.7 (sil) & F-F & 0 & 525 & 0.26 & 82 \\
\hline C-20 & 273.1 & 5.56 & 350 & 28.6 (sil) & F-F & 0 & 574 & 0.26 & 112 \\
\hline $\mathrm{C}-21$ & 273.1 & 5.56 & 350 & 29.0 (sil) & F-F & 0 & 525 & 0.23 & 133 \\
\hline $\mathrm{C}-22$ & 273.1 & 5.56 & 350 & 27.2 (sil) & F-F & 0 & 1000 & 0.45 & 70 \\
\hline $\mathrm{C}-23$ & 273.1 & 12.70 & 350 & 27.4 (sil) & F-F & 0 & 525 & 0.13 & 143 \\
\hline C-31 & 141.3 & 6.55 & 300 & 30.2 (cal) & F-F & 0 & 80 & 0.09 & 82 \\
\hline C-32 & 141.3 & 6.55 & 300 & 34.8 (cal) & F-F & 0 & 143 & 0.17 & 64 \\
\hline C-34 & 219.1 & 4.78 & 300 & 35.4 (cal) & F-F & 0 & 500 & 0.36 & 111 \\
\hline C-35 & 219.1 & 4.78 & 300 & 42.7 (cal) & F-F & 0 & 560 & 0.36 & 108 \\
\hline C-37 & 219.1 & 8.18 & 350 & 28.7 (cal) & F-F & 0 & 560 & 0.25 & 102 \\
\hline C-44 & 273.1 & 6.35 & 350 & 38.7 (cal) & F-F & 0 & 715 & 0.27 & 178 \\
\hline C-48 & 273.1 & 6.35 & 350 & 46.7 (cal) & F-F & 0 & 1050 & 0.37 & 188 \\
\hline C-49 & 273.1 & 6.35 & 350 & 47.0 (cal) & F-F & 0 & 1900 & 0.67 & 96 \\
\hline
\end{tabular}

In this table, $($ sil $)=$ concrete with siliceous aggregates, $(\mathrm{cal})=$ concrete with calcareous aggregates; P-P = pinned-pinned and F-F = fixed-fixed end conditions. 
Figure 4.17 shows the result of one of the numerical simulations, where the temperature field along the column and its deformed shape after failure can be seen, together with the picture of the fire test.
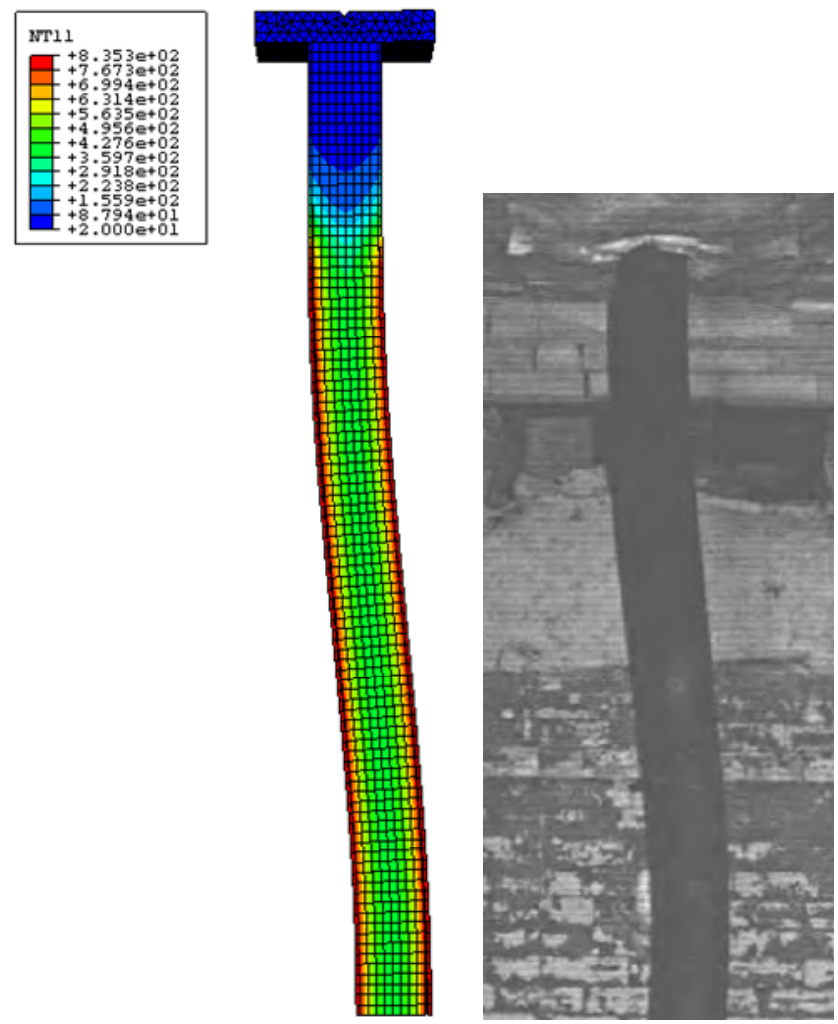

Figure 4.17. Deformed shape after exposure to standard fire, for column C-04 (compared with Lie \& Chabot 1992).

\subsubsection{Thermal response}

A first validation step consisted of comparing the evolution of temperature along the fire exposure time in the numerical simulations with the temperatures recorded in the tests at those sectional points where thermocouples were installed. The comparison between measured and calculated temperatures is shown in Figure 4.18 for one of the column specimens studied. 


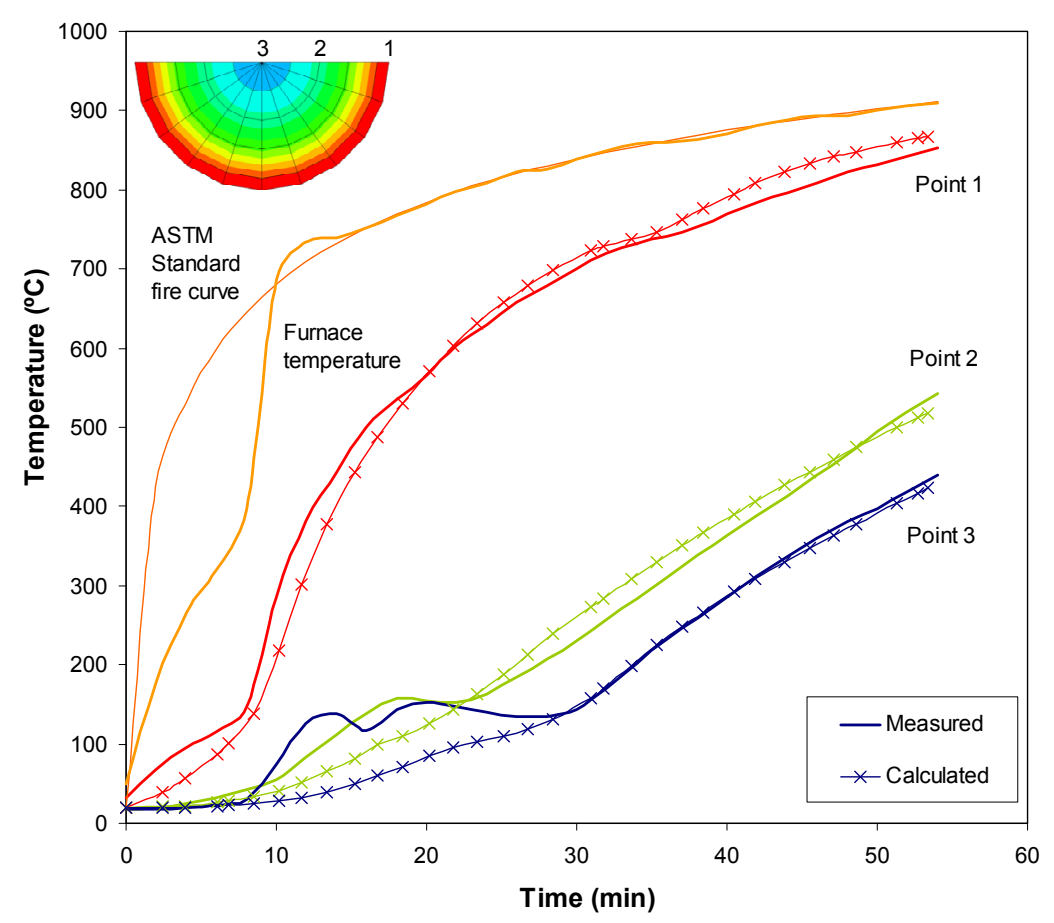

Figure 4.18. Comparison between measured and predicted temperatures for column C-02.

A constant value of $200 \mathrm{~W} / \mathrm{m}^{2} \mathrm{~K}$ was employed for the gap conductance at the steel-concrete interface and a moisture content of $3 \%$ or $10 \%$ in concrete weight, depending on the case study was considered. It was found that, in general, concrete with calcareous aggregates retained more humidity than concrete with siliceous aggregates, thus in this research a value of $10 \%$ was considered for the specimens filled with calcareous aggregates, whereas a $3 \%$ value was employed for the siliceous ones.

Employing these moisture values, the overall temperature-time response in the selected points followed accurately the test results, with the exception of the range of temperatures between 100 and $200{ }^{\circ} \mathrm{C}$ in the concrete layers, where the evaporation of moisture occurs. This phenomenon is treated in a simple manner in this model by introducing a peak point in the concrete specific heat formulation, as recommended in EN 1994-1-2 (CEN 2005c). Nevertheless, if the realistic moisture 
movement and evaporation within the concrete core wants to be predicted, a more complex hygro-thermal model would be needed.

As mentioned before, some of the tests did not follow as closely as desired the standard fire curve, which introduced some deviations in the fire response of the columns. Thus, the real furnace temperature-time curve reported from the fire tests was applied in the simulations, when available.

\subsubsection{Mechanical response}

The structural behaviour of CFT columns under fire was fully captured with the numerical model and can be easily understood through the example in Figure 4.19, which shows the axial displacement-time curve together with the axial force ratio versus time curves for both the steel tube and concrete core. The behaviour of CFT columns in fire can be divided into four stages clearly indicated in the figure, where the load transfer process from the steel tube to the concrete core can be noticed.

During the first minutes of heating, the steel tube heats up more rapidly and expands faster than concrete (stage 1) since it is directly exposed to fire and has a higher thermal conductivity. Because of this faster axial elongation of the steel tube and the occurrence of slip at the steel-concrete interface, the concrete core loses contact with the loading plate, thus progressively increasing the axial load ratio of steel until the whole applied load is sustained by the steel tube. The steel tube remains fully loaded during a significant period of time until the critical temperature of steel is reached. At this point, the local yielding of the steel tube occurs and it starts to shorten (stage 2), allowing the loading plate to contact the concrete core again. As the column shortens, the steel tube progressively transfers the load to the concrete core (stage 3 ) and an inversion in the axial force ratio takes place, in such a way that the concrete core becomes the main resistant element of the column, since the steel tube has already lost its load-bearing capacity. Because of its low thermal conductivity, the concrete core degrades slowly as temperature advances through the cross-section, until eventually the column fails when concrete loses completely its resistance and stiffness (stage 4). 


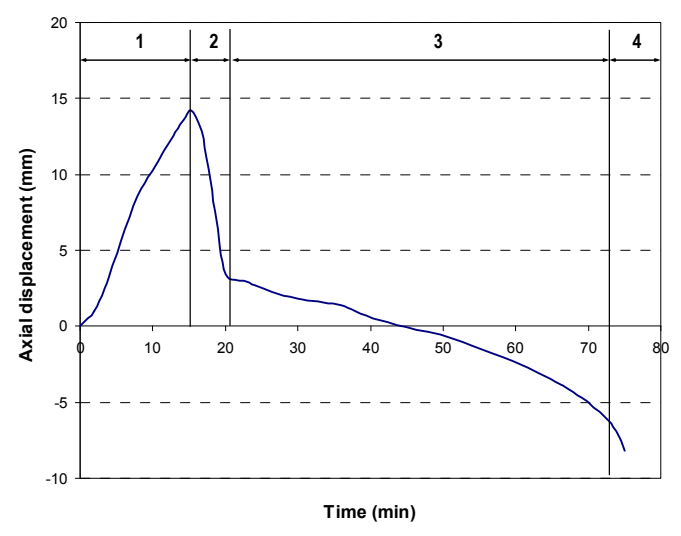

(a) Axial displacement versus time

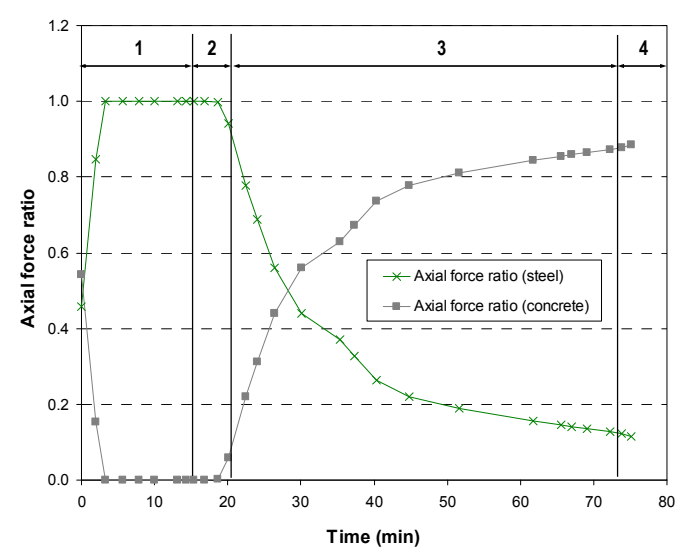

(b) Axial force ratio versus time
1)

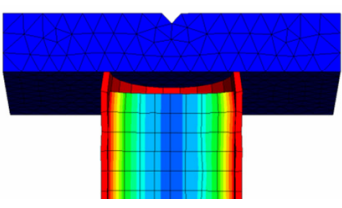

2)

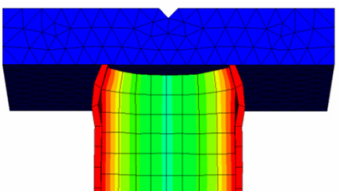

3)

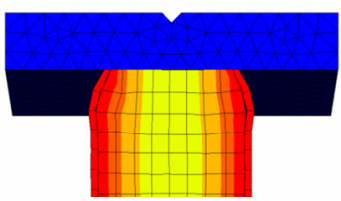

4)

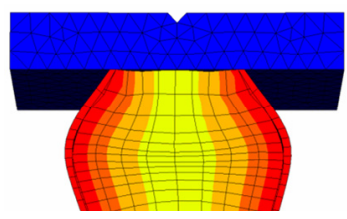

(c) Stages of the fire response of a CFT column

Figure 4.19. Axial displacement and axial force ratio versus time, for column C-11.

For each of the columns listed in Table 4.1, the axial displacement at the top of the column versus the fire exposure time was registered during the simulation, comparing this curve with the one obtained in the fire test. Figure 4.20 shows the comparison between both curves for two of the column specimens studied. 


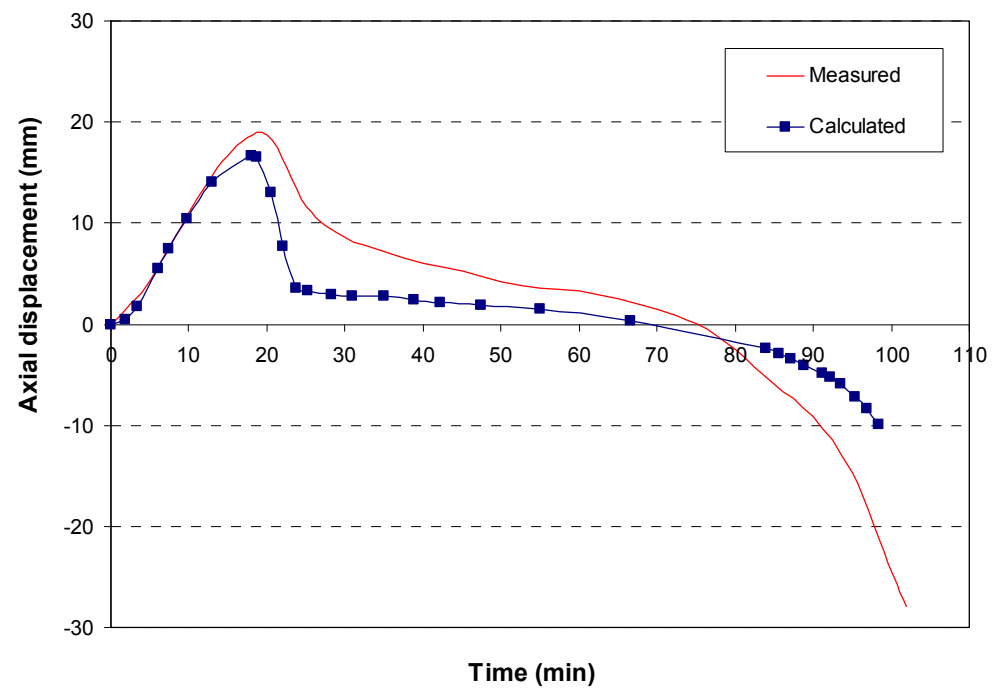

(a) Column C-13

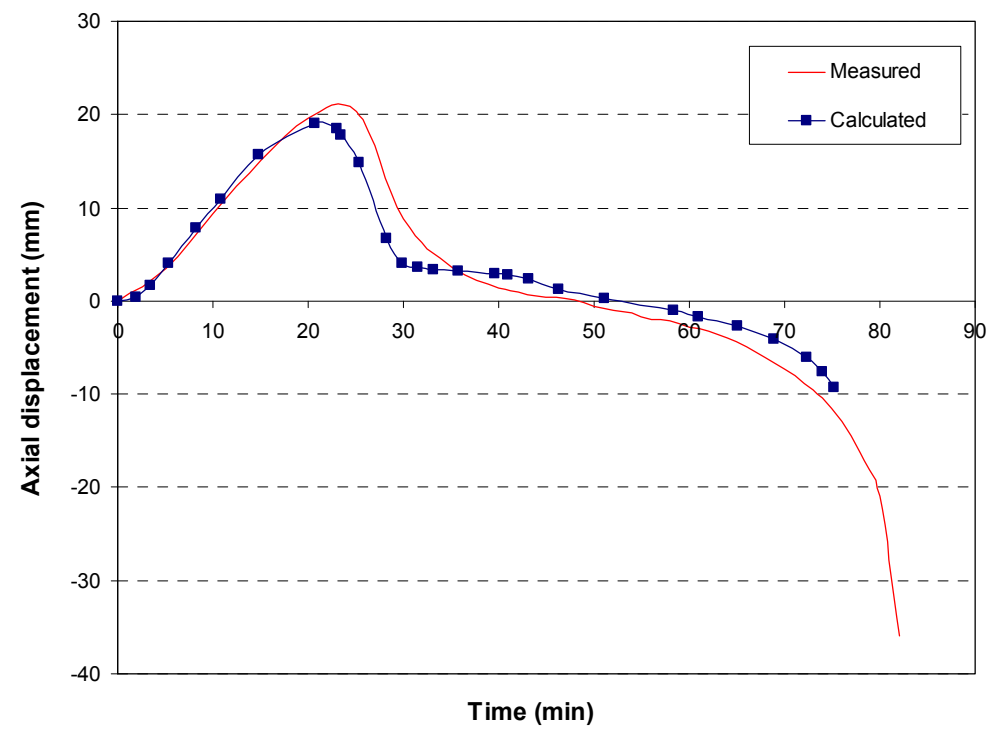

(b) Column C-17

Figure 4.20. Comparison of measured and predicted axial displacement. 
At this point a comment regarding the pinned-pinned specimens must be done. Despite being designed as hinged at both ends in the experiments, the numerical model showed better agreement with these tests when the supporting conditions were considered as pinned-fixed. Three different supporting conditions were studied for simulating the pinned-pinned columns, and the results for one of the specimens are those shown in Figure 4.21. It can be seen that the best prediction was obtained modelling the column as pinned-fixed. As it was already found by Renaud et al. (2004) in the CIDECT research project 15Q, the reason of this behaviour is that in real fire tests the unexposed ends of the column lying outside the furnace retain more stiffness, therefore introducing some rotational restraints to the column. In fact, the deformed shape of these column specimens after the tests, which was reported in Lie \& Chabot (1992), suggests employing pinned-fixed supporting conditions when simulating their fire behaviour.

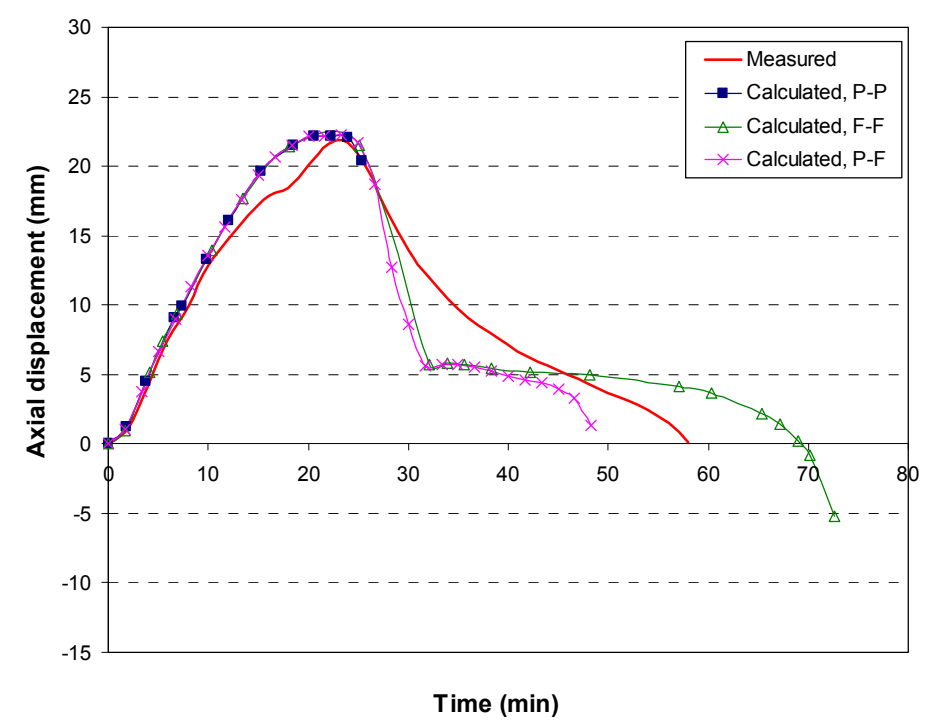

Figure 4.21. Comparison of measured and predicted axial displacement with different supporting conditions, for column C-06.

For modelling these specimens as pinned-fixed, the whole length of the column was used, since there is a loss of symmetry on the end conditions, but because of the sectional symmetry only half the section was modelled. 
From the axial displacement versus time curves, the fire resistance rating (FRR) and maximum axial displacement $\left(\delta_{\max }\right)$ was obtained for each of the specimens under study. These values are summarized in Table 4.2.

Table 4.2. Predicted and measured FRR and maximum axial displacement, Canadian tests

\begin{tabular}{|c|c|c|c|c|c|c|}
\hline \multirow{2}{*}{ Column No. } & \multicolumn{2}{|c|}{ FRR (min) } & \multirow{2}{*}{$\frac{F R R_{\text {test }}}{F R R_{N S}}$} & \multicolumn{2}{|c|}{$\delta_{\max }(\mathrm{mm})$} & \multirow{2}{*}{$\xi \delta_{\max }=\frac{\delta_{\text {max }, \text { test }}}{\delta_{\max , N S}}$} \\
\hline & Test & Simulation & & Test & Simulation & \\
\hline $\mathrm{C}-02$ & 55 & 55 & 1.00 & 24.57 & 25.44 & 0.97 \\
\hline $\mathrm{C}-04$ & 57 & 50 & 1.14 & 24.09 & 24.28 & 0.99 \\
\hline $\mathrm{C}-05$ & 76 & 72 & 1.06 & 22.77 & 22.17 & 1.03 \\
\hline $\mathrm{C}-06$ & 60 & 48 & 1.25 & 21.66 & 22.26 & 0.97 \\
\hline C-08 & 56 & 59 & 0.95 & 20.48 & 19.39 & 1.06 \\
\hline C-09 & 81 & 75 & 1.08 & 25.77 & 24.38 & 1.06 \\
\hline $\mathrm{C}-11$ & 80 & 77 & 1.04 & 18.13 & 14.14 & 1.28 \\
\hline C-13 & 102 & 98 & 1.04 & 18.77 & 16.71 & 1.12 \\
\hline C-15 & 73 & 47 & 1.55 & 19.52 & 18.93 & 1.03 \\
\hline $\mathrm{C}-16$ & 33 & 32 & 1.03 & 18.73 & 18.31 & 1.02 \\
\hline C-17 & 82 & 75 & 1.09 & 20.36 & 19.05 & 1.07 \\
\hline $\mathrm{C}-20$ & 112 & 150 & 0.75 & 19.44 & 15.26 & 1.27 \\
\hline $\mathrm{C}-21$ & 133 & 163 & 0.82 & 20.25 & 16.05 & 1.26 \\
\hline $\mathrm{C}-22$ & 70 & 79 & 0.89 & 5.51 & 7.06 & 0.78 \\
\hline $\mathrm{C}-23$ & 143 & 147 & 0.97 & 26.09 & 23.66 & 1.10 \\
\hline $\mathrm{C}-31$ & 82 & 65 & 1.26 & 30.53 & 27.05 & 1.13 \\
\hline $\mathrm{C}-32$ & 64 & 50 & 1.28 & 28.5 & 23.65 & 1.21 \\
\hline $\mathrm{C}-34$ & 111 & 101 & 1.10 & 20.09 & 16.67 & 1.21 \\
\hline $\mathrm{C}-35$ & 108 & 104 & 1.04 & 15.59 & 14.39 & 1.08 \\
\hline $\mathrm{C}-37$ & 102 & 75 & 1.36 & 20.2 & 19.43 & 1.04 \\
\hline C-44 & 178 & 180 & 0.99 & 20.36 & 16.28 & 1.25 \\
\hline C- -48 & 188 & 174 & 1.08 & 12.7 & 11.32 & 1.12 \\
\hline \multirow[t]{3}{*}{ C-49 } & 96 & 100 & 0.96 & 1.36 & 1.95 & 0.70 \\
\hline & \multicolumn{2}{|c|}{ Average } & 1.07 & \multicolumn{2}{|c|}{ Average } & 1.08 \\
\hline & \multicolumn{2}{|c|}{ Standard deviation } & 0.18 & \multicolumn{2}{|c|}{ Standard deviation } & 0.14 \\
\hline
\end{tabular}


Figure 4.22 shows the comparison between the numerical predictions and test results, in terms of fire resistance rating. As it can be seen, most of the values calculated lie in the region of the $15 \%$ error. Therefore, the agreement with the experiments was considered acceptable given the uncertainties in some of the test data, with a good average value of the error (1.07 mean value) and a moderated dispersion of results ( 0.18 standard deviation).

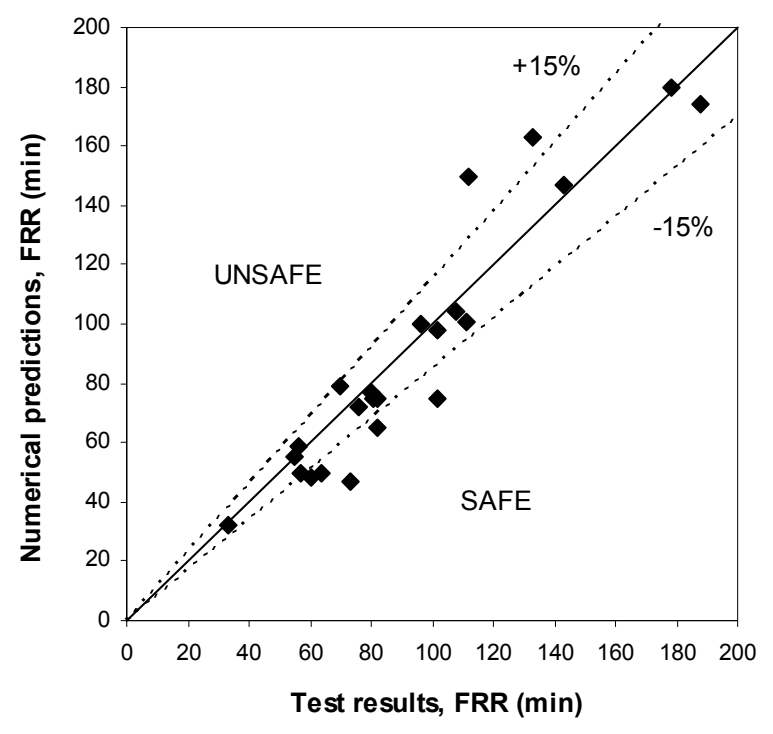

Figure 4.22. Comparison of fire resistance rating between the numerical predictions and the test results from NRCC.

The maximum axial displacement was also obtained from the simulations for each of the column specimens studied. Figure 4.23 presents the comparison between the predicted values and the values registered at the fire tests.

The comparison in terms of maximum axial displacement produced a similar error (1.08 mean value) and a more reduced dispersion ( 0.14 standard deviation). It is worth noting that the errors obtained can be attributed to the inaccessibility to the real steel yield strength data, as only information on the steel grade was available, but not the result from coupon tests. 


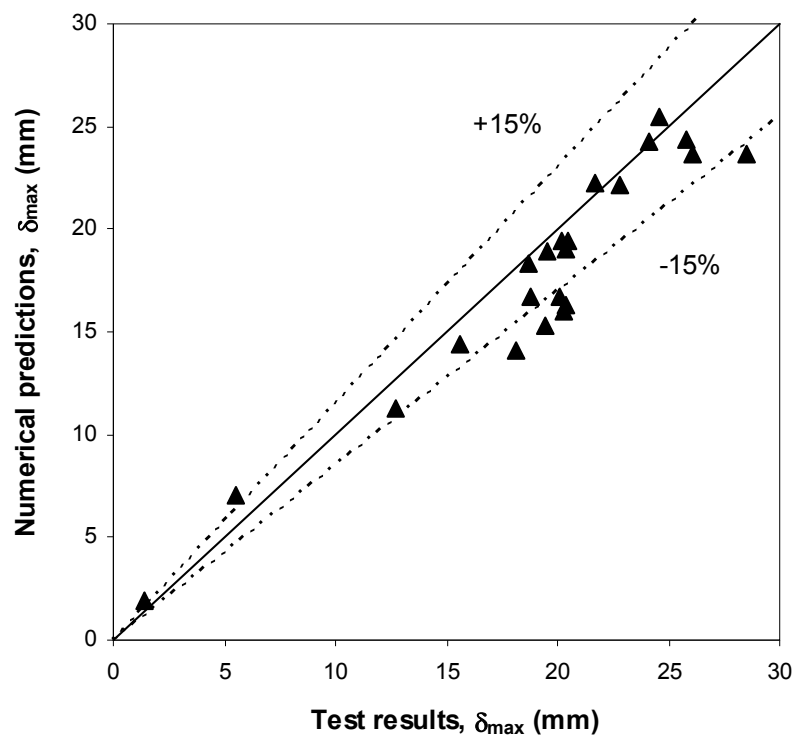

Figure 4.23. Comparison of maximum axial displacement between the numerical predictions and the test results from NRCC.

\subsubsection{Validation against own experiments}

On a second stage, the numerical model was validated against fire tests carried out in a parallel investigation by the research group to which the author of this thesis belongs. The experiments were performed in the testing facilities of AIDICO (Instituto Tecnológico de la Construcción) in Valencia, Spain.

In this experimental program, sixteen fire tests were carried out on normal and high strength concrete filled tubular columns of circular section. All the tested columns were $3180 \mathrm{~mm}$ long and had an external diameter of $159 \mathrm{~mm}$ and a steel tube wall thickness of $6 \mathrm{~mm}$. Plain, bar-reinforced and steel fiber reinforced concrete was used as infill. In the bar-reinforced specimens, four longitudinal reinforcing bars of $12 \mathrm{~mm}$ diameter and $500 \mathrm{MPa}$ yield strength were used, with a geometrical reinforcement ratio close to a $2.5 \%$. In the steel fiber reinforced specimens, $40 \mathrm{~kg} / \mathrm{m}^{3}$ high strength Dramix 40/60 steel fibers were used. The columns were tested under concentric load, and with pinned-fixed end conditions, except for one of the specimens, which was hinged at both ends. All the details of this experimental program can be found in Romero et al. (2011). 
Table 4.3 lists the specimens used for the validation of the numerical model, which were those filled with normal strength concrete (HSC specimens were left out of this comparison, as the scope of this thesis is restricted to NSC).

Table 4.3. List of CFT columns analysed, own tests, NSC (Romero et al. 2011)

\begin{tabular}{ccccccccc}
\hline $\begin{array}{c}\text { Column } \\
\text { No. }\end{array}$ & $\begin{array}{c}\boldsymbol{D} \\
(\mathbf{m m})\end{array}$ & $\begin{array}{c}\boldsymbol{t} \\
(\mathbf{m m})\end{array}$ & $\begin{array}{c}\boldsymbol{f}_{\boldsymbol{y}} \\
\left(\mathbf{N} / \mathbf{m m}^{\mathbf{2}}\right)\end{array}$ & $\begin{array}{c}\boldsymbol{f}_{\boldsymbol{c}} \\
\left(\mathbf{N} / \mathbf{m m}^{\mathbf{2}}\right)\end{array}$ & $\begin{array}{c}\text { End } \\
\text { Cond. }\end{array}$ & $\begin{array}{c}\boldsymbol{N} \\
(\mathbf{k N})\end{array}$ & $\boldsymbol{\mu}$ & $\begin{array}{c}\text { FRR } \\
(\mathbf{m i n})\end{array}$ \\
\hline C159-6-3-30-0-40-P-P & 159 & 6 & 337.8 & 30.1 & P-P & 338 & 0.4 & 18 \\
C159-6-3-30-0-20 & 159 & 6 & 337.8 & 35.75 & P-F & 198 & 0.2 & 42 \\
C159-6-3-30-0-40 & 159 & 6 & 337.8 & 28.55 & P-F & 396 & 0.4 & 25 \\
C159-6-3-30-0-60 & 159 & 6 & 337.8 & 34.05 & P-F & 594 & 0.6 & 14 \\
RC159-6-3-30-0-20 & 159 & 6 & 337.8 & 23.9 & P-F & 229 & 0.2 & 43 \\
RC159-6-3-30-0-40 & 159 & 6 & 337.8 & 30 & P-F & 458 & 0.4 & 30 \\
RC159-6-3-30-0-60 & 159 & 6 & 337.8 & 33.7 & P-F & 687 & 0.6 & 13 \\
FC159-6-3-30-0-20 & 159 & 6 & 337.8 & 28.3 & P-F & 198 & 0.2 & 36 \\
FC159-6-3-30-0-40 & 159 & 6 & 334.4 & 26.7 & P-F & 396 & 0.4 & 22 \\
\hline
\end{tabular}

In this table, $\mathrm{C}$ stands for plain concrete, $\mathrm{RC}$ for reinforced concrete and $\mathrm{FC}$ for steel fiber reinforced concrete; $\mathrm{P}-\mathrm{P}=$ pinned-pinned and $\mathrm{P}-\mathrm{F}=$ pinned-fixed end conditions.

For simulating the last two specimens, which made use of steel fibers as reinforcement, the thermal and mechanical properties of steel fiber reinforced concrete at elevated temperatures were taken from Lie \& Kodur (1995b).

Figure 4.24 presents the resulting deformed shape from the numerical simulation for one of the columns analysed, in comparison with the state of the column after failure in the real test.

For each of the columns listed in Table 4.3, the axial displacement at the top of the column along the fire exposure time was registered during the simulation, comparing this curve with the one obtained in the fire test.

From the axial displacement versus time curves, the fire resistance was obtained for each of the specimens under study. The fire resistance time of each column specimen was determined according to EN 1363-1 (CEN 1999). This standard establishes that for vertical members in compression, failure occurs when either of the following two criteria is reached:

- Axial displacement limit: $C=h / 100 \mathrm{~mm}$

- Axial displacement velocity limit: $d C / d t=3 h / 1000 \mathrm{~mm} / \mathrm{min}$ 
where $h$ is the initial height of the column in millimetres.
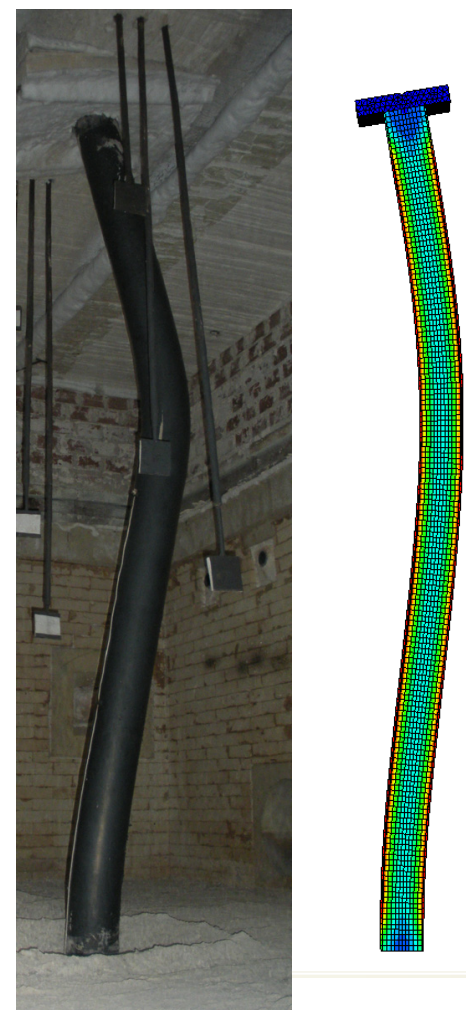

Figure 4.24. Deformed shape after exposure to standard fire, for column C159-6-3-30-0-20 (compared with Romero et al. 2011).

All the tested columns had an initial height of $h=3180 \mathrm{~mm}$, thus the limits applicable to these specimens are: $C=31.8 \mathrm{~mm}$ for the axial displacement and $\mathrm{dC} / \mathrm{dt}$ $=9.54 \mathrm{~mm} / \mathrm{min}$ for the axial displacement velocity.

Figure 4.25 shows the evolution of the axial displacement at the top end of the column against the fire exposure time for one of the specimens analysed. The curve obtained in the numerical simulation is compared with that registered in the fire test. The limits given by the two failure criteria are included on this graph.

The values of the error are summarized in Table 4.4 for those case specimens filled with normal strength concrete. 


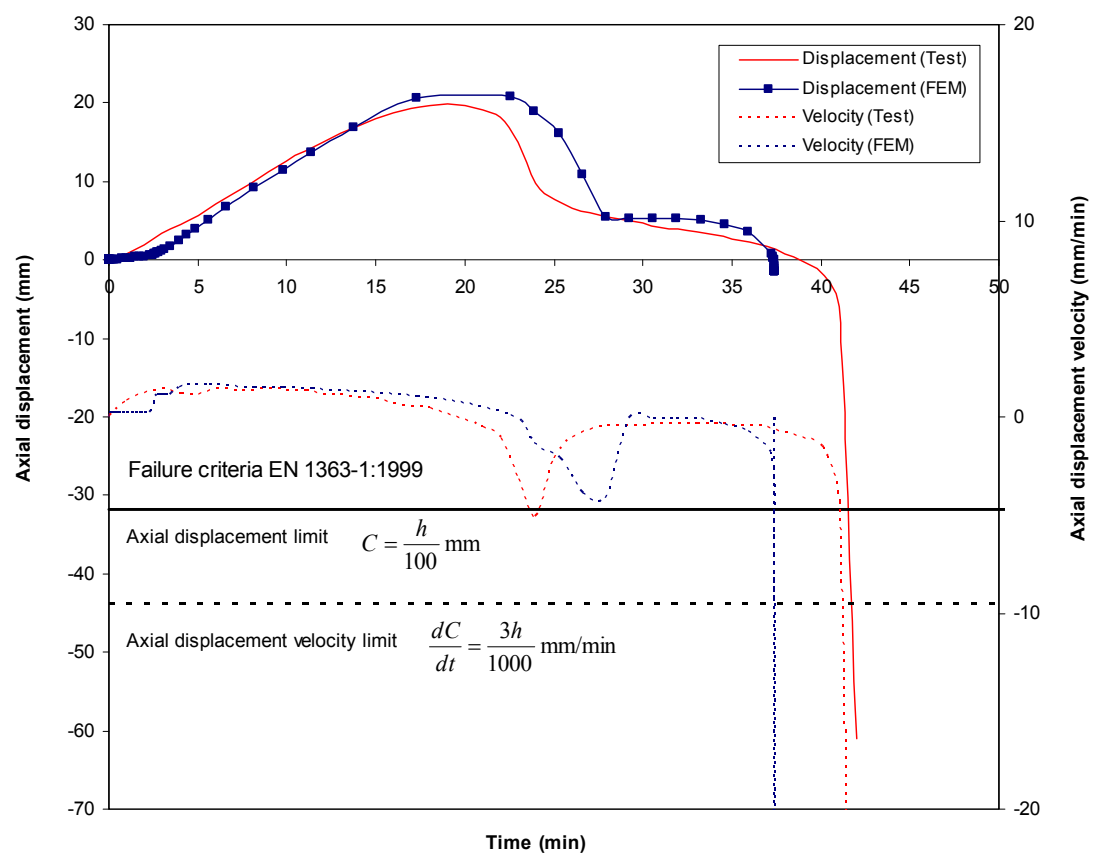

Figure 4.25. Axial displacement versus time curve, C159-6-3-30-0-20.

Table 4.4. Predicted and measured FRR and maximum axial displacement, own tests (normal strength concrete)

\begin{tabular}{|c|c|c|c|c|c|c|}
\hline \multirow{2}{*}{ Column No. } & \multicolumn{2}{|c|}{ FRR (min) } & \multirow{2}{*}{$\frac{F R R_{\text {test }}}{F R R_{N S}}$} & \multicolumn{2}{|c|}{$\delta_{\max }(\mathbf{m m})$} & \multirow{2}{*}{$\frac{\delta_{\text {max }, \text { test }}}{\delta_{\text {max }, N S}}$} \\
\hline & Test & Simulation & & Test & Simulation & \\
\hline C159-6-3-30-0-40-P-P & 18 & 17 & 1.06 & 15.76 & 17.3 & 0.91 \\
\hline C159-6-3-30-0-20 & 42 & 37 & 1.14 & 19.89 & 20.76 & 0.96 \\
\hline C159-6-3-30-0-40 & 25 & 20 & 1.25 & 14.06 & 15.91 & 0.88 \\
\hline C159-6-3-30-0-60 & 14 & 16 & 0.88 & 9.37 & 7.45 & 1.26 \\
\hline RC159-6-3-30-0-20 & 43 & 38 & 1.13 & 18.99 & 20.62 & 0.92 \\
\hline RC159-6-3-30-0-40 & 30 & 24 & 1.25 & 12.47 & 13.26 & 0.94 \\
\hline RC159-6-3-30-0-60 & 13 & 17 & 0.76 & 5.58 & 3.4 & 1.64 \\
\hline FC159-6-3-30-0-20 & 36 & 31 & 1.16 & 20.45 & 21.7 & 0.94 \\
\hline \multirow[t]{3}{*}{ FC159-6-3-30-0-40 } & 22 & 19 & 1.16 & 15.45 & 15.52 & 1.00 \\
\hline & \multicolumn{2}{|c|}{ Average } & 1.09 & \multicolumn{2}{|c|}{ Average } & 1.05 \\
\hline & \multicolumn{2}{|c|}{ Standard deviation } & 0.16 & \multicolumn{2}{|c|}{ Standard deviation } & 0.25 \\
\hline
\end{tabular}


As it can be seen in Figure 4.26, most of the values calculated lie in the region of the $15 \%$ error, with an average and standard deviation value (Table 4.4) similar to that obtained in the validation with the Canadian tests (Table 4.2), which confirms that the numerical model is sufficiently validated against different sources and capable for predicting the fire response of normal strength CFCHS columns. Furthermore, a clear trend towards safe results can be appreciated in Figure 4.26.

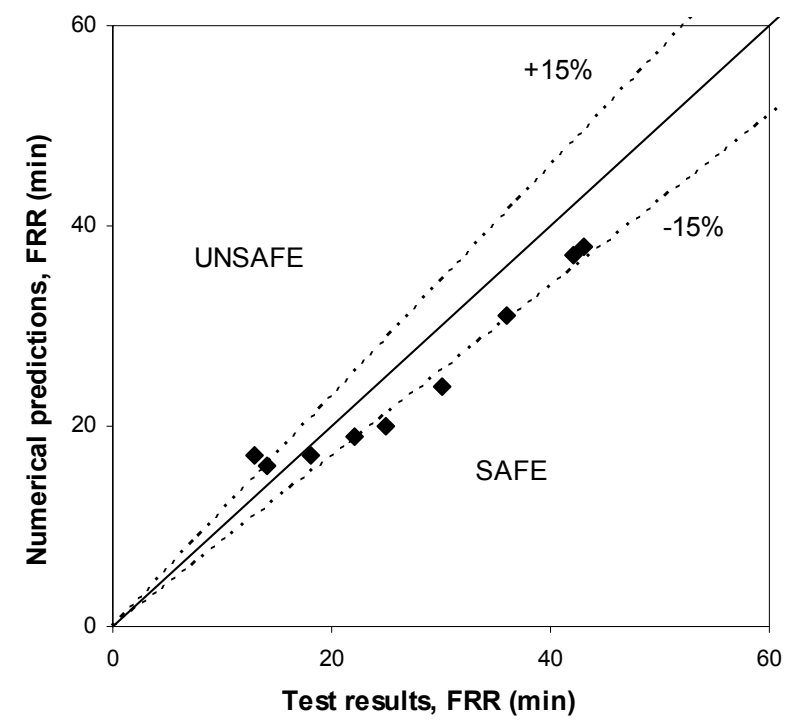

Figure 4.26. Comparison of fire resistance rating between calculated and test results, own tests filled with normal strength concrete.

Good results were also obtained when comparing the maximum axial displacement (Figure 4.27), with better average error than in the comparison with the Canadian tests, since in this experimental research the real steel yield strength had been obtained by means of coupon tests and was available in the simulations.

It can be noticed that those columns subjected to higher loads $(\mu=0.6)$ and thus higher second order effects produced a greater error with unsafe results, which may be attributed to the overestimation of the tensile strength of concrete by the Drucker Prager model, leading to higher failure times than those in the real fire tests. 


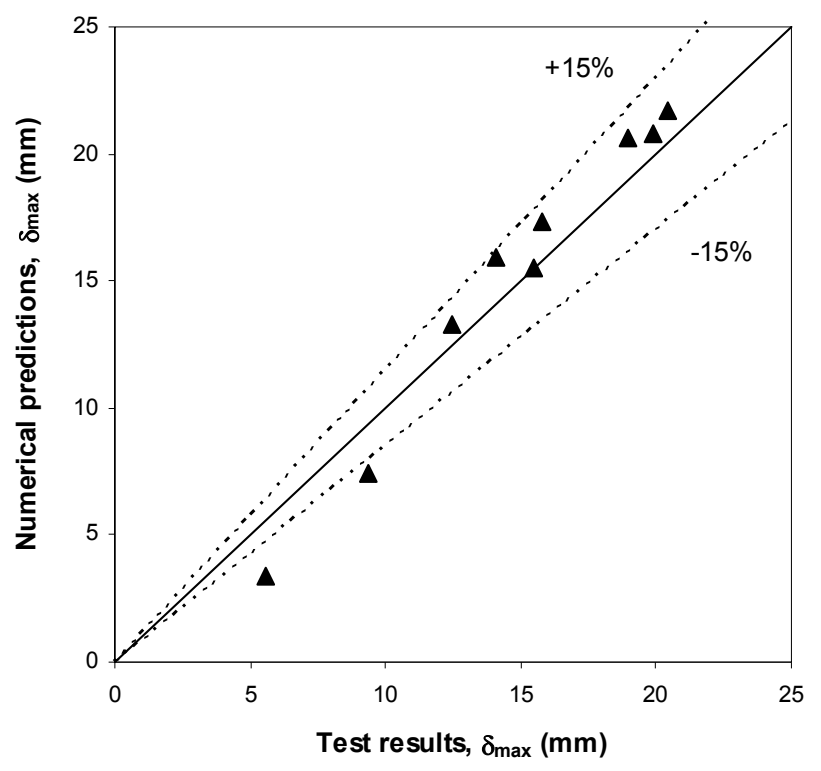

Figure 4.27. Comparison of maximum axial displacement between calculated and test results, own tests filled with normal strength concrete.

The typical failure mechanism described in Section 4.2.1.2 was observed in the specimens subjected to moderated load levels $(\mu=0.2)$. Nevertheless, for the higher load levels $(\mu=0.4$ and 0.6 ), a change in the failure mechanism was observed. This effect, which is due to the combination of high relative slenderness with high load levels, can be better understood through a deeper analysis of force distribution and stresses by means of the numerical model. For that purpose, specimens C159-6-3-30-0-20 and C159-6-3-30-0-60 are compared and their stress states analysed in Figure 4.28 and Figure 4.29, respectively.

The upper part of Figure 4.28 and Figure 4.29 shows the axial displacementtime curve together with the axial force ratio versus time curves for both the steel tube and concrete core. The lower part of these figures shows the distribution of normalized stresses in the steel tube and different points within the concrete core, together with the maximum stress that steel and concrete can reach, which varies along the fire exposure time. 


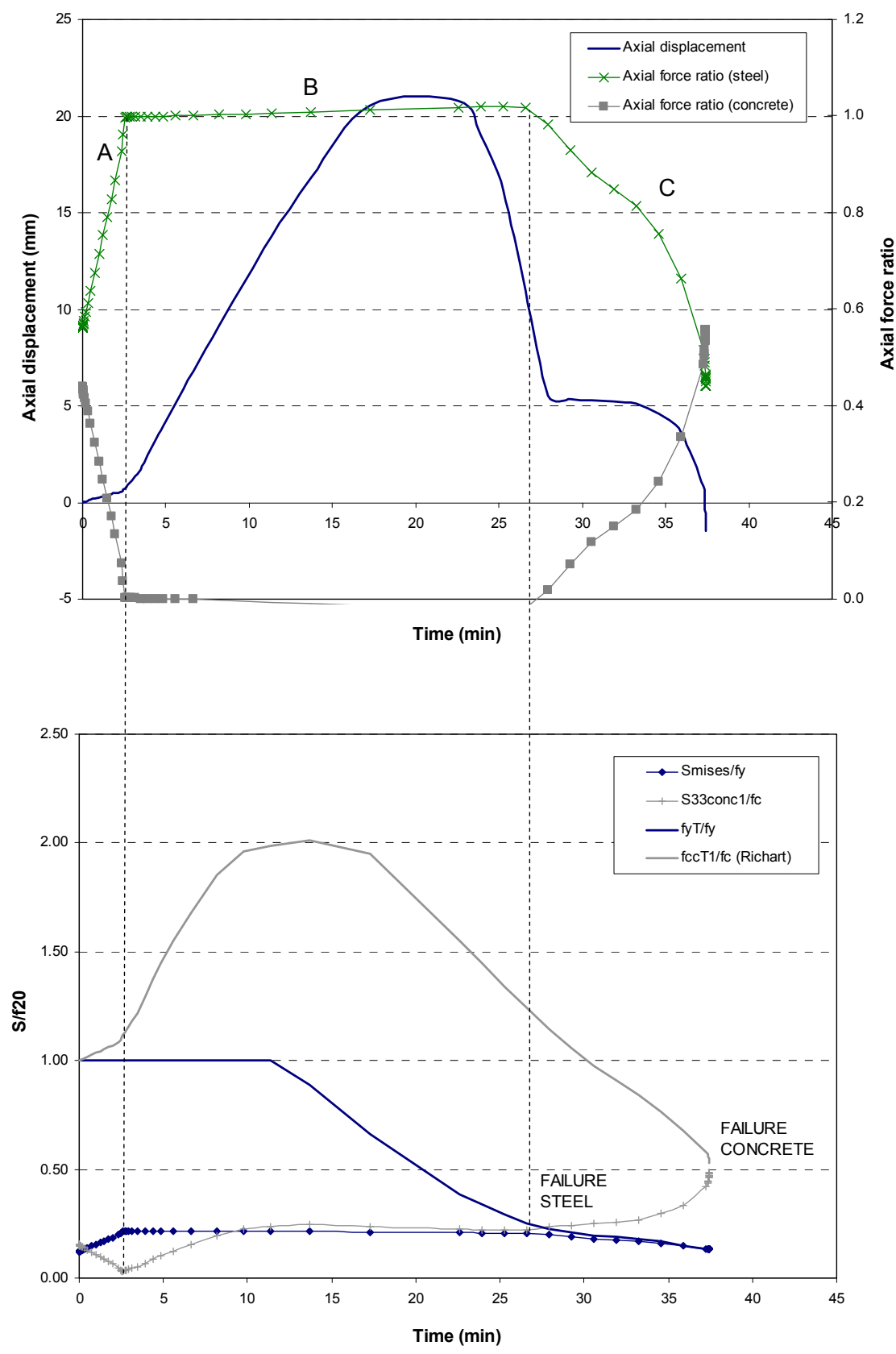

Figure 4.28. Force and stress distribution in the failure section, C159-6-3-30-0-20. 


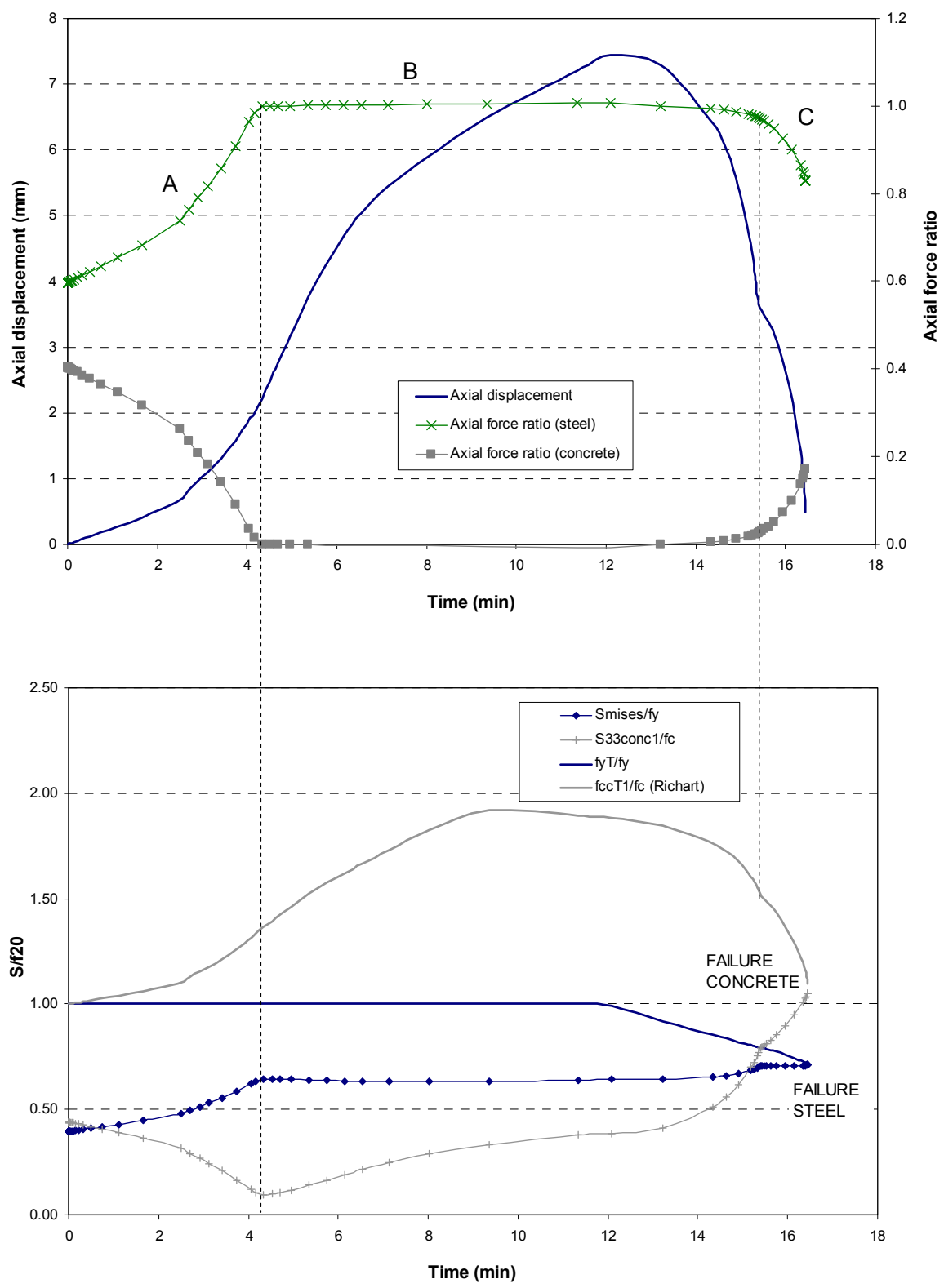

Figure 4.29. Force and stress distribution in the failure section, C159-6-3-30-0-60. 
During the first minutes of heating, the steel tube heats up and expands faster than the concrete core, since it is directly exposed to fire and has a higher thermal conductivity. Because of this faster axial elongation of the steel tube and the occurrence of slip at the steel-concrete interface, the concrete core loses contact with the loading device, thus progressively increasing the axial load ratio of steel (A) until the whole applied load is sustained by the steel tube (B). The steel tube remains fully loaded during a significant period of time until the critical temperature of steel is reached. At this point, the local yielding of the steel tube occurs and it starts to shorten, allowing the loading device to contact the concrete core again. As the column shortens, the steel tube progressively transfers the load to the concrete core (C).

From Figure 4.28, the point where the failure of the steel tube occurs can be identified with the intersection between the Mises equivalent stress at the steel tube (Smises $/ f_{y}$ ) and the yield strength of steel at elevated temperature $\left(f_{y T} / f_{y}\right)$, both normalized with the yield strength of steel at room temperature.

In a deeper analysis of the stress state in the concrete core, it can be seen (Figure 4.30 and Figure 4.31) that the cross-sectional temperature gradient within the concrete core gives rise to a field of self-balanced thermal stresses, which are compressive in the outer layers of concrete and tensile in the central part of the concrete. The longitudinal stress (S33) of three representative points inside the concrete core has been plotted in these figures. Compressive stresses are taken as possitive and tensile stresses are assumed to be negative. It can be seen that the stresses in the central layers of the concrete core (S33conc3) remain in tension and increasing with temperature until the applied load is transferred from the steel tube to the concrete core, when the stresses in the central part of the section undergo an inversion, changing from tension to compression. As can be seen, the total failure occurs when the stress in the outer layers of the concrete core $\left(\mathrm{S} 33 \mathrm{conc} 1 / f_{c}\right)$ reaches the limiting strength. 


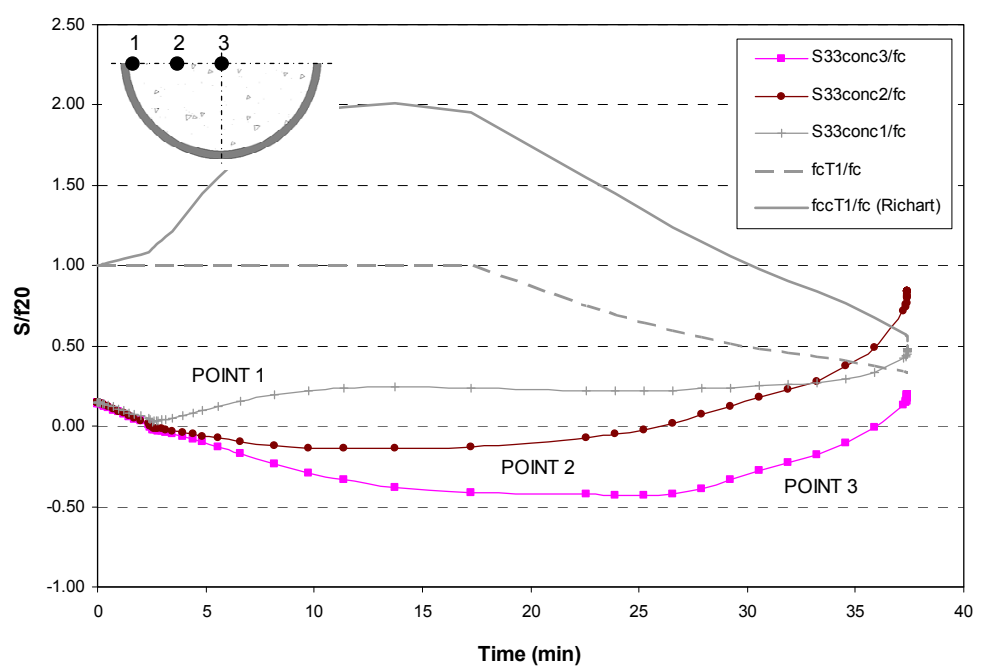

Figure 4.30. Stress distribution in the concrete core, C159-6-3-30-0-20.

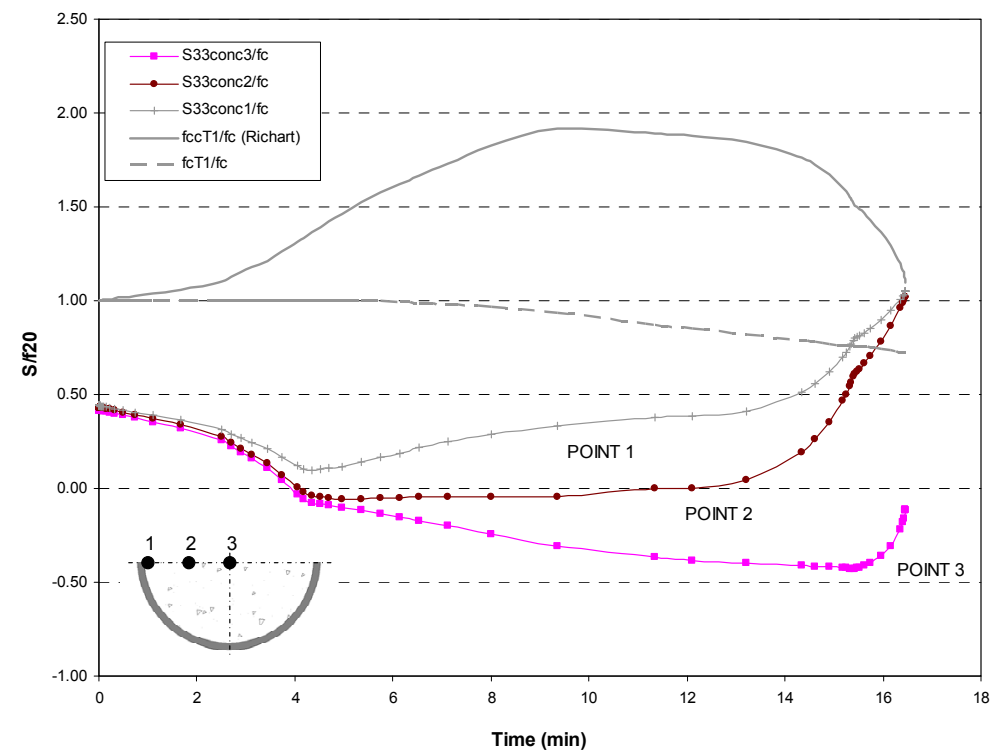

Figure 4.31. Stress distribution in the concrete core, C159-6-3-30-0-60. 
This behaviour can be explained by considering the differential thermal expansion through the cross-section of the column. Figure 4.32 helps to anlyze the effect of the thermal stresses in the final distribution of longitudinal stresses. The stress distribution in the column upper section can be seen in turn in Figure 4.33, where it can be observed how the steel tube and a small peripheral zone of the concrete core are in compression, while the central part of the concrete core is subjected to tensile stresses. As the column is heated, the steel tube expands faster than the concrete core, and remains fully loaded while its load-bearing capacity is not damaged by the elevated temperatures. Owing to the high temperature gradients within the column cross-section, the concrete core layers expand also at different rates, with the hottest (external) parts subjected to greater expansion. The internal layers, which are at lower temperatures, try to resist this differential expansion, causing the external layers to go into compression and undergoing tensile stresses to equilibrate the section.

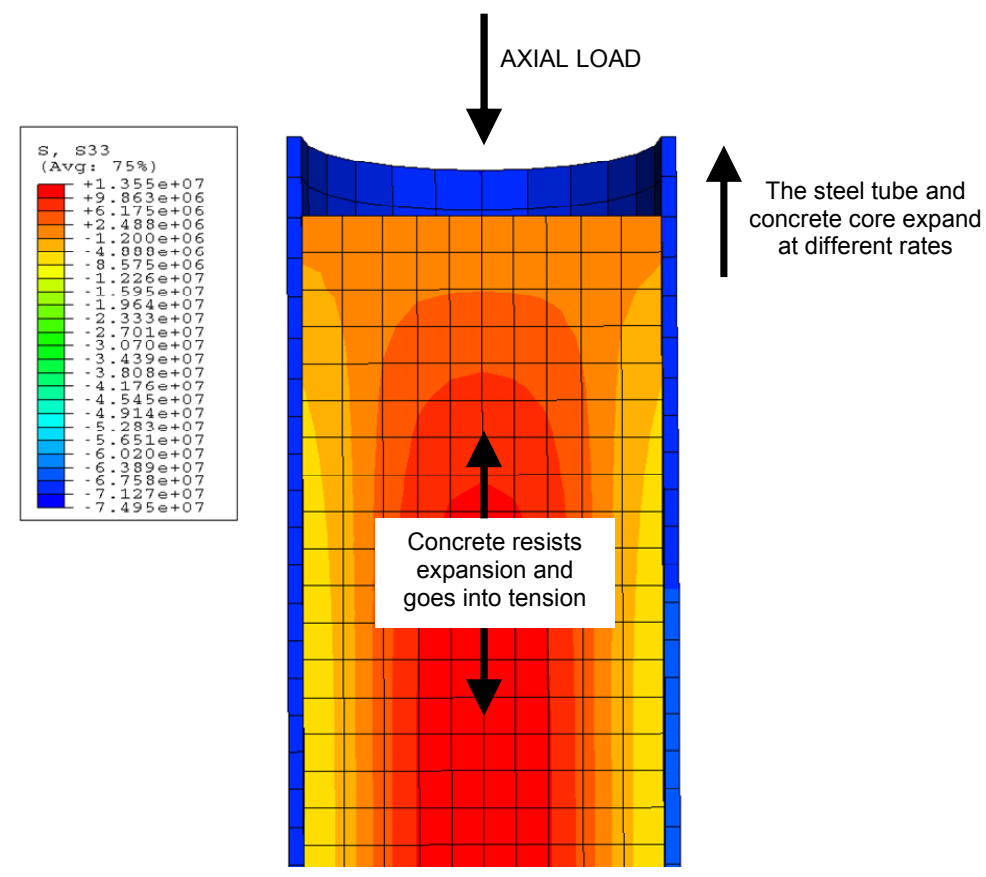

Figure 4.32. Distribution of longitudinal stresses, column C159-6-3-30-0-20.

This effect was also analysed by other authors as Bailey (2000) and Aribert et al. (2008), which described with clarity this stress evolution. 


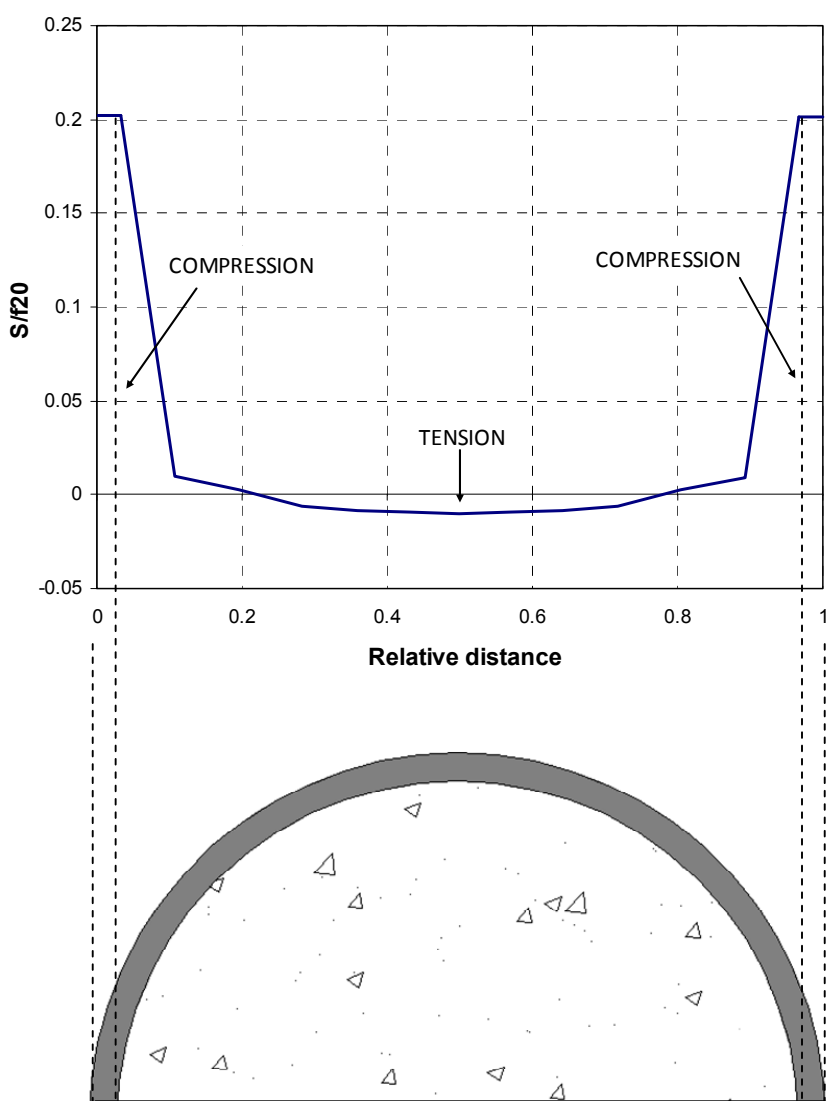

Figure 4.33. Distribution of longitudinal stresses in the column upper section, column C159-6-3-30-0-20.

The compressive strength of concrete at elevated temperature $\left(f_{c T}\right)$ given by EN 1994-1-2 (CEN 2005b) has to be increased in order to take into account the confinement effect. An ovalization of the section can be observed in the simulations, producing a lateral confining pressure $\left(f_{\text {lat }}\right)$ in the concrete core. So, the appropriate curve against which to compare is that of the confined compressive strength of concrete at elevated temperature $\left(f_{c c T l} / f_{c}\right)$ rather than that of the unconfined compressive strength $\left(f_{c T l} / f_{c}\right)$. Updating the equation from Richart et al. (1928) to high temperatures, the confined compressive strength of concrete at elevated temperature can be estimated through the following expression ( $\mathrm{Hu}$ et al. 2003):

$$
f_{c c T}=f_{c T}+4.1 f_{\text {lat }}
$$


where:

- $f_{c T}$ is the compressive strength of concrete at elevated temperature

- $f_{c c T}$ is the compressive strength of concrete at elevated temperature accounting for the confinement effect

- $f_{\text {lat }}$ is the lateral confining pressure

It can be noticed in Figure 4.28 that the failure of the entire column appears when the curve of the confined compressive strength of concrete $\left(f_{c c T I} / f_{c}\right)$ intersects with the longitudinal stress curve in the outer layers of concrete ( $\mathrm{S} 33 \mathrm{conc} 1 / f_{c}$ ), point where both the steel tube and the concrete core are at their maximum capacity.

However, when analysing specimen C159-6-3-30-0-60, loaded at a $60 \%$ of its load-bearing capacity at room temperature (Figure 4.29), a change in the described failure mechanism occurs.

In this case, both components of the composite section are loaded near their maximum capacity at room temperature, therefore when the hollow steel tube degrades with temperature and intends to transfer the load to the concrete core, it is not capable to sustain the load for a longer time due to the higher magnitude of the second order effects, so the column fails exactly when the steel tube yields. It can be seen in Figure 4.29 that the inversion in the axial load ratio does not occur, being the steel tube the component carrying the major part of the applied load during the whole fire exposure time. The redistribution of stresses between the steel and the concrete core is here self-balanced, producing that the failure occurs at the same time in the concrete and the steel.

Through this study, it can be concluded that it is important to secure a smaller ratio between the applied axial load and the individual capacities of the two components of the composite section to allow for the transference of load between the steel tube and concrete core and thus taking advantage of the contribution of concrete in the increment of the fire resistance time. 


\subsection{SENSITIVITY ANALYSIS}

An extensive sensitivity analysis was carried out in order to study the influence of the main aspects of the model and to find their optimal values. The aspects studied were the friction model and gap conductance value to be used at the steel-concrete interface, the initial geometric imperfection, the mechanical and thermal expansion models of the materials at elevated temperatures, the concrete moisture and density and the rebar finite element type. For this purpose, two column specimens from those tested at the National Research Council of Canada (Lie \& Chabot 1992) were selected, with similar material properties, buckling length and load level but very different $D / t$ ratio, so that the study can be valid for CFT columns with both elevated and reduced steel contribution. These column specimens are coded as C-04 and C-05 and their properties collected in Table 4.1. The influence of the rebar element type was studied by means of column C-48 from NRCC (Chabot \& Lie 1992).

\subsubsection{Steel-concrete interface friction model}

Three options were studied for the steel-concrete frictional interaction: the first option used the classical Coulomb friction model with a friction coefficient equal to 0.3 , the second option assumed a full slip between the steel tube and the concrete core (frictionless contact) and the third option considered the existence of a full bond at the steel-concrete interface (rough contact).

The full bond model deviated excessively from the real behaviour of the column, as it can be seen in Figure 4.34. In turn, the Coulomb friction model and full slip model produced exactly the same results, being both close to the measured curve, therefore it can be confirmed that a full slip occurs at the steel-concrete interface in the fire situation, since the different thermal expansions cause the separation of the steel tube from the concrete core at elevated temperatures. 


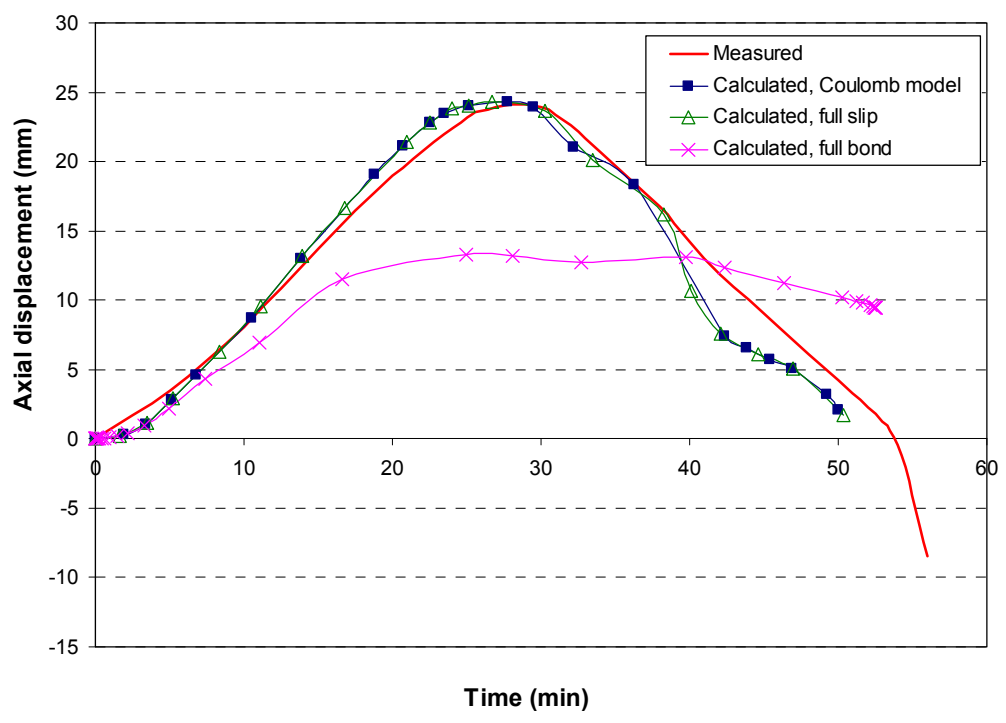

(a) Column C-04

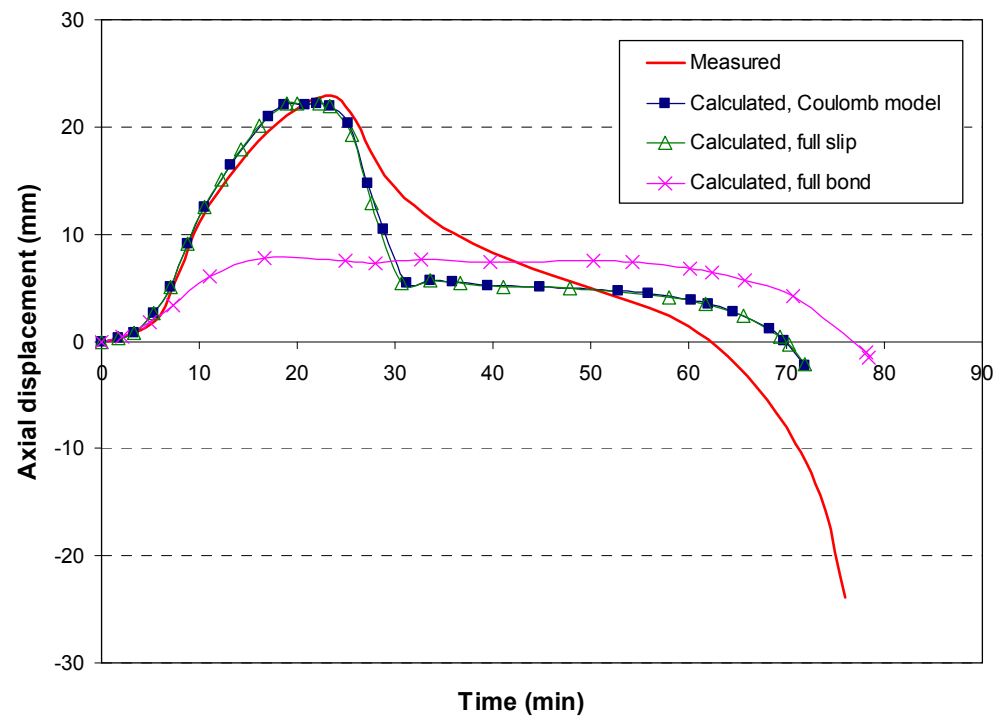

(b) Column C-05

Figure 4.34. Comparison of measured and predicted axial displacement with different friction models. 
To further confirm this fact, different values of the friction coefficient in the Coulomb model were studied, ranging from 0.3 to 0.8 , no difference being obtained in the overall fire response, see Figure 4.35. It can be therefore inferred that the value of the friction coefficient at the steel-concrete interface does not have any influence over the column fire behaviour, as the steel tube and concrete core slide relative to each other in the fire situation, and thus a frictionless model can be adopted.

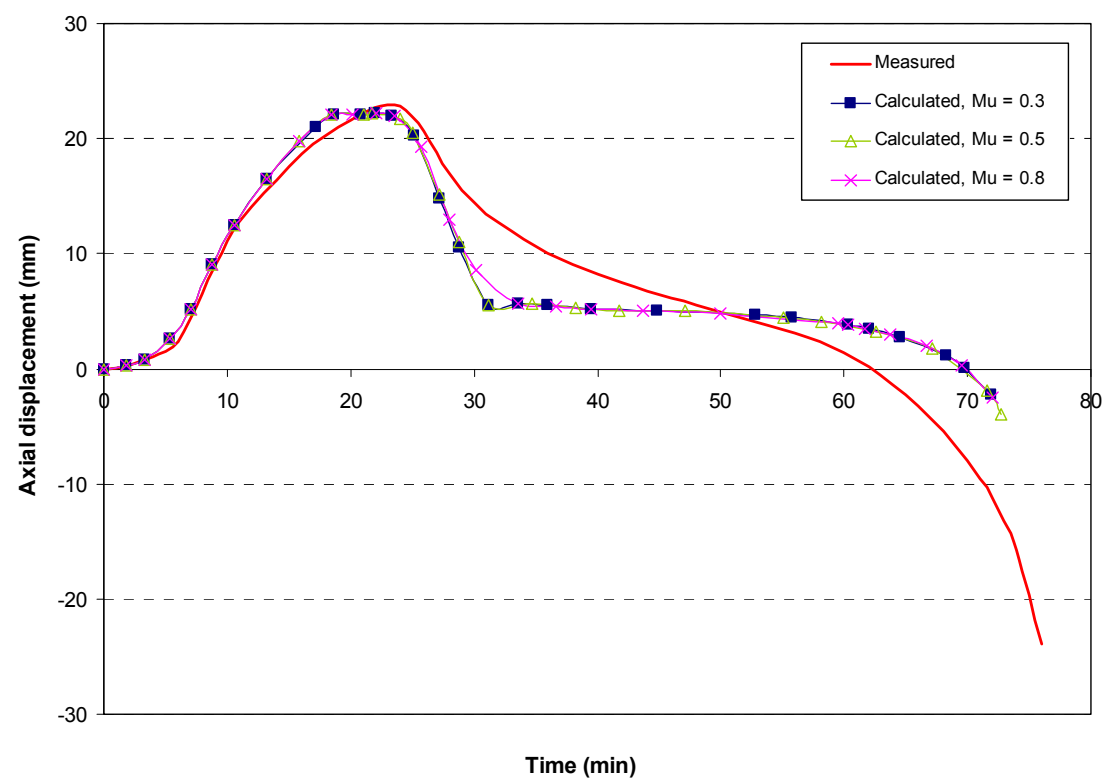

Figure 4.35. Comparison of measured and predicted axial displacement with different friction coefficients, for column C-05.

\subsubsection{Gap thermal conductance}

Existing mathematical models for the prediction of the temperature field in concrete filled steel tubular columns (Lie 1994) do not take into account the resistance to heat flow at the steel-concrete interface, resulting in a significant disagreement between measured and predicted temperatures. This resistance to heat flow at the steel-concrete interface is known as the contact thermal resistance and is usually expressed in terms of a joint contact conductance $h_{j}$, defined in terms of Newton's law of cooling: 


$$
q=h_{j} \cdot \Delta \theta
$$

As discussed in Section 4.1.8.1, the thermal conductance across the steelconcrete interface can be considered either dependent or independent on the gap clearance. In the first case, a fully coupled thermal-stress analysis is required. That is a more realistic approach but requires excessive computational time. Nevertheless, conducting a sequentially coupled thermal-stress analysis assuming the gap conductance to be independent of the gap clearance produces accurate enough results in a more permissible level of calculation times.

Another aspect to take into account is the dependence of the gap conductance with temperature. In a first approach, a constant value of $h_{j}=200 \mathrm{~W} / \mathrm{m}^{2} \mathrm{~K}$ for the gap conductance was employed, as recommended by Ding \& Wang (2008). In a second approach, the interfacial thermal conductance was expressed as a function of temperature as suggested by Ghojel (2004), adopting the following correlation proposed by the author for loaded circular steel tubes filled with plain or barreinforced concrete:

$$
h_{j}=160.5-63.8 \cdot \exp \left(-339.9 \cdot \theta^{-1.4}\right) \quad\left(\mathrm{W} / \mathrm{m}^{2} \mathrm{~K}\right)
$$

where $\theta$ is the temperature in degrees Celsius.

The third approach considered the existence of a perfect thermal contact at the steel-concrete interface, that is, the temperature at the contacting surfaces of steel and concrete is the same.

Figure 4.36 shows the comparison for the evolution of temperature at significant points of the cross-section under the three approaches studied, where it can be clearly seen that the perfect contact approach overestimates the temperature field, while the other two options (which consider a thermal resistance) produce more accurate predictions. 


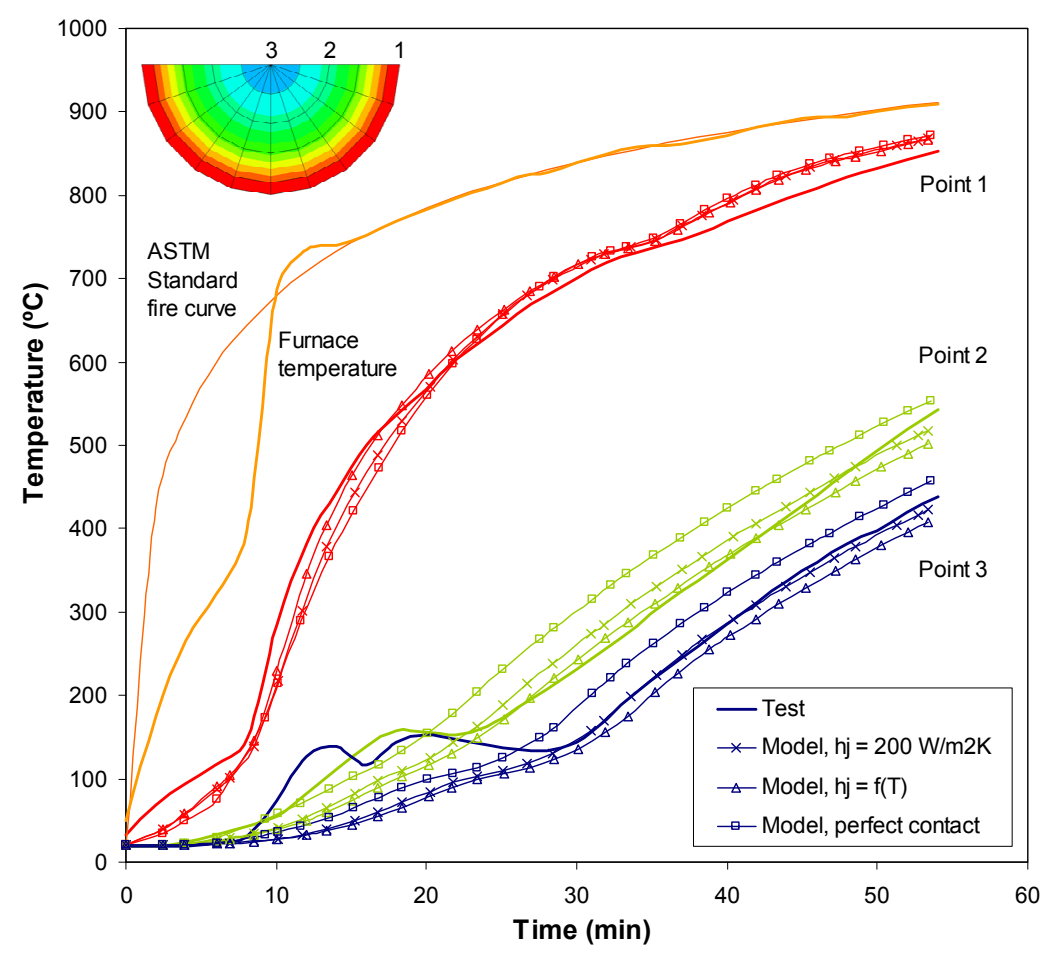

Figure 4.36. Comparison between measured and predicted temperatures with different gap conductance values, for column C-02.

As it can be seen in Figure 4.37, the model proposed by Ghojel produced the best estimations in terms of failure time, although adopting a constant value of $h_{j}$ $=200 \mathrm{~W} / \mathrm{m}^{2} \mathrm{~K}$ produced acceptable results as well, which in this case remain on the safe side. Assuming that no thermal resistance occurs at the steel-concrete interface is not so realistic and gives very conservative estimations, since it predicts a faster temperature rise. 


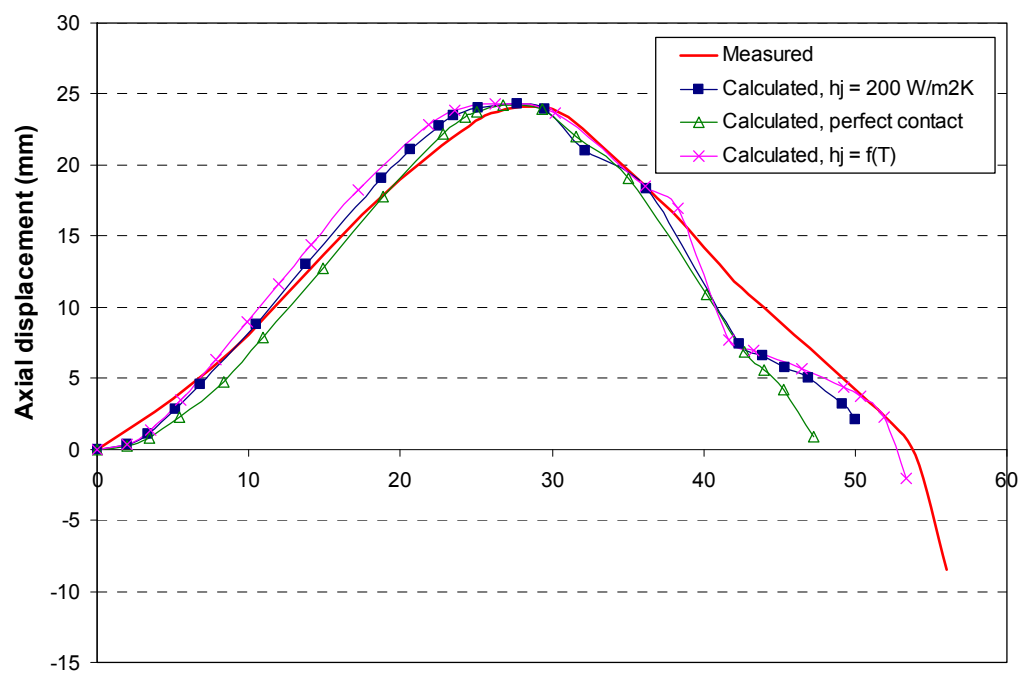

Time (min)

(a) Column C-04

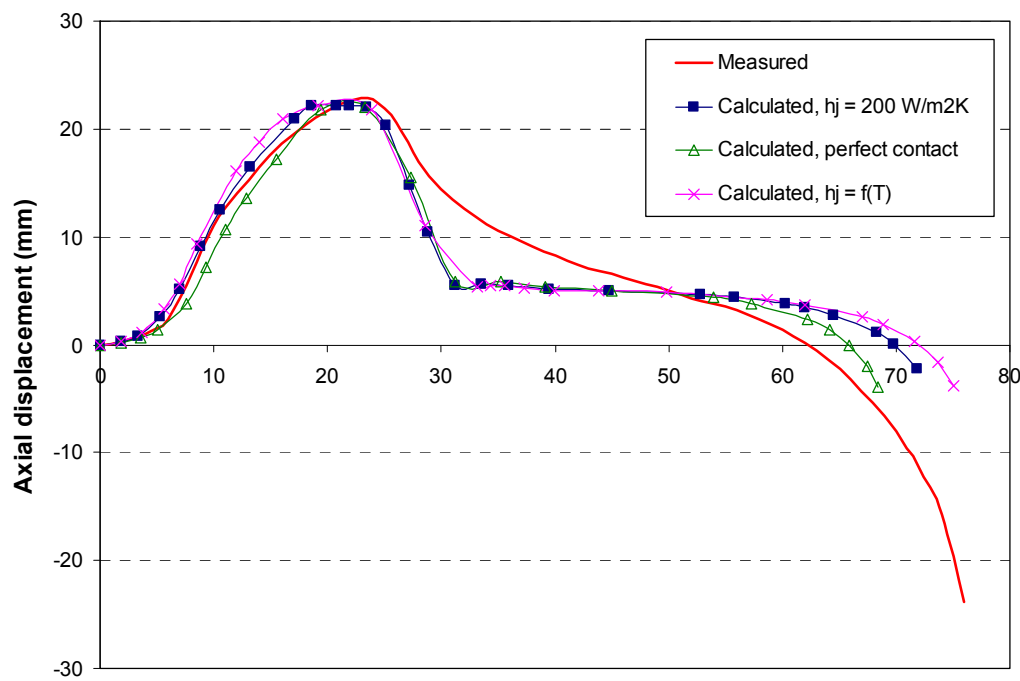

Time (min)

(b) Column C-05

Figure 4.37. Comparison of measured and predicted axial displacement with different gap conductance values. 


\subsubsection{Initial geometric imperfection}

In order to represent the initial geometric imperfection of the columns, the deformed shape of the pinned-pinned column first buckling mode was obtained, and afterwards amplified by means of an imperfection factor for each of the geometries under study.

Different values for the out-of-straightness of the column ranging from $L / 500$ to $L / 2000$ were studied, producing the results shown in Figure 4.38. From this study, it can be recommended that values no higher than $L / 500$ be adopted, being optimum to employ an amplitude of $L / 1000-L / 2000$, as normally assumed by researchers (Renaud et al. 2004, Ding \& Wang 2008, Hong \& Varma 2009). Lower values, as the $L / 7500$ value suggested by Galambos (1998) can give place to convergence problems if they are not of enough magnitude to induce the overall buckling of the column.

\subsubsection{Material mechanical models at elevated temperatures}

Several mechanical models at high temperatures were studied for both steel and concrete.

\section{Steel}

For steel, three models were studied and compared: EN 1993-1-2 (CEN 2005b), Lie (1984) and Yin et al. (2006). The formulation of these models has been included in Annex II "Material constitutive modelling". EN 1993-1-2 model produced the more accurate response, whereas the model from Lie predicted an excessively resistant behaviour, as it can be seen in Figure 4.39. The model from Yin did not produce a converged solution. As can be seen in Figure 4.19, the steel model determines the shape and extension of stages 1 and 2 at the axial displacement versus time curve, being better represented by EN 1993-1-2 model. According to these results, the model from EN 1993-1-2 was selected for defining the mechanical behaviour of steel at elevated temperatures. 


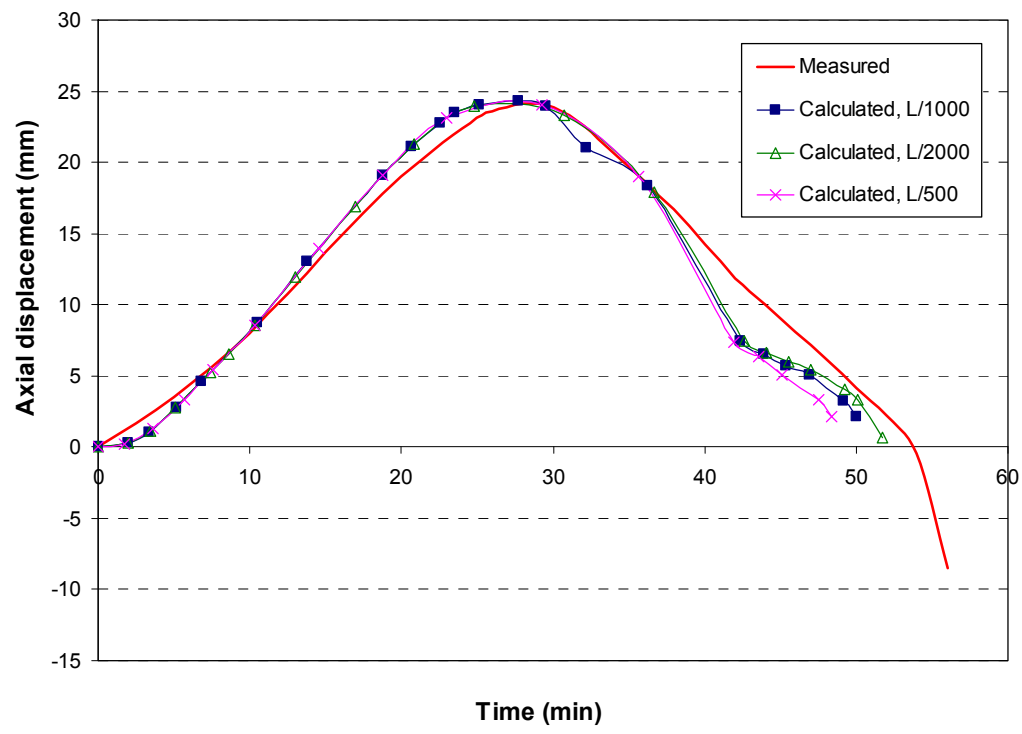

(a) Column C-04

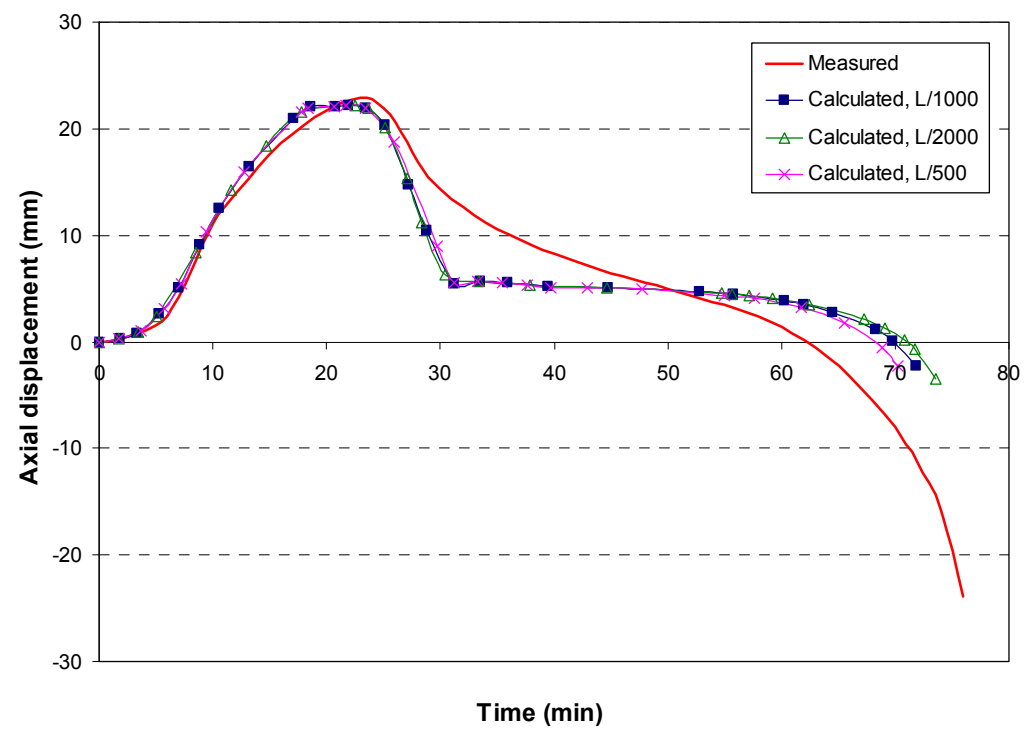

(b) Column C-05

Figure 4.38. Comparison of measured and predicted axial displacement with different initial imperfections. 


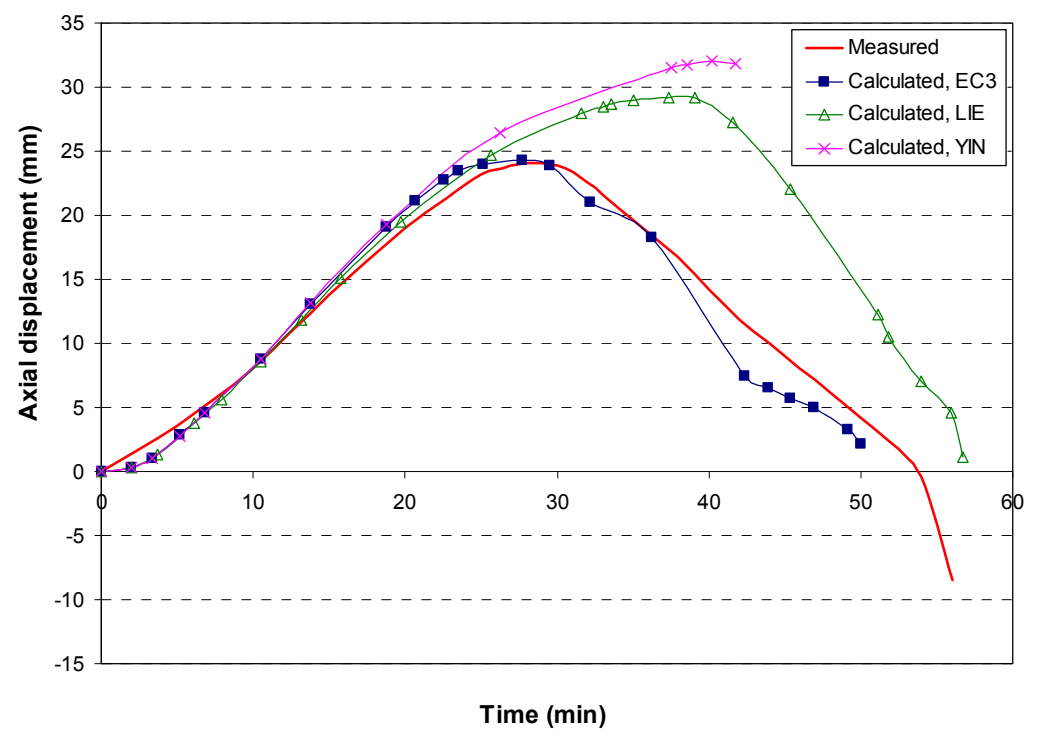

(a) Column C-04

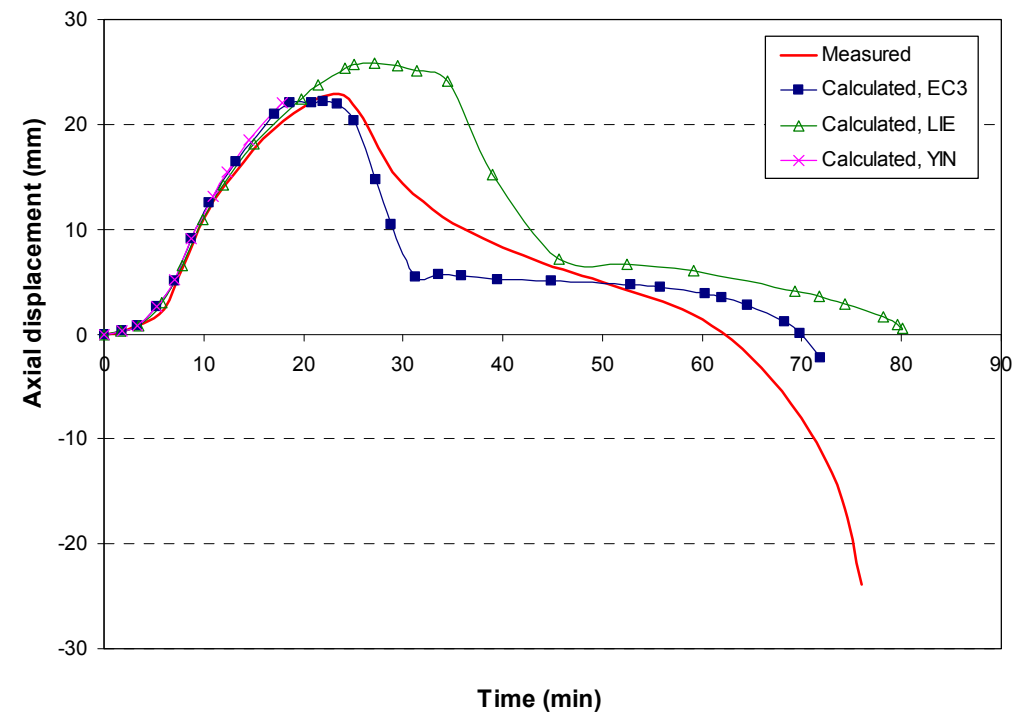

(b) Column C-05

Figure 4.39. Comparison of measured and predicted axial displacement with different steel models. 


\section{Concrete}

In the case of concrete, a variety of mechanical models at elevated temperatures exists in the literature. Five of them were studied in this research: Lie (1984), EN 1992-1-2 (CEN 2004a), Anderberg \& Thelandersson (1976), Li \& Purkiss (2005) and Schneider (1988). The formulation of these models has been included in Annex II "Material constitutive modelling".

The concrete model determines the extension of stage 3 at the axial displacement versus time curve (Figure 4.19) and fixes the position of the failure branch (stage 4 at Figure 4.19). Among all these models, the model from Lie was the one that best predicted the fire resistance of the columns, as it can be seen in Figure 4.40. Regarding EN 1992-1-2 model, it produced the most conservative results, deviating from the real response of the columns. Therefore, the stress-strain relations proposed by Lie were used for defining the mechanical behaviour of concrete at elevated temperatures in the numerical model.

\subsubsection{Thermal expansion coefficient}

\section{Steel}

Two options were studied for modelling the thermal expansion of steel at elevated temperatures. On one hand, the temperature dependent values of the thermal expansion coefficient from EN 1993-1-2 (CEN 2005b) were studied. On the other hand, the constant value recommended by Hong \& Varma (2009), $\alpha_{s}=12 \times 10^{-6}$ ${ }^{\circ} \mathrm{C}^{-1}$, was checked. The EN 1993-1-2 thermal expansion model produced very accurate results, whereas the constant value proposed by Hong \& Varma predicted a shorter maximum axial displacement, as shown in Figure 4.41. The temperature dependent formulation from EN 1993-1-2 was therefore selected.

\section{Concrete}

Two options were studied for modelling the thermal expansion of concrete at elevated temperatures: the temperature dependent formulation from EN 1992-1-2 (CEN 2004a) and the constant value recommended by Hong \& Varma (2009), $\alpha_{c}=$ $6 \times 10^{-6}{ }^{\circ} \mathrm{C}^{-1}$. This constant value produced remarkably better results for concrete, as shown in Figure 4.42, while the model form EN 1992-1-2 resulted in a very unrealistic response, giving place to an excessive axial displacement in the stage when the concrete is sustaining the majority of the applied load (stage 3 at Figure 4.19). 


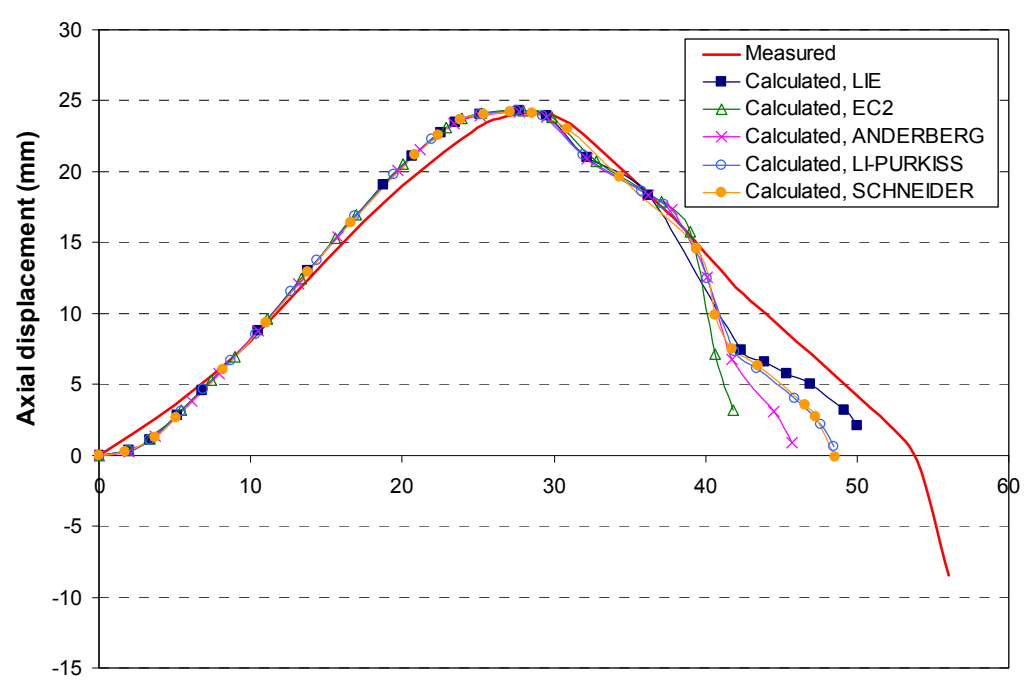

Time (min)

(a) Column C-04

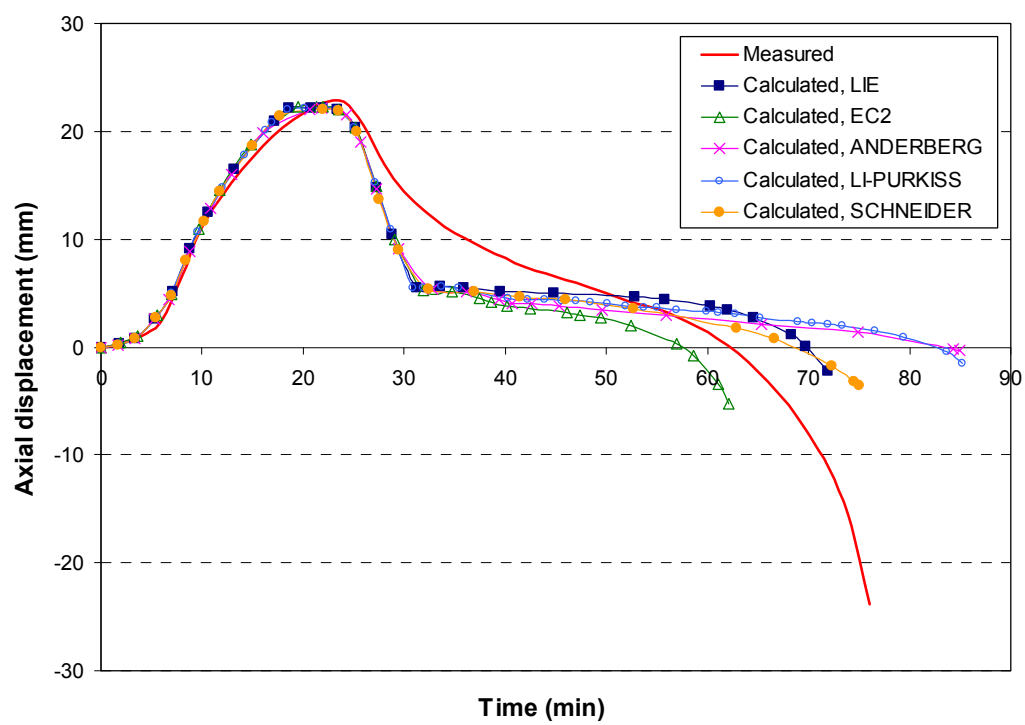

(b) Column C-05

Figure 4.40. Comparison of measured and predicted axial displacement with different concrete models. 


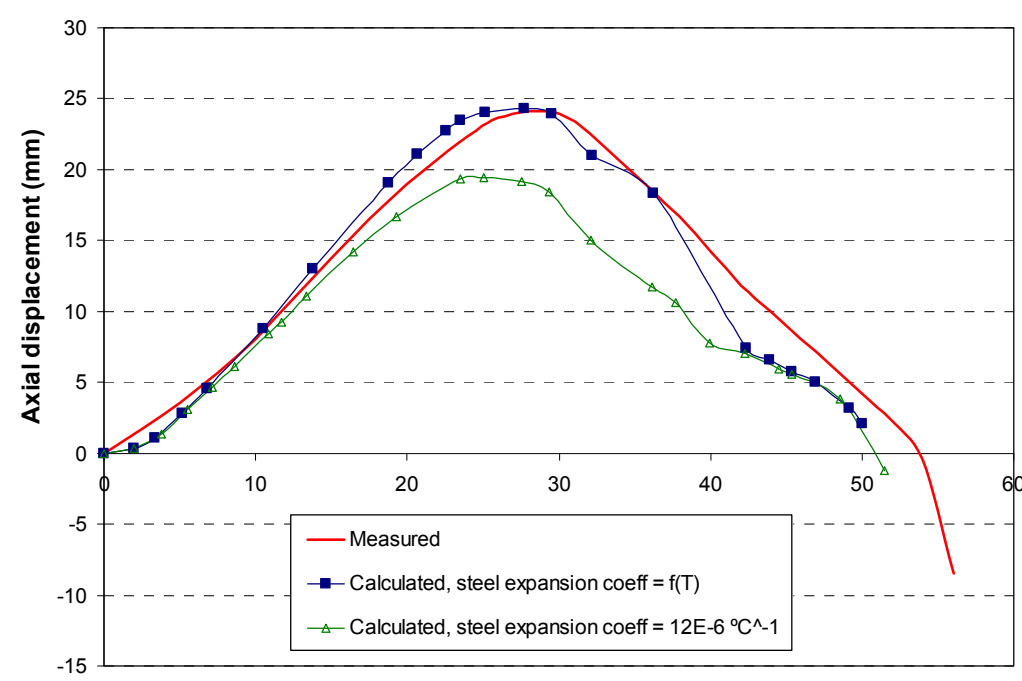

Time (min)

(a) Column C-04

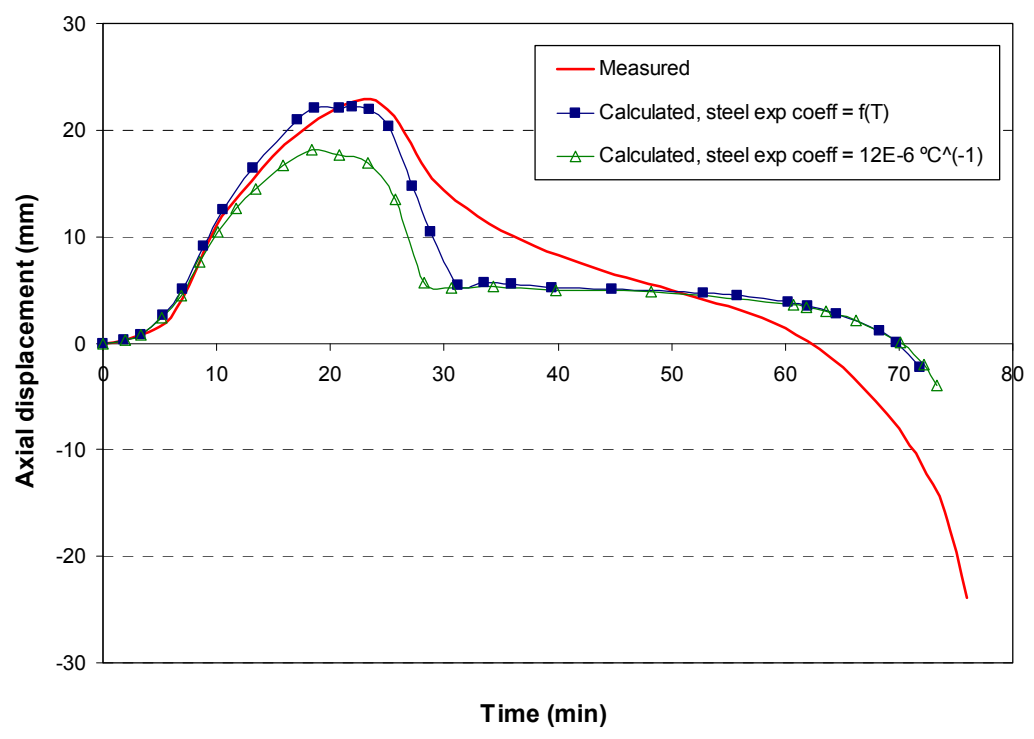

(b) Column C-05

Figure 4.41. Comparison of measured and predicted axial displacement with different steel expansion models. 


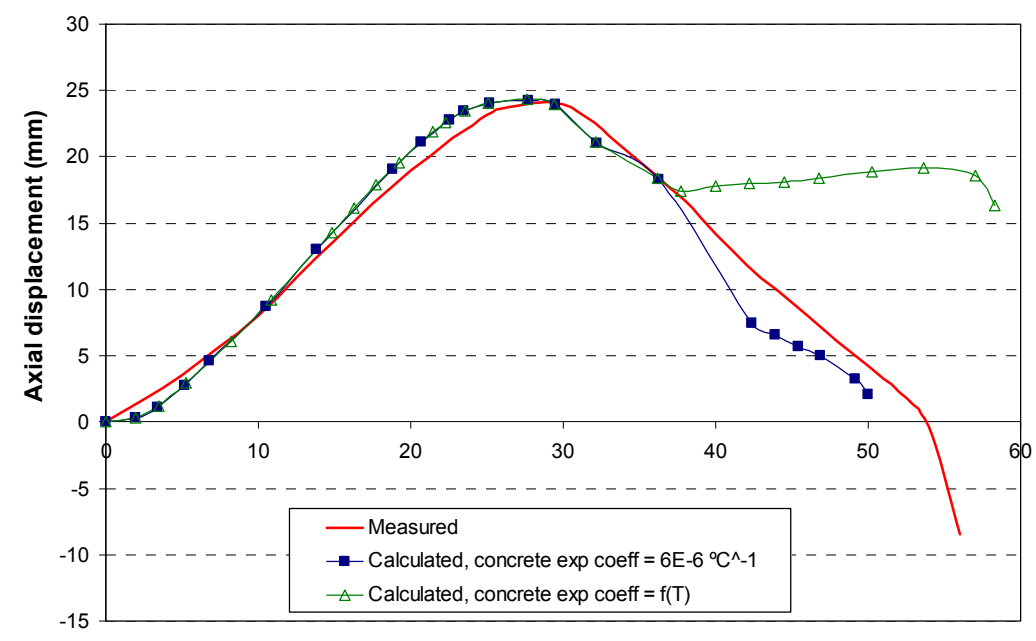

Time (min)

(a) Column C-04

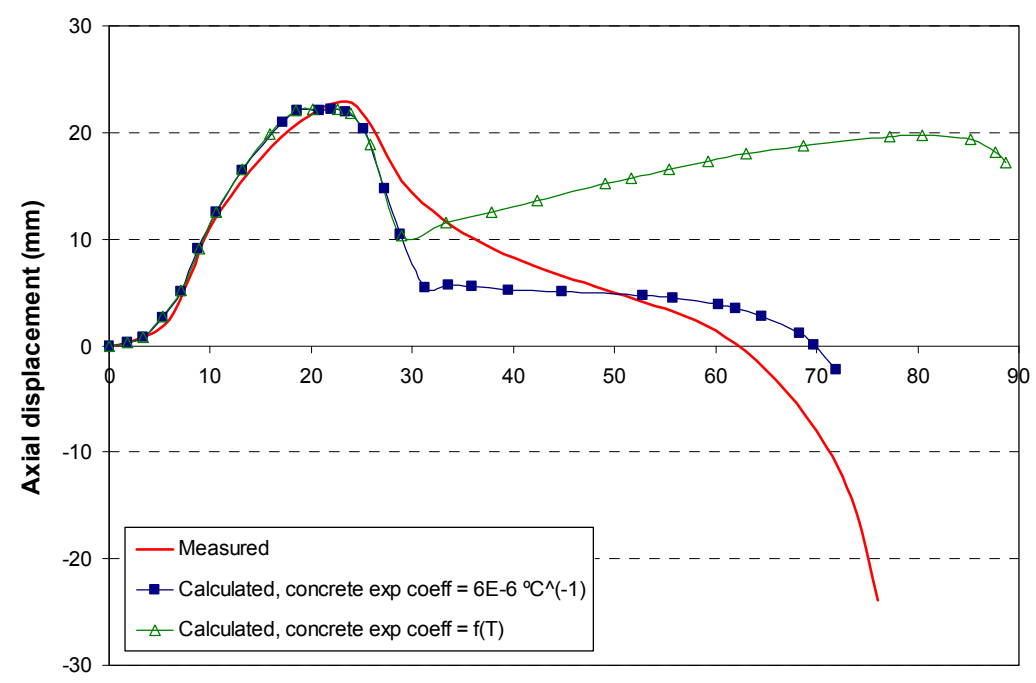

Time (min)

(b) Column C-05

Figure 4.42. Comparison of measured and predicted axial displacement with different concrete expansion models. 


\subsubsection{Concrete moisture}

The moisture content at the concrete infill was modelled through a peak value in the specific heat formulation, as recommended by EN 1994-1-2 (CEN 2005c). A first peak value of $2020 \mathrm{~J} / \mathrm{kgK}$ corresponding to a moisture content of $3 \%$ in concrete weight was implemented, and a second value of $5600 \mathrm{~J} / \mathrm{kgK}$ for a moisture content of $10 \%$ was next studied. For the specimens filled with siliceous aggregates concrete, the optimal results were obtained both in thermal and mechanical response with a $3 \%$ moisture value. This is shown in Figure 4.43 for the temperature field of column C-02 and in Figure 4.44 for the axial displacement response of columns C04 and $\mathrm{C}-05$.

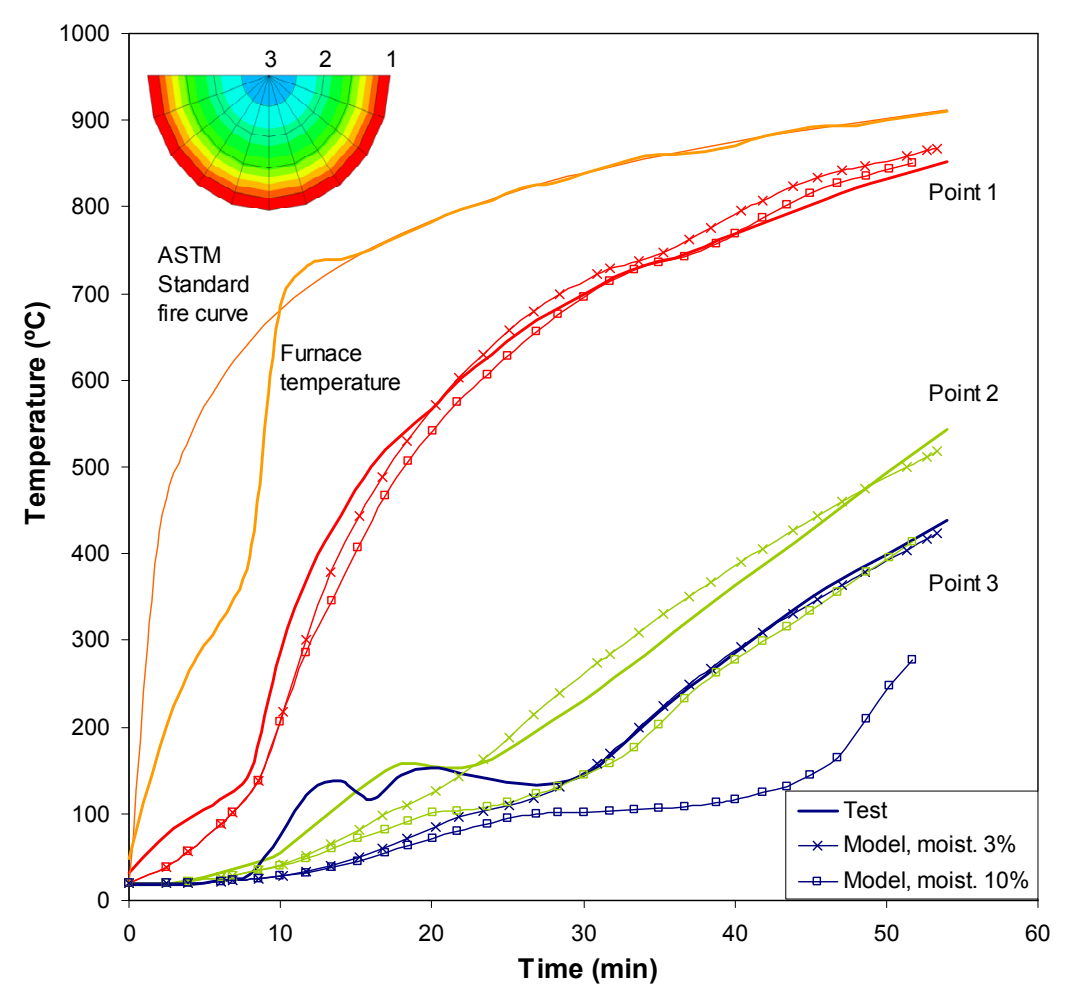

Figure 4.43. Comparison between measured and predicted temperatures with different moisture values, for column C-02. 


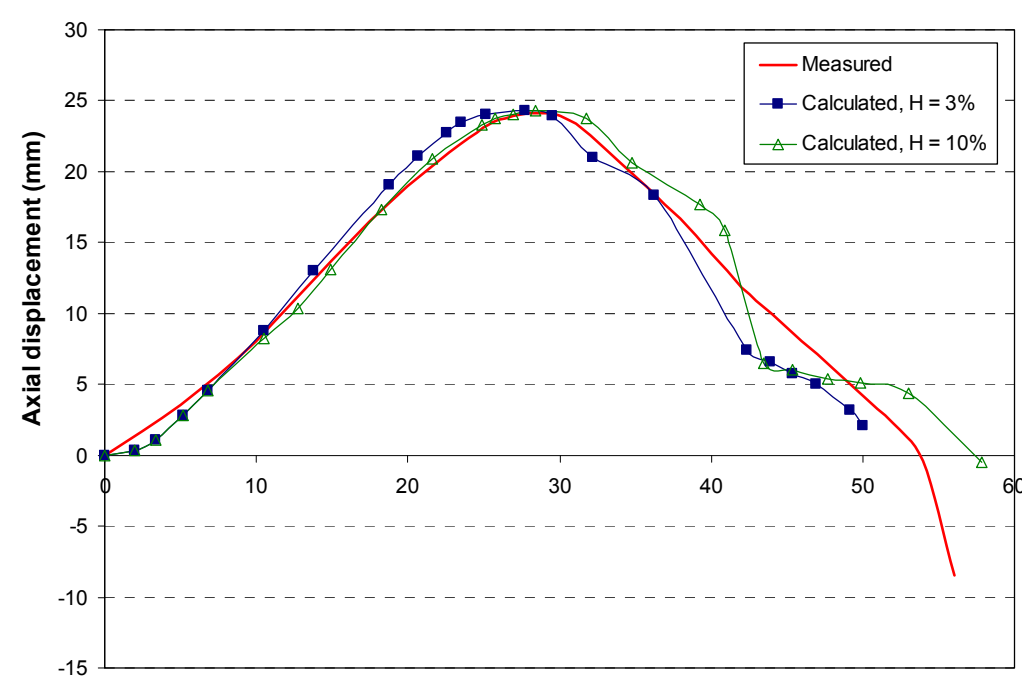

Time (min)

(a) Column C-04

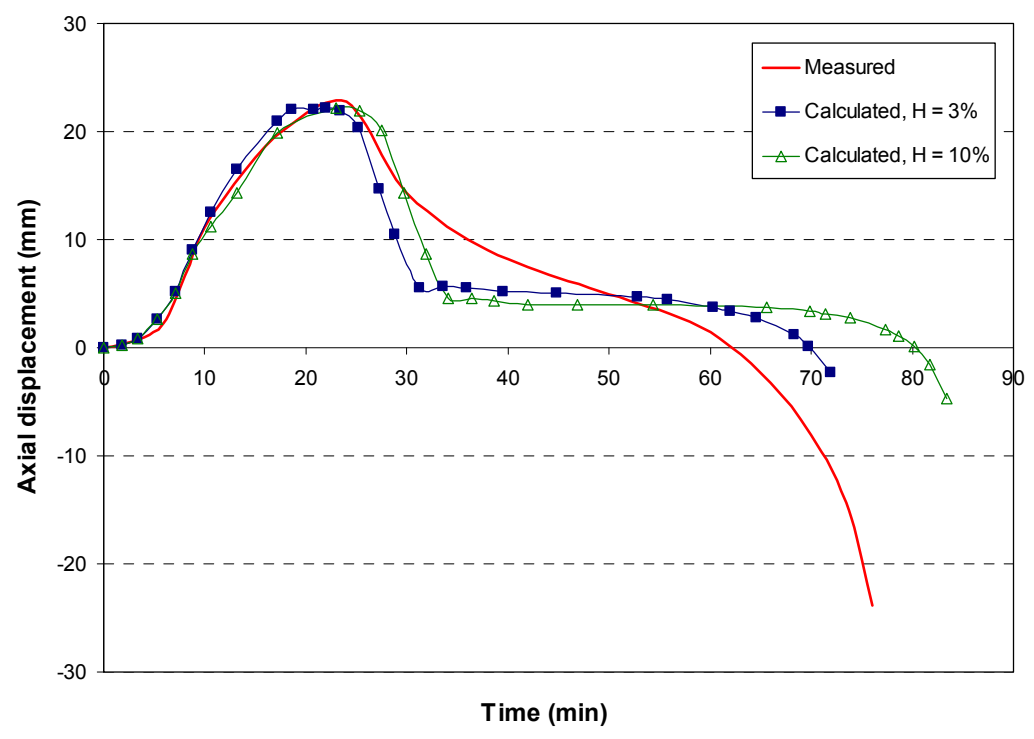

(b) Column C-05

Figure 4.44. Comparison of measured and predicted axial displacement with different moisture values. 
In turn, for those specimens filled with calcareous aggregates concrete, the optimal moisture value was found to be a $10 \%$, as can be seen in Figure 4.45. The real moisture content value at test date, which may be different for each column specimen, was not available for the Canadian tests and therefore a global value suitable for the majority of the tests was adopted. Nevertheless, when comparing with the tests carried out in Valencia (Romero et al. 2011), the real moisture content value was used in all the simulations, as it had been measured for all the tested specimens.

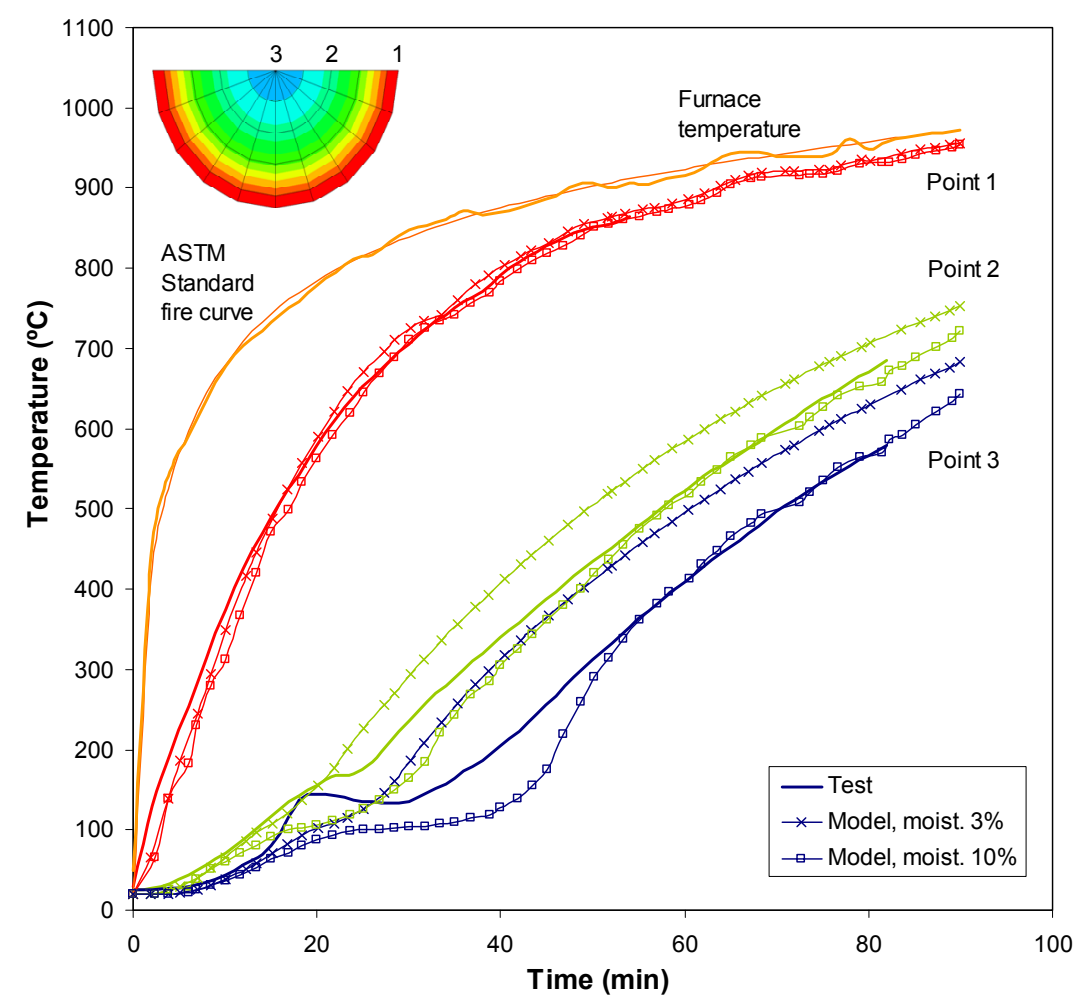

Figure 4.45. Comparison between measured and predicted temperatures with different moisture values, for column C-31. 


\subsubsection{Concrete density}

The variation of concrete density with temperature formulated in EN 1992-12 (CEN 2004a) was studied in contrast to the constant value of $2300 \mathrm{~kg} / \mathrm{m}^{3}$ adopted by most researchers. This study proved that there is no significant influence of this aspect over the fire behaviour of CFT columns, as can be seen in Figure 4.46. Thus, the temperature dependence of concrete density can be omitted in the model.

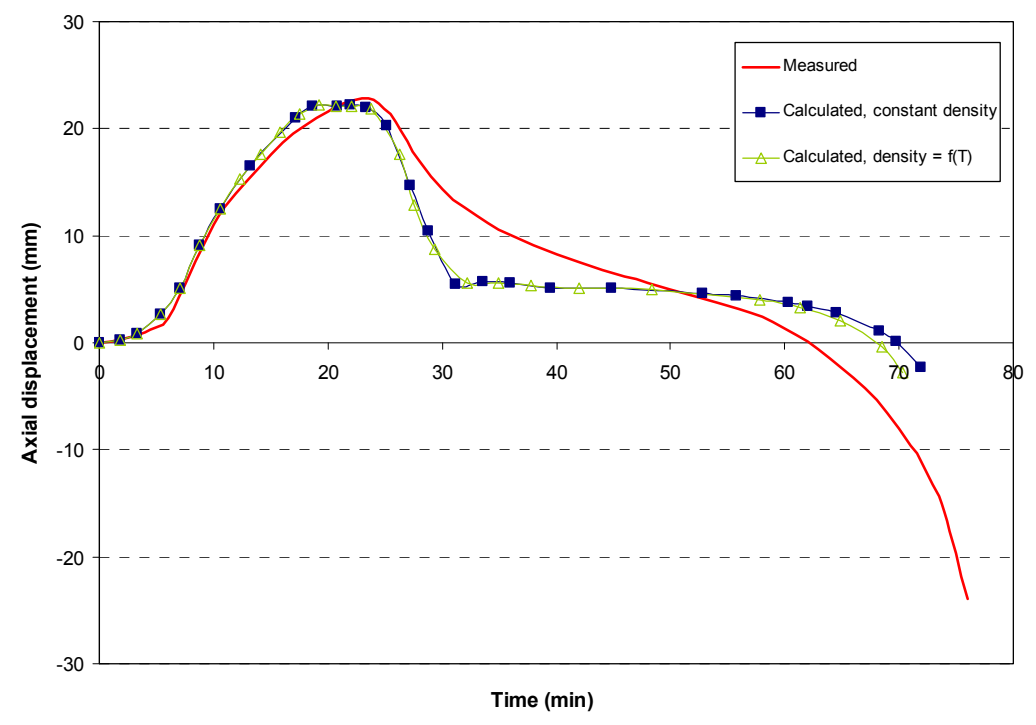

Figure 4.46. Comparison of measured and predicted axial displacement with different concrete density models.

\subsubsection{Rebar finite element type}

Two different finite element types for modelling the reinforcing steel bars were studied in this research: two-noded truss elements and three-dimensional eightnoded solid elements. The truss elements resulted in a more accurate prediction for the reinforced specimens studied, as it can be seen in Figure 4.47 (referred to as REBAR 1D), producing a more realistic response. Full bond was assumed between the steel reinforcing bars and concrete, tying both rebar nodes to their corresponding concrete nodes. 


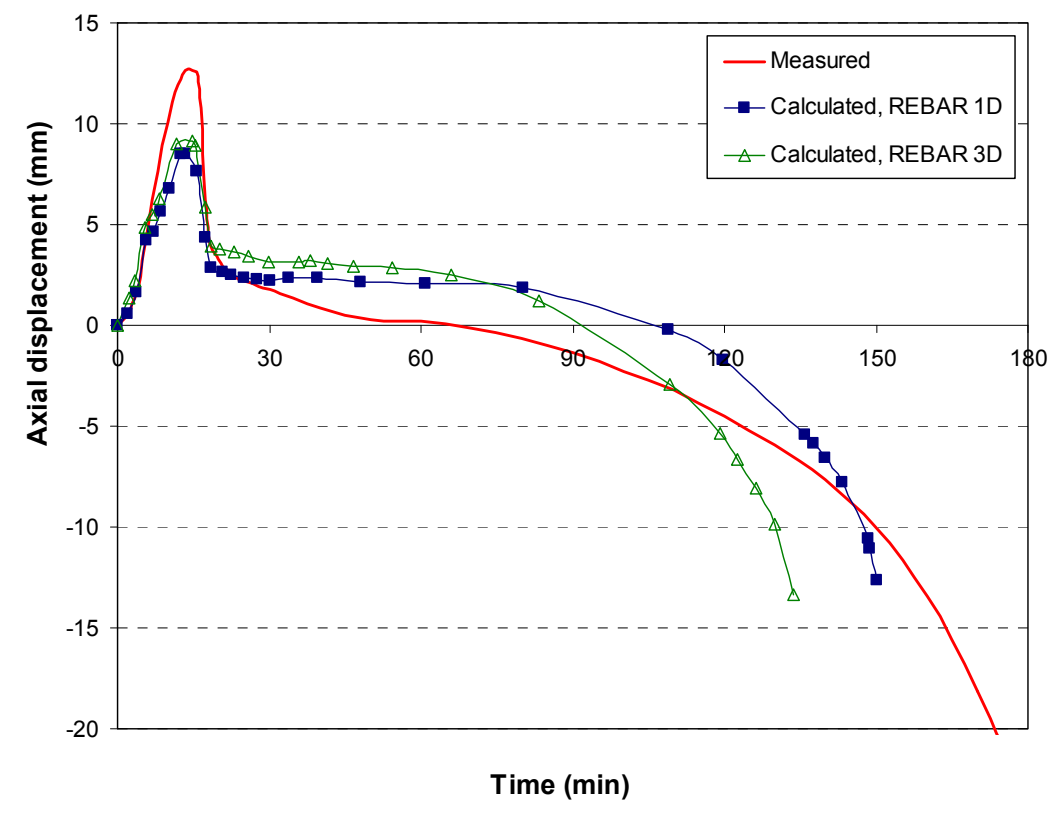

Figure 4.47. Comparison of measured and predicted axial displacement with different rebar element types, for column C-48. 


\section{CONCRETE FILLED ELLIPTICAL STEEL COLUMNS}

Few studies exist so far in the literature on elliptical hollow section columns filled with concrete. In particular, the fire behaviour of such columns has not been established yet, therefore it was found of great interest to use the numerical model presented in the previous chapter for studying the particularities of the fire behaviour of CFT columns with elliptical cross-section. Preliminar studies on CFEHS columns at room temperature are carried out, so as to serve as a basis for the subsequent development of the model at elevated temperatures, and once the model is set up, it is used to conduct parametric studies for evaluating the influence of the different variables which affect the fire behaviour of such columns and establishing a comparison in terms of fire performance with circular columns. 


\subsection{CONCRETE FILLED ELLIPTICAL HOLLOW SECTION COLUMNS AT ROOM TEMPERATURE}

The compressive behaviour of concrete filled elliptical hollow section stub columns has now been well established through experimental research and numerical modelling carried out by Yang et al. (2008) and Dai \& Lam (2010). Nevertheless, in order to demonstrate that the model developed for studying the behaviour of CFEHS columns exposed to fire is accurate, initial validation of the model at room temperature is required. For this purpose, the results from the tests by Yang et al. (2008) are taken as a reference.

\subsubsection{Description of the finite element model}

By means of the finite element analysis package ABAQUS (2010), a threedimensional numerical model for simulating the room temperature response of CFEHS stub columns under axial compression was developed. The full length and the complete cross-section of the columns was modelled, since the experiments had revealed that in some of the cases the response was dominated by shear failure of the concrete core and therefore an unsymmetrical deformed shape was expected to be obtained. Figure 5.1 shows the typical finite element model adopted for this numerical investigation.

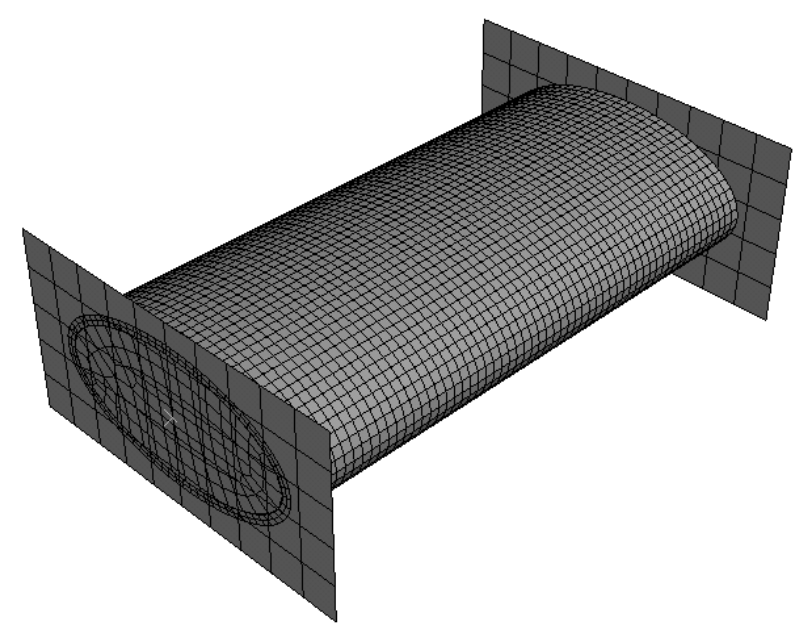

Figure 5.1. Three-dimensional finite element model for CFEHS stub columns. 
The steel tube and concrete core were meshed using three-dimensional eightnoded solid elements with reduced integration (C3D8R). Based on the results of a mesh sensitivity study, a suitable element size which provided accurate results with practical computational times was found: $5 \mathrm{~mm}$ for the steel tube and $10 \mathrm{~mm}$ for the concrete core, i.e. the concrete element size was twice the size of the steel elements.

As already found by Dai \& Lam (2010), two layers of elements through the thickness of the steel tube were required to accurately capture the observed experimental response. This finding is reflected in Figure 5.2, where it is clear that a mesh arrangement with only one layer of elements through the thickness of the steel tube underestimates the load-carrying capacity of the column and fails to accurately capture the deformation history exhibited in the test.

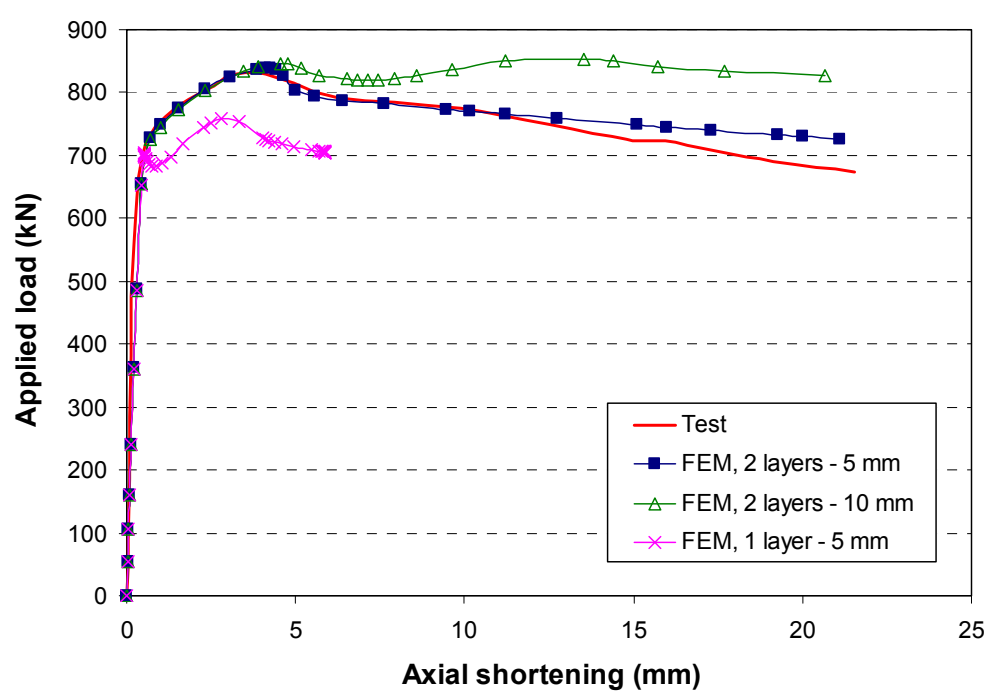

Figure 5.2. Comparison of experimental and numerical results with different steel tube meshes, $150 \times 75 \times 4$ C 30 .

The steel end plates were modelled as discrete rigid parts with all nodes coupled to a reference point located at the column axis. The axial load was applied to the upper rigid plate through its reference node as an imposed static displacement, transmitting load to both the concrete core and the steel tube. Following the testing procedure, all six degrees of freedom of the lower rigid plate were fixed, while the upper rigid plate was allowed to move along the column axis but was fixed against 
the other five degrees of freedom. The rigid plates were meshed using four-noded three-dimensional bilinear rigid quadrilateral elements (R3D4), with a maximum element size of $20 \mathrm{~mm}$.

The mechanical interaction between the contacting surfaces of the steel tube and the concrete infill was modelled as follows. In the normal direction, a "hard" contact formulation was used, which allows any pressure value when the surfaces are in contact and transmits no pressure when the surfaces do not contact. For the tangent interaction at the steel-concrete interface, the Coulomb friction model was used. It was found that values lower than 0.2 for the friction coefficient produced convergence difficulties, while values higher than 0.3 deviated from the observed response of the tested specimens. Thus, a value of 0.25 was adopted for the friction coefficient, as previously employed by Ellobody et al. (2006). Figure 5.3 shows the effect of the friction coefficient on the compressive behaviour of the columns.

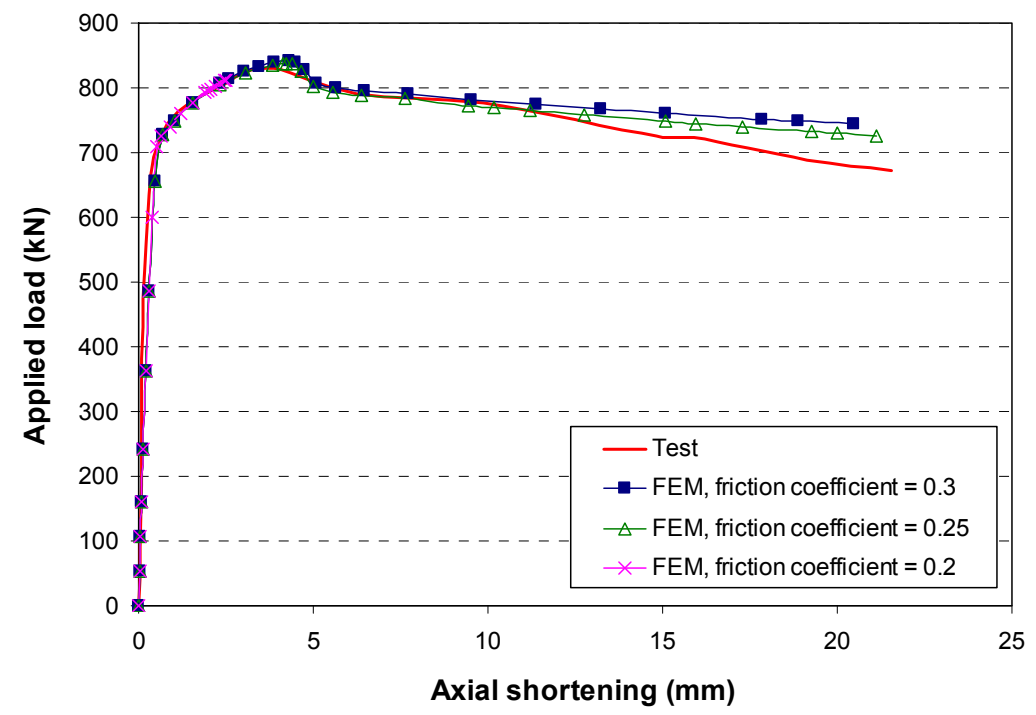

Figure 5.3. Comparison of experimental and numerical results with different friction coefficients, $150 \times 75 \times 4$ C30.

Dai \& Lam (2010) had previously shown that the use of different friction factors had little effect on the axial resistance of CFEHS columns, and suggested that a friction factor between 0.2 and 0.3 would provide an accurate reflection of the actual frictional contact and achieve rapid convergence. 
Note that in Section 4.3.1, it was concluded that, in the fire situation, the value of the friction coefficient at the steel-concrete interface does not have any influence over the response of the column, and therefore the selected value was not decisive in that case. Nevertheless, at room temperature and mainly for stub columns, the value of the friction coefficient can affect the response, as shown in Figure 5.3. The friction coefficient was found to influence only the descending branch of the load-displacement curve, where for this particular case a better agreement was obtained with a value of 0.25 .

The same steel-concrete mechanical interaction as that defined for the interface at the inner surface of the steel tube was employed to take into account the contact between the concrete core ends and the rigid plates. Relative displacement between the steel tube and the rigid end plates was prevented by means of a "tie" constraint.

\subsubsection{Material models at room temperature}

For the structural steel material model, the experimental data from the coupon tests performed for each of the elliptical hollow sections under study were used. These stress-strain relationships were introduced in an isotropic multiaxial plasticity model with the von Mises yield surface.

For concrete, the specific model developed by Dai \& Lam (2010) for taking into account the confinement effect in elliptical steel hollow sections was used. The model was based on that developed by other authors (Saenz 1964, Mander et al. 1988, Hu et al. 2003 and Ellobody et al. 2006) for concrete confined by circular steel tubes. Dai \& Lam (2010) proposed a modified four-part stress-strain curve, with a "quick softening" section after concrete crushing based on their findings on the differences in concrete confinement between circular and elliptical hollow sections.

The yielding part of the concrete model was considered by employing the Drucker-Prager yield criterion, with the values of the friction angle $(\beta)$ and flow stress ratio in triaxial tension to that in compression $(K)$ recommended by $\mathrm{Hu}$ et al. (2003) and adopted by Ellobody et al. (2006) in previous research: $\beta=20^{\circ}, K=0.8$. No plastic flow was considered, since the confinement effect was directly introduced to the model by means of the confined compressive stress-strain curve. Thus, a zero dilation angle $\left(\psi=0^{\circ}\right)$ was adopted. 


\subsubsection{Comparison between numerical and experimental results}

The numerical model at room temperature was validated by comparing its results with a series of tests on concrete filled elliptical stub columns carried out at the University of Leeds (Yang et al. 2008). From the 21 stub columns tested, only those 9 which were compositely loaded and non-greased were selected for this research. Those specimens were tested with full contact between the concrete infill and steel tube, and the load was applied simultaneously to the steel tube and concrete core. Three nominal tube thicknesses ( $4 \mathrm{~mm}, 5 \mathrm{~mm}$ and $6.3 \mathrm{~mm}$ ) and three nominal concrete grades (C30, C60 and C100) were employed, with an elliptical section of $150 \times 75 \mathrm{~mm}$ and a length of $300 \mathrm{~mm}$, common to the nine columns. The columns analysed in this section are listed in Table 5.1.

Table 5.1. List of room temperature CFEHS stub columns analysed from Yang et al. (2008)

\begin{tabular}{|c|c|c|c|c|c|c|}
\hline $\begin{array}{c}\text { Specimen } \\
\text { designation }\end{array}$ & $\begin{array}{c}2 a \\
(\mathrm{~mm})\end{array}$ & $\begin{array}{c}2 b \\
(\mathrm{~mm})\end{array}$ & $\begin{array}{c}t \\
(\mathbf{m m})\end{array}$ & $\begin{array}{c}\boldsymbol{f}_{\boldsymbol{y}} \\
\left(\mathrm{N} / \mathbf{m m}^{2}\right)\end{array}$ & $\begin{array}{c}f_{\text {ck,cube }} \\
\left(\mathbf{N} / \mathbf{m m}^{2}\right)\end{array}$ & $\begin{array}{c}N_{u, t \text { test }} \\
(\mathbf{k N})\end{array}$ \\
\hline $150 \times 75 \times 4$ C 30 & 150 & 75 & 4 & 376.5 & 36.9 & 839 \\
\hline $150 \times 75 \times 4$ C 60 & 150 & 75 & 4 & 376.5 & 59.8 & 974 \\
\hline $150 \times 75 \times 4 \_C 100$ & 150 & 75 & 4 & 376.5 & 98.4 & 1265 \\
\hline $150 \times 75 \times 5$ C 30 & 150 & 75 & 5 & 369 & 36.9 & 981 \\
\hline $150 \times 75 \times 5$ _C60 & 150 & 75 & 5 & 369 & 59.8 & 1084 \\
\hline $150 \times 75 \times 5 \_C 100$ & 150 & 75 & 5 & 369 & 98.4 & 1296 \\
\hline $150 \times 75 \times 6.3 \_C 30$ & 150 & 75 & 6.3 & 400.5 & 36.9 & 1193 \\
\hline $150 \times 75 \times 6.3 \_C 60$ & 150 & 75 & 6.3 & 400.5 & 59.8 & 1280 \\
\hline $150 \times 75 \times 6.3 \_\mathrm{C} 100$ & 150 & 75 & 6.3 & 400.5 & 98.4 & 1483 \\
\hline
\end{tabular}

For each of the nine columns analysed, the load versus end shortening response was obtained and compared with the one registered in the experimental tests. Figure 5.4 shows the comparison between the numerical and experimental results for the series of columns with a $150 \times 75 \times 4 \mathrm{~mm}$ cross-section.

The numerical model showed good agreement with the tests, as can be seen in Table 5.2. This table compares the maximum axial compressive loads obtained from the tests with the values predicted by means of the numerical model. The error is computed as the experimental result divided by the numerical result. An average error of 1.00 and a reduced standard deviation (0.02) were obtained. The maximum relative error was lower than a $5 \%$, which shows a good level of accuracy. 
As can be seen in the load versus end shortening curves of Figure 5.4, the agreement in terms of the overall response was also satisfactory, capturing both the loading ram and the softening part of the curve after reaching the maximum load. On the basis of the described comparisons, the numerical model is considered to be validated at room temperature.

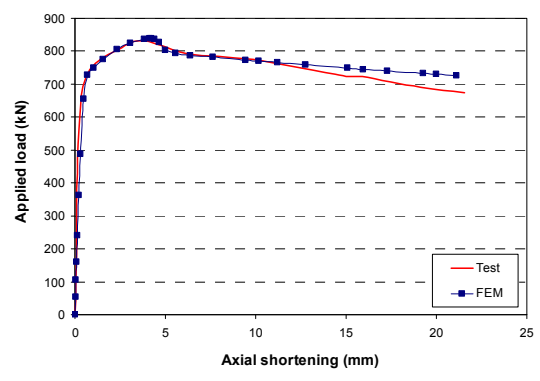

(a) $150 \times 75 \times 4$ C30

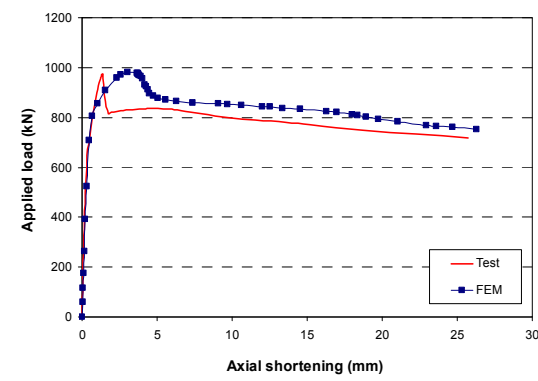

(b) $150 \times 75 \times 4$ C60

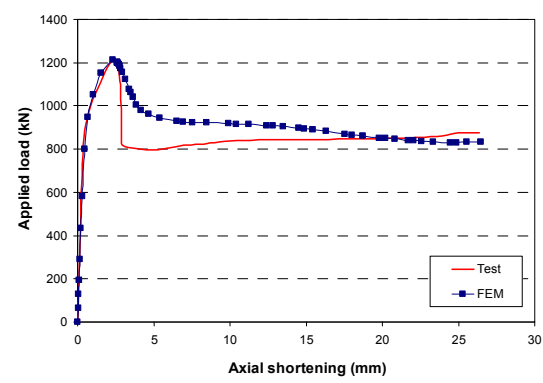

(c) $150 \times 75 \times 4 \_C 100$

Figure 5.4. Comparison of experimental and numerical results, for $150 \times 75 \times 4 \mathrm{~mm}$ columns. 
Table 5.2. Measured and predicted maximum axial loads

\begin{tabular}{|c|c|c|c|}
\hline \multirow{2}{*}{$\begin{array}{l}\text { Specimen } \\
\text { designation }\end{array}$} & \multicolumn{2}{|c|}{ Maximum load (kN) } & \multirow{2}{*}{$\xi=\frac{N_{u, t e s t}}{N_{u, F E M}}$} \\
\hline & Test, $N_{u, t e s t}$ & Simulation, $N_{u, F E M}$ & \\
\hline $150 \times 75 \times 4 \_C 30$ & 839 & 838 & 1.00 \\
\hline $150 \times 75 \times 4$ _C60 & 974 & 982 & 0.99 \\
\hline $150 \times 75 \times 4$ C100 & 1265 & 1213 & 1.04 \\
\hline 150×75×5_C30 & 981 & 963 & 1.02 \\
\hline $150 \times 75 \times 5$ _C60 & 1084 & 1095 & 0.99 \\
\hline $150 \times 75 \times 5 \_\mathrm{C} 100$ & 1296 & 1316 & 0.98 \\
\hline $150 \times 75 \times 6.3 \_C 30$ & 1192 & 1178 & 1.01 \\
\hline $150 \times 75 \times 6.3 \_C 60$ & 1280 & 1304 & 0.98 \\
\hline \multirow[t]{3}{*}{$150 \times 75 \times 6.3 \_\mathrm{C} 100$} & 1483 & 1506 & 0.98 \\
\hline & \multicolumn{2}{|l|}{ Average } & 1.00 \\
\hline & \multicolumn{2}{|c|}{ Standard deviation } & 0.02 \\
\hline
\end{tabular}

\subsubsection{Findings from the finite element modelling}

A number of findings have emerged from the modelling of the CFEHS at room temperature. The mesh density study revealed that an element size of $5 \mathrm{~mm}$ for the steel tube and $10 \mathrm{~mm}$ for the concrete core should be adopted to obtain accurate results and that at least two layers of elements through the thickness of the steel tube wall should be employed.

Although the loading and boundary conditions of all the stub column specimens were symmetric, modelling the full cross-section and length of the columns revealed a more realistic response in terms of deformed shape, since it was in some cases unsymmetrical, being dominated by shear failure of the concrete core. Nevertheless, in terms of maximum load, the results obtained from a quarter model with symmetrical boundary conditions were similar to the full model results.

As previously found in the experiments by Yang et al. (2008), two different failure patterns were observed. Figure 5.5 shows these typical failure modes obtained from the numerical analysis. In some of the specimens, outward local buckling of the tube wall occurred close to the column ends (Figure 5.5a), accompanied in some cases with a bulge at the centre of the column (Figure 5.5b). In both cases, inward buckling of the tube wall was prevented by the concrete core. In other cases, primarily those with thinner wall thicknesses, an inclined shear failure of the concrete core was obtained (Figure 5.5c), which is related to a loss of confinement. 


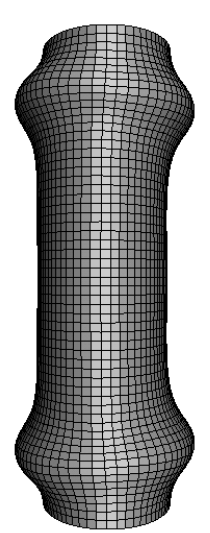

(a) $150 \times 75 \times 5 \_$C 30

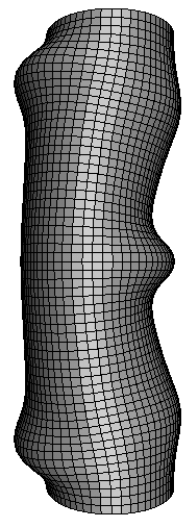

(b) $150 \times 75 \times 5 \_C 60$

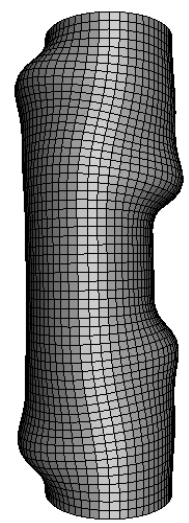

(c) $150 \times 75 \times 5 \_$C100

Figure 5.5. Different failure modes obtained from the FEA of the stub columns.

As was expected and confirmed by the experimental research (Yang et al. 2008), the compressive load-bearing capacity of the columns increased both with an increase in the steel tube wall thickness and with the strength of the concrete core.

\subsection{CONCRETE FILLED ELLIPTICAL HOLLOW SECTION COLUMNS EXPOSED TO FIRE}

Having demonstrated the ability of the numerical model to capture the observed response of circular CFT columns in the fire situation and that of the elliptical CFT columns at room temperature, it can be assumed that the numerical model will also yield accurate results for CFEHS columns in fire.

\subsubsection{Description of the finite element model}

Although the main characteristics of the finite element model developed in this thesis have been described in depth in Section 4.1 for concrete filled circular columns, the particularities of the modelling of the elliptical specimens are briefly summarized here.

For the analysis of the CFEHS in fire, two finite element models were needed: a thermal model and a mechanical model, since a sequentially coupled thermal-stress analysis was carried out. The steel tube and concrete core were meshed using three-dimensional eight-noded heat transfer solid elements with nodal temperature degree of freedom (DC3D8) for the thermal analysis and three- 
dimensional eight-noded solid elements with reduced integration (C3D8R) in the mechanical analysis. The same mesh density as that employed for modelling the circular specimens was used for the elliptical sections, as it had proved to be sufficient to accurately predict the thermal and mechanical behaviour of CFCHS columns in fire. Therefore, a maximum element size of $20 \mathrm{~mm}$ was employed for meshing both the concrete core and the steel tube. A higher mesh density would lead to unacceptable computational times for a transient thermal-stress analysis. Following the results of the numerical analysis of the stub columns at room temperature, two layers of elements through the thickness of the steel tube were employed.

The steel end plates were modelled in the same way as described in Section 5.1.1, and only used in the mechanical analysis. The columns were therefore fixended. The axial load was applied to the upper rigid plate through its reference node and maintained during the fire history. Owing to symmetry of both the geometry and the boundary conditions, only a quarter of the column was modelled. Since the columns analysed in this section were slender, the failure was expected to be due to global buckling, thus it was not necessary to model the entire member to account for a possible shear failure of the concrete core (which was observed in the CFEHS stub columns). Figure 5.6 shows the finite element mesh for one of the CFEHS column specimens analysed.

The numerical model contained an initial geometric imperfection generated by means of the first buckling mode shape of an equivalent hinged column multiplied by an amplification factor. For this purpose, a prior eigenvalue buckling analysis was conducted. Once the initial shape of the column was obtained, it was imported to the mechanical model as the starting geometry from which to run the analysis. An amplification factor equal to the maximum imperfection along the length of the column was then applied to the column. Following the results of the sensitivity analysis carried out for CFCHS columns, a value of $L / 1000$ for the amplification factor was used. 


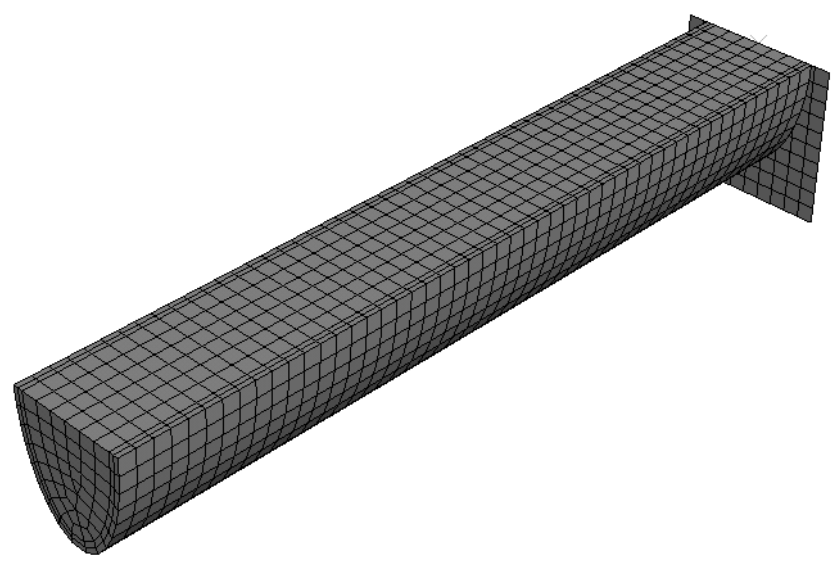

Figure 5.6. Typical finite element mesh of the model for slender CFEHS columns in fire.

\subsubsection{Material models at elevated temperatures}

The numerical simulations took into account the temperature dependent thermal and mechanical properties of steel and concrete. The adopted material models had shown in the sensitivity analysis section (Section 4.3) to represent accurately the response of these materials in fire.

For concrete, the mechanical model developed by Lie (1984) was employed, together with the hyperbolic Drucker-Prager yield surface. The thermal properties for concrete at elevated temperatures were extracted from EN 1992-1-2 (CEN 2004a).

For structural steel, the temperature dependent thermal and mechanical properties recommended in EN 1993-1-2 (CEN 2005b) were adopted. The isotropic multiaxial plasticity model with the von Mises yield surface was employed.

The value of the thermal expansion coefficient for concrete recommended by Hong \& Varma (2009) was employed: $\alpha_{c}=6 \times 10^{-6}{ }^{\circ} \mathrm{C}^{-1}$. For steel, the temperature dependent values of the thermal expansion coefficient from EN 1993-1-2 (CEN 2005b) were adopted.

The moisture content of the concrete infill was taken into account through a peak value in the specific heat, representing the latent heat of water vaporisation. A 
moisture content of $3 \%$ in concrete weight was considered in all cases. Hence, following the recommendations in EN 1994-1-2 (CEN 2005c), a specific heat peak value of $2020 \mathrm{~J} / \mathrm{kgK}$ was introduced.

\subsubsection{Analysis procedure}

A sequentially coupled thermal-stress analysis was used to conduct the numerical simulations, thus two different models were needed: a heat transfer model and a mechanical model. The analysis was performed by first conducting a pure heat transfer analysis for computing the temperature field and afterwards a stress/deformation analysis for calculating the structural response. Nodal temperatures were stored as a function of time in the heat transfer analysis results and then read into the stress analysis as a predefined field.

\subsubsection{Thermal analysis}

A nonlinear heat transfer analysis was first conducted for each of the column specimens under study. The standard ISO 834 fire curve (ISO 1980) was applied to the exposed surface of the CFT column specimens through the convection and radiation heat transfer mechanisms. The entire length of the columns was exposed to fire, in order to consider the worst case scenario, since protecting the column ends would introduce a higher rotational stiffness at elevated temperatures leading to a delay in the failure time. The values recommended in EN 1991-1-2 (CEN 2002) were adopted for the governing parameters of the heat transfer problem.

The results from the nonlinear heat transfer analysis consisted of the temperature-time curves for all the nodes within the three-dimensional model, which were subsequently applied as a thermal load to the mechanical model.

The thermal resistance at the boundary between the steel tube and the concrete core was considered through a gap conductance value of $200 \mathrm{~W} / \mathrm{m}^{2} \mathrm{~K}$, as was used when modelling the circular specimens.

\subsubsection{Structural analysis}

A nonlinear stress analysis was subsequently carried out, accounting for the nodal temperature-time curves previously calculated by means of the thermal model.

The finite element meshes and the node numbering were exactly the same as those used in the thermal model. 
In the first step, the load was applied at room temperature to the top end of the column through the loading plate. This load was maintained during the second step (the fire step), where the evolution of the temperature with the fire exposure time was imported from the thermal model.

The mechanical interaction between the steel tube and concrete infill was modelled as described in Section 4.1.8.2 for the circular specimens. In the normal direction, a "hard" contact formulation was used. For the tangent interaction, the Coulomb friction model was used, with a friction coefficient of 0.3 , although this factor had been found to have relatively little effect on the fire response of CFT columns in the sensitivity analysis for circular columns (Section 4.3). The same steel-concrete mechanical interaction was employed to model the contact between the concrete core ends and the rigid end plates. Relative displacement between the steel tube and the rigid end plates was prevented by introducing a "tie" constraint.

\subsubsection{Validation of the model for CFEHS columns at elevated temperatures}

Despite a great number of fire tests can be found in the literature on CFT columns of circular and square section, the fire resistance of elliptical hollow section columns filled with concrete has not yet been investigated through experimental testing.

Coinciding with the end of the redaction of this thesis, the first ever experimental investigations on fire exposed slender CFEHS columns have been conducted by the author's research group in Valencia, at the same time that other studies are emerging (Scullion et al. 2011a, 2011b, 2012) on unfilled EHS columns.

In the fire testing program carried out in Valencia, six CFEHS columns of cross-sectional dimensions $220 \times 110 \times 12 \mathrm{~mm}$ were tested, under both concentric and eccentric loads, using eccentricities of 20 and $50 \mathrm{~mm}$. The experiments were performed in the testing facilities of AIDICO (Instituto Tecnológico de la Construcción) in Valencia, Spain.

All the column specimens had a length of $3180 \mathrm{~mm}$ and were tested under pinned-fixed end conditions. Plain and bar-reinforced C30 grade concrete was used in this experimental program. Table 5.3 lists the main characteristics of the tested specimens. 
Table 5.3. List of CFEHS columns tested at elevated temperatures

\begin{tabular}{cccccccc}
\hline $\begin{array}{c}\text { Column } \\
\text { No. }\end{array}$ & $\begin{array}{c}\boldsymbol{f}_{\boldsymbol{y}} \\
\left(\mathbf{N} / \mathbf{m m}^{\mathbf{2}}\right)\end{array}$ & $\begin{array}{c}\boldsymbol{f}_{\boldsymbol{c}} \\
\left(\mathbf{N} / \mathbf{m m}^{2}\right)\end{array}$ & $\begin{array}{c}\mathbf{e} \\
(\mathbf{m m})\end{array}$ & $\begin{array}{c}\text { End } \\
\text { Cond. }\end{array}$ & $\begin{array}{c}\boldsymbol{N} \\
(\mathbf{k N})\end{array}$ & $\boldsymbol{\mu}$ & $\begin{array}{c}\text { FRR } \\
(\mathbf{m i n})\end{array}$ \\
\hline E220-110-12-3-30-50-20 & 348.06 & 38.17 & 50 & P-F & 198.96 & 0.2 & 28 \\
E220-110-12-3-30-20-20 & 347.54 & 39.11 & 20 & P-F & 281.84 & 0.2 & 26 \\
E220-110-12-3-30-00-20 & 372.45 & 34.72 & 00 & P-F & 397.19 & 0.2 & 21 \\
RE220-110-12-3-30-50-20 & 369.71 & 36.63 & 50 & P-F & 204.51 & 0.2 & 26 \\
RE220-110-12-3-30-20-20 & 347.54 & 37.83 & 20 & P-F & 287.94 & 0.2 & 25 \\
RE220-110-12-3-30-00-20 & 348.06 & 33.34 & 00 & P-F & 409.63 & 0.2 & 22 \\
\hline
\end{tabular}

Figure 5.8 presents the comparison of the axial displacement versus time curves obtained from the numerical simulation and the fire test, for one of the columns studied.

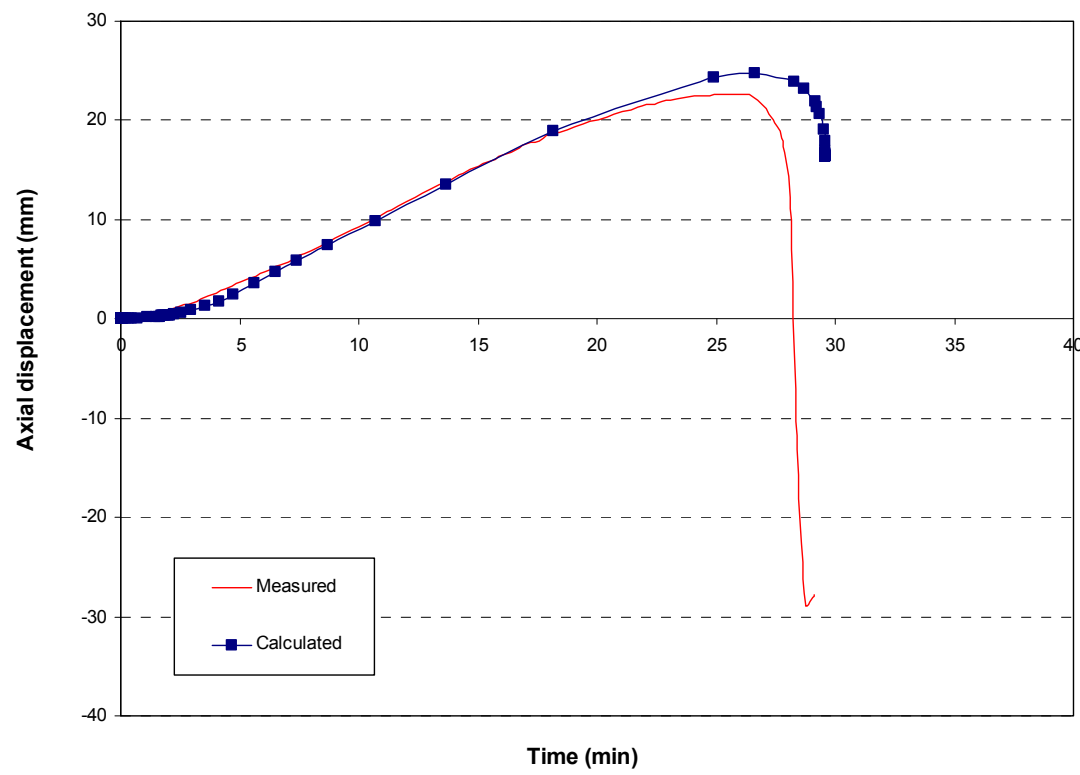

Figure 5.7. Comparison of measured and predicted axial displacement, column E220-110-12-3-30-50-20.

As can be seen, the shape of the predicted curve is very similar to the experimental result, although the fire resistance time is overestimated in a certain grade. This can be attributed to the non-uniform fire exposure of the column inside the testing furnace, where higher temperatures were found at the line of the gas burners, located at mid-height of the furnace. Therefore, the column was exposed to 
more severe temperatures at its mid-length, which suffered a faster deterioration, leading to a magnification of the second order effects and a more sudden failure of the column than in the simulations, where the fire exposure was assumed to be uniform.

In any case, the accuracy of the numerical model is acceptable as Table 5.4 reveals, with a controlled error and a reduced dispersion in the predictions.

Table 5.4. Predicted and measured FRR, tests for CFEHS columns

\begin{tabular}{cccc}
\hline \multirow{2}{*}{ Column No. } & \multicolumn{2}{c}{ FRR (min) } & \multirow{2}{*}{$\xi_{\text {FRR }}=\frac{F R R_{\text {test }}}{F R R_{N S}}$} \\
\cline { 2 - 3 } & Test & Simulation & 0.97 \\
\hline E220-110-12-3-30-50-20 & 28 & 29 & 0.93 \\
E220-110-12-3-30-20-20 & 26 & 28 & 0.81 \\
E220-110-12-3-30-00-20 & 21 & 26 & 0.87 \\
RE220-110-12-3-30-50-20 & 26 & 30 & 0.89 \\
RE220-110-12-3-30-20-20 & 25 & 28 & 0.88 \\
RE220-110-12-3-30-00-20 & 22 & 25 & $\mathbf{0 . 8 9}$ \\
\cline { 2 - 3 } & \multicolumn{3}{c}{ Average } \\
\hline
\end{tabular}

Therefore, given the lack of sources of validation available, the model is considered to provide a good level of accuracy for predicting the fire response of CFEHS columns.

\subsection{PARAMETRIC STUDIES}

The following parametric studies explore the influence of variation in global member slenderness, load level, cross-section slenderness and section size on the fire behaviour of CFEHS columns.

\subsubsection{Analysis cases}

Parametric studies were performed on the basis of a series of elliptical hollow sections of commercially available dimensions (Corus 2007); these sections are listed in Table 5.5. All the analysed specimens were fixed at both ends and subjected to a concentric axial load, which was maintained during the heating step. All hollow sections had a yield strength of $355 \mathrm{MPa}$ and were filled with C30 grade concrete. The nominal elliptical section sizes employed were $150 \times 75 \mathrm{~mm}$ and $300 \times 150 \mathrm{~mm}$. The studied thicknesses were 4, 5 and $6.3 \mathrm{~mm}$ for the $150 \times 75 \mathrm{~mm}$ sections and 8 , 
$10,12.5$ and $16 \mathrm{~mm}$ for the $300 \times 150 \mathrm{~mm}$ sections, in order to have a variety of cross-sectional slenderness values. Two additional sections were included in this study, so as to obtain different section factor values: $75 \times 37.5 \times 2 \mathrm{~mm}$ and $600 \times 300 \times 16 \mathrm{~mm}$. The length of the column specimens was varied from 1 to 4 metres in order to cover a wide range of member slenderness values. Three different load levels were applied to each column specimen: $20 \%, 40 \%$ and $60 \%$ of their minor axis buckling resistance at room temperature. This resistance was calculated in accordance with Clause 6.7.3.5 of EN 1994-1-1 (CEN 2004b), employing the buckling curve "a" given in Clause 6.3.1.2 of EN 1993-1-1 (CEN 2005a) for hot finished hollow section columns. The applicability of this buckling curve to EHS was confirmed by Chan \& Gardner (2009). The influence of enhanced concrete confinement was not considered in the room temperature resistance calculations. The material factors employed in the calculations were $\gamma_{s}=1.0$ and $\gamma_{c}=1.5$ for steel and concrete respectively. A total of 90 analysis cases were performed in this parametric study.

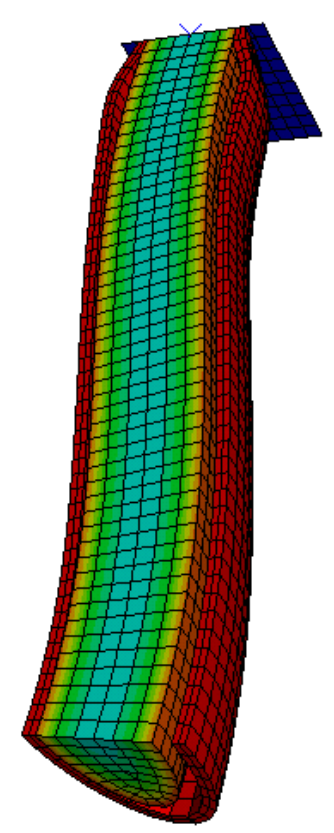

Figure 5.8. Deformed shape after fire exposure, $300 \times 150 \times 12.5 \mathrm{~mm}, L=2 \mathrm{~m}, \mu=0.2$. 
Figure 5.8 shows the typical deformed shape of the columns after exposure to fire. It can be seen how overall buckling of the column is accompanied by local buckling near the column ends and a progressive opening of the gap between the steel tube and the concrete core. The temperature field at the moment of the failure of the column is plotted in this figure, where a clear radial temperature gradient can be observed.

Table 5.5. List of CFEHS columns exposed to fire analysed in the parametric studies

\begin{tabular}{|c|c|c|c|c|c|c|c|c|c|}
\hline $\begin{array}{c}\text { Specimen } \\
\text { designation }\end{array}$ & $\mu$ & $\begin{array}{c}N \\
(\mathrm{kN})\end{array}$ & $\begin{array}{l}\text { FRR } \\
(\mathrm{min})\end{array}$ & $\mu$ & $\begin{array}{c}N \\
(\mathbf{k N})\end{array}$ & $\begin{array}{c}\text { FRR } \\
(\min )\end{array}$ & $\mu$ & $\begin{array}{c}N \\
(\mathbf{k N})\end{array}$ & $\begin{array}{l}\text { FRR } \\
\text { (min) }\end{array}$ \\
\hline $75 \times 37.5 \times 2 \_0.5$ & 0.20 & 30 & 22 & 0.40 & 60 & 16 & 0.60 & 91 & 12 \\
\hline $150 \times 75 \times 4 \_-1$ & 0.20 & 121 & 35 & 0.40 & 241 & 29 & 0.60 & 362 & 19 \\
\hline $150 \times 75 \times 4 \_2$ & 0.20 & 112 & 23 & 0.40 & 224 & 16 & 0.60 & 337 & 11 \\
\hline $150 \times 75 \times 4 \_3$ & 0.20 & 98 & 20 & 0.40 & 197 & 13 & 0.60 & 295 & 5 \\
\hline $150 \times 75 \times 4 \_4$ & 0.20 & 77 & 19 & 0.40 & 155 & 13 & 0.60 & 232 & 7 \\
\hline $150 \times 75 \times 5 \_1$ & 0.20 & 146 & 33 & 0.40 & 293 & 23 & 0.60 & 439 & 18 \\
\hline $150 \times 75 \times 5 \_2$ & 0.20 & 136 & 22 & 0.40 & 272 & 16 & 0.60 & 407 & 11 \\
\hline $150 \times 75 \times 5 \_3$ & 0.20 & 119 & 20 & 0.40 & 237 & 14 & 0.60 & 356 & 5 \\
\hline $150 \times 75 \times 5 \_4$ & 0.20 & 93 & 20 & 0.40 & 185 & 14 & 0.60 & 278 & 7 \\
\hline $150 \times 75 \times 6.3 \_1$ & 0.20 & 174 & 32 & 0.40 & 347 & 22 & 0.60 & 521 & 20 \\
\hline $150 \times 75 \times 6.3 \_2$ & 0.20 & 161 & 23 & 0.40 & 322 & 16 & 0.60 & 483 & 10 \\
\hline $150 \times 75 \times 6.3 \_3$ & 0.20 & 141 & 20 & 0.40 & 281 & 14 & 0.60 & 422 & 2 \\
\hline $150 \times 75 \times 6.3 \_4$ & 0.20 & 110 & 19 & 0.40 & 219 & 14 & 0.60 & 329 & 1 \\
\hline $300 \times 150 \times 8 \_1$ & 0.20 & 490 & 87 & 0.40 & 979 & 41 & 0.60 & 1469 & 26 \\
\hline $300 \times 150 \times 8 \_2$ & 0.20 & 483 & 65 & 0.40 & 966 & 37 & 0.60 & 1449 & 25 \\
\hline $300 \times 150 \times 8 \_3$ & 0.20 & 467 & 48 & 0.40 & 935 & 29 & 0.60 & 1402 & 21 \\
\hline $300 \times 150 \times 8 \_4$ & 0.20 & 449 & 28 & 0.40 & 898 & 19 & 0.60 & 1347 & 14 \\
\hline $300 \times 150 \times 10 \_1$ & 0.20 & 594 & 71 & 0.40 & 1188 & 36 & 0.60 & 1782 & 25 \\
\hline $300 \times 150 \times 10 \_2$ & 0.20 & 585 & 55 & 0.40 & 1171 & 32 & 0.60 & 1756 & 24 \\
\hline $300 \times 150 \times 10^{-} 3$ & 0.20 & 566 & 41 & 0.40 & 1132 & 25 & 0.60 & 1699 & 20 \\
\hline $300 \times 150 \times 10^{-} 4$ & 0.20 & 543 & 29 & 0.40 & 1086 & 20 & 0.60 & 1630 & 15 \\
\hline $300 \times 150 \times 12.5 \_1$ & 0.20 & 700 & 61 & 0.40 & 1401 & 34 & 0.60 & 2101 & 26 \\
\hline $300 \times 150 \times 12.5 \_2$ & 0.20 & 690 & 49 & 0.40 & 1381 & 31 & 0.60 & 2071 & 24 \\
\hline $300 \times 150 \times 12.5 \_3$ & 0.20 & 668 & 37 & 0.40 & 1335 & 26 & 0.60 & 2003 & 21 \\
\hline $300 \times 150 \times 12.5 \_4$ & 0.20 & 640 & 31 & 0.40 & 1281 & 22 & 0.60 & 1921 & 15 \\
\hline $300 \times 150 \times 16 \_1$ & 0.20 & 845 & 55 & 0.40 & 1690 & 35 & 0.60 & 2536 & 27 \\
\hline $300 \times 150 \times 16 \_2$ & 0.20 & 832 & 48 & 0.40 & 1665 & 32 & 0.60 & 2497 & 25 \\
\hline $300 \times 150 \times 16 \_3$ & 0.20 & 805 & 36 & 0.40 & 1610 & 27 & 0.60 & 2415 & 22 \\
\hline $300 \times 150 \times 16 \_4$ & 0.20 & 772 & 33 & 0.40 & 1543 & 24 & 0.60 & 2315 & 16 \\
\hline $600 \times 300 \times 16 \_4$ & 0.20 & 1932 & 133 & 0.40 & 3864 & 67 & 0.60 & 5796 & 41 \\
\hline
\end{tabular}


Table 5.5 presents the results of all analysed column specimens. The fire resistance rating (FRR) for each column is expressed as the time measured in minutes that it is capable of sustaining the applied load before collapsing. The FRR of the columns was determined according to EN 1363-1 (CEN 1999). The failure criteria established by this standard were previously described in Section 4.2.2. In this table, the column specimens have been named according to their dimensions: $2 a(\mathrm{~mm}) \times 2 b(\mathrm{~mm}) \times t(\mathrm{~mm}) \_L(\mathrm{~m})$.

Figure 5.9 shows the evolution of the axial displacement at the top end of the column against the fire exposure time, for two of the analysed columns - (a) EHS $300 \times 150 \times 10 \mathrm{~mm}, L=2 \mathrm{~m}, \mu=0.2$ and (b) EHS $300 \times 150 \times 10 \mathrm{~mm}, L=4 \mathrm{~m}, \mu=0.2$ - . The limits given by the two failure criteria are included on the graphs.

A clear difference between the overall responses of these two columns can be observed. In Figure 5.9(a), the four typical stages of the fire response of a CFT column can be easily identified: expansion of the steel tube, followed by local yielding and subsequent transfer of the applied load to the concrete core, up to the final column failure. Nevertheless, in Figure 5.9(b) only two stages can be identified in the fire response (expansion of the steel tube and final failure), since the column buckles before the loading plate has come back into contact with the concrete core. This effect occurs in columns with high slenderness, where failure of the column is initiated at an early stage of the fire exposure, when the steel tube is still sustaining the load without the contribution of the concrete core. Therefore, it can be inferred that the contribution of the concrete core to the load-bearing capacity of the columns in a fire situation strongly depends on their slenderness. 


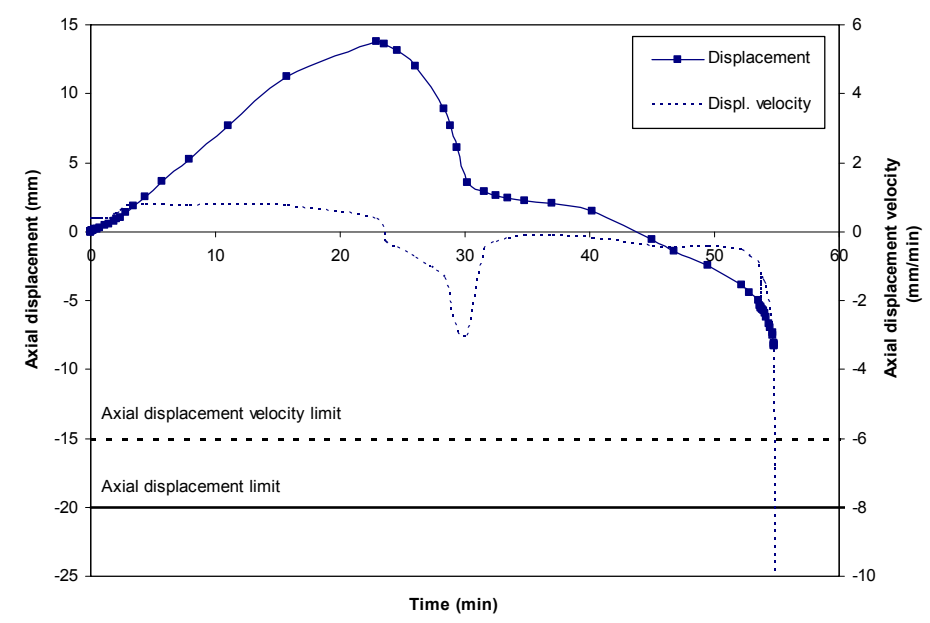

(a) $300 \times 150 \times 10 \mathrm{~mm}, L=2 \mathrm{~m}, \mu=0.2$

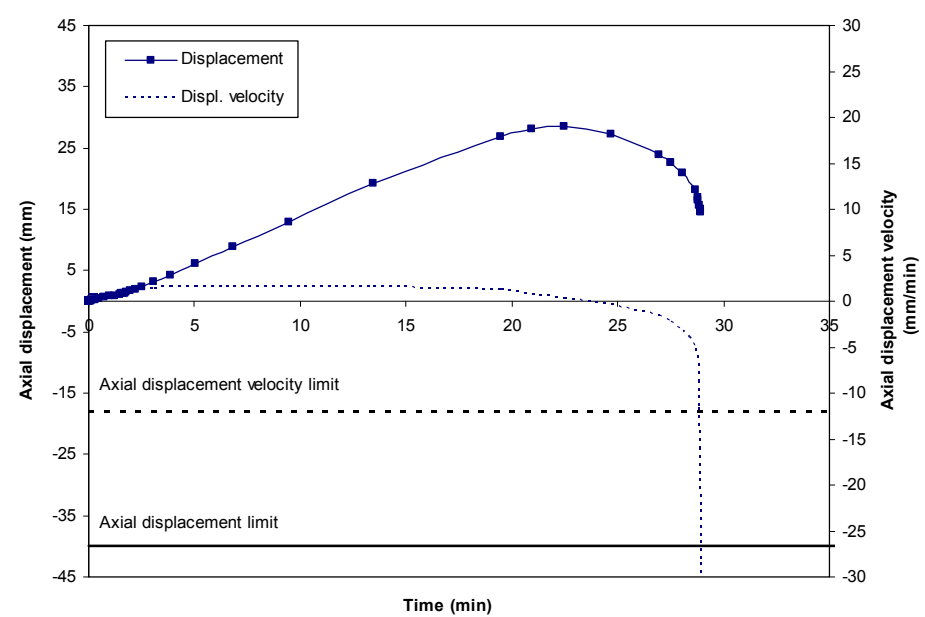

(b) $300 \times 150 \times 10 \mathrm{~mm}, L=4 \mathrm{~m}, \mu=0.2$

Figure 5.9. Axial displacement versus time curves. 


\subsubsection{Effect of column slenderness}

It is known that the slenderness plays an important role in the buckling resistance of a column subjected to axial compression. In order to illustrate the effect of the column slenderness on the fire resistance of CFEHS columns, a set of columns with fixed cross-sectional dimensions $-150 \times 75 \times 5 \mathrm{~mm}$ and $300 \times 150 \times 10$ $\mathrm{mm}-$ were chosen. The influence of the relative slenderness was investigated by varying the column length from 1 to $4 \mathrm{~m}$ with an initial imperfection of $L / 1000$. Three different loading levels were taken into account for this study: $20 \%, 40 \%$ and $60 \%$ of the room temperature buckling resistance of the columns.

The interrelationship between the fire resistance period of a column and its relative slenderness at room temperature is plotted in Figure 5.10. As expected, the FRR of the columns decreased with an increase in relative slenderness. Higher load levels produced the same trend, but with lower fire resistance times. The FRR levels shown in Figure 5.10(b) are higher than those in Figure 5.10(a), since the larger the cross-section, the greater the effect of the concrete filling in delaying the temperature increase.

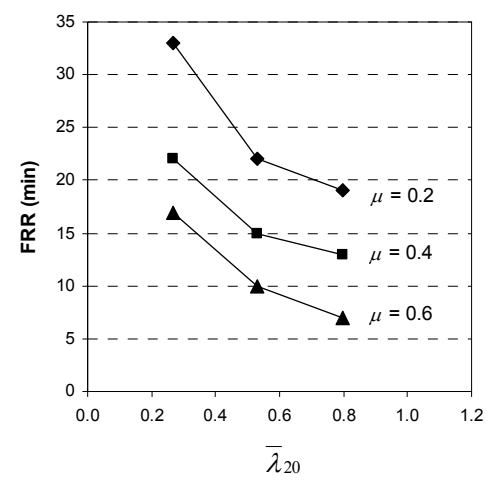

(a) $150 \times 75 \times 5 \mathrm{~mm}$

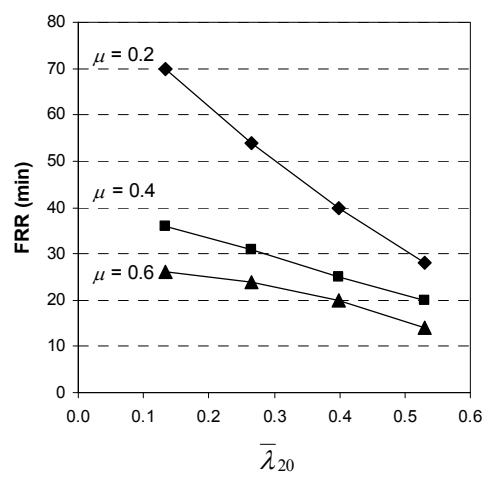

(b) $300 \times 150 \times 10 \mathrm{~mm}$

Figure 5.10. Effect of the relative slenderness on the fire resistance rating of the columns. 


\subsubsection{Effect of load level}

The effect of load level on the fire resistance of CFEHS columns was studied by fixing the cross-section to $150 \times 75 \times 5 \mathrm{~mm}$ or $300 \times 150 \times 10 \mathrm{~mm}$ and the length of the column. Three loading levels were considered: $20 \%, 40 \%$ and $60 \%$ of the room temperature buckling resistance of the columns. The parametric study was repeated for four different lengths $(1,2,3$ and $4 \mathrm{~m})$. The results from this analysis are plotted in Figure 5.11. As expected, the fire resistance rating of the column decreased with an increase in the applied load. The drop in the fire resistance period was more abrupt for the larger columns in Figure 5.11(b), which attain higher FRR values than those in Figure 5.11(a), due to the higher thermal and mechanical contribution of the concrete core.

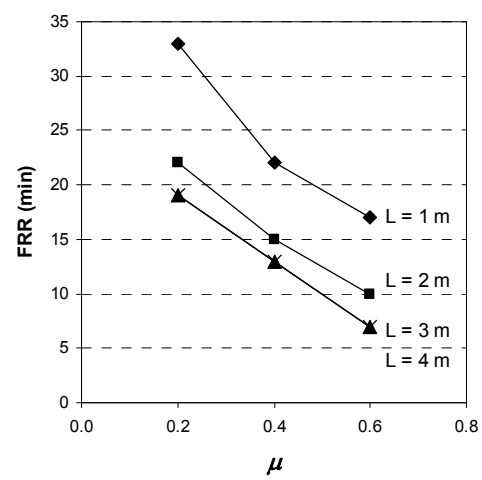

(a) $150 \times 75 \times 5 \mathrm{~mm}$

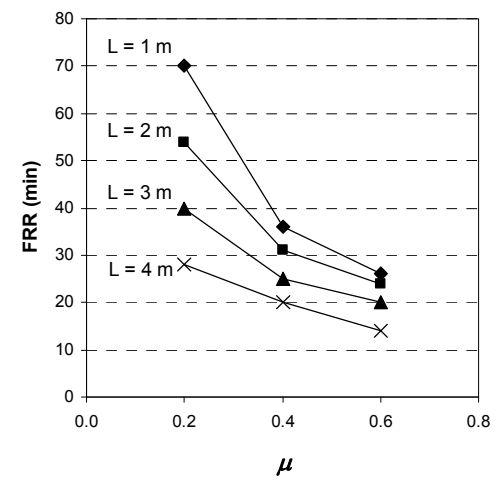

(b) $300 \times 150 \times 10 \mathrm{~mm}$

Figure 5.11. Effect of the load level on the fire resistance rating of the columns.

\subsubsection{Effect of cross-section slenderness}

The effect of cross-section slenderness on the fire resistance of CFEHS columns was examined by varying the thickness of the columns, while maintaining fixed external dimensions, length and loading level. The cross-section slenderness was evaluated through the parameter $D_{e} / t \varepsilon^{2}$, where $D_{e}$ is the equivalent diameter and $\varepsilon^{2}=235 / f_{y}$. The equivalent diameter of the elliptical sections was calculated according to the expression proposed by Ruiz-Teran \& Gardner (2008) for axial compression. 
The cross-sectional dimensions $2 a$ and $2 b$ were fixed to $300 \mathrm{~mm}$ and $150 \mathrm{~mm}$ respectively, and the thickness was varied in the range of commercial values (i.e. 8 , $10,12.5$ and $16 \mathrm{~mm}$ ). The length of the columns was fixed to $1 \mathrm{~m}$ and the load level to $20 \%$ of their room temperature axial compression resistance for buckling about the minor axis. The same procedure was repeated for $4 \mathrm{~m}$ length columns under the same load level. The effect of the cross-section slenderness on the fire resistance rating of the columns is illustrated in Figure 5.12.

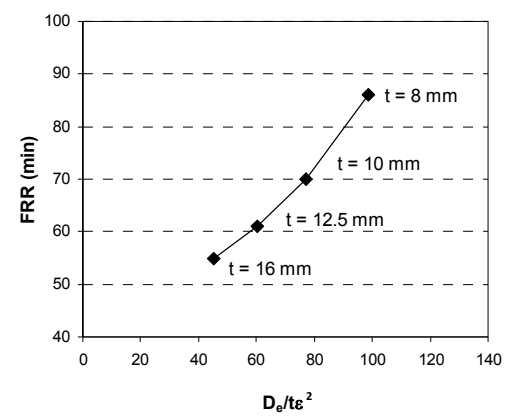

(a) $300 \times 150 \mathrm{~mm}, L=1 \mathrm{~m}, \mu=0.2$

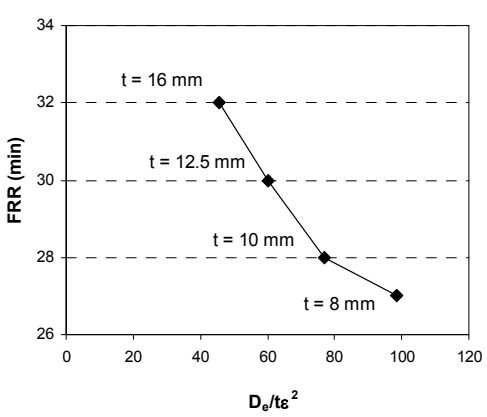

(b) $300 \times 150 \mathrm{~mm}, L=4 \mathrm{~m}, \mu=0.2$

Figure 5.12. Effect of the cross-sectional slenderness on the fire resistance rating of the columns.

For stocky columns loaded at a low percentage of their room temperature capacity, it was found that the higher the slenderness of the steel section, the higher the fire resistance of the column, which is the case in Figure 5.12(a). This means that columns with lower steel tube wall thicknesses achieve higher fire resistance for the same external dimensions. The explanation of this may reside in the fact that for a given section size, lower thicknesses of the steel tube wall allow more quantity of concrete to fill the column and thus contributing to delay its heating, which lengthens the fire resistance rating. This behaviour holds true for this particular range of columns, where the fire response is highly influenced by the amount of concrete filling, since after the expansion and subsequent yielding of the steel tube, the loading plate comes back into contact with the concrete core, which will sustain the load until the final failure.

However, the more slender columns show the inverse response: the higher the slenderness of the steel section (and thus the lower the steel tube wall thickness), the lower the fire resistance of the column, as it can be seen in Figure 5.12(b). This is the logical response expected for these columns, since their failure is initiated by 
the local buckling of the steel tube at an early stage when it is still sustaining the load without the contribution of the concrete core. The slenderness of the unfilled steel tube (and thus its thickness) is therefore a relevant factor in this case, whereas the amount of concrete filling does not influence the response.

\subsubsection{Effect of section size}

The effect of the section size was measured by means of the $A / V$ ratio (also known as section factor), where $A$ is the area of the fire exposed surface of the column per unit length and $V$ is the volume of the composite column per unit length.

From the series of columns studied, four of them with the same crosssectional slenderness, member slenderness and loading level were selected: $75 \times 37.5 \times 2 \mathrm{~mm}$ with $0.5 \mathrm{~m}$ length, $150 \times 75 \times 4 \mathrm{~mm}$ with $1 \mathrm{~m}$ length, $300 \times 150 \times 8 \mathrm{~mm}$ with $2 \mathrm{~m}$ length and $600 \times 300 \times 16 \mathrm{~mm}$ with $4 \mathrm{~m}$ length. The procedure was repeated for three loading levels: $20 \%, 40 \%$ and $60 \%$ of their room temperature buckling resistance. The interrelationship between the fire resistance period of a column and its section factor is plotted in Figure 5.13.

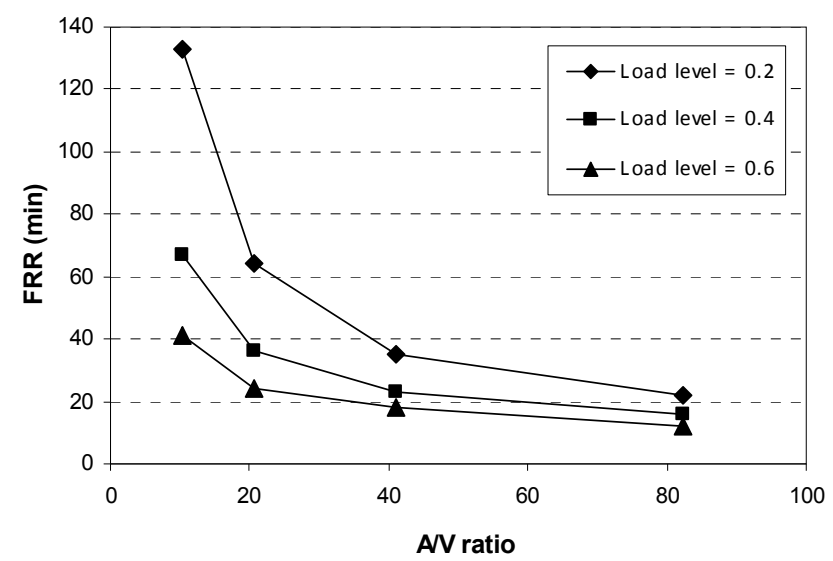

Figure 5.13. Effect of the section factor on the fire resistance rating of the columns.

A column with a high $A / V$ ratio exposes a relatively high surface to the fire, heating up faster, while a column with a low $A / V$ ratio exposes a lower surface to the fire for the same volume, thus delaying its heating. Therefore, as expected, the columns with the higher $A / V$ ratios had a lower fire resistance period than those with 
low $A / V$ ratios. The same trend was followed for all three load levels, but was steeper for the lower one. From Figure 5.13, it can be concluded that for high $A / V$ ratios, the effect of a change in the load level is minor. Conversely, for columns with a low $A / V$ ratio, an important difference in terms of fire resistance can be found under different load levels.

\subsection{COMPARISON BETWEEN ELLIPTICAL AND CIRCULAR CFT COLUMNS IN FIRE}

In order to study the differences in fire performance between CFEHS columns and CFCHS columns, a series of circular sections equivalent to the elliptical sections previously analysed were numerically examined.

The circular columns were designed to have the same buckling resistance at room temperature as the corresponding elliptical columns, whilst maintaining the same length. This was selected for practical purposes, in order to serve as a reference to designers when having to choose between circular and elliptical sections for a given inter-storey height and design load. The diameters of the circular sections were determined by fixing the thickness of the steel tube to be the same as that of the elliptical sections. The main characteristics of the circular columns analysed in this section are listed in Table 5.6, together with the fire resistance rating obtained from the simulations for the three different loading levels under consideration. In this table, the column specimens have been named according to their dimensions: $D(\mathrm{~mm}) \times t(\mathrm{~mm}) \_L(\mathrm{~m})$ for the circular columns and $2 a(\mathrm{~mm}) \times 2 b(\mathrm{~mm}) \times t(\mathrm{~mm}) \_L(\mathrm{~m})$ for the elliptical columns.

Table 5.6. List of CFCHS columns equivalent to the previously analyzed CFEHS columns

\begin{tabular}{ll|ccc|ccc|ccc}
\hline $\begin{array}{c}\text { Specimen } \\
\text { designation }\end{array}$ & $\begin{array}{c}\text { Equivalent } \\
\text { EHS column }\end{array}$ & $\boldsymbol{\mu}$ & $\begin{array}{c}\boldsymbol{N} \\
(\mathbf{k N})\end{array}$ & $\begin{array}{c}\text { FRR } \\
(\mathbf{m i n})\end{array}$ & $\boldsymbol{\mu}$ & $\begin{array}{c}\boldsymbol{N} \\
(\mathbf{k N})\end{array}$ & $\begin{array}{c}\text { FRR } \\
(\mathbf{m i n})\end{array}$ & $\boldsymbol{\mu}$ & $\begin{array}{c}\boldsymbol{N} \\
(\mathbf{k N})\end{array}$ & $\begin{array}{c}\text { FRR } \\
(\mathbf{m i n})\end{array}$ \\
\hline $108.74 \times 5 \_1$ & $150 \times 75 \times 5 \_1$ & 0.20 & 146 & 41 & 0.40 & 293 & 26 & 0.60 & 439 & 19 \\
$106.38 \times 5 \_2$ & $150 \times 75 \times 5 \_2$ & 0.20 & 136 & 30 & 0.40 & 272 & 19 & 0.60 & 407 & 15 \\
$101.64 \times 5 \_3$ & $150 \times 75 \times 5 \_3$ & 0.20 & 119 & 20 & 0.40 & 237 & 14 & 0.60 & 356 & 7 \\
$95.29 \times 5 \_4$ & $150 \times 75 \times 5 \_4$ & 0.20 & 93 & 18 & 0.40 & 185 & 12 & 0.60 & 278 & 5 \\
$219.95 \times 10 \_1$ & $300 \times 150 \times 10 \_1$ & 0.20 & 594 & 91 & 0.40 & 1188 & 38 & 0.60 & 1782 & 25 \\
$217.48 \times 10 \_2$ & $300 \times 150 \times 10 \_2$ & 0.20 & 585 & 75 & 0.40 & 1171 & 36 & 0.60 & 1756 & 25 \\
$215.39 \times 10 \_3$ & $300 \times 150 \times 10 \_3$ & 0.20 & 566 & 59 & 0.40 & 1132 & 31 & 0.60 & 1699 & 23 \\
$212.77 \times 10 \_4$ & $300 \times 150 \times 10 \_4$ & 0.20 & 543 & 47 & 0.40 & 1086 & 28 & 0.60 & 1630 & 21 \\
\hline
\end{tabular}


Through the numerical analysis of the equivalent circular columns and its comparison with the previously calculated elliptical columns it was observed that CFCHS columns achieved in general a higher fire resistance than their equivalent CFEHS columns, due to the lower $A / V$ ratio of the circular columns for the same room temperature resistance. A lower section factor results in a delay in the temperature field evolution and thus an increase in fire resistance rating. Only for the $150 \times 75 \times 5 \mathrm{~mm}$ of $4 \mathrm{~m}$ length did the elliptical column resist longer than the circular column, due to the fact that, for this particular column, the $A / V$ ratio of the elliptical column was lower than that of its equivalent circular column.
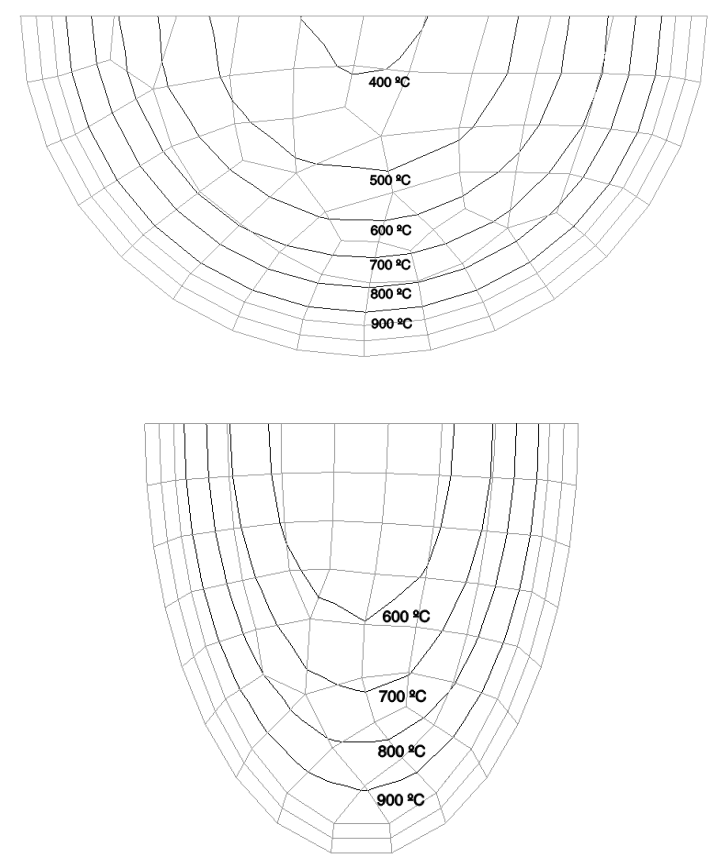

Figure 5.14. Comparison of the cross-sectional temperature field between CFCHS $219.95 \times 10 \mathrm{~mm}$ and CFEHS $300 \times 150 \times 10 \mathrm{~mm}$, after 90 minutes of fire exposure.

This effect can easily be noticed if the temperature field of the elliptical and its equivalent circular section are compared for the same fire exposure time. Figure 5.14 shows the resulting cross-sectional temperature fields for an elliptical column and its equivalent circular column after 90 minutes of exposure to fire. It can be seen that for the same exposure time, and thus a similar temperature at the steel surface, the temperatures along the concrete core are higher in the elliptical column than in 
the circular. This is due to the higher $A / V$ ratio of the elliptical column, which exposes a greater surface to the fire and therefore heats up faster.

This difference in the thermal response of both sections can be clearly seen in Figure 5.15, where the temperature evolution along the cross-section is compared for different fire exposure times. The relative distance to the centre of the section is expressed as the distance from a particular point of the cross-section to its centre, divided by the radius. A value equal to unity means a point located at the exposed surface, while a value equal to cero corresponds to the centre of the section. It can be seen that, for a particular fire exposure time, the temperatures in the elliptical columns are higher than in the circular columns across all the section.

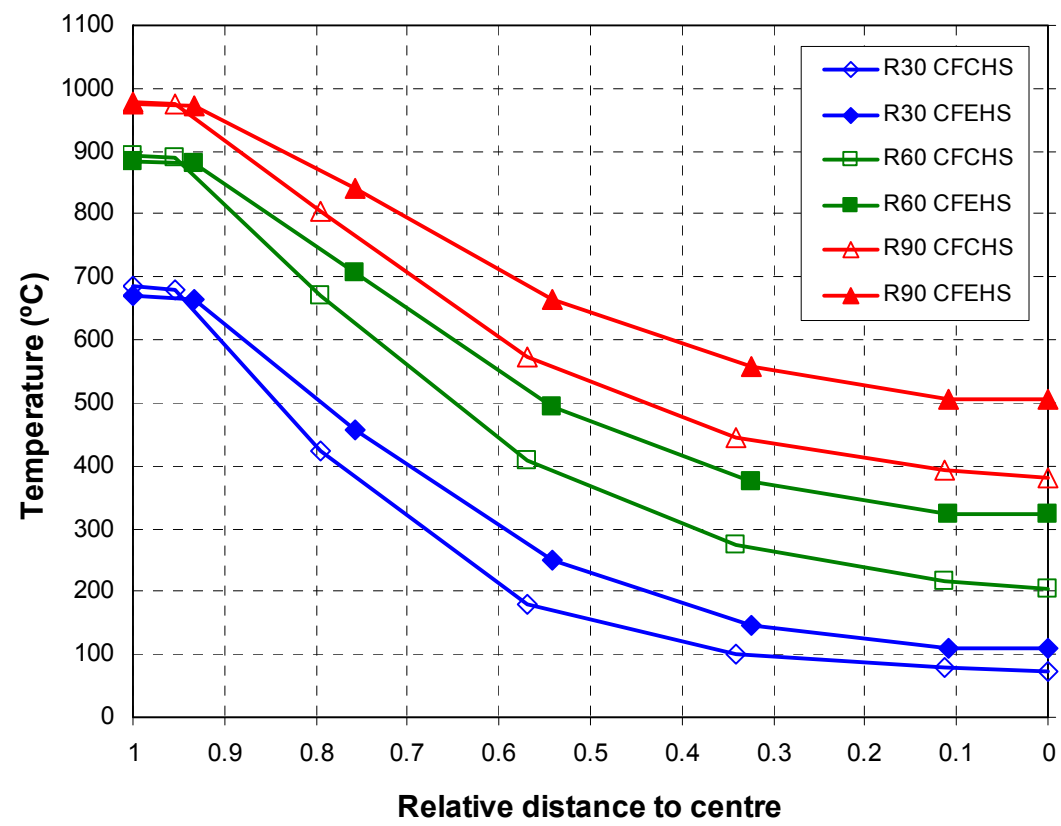

Figure 5.15. Comparison of the cross-sectional temperature evolution between circular and elliptical columns for different exposure times.

In terms of fire resistance rating, a comparison is shown in Figure 5.16 between circular and elliptical columns with different lengths and load levels. It can be seen that the circular columns attain higher fire resistance ratings than their elliptical counterparts; the difference is more pronounced for the stocky columns 
and for low loading levels. As the length and therefore the slenderness of the column increases, the difference in fire performance between elliptical and circular shapes is not so clear for the $150 \times 75 \times 5 \mathrm{~mm}$ columns, since the failure is due to yielding of the steel tube wall followed by global buckling before the concrete core comes back into contact with the loading plate, and thus the section shape and its related temperature distribution within the cross-section have less influence over the response of the columns. This aspect can also be appreciated in the larger columns $(300 \times 150 \times 10$ $\mathrm{mm}$ ) for load levels of 0.4 and 0.6 , where the difference is clearly narrower than for a load level of 0.2 . The explanation resides in the fact that for these high load magnitudes the sectional effects are of less importance since the severity of the load limits the temperature development within the cross-section and hence the sectional shape and its effect on the temperature distribution is not crucial.

For the set of columns compared in this section, the average improvement in fire resistance achieved by the circular columns over the elliptical columns was about $20 \%$, with less use of steel in all cases (6\% less on average) and a similar volume of concrete, except for columns $150 \times 75 \times 5 \mathrm{~mm}$ with 3 and $4 \mathrm{~m}$ length, where the amount of concrete was considerably reduced in the circular columns. It is worth noting that this comparison was carried out by considering buckling of the elliptical columns about their minor axis. Therefore, for the same length and load-bearing capacity at room temperature, the slenderness of the elliptical columns was higher than that of the circular ones, which is magnified when exposed to fire (due to the different rate of loss of strength and stiffness with temperature) and explains the high differences encountered in some cases even when the amount of material employed in the circular columns was lower. 


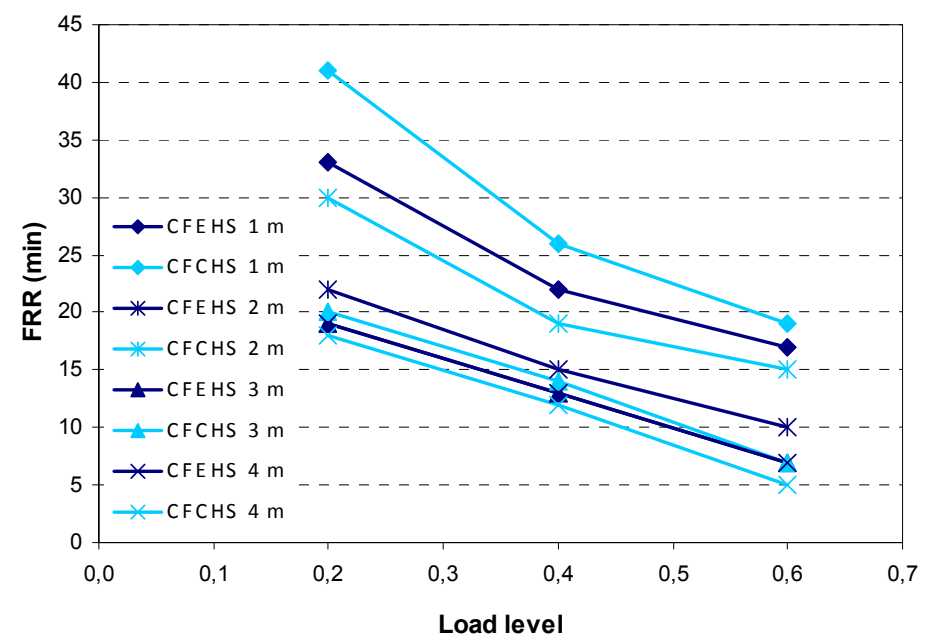

(a) $150 \times 75 \times 5 \mathrm{~mm}$

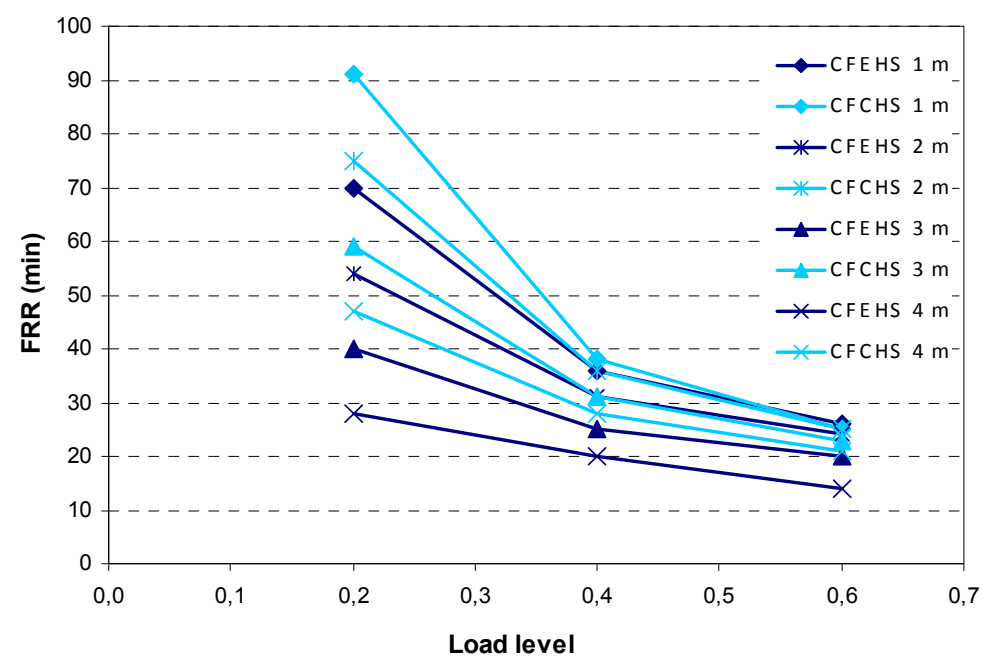

(b) $300 \times 150 \times 10 \mathrm{~mm}$

Figure 5.16. Comparison between elliptical and circular columns for different lengths and load levels. 


\section{DEVELOPMENT OF A SIMPLE CALCULATION MODEL}

Once proved that the numerical model developed in this work is capable for representing the fire behaviour of concrete filled tubular columns of circular and elliptical shape, it is used in this chapter for developing a simple calculation model which improves the accuracy of the existing calculation methods which can be found in the design codes and which can serve as a basis for designers when calculating the fire resistance of this type of columns. 


\subsection{REVIEW OF EXISTING DESIGN GUIDANCE}

Several design codes are in use nowadays, which establish methods for calculating the fire resistance of CFT columns. These methods are a result of the numerical and experimental investigations carried out by the main groups working in this matter.

The Chinese Code DBJ13-51 (2003), incorporates the expressions proposed by Han et al. (2003a,b) for calculating the strength index of unprotected columns in the fire situation, or alternatively, the thickness of the external fire protection required to achieve a certain fire resistance. Practitioners in Japan (Harada 2004) use the simple formula given in the design guide manual for CFT columns published by the Association of New Urban Housing Technology (ANUHT 2004).

In North America, several codes, amongst which one can find the National Building Code of Canada (NRCC 2005), ASCE/SFPE 29-99 (ASCE 1999) and ACI 216 (ACI 2007) use the single design equation proposed by Kodur and co-workers (Kodur 1999, 2007, Kodur \& MacKinnon 2000).

In Europe, the most extended methods for calculating the fire resistance of CFT columns are those included in EN 1994-1-2 (CEN 2005c), which will be studied more in depth in the subsequent sections.

\subsubsection{Simple calculation model in Annex H of EN 1994-1-2}

Annex H (informative) of EN 1994-1-2 (CEN 2005c) provides a simple calculation model which is specific for concrete filled hollow section columns subjected to fire. This model is based on the Guiaux and Janss (1970) method developed for composite hollow section columns at room temperature, which was generalised for its use at elevated temperatures. It establishes that the design axial buckling load can be obtained from the following equilibrium equation:

$$
N_{f i, R d}(\varepsilon)=N_{f i, c r}(\varepsilon)=N_{f i, p l, R d}(\varepsilon)
$$

where $N_{f, R d}(\varepsilon)$ is the design value of the fire resistance of the column in axial compression, $N_{f, c r}(\varepsilon)$ is the Euler buckling load of the column in the fire situation and $N_{f i, p l, R d}(\varepsilon)$ is the design value of the plastic resistance to axial compression of the cross-section at elevated temperature. In this method, these values correspond to a certain axial strain and therefore to a certain stress distribution within the cross- 
section, and need to be evaluated through an incremental procedure, until the equilibrium is found.

The procedure is based on increasing the strain in steps until $N_{f i, c r}(\varepsilon)$ and $N_{f i, p l, R d}(\varepsilon)$ are equal, subjected to the condition that the axial strain of all the components of the cross-section is the same. This procedure is illustrated in Figure 6.1. The instantaneous values of the stress and tangent modulus of each material for a particular temperature are used, varying with the strain level.

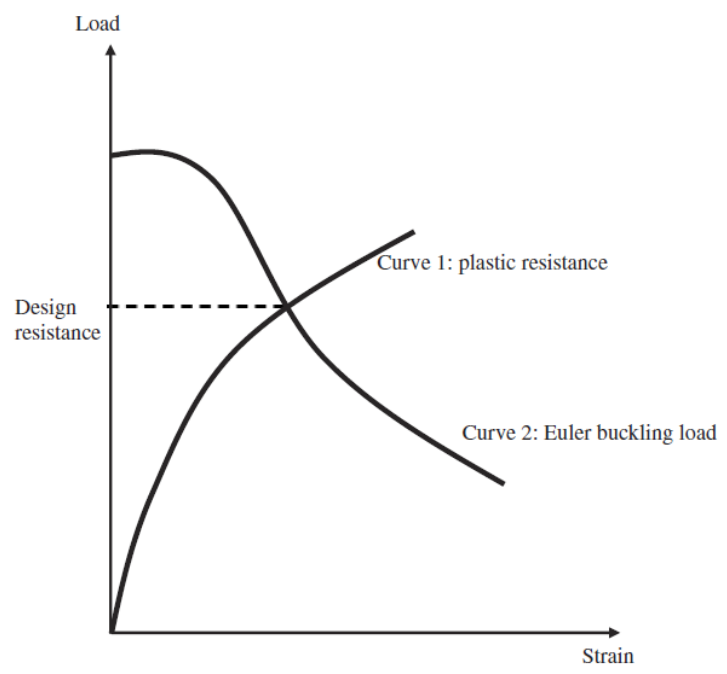

Figure 6.1. Procedure for obtaining the fire buckling resistance of the column with the method in Annex H (Wang 2005).

When using this method, a contradictory situation may arise where the fire resistance of short columns is found smaller than that of the longer columns, or even negative equilibrium values of the load can be obtained. In fact, at elevated temperatures, the application of the method can lead to equilibrium strains which are in the softening regime for some concrete layers where the tangent stiffness of concrete becomes negative.

The CTICM group (Renaud et al. 2004) conducted a numerical investigation which revealed important shortcomings of the tangent method. It was found out that Annex $\mathrm{H}$ produces fire buckling loads which lay on the unsafe side when the relative slenderness of the column at room temperature exceeds 0.4 (Aribert et al. 2008). These findings have recently led to the inclusion of an amendment to the existing 
Annex $\mathrm{H}$ which states that the relative slenderness of the columns should be limited to $\bar{\lambda} \leq 0.5$ for the use of the method.

The method in Annex $\mathrm{H}$ can only be applied to columns with buckling lengths in the fire situation $\ell_{\theta} \leq 4.5 \mathrm{~m}$, diameter of cross-section $140 \mathrm{~mm} \leq D \leq$ $400 \mathrm{~mm}$, concrete grades $\mathrm{C} 20 / 25-\mathrm{C} 40 / 50$ and standard fire resistance $R \leq 120 \mathrm{~min}$.

\subsubsection{General method for composite columns in Clause 4.3.5.1 of EN 1994-1-2}

While the method in Annex H of EN 1994-1-2 (CEN 2005c) has revealed to produce unsafe results for slender columns (Aribert et al. 2008) and has duly been criticised because of its complexity, the general calculation method in Clause 4.3.5.1 can be used instead, as it is done for other type of composite columns. In fact, the method in Annex G of the same code for partially encased steel sections follows the general rules given in Clause 4.3.5.1. However, in the case of concrete filled tubular columns, only few studies have been carried out so far to investigate its applicability (Wang 1997, Renaud et al. 2004, Aribert et al. 2008).

In this method, the design value of the resistance of composite columns in axial compression exposed to fire $\left(N_{f i, R d}\right)$ is calculated as:

$$
N_{f i, R d}=\chi N_{f i, p l, R d}
$$

where $\chi$ is the reduction coefficient for buckling curve "c" given in Clause 6.3.1.2 of EN 1993-1-1 (CEN 2005a) (obtained from the value of the relative slenderness at elevated temperature) and $N_{f i, p l, R d}$ is the design value of the plastic resistance of the cross-section to axial compression in fire.

The design value of the plastic resistance of the cross-section in the fire situation $\left(N_{f i, p l, R d}\right)$ is given by:

$$
\begin{aligned}
& N_{f i, p l, R d}=\sum_{j}\left(A_{a, \theta} f_{a y, \theta}\right) / \gamma_{M, f i, a}+\sum_{k}\left(A_{s, \theta} f_{s y, \theta}\right) / \gamma_{M, f i, s}+ \\
& +\sum_{m}\left(A_{c, \theta} f_{c, \theta}\right) / \gamma_{M, f i, c}
\end{aligned}
$$

where $A_{i, \theta}$ is the area of each element of the cross-section to which a certain temperature $\theta$ is attributed and subscripts " $a$ ", " $s$ " and " $c$ " refer to the steel profile, reinforcing bars and concrete core, respectively. $\gamma_{M, f i, i}$ are the partial factors for the materials in the fire situation. 
The effective flexural stiffness of the column can be calculated through:

$$
(E I)_{f i, e f f}=\sum_{j}\left(\varphi_{a, \theta} E_{a, \theta} I_{a, \theta}\right)+\sum_{k}\left(\varphi_{s, \theta} E_{s, \theta} I_{s, \theta}\right)+\sum_{m}\left(\varphi_{c, \theta} E_{c, \sec , \theta} I_{c, \theta}\right)
$$

where $I_{i, \theta}$ is the second moment of area of each element of the cross-section to which a certain temperature $\theta$ is attributed, $\varphi_{i, \theta}$ is a reduction coefficient depending on the effect of thermal stresses and $E_{c, s e c, \theta}$ is the secant modulus of concrete at the temperature $\theta$. For composite columns with partially encased steel sections, the reduction coefficients have been defined in Annex G of EN 1994-1-2 (CEN 2005c). However, for concrete filled sections, the values of these reduction coefficients still have to be established.

The flexural stiffness reduction coefficients were introduced in this formulation to account for the effect of the self-equilibrated thermal stresses caused by the non-uniform temperature distribution within the composite cross-section and the unequal thermal expansion of steel and concrete (Lennon et al. 2007). In the absence of predefined values for these coefficients, as it is the case of CFT columns, a common approach in practice is to take them as equal to unity (Lennon et al. 2007). Only studies from the CTICM group (Renaud et al. 2004, Aribert et al. 2008) can be found in the literature on the suitable values of these coefficients.

Once the effective flexural stiffness is calculated, the Euler buckling load in the fire situation is obtained:

$$
N_{f i, c r}=\pi^{2}(E I)_{f i, e f f} / \ell_{\theta}^{2}
$$

where $\ell_{\theta}$ is the effective length of the column at a certain temperature $\theta$.

The relative slenderness of the column at elevated temperatures is given by:

$$
\bar{\lambda}_{\theta}=\sqrt{N_{f i, p l, R} / N_{f i, c r}}
$$

where $N_{f i, p l, R}$ is the value of $N_{f i, p l, R d}$ when the material factors are taken as 1.0. This value of the relative slenderness is used to enter to the buckling curve "c", from where the reduction coefficient $\chi$ needed for determining the buckling load is finally obtained. 


\subsubsection{French National Annex to EN 1994-1-2}

The French National Annex to EN 1994-1-2 (NF EN 1994-1-2/NA) (AFNOR 2007) is based on the general method described in Clause 4.3.5.1 of EN 1994-1-2 (CEN 2005c). In this National Annex, specific values for the flexural stiffness reduction coefficients have been included to account for the effect of the differential thermal stresses within the composite cross-section. These values are a result of an extensive parametric investigation carried out at the CTICM (Renaud et al. 2004). For the concrete core, a reduction coefficient of 0.8 is specified, resulting in $\varphi_{c, \theta}=$ 1.2, which includes implicitly the use of the initial tangent modulus of concrete (calculated as 3/2 times the secant modulus, therefore $0.8 \times 3 / 2=1.2$ for direct application over the secant modulus), while for the steel hollow section the value of the reduction coefficient $\varphi_{a, \theta}$ depends on the fire duration and the size of the steel section, according to Clause 4(2) of NF EN 1994-1-2/NA.

The method included in the French National Annex establishes also specific buckling curves with a discontinuity at a certain value of the relative slenderness, called the "transition relative slenderness". This transition value is dependent on the fire exposure time, and is equal to 1.0 for R30 and 1.35 for R60 in the case of unreinforced columns. For reinforced columns, the transition slenderness is obtained from selection charts (given in AFNOR 2007) in function of the fire period, diameter of the column and percentage of reinforcement. Before reaching the transition value, the buckling curve follows the shape of the EN 1993-1-1 (CEN 2005a) curves but with a different imperfection factor for the different fire periods ( $\alpha=0.21$ for R30, $\alpha=0.265$ for R60 and $\alpha=0.34$ for R90/120). For relative slenderness values above the transition slenderness, the method makes use of specific buckling curves in the form:

$$
\chi=\beta\left(\bar{\lambda}_{\theta}\right)^{-\gamma}
$$

with non-dimensional coefficients $\beta$ and $\gamma$ as a function of the sectional dimensions.

The French method is limited to buckling lengths in the fire situation $\ell_{\theta} / D \leq 30$, concrete grades $\mathrm{C} 20 / 25-\mathrm{C} 60 / 75, D \leq 610 \mathrm{~mm}$. For centrally loaded unreinforced CFT columns a minimum dimension is required depending on the fire resistance class: $D>100 \mathrm{~mm}$ for R30 and $D>150 \mathrm{~mm}$ for R60. For unreinforced columns longer fire resistance times cannot be evaluated by this method, since a minimum percentage of reinforcement is required for achieving a R90 or higher fire resistance class. For columns with reinforcement, the minimum dimensions required are $D>150 \mathrm{~mm}$ for R30/R60 and $D>200 \mathrm{~mm}$ for $\mathrm{R} 90 / 120$, with a minimum 
reinforcement ratio for concentric loads equal to $1 \%$ and a maximum percentage of reinforcement equal to $5 \%$.

\subsubsection{Simplified design equation proposed by Kodur}

Kodur (1999) proposed a simplified equation based on the results of parametric studies supported by an experimental program carried out in the Institute for Research in Construction, NRCC (Canada) (Lie \& Chabot 1992, Chabot \& Lie 1992, Kodur \& Lie 1995) on circular and square concrete filled tubular columns under fire. This approach is used in the United States and Canada after having been incorporated into several building codes (ASCE 1999, NBCC 2005, ACI 2007) and design guides (Ruddy et al. 2003).

Kodur's design equation directly provides the fire resistance time of the column in minutes as a function of different parameters such as the concrete strength, the column diameter and effective length, the type of concrete filling, cross-sectional shape and percentage of steel reinforcement.

The fire resistance time of a column can be evaluated by the following equation as a function of the different parameters:

$$
R=f \frac{f_{c}+20}{\ell_{\theta}-1000} D^{2} \sqrt{\frac{D}{N}}
$$

where $R$ is the fire resistance time in minutes, $f_{c}$ is the concrete strength at the age of 28 days in $\mathrm{MPa}, D$ is the outside diameter of the column in $\mathrm{mm}$ (also applicable to square columns if the width is used instead), $N$ is the applied load in $\mathrm{kN}, \ell_{\theta}$ is the effective buckling length of the column in $\mathrm{mm}$ and $f$ is a coefficient which includes the effect of the rest of the parameters, given in Kodur (1999). This coefficient is tabulated as a function of the type of concrete filling (plain, bar-reinforced or fibrereinforced concrete), the type of aggregate used (carbonate or siliceous), the percentage of reinforcement, the thickness of the concrete cover, and the crosssectional shape of the column (circular or square).

If the maximum axial load that a column can sustain for a specified fire endurance period wants to be obtained, equation (6.8) can be rewritten as follows (Kodur \& MacKinnon 2000): 
$N_{f i, R d}=\left(\frac{f\left(f_{c}+20\right) D^{2.5}}{R\left(\ell_{\theta}-1000\right)}\right)^{2} \leq N_{f i, R d, \text { max }}$

The buckling resistance obtained through this equation is limited to a maximum value $N_{f, R d, \max }$ which is equal to 1.0 times the design capacity of the concrete core at room temperature $\left(N_{R d, c}\right)$ for unreinforced columns, 1.1 times $N_{R d, c}$ for steel-fibre reinforced columns and 1.7 times $N_{R d, c}$ for bar-reinforced columns. The design capacity of the concrete core at room temperature, calculated in accordance with Clause 18.4 of CAN/CSA-S16.1-94 (CSA 1994), is obtained as follows:

$N_{R d, c}=\frac{0.85 \phi_{c} f_{c} A_{c}}{\lambda_{c}{ }^{2}}\left(\sqrt{1+\frac{0.25}{\lambda_{c}{ }^{4}}}-\frac{0.5}{\lambda_{c}{ }^{2}}\right)$

where $\phi_{c}=0.6$ and $\lambda_{c}$ is the slenderness of the column considering the concrete cross-section only, which can be calculated as:

$\lambda_{c}=\sqrt{\frac{N_{f i, p l, R, c}}{N_{f i, c r, c}}}=\sqrt{\frac{f_{c} A_{c}}{\frac{\pi^{2} E_{c} I_{c}}{\ell_{\theta}^{2}}}}=\frac{\ell_{\theta}}{r_{c}} \sqrt{\frac{f_{c}}{\pi^{2} E_{c}}}$

with $r_{c}$ the radius of gyration of the concrete area and $E_{c}$ the initial elastic modulus of concrete.

The applicability of both equations is limited to $f_{c}=20-40 \mathrm{MPa}, D=140-$ $410 \mathrm{~mm}, R \leq 120 \mathrm{~min}$ and $\ell_{\theta}=2000-4000 \mathrm{~mm}$ for columns without any reinforcement. Therefore, the method cannot be applied to columns with a high slenderness. For bar-reinforced columns the method is valid for $f_{c}=20-55 \mathrm{MPa}, D$ $=165-410 \mathrm{~mm}, R \leq 180 \mathrm{~min}$ and $\ell_{\theta}=2000-4500 \mathrm{~mm}$. In addition, the percentage of reinforcement must be comprised between $1.5 \%$ and $5 \%$.

\subsubsection{Strength index formulation proposed by Han et al.}

Han and co-workers (Han et al. 2003) proposed a formulation which makes possible to determine the strength index (SI) of circular CFT columns filled with plain concrete, based on the results of parametric and experimental studies carried out at the Tianjin Fire Research Institute (China). The formulation was obtained by 
using regression analysis, and is valid for circular hollow steel columns without fire protection, filled with plain concrete. Also columns with external fire protection were investigated, and the design equations developed were incorporated in the Chinese code DBJ13-51 (DBJ 2003).

The strength index is defined as:

$$
S I=\frac{N_{u}(t)}{N_{u}}= \begin{cases}\frac{1}{1+a \cdot t_{0}^{2.5}}, & t_{0} \leq t_{1} \\ \frac{1}{b \cdot t_{0}+c}, & t_{1}<t_{0} \leq t_{2} \\ k \cdot t_{0}+d, & t_{0}>t_{2}\end{cases}
$$

where $N_{u}(t)$ is the ultimate strength of the column corresponding to the fire resistance time $(t)$ and $N_{u}$ is the ultimate strength of the column at room temperature, $t_{0}=t / 100, t_{1}$ and $t_{2}$ are transition times depending on the value of $D_{0}=D / 600$ and $\lambda_{0}=\lambda / 40 . a, b, c, d, k$ are regression coefficients which also depend on $D_{0}, \lambda_{0}$ and $t_{1}$, $t_{2}$. For simplicity, the definition of the different coefficients of this formulation has not been transcribed here, but it can be found in Han et al. (2003).

The validity limits of Han's design equation are: $t \leq 180 \mathrm{~min}, D=150-2000$ $\mathrm{mm}, f_{y}=200-500 \mathrm{MPa}, f_{c}=20-60 \mathrm{MPa}$ and $\lambda=15-80$ (slenderness ratio defined here as $\lambda=4 L / D)$.

\subsubsection{Fire resistance design formula used in Japan}

The actual state of the fire design codes in Japan was reviewed by Harada (2004). Regarding concrete filled steel tubular columns, the Association of New Urban Housing Technology in Japan published a design guide manual (ANUHT 2004) where a simple equation for obtaining the ultimate load of the column under a certain fire period can be found. For circular columns, the expression is as follows:

$$
\frac{N_{f i, R d}}{A_{c} f_{c}}=\left(5.75 \cdot 10^{-5} \cdot f_{c}^{2.63} \cdot t+1\right)^{-0.214}
$$

where $A_{c}$ is the cross-sectional area of concrete in $\mathrm{mm}^{2}, f_{c}$ is the specified 28 day concrete strength in $\mathrm{MPa}$ and $t$ is the fire resistance time in minutes. 


\subsection{EVALUATION OF THE CURRENT CALCULATION METHODS IN EUROCODE 4}

In this section, the accuracy of the calculation methods available in Eurocode 4 Part 1.2 (CEN 2005c) for concrete filled tubular columns is verified against tests results from different sources. The results from the NRCC fire tests (Chabot \& Lie 1992, Lie \& Chabot 1992) are used, as well as the results from the own tests carried out in Valencia on slender CFT columns (Romero et al. 2011). Only those columns filled with normal strength concrete are used for this study, as the current field of application of the methods in Eurocode 4 is C20/25-C40/50. Also note that this study is focused on centrally loaded columns.

Clause 4.3.5.1 in EN 1994-1-2 (CEN 2005c) provides a simple calculation model for composite columns in general, while Annex $\mathrm{H}$ in the same code gives a specific method for unprotected concrete filled hollow sections.

Both calculation methods are used in this study, with Clause 4.3.5.1 hereafter referred to as EC4 and Annex $\mathrm{H}$ referred to as EC4(H). Both methods were described in Section 6.1.

As it was pointed out in Section 6.1.2, the general method in Clause 4.3.5.1 in EN 1994-1-2 (CEN 2005c) makes use of a set of flexural stiffness reduction coefficients which account for the effect of the thermal stresses caused by the nonuniform temperature distribution within the composite cross-section. However, as the values of these reduction coefficients are not given in the code for CFT columns, a common approach in practice is to take them as equal to unity, which is equivalent to neglecting the effect of the thermal stresses. In this preliminary study, flexural stiffness reduction coefficients equal to unity have been used for the application of the general method in Clause 4.3.5.1 (EC4), although further study is needed for deriving the suitable values of these coefficients for the case of CFT columns.

For each column specimen studied, the cross-sectional temperature field at the time of failure was obtained from the experiments, were information of the temperatures registered during the tests by the thermocouples was available. The cross-section was divided into a number of concentric circular layers, and each of these layers was assigned a representative temperature, obtained by using linear interpolation from the thermocouples measurements. Once the cross-sectional temperature field at the time of failure was known, the buckling resistance of the columns was then evaluated through the application of the reduction coefficients of 
strength and stiffness corresponding to each layer for the failure time, according to the code provisions.

The errors obtained in the prediction of the buckling load with reference to the test load by applying the two different calculation methods (Clause 4.3.5.1 and Annex H) are presented in Table 6.1 for the Canadian tests (Chabot \& Lie 1992, Lie \& Chabot 1992) and in Table 6.2 for the own tests (Romero et al. 2011).

Table 6.1. Comparison of the buckling resistance at the time of failure between Eurocode 4 and experiments, Canadian tests

\begin{tabular}{ccccccc}
\hline & & \multicolumn{5}{c}{ Axial load (kN) } \\
\cline { 2 - 7 } Column No. & FRR (min) & Test & EC4 & Test/EC4 & EC4(H) & Test/EC4(H) \\
\hline C-02 & 55 & 110 & 158.49 & 0.69 & 79.39 & 1.39 \\
C-04 & 57 & 131 & 155.46 & 0.84 & 78.14 & 1.68 \\
C-05 & 76 & 150 & 177.00 & 0.85 & 82.64 & 1.82 \\
C-06 & 60 & 150 & 213.62 & 0.70 & 122.71 & 1.22 \\
C-08 & 56 & 218 & 314.05 & 0.69 & 348.39 & 0.63 \\
C-09 & 81 & 150 & 153.98 & 0.97 & 64.10 & 2.34 \\
C-11 & 80 & 492 & 381.92 & 1.29 & 316.69 & 1.55 \\
C-13 & 102 & 384 & 315.14 & 1.22 & 199.50 & 1.92 \\
C-15 & 73 & 525 & 460.12 & 1.14 & 235.40 & 2.23 \\
C-17 & 82 & 525 & 472.02 & 1.11 & 331.39 & 1.58 \\
C-20 & 112 & 574 & 795.54 & 0.72 & 920.57 & 0.62 \\
C-21 & 133 & 525 & 541.44 & 0.97 & 449.29 & 1.17 \\
C-22 & 70 & 1000 & 957.28 & 1.04 & 796.82 & 1.25 \\
C-23 & 143 & 525 & 1198.17 & 0.44 & 1019.87 & 0.51 \\
C-31 & 82 & 80 & 127.36 & 0.63 & 62.84 & 1.27 \\
C-32 & 64 & 143 & 133.58 & 1.07 & 54.37 & 2.63 \\
C-34 & 111 & 500 & 432.02 & 1.16 & 407.02 & 1.23 \\
C-35 & 108 & 560 & 346.30 & 1.62 & 207.32 & 2.70 \\
C-37 & 102 & 560 & 484.09 & 1.16 & 404.59 & 1.38 \\
C-44 & 178 & 715 & 628.87 & 1.14 & 578.16 & 1.24 \\
C-48 & 188 & 1050 & 996.67 & 1.05 & 890.28 & 1.18 \\
C-49 & 96 & 1900 & 2035.23 & 0.93 & 2132.94 & 0.89 \\
\cline { 2 - 6 } & & Average & $\mathbf{0 . 9 7}$ & & $\mathbf{1 . 4 7}$ \\
& & Standard deviation & $\mathbf{0 . 2 6}$ & & $\mathbf{0 . 6 1}$ \\
\hline
\end{tabular}

As can be seen in Table 6.1, when applying the methods to the Canadian tests, reasonable results were obtained by means of the general model in Clause 4.3.5.1 (0.97 average error) with a moderated dispersion, while Annex H produced safe results, although with a high error in the predictions (1.47 average error) and elevated dispersion, resulting in some cases too conservative.

As pointed out by Aribert et al. (2008), the method in Annex H does not take into account the effects of self-equilibrated thermal stresses and those of geometrical second-order local behaviour, which are crucial for the stability of the column. As 
the method is sectional, the strain in all the fibres within the cross-section of the column is assumed to be equal. This approach clearly neglects the effects of the differential longitudinal expansion between the steel tube and concrete core, thus assuming that a full bond occurs. All these factors lead to important deviations from the actual fire response of CFT columns.

Table 6.2. Comparison of the buckling resistance at the time of failure between Eurocode 4 and experiments, own tests (Romero et al. 2011)

\begin{tabular}{|c|c|c|c|c|c|c|}
\hline \multirow[b]{2}{*}{ Column No. } & \multirow[b]{2}{*}{$\begin{array}{r}\text { FRR } \\
(\mathrm{min})\end{array}$} & \multicolumn{5}{|c|}{ Axial load (kN) } \\
\hline & & Test & EC4 & $\begin{array}{c}\text { Test } \\
/ \text { EC4 }\end{array}$ & EC4(H) & $\begin{array}{c}\text { Test/ } \\
\text { EC4(H) }\end{array}$ \\
\hline C159-6-3-30-0-40-P-P & 18 & 338 & 346.29 & 0.98 & 364.60 & 0.93 \\
\hline C159-6-3-30-0-20 & 42 & 198 & 257.58 & 0.77 & 241.54 & 0.82 \\
\hline C159-6-3-30-0-40 & 25 & 396 & 490.40 & 0.81 & 507.36 & 0.78 \\
\hline C159-6-3-30-0-60 & 14 & 594 & 706.38 & 0.84 & 705.94 & 0.84 \\
\hline $\mathrm{RC} 159-6-3-30-0-20$ & 43 & 229 & 352.83 & 0.65 & 283.74 & 0.81 \\
\hline RC159-6-3-30-0-40 & 30 & 458 & 391.31 & 1.17 & 353.42 & 1.30 \\
\hline RC159-6-3-30-0-60 & 13 & 687 & 1146.18 & 0.60 & 1030.35 & 0.67 \\
\hline FC159-6-3-30-0-20 & 36 & 198 & 267.94 & 0.74 & 293.99 & 0.67 \\
\hline \multirow[t]{2}{*}{ FC159-6-3-30-0-40 } & 22 & 396 & 360.74 & 1.10 & 418.47 & 0.95 \\
\hline & & \multicolumn{2}{|c|}{$\begin{array}{c}\text { Average } \\
\text { Standard deviation }\end{array}$} & $\begin{array}{l}0.85 \\
0.19\end{array}$ & & $\begin{array}{l}0.86 \\
0.19\end{array}$ \\
\hline
\end{tabular}

Despite the method in Annex $\mathrm{H}$ was found conservative in comparison with the Canadian tests results, when comparing with the tests carried out in Valencia (Table 6.2) unsafe results were obtained under both methods (Clause 4.3.5.1 with 0.85 average error and Annex $\mathrm{H}$ with 0.86 average error). The explanation to this difference resides in the slenderness of these columns, which is higher than that of the Canadian specimens. While the columns tested in Canada had room temperature relative slenderness values between 0.29 and 0.57 (except for two hinged columns which presented higher values), the slenderness of the columns tested in Valencia ranged from 0.61 to 0.88 . Thus, while for stocky columns the methods in Eurocode 4 provide in general safe results, for slender columns both methods lead to unsafe results. This confirms the findings from the CTICM group (Aribert et al. 2008), who found that the method in Eurocode 4 - referring to Annex $\mathrm{H}$ - leads to buckling loads that result unsafe when the relative slenderness of the columns exceeds about 0.4 . 


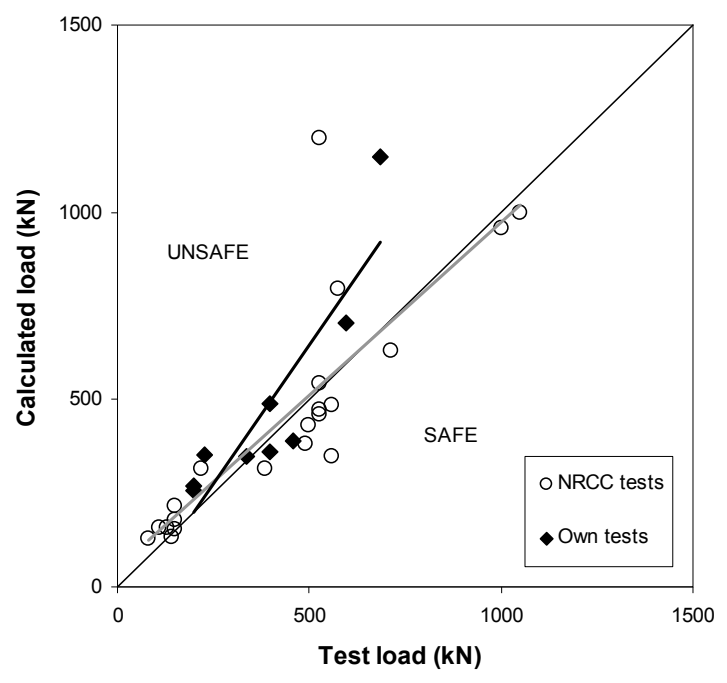

(a) Clause 4.3.5.1

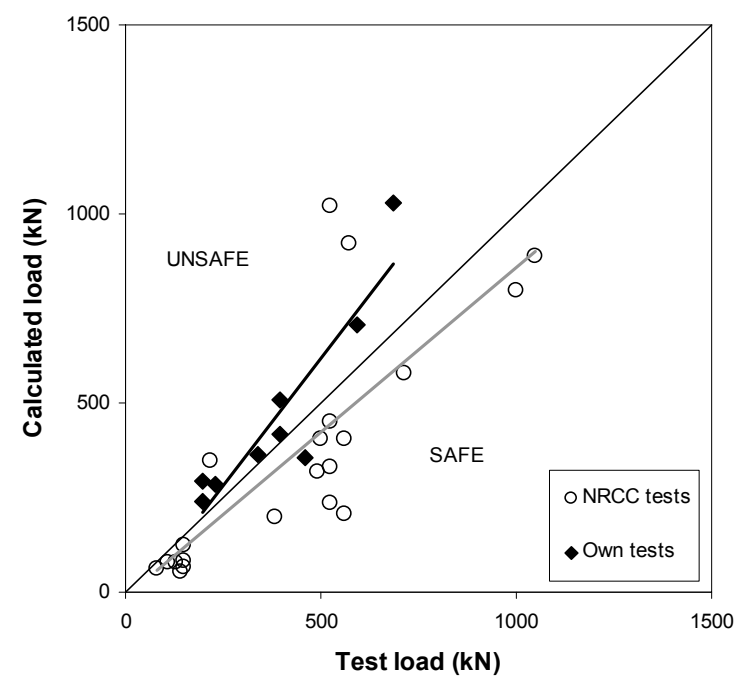

(b) Annex $\mathrm{H}$

Figure 6.2. Comparison of the Eurocode 4 predictions with the tests. 
As can be seen in Figure 6.2, the trend in the predictions for the NRCC specimens was close to the test results, while the predictions for the tests on slender columns from Valencia turned unsafe and deviated from the reference values. Some dispersion can be observed in the prediction of the Canadian specimens, which is attributed to errors in the measurements of the thermocouples, affecting the accuracy of the temperature field used for the calculations. It can also be observed that, for the Canadian specimens, safer predictions were obtained with Annex $\mathrm{H}$ as compared to the general model in Clause 4.3.5.1.

In general, it can be concluded that for slender columns, both methods in Eurocode 4 Part 1.2 - the general method in Clause 4.3.5.1 and the specific method in Annex $\mathrm{H}$ - produce unsafe results.

Regarding the first method, Clause 4.3.5.1, it seems clear that neglecting the effect of the thermal stresses when applying the simple calculation model to CFT columns results in an important deviation from the actual buckling response at elevated temperatures. Therefore, suitable values of the flexural stiffness reduction coefficients must be derived if the method wants to be applied to CFT columns. With respect to the second method, Annex H, it is currently under revision and an upper limit for its applicability has been established to a maximum relative slenderness equal to 0.5 , which is in accordance with this study.

Summarizing all the findings exposed above, this study evidences some limitations in the Eurocode 4 Part 1.2 simple calculation model when predicting the fire resistance of CFT columns at elevated temperatures and suggests that the model should be revised on the bases of these findings.

\subsection{DEVELOPMENT OF A NEW SIMPLE CALCULATION MODEL FOR AXIALLY LOADED CFT COLUMNS}

\subsubsection{Parametric studies}

Parametric studies were performed by means of the numerical model described in Section 4.1. The main parameters affecting the buckling resistance of unreinforced CFT columns at elevated temperatures were investigated through these parametric studies. The parameters studied were the outer diameter of the column $(D)$, the thickness of the steel tube wall $(t)$, the relative slenderness of the column at room temperature $(\bar{\lambda})$ and the standard fire period $(R)$, widely covering the range of values which can be found in practice. A summary of the cases analysed in this parametric study is shown in Table 6.3. 
Table 6.3. Summary of the analysis cases in the parametric studies

\begin{tabular}{ccccccc}
\hline Variable & \multicolumn{5}{c}{ Specified values } \\
\hline$D(\mathrm{~mm})$ & 139.7 & 193.7 & 273 & 323.9 & 406.4 & 508 \\
$t(\mathrm{~mm})$ & $3.2 ; 12.5$ & $5 ; 16$ & $5 ; 16$ & $6.3 ; 16$ & $8 ; 16$ & $10 ; 16$ \\
$\bar{\lambda}$ & \multicolumn{5}{c}{$0.3 ; 0.5 ; 1 ; 1.5 ; 2$} \\
$R(\mathrm{~min})$ & $30 ; 60 ; 90 ; 120$ \\
\hline
\end{tabular}

The composite sections analysed in this parametric study considered a steel yield strength of $355 \mathrm{MPa}$ as most commonly used, and concrete compressive strength of $30 \mathrm{MPa}$, since this study is limited to normal strength concrete. Six different circular section sizes of commercially available dimensions were employed: 139.7, 193.7, 273, 323.9, 406.4 and $508 \mathrm{~mm}$. For each diameter, two steel tube wall thicknesses were selected: the minimum and maximum commercially available values, although it is noteworthy that the minimum thickness was chosen as the first value which produced a class 3 section (thin-walled sections were not included in this study). For each cross-section, five different column lengths were used, corresponding to slenderness values at room temperature of $0.3,0.5,1,1.5$ and 2. The relative slenderness values of the columns at room temperature were calculated in accordance with Clause 6.7.3.3 of EN 1994-1-1 (CEN 2004b) assuming hinged end conditions. The influence of enhanced concrete confinement was not considered in the room temperature calculations.

The maximum slenderness analysed for each cross-section was selected in such a way that the associated buckling length of the column did not exceed 10 meters, in order to reduce the computational cost of this study. Therefore, the combinations of diameters and member slenderness were as follows: $D=139.7 \mathrm{~mm}$ $(\bar{\lambda}=0.3,0.5,1,1.5,2) ; D=193.7 \mathrm{~mm}(\bar{\lambda}=0.3,0.5,1,1.5,2) ; D=273 \mathrm{~mm}(\bar{\lambda}=$ $0.3,0.5,1,1.5) ; D=323.9 \mathrm{~mm}(\bar{\lambda}=0.3,0.5,1) ; D=406.4 \mathrm{~mm}(\bar{\lambda}=0.3,0.5,1)$; $508 \mathrm{~mm}(\bar{\lambda}=0.3,0.5)$.

For each column, four different standard fire resistance classes were considered: 30, 60, 90 and 120 minutes (hereafter referred to as R30, R60, R90 and R120), which are the common values prescribed in the design codes. Each column specimen employed a different combination of the specified values of the variables shown in Table 6.3. In total, the number of specimens analysed in this parametric study was 176 .

The procedure employed in this research to calculate the buckling resistances which correspond to the different fire exposure times analysed (30, 60, 90 and 120 minutes) was as follows. In a first step, the fire resistance time of the column was 
obtained by means of the numerical model under several values of the applied axial load (in general, 10 different values were used), so as to be able to build up a curve of the evolution of the buckling load versus the fire exposure time. In a second step, the value of the buckling load corresponding to the desired standard time (R30, R60, R90 or R120) was obtained from this curve by using linear interpolation. Special care was taken in the vicinity of the standard fire times, where the curve was refined, so that the error in the interpolation was minimum.

Figure 6.3 explains graphically the process followed for obtaining the buckling resistance of a column at the specified standard fire times. As can be seen, this procedure requires an elevated number of calculations to perform for each column specimen, which limits the extension of this parametric analysis.

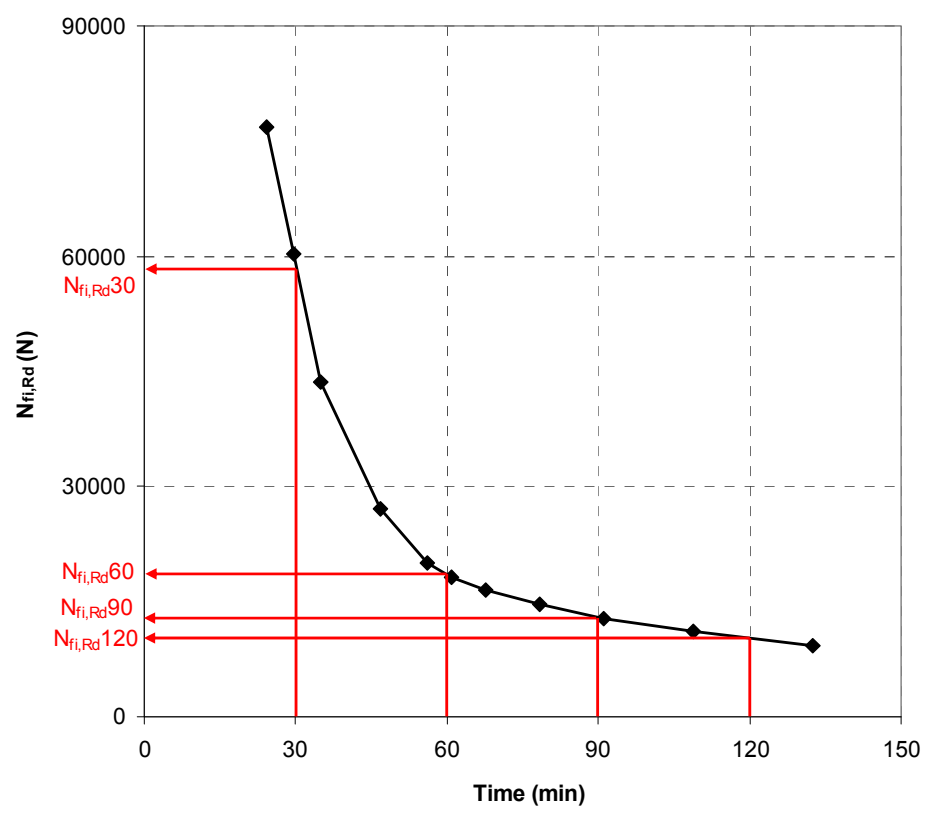

Figure 6.3. Process for obtaining the buckling resistance of the columns at the different standard fire periods.

For building up the buckling resistance versus time curve corresponding to each geometry, an average of 10 simulations were needed, giving a total number of about 500 simulations performed for obtaining the buckling resistance at the specified standard fire periods of all the column specimens analysed. 


\subsubsection{Analysis of results}

From the results of all the calculations performed in the parametric studies, the numerical buckling coefficient was computed. It was defined as the column axial buckling resistance obtained from the numerical simulation divided by the design value of the cross-sectional plastic resistance, both in the fire situation: $\chi^{N U M}$ $=N_{f i, R d}{ }^{N U M} / N_{f i, p l, R d}$. This value was plotted against the relative slenderness at elevated temperature $\bar{\lambda}_{\theta}$, calculated as described in Section 6.1.2 and using flexural stiffness reduction coefficients equal to unity (i.e. neglecting the effect of the thermal stresses). Figure 6.4 shows the results for all the columns analysed in this research, were buckling curve "c" has been superimposed for comparison purposes. As can be seen, most of the values lie below the buckling curve "c" being therefore unsafe, except for columns with high relative slenderness values (generally corresponding to specimens with room temperature slenderness over 1.5) and columns with a very small slenderness.

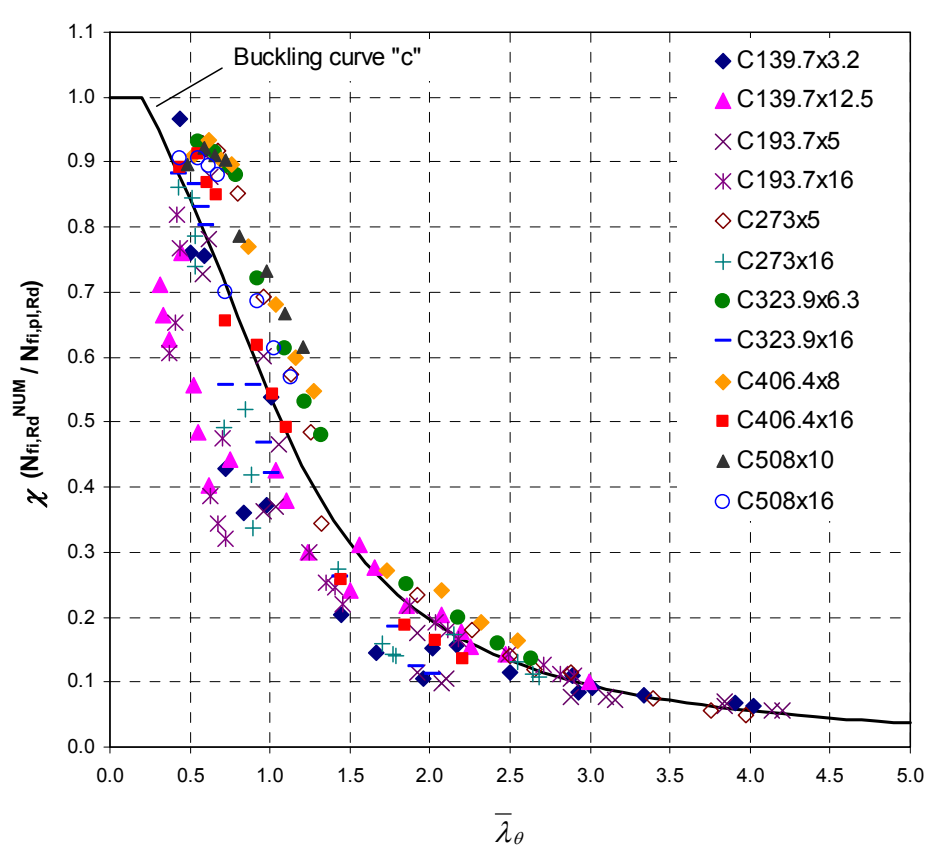

Figure 6.4. Evolution of the buckling coefficient with the relative slenderness at elevated temperature (neglecting the flexural stiffness reduction coefficients). 
It becomes clear from this graph that columns with intermediate slenderness deviate from the theoretical buckling curve at elevated temperatures and therefore need another consideration.

If the flexural stiffness reduction coefficients from the French National Annex to EN 1994-1-2 (AFNOR 2007) are used, the previous plot takes the aspect shown in Figure 6.5, where it can be seen that most of the points lie above buckling curve "c", therefore resulting in safe predictions, although with a noticeable deviation from the actual buckling curve.

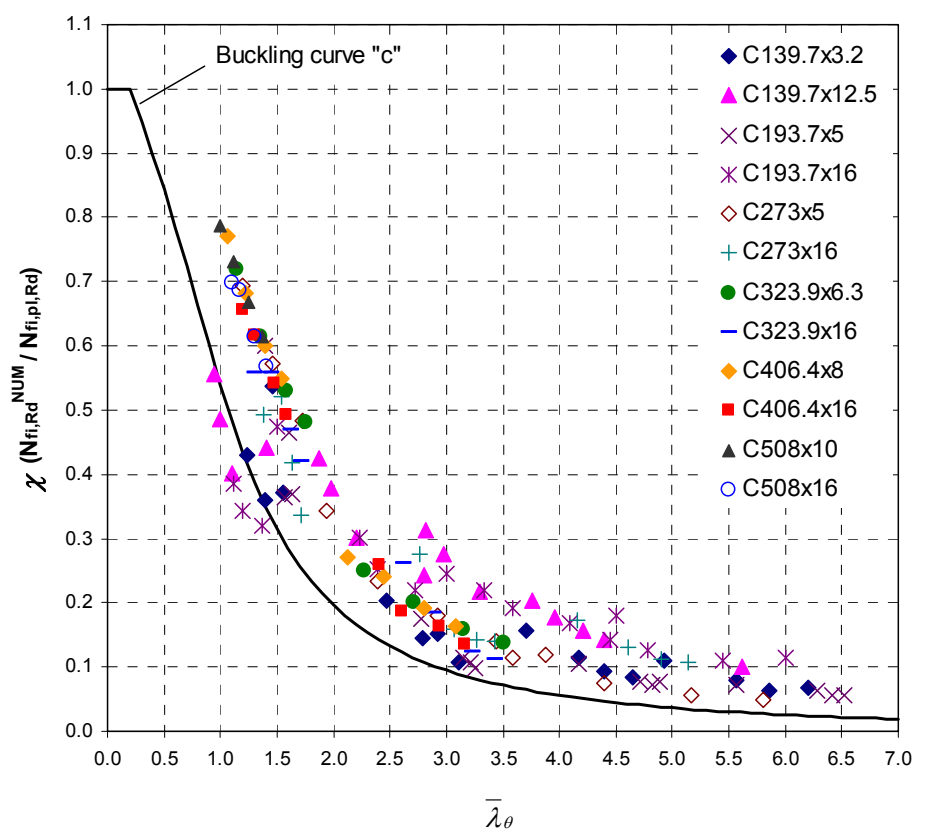

Figure 6.5. Evolution of the buckling coefficient with the relative slenderness at elevated temperature (with French coefficients).

This result suggests that a set of flexural stiffness reduction coefficients $\varphi_{i, \theta}$ must be developed for CFT columns in combination with a possible revision of the buckling curve which provides a better fit to the data, matter that will be studied in depth throughout this section. 
Another important aspect can be observed from Figure 6.4. In the range of low slenderness, for each diameter of the columns analysed, the buckling coefficient $\chi$ of the columns with the maximum wall thickness of the tube (reduced $D / t$ values) appeared to be smaller than the $\chi$ values of the columns with the minimum wall thickness and thus having a higher $D / t$; e.g. the points for columns of $406.4 \times 16 \mathrm{~mm}$ section lie below the points corresponding to columns of $406.4 \times 8 \mathrm{~mm}$ section). This result was more evident in stocky columns $(\bar{\lambda} \leq 0.5)$, while for slender columns the difference was not so clear. It is worth noting that this phenomenon was found when comparing buckling coefficients (where the buckling load is referred to the crosssectional plastic resistance) and not with the absolute value of the buckling load, which resulted generally in higher values for the columns with a higher steel tube wall thickness.

The explanation of this effect may reside in the fact that for a given section size, lower thicknesses of the steel tube wall allow more quantity of concrete to fill the column and thus contributing to delay its heating and as a consequence being able to sustain a higher load. This behaviour holds true for this particular range of columns, where the fire response is highly influenced by the amount of concrete filling. However, the more slender columns show the inverse response, since their failure is initiated by the local buckling of the steel tube at an early stage when it is still sustaining the load without the contribution of the concrete core. The slenderness of the unfilled steel tube (and thus its thickness) is therefore a relevant factor in this case, whereas the amount of concrete filling does not play an important role here. This phenomenon has also been pointed out by Kodur \& MacKinnon (2000) and has been observed in real fire tests (Kordina \& Klingsch 1983, Lie \& Chabot 1992).

\subsubsection{Study and discussion of Eurocode 4 Part 1.2}

On the basis of the results of the parametric studies presented above, a comparison is done in this section between the current calculation methods available in the Eurocode 4 Part 1.2 (CEN 2005c) for CFT columns. Four different approaches are studied (see Sections 6.1.1 - 6.1.3): Clause 4.3.5.1 with flexural stiffness reduction coefficients equal to unity (EC4(1)), Clause 4.3.5.1 with the reduction coefficients proposed by Aribert et al. (2008) (EC4(2)), Annex H $(\mathrm{EC} 4(\mathrm{H}))$, and French National Annex (EC4(NF)). For each method, the numerical temperature field obtained at the standard fire resistance classes (R30, R60, R90 and R120 minutes) was applied, and following the code provisions the buckling load was calculated. 
Figure 6.6 shows a comparison between the predictions and the numerical simulations in terms of normalised buckling load (divided by the theoretical crosssectional plastic resistance).

a)

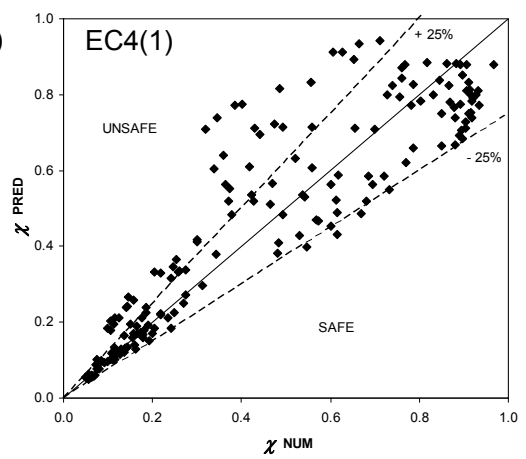

c)

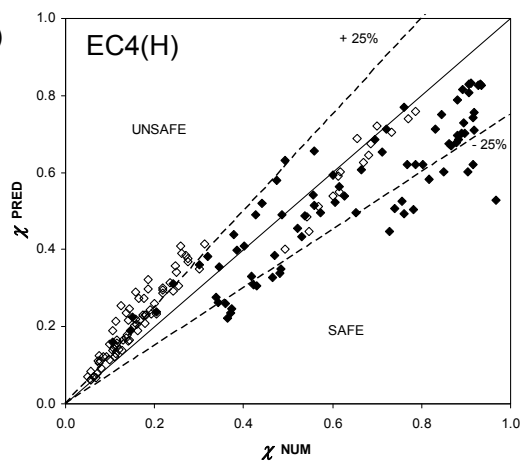

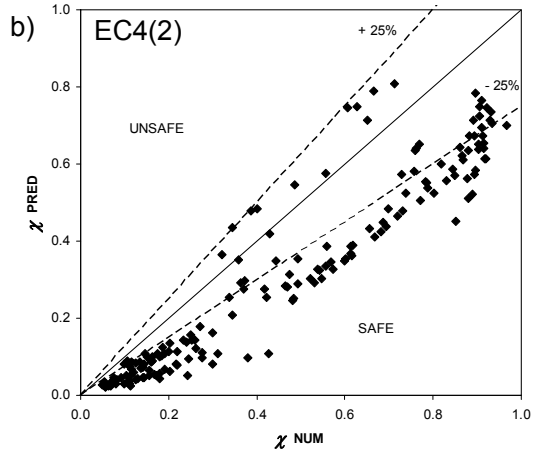

d)

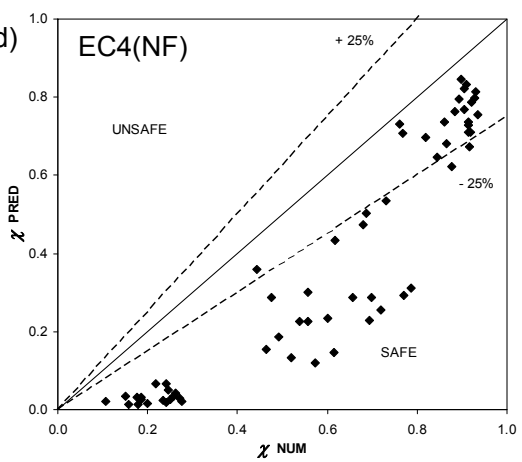

Figure 6.6. Comparison between the different approaches studied in terms of the normalised buckling resistance: a) EC4(1), b) EC4(2), c) EC4(H), d) EC4(NF).

Figure 6.7 plots the relative error of the predictions $\xi$ against the relative slenderness of the columns at room temperature, for each of the design approaches studied. The relative error was computed as follows:

$\xi=1-\frac{N_{f i, R d}^{P R E D}-N_{f i, R d}^{N U M}}{N_{f i, R d}^{N U M}}$

where $N_{f i, R d}{ }^{P R E D}$ is the predicted buckling resistance with the calculation method employed and $N_{f i, R d}{ }^{N U M}$ is the numerical simulation result, which is taken here as the 
reference value. Therefore, values greater than 1 mean safe predictions, while values lower than 1 mean unsafe predictions.

a)

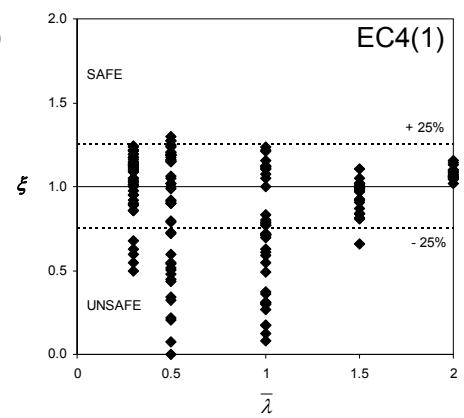

c)

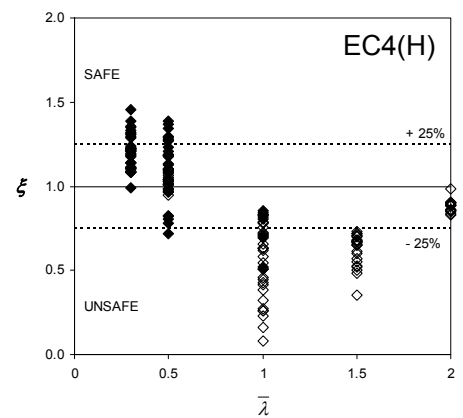

b)

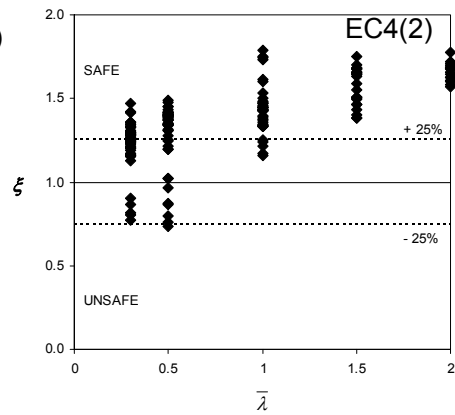

d)

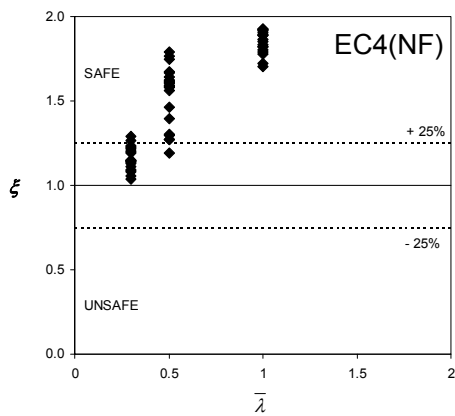

Figure 6.7. Evolution of the prediction errors with the relative slenderness of the columns, for the different approaches studied: a) EC4(1), b) EC4(2), c) EC4(H), d)

EC4(NF).

As can be seen in Figure 6.6a and Figure 6.7a, EC4(1) yields unsafe results with a high dispersion of values for all the range of slenderness studied, except for $\bar{\lambda}=2$, when the predictions become safe and the dispersion is much lower. Therefore, to neglect the flexural stiffness reduction coefficients when applying Clause 4.3.5.1 of EC4 to CFT columns produces inadmissible errors. Nevertheless, when the French coefficients are used in combination with Clause 4.3.5.1, Figure $6.6 \mathrm{~b}$ and Figure $6.7 \mathrm{~b}(\mathrm{EC} 4(2))$, safe results are obtained in all the range of slenderness studied (except for some cases with $\bar{\lambda} \leq 0.5$ ), but with high errors and an elevated dispersion of results. As the slenderness is increased, the predictions become safer but the errors produced by this method are higher. Annex $\mathrm{H}$ predictions $(\mathrm{EC} 4(\mathrm{H}))$ turn from safe at low slenderness $(\bar{\lambda}=0.3)$ to unsafe for intermediate slenderness $(\bar{\lambda}=0.5-1.5)$ and close to the reference value again at $\bar{\lambda}$ 
$=2$, Figure $6.6 \mathrm{c}$ and Figure 6.7c. This confirms the results from the CTICM group (Renaud et al. 2004, Aribert et al. 2008), who found that the method in Annex H is unsafe for slenderness values over 0.4. Note that in these two figures, those cases which are out of the applicability limits of Annex $\mathrm{H}\left(\ell_{\theta}>4.5 \mathrm{~m}\right)$ have been plotted with an empty mark. The magnitude of the error produced by Annex $\mathrm{H}$ is lower, but still leading to high errors, which in most of the cases are over a $25 \%$. Finally, EC4(NF) produces safe results for all the cases analysed, but with a high error which increases with the slenderness, Figure $6.6 \mathrm{~d}$ and Figure $6.7 \mathrm{~d}$. Note that the number of points plotted in these two last figures is lower, since some column specimens are out of the applicability limits of the French method (only R30 and R60 are allowed for unreinforced columns).

\subsubsection{Simplified cross-sectional temperature field}

In both Annex H and Clause 4.3.5.1 of EN 1994-1-2 (CEN 2005c) it is required that the designer obtains the cross-sectional temperature field in the composite cross-section after a given duration of fire exposure prior to applying the method to calculate the design axial buckling load. Nevertheless, no simplified method for the temperature evaluation is given in the code which helps the designer obtain easily this temperature field. In order to help practitioners in the future, a simple method for evaluating the temperature field within the cross-section of a CFT column of any dimensions is proposed here.

It would be desirable to obtain a uniform equivalent temperature for the whole concrete core $\left(\theta_{c, e q}\right)$ and another one for the steel tube $\left(\theta_{a, e q}\right)$ so as to obtain the same fire resistance of the column as by using the real non-uniform temperature distribution. This approach is already used in Annex G of EN 1994-1-2 (CEN 2005c) for composite columns with partially encased steel sections. The benefit of this approach is that the designer can evaluate the fire resistance of the column by using a single strength and stiffness value for each component of the composite cross-section corresponding to its temperature. A calculation procedure was proposed by Leskela (2009), whose recommendations are followed hereafter.

\section{Calculation of the equivalent temperature for the concrete core}

The concrete cross-section is subdivided in a number of $n$ layers, being $A_{c, \theta, i}$ the area of a particular layer $i$ at the temperature $\theta$ and $I_{c, \theta, i}$ the second moment of area of that same layer. The equivalent temperature representing the whole concrete core can be found through two different approaches: 
a) Plastic resistance approach

The plastic resistance to axial compression of the concrete core in the fire situation is equal to:

$$
N_{f i, p l, R d, c}=\sum_{i=1}^{n}\left(A_{c, \theta, i} f_{c, \theta, i}\right)=\sum_{i=1}^{n}\left(A_{c, \theta, i} k_{c, \theta, i} f_{c}\right)=f_{c} \sum_{i=1}^{n}\left(A_{c, \theta, i} k_{c, \theta, i}\right)
$$

A single equivalent temperature is needed, which produces the same plastic resistance through its corresponding reduction factor when applied to the whole concrete core:

$$
\begin{aligned}
& N_{f i, p l, R d, c}=f_{c} \sum_{i=1}^{n}\left(A_{c, \theta, i} k_{c, \theta, i}\right)=k_{c, \theta}\left(\theta_{c, e q 1}\right) f_{c} A_{c} \rightarrow \\
& \rightarrow k_{c, \theta}\left(\theta_{c, e q 1}\right)=\frac{\sum_{i=1}^{n}\left(A_{c, \theta, i} k_{c, \theta, i}\right)}{A_{c}}
\end{aligned}
$$

Once this reduction coefficient is calculated, the equivalent temperature $\theta_{c, \text { eqI }}$ representing the whole concrete core can be found through Table 3.3 in EN 1994-1-2 (CEN 2005c) by using linear interpolation.

b) Flexural stiffness approach

The flexural stiffness of the concrete core in the fire situation is equal to:

$$
\begin{aligned}
& (E I)_{f i, c}=\sum_{i=1}^{n}\left(E_{c, \sec , \theta, i} I_{c, \theta, i}\right)=\sum_{i=1}^{n}\left(\frac{f_{c, \theta, i}}{\varepsilon_{c u, \theta, i}} I_{c, \theta, i}\right)=\frac{f_{c}}{\varepsilon_{c u}} \sum_{i=1}^{n}\left(\frac{k_{c, \theta, i}}{\frac{\varepsilon_{c u, \theta, i}}{\varepsilon_{c u}}} I_{c, \theta, i}\right)= \\
& =E_{c, \sec } \sum_{i=1}^{n}\left(k_{E c, \theta, i} I_{c, \theta, i}\right)
\end{aligned}
$$

with $k_{E c, \theta, i}=k_{c, \theta, i} \varepsilon_{c u} / \varepsilon_{c u, \theta, i}$.

It is required to obtain an equivalent temperature which produces the same flexural stiffness through its corresponding reduction factor when applied to the whole concrete core: 


$$
\begin{aligned}
& (E I)_{f i, c}=E_{c, \sec } \sum_{i=1}^{n}\left(k_{E c, \theta, i} I_{c, \theta, i}\right)=k_{E c, \theta}\left(\theta_{c, e q 2}\right) E_{c, \sec } I_{c} \rightarrow \\
& \rightarrow k_{E c, \theta}\left(\theta_{c, e q 2}\right)=\frac{\sum_{i=1}^{n}\left(k_{E c, \theta, i} I_{c, \theta, i}\right)}{I_{c}}
\end{aligned}
$$

Once this coefficient is calculated, the equivalent temperature $\theta_{c, e q 2}$ representing the whole concrete core can be found through Table 3.3 in EN 1994-12 (CEN 2005c) by using linear interpolation and considering $k_{E c, \theta}=k_{c, \theta} \varepsilon_{c u} / \varepsilon_{c u, \theta}$.

Conservatively, the equivalent temperature of the concrete core is defined as the maximum of the temperatures obtained through the two approaches described above:

$$
\theta_{c, e q}=\max \left\{\theta_{c, e q 1}, \theta_{c, e q 2}\right\}
$$

The previous procedure was applied to the different cross-sections used in the parametric studies, for which the temperature field had been calculated by means of the numerical model. The diameters studied covered a wide range of section factor values $\left(A_{m} / V\right.$ from 7.87 to 28.63). In this research, the number of layers $n$ within the concrete cross-section was chosen in such a way that the width of the individual layers did not exceed $20 \mathrm{~mm}$. Therefore, as the diameter of the column increases, a higher number of layers is required. The equivalent temperature of the concrete core was obtained for four different standard fire resistance classes: R30, R60, R90 and R120. The evolution of the equivalent temperature of the concrete core with the section factor of the columns is plotted in Figure 6.8. As expected, as the fire exposure time increases, the equivalent temperatures also increase. The equivalent temperatures are also affected by the section factor of the columns, reaching higher values for those columns with higher section factors (i.e. small diameters), which expose a relatively high surface to the fire for the same volume and thus heat up faster. For each section factor and fire period, two points are plotted, corresponding to the two different steel tube wall thicknesses analysed. It can be observed that no significant influence is obtained with a change in the steel tube wall thickness, and therefore this parameter will not be taken into account in the development of the equivalent temperature proposal. 


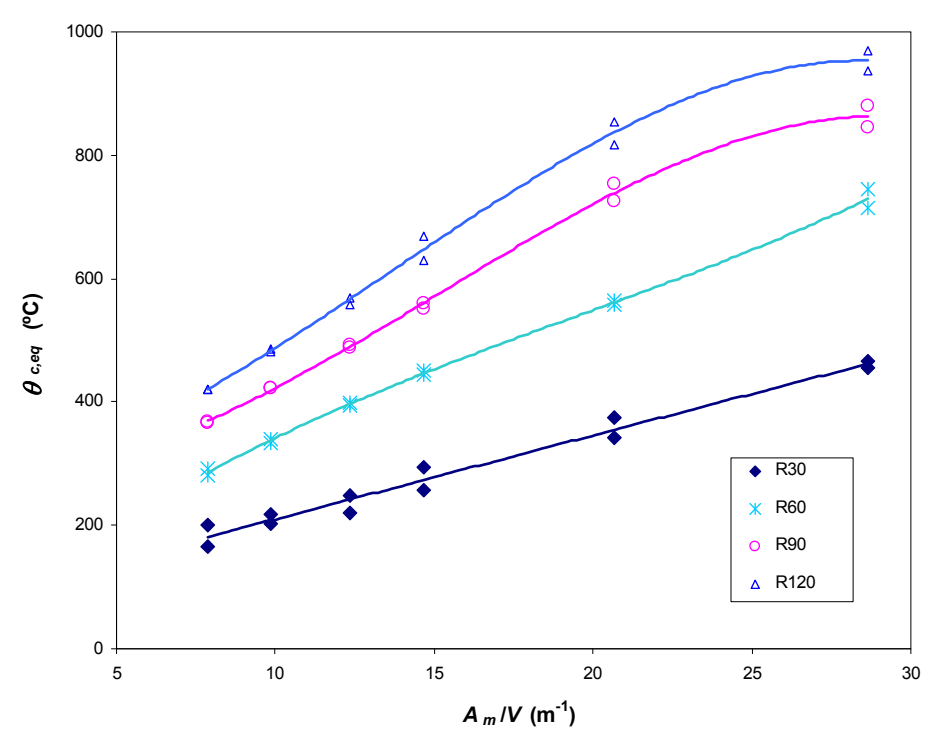

Figure 6.8. Evolution of the equivalent temperature of the concrete core with the section factor, for the standard fire resistance classes.

For each of the standard fire resistance classes studied, a regression curve was fitted to the data, as can be seen in Figure 6.8. With the aid of the regression equations, a selection chart was built up (Table 6.4) to facilitate designers obtain the equivalent temperature of the concrete core for a particular fire period directly from the value of the section factor of the column. For intermediate values of the section factor, linear interpolation can be used. Note that the section factor of a circular CFT column is calculated as $4 / D\left(\mathrm{~m}^{-1}\right)$.

It is worth noting that the temperatures close to $1000{ }^{\circ} \mathrm{C}$ which are obtained at R120 for the smaller diameters (high section factors) are only indicative, nevertheless they cannot be reached in practice, since they would correspond to columns loaded at a very low level. 
Table 6.4. Values of the equivalent temperatures for concrete $\left(\theta_{c, e q}\right)$ and steel $\left(\theta_{a, e q}\right)$ in function of the section factor

\begin{tabular}{|c|c|c|c|c|c|c|c|c|c|}
\hline & \multicolumn{2}{|c|}{ R30 } & \multicolumn{2}{|c|}{ R60 } & \multicolumn{2}{|c|}{ R90 } & \multicolumn{2}{|c|}{ R120 } \\
\hline & & $\begin{array}{l}\theta_{c, e q} \\
\left({ }^{\circ} \mathbf{C}\right)\end{array}$ & $\begin{array}{l}\theta_{a, e q} \\
\left({ }^{\circ} \mathrm{C}\right)\end{array}$ & $\begin{array}{l}\theta_{c, e q} \\
\left({ }^{\circ} \mathbf{C}\right)\end{array}$ & $\begin{array}{l}\theta_{a, e q} \\
\left({ }^{\circ} \mathrm{C}\right)\end{array}$ & $\begin{array}{l}\theta_{c, e q} \\
\left({ }^{\circ} \mathrm{C}\right)\end{array}$ & $\begin{array}{l}\theta_{a, e q} \\
\left({ }^{\circ} \mathrm{C}\right)\end{array}$ & $\begin{array}{l}\theta_{c, e q} \\
\left({ }^{\circ} \mathrm{C}\right)\end{array}$ & $\begin{array}{l}\theta_{a, e q} \\
\left({ }^{\circ} \mathrm{C}\right)\end{array}$ \\
\hline \multirow{6}{*}{$\begin{array}{l}A_{m} / V \\
\left(m^{-1}\right)\end{array}$} & 5 & 141 & 636 & 197 & 857 & 316 & 957 & 344 & 1013 \\
\hline & 10 & 210 & 652 & 342 & 869 & 422 & 964 & 487 & 1018 \\
\hline & 15 & 278 & 669 & 453 & 880 & 571 & 971 & 659 & 1024 \\
\hline & 20 & 346 & 686 & 549 & 891 & 721 & 978 & 819 & 1030 \\
\hline & 25 & 413 & 703 & 647 & 903 & 831 & 985 & 928 & 1035 \\
\hline & 30 & 480 & 719 & 764 & 914 & 860 & 992 & 947 & 1041 \\
\hline
\end{tabular}

A single equation for the equivalent temperature of concrete valid for any fire resistance period was also developed by using a multiple nonlinear regression analysis, which includes the effect of $A_{m} / V$ and $R$ :

$$
\begin{aligned}
& \theta_{c, e q}=-186.44+5.764 R-0.026 R^{2}+22.577 A_{m} / V-0.32\left(A_{m} / V\right)^{2}+ \\
& +0.14 R \cdot A_{m} / V
\end{aligned}
$$

This equation can be used as an alternative to the selection chart.

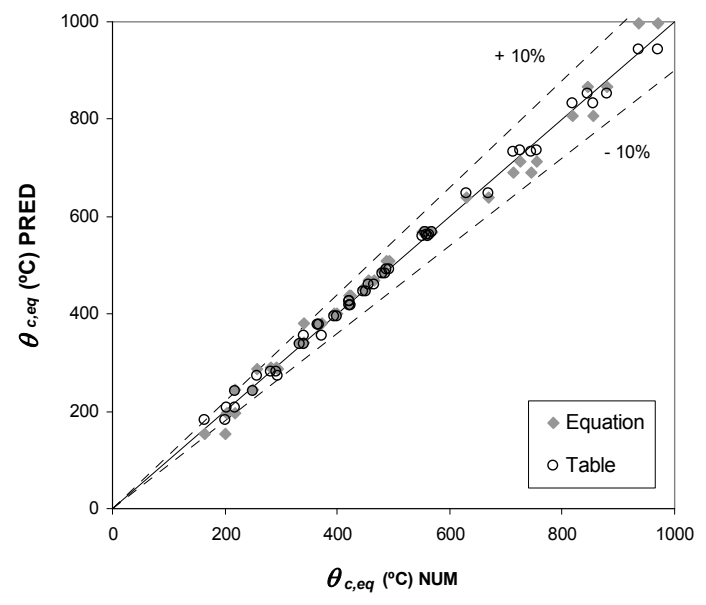

Figure 6.9. Comparison between predicted and simulated equivalent temperatures for the concrete core. 
A comparison can be seen in Figure 6.9 between the equivalent temperatures obtained by means of equation (6.20) or alternatively from Table 6.4 and the temperatures obtained from the numerical simulations. A good agreement is obtained under both proposals, with errors generally lower than a $10 \%$.

\section{Calculation of the equivalent temperature for the steel tube}

In the case of the steel tube, the equivalent temperature corresponding to each of the columns for a standard fire time was obtained directly from the numerical analysis without the need of employing the procedure described for the concrete core, since its temperature remains almost uniform through the wall thickness for each fire period. The evolution of the equivalent temperature of the steel tube with the section factor of the columns is plotted in Figure 6.10.

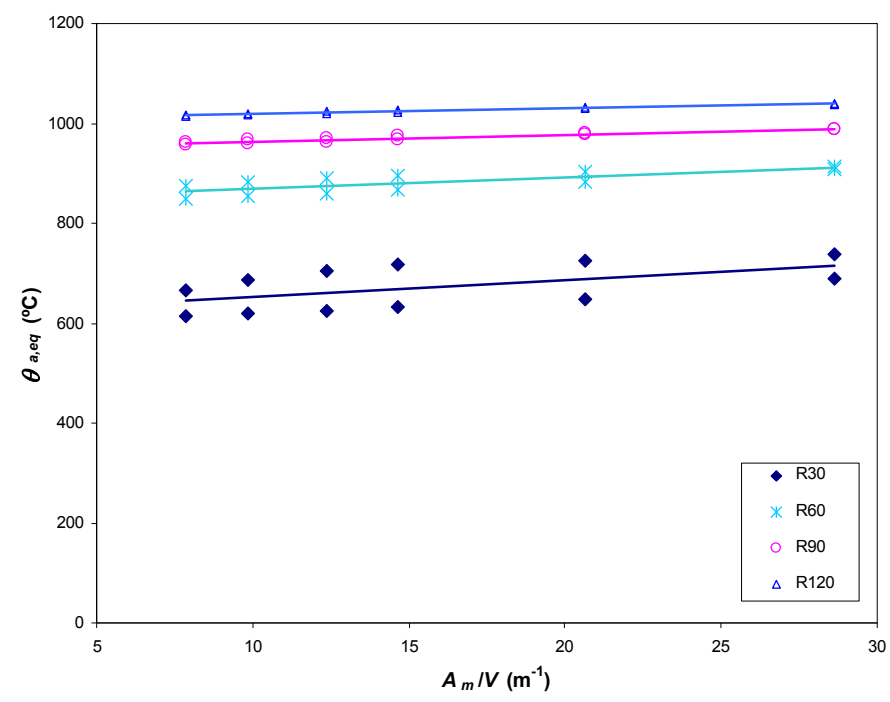

Figure 6.10. Evolution of the equivalent temperature of the steel tube with the section factor, for the standard fire resistance classes.

As can be seen, as the fire exposure time increases, the equivalent temperatures also increase. In the case of the steel tube, the equivalent temperatures are not so affected by the section factor as in the case of the concrete core, remaining almost constant for a certain fire exposure time, with only a slight increase which results less pronounced for the higher fire times. For each section factor and fire period, two points are plotted, corresponding to the two different steel tube wall 
thicknesses analysed. It can be observed that no significant influence is obtained with a change in the steel tube wall thickness, except for the lower fire period (R30).

For each of the standard fire resistance classes studied, a regression curve was fitted to the data, as can be seen in Figure 6.10.

The equivalent temperatures for the steel tube $\left(\theta_{a, e q}\right)$, obtained by means of the regression equations, have been included in Table 6.4 for the different values of the section factor and the four standard fire resistance classes. For intermediate values of the section factor, linear interpolation can be used.

An alternative equation for the equivalent temperature of the steel section was developed by using a multiple nonlinear regression analysis, including the effect of $A_{m} / V$ and $R$ and therefore valid for any fire resistance period:

$$
\theta_{a, e q}=342.1+10.77 R-0.044 R^{2}+3.922 A_{m} / V-0.025 R \cdot A_{m} / V
$$

The temperature obtained through this equation can be used instead of that obtained by means of the selection chart.

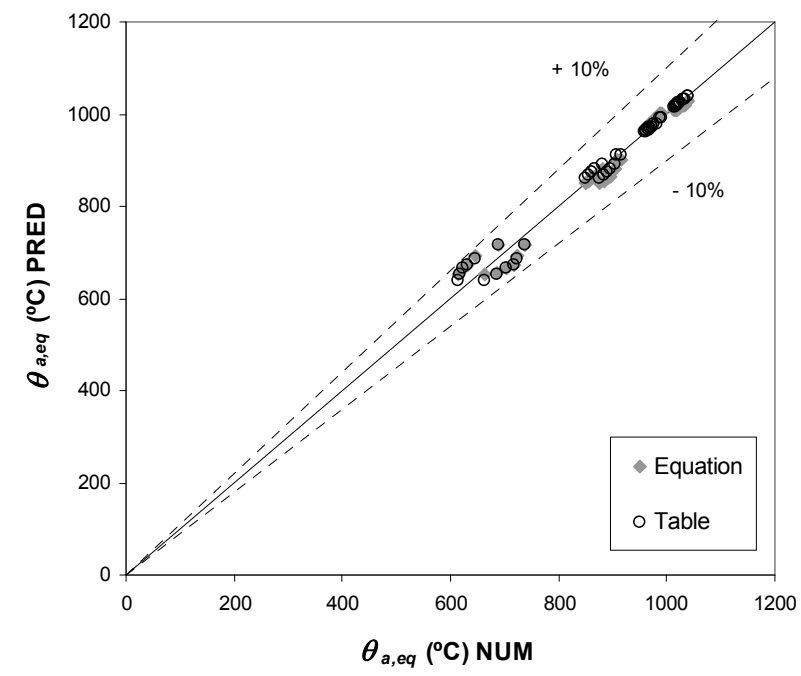

Figure 6.11. Comparison between predicted and simulated equivalent temperatures for the steel tube. 
A comparison can be seen in Figure 6.11 between the equivalent temperatures obtained by means of equation (6.21) or alternatively from Table 6.4 and the temperatures obtained from the numerical simulations. As can be seen, similar results are obtained under the two approaches, with excellent agreement with the simulations.

\subsubsection{Flexural stiffness reduction coefficients}

The applicability of the general principles in Clause 4.3.5.1 of Eurocode 4 Part 1.2 (CEN 2005c) has been studied in Section 6.3.2 by comparing the predictions of the method (with some assumptions regarding the flexural stiffness reduction coefficients) to the results obtained by means of the numerical model. It has been revealed that the predicted buckling loads result in most cases unsafe when the reduction coefficients are assumed to be equal to unity.

Thus, a set of flexural stiffness reduction coefficients different to unity should be applied. Also the buckling curve should be revised as suggested by other authors (Wang 1997, Aribert et al. 2008, Leskela 2009).

Through the results of the parametric studies presented in Section 6.3.1, the values of these coefficients are derived for the standard fire exposure times. The procedure employed to calculate the theoretical values of the coefficients is described next.

In what follows, the value of the concrete flexural stiffness reduction coefficient is taken as $\varphi_{c, \theta}=0.8$ and the initial tangent stiffness is used (calculated as $3 / 2$ times the secant modulus), as the researchers from CTICM proposed (Renaud et al. 2004, Aribert et al. 2008). In fact, the value of 0.8 is already being used in Annex G of EN 1994-1-2 (CEN 2005c) for composite columns with partially encased steel sections. If the secant modulus of concrete is used, as it is specified in Clause 4.3.5.1 of EN 1994-1-2, the coefficient $\varphi_{c, \theta}$ should be taken as 1.2. This value accounts for the effect of the differential thermal stresses produced by the unequal temperature field along the width of the concrete cross-section, which other authors have reported in their research (Bailey 2000, Wang \& Orton 2008, Aribert et al. 2008). The reduction coefficient for the steel tube are then derived from the numerical data and assuming the concrete contribution to be known.

By means of the numerical simulations results, the buckling coefficient corresponding to each column is obtained as the computed buckling resistance divided by the theoretical cross-sectional plastic resistance at the time of failure. 


$$
\chi^{N U M}=\frac{N_{f i, R d}^{N U M}}{N_{f i, p l, R d}}
$$

Once the buckling coefficient $\chi^{N U M}$ is calculated, the relative slenderness of the column at elevated temperature $\bar{\lambda}_{\theta}{ }^{N U M}$ can be obtained from the corresponding buckling curve (here, buckling curve "a" was used, since it showed to produce a better fit to the data). With this value, the elastic critical load in the fire situation can be derived from equation (6.6):

$$
N_{f i, c r}^{N U M}=\frac{N_{f i, p l, R}}{\left(\bar{\lambda}_{\theta}^{N U M}\right)^{2}}
$$

where $N_{f i, p l, R}$ can be calculated with equation (6.3).

Buckling curve "a" was not chosen for the elevated temperature design by chance; in fact this curve was selected as an intend of using the same buckling curve as in the main part of Eurocode 4 for room temperature design (EN 1994-1-1) (CEN 2004b), which employs buckling curve "a" for CFT columns with a percentage of reinforcement under a 3\%. As later on will be demonstrated, this buckling curve provided a better fit to the analysis data. Wang (1997) also defended the use of column buckling curve "a" instead of "c" on his work, proving that more accurate results were obtained when using the elevated temperature material models in the main text of Eurocode 4 Part 1.2 (CEN 2005c).

Using now the definition of the Euler buckling load (equation (6.5)), the numerical value of the effective flexural stiffness of the column in the fire situation can be determined:

$$
(E I)_{f i, e f f}{ }^{N U M}=\frac{N_{f i, c r}{ }^{N U M} \cdot \ell_{\theta}^{2}}{\pi^{2}}=\sum_{j}\left(\varphi_{a, \theta} E_{a, \theta} I_{a, \theta}\right)+\sum_{m}\left(\varphi_{c, \theta} E_{c, \theta} I_{c, \theta}\right)
$$

which is set equal with the summation of the contribution of the different layers.

Through this value and being known $E_{a, \theta} I_{a, \theta}$ for the steel tube layers and $E_{c, \theta} I_{c, \theta}$ for the different layers within the concrete core, the reduction coefficient for steel can be obtained, provided that a fixed value is assigned to the reduction coefficient of concrete, which here was equalled to 0.8 , and considering only one layer in the steel tube wall. 
$\varphi_{a, \theta}=\frac{(E I)_{f i, e f f}^{N U M}-\sum_{m}\left(\varphi_{c, \theta} E_{c, \theta} I_{c, \theta}\right)}{E_{a, \theta} I_{a, \theta}}$

Following this procedure, the numerical value of the steel flexural stiffness reduction coefficient was obtained for each of the columns analysed in the parametric study. Through a statistical study of the values obtained, it became clear that this coefficient is a complex function of the different variables that interact in the problem, such as the member slenderness (through $\bar{\lambda}$ or $\ell_{\theta} / D$ ), cross-sectional slenderness $(D / t)$ and section factor $\left(A_{m} / V\right)$, and cannot be readily transformed into a unique value of the coefficient or a simple analytical expression. Therefore, an equation depending on the different parameters or alternatively a set of tabulated data must be developed.

A correlation analysis was first performed in order to investigate the strength of the dependency between $\varphi_{a, \theta}$ and the independent variables. The results showed that there was a high correlation with the relative slenderness (an therefore with $\left.\ell_{\theta} / D\right)$ and a moderated correlation with $D / t$ and $A_{m} / V$. Nevertheless, no correlation was found with the standard fire exposure time $(R)$, and therefore this variable was not used in the development of the design equation.

\section{Design equation}

On a first instance, the shape of the relationship of $\varphi_{a, \theta}$ with each of the independent variables was studied by means of univariant analysis, and afterwards a more complex equation which used the three independent variables was built up, in the form of a product of three factors:

$$
\varphi_{a, \theta}=\varphi_{a, \theta 1}(D / t) \times \varphi_{a, \theta 2}\left(A_{m} / V\right) \times \varphi_{a, \theta 3}\left(\ell_{\theta} / D\right)
$$

where the first term $\left(\varphi_{a, \theta l}\right)$ represents the influence of the cross-sectional slenderness, the second term $\left(\varphi_{a, \theta 2}\right)$ represents the effect of the section factor (which determines the temperature field pattern within the cross-section) and the third term $\left(\varphi_{a, \theta 3}\right)$ measures the influence of the member slenderness.

Based on the results of the statistical analysis, the following shape of the functions was proposed:

$$
\varphi_{a, \theta}=\varphi_{a, \theta 1}(D / t) \times\left(a_{0}+a_{1} \cdot\left(A_{m} / V\right)^{a_{2}}\right) \times\left(b_{0}+b_{1} \cdot\left(\ell_{\theta} / D\right)^{b_{2}}\right)
$$


The first factor $\varphi_{a, \theta l}$ was found to have only a moderate effect for the stocky columns $\left(\ell_{\theta} / D \leq 12\right)$, whereas for slender columns it did not show an important influence, therefore it was designed as a correction factor which must only be applied to columns with low slenderness.

A multiple nonlinear regression analysis of the numerical data was conducted in order to obtain the coefficients associated with the proposed equation. The corresponding regression equation results:

$$
\begin{aligned}
& \varphi_{a, \theta}=\varphi_{a, \theta 1}(D / t) \times \\
& \times\left(2.747-1.48 \cdot\left(A_{m} / V\right)^{0.08}\right) \times\left(0.0813+0.0133 \cdot\left(\ell_{\theta} / D\right)^{1.097}\right) \leq 1
\end{aligned}
$$

In this equation, the reduction coefficient $\varphi_{a, \theta}$ is a product of two partial reduction coefficients lower than unity, $\varphi_{a, \theta 2}$ and $\varphi_{a, \theta 3}$, which are corrected by the factor $\varphi_{a, \theta l}$ as a function of $D / t$ only for stocky columns $\left(\ell_{\theta} / D \leq 12\right)$, using the values tabulated in Table 6.5. For $\ell_{\theta} / D>12$, the factor $\varphi_{a, \theta 1}$ is equal to unity.

Table 6.5. Values of the partial reduction coefficient for steel $\varphi_{a, \theta 1}$ to include in the design equation for stocky columns $\left(\ell_{\theta} / D \leq 12\right)$

\begin{tabular}{cc}
\hline $\boldsymbol{D} / \boldsymbol{t}$ & $\boldsymbol{\varphi}_{a, \boldsymbol{\theta} \boldsymbol{1}}$ \\
\hline$<15$ & 0.75 \\
$15-35$ & 1 \\
$35-45$ & 1.25 \\
$>45$ & 2.5 \\
\hline
\end{tabular}

For $\ell_{\theta} / D \geq 46$, which corresponds to columns with relative slenderness at room temperature $\bar{\lambda}$ around 2 , the total factor $\varphi_{a, \theta}$ can be taken as equal to unity, which means that the reduction coefficient for the steel tube can be neglected.

Once the reduction coefficients have been calculated through the proposed equation, the general principles in Clause 4.3.5.1 of EN 1994-1-2 (CEN 2005c) can be followed, with the only particularity of using buckling curve "a" instead of "c".

The design equation presented here was applied to all the data available from the parametric studies in order to obtain the predicted values of the buckling resistance, and for each case specimen the error was measured with the expression in (6.14), obtaining an average value of the error equal to 1.09 (safe) and a standard deviation of 0.11 . 
Figure 6.12a shows a comparison between the predictions and the numerical simulations in terms of normalised buckling load (divided by the theoretical plastic resistance) and Figure $6.12 \mathrm{~b}$ plots the errors of the predictions against the relative slenderness of the columns at room temperature, for the proposed method using the design equation (6.28) and buckling curve "a".

a)

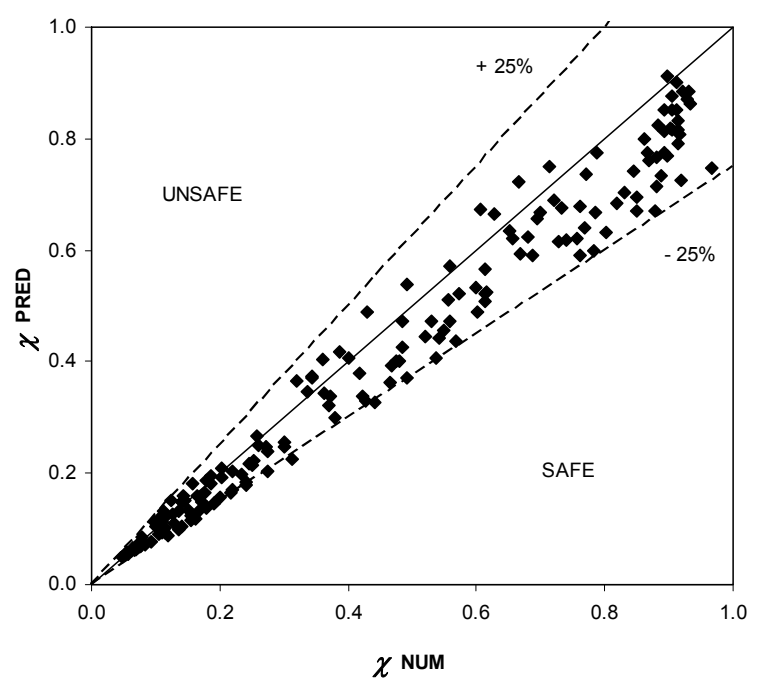

b)

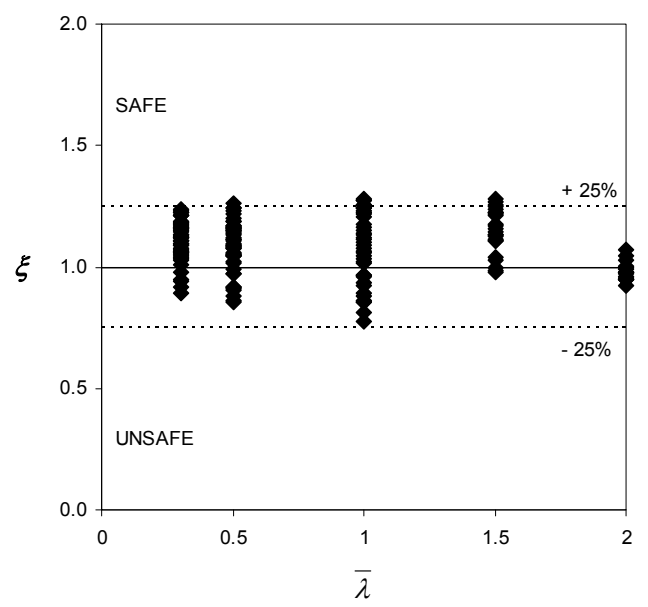

Figure 6.12. Comparison between the proposed method (design equation) and numerical simulations: a) Normalised buckling load, b) Relative error. 
As can be seen, there is a good agreement between the predicted and reference values, with a maximum relative error of a $25 \%$ (only exceeded in a few number of cases which lay on the safe side) and a reasonably uniform distribution of the prediction errors for all the range of relative slenderness studied. Figure 6.13 presents the evolution of the buckling coefficient with the relative slenderness at elevated temperature.

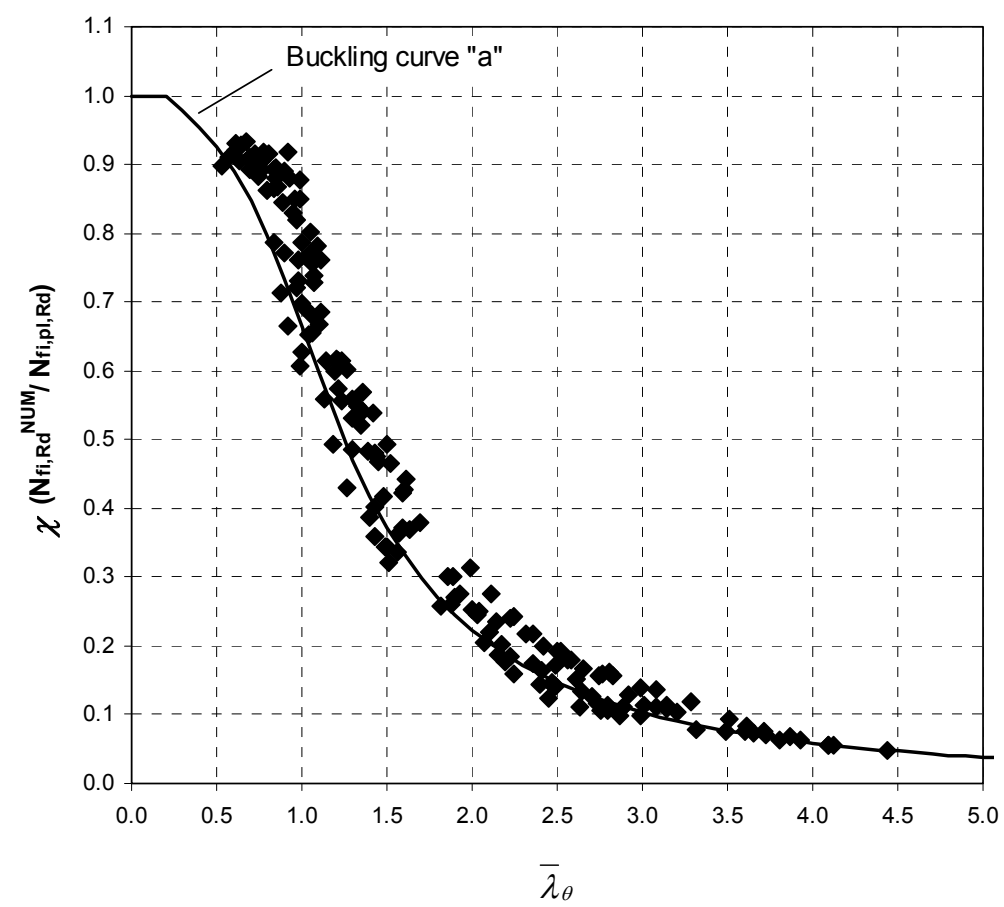

Figure 6.13. Evolution of the buckling coefficient with the relative slenderness at elevated temperature, calculated with the proposed method (design equation).

Using the coefficients obtained by means of the design equation (6.28), the data follow closely the reference buckling curve "a", as can be seen in Figure 6.13, with an excellent agreement for the higher slenderness and a moderated dispersion for intermediate slenderness but still following the shape of the normalised buckling curve and remaining on the safe side for short columns. 
The frequency histogram plotted in Figure 6.14 shows that the prediction errors follow the shape of a normal distribution, with the mean value located on the safe side (where the most repeated values can be found) and a narrow dispersion.

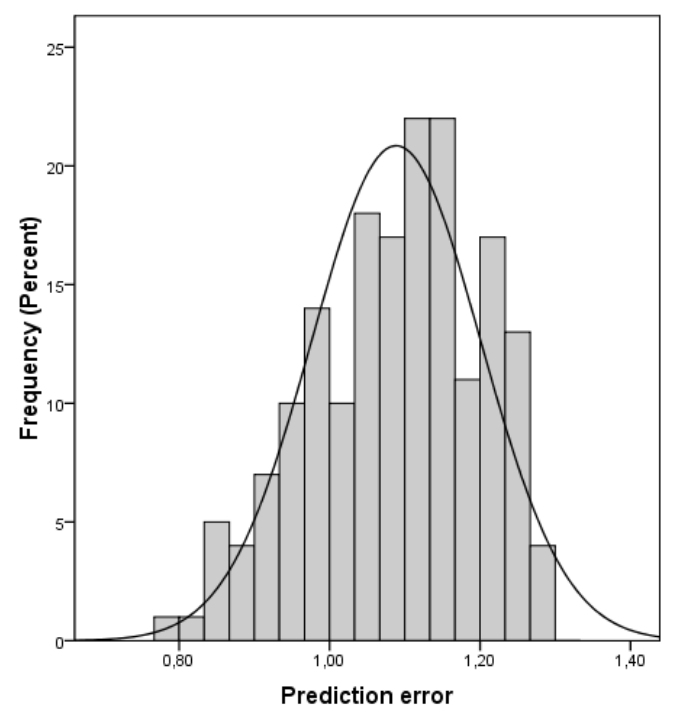

Figure 6.14. Frequency histogram for the prediction error obtained with the proposed method (design equation).

\section{Tabulated data}

A more simplistic proposal was also developed, in the form of a selection table where the values of the reduction coefficient $\varphi_{a, \theta}$ can be obtained as a function of the section factor $A_{m} / V$ and the elevated temperature slenderness, measured as $\ell_{\theta} / D$. The values of the reduction coefficient for the steel tube for different combinations of the two parameters can be found in Table 6.6. For intermediate values of $\ell_{\theta} / D$, linear interpolation may be used. To account for the effect of the cross-sectional slenderness of the steel tube, the resulting coefficient must be corrected by the factor $\varphi_{a, \theta l}$ as a function of $D / t$ if $\ell_{\theta} / D \leq 12$, using the values given in Table 6.5. Again, for higher values of $\ell_{\theta} / D$, no correction is needed. 
Table 6.6. Values of the reduction coefficient for steel $\varphi_{a, \theta}$ (tabulated method)

$$
\begin{array}{|c|c|cccc|}
\cline { 3 - 6 } \multicolumn{2}{c|}{} & \multicolumn{4}{c|}{\boldsymbol{A}_{\boldsymbol{m}} / \boldsymbol{V}\left(\mathbf{m}^{-\mathbf{1}}\right)} \\
\cline { 3 - 6 } \ell_{\theta} / D & <\mathbf{1 0} & \mathbf{1 0}-\mathbf{1 5} & \mathbf{1 5}-\mathbf{2 0} & \geq \mathbf{2 0} \\
\hline \multirow{4}{*}{} & \leq \mathbf{1 2} & 0.4 & 0.35 & 0.3 & 0.25 \\
& \mathbf{2 4} & - & 0.5 & 0.5 & 0.4 \\
& \mathbf{3 6} & - & - & 0.7 & 0.7 \\
& \geq \mathbf{4 6} & - & - & - & 1 \\
\hline
\end{array}
$$

The reduction coefficient of concrete $\varphi_{c, \theta}$ must be taken as a constant value equal to 0.8 and used with the tangent modulus. With these values, the general principles in Clause 4.3.5.1 of EN 1994-1-2 (CEN 2005c) can be followed, using buckling curve "a" as mentioned before. With the tabulated method, a mean error equal to 1.04 with a standard deviation of 0.11 was obtained.

In the case of using the tabulated method, the following curves are obtained. In Figure 6.15a, a comparison is shown between the predictions and the numerical simulations in terms of normalised buckling load. Figure $6.15 \mathrm{~b}$ plots the errors of the predictions against the relative slenderness of the columns at room temperature, using the proposed coefficients in Table 6.6 and buckling curve "a".

Again, good agreement is obtained between the predicted and reference values, with a maximum relative error of a $25 \%$ and a reasonably uniform distribution of the prediction errors for all the range of relative slenderness studied. It can be seen that the trend of the predictions is less conservative than that obtained with the design equation, but still leading to safe results in average (1.04 versus 1.09 comparing the mean error). 
a)

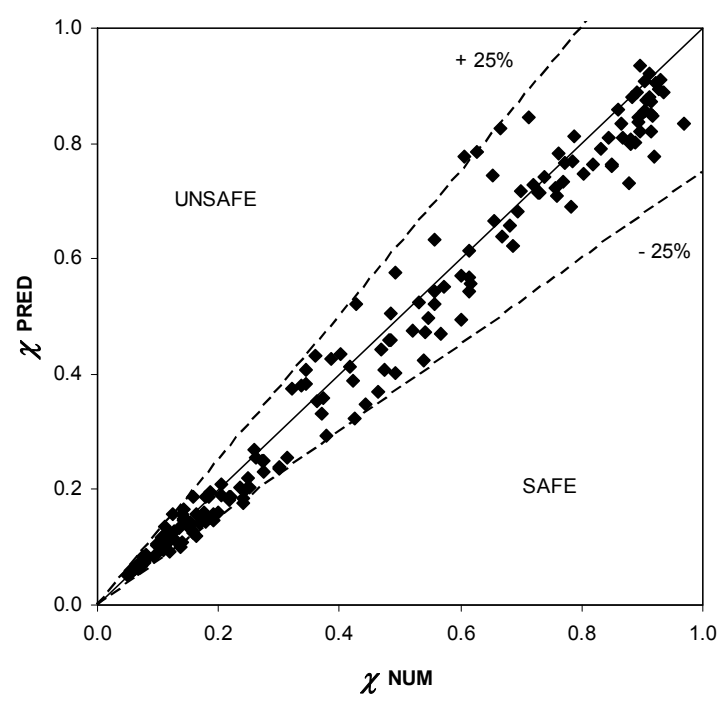

b)

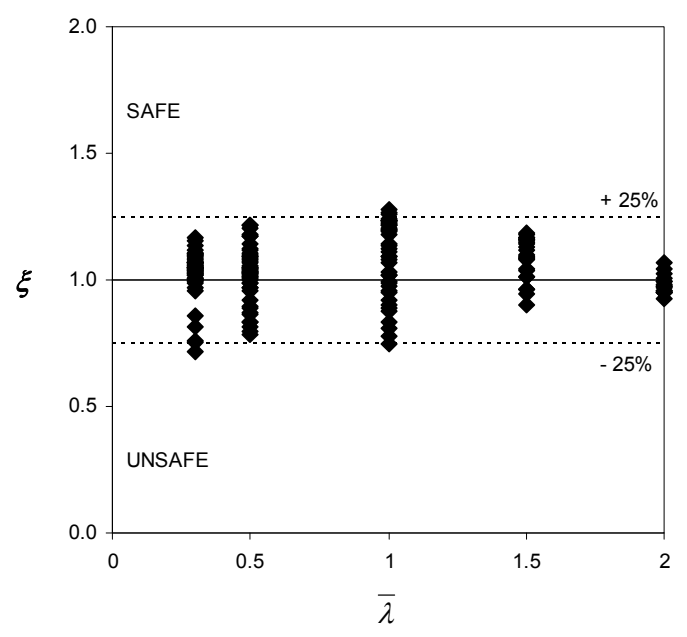

Figure 6.15. Comparison between the proposed method (tabulated data) and numerical simulations: a) Normalised buckling load, b) Relative error.

Figure 6.16 presents the evolution of the buckling coefficient with the relative slenderness at elevated temperature. Using the proposed coefficients in Table 6.6, the data match the reference buckling curve "a", with an excellent agreement for the higher slenderness and a moderated dispersion for intermediate slenderness. 


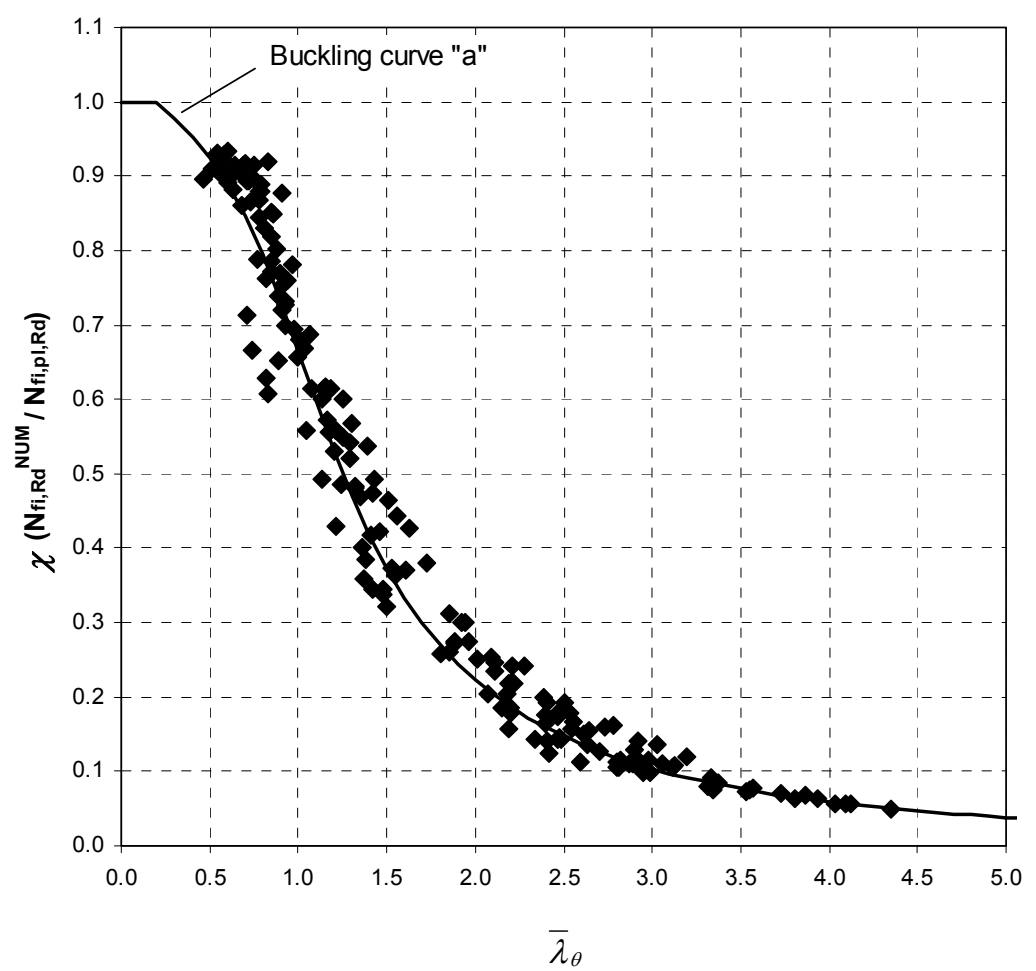

Figure 6.16. Evolution of the buckling coefficient with the relative slenderness at elevated temperature, calculated with the proposed method (tabulated data).

From the frequency histogram plotted in Figure 6.17, it can be seen that the prediction errors obtained with the tabulated method follow the shape of a normal distribution, with the mean value located on the safe side, although in this case closer to unity as compared to the results obtained with the design equation (see Figure 6.14). 


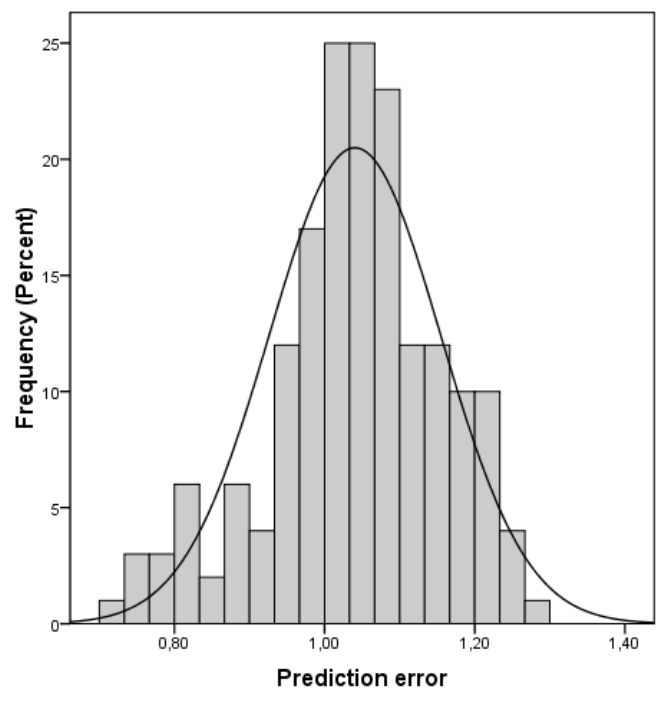

Figure 6.17. Frequency histogram for the prediction error obtained with the proposed method (tabulated data).

It is worth noting that the resulting flexural stiffness reduction coefficients are much lower for steel than for concrete, which means that the flexural stiffness of the steel tube is more highly affected than that of the concrete core in the fire situation. The explanation to the low values of the steel reduction coefficient is that it incorporates the effect of the overload of the steel tube during the early stages of the fire exposure. To the author's point of view, more than representing the possible effect of the thermal stresses, in the case of steel, this coefficient acts as a reduction factor to account for this overload, which is generally not taken into account and reduces significantly the fire resistance of the column. How this overload affects the fire performance of the column is a complex combination of different factors such as the member slenderness, the cross-sectional dimensions and the fire exposure time, which are included in the proposed equations. Nevertheless, in the case of concrete, the reduction coefficient represents the effect of the differential thermal stresses developed as a result of the non-uniform temperature distribution within the concrete core, which other authors have explained before (Bailey 2000, Wang \& Orton 2008, Aribert et al. 2008). 
The proposed calculation method can only be applied in the following conditions:

- Buckling length in the fire situation: $\ell_{\theta} / D<50$ and $\ell_{\theta}<10 \mathrm{~m} *$

- Diameter of the cross-section: $139.7 \mathrm{~mm} \leq D \leq 508 \mathrm{~mm}$

- Normal strength concrete: C20/25 - C40/50

- Standard fire resistance: $R \leq 120 \mathrm{~min}$

* Note that a buckling length equal to 10 meters in the fire situation corresponds to a column with a real length equal to 20 meters placed on an intermediate storey, according to Clause 4.3.5.1(10) in EN 1994-1-2 (CEN 2005c), which assumes $\ell_{\theta}=0.5 \mathrm{~L}$ for this situation.

\subsubsection{Comparison of the proposed method with experiments}

The proposed method is compared in this section with real fire tests carried out in the laboratories of AIDICO (Valencia, Spain) (Romero et al. 2011) and also against the tests available in the literature from the experimental program conducted at the Institute for Research in Construction, NRCC (Lie \& Chabot 1992).

From both sources, only those column specimens within the range of application of the method were selected, i.e. columns of circular cross-section, filled with plain (unreinforced) normal strength concrete (C20-C40) and centrally loaded. Figure 6.18 compares the results of all the tests against the predictions of the method, in terms of the failure load. For the Canadian tests, the equivalent temperatures of steel and concrete were obtained for the failure time reported at the tests from the proposed equations in Section 6.3.3 and afterwards the method in Section 6.3.4 was applied using the calculated temperatures. It can be seen in Figure 6.18 that the accuracy of the method was reasonable given the uncertainties that one can find when using data from external tests, and in general the predictions were conservative. 


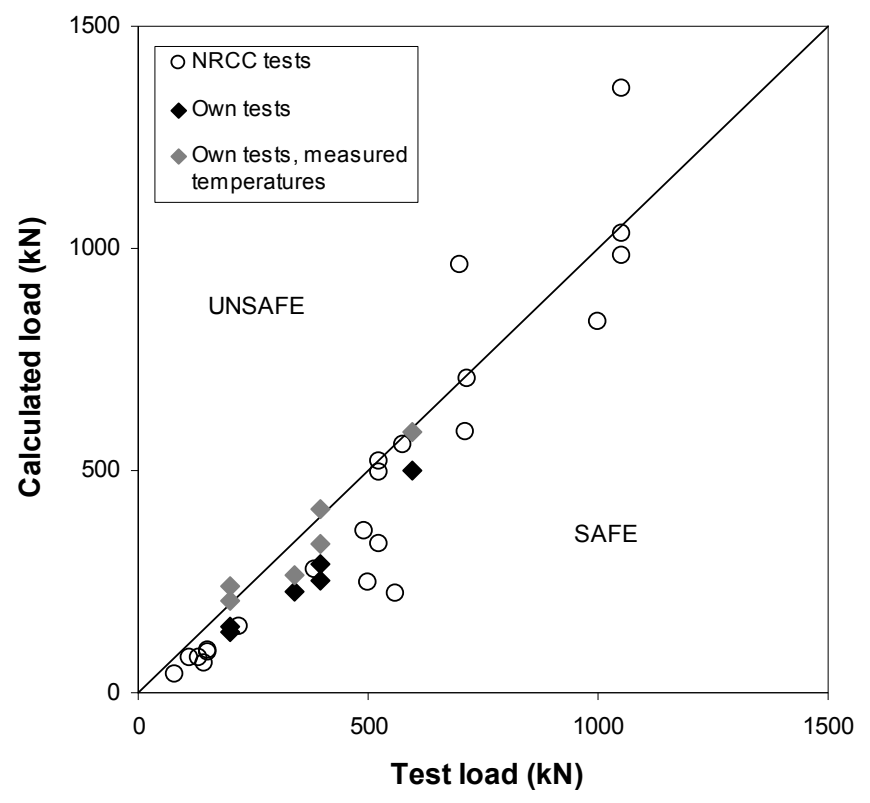

Figure 6.18. Comparison of ultimate loads between the proposed method and tests.

For comparing with the tests from Valencia, two options were considered: using the calculated equivalent temperatures for steel and concrete and using the real temperatures measured at the tests. As can be observed in Figure 6.18, a better approximation was obviously obtained under the second option, since the real temperatures were employed; in any case using the equivalent temperatures produced safe results for all the specimens compared, which confirms that the method described in Section 6.3.3 for obtaining the simplified cross-sectional temperature field can be safely applied in combination with the general principles in Clause 4.3.5.1 of EN 1994-1-2 (CEN 2005c), with the flexural stiffness reduction coefficients calculated as described in Section 6.3.4 and the use of buckling curve "a".

Figure 6.19 compares the results of the proposed method with the values of the predictions obtained by means of other three methods which are being used worldwide and which were previously described in Section 6.1: the design equation proposed by Kodur (1999) (used in North America), the strength index formulation proposed by Han et al. (2003a) (used in China) and the method from ANUHT 
(2004) (used in Japan). As can be seen, the proposed method results generally safer than the rest of the methods. A wide dispersion of results is found under all the methods when comparing with real fire tests, being higher for the formulations from Han and Kodur, while the Japanese method seems to provide a narrower dispersion and more accurate predictions. Compared to the rest of the methods, it can be concluded that the proposed method provides a reasonable accuracy in the predictions and tends to be on the safe side.

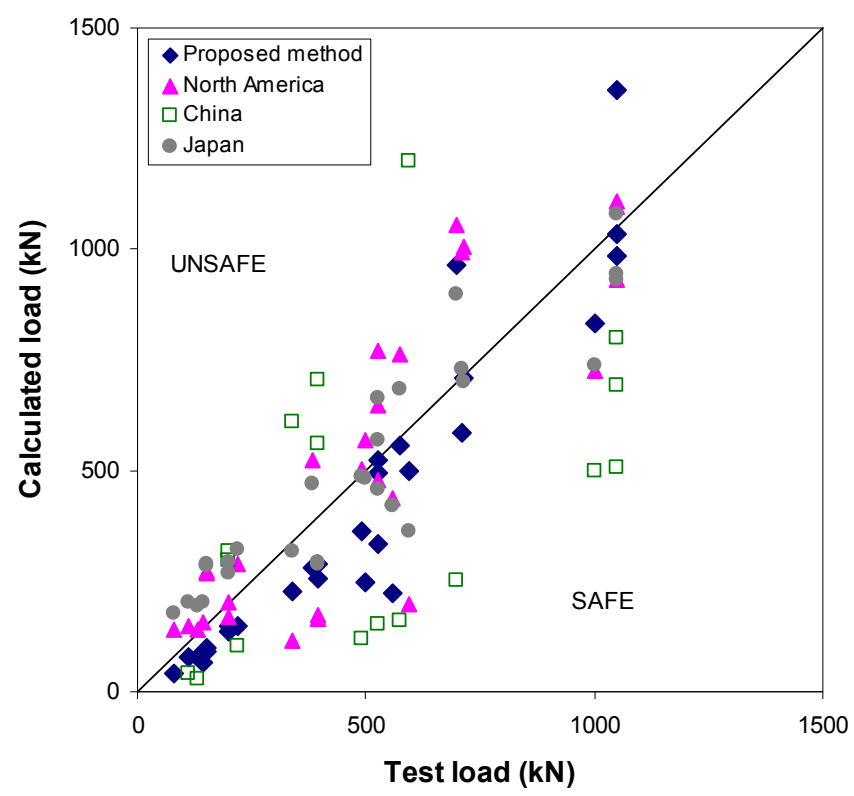

Figure 6.19. Comparison of ultimate loads between the proposed method, other methods and tests.

\subsubsection{Design example}

The following design example illustrates the application of the proposed simple calculation model for obtaining the buckling resistance of an axially loaded CFT column for a specified standard fire period.

Consider that the designer wants to calculate the maximum axial load that a column placed on the top floor of a building can sustain during a period of 60 minutes of fire exposure. The column has the following characteristics: 
- Column length: $L=3000 \mathrm{~mm}$

- Cross-sectional dimensions: $D \times t=159 \times 6 \mathrm{~mm}$

- Steel yield strength: $f_{y}=355 \mathrm{MPa}$

- Compressive strength of concrete: $f_{c}=30 \mathrm{MPa}$

First, the following parameters must be calculated:

- Section factor of the column: $A_{m} / V=4 / D=4 / 159 \times 1000=25.16 \mathrm{~m}^{-1}$

- Member slenderness in the fire situation: $\ell_{\theta} / D=(0.7 * \times 3000) / 159=13.21$

- Cross-sectional slenderness: $D / t=159 / 6=26.5$

*According to Clause 4.3.5.1(10) of EN 1994-1-2 (CEN 2005c), for a column on the top floor of a building, the buckling length in the fire situation is calculated as 0.7 times the column length.

Note that the column in this example is being verified for axial loading conditions, which requires that the loads transferred to the column are balanced and do not introduce any bending effects at the top of the column.

On a first stage, the equivalent temperatures for the steel tube and concrete core must be obtained, by means of the proposed equations, or alternatively using the values in Table 6.4 .

For the section factor of the column and the required standard fire period R60, the proposed equations (6.20) and (6.21) produce the following values, for the concrete core:

$\theta_{c, e q}=-186.44+5.764 \times 60-0.026 \times 60^{2}+22.577 \times 25.16-0.32 \times 25.16^{2}+$ $+0.14 \times 60 \times 25.16=642.61^{\circ} \mathrm{C}$

and for the steel tube:

$\theta_{a, e q}=342.1+10.77 \times 60-0.044 \times 60^{2}+3.922 \times 25.16-0.025 \times 60 \times 25.16=$ $=890.84^{\circ} \mathrm{C}$

Alternatively, linear interpolation can be used in Table 6.4, obtaining 650.74 ${ }^{\circ} \mathrm{C}$ for the concrete core and $903.35^{\circ} \mathrm{C}$ for the steel tube. The temperatures obtained through the equations are used in this case.

Once the equivalent temperatures of steel and concrete are known for the specified fire period, the design values of the cross-sectional plastic resistance and 
effective flexural stiffness of the column can be calculated, following the rules in Clause 4.3.5.1 of EN 1994-1-2 (CEN 2005c) and considering only one layer for the steel tube and concrete core:

$$
\begin{aligned}
& N_{f i, p l, R d}=A_{a} f_{a y}\left(\theta_{a, e q}\right)+A_{c} f_{c}\left(\theta_{c, e q}\right)= \\
& =2883.98 \mathrm{~mm}^{2} \times k_{y}(890.84) \times 355 \mathrm{MPa}+16971.67 \mathrm{~mm}^{2} \times k_{c}(642.61) \times 30 \mathrm{MPa}= \\
& =2883.98 \times 0.0646 \times 355+16971.67 \times 0.3861 \times 30=262721.17 \mathrm{~N}=262.72 \mathrm{kN}
\end{aligned}
$$

The partial factors for the materials in the fire situation, $\gamma_{M, f i, i}$ have been taken as unity, as established in Clause 2.3 of EN 1994-1-2 (CEN 2005c).

Prior to obtaining the effective flexural stiffness, the values of the reduction coefficients $\varphi_{a, \theta}$ and $\varphi_{c, \theta}$ must be determined. The reduction coefficient of the concrete core is equal to 0.8 , and the reduction coefficient for the steel tube can be obtained from equation (6.28), resulting:

$$
\begin{aligned}
& \varphi_{a, \theta}=\varphi_{a, \theta 1} \times \varphi_{a, \theta 2} \times \varphi_{a, \theta 3}= \\
& =1 \times\left(2.747-1.48 \cdot 25.16^{0.08}\right) \times\left(0.0813+0.0133 .13 .21^{1.097}\right)=1 \times 0.83 \times 0.31=0.26
\end{aligned}
$$

Note that in this case the correction factor depending on the cross-sectional slenderness $\varphi_{a, \theta l}$ is not needed, since $\ell_{\theta} / D>12$, therefore it is equal to unity.

The reduction coefficient for the steel tube can also be obtained from Table 6.6 , where a value of 0.27 is found by using linear interpolation.

The effective flexural stiffness of the column after 60 minutes of fire exposure is:

$$
\begin{aligned}
& (E I)_{f i, e f f}=\varphi_{a, \theta} E_{a}\left(\theta_{a, e q}\right) I_{a}+\varphi_{c, \theta} E_{c}\left(\theta_{c, e q}\right) I_{c}= \\
& =0.26 \times 210000 \mathrm{MPa} \times k_{E}(890.84) \times 8451869.91 \mathrm{~mm}^{4}+ \\
& +0.8 \times 3 / 2 \times k_{c}(642.61) \times 30 \mathrm{MPa} / \varepsilon_{c u}(642.61) \times 22921299.6 \mathrm{~mm}^{4}= \\
& =0.26 \times 210000 \times 0.0696 \times 8451869.91+0.8 \times 3 / 2 \times 0.3861 \times 30 / 0.025 \times 22921299.6= \\
& =44862.33 \cdot 10^{6} \mathrm{~N} \cdot \mathrm{mm}^{2}
\end{aligned}
$$

Now, the Euler buckling load in the fire situation can be calculated as: 


$$
\begin{aligned}
& N_{f i, c r}=\pi^{2}(E I)_{f i, e f f} / \ell_{\theta}^{2}=\pi^{2} \times 44862.33 \cdot 10^{6} /(0.7 \times 3000)^{2}=100401.98 \mathrm{~N}= \\
& =100.4 \mathrm{kN}
\end{aligned}
$$

and the relative slenderness of the column at elevated temperature therefore results:

$$
\bar{\lambda}_{\theta}=\sqrt{N_{f i, p l, R} / N_{f i, c r}}=\sqrt{262.72 / 100.4}=1.62
$$

This value of the relative slenderness is used to enter to the buckling curve "a", from where the reduction coefficient needed for determining the buckling load is obtained, which in this case is $\chi=0.32$.

Finally, the design value of the resistance of the column to axial compression after a period of 60 minutes results:

$$
N_{f i, R d}=\chi N_{f i, p l, R d}=0.32 \times 262.72 \mathrm{kN}=84.07 \mathrm{kN}
$$

\subsection{EXTENSION OF THE METHOD TO REINFORCED COLUMNS}

\subsubsection{Parametric studies}

For columns with reinforcement, equivalent parametric studies to those previously presented in Section 6.3.1 were performed, using the same parameters: outer diameter of the column $(D)$, thickness of the steel tube wall $(t)$, relative slenderness of the column at room temperature $(\bar{\lambda})$ and standard fire period $(R)$. Additionally, two different values of the percentage of reinforcement $(\rho)$ were used: $2.5 \%$ and $5 \%$, with a constant value of the concrete cover $u_{s}=30 \mathrm{~mm}$. This choice places on the safe side, since higher values of the concrete cover have a favourable effect on the fire behaviour of the columns (Renaud et al. 2004). The percentage of reinforcement (or reinforcement ratio) is defined as $\rho=A_{s} /\left(A_{c}+A_{s}\right)$, with $A_{s}$ the total cross-sectional area of the reinforcing bars and $A_{c}$ the cross-sectional area of concrete, excluding the space taken by the reinforcing bars. The concrete cover $u_{s}$ is measured as the minimum distance between the axis of the longitudinal reinforcements and the internal surface of the steel tube.

For the concrete infill, a compressive strength of $30 \mathrm{MPa}$ was assumed. For the structural steel, a yield strength of $355 \mathrm{MPa}$ was used, while for the reinforcing steel, a yield strength equal to $500 \mathrm{MPa}$ was considered. 
Six different circular section sizes of commercially available dimensions were employed: 139.7, 193.7, 273, 323.9, 406.4 and $508 \mathrm{~mm}$. For each diameter, two steel tube wall thicknesses were selected. For each cross-section, different column lengths were used, corresponding to different slenderness values at room temperature. The combinations of diameters and member slenderness were as follows: $D=139.7 \mathrm{~mm}(\bar{\lambda}=0.3,0.5,1,1.5,2) ; D=193.7 \mathrm{~mm}(\bar{\lambda}=0.3,0.5,1$, $1.5,2) ; D=273 \mathrm{~mm}(\bar{\lambda}=0.3,0.5,1,1.5) ; D=323.9 \mathrm{~mm}(\bar{\lambda}=0.3,0.5,1) ; D=$ $406.4 \mathrm{~mm}(\bar{\lambda}=0.3,0.5,1) ; 508 \mathrm{~mm}(\bar{\lambda}=0.3,0.5)$. For each column, four different standard fire resistance periods were considered: $30,60,90$ and 120 minutes. In total, the number of specimens analysed in this parametric study considering the two different reinforcement ratios was 352. A summary of the cases analysed in this parametric study is shown in Table 6.7.

Table 6.7. Summary of the analysis cases in the parametric studies, reinforced columns

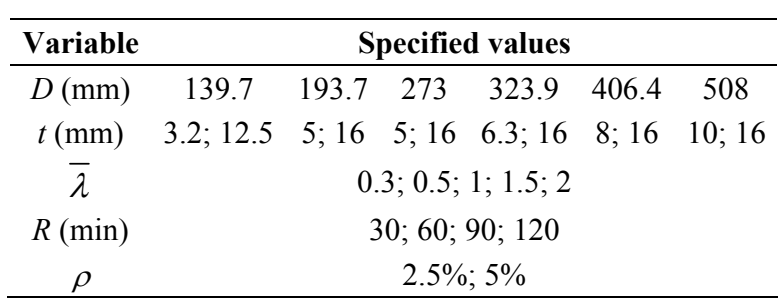

The process followed for obtaining the buckling resistance of the columns at the different standard fire periods was as described in Section 6.3.1, where for the case of the reinforced specimens, a total number of about 1000 simulations were needed for extracting the exact values of the buckling loads corresponding to the standard fire periods studied.

\subsubsection{Analysis of results}

From the results of this new series of simulations for reinforced columns, the numerical buckling coefficient was computed. It was defined as the column axial buckling resistance obtained from the numerical simulation divided by the design value of the cross-sectional plastic resistance, both in the fire situation: $\chi^{\text {NUM }}$ $=N_{f i, R d}{ }^{N U M} / N_{f, p l, R d}$. This value is plotted in Figure 6.20 against the relative slenderness of the columns at elevated temperature $\bar{\lambda}_{\theta}$, calculated as described in Section 6.1.2 and using flexural stiffness reduction coefficients equal to unity. This was done for the two different values of the percentage of reinforcement. The results for unreinforced columns have been also included in Figure 6.20, and buckling 
curve "c" has been superimposed for comparison purposes. Similar results to those obtained for unreinforced columns were found, with a similar trend in the three series of results, although it is important to note that lower values of the buckling coefficient are obtained as the reinforcement ratio increases. Therefore, for higher values of the percentage of reinforcement, the results are more deviated from the reference buckling curve and thus leading to more unsafe results. This suggests that the buckling curve should be revised for reinforced CFT columns, as a function of the percentage of reinforcement.

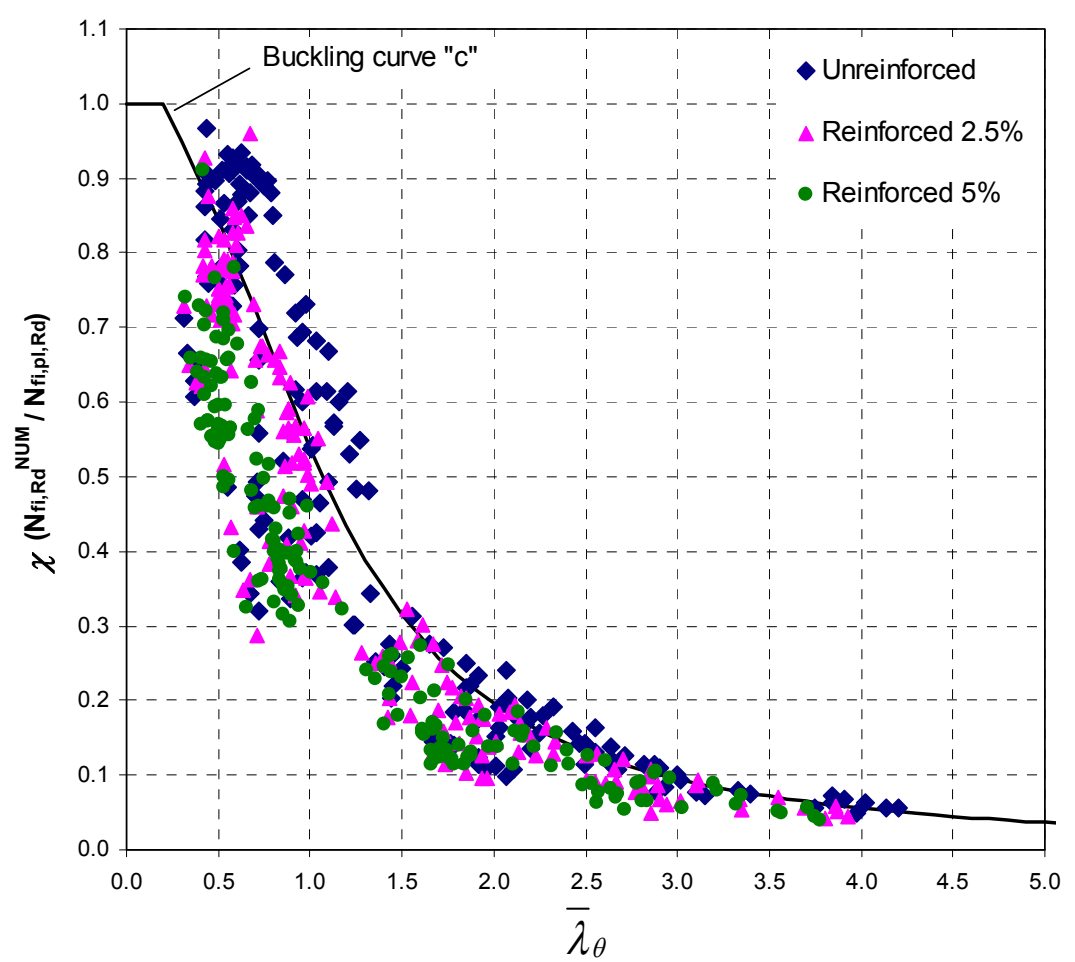

Figure 6.20. Evolution of the buckling coefficient with the relative slenderness at elevated temperature, for different reinforcement ratios.

\subsubsection{Study and discussion of Eurocode 4 Part 1.2}

As was done in Section 6.3.2, based on the results of the parametric studies presented above, a comparison is done in this section between the current calculation methods available in the Eurocode 4 Part 1.2 (CEN 2005c) for reinforced 
CFT columns. Four different approaches are studied (see Sections 6.1.1 - 6.1.3): Clause 4.3.5.1 with flexural stiffness reduction coefficients equal to unity (EC4(1)), Clause 4.3.5.1 with the reduction coefficients proposed by Aribert et al. (2008) (EC4(2)), Annex H (EC4(H)), and French National Annex (EC4(NF)).

Figure 6.21 shows a comparison between the predictions and the numerical simulations in terms of normalised buckling load (divided by the theoretical crosssectional plastic resistance).

a)

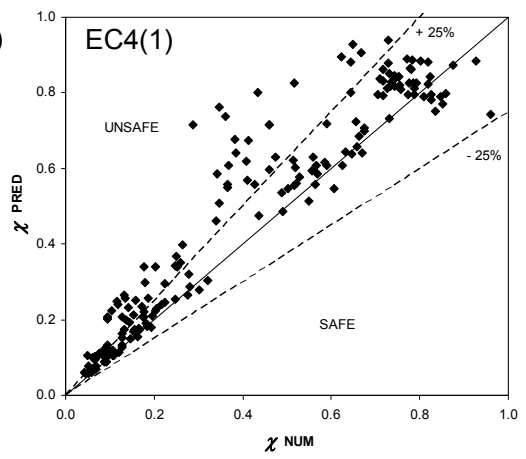

c)

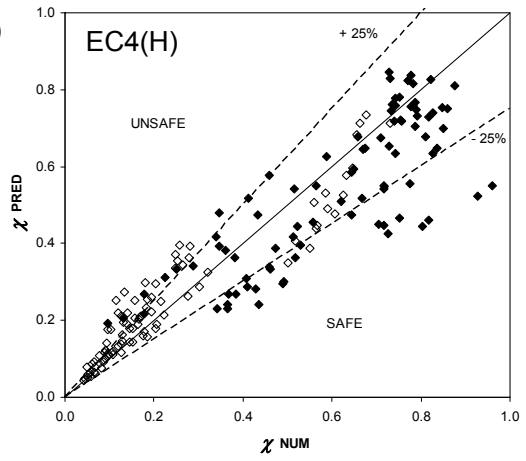

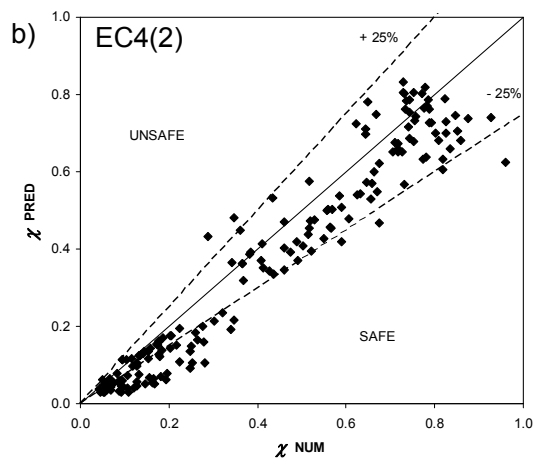

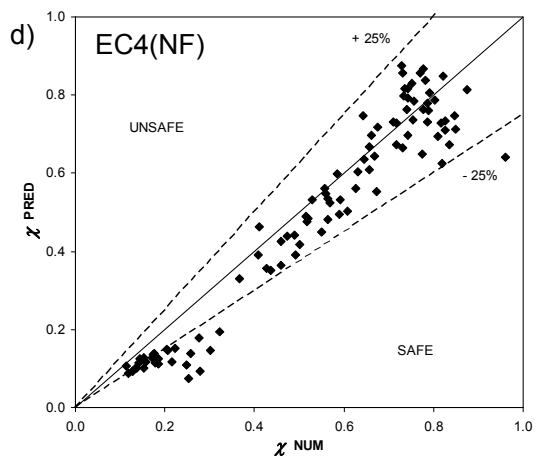

Figure 6.21. Comparison between the different approaches studied in terms of the normalised buckling resistance: a) EC4(1), b) EC4(2), c) EC4(H), d) EC4(NF). Reinforced columns with $2.5 \%$ reinforcement ratio.

Figure 6.22 plots the relative error of the predictions $\xi$ against the relative slenderness of the columns at room temperature, for each of the design approaches studied. The relative error was computed as in Section 6.3.2, with values greater than 1 meaning safe predictions and values lower than 1 meaning unsafe predictions. 
a)

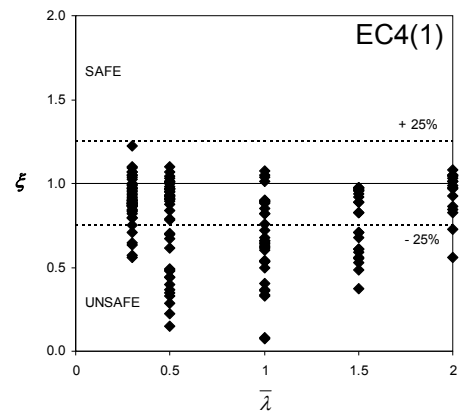

c)

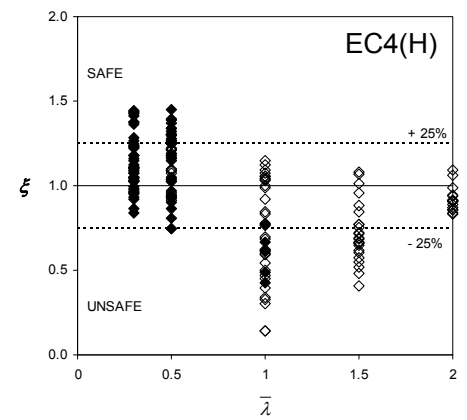

b)

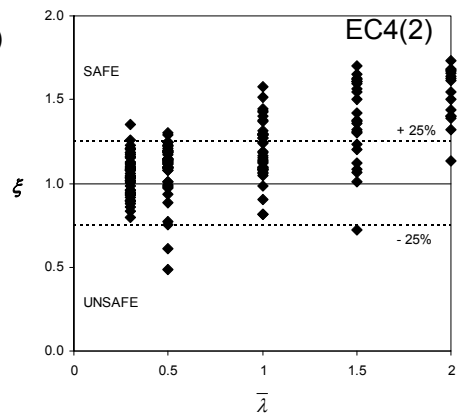

d)

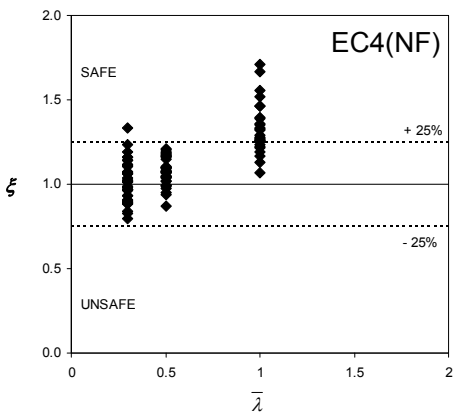

Figure 6.22. Evolution of the prediction errors with the relative slenderness of the columns, for the different approaches studied: a) EC4(1), b) EC4(2), c) EC4(H), d) EC4(NF). Reinforced columns with $2.5 \%$ reinforcement ratio.

As can be seen in Figure 6.21a and Figure 6.22a, EC4(1) yields unsafe results with a high dispersion of values for all the range of slenderness studied. Therefore, the flexural stiffness reduction coefficients cannot be neglected when applying Clause 4.3.5.1 to reinforced CFT columns. Nevertheless, when the French coefficients are used in combination with Clause 4.3.5.1, Figure 6.21b and Figure $6.22 \mathrm{~b}(\mathrm{EC} 4(2))$, safe results are generally obtained, but with high errors and an elevated dispersion of results. As the slenderness is increased, the predictions become safer but the errors produced by this method are higher. Annex $\mathrm{H}$ predictions $(\mathrm{EC} 4(\mathrm{H}))$ turn from safe at low slenderness $(\bar{\lambda}=0.3)$ to unsafe for intermediate slenderness $(\bar{\lambda}=0.5-1.5)$ and close to the reference value again at $\bar{\lambda}$ $=2$, Figure 6.21c and Figure 6.22c. This effect was also observed for unreinforced columns, and confirms the findings from the CTICM group (Renaud et al. 2004, Aribert et al. 2008). Note that in these two figures, those cases which are out of the applicability limits of Annex $\mathrm{H}\left(\ell_{\theta}>4.5 \mathrm{~m}\right)$ have been plotted with an empty mark. Finally, EC4(NF) produces safe results for most of the cases analysed, but with a 
high error for slender columns Figure 6.21d and Figure 6.22d. Compared with the results obtained for unreinforced columns (see Section 6.3.2), it was observed that for reinforced columns, all the methods produced a higher dispersion in the predictions and, in general, less conservative results were obtained.

\subsubsection{Simplified cross-sectional temperature field}

The temperature field of a CFT column with reinforcement is almost equal to that of an unreinforced column of the same cross-section. The presence of the reinforcing bars does not modify significantly the development of temperatures within the cross-section, therefore the equivalent temperatures of the steel tube and concrete core can be considered equal to the corresponding temperatures of the unreinforced columns, for which a proposal was given in Section 6.3.3.

In the case of the reinforcing bars, the equivalent temperatures corresponding to the different cross-sectional dimensions and standard fire periods can be obtained directly from the numerical results of the parametric studies presented in Section 6.4.1. Although only one value of the concrete cover was studied $\left(u_{s}=30 \mathrm{~mm}\right)$, it is known that higher values of the concrete cover would reduce the temperature of the reinforcing bars, and therefore the proposed temperatures are on the safe side.

The evolution of the equivalent temperature of the reinforcing bars with the section factor of the columns is plotted in Figure 6.23. As can be seen, as the fire exposure time increases, the equivalent temperature of the reinforcing bars becomes higher. An increase in the temperature was also found with the section factor. For each section factor and fire period, two points are plotted, corresponding to the two different steel tube wall thicknesses analysed for each cross-section. It can be observed that no significant influence is obtained with a change in the steel tube wall thickness, except for the lower fire period (R30), where higher temperatures were found for the sections with a lower steel tube wall thickness, since the reinforcing bars were located at a shorter distance from the exposed surface. 


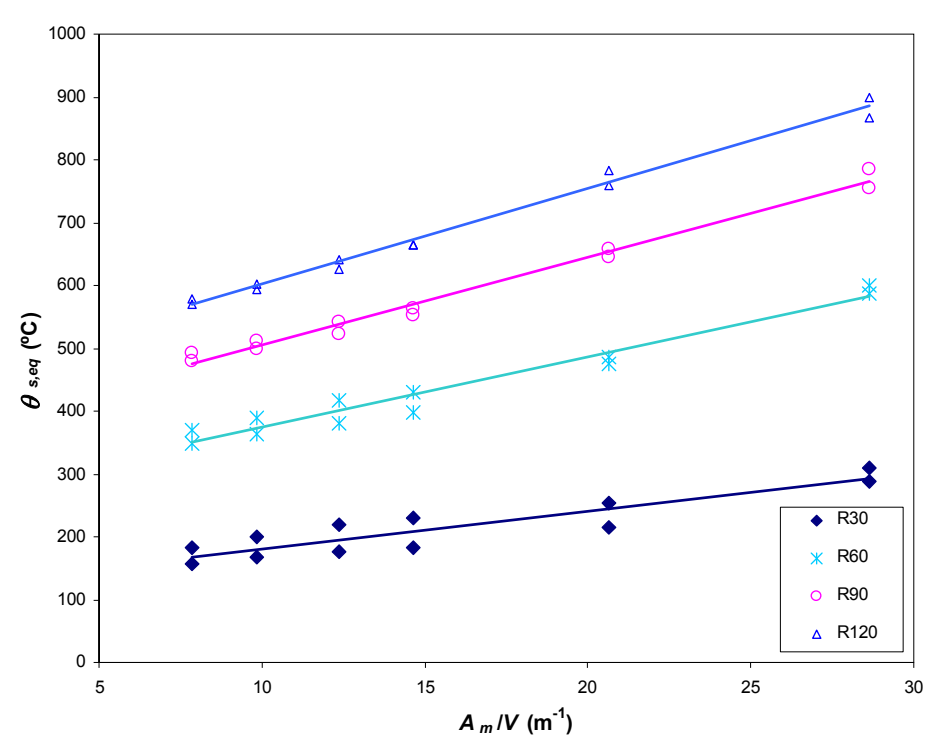

Figure 6.23. Evolution of the equivalent temperature of the reinforcing bars with the section factor, for the standard fire resistance classes.

For each of the standard fire resistance classes studied, a regression curve was fitted to the data, as can be seen in Figure 6.23. With the aid of the regression equations, a selection chart was built up (Table 6.8), which permits to obtain the equivalent temperature of the reinforcing bars for a particular fire period directly from the value of the section factor of the column. For intermediate values of the section factor, linear interpolation can be used.

Table 6.8. Values of the equivalent temperatures for the reinforcing bars $\left(\theta_{s, e q}\right)$ in function of the section factor

\begin{tabular}{|c|c|cccc|}
\cline { 3 - 6 } \multicolumn{2}{|c|}{} & \multicolumn{4}{|c|}{$\boldsymbol{\theta}_{\text {s,eq }}\left({ }^{\mathbf{0}} \mathbf{C}\right)$} \\
\cline { 3 - 6 } \multicolumn{2}{|c|}{} & $\mathbf{R 3 0}$ & $\mathbf{R 6 0}$ & $\mathbf{R 9 0}$ & $\mathbf{R 1 2 0}$ \\
\hline & $\mathbf{5}$ & 152 & 318 & 435 & 525 \\
& $\mathbf{1 0}$ & 181 & 374 & 505 & 601 \\
$\boldsymbol{A}_{\boldsymbol{m}} / \boldsymbol{V}$ & $\mathbf{1 5}$ & 211 & 430 & 575 & 677 \\
$\mathbf{( m}^{-1} \mathbf{)}$ & $\mathbf{2 0}$ & 241 & 485 & 644 & 754 \\
& $\mathbf{2 5}$ & 271 & 541 & 714 & 830 \\
& $\mathbf{3 0}$ & 301 & 597 & 784 & 906 \\
\hline
\end{tabular}


An alternative equation for the equivalent temperature of the reinforcing bars was developed by using a multiple nonlinear regression analysis, including the effect of $A_{m} / V$ and $R$ and therefore valid for any fire resistance period:

$$
\theta_{s, e q}=-119.36+8.535 R-0.033 R^{2}+3.948 A_{m} / V+0.102 R \cdot A_{m} / V
$$

The temperature obtained through this equation can be used instead of that obtained by means of the selection chart. A comparison can be seen in Figure 6.24 between the equivalent temperatures obtained by means of equation (6.29) or alternatively from Table 6.8 and the temperatures obtained from the numerical simulations. As can be seen, similar results are obtained under the two approaches, with excellent agreement with the simulations.

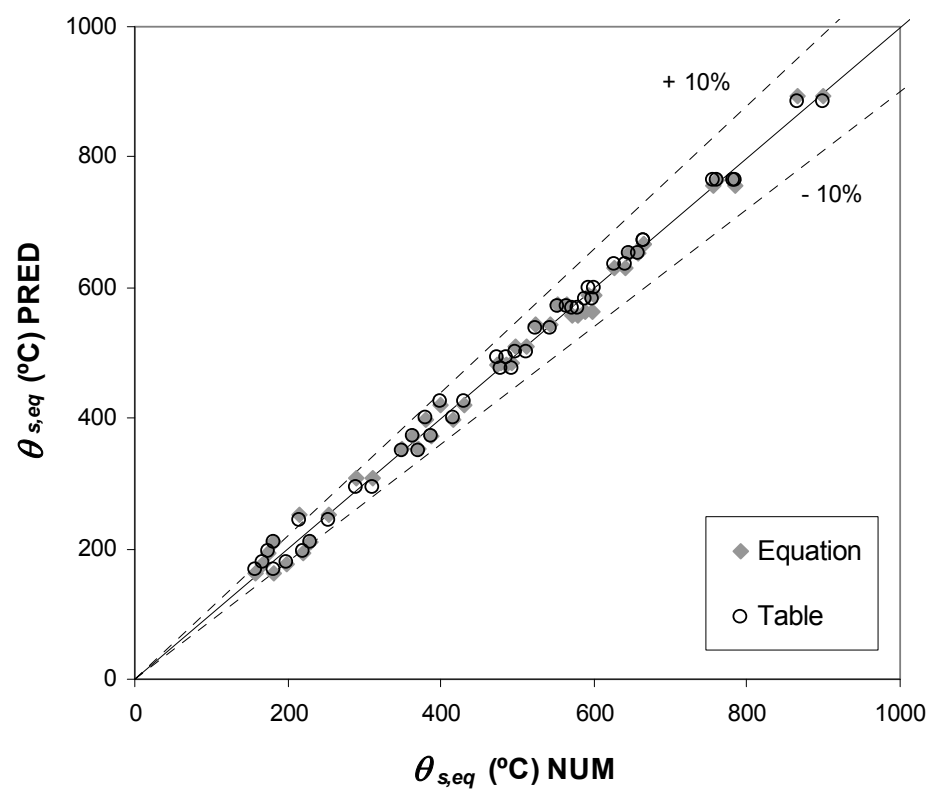

Figure 6.24. Comparison between predicted and simulated equivalent temperatures for the reinforcing bars. 


\subsubsection{Flexural stiffness reduction coefficients}

Expressions and tables for obtaining the values of the flexural stiffness reduction coefficients for steel $\left(\varphi_{a, \theta}\right)$ and concrete $\left(\varphi_{c, \theta}\right)$ were proposed in Section 6.3.4 for unreinforced CFCHS columns, which must be used in combination with buckling curve "a" when applying the general calculation model in Clause 4.3.5.1 of EN 1994-1-2 (CEN 2005c). For the concrete core, a constant reduction coefficient equal to 0.8 (with the initial tangent stiffness) was proposed, while for the steel tube a design equation was developed, as function of the member slenderness (through $\left.\ell_{\theta} / D\right)$, cross-sectional slenderness $(D / t)$ and section factor $\left(A_{m} / V\right)$, see equation (6.28). Alternatively, Table 6.6 can be used for obtaining the reduction coefficient for the steel tube.

In this section, the validity of the proposed expressions for the flexural stiffness reduction coefficients of the steel tube and concrete core is studied for the case of reinforced columns, and the reduction coefficient corresponding to the reinforcing bars $\left(\varphi_{s, \theta}\right)$ is derived. In addition, the more suitable buckling curves are studied for the case of reinforced specimens.

As was found in Section 6.4.1.1, as the reinforcement ratio increases, the normalised buckling load (or buckling coefficient) decreases, which gives as a result a higher deviation from the reference buckling curve, leading to unsafe results. Hence, it seems reasonable to modify the buckling curve for increasing reinforcement ratios. After a deep analysis of the numerical results for reinforced columns, buckling curve "b" was selected as the best fit to the data for a $2.5 \%$ reinforcement ratio, while buckling curve "c" was found the most suitable for the data corresponding to a $5 \%$ reinforcement ratio. Using the values of the flexural stiffness reduction coefficients for the steel tube $\left(\varphi_{a, \theta}\right)$ and concrete core $\left(\varphi_{c, \theta}\right)$ already proposed for unreinforced columns, the third coefficient corresponding to the reinforcing bars $\left(\varphi_{s, \theta}\right)$ was derived from statistical analysis. For a percentage of reinforcement equal to a $2.5 \%$, a constant value $\varphi_{s, \theta}=0.6$ was selected, while for a $5 \%$ reinforcement ratio $\varphi_{s, \theta}=0.3$ was obtained. No influence was observed of the rest of the parameters investigated (e.g. standard fire period, section factor, member slenderness, etc.) over the value of this reduction coefficient, so a constant value can be assumed for each reinforcement ratio. The proposed expressions for the reduction coefficients of the steel tube and concrete core, taken from the proposal for unreinforced columns, were found to be appropriate also for reinforced columns, so they can be used as general values for CFT columns with any reinforcement ratio. 
In order to summarize the results obtained in this section, the average and standard deviation values of the prediction errors of the proposals for the different reinforcement ratios studied is given in Table 6.9, where the values for unreinforced columns have also been included for comparison.

Table 6.9. Summary of the errors in the prediction of the buckling resistance for reinforced columns

\begin{tabular}{ccccccc}
\cline { 2 - 7 } & $\begin{array}{c}\boldsymbol{\rho} \boldsymbol{\rho}=\mathbf{0 \%} \\
\text { (unreinforced) }\end{array}$ & \multicolumn{2}{c}{$\boldsymbol{\rho}=\mathbf{2 . 5 \%}$} & \multicolumn{2}{c}{$\boldsymbol{\rho}=\mathbf{5 \%}$} \\
\cline { 2 - 7 } & Mean & Std. dev. & Mean & Std. dev. & Mean & Std. dev. \\
\hline Design equation & 1.09 & 0.11 & 1.04 & 0.14 & 1.05 & 0.18 \\
Tabulated data & 1.04 & 0.11 & 1.00 & 0.14 & 1.00 & 0.18 \\
\hline
\end{tabular}

As can be seen, safer values are obtained by means of the design equation (6.28) than using the values in Table 6.6 for the evaluation of the reduction coefficient of the steel tube. This occurs for all the different reinforcement ratios studied. In any case, a good average value is obtained for all reinforcement ratios and under both approaches (design equation and tabulated data), although as the reinforcement ratio increases, the dispersion in the results also increase, which can be seen in the higher values of the standard deviation for $\rho=2.5 \%(0.14)$ and $\rho=5 \%(0.18)$ against 0.11 for unreinforced columns.

As an example of the results obtained with the proposal for reinforced columns, a comparison is shown in Figure 6.25 between the predictions and the numerical simulations in terms of normalised buckling load, for columns with a $2.5 \%$ reinforcement ratio and using the values in Table 6.6 for the evaluation of the reduction coefficient of the steel tube. For the concrete core, $\varphi_{c, \theta}=0.8$ and for the reinforcing bars, a value $\varphi_{s, \theta}=0.6$ has been used. The buckling curve corresponding to this percentage of reinforcement has been used, i.e., buckling curve " $b$ ".

Figure 6.26 presents the evolution of the buckling coefficient with the relative slenderness of the columns at elevated temperature, calculated with the proposed flexural stiffness reduction coefficients. It can be seen that the data follow closely the reference buckling curve ("b" in this case) in all the range of slenderness. 


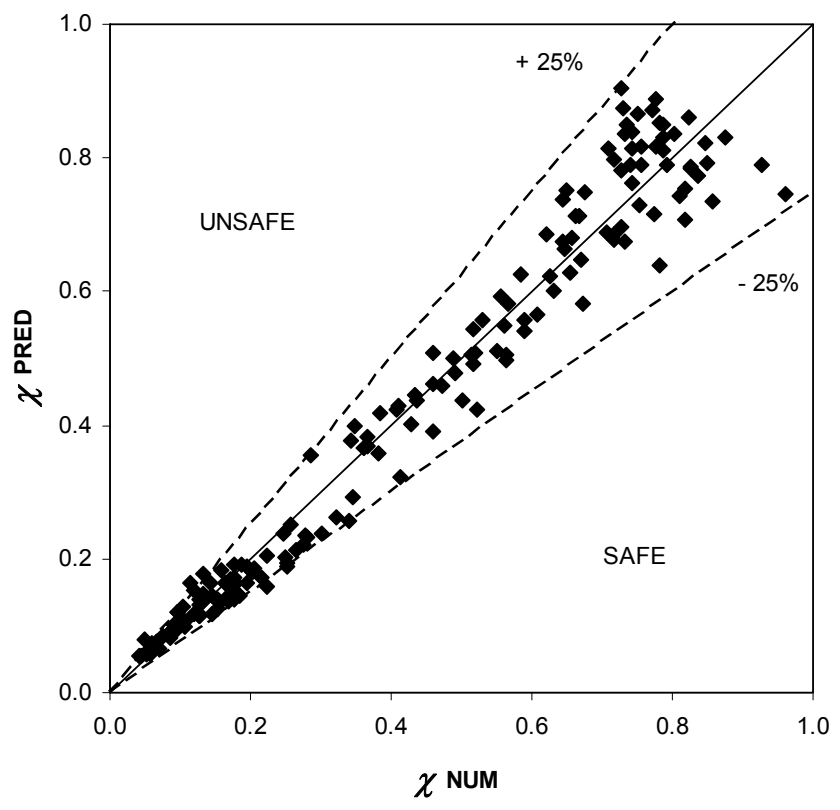

Figure 6.25. Comparison between the predictions and numerical simulations for reinforced columns, in terms of normalised buckling load. Tabulated data, $2.5 \%$ reinforcement ratio.

According to the results of this section, the following buckling curves and values of the flexural stiffness reduction coefficient for the reinforcing bars are proposed, which are summarized in Table 6.10.

Table 6.10. Summary of the proposed buckling curve and reduction coefficient of the reinforcing bars

\begin{tabular}{cccc}
\hline Reinforcement ratio & $\begin{array}{c}\boldsymbol{\rho}=\mathbf{0 \%} \\
\text { (unreinforced) }\end{array}$ & $\mathbf{0 \%}<\boldsymbol{\rho} \leq \mathbf{2 . 5 \%}$ & $\mathbf{2 . 5 \%}<\boldsymbol{\rho} \leq \mathbf{5 \%}$ \\
\hline Buckling curve & "a" $(\alpha=0.21)$ & "b" $(\alpha=0.34)$ & "c" $(\alpha=0.49)$ \\
$\varphi_{s, \boldsymbol{\theta}}$ & - & 0.6 & 0.3 \\
\hline
\end{tabular}

Although only two percentages of reinforcement have been studied $(2.5 \%$ and $5 \%$, for each range of values $(0 \%<\rho \leq 2.5 \%$ and $2.5 \%<\rho \leq 5 \%)$ the buckling curve and reduction coefficient corresponding to the upper limit $(2.5 \%$ or $5 \%)$ have been assigned, which places on the safe side. 


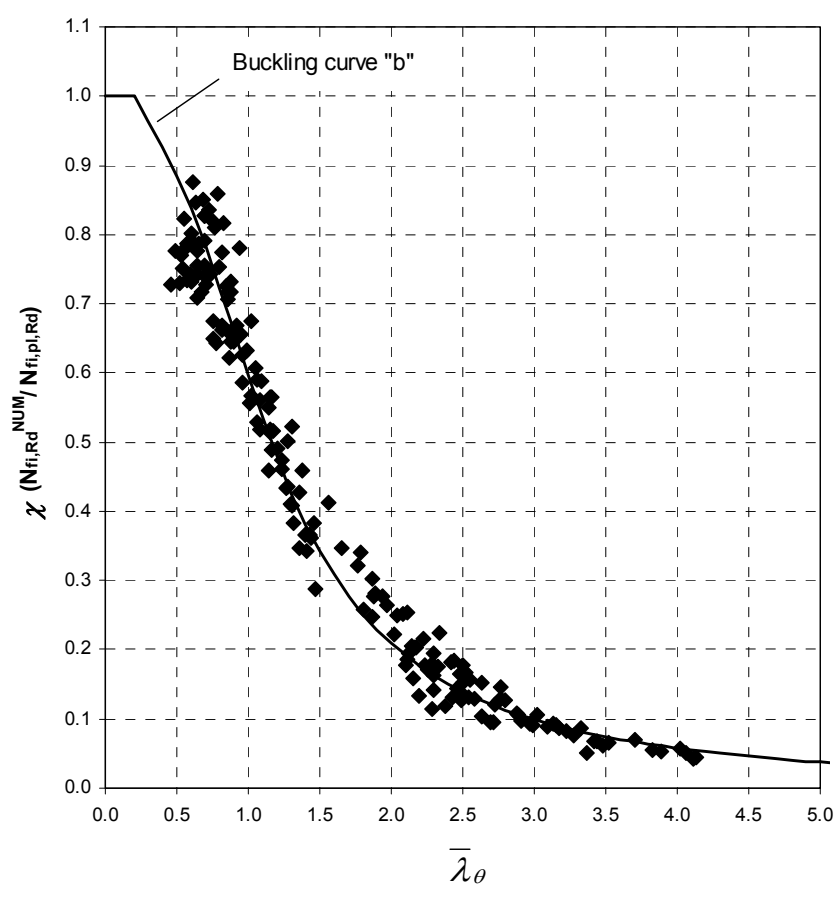

Figure 6.26. Evolution of the buckling coefficient with the relative slenderness at elevated temperature, for reinforced columns. Tabulated data, $2.5 \%$ reinforcement ratio.

\subsubsection{Comparison of the proposed method with experiments}

In this section, the accuracy of the proposed method for bar-reinforced CFT columns is compared with results of real fire tests. From the research program carried out in Valencia (Romero et al. 2011), three reinforced columns can be used (specimens RC159-6-3-30-0-20 to RC159-6-3-30-0-60 in Table 4.3), while other two bar-reinforced specimens can be found amongst the fire tests carried out at the NRCC (Chabot \& Lie 1992), specimens C-48 and C-49 in Table 4.1.

Columns falling out of the applicability range of the method were left out of this comparative study (i.e. columns filled with high strength concrete or with sections other than circular). Figure 6.27 compares the results of the tests against the predictions of the method, in terms of the failure load. It can be seen that the accuracy of the method was reasonable and, in general, safe predictions were obtained. 


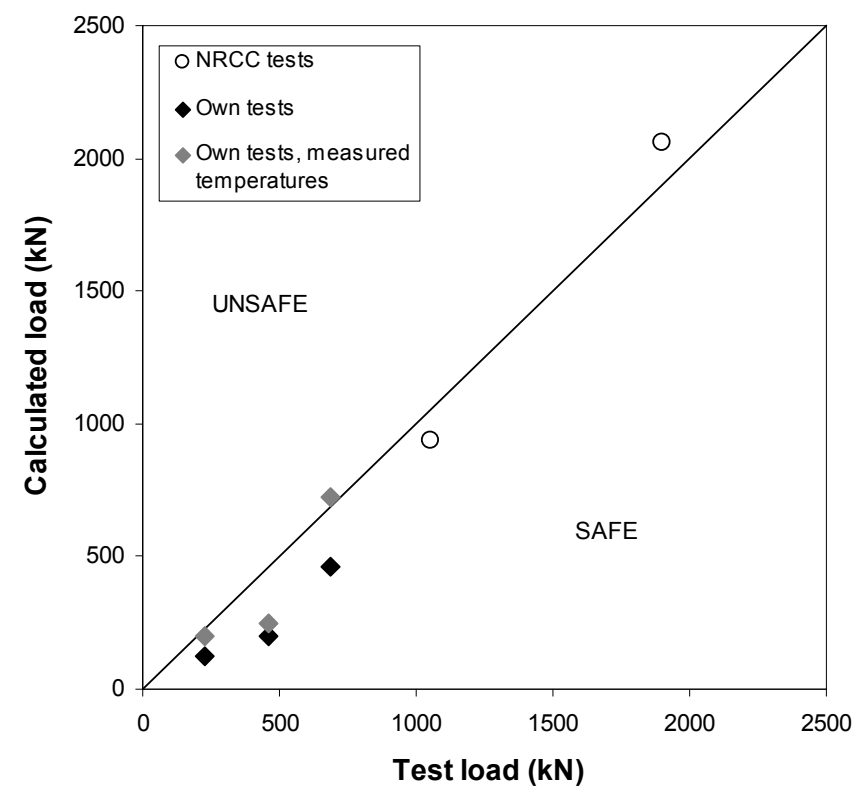

Figure 6.27. Comparison of ultimate loads between the proposed method for reinforced columns and tests.

It is worth noting that, even though column C-48 - with a fire resistance time of 188 minutes - falls out of the applicability limits of the method ( $R \leq 120 \mathrm{~min}$ ), a good estimation was also obtained for this specimen.

For comparing with the tests from Romero et al. (2011), two options were considered: using the equivalent temperatures of steel and concrete given by the proposed method and using the real temperatures measured at the tests. As can be observed in Figure 6.27, a better approximation was obviously obtained using the measured temperatures; in any case, using the equivalent temperatures safe results were obtained for all the specimens compared. Therefore, it can be concluded that the proposed method is also valid for estimating the fire resistance of reinforced CFT columns.

Figure 6.28 compares the results of the proposed method with the values of the predictions obtained by means of the simplified design equation from Kodur (1999) used in North America, which was presented in Section 6.1.4. The rest of the methods (from China and Japan) are not used for this comparison, since they are only valid for columns filled with plain concrete. As can be seen, the proposed 
method results in more accurate predictions than the formula from Kodur, with a narrower dispersion. It can be therefore concluded that, compared to the existing methods, the proposed simple calculation model provides a reasonable accuracy also for bar-reinforced columns.

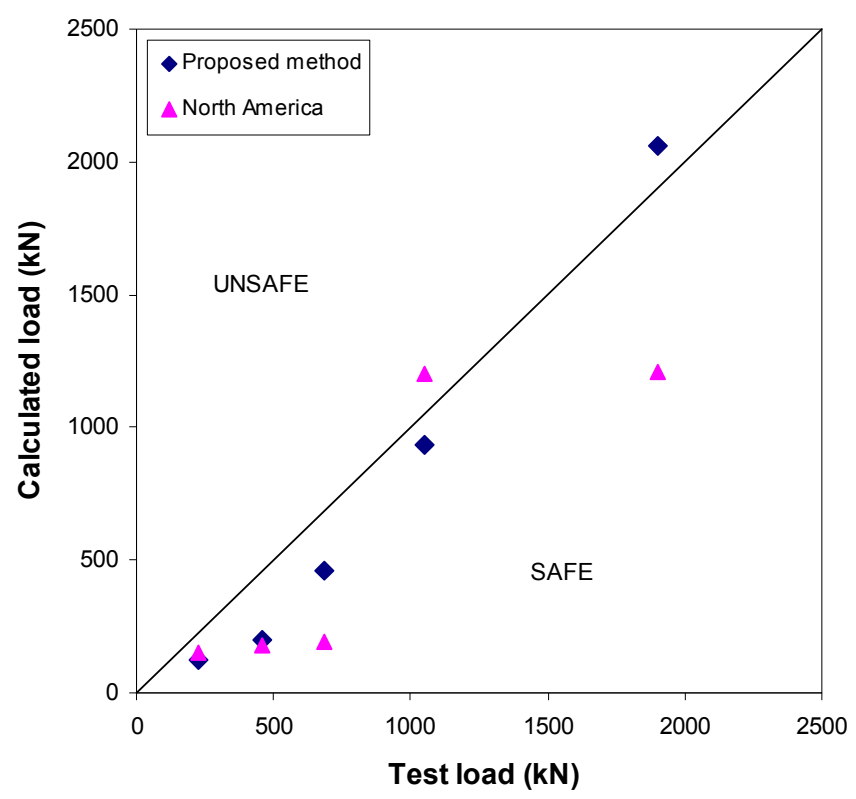

Figure 6.28. Comparison of ultimate loads between the proposed method for reinforced columns, Kodur formula and tests.

\subsection{APPLICATION OF THE PROPOSED METHOD TO CFEHS COLUMNS}

In this section, the validity of the proposed simple calculation model is verified for columns with elliptical cross-section. On a first stage, the proposal in Section 6.3.3 for the equivalent temperatures of the steel tube and concrete core is studied, and on a second stage, the validity of the flexural stiffness reduction coefficients developed in Section 6.3.4 is analysed for the elliptical shapes. The proposal for reinforced columns developed in Section 6.4 is also studied for elliptical columns. 


\subsubsection{Simplified cross-sectional temperature field}

For the study of the equivalent temperatures of the steel tube and concrete core, a series of commercially available elliptical geometries are studied. Six different geometries are used, selecting for steel tube wall thickness an intermediate value within the available range (Corus 2007): $150 \times 75 \times 5 \mathrm{~mm}, 200 \times 100 \times 8 \mathrm{~mm}$, $250 \times 125 \times 10 \mathrm{~mm}, 300 \times 150 \times 12.5 \mathrm{~mm}, 400 \times 200 \times 12.5 \mathrm{~mm}$ and $500 \times 250 \times 12.5 \mathrm{~mm}$. For each of the selected geometries, a heat transfer analysis was performed by means of the numerical model previously described in Section 5.2, and once the temperature field had been obtained for the six geometries, the procedure explained in Section 6.3.3 was applied to these sections, so as to obtain the equivalent temperatures of the steel tube and the concrete core corresponding to the standard fire periods (R30, R60, R90 and R120). Figure 6.29 shows the evolution of the equivalent temperature of the concrete core with the section factor for CFEHS columns, while Figure 6.30 represents the evolution of the equivalent temperature of the steel tube.

The trend in the evolution of the equivalent temperatures with the section factor and fire resistance period is similar to that obtained for the circular columns (see Figure 6.8 and Figure 6.10), although it can be seen that the section factor values for the elliptical columns (from 10 to $45 \mathrm{~m}^{-1}$ ) are comparatively higher than those of the circular columns (from 5 to $30 \mathrm{~m}^{-1}$ ). In effect, the circular shape is "thermally" more efficient than the elliptical shape, since it exposes a lower surface for a certain volume, and thus it results in more reduced section factor values.

For each of the standard fire resistance classes studied, a regression curve was fitted to the data, as can be seen in both Figure 6.29 and Figure 6.30. With the aid of the regression equations, a selection chart was built up (Table 6.11), which permits to obtain the equivalent temperature of the steel tube and concrete core for a particular fire period directly from the value of the section factor of the column. For intermediate values of the section factor, linear interpolation can be used. 


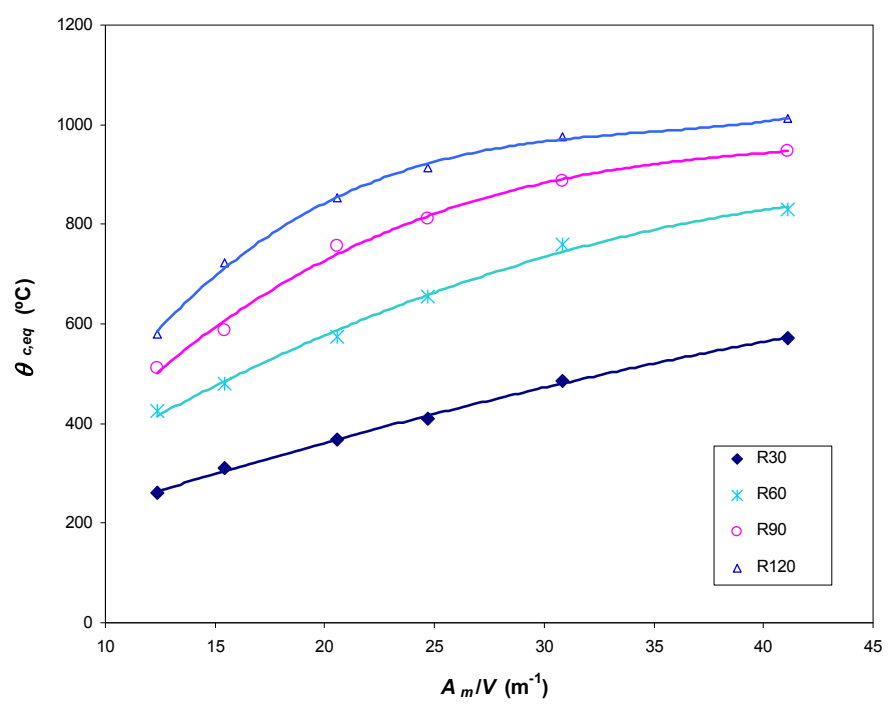

Figure 6.29. Evolution of the equivalent temperature of the concrete core with the section factor, for the standard fire resistance classes.

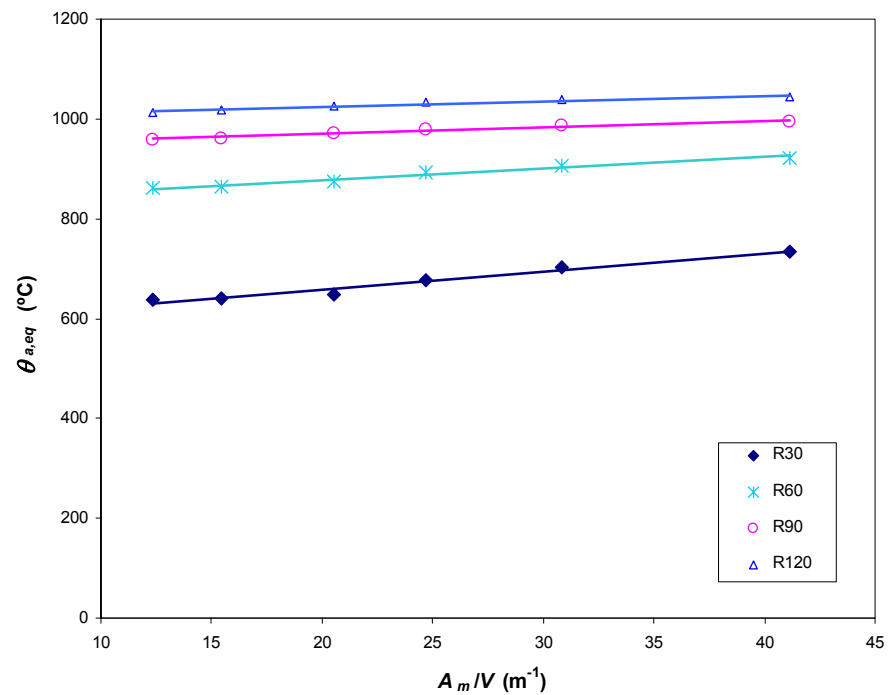

Figure 6.30. Evolution of the equivalent temperature of the steel tube with the section factor, for the standard fire resistance classes. 
Table 6.11. Values of the equivalent temperatures for concrete $\left(\theta_{c, e q}\right)$ and steel $\left(\theta_{a, e q}\right)$ in function of the section factor, for CFEHS columns

\begin{tabular}{|c|c|c|c|c|c|c|c|c|c|}
\hline & \multicolumn{2}{|c|}{ R30 } & \multicolumn{2}{|c|}{ R60 } & \multicolumn{2}{|c|}{ R90 } & \multicolumn{2}{|c|}{ R120 } \\
\hline & & $\begin{array}{r}\theta_{c, e q} \\
\left({ }^{\circ} \mathrm{C}\right)\end{array}$ & $\begin{array}{l}\theta_{a, e q} \\
\left({ }^{\circ} \mathrm{C}\right)\end{array}$ & $\begin{array}{l}\theta_{c, e q} \\
\left({ }^{\circ} \mathrm{C}\right)\end{array}$ & $\begin{array}{l}\theta_{a, e q} \\
\left({ }^{\circ} \mathrm{C}\right)\end{array}$ & $\begin{array}{l}\theta_{c, e q} \\
\left({ }^{\circ} \mathrm{C}\right)\end{array}$ & $\begin{array}{l}\theta_{a, e q} \\
\left({ }^{\circ} \mathrm{C}\right)\end{array}$ & $\begin{array}{l}\theta_{c, e q} \\
\left({ }^{\circ} \mathbf{C}\right)\end{array}$ & $\begin{array}{l}\theta_{a, e q} \\
\left({ }^{\circ} \mathrm{C}\right)\end{array}$ \\
\hline \multirow{8}{*}{$\begin{array}{c}A_{m} / V \\
\left(\mathrm{~m}^{-1}\right)\end{array}$} & 10 & 232 & 623 & 359 & 855 & 410 & 956 & 465 & 1014 \\
\hline & 15 & 299 & 641 & 475 & 866 & 593 & 963 & 696 & 1019 \\
\hline & 20 & 361 & 659 & 577 & 878 & 727 & 970 & 842 & 1024 \\
\hline & 25 & 419 & 677 & 663 & 889 & 822 & 976 & 925 & 1029 \\
\hline & 30 & 472 & 695 & 734 & 900 & 884 & 983 & 965 & 1034 \\
\hline & 35 & 520 & 713 & 789 & 912 & 922 & 990 & 985 & 1040 \\
\hline & 40 & 564 & 731 & 828 & 923 & 945 & 997 & 1005 & 1045 \\
\hline & 45 & 603 & 749 & 853 & 934 & 961 & 1004 & 1046 & 1050 \\
\hline
\end{tabular}

Alternative equations for the equivalent temperatures of the concrete core and steel tube were also developed by using multiple nonlinear regression analysis. These expressions include the effect of $A_{m} / V$ and $R$ and therefore are valid for any fire resistance period.

For the concrete core:

$$
\begin{aligned}
& \theta_{c, e q}=-395.503+9.304 R-0.035 R^{2}+33.698 A_{m} / V-0.425\left(A_{m} / V\right)^{2}+ \\
& +0.035 R \cdot A_{m} / V
\end{aligned}
$$

For the steel tube:

$$
\theta_{a, e q}=300.845+11.209 R-0.044 R^{2}+4.219 A_{m} / V-0.029 R \cdot A_{m} / V
$$

These equations can be used as an alternative to the selection chart in Table 6.11 .

Although specific tables and equations have been developed for the equivalent temperatures of steel and concrete in the case of elliptical sections, the validity of the expressions which were proposed in Section 6.3.3 for circular sections is next checked for elliptical sections. For that purpose, the equivalent temperature of the concrete core is obtained by means of equation (6.20) (specific for CFCHS columns), equation (6.30) (specific for CFEHS columns) and Table 6.11 (specific for CFEHS columns), and compared with the equivalent temperature obtained from the numerical simulations. The prediction errors are computed as the simulation results divided by the predicted values, and are given in Table 6.12. 
Table 6.12. Prediction errors obtained for the equivalent temperature of concrete

\begin{tabular}{|c|c|c|c|c|c|c|c|c|}
\hline \multirow[b]{2}{*}{$\begin{array}{c}2 a \\
(\mathbf{m m})\end{array}$} & \multirow[b]{2}{*}{$\begin{array}{c}2 b \\
(\mathrm{~mm})\end{array}$} & \multirow[b]{2}{*}{$\begin{array}{c}t \\
(\mathbf{m m})\end{array}$} & \multirow[b]{2}{*}{$\begin{array}{l}A_{m} / V \\
\left(\mathrm{~m}^{-1}\right)\end{array}$} & \multirow[b]{2}{*}{$\begin{array}{c}R \\
(\min ) \\
\end{array}$} & \multirow[b]{2}{*}{$\begin{array}{c}\theta_{c, e q}{ }^{N U M} \\
\left({ }^{\circ} \mathrm{C}\right)\end{array}$} & \multicolumn{3}{|c|}{ Prediction error $\left(\theta_{c, e q}{ }^{N U M} / \theta_{c, e q}{ }^{P R E D}\right)$} \\
\hline & & & & & & Eq. CHS & Eq. EHS & Table EHS \\
\hline 150 & 75 & 5 & 41.12 & 30 & 572.20 & 1.09 & 1.02 & 1.00 \\
\hline 150 & 75 & 5 & 41.12 & 60 & 830.19 & 1.04 & 1.05 & 1.00 \\
\hline 150 & 75 & 5 & 41.12 & 90 & 947.00 & 0.92 & 0.99 & 1.00 \\
\hline 150 & 75 & 5 & 41.12 & 120 & 1011.64 & 0.84 & 0.96 & 1.00 \\
\hline 200 & 100 & 8 & 30.84 & 30 & 485.19 & 1.00 & 0.93 & 1.01 \\
\hline 200 & 100 & 8 & 30.84 & 60 & 759.66 & 1.06 & 1.03 & 1.02 \\
\hline 200 & 100 & 8 & 30.84 & 90 & 888.03 & 0.98 & 1.00 & 1.00 \\
\hline 200 & 100 & 8 & 30.84 & 120 & 975.73 & 0.94 & 0.99 & 1.01 \\
\hline 250 & 125 & 10 & 24.67 & 30 & 409.24 & 0.95 & 0.91 & 0.99 \\
\hline 250 & 125 & 10 & 24.67 & 60 & 656.04 & 1.03 & 0.99 & 1.00 \\
\hline 250 & 125 & 10 & 24.67 & 90 & 811.85 & 1.02 & 1.00 & 1.00 \\
\hline 250 & 125 & 10 & 24.67 & 120 & 913.33 & 1.01 & 1.02 & 0.99 \\
\hline 300 & 150 & 12.5 & 20.56 & 30 & 367.90 & 0.97 & 0.95 & 1.00 \\
\hline 300 & 150 & 12.5 & 20.56 & 60 & 573.55 & 1.01 & 0.97 & 0.98 \\
\hline 300 & 150 & 12.5 & 20.56 & 90 & 756.61 & 1.07 & 1.03 & 1.03 \\
\hline 300 & 150 & 12.5 & 20.56 & 120 & 852.46 & 1.06 & 1.04 & 1.00 \\
\hline 400 & 200 & 12.5 & 15.42 & 30 & 309.25 & 1.03 & 1.08 & 1.02 \\
\hline 400 & 200 & 12.5 & 15.42 & 60 & 480.30 & 1.03 & 0.98 & 0.99 \\
\hline 400 & 200 & 12.5 & 15.42 & 90 & 585.66 & 1.00 & 0.94 & 0.97 \\
\hline 400 & 200 & 12.5 & 15.42 & 120 & 721.77 & 1.09 & 1.03 & 1.02 \\
\hline 500 & 250 & 12.5 & 12.34 & 30 & 261.15 & 1.07 & 1.21 & 0.99 \\
\hline 500 & 250 & 12.5 & 12.34 & 60 & 423.94 & 1.06 & 1.02 & 1.03 \\
\hline 500 & 250 & 12.5 & 12.34 & 90 & 511.11 & 1.01 & 0.93 & 1.03 \\
\hline 500 & 250 & 12.5 & 12.34 & 120 & 579.22 & 1.02 & 0.93 & 1.01 \\
\hline \multicolumn{3}{|c|}{ Average } & & & & 1.01 & 1.00 & 1.00 \\
\hline \multicolumn{3}{|c|}{ Standard deviation } & & & & 0.06 & 0.06 & 0.02 \\
\hline
\end{tabular}

where:

- Eq. CHS is the prediction using the proposal for CFCHS columns (equation (6.20))

- Eq. EHS is the prediction using the proposal for CFEHS columns (equation (6.30))

- Table EHS is the prediction using Table 6.11 
As can be seen, the average error and standard deviation obtained with the two regression equations specific for circular (equation (6.20)) and elliptical columns (equation (6.30)) are very similar (1.01 versus 1.00 average error and 0.06 standard deviation in both cases), therefore the equation proposed for CFCHS columns can be adopted as valid for both geometries. In fact, this equation is given in function of the section factor instead of the diameter of the column, and thus it can be easily applied to different geometries. If a higher precision wants to be obtained in the prediction, Table 6.11 (specific for CFEHS columns) can be used, with a more reduced dispersion (0.02 standard deviation).

The same comparison is presented in Table 6.13 for the equivalent temperature of the steel tube, which is obtained by means of equation (6.21) (specific for CFCHS columns), equation (6.31) (specific for CFEHS columns) and Table 6.11 (specific for CFEHS columns), and compared with the equivalent temperature obtained from the numerical simulations.

For the steel tube, the average error and standard deviation obtained with the two regression equations specific for circular (equation (6.21)) and elliptical columns (equation (6.31)) are comparable (0.99 versus 1.00 average error with a very reduced standard deviation in both cases), therefore the equation for the steel tube equivalent temperature proposed for CFCHS columns can be also used for elliptical columns. An excellent agreement is also obtained though Table 6.11 (1.00 average error and 0.01 standard deviation). 
Table 6.13. Prediction errors obtained for the equivalent temperature of steel

\begin{tabular}{|c|c|c|c|c|c|c|c|c|}
\hline \multirow[b]{2}{*}{$\begin{array}{c}2 a \\
(\mathrm{~mm})\end{array}$} & \multirow[b]{2}{*}{$\begin{array}{c}2 b \\
(\mathrm{~mm})\end{array}$} & \multirow[b]{2}{*}{$\begin{array}{c}t \\
(\mathbf{m m})\end{array}$} & \multirow[b]{2}{*}{$\begin{array}{c}A_{m} / V \\
\left(\mathbf{m}^{-1}\right)\end{array}$} & \multirow[b]{2}{*}{$\begin{array}{c}R \\
(\mathbf{m i n}) \\
\end{array}$} & \multirow[b]{2}{*}{$\begin{array}{c}\theta_{a, e q}{ }^{N U M} \\
\left({ }^{\circ} \mathrm{C}\right)\end{array}$} & \multicolumn{3}{|c|}{ Prediction error $\left(\theta_{a, e q}{ }^{N U M} / \theta_{a, e q}{ }^{P R E D}\right)$} \\
\hline & & & & & & Eq. CHS & Eq. EHS & Table EHS \\
\hline 150 & 75 & 5 & 41.12 & 30 & 733.66 & 0.97 & 1.00 & 1.00 \\
\hline 150 & 75 & 5 & 41.12 & 60 & 921.77 & 0.99 & 1.01 & 1.00 \\
\hline 150 & 75 & 5 & 41.12 & 90 & 995.05 & 0.97 & 0.98 & 1.00 \\
\hline 150 & 75 & 5 & 41.12 & 120 & 1042.57 & 1.00 & 1.00 & 1.00 \\
\hline 200 & 100 & 8 & 30.84 & 30 & 703.68 & 0.97 & 1.00 & 1.01 \\
\hline 200 & 100 & 8 & 30.84 & 60 & 906.97 & 1.00 & 1.02 & 1.01 \\
\hline 200 & 100 & 8 & 30.84 & 90 & 987.32 & 0.98 & 0.98 & 1.00 \\
\hline 200 & 100 & 8 & 30.84 & 120 & 1037.80 & 1.01 & 1.00 & 1.00 \\
\hline 250 & 125 & 10 & 24.67 & 30 & 677.34 & 0.96 & 1.00 & 1.00 \\
\hline 250 & 125 & 10 & 24.67 & 60 & 892.13 & 1.00 & 1.02 & 1.00 \\
\hline 250 & 125 & 10 & 24.67 & 90 & 978.98 & 0.98 & 0.99 & 1.00 \\
\hline 250 & 125 & 10 & 24.67 & 120 & 1032.13 & 1.01 & 1.00 & 1.00 \\
\hline 300 & 150 & 12.5 & 20.56 & 30 & 649.06 & 0.94 & 0.97 & 0.98 \\
\hline 300 & 150 & 12.5 & 20.56 & 60 & 875.62 & 1.00 & 1.01 & 1.00 \\
\hline 300 & 150 & 12.5 & 20.56 & 90 & 971.04 & 0.98 & 0.98 & 1.00 \\
\hline 300 & 150 & 12.5 & 20.56 & 120 & 1026.43 & 1.01 & 1.00 & 1.00 \\
\hline 400 & 200 & 12.5 & 15.42 & 30 & 640.32 & 0.95 & 0.99 & 1.00 \\
\hline 400 & 200 & 12.5 & 15.42 & 60 & 864.35 & 1.00 & 1.01 & 1.00 \\
\hline 400 & 200 & 12.5 & 15.42 & 90 & 961.58 & 0.98 & 0.98 & 1.00 \\
\hline 400 & 200 & 12.5 & 15.42 & 120 & 1018.17 & 1.00 & 0.99 & 1.00 \\
\hline 500 & 250 & 12.5 & 12.34 & 30 & 637.96 & 0.96 & 1.00 & 1.01 \\
\hline 500 & 250 & 12.5 & 12.34 & 60 & 860.95 & 1.00 & 1.02 & 1.00 \\
\hline 500 & 250 & 12.5 & 12.34 & 90 & 957.66 & 0.98 & 0.98 & 1.00 \\
\hline 500 & 250 & 12.5 & 12.34 & 120 & 1013.52 & 1.00 & 0.99 & 1.00 \\
\hline \multicolumn{3}{|c|}{ Average } & & & & 0.99 & 1.00 & 1.00 \\
\hline \multicolumn{3}{|c|}{ Standard deviation } & & & & 0.02 & 0.01 & 0.01 \\
\hline
\end{tabular}

where:

- Eq. CHS is the prediction using the proposal for CFCHS columns (equation (6.21))

- Eq. EHS is the prediction using the proposal for CFEHS columns (equation (6.31))

- Table EHS is the prediction using Table 6.11 
For CFCHS columns with reinforcement, the equivalent temperatures of the reinforcing bars were derived in Section 6.4.3, for a concrete cover value equal to 30 $\mathrm{mm}$. In order to evaluate the applicability of the proposed expressions and tables to CFEHS columns, the temperatures corresponding to the reinforcing bars are obtained from the numerical simulations of the elliptical sections studied. The temperature of the reinforcing bars was taken as that of the concrete core at their same location, i.e., at a depth equal to $30 \mathrm{~mm}$ measured from the internal surface of the steel tube. Figure 6.31 shows the evolution of the equivalent temperature of the reinforcing bars with the section factor for CFEHS columns.

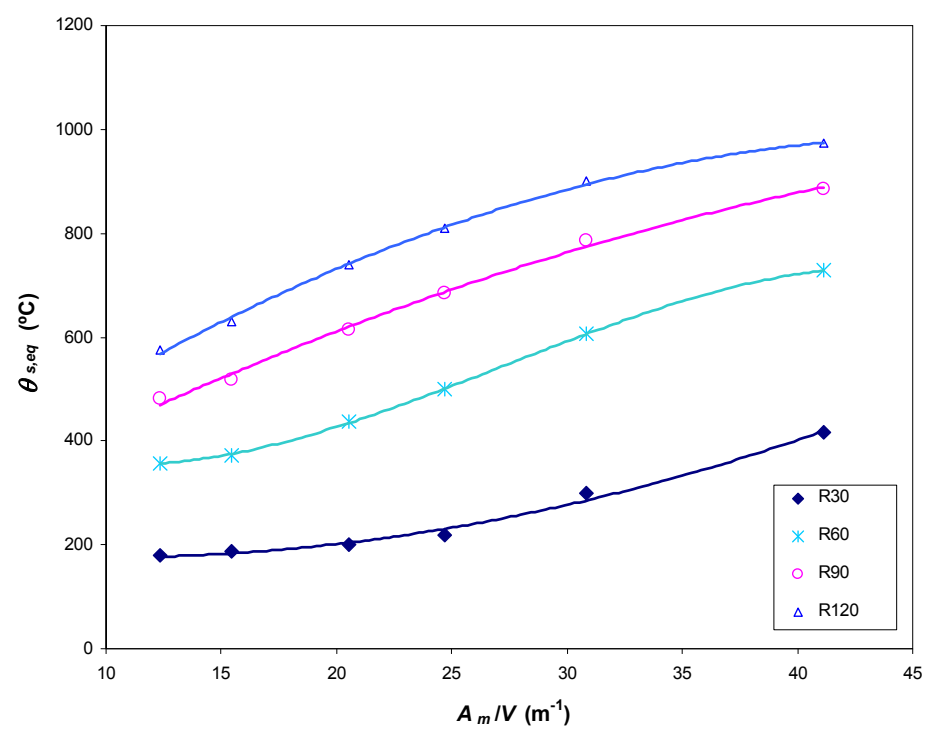

Figure 6.31. Evolution of the equivalent temperature of the reinforcing bars with the section factor, for the standard fire resistance classes.

As the fire exposure time increases, the equivalent temperature of the reinforcing bars becomes higher. Also an increase in the temperature is found for increasing section factors. These results are similar to those obtained for the circular columns, although a faster increase in temperatures can be observed for the elliptical shapes.

For each of the standard fire resistance classes studied, a regression curve was fitted to the data, as can be seen in Figure 6.31. Unlike for circular columns, the evolution of the temperatures results nonlinear in this case. 
From these regression equations, a selection chart was built up (Table 6.14), which permits to obtain the equivalent temperature of the reinforcing bars for a particular fire period directly from the value of the section factor of the column. For intermediate values of the section factor, linear interpolation can be used.

Table 6.14. Values of the equivalent temperatures for the reinforcing bars $\left(\theta_{s, e q}\right)$ in function of the section factor, for CFEHS columns

\begin{tabular}{|c|c|cccc|}
\cline { 3 - 6 } \multicolumn{2}{c|}{} & \multicolumn{4}{|c|}{$\boldsymbol{\theta}_{\text {s, eq }}\left({ }^{\mathbf{}} \mathbf{C}\right)$} \\
\cline { 3 - 6 } \multicolumn{2}{c|}{} & $\mathbf{R 3 0}$ & $\mathbf{R 6 0}$ & $\mathbf{R 9 0}$ & $\mathbf{R 1 2 0}$ \\
\hline & $\mathbf{1 0}$ & 176 & 355 & 422 & 510 \\
& $\mathbf{1 5}$ & 182 & 371 & 521 & 629 \\
& $\mathbf{2 0}$ & 201 & 427 & 611 & 731 \\
$\boldsymbol{A}_{\boldsymbol{m}} / \boldsymbol{V}$ & $\mathbf{2 5}$ & 233 & 506 & 692 & 816 \\
$\left(\mathbf{m}^{-\mathbf{1}}\right)$ & $\mathbf{3 0}$ & 277 & 593 & 763 & 884 \\
& $\mathbf{3 5}$ & 333 & 671 & 825 & 935 \\
& $\mathbf{4 0}$ & 402 & 724 & 878 & 969 \\
& $\mathbf{4 5}$ & 483 & 736 & 922 & 986 \\
\hline
\end{tabular}

An alternative equation for the equivalent temperature of the reinforcing bars was developed by using a multiple nonlinear regression analysis, including the effect of $A_{m} / V$ and $R$ and therefore valid for any fire resistance period:

$\theta_{s, e q}=-255.1+10.106 R-0.039 R^{2}+8.036 A_{m} / V+0.062 R \cdot A_{m} / V$

Although specific tables and equations have been developed for the equivalent temperatures of the reinforcing bars in the case of elliptical sections, the validity of the expressions which were proposed in Section 6.4.3 for circular columns is next checked for elliptical sections. For that purpose, the equivalent temperature of the reinforcing bars is obtained by means of equation (6.29) (specific for CFCHS columns), equation (6.32) (specific for CFEHS columns) and Table 6.14 (specific for CFEHS columns), and compared with the equivalent temperature obtained from the numerical simulations. The prediction errors are computed as the simulation results divided by the predicted values, and are given in Table 6.15. 
Table 6.15. Prediction errors obtained for the equivalent temperature of the reinforcing bars

\begin{tabular}{|c|c|c|c|c|c|c|c|c|}
\hline \multirow[b]{2}{*}{$\begin{array}{c}2 a \\
(\mathrm{~mm})\end{array}$} & \multirow[b]{2}{*}{$\begin{array}{c}2 b \\
(\mathrm{~mm})\end{array}$} & \multirow[b]{2}{*}{$\begin{array}{c}t \\
(\mathbf{m m})\end{array}$} & \multirow[b]{2}{*}{$\begin{array}{l}A_{m} / V \\
\left(\mathbf{m}^{-1}\right)\end{array}$} & \multirow[b]{2}{*}{$\begin{array}{c}R \\
(\min )\end{array}$} & \multirow[b]{2}{*}{$\begin{array}{c}\theta_{s, e q}{ }^{N U M} \\
\left({ }^{\circ} \mathrm{C}\right)\end{array}$} & \multicolumn{3}{|c|}{ Prediction error $\left(\theta_{s, e q}{ }^{N U M} / \theta_{s, e q}{ }^{P R E D}\right)$} \\
\hline & & & & & & Eq. CHS & Eq. EHS & Table EHS \\
\hline 150 & 75 & 5 & 41.12 & 30 & 415.31 & 1.05 & 0.99 & 0.99 \\
\hline 150 & 75 & 5 & 41.12 & 60 & 728.09 & 1.06 & 1.05 & 1.00 \\
\hline 150 & 75 & 5 & 41.12 & 90 & 884.58 & 0.96 & 0.98 & 1.00 \\
\hline 150 & 75 & 5 & 41.12 & 120 & 972.42 & 0.89 & 0.94 & 1.00 \\
\hline 200 & 100 & 8 & 30.84 & 30 & 299.54 & 0.93 & 0.94 & 1.05 \\
\hline 200 & 100 & 8 & 30.84 & 60 & 605.83 & 1.04 & 1.06 & 1.00 \\
\hline 200 & 100 & 8 & 30.84 & 90 & 786.79 & 1.00 & 1.04 & 1.02 \\
\hline 200 & 100 & 8 & 30.84 & 120 & 899.89 & 0.97 & 1.03 & 1.01 \\
\hline 250 & 125 & 10 & 24.67 & 30 & 219.77 & 0.79 & 0.85 & 0.95 \\
\hline 250 & 125 & 10 & 24.67 & 60 & 499.51 & 0.96 & 1.00 & 1.00 \\
\hline 250 & 125 & 10 & 24.67 & 90 & 684.34 & 0.97 & 1.01 & 1.00 \\
\hline 250 & 125 & 10 & 24.67 & 120 & 810.18 & 0.98 & 1.04 & 1.00 \\
\hline 300 & 150 & 12.5 & 20.56 & 30 & 199.90 & 0.80 & 0.92 & 0.98 \\
\hline 300 & 150 & 12.5 & 20.56 & 60 & 436.26 & 0.91 & 0.96 & 1.00 \\
\hline 300 & 150 & 12.5 & 20.56 & 90 & 613.97 & 0.94 & 0.99 & 0.99 \\
\hline 300 & 150 & 12.5 & 20.56 & 120 & 740.06 & 0.97 & 1.04 & 1.00 \\
\hline 400 & 200 & 12.5 & 15.42 & 30 & 186.84 & 0.87 & 1.13 & 1.02 \\
\hline 400 & 200 & 12.5 & 15.42 & 60 & 373.33 & 0.87 & 0.95 & 0.99 \\
\hline 400 & 200 & 12.5 & 15.42 & 90 & 517.79 & 0.89 & 0.94 & 0.98 \\
\hline 400 & 200 & 12.5 & 15.42 & 120 & 630.37 & 0.93 & 0.99 & 0.99 \\
\hline 500 & 250 & 12.5 & 12.34 & 30 & 178.54 & 0.92 & 1.32 & 1.00 \\
\hline 500 & 250 & 12.5 & 12.34 & 60 & 357.36 & 0.90 & 1.00 & 0.99 \\
\hline 500 & 250 & 12.5 & 12.34 & 90 & 481.08 & 0.89 & 0.95 & 1.03 \\
\hline 500 & 250 & 12.5 & 12.34 & 120 & 574.29 & 0.91 & 0.98 & 1.02 \\
\hline \multicolumn{3}{|c|}{ Average } & & & & 0.93 & 1.01 & 1.00 \\
\hline \multicolumn{3}{|c|}{ Standard deviation } & & & & $\mathbf{0 . 0 7}$ & 0.09 & 0.02 \\
\hline
\end{tabular}

where:

- Eq. CHS is the prediction using the proposal for CFCHS columns (equation (6.29))

- Eq. EHS is the prediction using the proposal for CFEHS columns (equation (6.32))

- Table EHS is the prediction using Table 6.14 
As can be seen, the dispersion obtained with the two regression equations specific for circular (equation (6.29)) and elliptical columns (equation (6.32)) is similar ( 0.07 versus 0.09 standard deviation), although the accuracy of the specific expression for elliptical columns is higher (1.01 versus 0.93 average error). This is due to the differences in the development of temperatures in these two shapes: while in the circular sections a unidirectional heat transfer occurs, producing an axisymmetric temperature field, in the elliptical sections the heat flux is multidirectional, producing unequal temperature gradients in the different directions. Therefore, the temperature at a $30 \mathrm{~mm}$ depth in a circular column is not exactly equivalent to that corresponding to the same depth in the elliptical geometry. Thus, it seems more appropriate in this case to use the equation proposed for CFEHS columns. If a higher precision wants to be obtained, Table 6.14 (specific for CFEHS columns) can be used, with a lower dispersion (0.02 standard deviation) and 1.00 average error.

\subsubsection{Flexural stiffness reduction coefficients}

A set of flexural stiffness reduction coefficients was proposed in Section 6.3.4 for unreinforced CFCHS columns, which must be used in combination with buckling curve "a" when applying the general calculation model in Clause 4.3.5.1 of EN 1994-1-2 (CEN 2005c). For the concrete core, a constant reduction coefficient $\left(\varphi_{c, \theta}\right)$ equal to 0.8 (with the initial tangent stiffness) was proposed, while for the steel tube $\left(\varphi_{a, \theta}\right)$ a design equation was developed, as function of the member slenderness (through $\left.\ell_{\theta} / D\right)$, cross-sectional slenderness $(D / t)$ and section factor $\left(A_{m} / V\right)$. The proposed equation for CFCHS columns is reproduced here (see equation (6.33)) for a better understanding. Alternatively, Table 6.6 can be used for obtaining the reduction coefficient for the steel tube.

$$
\begin{aligned}
& \varphi_{a, \theta}=\varphi_{a, \theta 1}(D / t) \times \\
& \times\left(2.747-1.48 \cdot\left(A_{m} / V\right)^{0.08}\right) \times\left(0.0813+0.0133 \cdot\left(\ell_{\theta} / D\right)^{1.097}\right) \leq 1
\end{aligned}
$$

In this section, the validity of the proposed expressions for the flexural stiffness reduction coefficients is studied for the case of CFEHS columns.

The shape of an ellipse is characterized by its outside dimensions $2 a$ (major axis) and $2 b$ (minor axis), therefore equation (6.33) cannot be evaluated through a single diameter in this case. Instead, an equivalent diameter must be assigned. In the first term of equation (6.33), a value $D_{e q}=P / \pi$ was used (i.e. the diameter of that 
circle which has the same perimeter $P$ than the elliptical section), while in the third term several options were considered:

- Option 1: using the major axis dimension $(D=2 a)$

- Option 2: using the minor axis dimension $(D=2 b)$

- Option 3: using $D=P / \pi$.

The same three options where considered for entering to Table 6.6 with a value of $\ell_{\theta} / D$.

A set of numerical results was available for the series of CFEHS columns analysed in the parametric studies presented in Section 5.3. These simulation results were used for studying the validity of the proposed method for elliptical columns. For this purpose, the values of the buckling resistance from the numerical simulations $\left(N_{f i, R d}{ }^{N U M}\right)$ were compared with those obtained by means of the application of the simple calculation model $\left(N_{f i, R d}{ }^{P R E D}\right)$. The error in the predictions was computed as:

$\xi=1-\frac{N_{f i, R d}^{P R E D}-N_{f i, R d}^{N U M}}{N_{f i, R d}^{N U M}}$

Table 6.16 summarises the average and standard deviation of the error in the evaluation of the buckling resistance of the columns obtained by means of the proposed method using each of the three options for calculating the reduction coefficient of the steel tube $\left(\varphi_{a, \theta}\right)$, and using either the design equation (6.33) or the values in Table 6.6.

Table 6.16. Summary of the errors in the prediction of the buckling resistance for CFEHS columns

\begin{tabular}{cccccccc}
\hline & \multicolumn{2}{c}{$\begin{array}{c}\text { Option 1 } \\
(\boldsymbol{D}=\mathbf{2 a})\end{array}$} & \multicolumn{2}{c}{$\begin{array}{c}\text { Option 2 } \\
(\boldsymbol{D}=\mathbf{2 b})\end{array}$} & \multicolumn{2}{c}{$\begin{array}{c}\text { Option 3 } \\
(\boldsymbol{D}=\boldsymbol{P} / \boldsymbol{\pi})\end{array}$} \\
\cline { 2 - 7 } & Mean & Std. dev. & Mean & Std. dev. & Mean & Std. dev. \\
\hline Design equation (6.33) & 1.20 & 0.14 & 1.01 & 0.14 & 1.14 & 0.13 \\
Tabulated data (Table 6.6) & 1.02 & 0.19 & 0.95 & 0.13 & 1.01 & 0.17 \\
\hline
\end{tabular}

According to the results in this table, option 2 seems to be the most appropriate when applying the proposed method to elliptical columns. With the use of the design equation, this option provides a better average error (closer to unity), 
while for the tabulated data, although the mean value is not so accurate, the dispersion results much lower than under the other options.

Therefore, it is suggested to use the minor axis dimension $(D=2 b)$ for evaluating the $\ell_{\theta} / D$ of an elliptical column loaded in axial compression. This assumption is reasonable, since under concentric axial load, an elliptical column is more likely to buckle about its minor axis. For eccentric loads, further studies would be needed.

Although the results obtained by the application of the proposed method for CFCHS columns to elliptical columns are reasonably accurate, they can be improved. A deeper study of the CFEHS columns analysed reveals that the section factor values of the elliptical columns result considerably higher than those of the circular columns, with all the analysed columns having values of $A_{m} / V>20(41.12$ $\mathrm{m}^{-1}$ for $150 \times 75 \mathrm{~mm}$ ), and therefore corresponding to the last column in Table 6.6. This suggests that a column should be added to this table in order to cover higher section factor values which can be reached for CFEHS columns. A proposal is given in Table 6.17 for columns with higher section factor values, which extends the applicability of Table 6.6 and is valid for both circular and elliptical CFT columns.

Table 6.17. Values of the reduction coefficient for steel $\varphi_{a, \theta}$ (tabulated method)

$$
\begin{array}{|c|c|ccccc|}
\cline { 3 - 7 } \multicolumn{2}{c|}{} & \multicolumn{5}{|c|}{\boldsymbol{A}_{\boldsymbol{m}} / \boldsymbol{V}\left(\mathbf{m}^{\mathbf{- 1}}\right)} \\
\cline { 3 - 7 } \multicolumn{1}{c|}{} & <\mathbf{1 0} & \mathbf{1 0}-\mathbf{1 5} & \mathbf{1 5 - 2 0} & \mathbf{2 0}-\mathbf{4 0} & \mathbf{4 0 0} \\
\hline \multirow{4}{*}{\ell_{\theta} / D} & \leq \mathbf{1 2} & 0.4 & 0.35 & 0.3 & 0.25 & 0.2 \\
& \mathbf{2 4} & - & 0.5 & 0.5 & 0.4 & 0.3 \\
& \mathbf{3 6} & - & - & 0.7 & 0.7 & 0.7 \\
& \geq \mathbf{4 6} & - & - & - & 1 & 1 \\
\hline
\end{array}
$$

Using the updated table, a better agreement between the predictions and simulation results for the elliptical columns is found, with an average error equal to 1.00 and a standard deviation of 0.15 (see Table 6.18).

It is worth noting that the range of $D / t$ values is narrower for elliptical columns than for circular columns, with most of the analysed sections falling between the limits 15-35 in Table 6.5, so the partial reduction coefficient $\varphi_{a, \theta I}$ adopts the same value for the majority of the analysed columns $\left(\varphi_{a, \theta I}=1\right)$. Although the effect of the cross-sectional slenderness can also be observed in elliptical columns (as it was proved in Section 5.3.4), the range of commercially available steel tube wall thicknesses for EHS profiles is not as broad as it is for CHS columns, therefore producing a lower variability in $D / t$ (14.46 - 28.91 for the EHS columns 
studied, against 11.18 - 54.60 for the CHS columns studied). For the range of intermediate $D / t$ values which correspond to CFEHS columns, a value $\varphi_{a, \theta 1}=1$ results in good agreement with the numerical simulations.

Finally, a specific formulation was developed for CFEHS columns. Using the simulation results available for the series of CFEHS columns analysed in the parametric studies presented in Section 5.3, the reduction coefficient for the steel tube $\varphi_{a, \theta}$ was calculated, fixing $\varphi_{c, \theta}=0.8$ and employing the procedure explained in Section 6.3.4. A multiple nonlinear regression analysis was conducted over the theoretical values of $\varphi_{a, \theta}$ for the elliptical columns, using the shape of the previously proposed equation (6.33), and the following coefficients were obtained:

$$
\begin{aligned}
& \varphi_{a, \theta}=\varphi_{a, \theta 1}\left(D_{e q} / t\right) \times \\
& \times\left(1.73-0.72 \cdot\left(A_{m} / V\right)^{0.047}\right) \times\left(0.118+0.0015 \cdot\left(\ell_{\theta} / 2 b\right)^{1.72}\right) \leq 1
\end{aligned}
$$

In this equation, the reduction coefficient $\varphi_{a, \theta}$ is a product of two partial reduction coefficients lower than unity, $\varphi_{a, \theta 2}$ and $\varphi_{a, \theta 3}$, which are corrected by the factor $\varphi_{a, \theta l}$ as a function of $D_{e q} / t$ only for stocky columns $\left(\ell_{\theta} / 2 b \leq 12\right)$, using the values tabulated in Table 6.5. For $\ell_{\theta} / 2 b>12$, the factor $\varphi_{a, \theta l}$ is equal to unity. The equivalent diameter for evaluating the first term in this equation is calculated as $D_{e q}$ $=P / \pi$, with $P=$ the perimeter of the elliptical section.

Using the proposed equation (6.35), a mean value of the error equal to 1.04 (safe) was obtained, with a reduced dispersion (0.10 standard deviation). The average and standard deviation values obtained under the different approaches studied are summarised in Table 6.18, where it can be seen that this option produced more conservative predictions and a controlled dispersion of results, although the proposal for circular columns (design equation or tabulated data) can also be applied to elliptical columns with accurate results.

Table 6.18. Summary of the errors in the prediction of the buckling resistance for CFEHS columns

\begin{tabular}{ccc}
\cline { 2 - 3 } & \multicolumn{2}{c}{$\begin{array}{c}\text { Option 2 } \\
(\boldsymbol{D}=\mathbf{2 b})\end{array}$} \\
\cline { 2 - 3 } & Mean & Std. dev. \\
\hline Design equation (6.33) for CFCHS & 1.01 & 0.14 \\
Tabulated data (Table 6.17) & 1.00 & 0.15 \\
Design equation (6.35) for CFEHS & 1.04 & 0.10 \\
\hline
\end{tabular}


In Figure 6.32, a comparison is shown between the predictions and the numerical simulations in terms of normalised buckling load, for the proposed equation (6.35), specific for elliptical columns.

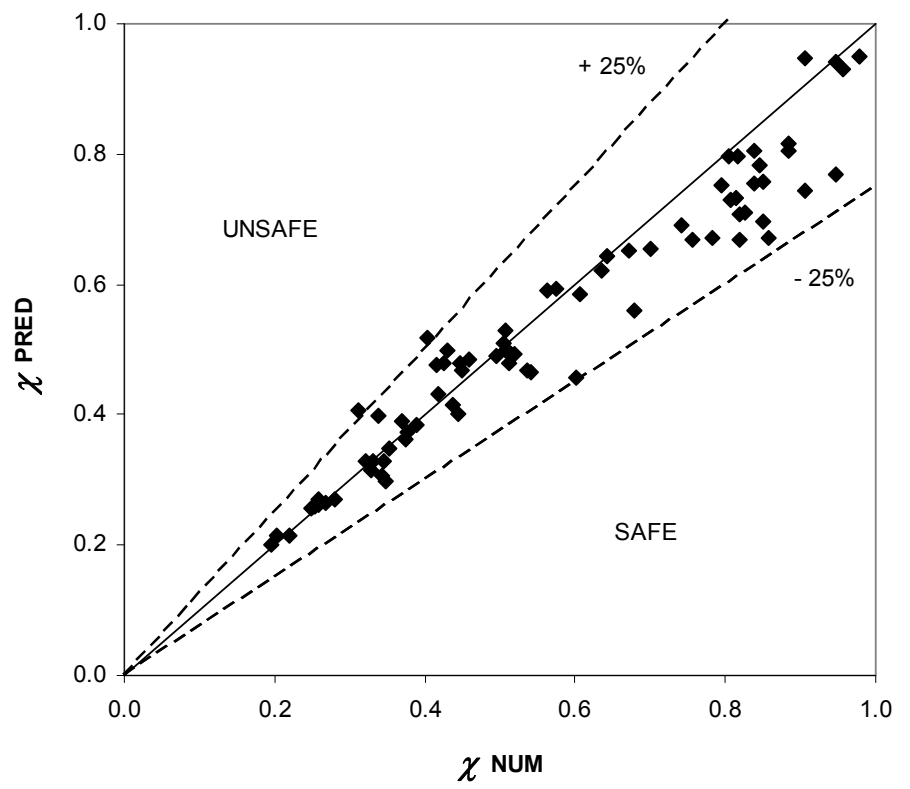

Figure 6.32. Comparison between the predictions and numerical simulations for CFEHS columns, in terms of normalised buckling load.

Figure 6.33 presents the evolution of the buckling coefficient with the relative slenderness at elevated temperature, using the proposed equation (6.35). It can be seen that the data follow closely the reference buckling curve "a", with an excellent agreement for the higher slenderness and a moderated dispersion for intermediate slenderness. For low slenderness values, buckling coefficients higher that unity are obtained in some cases, which are attributed to the confinement effect in stub columns, which was not accounted for in the development of the design equation. 


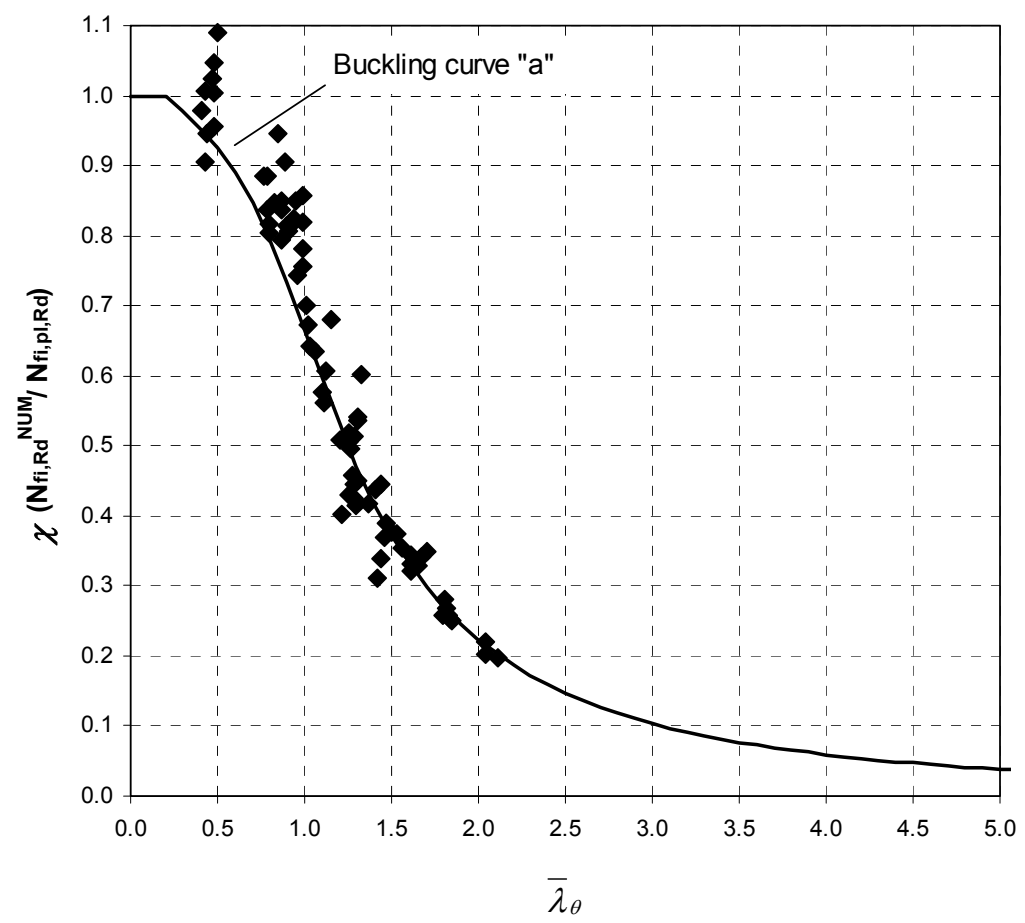

Figure 6.33. Evolution of the buckling coefficient with the relative slenderness at elevated temperature, for CFEHS columns.

In conclusion, the proposed method for circular columns can also be applied to elliptical columns, under the two options: design equation or tabulated method, using in the last case the updated Table 6.17. If a higher precision wants to be obtained, equation (6.35) specific for elliptical columns can be applied, although equation (6.33) can be used for both circular and elliptical columns, producing accurate results.

\subsubsection{Comparison of the proposed method with experiments}

The accuracy of the design proposal exposed above for CFEHS columns is next verified against the results of the fire tests carried out recently in Valencia on slender CFEHS columns. From the list of tests presented in Section 5.2.4, only specimens E220-110-12-3-30-00-20 and RE220-110-12-3-30-00-20 are studied, corresponding to columns loaded under concentric axial load. For each case, the 
applied axial load is compared with the predicted buckling load at the time of failure, using the proposed method.

The equivalent temperatures of the steel tube, concrete core and reinforcing bars are evaluated under two approaches:

- Option 1: Equations (6.20), (6.21) and (6.29), developed for CFCHS columns

- Option 2: Equations (6.30), (6.31) and (6.32), developed for CFEHS columns

Also the realistic temperature field obtained from the experiments is used here for comparison, where the representative temperatures of the different layers in which the section is subdivided are interpolated from the measurements at the location of the thermocouples (option 3).

After obtaining the corresponding temperatures for the steel tube, concrete core and reinforcing bars, the simple calculation method described in the previous sections is applied for obtaining the buckling resistance of the columns, using equation (6.33) or (6.35) for the flexural stiffness reduction coefficient of the steel tube. Table 6.19 summarises the results obtained under the three different options, for one of the columns studied.

Table 6.19. Summary of the results in the prediction of the fire buckling load, for column E220-110-12-3-30-00-20

\begin{tabular}{|c|c|c|c|c|c|c|c|}
\hline & & \multicolumn{2}{|c|}{$\begin{array}{c}\text { Option 1 } \\
\text { (Proposal CHS) }\end{array}$} & \multicolumn{2}{|c|}{$\begin{array}{c}\text { Option 2 } \\
\text { (Proposal EHS) }\end{array}$} & \multicolumn{2}{|c|}{$\begin{array}{c}\text { Option 3 } \\
\text { (Measured temp.) }\end{array}$} \\
\hline & $N(\mathrm{kN})$ & $N_{f i, R d}(\mathrm{kN})$ & $N / N_{f i, R d}$ & $N_{f i, R d}(\mathbf{k N})$ & $N / N_{f i, R d}$ & $N_{f i, R d}(\mathbf{k N})$ & $N / N_{f i, R d}$ \\
\hline Equation (6.33) & 397.19 & 287.88 & 1.38 & 332.32 & 1.20 & 283.81 & 1.40 \\
\hline Equation (6.35) & 397.19 & 275.01 & 1.44 & 316.98 & 1.25 & 271.86 & 1.46 \\
\hline
\end{tabular}

As it can be seen in Table 6.19, the option which produced a better agreement with the test result is option 2, with an error equal to 1.20 (safe) using equation (6.33) and 1.25 using equation (6.35) for the reduction coefficients. The result obtained by means of using the equivalent temperature expression developed for circular columns produced a higher error, although comparable to that obtained with the real temperatures from the test and both options resulting in safe predictions. Similar results were obtained for column RE220-110-12-3-30-00-20. A comparison with the test results can be clearly seen in Figure 6.34 for the two column specimens studied, where equation (6.33) has been used for calculating the steel tube reduction coefficient. 


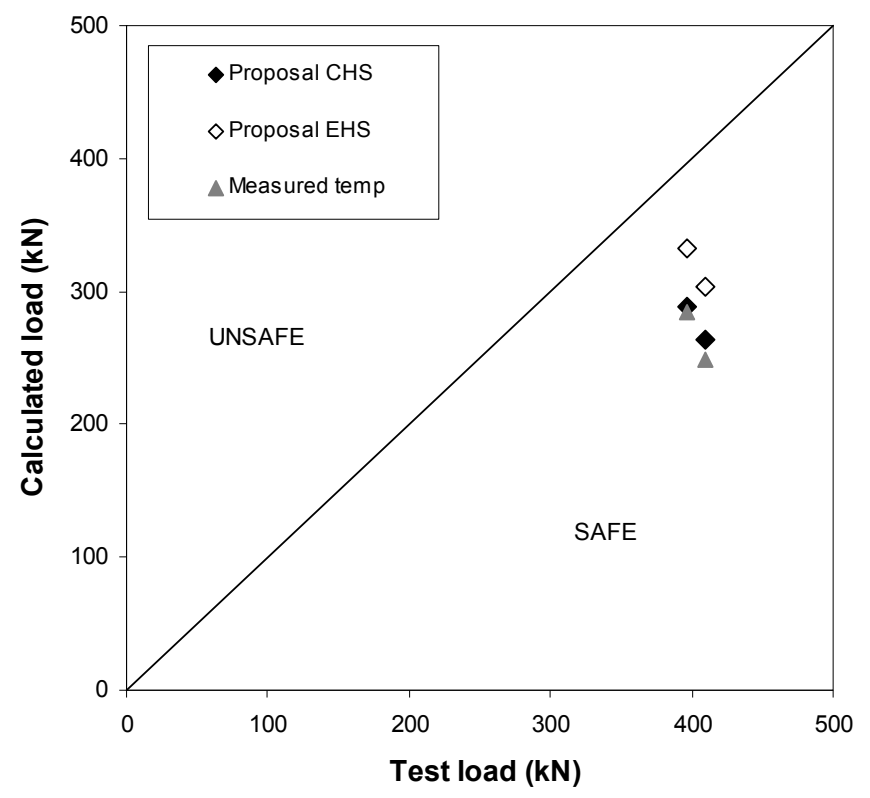

Figure 6.34. Comparison of ultimate loads between the proposed method and tests, for CFEHS columns.

From this figure, it can be concluded that the proposed method produces reasonable results for elliptical columns, using either the equivalent temperature equations for circular or elliptical columns, although with more precision when the specific expressions for elliptical columns are used. Similar results are obtained using the real temperature field from the tests, which confirms that the method is valid for its application to elliptical columns. 


\subsection{OVERVIEW OF THE PROPOSED CALCULATION METHOD}

A method has been given for the calculation of the fire resistance of unreinforced and bar-reinforced concrete filled tubular columns of circular and elliptical shape. The proposed method follows the guidelines in Clause 4.3.5.1 of EN 1994-1-2 (CEN 2005c), using specific expressions for evaluating the temperatures of the different components of the composite section, as well as their flexural stiffness reduction coefficients and the suitable buckling curve for the different reinforcing ratios. An overview of the proposed method is given next.

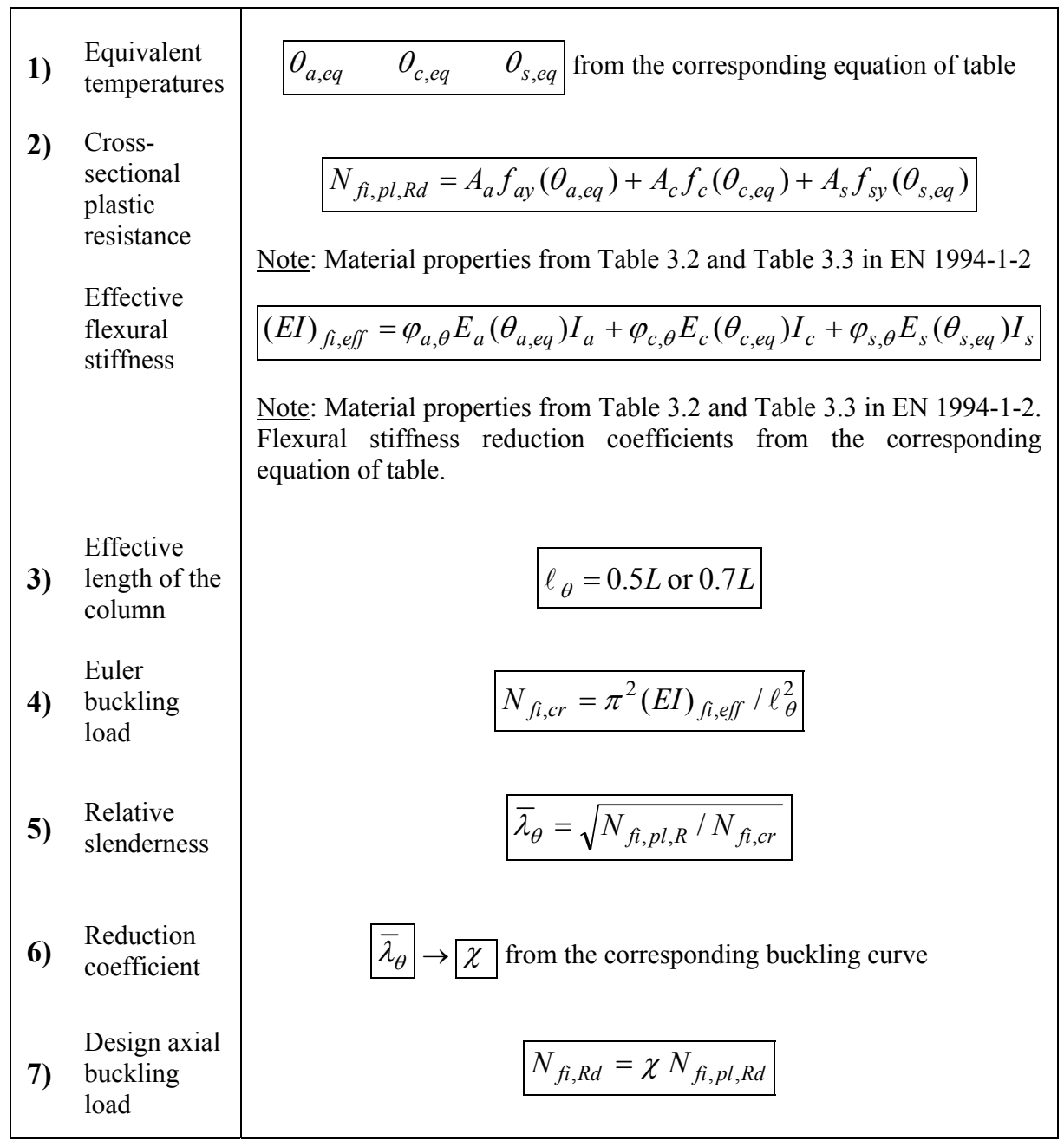


The expressions and tables needed for the evaluation of the equivalent temperatures in step 1) are the following:

\begin{tabular}{|l|c|}
\hline \multicolumn{2}{|c|}{ CFCHS columns } \\
\hline$\theta_{a, e q}=342.1+10.77 R-0.044 R^{2}+3.922 A_{m} / V-0.025 R \cdot A_{m} / V$ & \\
$\theta_{c, e q}=-186.44+5.764 R-0.026 R^{2}+22.577 A_{m} / V-0.32\left(A_{m} / V\right)^{2}+$ & Or Table \\
$+0.14 R \cdot A_{m} / V$ & \\
\hline$\theta_{s, e q}=-119.36+8.535 R-0.033 R^{2}+3.948 A_{m} / V+0.102 R \cdot A_{m} / V$ & Or Table \\
6.21
\end{tabular}

Table 6.20. Values of the equivalent temperatures for concrete $\left(\theta_{c, e q}\right)$ and steel $\left(\theta_{a, e q}\right)$ in function of the section factor, for CFCHS columns

\begin{tabular}{|c|c|c|c|c|c|c|c|c|c|}
\hline & \multicolumn{2}{|c|}{ R30 } & \multicolumn{2}{|c|}{ R60 } & \multicolumn{2}{|c|}{ R90 } & \multicolumn{2}{|c|}{ R120 } \\
\hline & & $\begin{array}{l}\theta_{c, e q} \\
\left({ }^{\circ} \mathrm{C}\right)\end{array}$ & $\begin{array}{l}\theta_{a, e q} \\
\left({ }^{\circ} \mathrm{C}\right)\end{array}$ & $\begin{array}{l}\theta_{c, e q} \\
\left({ }^{\circ} \mathrm{C}\right)\end{array}$ & $\begin{array}{l}\theta_{a, e q} \\
\left({ }^{\circ} \mathrm{C}\right)\end{array}$ & $\begin{array}{l}\theta_{c, e q} \\
\left({ }^{\circ} \mathrm{C}\right)\end{array}$ & $\begin{array}{l}\theta_{a, e q} \\
\left({ }^{\circ} \mathrm{C}\right)\end{array}$ & $\begin{array}{l}\theta_{c, e q} \\
\left({ }^{\circ} \mathrm{C}\right)\end{array}$ & $\begin{array}{l}\theta_{a, e q} \\
\left({ }^{\circ} \mathrm{C}\right)\end{array}$ \\
\hline \multirow{6}{*}{$\begin{array}{c}A_{m} / V \\
\left(\mathbf{m}^{-1}\right)\end{array}$} & 5 & 141 & 636 & 197 & 857 & 316 & 957 & 344 & 1013 \\
\hline & 10 & 210 & 652 & 342 & 869 & 422 & 964 & 487 & 1018 \\
\hline & 15 & 278 & 669 & 453 & 880 & 571 & 971 & 659 & 1024 \\
\hline & 20 & 346 & 686 & 549 & 891 & 721 & 978 & 819 & 1030 \\
\hline & 25 & 413 & 703 & 647 & 903 & 831 & 985 & 928 & 1035 \\
\hline & 30 & 480 & 719 & 764 & 914 & 860 & 992 & 947 & 1041 \\
\hline
\end{tabular}

Table 6.21. Values of the equivalent temperatures for the reinforcing bars $\left(\theta_{s, e q}\right)$ in function of the section factor, for CFCHS columns

\begin{tabular}{|c|c|cccc|}
\cline { 3 - 5 } \multicolumn{2}{c|}{} & \multicolumn{4}{|c|}{$\boldsymbol{\theta}_{\text {s,eq }}\left({ }^{\mathbf{0}} \mathbf{C}\right)$} \\
\cline { 3 - 6 } \multicolumn{2}{c|}{} & $\mathbf{R 3 0}$ & $\mathbf{R 6 0}$ & $\mathbf{R 9 0}$ & $\mathbf{R 1 2 0}$ \\
\hline & $\mathbf{5}$ & 152 & 318 & 435 & 525 \\
& $\mathbf{1 0}$ & 181 & 374 & 505 & 601 \\
$\boldsymbol{A}_{\boldsymbol{m}} / \boldsymbol{V}$ & $\mathbf{1 5}$ & 211 & 430 & 575 & 677 \\
$\mathbf{( m}^{-\mathbf{1}} \mathbf{)}$ & $\mathbf{2 0}$ & 241 & 485 & 644 & 754 \\
& $\mathbf{2 5}$ & 271 & 541 & 714 & 830 \\
& $\mathbf{3 0}$ & 301 & 597 & 784 & 906 \\
\hline
\end{tabular}




\begin{tabular}{|l|c|}
\hline \multicolumn{2}{|c|}{ CFEHS columns } \\
\hline$\theta_{a, e q}=300.845+11.209 R-0.044 R^{2}+4.219 A_{m} / V-0.029 R \cdot A_{m} / V$ & \\
$\theta_{c, e q}=-395.503+9.304 R-0.035 R^{2}+33.698 A_{m} / V-0.425\left(A_{m} / V\right)^{2}+$ & $\begin{array}{c}\text { Or Table } \\
6.22 \\
+0.035 R \cdot A_{m} / V\end{array}$ \\
\hline$\theta_{s, e q}=-255.1+10.106 R-0.039 R^{2}+8.036 A_{m} / V+0.062 R \cdot A_{m} / V$ & $\begin{array}{c}\text { Or Table } \\
6.23\end{array}$ \\
\hline
\end{tabular}

Table 6.22. Values of the equivalent temperatures for concrete $\left(\theta_{c, e q}\right)$ and steel $\left(\theta_{a, e q}\right)$ in function of the section factor, for CFEHS columns

\begin{tabular}{|c|c|c|c|c|c|c|c|c|c|}
\hline & \multicolumn{2}{|c|}{ R30 } & \multicolumn{2}{|c|}{ R60 } & \multicolumn{2}{|c|}{ R90 } & \multicolumn{2}{|c|}{ R120 } \\
\hline & & $\begin{array}{r}\theta_{c, e q} \\
\left({ }^{\circ} \mathrm{C}\right)\end{array}$ & $\begin{array}{l}\theta_{a, e q} \\
\left({ }^{\circ} \mathrm{C}\right)\end{array}$ & $\begin{array}{l}\theta_{c, e q} \\
\left({ }^{\circ} \mathrm{C}\right)\end{array}$ & $\begin{array}{l}\theta_{a, e q} \\
\left({ }^{\circ} \mathrm{C}\right)\end{array}$ & $\begin{array}{l}\theta_{c, e q} \\
\left({ }^{\circ} \mathbf{C}\right)\end{array}$ & $\begin{array}{l}\theta_{a, e q} \\
\left({ }^{\circ} \mathrm{C}\right)\end{array}$ & $\begin{array}{l}\theta_{c, e q} \\
\left({ }^{\circ} \mathbf{C}\right)\end{array}$ & $\begin{array}{l}\theta_{a, e q} \\
\left({ }^{\circ} \mathbf{C}\right)\end{array}$ \\
\hline \multirow{8}{*}{$\begin{array}{c}A_{m} / V \\
\left(m^{-1}\right)\end{array}$} & 10 & 232 & 623 & 359 & 855 & 410 & 956 & 465 & 1014 \\
\hline & 15 & 299 & 641 & 475 & 866 & 593 & 963 & 696 & 1019 \\
\hline & 20 & 361 & 659 & 577 & 878 & 727 & 970 & 842 & 1024 \\
\hline & 25 & 419 & 677 & 663 & 889 & 822 & 976 & 925 & 1029 \\
\hline & 30 & 472 & 695 & 734 & 900 & 884 & 983 & 965 & 1034 \\
\hline & 35 & 520 & 713 & 789 & 912 & 922 & 990 & 985 & 1040 \\
\hline & 40 & 564 & 731 & 828 & 923 & 945 & 997 & 1005 & 1045 \\
\hline & 45 & 603 & 749 & 853 & 934 & 961 & 1004 & 1046 & 1050 \\
\hline
\end{tabular}

Table 6.23. Values of the equivalent temperatures for the reinforcing bars $\left(\theta_{s, e q}\right)$ in function of the section factor, for CFEHS columns

\begin{tabular}{|l|c|cccc|}
\cline { 3 - 5 } \multicolumn{2}{c|}{} & \multicolumn{4}{|c|}{$\boldsymbol{\theta}_{\text {s,eq }}\left({ }^{\mathbf{0}} \mathbf{C}\right)$} \\
\cline { 3 - 6 } \multicolumn{2}{c|}{} & $\mathbf{R 3 0}$ & $\mathbf{R 6 0}$ & $\mathbf{R 9 0}$ & $\mathbf{R 1 2 0}$ \\
\hline & $\mathbf{1 0}$ & 176 & 355 & 422 & 510 \\
& $\mathbf{1 5}$ & 182 & 371 & 521 & 629 \\
& $\mathbf{2 0}$ & 201 & 427 & 611 & 731 \\
$\boldsymbol{A}_{\boldsymbol{m}} / \boldsymbol{V}$ & $\mathbf{2 5}$ & 233 & 506 & 692 & 816 \\
$\mathbf{( m}^{-1} \mathbf{)}$ & $\mathbf{3 0}$ & 277 & 593 & 763 & 884 \\
& $\mathbf{3 5}$ & 333 & 671 & 825 & 935 \\
& $\mathbf{4 0}$ & 402 & 724 & 878 & 969 \\
& $\mathbf{4 5}$ & 483 & 736 & 922 & 986 \\
\hline
\end{tabular}


In step 2), the flexural stiffness reduction coefficients can be determined from the following expressions and tables:

\begin{tabular}{|c|l|}
\hline$\varphi_{a, \theta}$ & $\begin{array}{l}\text { CFCHS columns } \\
\varphi_{a, \theta}=\varphi_{a, \theta 1}(D / t) \times\left(2.747-1.48 \cdot\left(A_{m} / V\right)^{0.08}\right) \times\left(0.0813+0.0133 \cdot\left(\ell_{\theta} / D\right)^{1.097}\right) \\
\text { CFEHS columns } \\
\varphi_{a, \theta}=\varphi_{a, \theta 1}\left(D_{e q} / t\right) \times\left(1.73-0.72 \cdot\left(A_{m} / V\right)^{0.047}\right) \times\left(0.118+0.0015 \cdot\left(\ell_{\theta} / 2 b\right)^{1.72}\right) \\
\text { or alternatively from Table } 6.25 \\
\text { Note: These values must be corrected with the partial coefficient } \varphi_{a, \theta 1} \text { for } \ell_{\theta} / D \leq 12 .\end{array}$ \\
\hline$\varphi_{c, \theta}$ & 0.8 \\
\hline$\varphi_{s, \theta}$ & from Table 6.26 \\
\hline
\end{tabular}

Table 6.24. Values of the partial reduction coefficient for steel $\varphi_{a, \theta 1}\left(\ell_{\theta} / D \leq 12\right)$

\begin{tabular}{cc}
\hline $\boldsymbol{D} / \boldsymbol{t}$ & $\boldsymbol{\varphi}_{a, \theta \boldsymbol{I}}$ \\
\hline$<15$ & 0.75 \\
$15-35$ & 1 \\
$35-45$ & 1.25 \\
$>45$ & 2.5 \\
\hline
\end{tabular}

Table 6.25. Values of the reduction coefficient for steel $\varphi_{a, \theta}$

\begin{tabular}{|c|c|ccccc|}
\cline { 3 - 7 } \multicolumn{2}{c|}{} & \multicolumn{5}{|c|}{$\boldsymbol{A}_{\boldsymbol{m}} / \boldsymbol{V}\left(\mathbf{m}^{-\mathbf{1}}\right)$} \\
\cline { 3 - 7 }$\ell_{\theta} / D$ & $<\mathbf{1 0}$ & $\mathbf{1 0}-\mathbf{1 5}$ & $\mathbf{1 5 - 2 0}$ & $\mathbf{2 0}-\mathbf{4 0}$ & $\mathbf{1 5 0}$ \\
\hline \multirow{4}{*}{$\ell$} & $\leq \mathbf{1 2}$ & 0.4 & 0.35 & 0.3 & 0.25 & 0.2 \\
& $\mathbf{2 4}$ & - & 0.5 & 0.5 & 0.4 & 0.3 \\
& $\mathbf{3 6}$ & - & - & 0.7 & 0.7 & 0.7 \\
& $\geq \mathbf{4 6}$ & - & - & - & 1 & 1 \\
\hline
\end{tabular}

In step 6), the buckling curve must be selected from Table 6.26, in function of the reinforcement ratio.

Table 6.26. Buckling curve and reduction coefficient of the reinforcing bars

\begin{tabular}{cccc}
\hline Reinforcement ratio & $\boldsymbol{\rho}=\mathbf{0 \%}$ & $\mathbf{0 \%}<\boldsymbol{\rho} \leq \mathbf{2 . 5 \%}$ & $\mathbf{2 . 5 \%}<\boldsymbol{\rho} \leq \mathbf{5 \%}$ \\
\hline Buckling curve & "a" $(\alpha=0.21)$ & "b" $(\alpha=0.34)$ & "c" $(\alpha=0.49)$ \\
$\varphi_{s, \boldsymbol{\theta}}$ & - & 0.6 & 0.3 \\
\hline
\end{tabular}





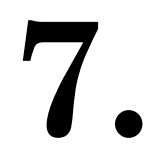

\section{CONCLUSIONS}

This chapter presents the main conclusions drawn from the work in this dissertation. In addition, suggestions for future work are given at the end of the chapter. 


\subsection{GENERAL CONCLUSIONS}

In this dissertation, the fire behaviour of axially loaded concrete filled steel tubular columns of circular and elliptical cross-section was investigated through numerical modelling. A realistic three-dimensional finite element model was developed, carrying out a comprehensive sensitivity analysis on the main modelling aspects. The accuracy of the numerical model was verified by means of test results available in the literature as well as against own tests, showing that it can provide a realistic representation of the fire response of normal strength concrete filled circular hollow section columns. Elliptical columns were also studied through numerical modelling and compared against the circular shapes. The validated model was used for conducting parametric studies and, based on their results, developing a simple calculation method for evaluating the fire resistance of CFT columns which is in line with the general rules in Eurocode 4 Part 1.2. Therefore, it can be concluded that the general aim of this thesis and its associated specific objectives have been sufficiently covered in this work.

\subsection{SPECIFIC CONCLUSIONS}

From the numerical investigation on the fire behaviour of CFT columns, some conclusions were drawn:

- The numerical model is sufficiently validated against different sources and capable for predicting the fire response of normal strength CFCHS columns. Good agreement with the tests is obtained in the prediction of the thermal and mechanical response of the columns.

- The temperature evolution at certain locations within the cross-section follows accurately the test results, with the exception of the range of temperatures between 100 and $200{ }^{\circ} \mathrm{C}$ in the concrete layers, where the evaporation of moisture occurs.

- If the realistic moisture movement and evaporation within the concrete core wants to be predicted, a more complex hydro-thermal model would be needed.

- The fire behaviour of CFT columns can be divided into four stages, according to the evolution of the load transfer process between the two components of the composite section - steel tube and concrete core -. 
- The typical failure mechanism comprised by those four stages can be observed in the specimens subjected to moderated load levels. Nevertheless, for high load levels, a change in the failure mechanism was observed.

- It is important to secure a reduced ratio between the applied axial load and the individual capacities of the two components of the composite section to allow for the transference of load between the steel tube and concrete core and thus taking advantage of the contribution of concrete in the increment of the fire resistance time.

By means of the validated numerical model, a comprehensive sensitivity analysis was carried out, from which a number of modelling recommendations were obtained:

- For modelling the tangent behaviour at the steel-concrete interface, a full slip can be assumed and thus a frictionless contact model adopted, since in fire situation the different thermal expansions cause the transverse separation of the steel tube from the concrete core.

- In case that a Coulomb friction model is selected, the value of the friction coefficient at the steel-concrete interface does not have any influence on the column behaviour under fire.

- Regarding the gap thermal conductance at the steel-concrete interface, the model proposed by Ghojel (2004) produces the best estimations in failure time, although adopting a constant value of $h_{j}=200 \mathrm{~W} / \mathrm{m}^{2} \mathrm{~K}$ is more simplistic and produces acceptable results as well.

- It is recommended to employ an amplitude value of $L / 1000-L / 2000$ for the initial geometric imperfection of the columns.

- For steel, the EN1993-1-2 (CEN 2005b) mechanical model produces the most accurate response, while for concrete the model developed by Lie (1984) is the one that best predicts the overall behaviour in the fire situation.

- The EN1993-1-2 (CEN 2005b) thermal expansion model gives very accurate results for steel, whereas for concrete the constant value $\alpha_{c}=6 \times 10^{-6}{ }^{\circ} \mathrm{C}^{-1}$ recommended by Hong \& Varma (2009) produces the best results.

- The optimal results are obtained both in the thermal and mechanical response with a moisture content value at the concrete core of $3 \%$ for the specimens filled with siliceous aggregates concrete and with a $10 \%$ for those filled with concrete with calcareous aggregates, even though this variable should be 
reported in the tests for every specimen and its exact value introduced to the model.

- A constant value of $2300 \mathrm{~kg} / \mathrm{m}^{3}$ is sufficient for modelling the concrete density. There is no significant influence of the temperature variation of this parameter over the fire behaviour of the columns.

- It is recommended to employ two-noded truss elements for modelling the longitudinal steel bars in the reinforced column specimens.

The fire response of concrete filled elliptical hollow section columns was also studied through finite element modelling. Parametric studies were conducted in order to assess the influence of the column slenderness, load level, cross-section slenderness and section size on the fire response of the concrete filled elliptical columns. Some conclusions were drawn:

- The fire resistance of the columns decreases with an increase in member slenderness and load level, as well as with an increase of the section factor.

- The influence of the cross-section slenderness and section thickness is not so clear, with opposing trends obtained for stocky and slender columns, which is related to their different failure modes.

A comparative study between elliptical and circular concrete filled hollow section columns in fire was also presented. This study showed that for a certain column length and load-bearing capacity at room temperature, the circular columns attain higher fire resistance than the elliptical columns, with reduced material use. This is only valid for centrally loaded columns, while for eccentric loads different results may be expected.

This thesis also reviewed the current design guidelines for calculating the fire resistance of CFT columns, specially focusing on the methods in Eurocode 4 Part 1.2. The main conclusion drawn from the study of the code provisions was that the methods in Eurocode 4 Part 1.2 - the general method in Clause 4.3.5.1 and the specific method in Annex $\mathrm{H}$ - may lead to unsafe results for slender columns loaded in central compression.

Given the inaccuracy and limitations of the methods in Eurocode 4, a new proposal based on the general rules for composite columns in Clause 4.3.5.1 was developed by means of parametric studies. The main conclusions extracted from the parametric studies and from the development of the simple calculation method are the following: 
- A uniform equivalent temperature can be used to represent the whole concrete core and the steel tube so as to obtain the same fire resistance of the column as by using the real non-uniform temperature distribution. Expressions and tables for the equivalent temperatures were proposed, producing accurate predictions.

- A flexural stiffness reduction coefficient equal to 0.8 applied over the initial tangent modulus of concrete can be assumed to account for the thermal stresses, while for the steel tube more conservative coefficients are needed, in order to include the overload effect.

- The equations and tables proposed in this work can be used in combination with buckling curve "a" to obtain a good estimation of the buckling resistance of unreinforced CFT columns.

- For reinforced columns, it has been observed that as the reinforcement ratio increases, the normalised buckling load decreases, therefore different buckling curves are proposed for increasing reinforcement ratios. Buckling curve " $b$ " is proposed for a $2.5 \%$ reinforcement ratio, while buckling curve "c" is recommended for a $5 \%$ reinforcement ratio.

- The proposed expressions for the equivalent temperatures and reduction coefficients of the steel tube and concrete core are also valid for reinforced columns, combined with specific temperatures and reduction coefficients corresponding to the reinforcing bars, depending on the reinforcement ratio.

- Good agreement is obtained between the proposed method predictions and the numerical simulations, improving the accuracy of the currently available methods in Eurocode 4 Part 1.2.

- The proposed method also provides a good estimation of the buckling resistance of CFT columns at elevated temperatures as compared with real fire tests, producing safe predictions in the majority of the cases. Compared to other methods, the proposed method provides a reasonable accuracy in the predictions and tends to be on the safe side.

- The proposed method for circular columns can also be applied to elliptical columns producing reasonable results, nevertheless, specific expressions and tables have been proposed for elliptical columns, leading to accurate predictions. 


\subsection{FUTURE WORK}

After analysing the results of this investigation and given the extension of the problem studied, which cannot be covered by a single dissertation if all the different possible case scenarios want to be explored, some recommendations on future work can be given.

As a first future task, the numerical model should be extended to columns filled with high strength concrete. For these concrete mixtures, the development of high pore pressures when exposed to fire increases the probability of being affected by spalling, and therefore this phenomenon should be accounted for in the model. In that case, an advanced thermo-hygro-mechanical model would be needed, which is capable for predicting the moisture migration and pore pressure development within the concrete core.

Since this thesis focused on columns loaded in axial compression, the study of eccentrically loaded columns was left out for future work. Therefore, the numerical model should be validated against tests with eccentricity and equivalent parametric studies to those presented in this thesis should be carried out for eccentrically loaded columns, covering the values of all the parameters investigated in this research (e.g. cross-sectional dimensions, member slenderness, standard fire periods and reinforcement ratios).

Studying the effect of the load eccentricity is also interesting for comparing the differences in fire performance between circular and elliptical columns. It was seen in this work that, under concentric axial load, the circular columns are more efficient in fire performance than their elliptical counterparts; nevertheless this difference is not so clear for eccentrically loaded columns, where the elliptical shapes can gain advantage.

In order to complete the design proposal for bar-reinforced columns, different concrete cover values should be studied and also higher standard fire periods should be considered (up to 180 or even 240 minutes), since reinforced columns can achieve higher fire periods as the tests carried out in Canada demonstrate.

The use of steel fibers as reinforcement for CFT columns should also be studied and included in the proposed calculation method, since their usage has increased in the last years and fire tests are nowadays available for the validation of the model.

Another aspect which would be desirable to study in the future is the effect of the boundary conditions of this type of columns in real buildings and how they 
affect their fire behaviour. Throughout this work, the boundary conditions considered have been those which can be found in fire testing furnaces. Nevertheless, these end conditions do not reproduce the real conditions to which a column can be subjected in real construction, and therefore an extensive study of this aspect should be needed. It would be interesting to study the effect of different values of the axial and rotational restraints at the column ends on its fire resistance, which is being investigated by other research groups at the moment.

In this line, it would be important to study the local behaviour in the connections when exposed to fire, both experimentally and through numerical modelling.

Associated to these aspects is the problem of determining the buckling length of a column in the fire situation, which is a key factor when applying any calculation method based on stability analysis. Further study on the real stiffness of the column ends in the fire situation and the evolution of the effective buckling length along the fire exposure is found essential.

Finally, it is suggested to study in the future other types of cross-sectional geometries in order to broaden this study (e.g. square or rectangular sections), as well as innovative solutions such as concrete filled double skin steel tubular columns, which are being increasingly used in the construction industry. 



\section{REFERENCES}


ABAQUS. 2010. ABAQUS/Standard Version 6.10 User's Manual: Volumes I-III. Pawtucket, Rhode Island: Hibbitt, Karlsson \& Sorensen, Inc.

ACI. 2007. ACI 216.1M-07: Standard Method for Determining Fire Resistance of Concrete and Masonry Construction Assemblies. Detroit, USA: American Concrete Institute.

AFNOR. 2007. Calcul simplifié de la résistance au feu des profils creux remplis de béton exposés aux conditions d'incendie normalisé. Annexe PCRB, pp. 9-16, NF-EN 1994-1-2/NA. Paris, France: Association Française de Normalisation.

Al-Khaleefi AM, Terro MJ, Alex AP, Wang Y. 2002. Prediction of fire resistance of concrete filled tubular steel columns using neural networks. Fire Safety Journal 37(4):339-352.

Anderberg Y, Thelandersson S. 1976. Stress and deformation characteristics of concrete, 2-experimental investigation and material behaviour model. Bulletin 54. Lund, Sweden: Lund Institute of Technology.

Aribert JM, Renaud C, Zhao B. 2008. Simple fire design for composite hollowsection columns. Structures \& Buildings 161:325-336.

ASCE. 1999. ASCE/SFPE 29-99: Standard Calculation Method for Structural Fire Protection. Reston, USA: American Society of Civil Engineers.

Associated Factory Mutual Fire Insurance Companies (AFMFIC). 1917. Fire tests of building columns. Chicago, Illinois: Underwriters' Laboratories.

Association of New Urban Housing Technology (ANUHT). 2004. Fire resistance design of non-insulated CFT columns - Guidelines, technical explanations and design examples (in Japanese).

ASTM. 1990. Standard ASTM E119-88: Standard methods of fire test of building construction and materials. Philadelphia, Pa: American Society for Testing and Materials.

Bailey C. 2000. Effective lengths of concrete-filled steel square hollow sections in fire. Structures and Buildings 140(2):169-178.

Bergmann R, Matsui C, Meinsma C, Dutta D. 1995. Design guide for concrete filled hollow section columns under static and seismic loading. Köln, Germany: Comité International pour le Développement et l'Etude de la Construction Tubulaire (CIDECT). 
Bianco M, Bilardi G, Pesavento F, Pucci G, Schrefler BA. 2003. A frontal solver tuned for fully coupled non-linear hygro-thermo-mechanical problems. International Journal for Numerical Methods in Engineering 57:1801-1818.

Buchanan AH. 2001. Structural design for fire safety. Chichester, England: John Wiley \& Sons Ltd.

Canadian Commission on Building and Fire Codes. 2005. NBCC, National Building Code of Canada. National Research Council of Canada, Ottawa, Canada.

CEN. 1999. EN 1363-1: Fire resistance tests. Part 1: General requirements. Brussels, Belgium: Comité Européen de Normalisation.

CEN. 2002. EN 1991-1-2, Eurocode 1: Actions on structures, Part 1.2: General actions - Actions on structures exposed to fire. Brussels, Belgium: Comité Européen de Normalisation.

CEN. 2004a. EN 1992-1-2, Eurocode 2: Design of concrete structures, Part 1.2: General rules - Structural fire design. Brussels, Belgium: Comité Européen de Normalisation.

CEN. 2004b. EN 1994-1-1, Eurocode 4: Design of composite steel and concrete structures. Part 1-1: General rules and rules for buildings. Brussels, Belgium: Comité Européen de Normalisation.

CEN. 2005a. EN 1993-1-1, Eurocode 3: Design of steel structures. Part 1-1: General rules and rules for buildings. Brussels, Belgium: Comité Européen de Normalisation.

CEN. 2005b. EN 1993-1-2, Eurocode 3: Design of steel structures, Part 1.2: General rules - Structural fire design. Brussels, Belgium: Comité Européen de Normalisation.

CEN. 2005c. EN 1994-1-2, Eurocode 4: Design of composite steel and concrete structures, Part 1.2: General rules - Structural fire design. Brussels, Belgium: Comité Européen de Normalisation.

CEN. 2006. EN 10210-2. Hot finished structural hollow sections of non-alloy and fine grain steels. Part 2: Tolerances, dimensions and sectional properties. Brussels, Belgium: Comité Européen de Normalisation.

Chabot M, Lie TT. 1992. Experimental studies on the fire resistance of hollow steel columns filled with bar-reinforced concrete. Internal report No. 628. Ottawa, 
Canada: Institute for Research in Construction, National Research Council of Canada (NRCC).

Chan TM, Gardner L. 2008a. Compressive resistance of hot-rolled elliptical hollow sections. Engineering Structures 30(2):522-532.

Chan TM, Gardner L. 2008b. Bending strength of hot-rolled elliptical hollow sections. Journal of Constructional Steel Research 64(9):971-986.

Chan TM, Gardner L. 2009. Flexural buckling of elliptical hollow section columns. Journal of Structural Engineering (ASCE) 135:546-557.

Chan TM, Gardner L, Law KH. 2010. Structural design of elliptical hollow sections: a review. Structures and Buildings 163(6):391-402.

Chen WF. 1982. Plasticity in reinforced concrete. McGraw-Hill.

Chung K, Park S, Choi S. 2008. Material effect for predicting the fire resistance of concrete-filled square steel tube column under constant axial load. Journal of Constructional Steel Research 64:1505-1515.

Chung K, Park S, Choi S. 2009. Fire resistance of concrete filled square steel tube columns subjected to eccentric axial load. Steel Structures 9(1):69-76.

CIDECT. 1970. Monograph No. 1: Concrete filled hollow section steel columns. Design manual, British edition.

CIDECT. 1979. Monographie No. 5: Calcul des poteaux en prolils creux remplis de beton.

COMETUBE. 1976. Fire resistance of structural hollow sections. Cometube research. CIDECT programme 15A. Final report.

Corus. 2007. Celsius 355 Ovals - Sizes and Capacities, EC3 Version. Corus Tubes Structural \& conveyance business.

CSA. 1994. CAN/CSA-S16.1-94. Limit States Design of Steel Structures. Toronto, Canada: Canadian Standards Association.

Dai X, Lam D. 2010. Numerical modelling of the axial compressive behaviour of short concrete-filled elliptical steel columns. Journal of Constructional Steel Research 66:931-942.

Dai XH, Lam D. 2012. Shape effect on the behaviour of axially loaded concrete filled steel tubular stub columns at elevated temperature. Journal of Constructional Steel Research 73:117-127. 
DBJ. 2003. DBJ13-51-2003: Technical specification for concrete-filled steel tubular structures (in Chinese). Fuzhou: The Construction Department of Fujian Province.

Diederichs U. 1987. Modelle zur beschreibung der betonverformung bei instantionaren temperaturen. In abschlußkolloquium bauwerke unter brandeinwirkung. Technische Universität Braunschweig.

Ding J, Wang YC. 2008. Realistic modelling of thermal and structural behaviour of unprotected concrete filled tubular columns in fire. Journal of Constructional Steel Research 64:1086-1102.

Drucker DC, Prager W. 1952. Soil mechanics and plastic analysis or limit design. Quarterly of Applied Mathematics 10:157-165.

Dusinberre GM. 1961. Heat transfer calculations by finite differences. Scranton, Pa: International Textbook Company.

ECCS. 1988. Calculation of the fire resistance of centrally loaded composite steelconcrete columns exposed to the standard fire. Technical note. ECCS Technical Committee 3 - Fire Safety of Steel Structures. Brussels, Belgium: European Convention for Constructional Steelwork (ECCS).

Ellobody E, Young B. 2010. Investigation of concrete encased steel composite columns at elevated temperatures. Thin-Walled Structures 48:597-608.

Ellobody E, Young B, Lam D. 2006. Behaviour of normal and high strength concrete-filled compact steel tube circular stub columns. Journal of Constructional Steel Research 62:706-715.

Espinos A, Gardner L, Romero M, Hospitaler A. 2011. Fire behaviour of concrete filled elliptical steel columns. Thin-Walled Structures 49(2):239-255.

Espinos A, Romero ML, Hospitaler A. 2010. Advanced model for predicting the fire response of concrete filled tubular columns. Journal of Constructional Steel Research 66(8-9):1030-1046.

Espinos A, Romero ML, Hospitaler A. 2012. Simple calculation model for evaluating the fire resistance of unreinforced concrete filled tubular columns. Engineering Structures 42:231-244.

FIB. 2010. Model Code 2010. Lausanne, Switzerland: Fédération Internationale du Béton. 
Franssen JM. 2003. SAFIR - A thermal/structural program modeling structures under fire. Proceedings of the NASCC Conference. American Institute for Steel Construction, Baltimore.

Galambos TV. 1998. Guide to stability design criteria for metal structures. Fifth edition. New York: John Wiley and Sons Inc.

Gardner L, Chan TM. 2007. Cross-section classification of elliptical hollow sections. Steel and Composite Structures 7(3):185-200.

Gardner L, Chan TM, Abela JM. 2011. Structural behaviour of elliptical hollow sections under combined compression and uniaxial bending. Advanced Steel Construction 7(1):86-112.

Gardner L, Chan TM, Wadee MA. 2008. Shear response of elliptical hollow sections. Structures and Buildings 161(6):301-309.

Gardner L, Ministro A. 2005. Structural steel oval hollow sections. Structural Engineer 83(21):32-36.

Ghojel J. 2004. Experimental and analytical technique for estimating interface thermal conductance in composite structural elements under simulated fire conditions. Experimental Thermal and Fluid Science 28:347-354.

Grandjean G, Grimault JP, Petit L. 1980. Determination de la duree au feu des profils creux remplis de beton. CIDECT Research Project 15B-80/10. Cologne, Germany: Comité International pour le Développement et l'Etude de la Construction Tubulaire.

Guiaux P, Janns J. 1970. Comportement au flambement des colonnes constituées de tubes en acier remplis de béton. CRIF, MT 65.

Han LH. 1998. Fire resistance of concrete filled steel tubular columns. Advances in Structural Engineering 2(1):35-39.

Han LH. 2000. Concrete filled steel tubular structures. Peking: Science Press.

Han LH. 2001. Fire performance of concrete filled steel tubular beam-columns. Journal of Constructional Steel Research 57(6):697-711.

Han LH, Huo JS. 2003. Concrete-filled hollow structural steel columns after exposure to ISO-834 fire standard. Journal of Structural Engineering (ASCE) 129(1):68-78. 
Han LH, Huo JS, Wang YC. 2005. Compressive and flexural behaviour of concrete filled steel tubes after exposure to standard fire. Journal of Constructional Steel Research 61:882-901.

Han LH, Lin XK. 2004. Tests on cyclic behaviour of concrete-filled hollow structural steel columns after exposure to the ISO-834 standard fire. Journal of Structural Engineering (ASCE) 130(11):1807-1819.

Han LH, Yang YF, Xu L. 2003. An experimental study and calculation on the fire resistance of concrete filled SHS and RHS columns. Journal of Constructional Steel Research 59(4):427-452.

Han LH, Zhao XL, Yang YF, Feng JB. 2003. Experimental study and calculation of fire resistance of concrete-filled hollow steel columns. Journal of Structural Engineering (ASCE) 129(3):346-356.

Harada K. 2004. Actual state of the codes on fire design in Japan. Proceedings of the Workshop "Fire Design of Concrete Structures: What now? What next?". Milan, Italy, December 2-3, 2004. Brescia, Italy: Starrylink Editrice.

Hass R, Ameler J, Zies H. 2000. Fire Resistance of Hollow Section Composite Columns with High Strength Concrete Filling. CIDECT Research Project 15P12/00. Brunswick, Germany: Comité International pour le Développement et l'Etude de la Construction Tubulaire.

Hicks SJ, Newman GM. 2002. Design guide for SHS concrete filled columns. Corus Tubes.

Hognestad E. 1951. A study of combined bending and axial load in reinforced concrete members. University of Illinois Engineering Experiment Station Bulletin No. 399. Urbana, Illinois.

Hong S. 2007. Fundamental behaviour and stability of CFT columns under fire loading. PhD thesis. West Lafayette, Indiana: Purdue University.

Hong S, Varma AH. 2009. Analytical modeling of the standard fire behavior of loaded CFT columns. Journal of Constructional Steel Research 65:54-69.

Hu HT, Huang CS, Wu MH, Wu YM. 2003. Nonlinear analysis of axially loaded concrete-filled tube columns with confinement effect. Journal of Structural Engineering (ASCE) 129(10):1322-1329. 
Iding RH, Bresler B, Nizamuddin Z. 1977. FIRES-T3. A computer program for the fires response of structures - Thermal. Report No. UCB-FRG 77-15. University of Berkeley, California.

Ikeda K, Ohmiya Y. 2009. Fire safety engineering of concrete-filled steel tubular column without fire protection. Fire Science and Technology 28(3):106-131.

Ingberg SH, Sale PD. 1926. Proceedings of the American Society for Testing and Materials 26, II.

ISO. 1980. ISO 834: Fire resistance tests, elements of building construction. Switzerland: International Standards Organisation.

Khoury GA, Anderberg Y, Both K, Fellinger J, Høj NP, Majorana C. 2007. Fire design of concrete structures - materials, structures and modelling. Lausanne, Switzerland: FIB (Fédération Internationale du Béton).

Khoury GA, Dias WPS, Sullivan PJES. 1986. Deformation of concrete and cement paste loaded at constant temperatures from 140 to $720^{\circ} \mathrm{C}$. Materials and Structures 19(110):97-104.

Khoury GA, Grainger BN, Sullivan PJE. 1985. Transient thermal strain of concrete: literature review, conditions within specimen and behaviour of individual constituents. Magazine of Concrete Research 37(132):131-144.

Kim DK, Choi SM, Kim JH, Chung KS, Park SH. 2005. Experimental study on fire resistance of concrete-filled steel tube column under constant axial loads. International Journal of Steel Structures 5(4):305-313.

Kodur VKR. 1998a. Performance of high strength concrete filled steel columns exposed to fire. Journal of Structural Engineering (ASCE) 25:975-981.

Kodur VKR. 1998b. Design equations for evaluating fire resistance of SFRC-filled HSS columns. Journal of Structural Engineering (ASCE) 124(6):671-677.

Kodur VKR. 1999. Performance-based fire resistance design of concrete-filled steel columns. Journal of Constructional Steel Research 51(1):21-36.

Kodur VKR. 2007. Guidelines for fire resistant design of concrete-filled steel HSS columns - State-of-the-art and research needs. Steel Structures 7:173-182.

Kodur VKR, Latour JC. 2005. Experimental studies on the fire resistance of hollow steel columns filled with high-strength concrete. Institute for Research in Construction, National Research Council of Canada (NRCC), Ottawa, Canada. 
Kodur VKR, Lie TT. 1995. Experimental studies on the fire resistance of circular hollow steel columns filled with steel-fibre-reinforced concrete. Internal report No. 691. Ottawa, Canada: Institute for Research in Construction, National Research Council of Canada.

Kodur VKR, Lie TT. 1996. Fire resistance of circular steel columns filled with fiberreinforced concrete. Journal of Structural Engineering 122(7):776-782.

Kodur VKR, MacKinnon DH. 2000. Design of concrete-filled hollow structural steel columns for fire endurance. Engineering Journal-AISC 37(1):13-24.

Kordina K, Klingsch W. 1983. Fire resistance of composite columns of concrete filled hollow sections. CIDECT Research Project 15C1/C2-83/27. Cologne, Germany: Comité International pour le Développement et l'Etude de la Construction Tubulaire.

Lacuesta C, Romero ML, Ivorra S, Portoles JM. 2006. A three-dimensional numerical model of circular concrete filled columns. In: Proceedings of the Eighth International Conference on Computational Structures Technology. Stirlingshire, UK: B.H.V. Topping, G. Montero, R. Montenegro (Editors). Paper 22, doi:10.4203/ccp.83.22.

Lam D, Dai X. 2009. Modelling the confinement effect of composite concrete-filled elliptical steel columns. In: Proceedings of the Sixth International Conference on Advances in Steel Structures, pp. 49-62. Hong Kong, China: The Hong Kong Institute of Steel Construction.

Lam D, Gardner L, Burdett M. 2010. Behaviour of axially loaded concrete filled stainless steel elliptical stub columns. Advances in Structural Engineering 13(3):493-500.

Law KH, Gardner L. 2012. Lateral instability of elliptical hollow section beams. Engineering Structures 37:152-166.

Leite G, Gomide K, Moreno A, Silva V. 2010. Fire resistance of axially loaded slender concrete filled steel tubular columns. In: Structures in fire: proceedings of the 6th international conference, pp. 433-440. Lancaster: Destech publications, inc.

Lennon T, Moore DB, Wang YC, Bailey CG. 2007. Designers' guide to EN 1991-12, EN 1992-1-2, EN 1993-1-2 and EN 1994-1-2. Thomas Telford Limited. 
Leskela MV. 2009. Inconsistencies in the fire design rules of composite columns to EN 1994-1-2. Steel Concrete Composite and Hybrid Structures, pp. 489-494. Leeds, England.

Li LY, Purkiss J. 2005. Stress-strain constitutive equations of concrete material at elevated temperatures. Fire Safety Journal 40(7):669-686.

Lie TT. 1984. A procedure to calculate fire resistance of structural members. Fire and materials 8(1):40-48.

Lie TT. 1994. Fire resistance of circular steel columns filled with bar-reinforced concrete. Journal of Structural Engineering (ASCE) 120(5):1489-1509.

Lie TT, Caron SE. 1988a. Fire resistance of circular hollow steel columns filled with siliceous aggregate concrete: Test results. Internal report No. 570. Ottawa, Canada: Institute for Research in Construction, National Research Council of Canada (NRCC).

Lie TT, Caron SE. 1988b. Fire resistance of circular hollow steel columns filled with carbonate aggregate concrete: Test results. Internal report No. 573. Ottawa, Canada: Institute for Research in Construction, National Research Council of Canada (NRCC).

Lie TT, Chabot M. 1990. A method to predict the fire resistance of circular concrete filled hollow steel columns. Journal of Fire Protection Engineering 2(4):111126.

Lie TT, Chabot M. 1992. Experimental studies on the fire resistance of hollow steel columns filled with plain concrete. Internal report No. 611. Ottawa, Canada: Institute for Research in Construction, National Research Council of Canada (NRCC).

Lie TT, Irwin RJ. 1995. Fire resistance of rectangular steel columns filled with barreinforced concrete. Journal of Structural Engineering (ASCE) 121(5):797805 .

Lie TT, Kodur VKR. 1995a. Fire resistance of steel hollow structural section columns filled with bar-reinforced concrete. Internal report No. 678. Ottawa, Canada: Institute for Research in Construction, National Research Council of Canada.

Lie TT, Kodur VKR. 1995b. Effect of temperature on thermal and mechanical properties of steel fibre-reinforced concrete. Internal report No. 695. Ottawa, 
Canada: Institute for Research in Construction, National Research Council of Canada.

Lie TT, Kodur VKR. 1996. Fire resistance of steel columns filled with barreinforced concrete. Journal of Structural Engineering (ASCE) 122(1):30-36.

Lie TT, Stringer DC. 1994. Calculation of fire resistance of steel hollow structural steel columns filled with plain concrete. Canadian Journal of Civil Engineering 21(3):382-385.

Lu H, Zhao X, Han L. 2009. Fire behaviour of high strength self-consolidating concrete filled steel tubular stub columns. Journal of Constructional Steel Research 65(10-11):1995-2010.

Mander JB, Priestley MJN, Park R. 1988. Theoretical stress-strain model for confined concrete. Journal of Structural Engineering (ASCE) 114(8):18041826.

Moura Correia AJP, Rodrigues JPC. 2011. Fire resistance of partially encased steel columns with restrained thermal elongation. Journal of Constructional Steel Research 67:593-601.

Packer JA. 2008. Going elliptical. Modern Steel Construction 48(3):65-67.

Park S, Choi S, Chung K. 2008. A study on the fire-resistance of concrete-filled steel square tube columns without fire protection under constant central axial loads. Steel and Composite Structures 8(6):491-510.

Park S, Chung K, Choi S. 2007. A study on failure prediction and design equation of concrete filled square steel tube columns under fire condition. Steel Structures 7(3):183-191.

Phan LT. 1996. Fire performance of high-strength concrete: a report of the state-ofthe-art. Gaithersburg, Maryland: Building and Fire Research Laboratory, National Institute of Standards and Technology.

Poh KW. 2001. Stress-strain-temperature relationships for structural steel. Journal of Materials in Civil Engineering 13(5):371-379.

Portolés JM., Romero ML, Bonet JL and Filippou FC. 2011. Experimental study of high strength concrete-filled circular tubular columns under eccentric loading. Journal of Constructional Steel Research 67:623-633. 
Portolés JM, Romero ML, Filippou FC, Bonet JL. 2011. Simulation and design recommendations of eccentrically loaded slender concrete-filled tubular columns. Engineering Structures 33(5):1576-1593.

Purkiss JA. 2007. Fire Safety Engineering. Design of Structures (Second Edition). Oxford, UK: Butterworth-Heinemann - Elsevier Ltd.

Renaud C. 2003. Modelisation numerique, experimentation et dimensionnement practique des poteaux mixtes avec profil creux exposes a l'incendie. $\mathrm{PhD}$ thesis. Institut National des Sciences Appliquees de Rennes, France.

Renaud C, Aribert JM, Zhao B. 2003. Advanced numerical model for the fire behaviour of composite columns with hollow steel section. Steel and Composite Structures 3(2):75-95.

Renaud C, Joyeux D, Kruppa J. 2004. Improvement and extension of the simple calculation method for fire resistance of unprotected concrete filled hollow columns. CIDECT Research Project 15Q-12/03. Saint-Rémy-lès-Chevreuse, France: Centre Technique Industriel de la Construction Métallique (CTICM).

Renaud C, Kruppa J. 2004. Unprotected concrete filled columns fire tests Verification of 15Q. CIDECT Research Project 15R. Saint-Rémy-lèsChevreuse, France: Centre Technique Industriel de la Construction Métallique (CTICM).

Ribeiro JCL, Fakury RH, de Las Casas EB. 2008. Eurocode structural fire design and its application for composite circular hollow section columns. Journal of the Brazilian Society of Mechanical Science and Engineering 30(1):39-46.

Richart FE, Brantzaeg A, Brown RL. 1928. A study of failure of concrete under combined compressive stresses. Bulletin $\mathrm{n}^{\mathrm{o}}$ 185. Engineering Experiment Station, University of Illinois, Urbana, IL.

Ritter W. 1899. Die bauweise hennebique. Schweizerische Bauzeitung 33.

Romero ML, Moliner V, Espinos A, Ibañez C, Hospitaler A. 2011. Fire behavior of axially loaded slender high strength concrete-filled tubular columns. Journal of Constructional Steel Research 67(12):1953-1965.

Ruddy JL, Marlo JP, Ioannides SA, Alfawakhiri F. 2003. Fire Resistance of Structural Steel Framing. Steel Design Guide 19. Chicago, USA: American Institute of Steel Construction. 
Ruiz-Teran AM, Gardner L. 2008. Elastic buckling of elliptical tubes. Thin-Walled Structures 46(11):1304-1318.

Rush D, Bisby L, Melandinos A, Lane B. 2011. Fire resistance design of unprotected concrete filled steel hollow sections: meta-analysis of available furnace test data. International Association of Fire Safety Science.

Saenz LP. 1964. Discussion of 'Equation for the stress-strain curve of concrete' by P. Desayi, and S. Krishnan. Journal of the American Concrete Institute 61:1229-1235.

Sakumoto Y, Okada T, Yoshida M, Taska S. 1994. Fire resistance of concrete filled fire resistant steel tube columns. Journal of Materials in Civil Engineering 6(2):169-184.

Schaumann P, Kodur V, Bahr O. 2009. Fire behaviour of hollow structural section steel columns filled with high strength concrete. Journal of Constructional Steel Research 65:1794-1802.

Schneider U. 1986. Modelling of concrete behaviour at high temperatures. Anchor RD, Malhotra HL, Purkiss JA, editors. Proceedings of the international conference of design of structures against fire, pp. 53-69. New York: Elsevier.

Schneider U. 1988. Concrete at high temperatures - A general review. Fire Safety Journal 13:55-68.

Schneider U, Haksever A. 1976. Bestimmung der aquialenten branddauer vor statisch bestimmt gelagerten stahlbetonbalken bei naturlichen branden. Bericht des Instituts fur Baustoffkunde und Stahlbetonbau der Technischen Universität Braunschweig. Braunschweig, Germany.

Scullion T, Ali F, Nadjai A. 2011a. Experimental study on performance of elliptical section steel columns, under hydrocarbon fire. Journal of Constructional Steel Research 67(6):986-991.

Scullion T, Ali F, Nadjai A. 2011b. Effect of axial restraint on the performance of Elliptical Hollow Section steel columns, in hydrocarbon fire. Engineering Structures 33(12):3155-3161.

Scullion T, Ali F, Nadjai A. 2012. Finite element numerical evaluation of elliptical hollow section steel columns in fire. Thin-Walled Structures 55:22-36. 
Silvestre N. 2008. Buckling behaviour of elliptical cylindrical shells and tubes under compression. International Journal of Solids and Structures 45(16):44274447.

Song TY, Han LH, Yu HX. 2010. Concrete filled steel tube stub columns under combined temperature and loading. Journal of Constructional Steel Research 66:369-384.

Sterner E, Wickström U. 1990. TASEF - Temperature Analysis of Structures Exposed to Fire. SP Report 1990:05. Borås, Sweden: Swedish National Testing and Research Institute.

Tan KH, Tang CY. 2004. Interaction model for unprotected concrete filled steel columns under standard fire conditions. Journal of Structural Engineering (ASCE) 130(9):1405-1413.

Tao Z, Han LH, Uy B, Chen X. 2011. Post-fire bond between the steel tube and concrete in concrete-filled steel tubular columns. Journal of Constructional Steel Research 67:484-496.

Terro MJ. 1998. Numerical modelling of the behaviour of concrete structures. $A C I$ Structural Journal 95(2):183-193.

Toh WS, Tan KH, Fung TC. 2000. Compressive resistance of steel columns in fire: Rankine approach. Journal of Structural Engineering (ASCE) 126(3):398-405.

Twilt L, Hass R, Klingsch W, Edwards M, Dutta D. 1996. Design guide for structural hollow section columns exposed to fire. Cologne, Germany: Comité International pour le Développement et l'Etude de la Construction Tubulaire (CIDECT).

Wainman DE, Toner RP. 1992. BS476: Part 21 Fire Resistance Tests. The construction and testing of three loaded CHS columns filled with concrete. Moorgate, Rotherham (UK): Swinden Laboratories. British Steel Technical.

Wang HB. 1995. Heat transfer analysis of components of construction exposed to fire. PhD Thesis. Dept. of Civil Engineering and Construction, University of Salford, UK.

Wang YC. 1997. Some considerations in the design of unprotected concrete-filled steel tubular columns under fire conditions. Journal of Constructional Steel Research 44(3):203-223. 
Wang YC. 1999. The effects of structural continuity on the fire resistance of concrete filled columns in non-sway frames. Journal of Constructional Steel Research 50:177-197.

Wang YC. 2000. A simple method for calculating the fire resistance of concretefilled CHS columns. Journal of Constructional Steel Research 54(3):365-386.

Wang YC. 2005. Performance of steel-concrete composite structures in fire. Progress in Structural Engineering and Materials 7(2):86-102.

Wang YC, Kodur VKR. 1999. An approach for calculating the failure loads of unprotected concrete-filled steel columns exposed to fire. Structural Engineering and Mechanics 7(2):127-45.

Wang Y, Kodur V. 2000. Research toward use of unprotected steel structures. Journal of Structural Engineering 126(12):1442-1450.

Wang YC, Orton AH. 2008. Fire resistant design of concrete filled tubular steel columns. The Structural Engineer 7:40-45.

Wang ZH, Tan KH. 2006. Green's function solution for transient heat conduction in concrete-filled CHS subjected to fire. Engineering Structures 28(11):15741585 .

Wardenier, J. 2001. Hollow Sections In Structural Applications. CIDECT (Comité International pour le Développement et l'Etude de la Construction Tubulaire).

Witteveen J, Twilt L, Bylaard FSK. 1977. The stability of braced and unbraced frames at elevated temperatures. Second International Colloquium on Column Strength. Liège, Belgium.

Yang H, Han LH, Wang YC. 2008a. Effects of heating and loading histories on post fire cooling behaviour of concrete filled steel tubular columns. Journal of Constructional Steel Research 64(5):556-570.

Yang H, Lam D, Gardner L. 2008b. Testing and analysis of concrete-filled elliptical hollow sections. Engineering Structures 30:3771-3781.

Yin J, Zha XX, Li LY. 2006. Fire resistance of axially loaded concrete filled steel tube columns. Journal of Constructional Steel Research 62(7):723-729.

Youssef MA, Moftah M. 2007. General stress-strain relationship for concrete at elevated temperatures. Engineering Structures 29:2618-2634. 
Zha XX. 2003. FE analysis of fire resistance of concrete filled CHS columns. Journal of Constructional Steel Research 59:769-779.

Zhao XL, Han LH, Lu H. 2010. Concrete-filled tubular members and connections. Abingdon, Oxon: Spon Press.

Zhao XL, Packer JA. 2009. Tests and design of concrete-filled elliptical hollow section stub columns. Thin-Walled Structures 47:617-628. 


\section{ANNEX I. COMPENDIUM OF PUBLICATIONS}

\section{ARTICLE 1}

Published in Journal of Constructional Steel Research 66 (2010) 1030-1046

For copyright restrictions, the article is presented in its pre-print version. 



\title{
ADVANCED MODEL FOR PREDICTING THE FIRE RESPONSE OF CONCRETE FILLED TUBULAR COLUMNS
}

\author{
Ana Espinos, Manuel L. Romero, Antonio Hospitaler \\ Instituto de Ciencia y Tecnología del Hormigón (ICITECH) \\ Universidad Politécnica de Valencia, Camino de Vera $s / n$, \\ 46022 Valencia (Spain)
}

\begin{abstract}
In this work, a nonlinear finite element three-dimensional model is presented and validated in order to study the behaviour of axially loaded concrete filled tubular (CFT) columns with circular cross-section exposed to fire. A realistic sequentially coupled nonlinear thermal-stress analysis is conducted for a series of columns available in the literature. The model is validated by comparing the simulation results with the real fire resistance tests. By means of this model, and extensive sensitivity analysis is performed over a wide range of aspects concerning the finite element modelling of the problem under study, including new key factors not studied previously. Based on this sensitivity analysis several modelling recommendations are given in this paper, which will be useful for future research work. The validated numerical model is furthermore employed to study and discuss the Eurocode 4 Part 1-2 simple calculation model, which is deeply analysed in this paper.
\end{abstract}

Keywords: Fire resistance; Concrete filled tubular column; Finite element analysis; Simple calculation model

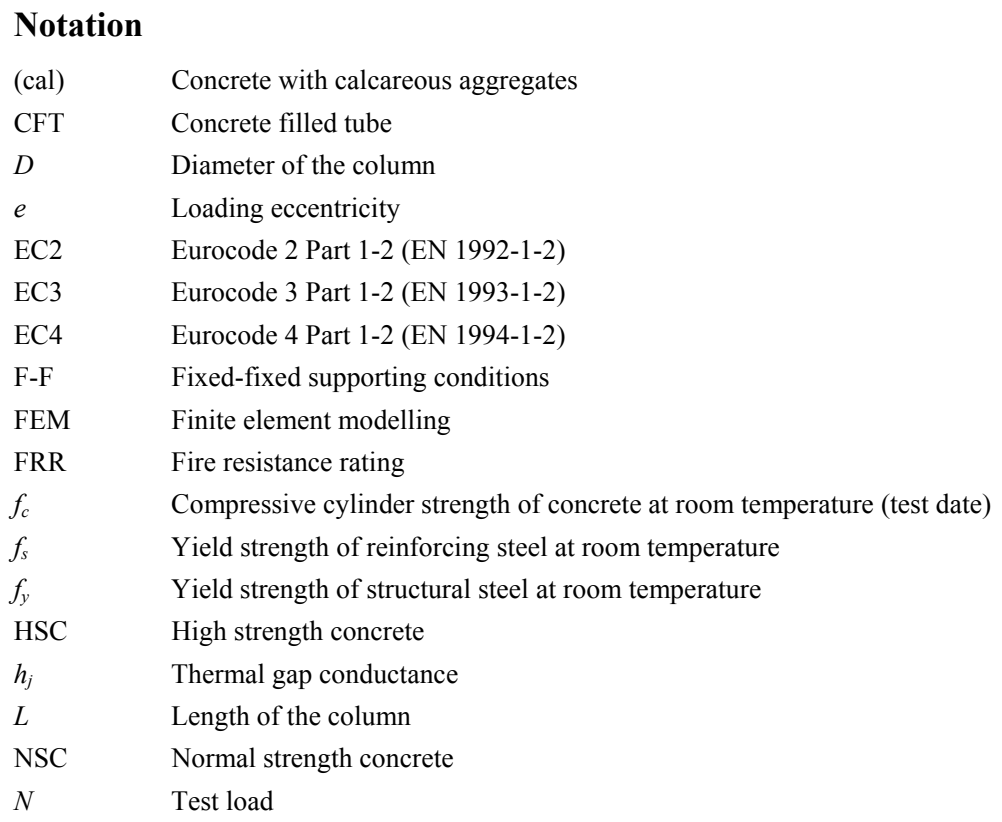




$\begin{array}{ll}N_{R d} & \text { Resistance of the column in axial compression at room temperature } \\ \text { P-P } & \text { Pinned-pinned supporting conditions } \\ q & \text { Heat flux } \\ \text { (sil) } & \text { Concrete with siliceous aggregates } \\ T & \text { Temperature } \\ t & \text { Thickness of the steel tube } \\ \alpha_{c} & \text { Concrete thermal expansion coefficient } \\ \alpha_{S} & \text { Steel thermal expansion coefficient } \\ \delta_{\max } & \text { Maximum axial displacement } \\ \mu=N / N_{R d} & \text { Axial load level } \\ \xi & \text { Relative error }\end{array}$

\section{Introduction}

In the last few years, concrete filled tubular columns have become popular among designers and structural engineers, due to a series of highly appreciated advantages: high load-bearing capacity, high seismic resistance, attractive appearance, reduced crosssection, fast construction technology and high fire resistance without external protection. Due to the heat sink effect of the concrete infill that delays the rise of temperatures in the cross-section and the shield effect of the steel tube protecting the concrete core from direct exposure and retaining its integrity, CFT columns can reach high fire resistance times without external fire protection [25]. Nevertheless, in fire situation the degradation of the material properties gives rise to an extremely nonlinear behaviour of these columns, which makes it difficult to predict their failure. In fact, the analytical methods [19] developed in this field are not able to predict accurately the fire response of CFT columns, reason why it is necessary to resort to numerical models. Up until now, a large number of numerical simulations have been conducted worldwide [10], [14], [21], [23], [27], nevertheless some important features need to be included in the model in order to obtain a more realistic representation of the fire behaviour of these types of composite columns. Relevant aspects such as the thermal conductance and the friction model at the steel-concrete interface, the thermal expansion coefficients of steel and concrete or the type of finite element employed to model the reinforcing bars must be carefully taken into account.

Some sectional numerical models [23] have been used to predict the fire behaviour of CFT columns, obtaining quite satisfactory results. Nevertheless, these models were not able to represent the complex local effects and contact mechanisms that take place in a real fire situation. Therefore, if the real behaviour of the columns in fire wants to be studied in depth, a three-dimensional model is needed.

With that aim, Ding and Wang [10] presented an advanced three-dimensional model for circular and square CFT columns in fire. They included some important features which had often been neglected by other researchers (i.e. the thermal resistance at the steel-concrete interface) and obtained very satisfactory results in fire resistance rating, although the overall response of the column measured in terms of axial displacement along time could be improved. This will be one of the objectives of this paper, not only to obtain an accurate estimation of the fire resistance time, but also to capture with precision the whole response of the column along the fire exposure time.

Hong and Varma [14] also developed an advanced three-dimensional model for predicting the standard fire behaviour of square CFT columns. Nevertheless, these authors assumed no heat loss at the steelconcrete boundary, aspect that might have produced important deviations in their nu- 
merical predictions. Again the complete time response of the column in fire could not be captured and only a quantitative estimation of the fire resistance rating was obtained.

In this work, a three-dimensional nonlinear finite element model was developed in order to study the real fire behaviour of CFT columns, in such a way that the whole response during the fire exposure time is obtained with precision. This model included a wide range of realistic and innovative considerations that have not been taken into account by other researchers. One of the novelties of the model presented here is the incorporation of the temperature dependent formulation of the interface thermal conductance proposed by Ghojel [12], which gives a very realistic prediction of the crosssectional temperature field.

The nonlinear finite element analysis package ABAQUS [1] was chosen to carry out this research, in order to take advantage of the experience gained by the authors in previous work with this tool, which was used to study the buckling behaviour of CFT columns at room temperature, obtaining very satisfactory results.

The numerical model presented in this paper was validated by comparing the simulation results with experimental fire tests carried out by other researchers and available in the literature [9], [13], [16], [18], showing good agreement with the tests both in fire resistance rating and maximum axial displacement during the whole fire exposure time. The values adopted for the main variables of the problem were a result of an extensive sensitivity analysis conducted in this research, which gives important modelling recommendations for future work. Aspects like the friction model and gap thermal conductance at the steel-concrete interface, the initial geometric imperfection, the mechanical and thermal expansion models of the materials at elevated temperatures, the concrete moisture and density or the rebar element type are deeply analysed in the sensitivity analysis presented here.
The aim of this work is to understand and represent as much close to reality as possible the behaviour of axially loaded CFT columns in fire situation. Although the model presented in this paper was developed for normal strength concrete filling, the range of the "medium" strengths (that is, concrete strengths between 40 and $50 \mathrm{MPa}$ ) was also explored. It was found that complex phenomena arise when reaching these medium strengths, so a more advanced thermo-hydro-mechanical model capable to capture the occurrence of spalling is needed in order to predict accurately the fire response of medium and high strength CFT columns. In fact, other authors [23] found the same errors in their predictions when incorporating the high strength concrete filling to the model and attributed this divergence in the results to the local effects that occur in HSC filled hollow steel columns when there is no reinforcement.

By means of the validated model, the provisions of Eurocode 4 Part 1-2 will be discussed in this paper. Firstly, the influence of the cross-sectional temperature distribution employed as the first step for calculating the design axial buckling load will be studied. Secondly, the effect of the end conditions and the relative slenderness of the column will be analysed.

\section{Numerical model}

\subsection{Geometry and finite element mesh of the model}

A three-dimensional numerical model for simulating the fire behaviour of concrete filled circular steel hollow section columns was developed employing the general purpose nonlinear finite element analysis package ABAQUS [1]. The main parameters of the model were the column length $(L)$, the external diameter $(D)$, the steel tube thickness $(t)$, the loading eccentricity $(e)$, the supporting conditions, the axial load level $(\mu)$ and the thermal and mechanical material properties. It consisted of three parts: the concrete core, the steel tube and the loading plate. Due to symmetry on both the geome- 
try and the boundary conditions, only a quarter of the column was modelled, for those specimens with pinned-pinned or fixed-fixed end conditions. For the pinned-fixed columns, the whole length was required due to the loss of symmetry on the boundary conditions, and therefore the columns were modelled with their whole length and half section.

The loading plate was modelled as a perfectly elastic part and through this element the applied axial load was transmitted to both the concrete core and the steel tube.

The model was meshed with threedimensional eight-node solid elements for both the steel tube and the concrete core, and two-node elements for the reinforcing bars. The mesh density was controlled to have a maximum element size of $2 \mathrm{~cm}$, what proved to be sufficient to predict with enough accuracy the thermal and mechanical behaviour of the CFT columns under fire. Fig. 1 shows the finite element mesh for one of the CFT column specimens analysed.
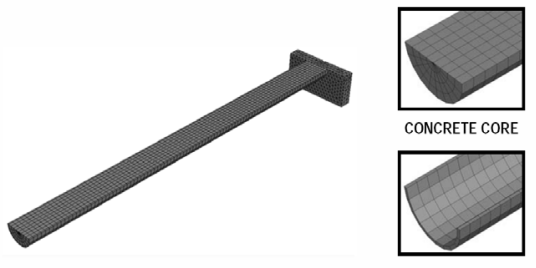

STEEL TUBE

Fig. 1. Three-dimensional finite element model for CFT columns.

\subsection{Material properties at elevated temperatures}

The numerical model took into account the temperature dependent thermal and mechanical properties of the materials. All the selected values that are presented here will be further discussed in the sensitivity analysis section.

For concrete, the mechanical model developed by Lie [19] was employed, as it showed the more realistic response. It had been previously proved by Hong-Varma [14] that this model was the one that best predicted the behaviour of the concrete infill in CFT columns, which will be confirmed in this research. The implemented concrete mechanical model employed the hyperbolic Drucker-Prager yield surface. The thermal properties for concrete at elevated temperatures were extracted from EN 1992-1-2 [6].

For structural steel, the temperature dependent thermal and mechanical properties recommended in EN 1993-1-2 [7] were adopted. The isotropic multiaxial plasticity model with the Von Mises yield surface was employed.

For the reinforcing steel, the thermal properties were the same that those used for the structural steel, as indicated in EN 19941-2 [8]. The strength and deformation properties were obtained by means of the same mathematical model as that of the structural steel, but with the reduction factors recommended in EN 1992-1-2 [6].

The value of the thermal expansion coefficient for concrete recommended by Hong-Varma [14] was employed: $\alpha_{c}=6 \times 10^{-6}$ ${ }^{\circ} \mathrm{C}^{-1}$. For steel, the temperature dependent values of the thermal expansion coefficient from EN 1993-1-2 [7] were adopted.

The moisture content of the concrete infill was taken into account through a peak value in the specific heat, representing the latent heat of water vaporization. EN 19941-2 [8] recommends a peak value of 2020 $\mathrm{J} / \mathrm{kgK}$ for a moisture content of $3 \%$ in concrete weight, and $5600 \mathrm{~J} / \mathrm{kgK}$ for a moisture content of $10 \%$. In this research, the best correlation when comparing with tested columns was obtained with a $3 \%$ for the siliceous aggregates specimens, while for the calcareous aggregates specimens the optimum value was a $10 \%$.

\subsection{Initial geometric imperfection of the column}

The proposed numerical model took into account the initial geometric imperfec- 
tion of the column specimens due to the manufacturing process, which makes them no to be perfectly straight. This initial geometric imperfection of the column specimens was simulated in the model as the first buckling mode shape of the hinged column multiplied by an amplification factor. For this purpose, a previous eigenvalue analysis of the model was conducted over a pinnedpinned column subjected to axial loading. Once the initial shape of the column was obtained, it was imported to the mechanical model as the starting geometry from which to run the analysis. An amplification factor equal to the maximum imperfection along the length of the column was then applied to the column. The value of $L / 1000$ employed by the majority of researchers for the amplification factor was used. The selection of this value will be discussed in the later sensitivity analysis section.

The deformed shape obtained for each of the column specimens by means of this procedure was employed as the initial geometry for conducting the thermalmechanical analysis.

\subsection{Analysis procedure}

Two different approaches can be considered when conducting the thermalmechanical analysis of the model. The first one, more basic and less time-consuming is to perform a sequentially coupled thermalstress analysis. In this type of analysis, the stress/displacement solution is dependent on the temperature field but there is no inverse dependency. This type of analysis can be run as long as the thermal resistance at the steelconcrete boundary is thought to be independent from the gap clearance. The average computation time of this approach is between two and three hours, depending on the output variables requested.

The second approach, highly nonlinear and thus more computationally costly, is to perform a fully coupled thermal-stress analysis, assuming that the thermal resistance on the steel-concrete boundary is a function of the gap clearance. The gap conductance will decrease as the two contacting surfaces progressively separate from each other due to the thermal expansion differentials. In that case, the thermal and mechanical solutions affect each other strongly and the stress/displacement and temperature fields must be solved simultaneously. This approach required several days of computing time and generated many convergence problems.

Because of the high computing time requirements of the second approach, a sequentially coupled thermal-stress analysis was designed for this research. Therefore, two different models were needed: a heat transfer model and a mechanical model. The analysis was performed by first conducting a pure heat transfer analysis for computing the temperature field and afterwards a stress/deformation analysis for calculating the structural response. Nodal temperatures were stored as a function of time in the heat transfer analysis results and then read into the stress analysis as a predefined field.

Having obtained accurate enough results through a simple sequentially coupled thermal-stress analysis, as it will be demonstrated later on in the validation section, it can be concluded that there is no need to perform a fully coupled analysis, which is highly time-consuming and in most occasions leads to convergence problems.

\subsection{Thermal analysis}

A nonlinear heat transfer analysis was conducted for each of the column specimens under study. A finite element formulation of the basic energy balance equation together with the Fourier law, which governs the heat conduction, was employed.

For conducting the thermal analysis, the standard ISO-834 [15] or ASTM-E119 [4] fire curve, depending on the specimen studied, was applied to the exposed surface of the CFT column specimens as a thermal load, through the convection and radiation heat transfer mechanisms. In those cases where the fire curve applied at the test deviated from the reference, the real furnace temperature-time curve reported in the litera- 
ture was used, since this can be an important source of error when validating the model.

The values recommended in EN 19911-2 [5] were adopted for the governing parameters of the heat transfer problem:

- Coefficient of convective heat transfer at the exposed surface: $h=25 \mathrm{~W} / \mathrm{m}^{2} \mathrm{~K}$

- Configuration factor for radiation at the exposed surface: $\Phi=1$

- Stephan-Boltzmann constant:

$$
\sigma=5.67 \cdot 10^{-8} \mathrm{~W} / \mathrm{m}^{2} \mathrm{~K}^{4}
$$

- Emissivity of the exposed surface:

$$
\varepsilon_{m}=0.7
$$

- Emissivity of the fire: $\varepsilon_{f}=1$

- Initial temperature: $T_{0}=20^{\circ} \mathrm{C}$

The three-dimensional eight-node heat transfer solid element with nodal temperature degree of freedom DC3D8 was used to mesh the thermal model. The longitudinal steel reinforcing bars for the reinforced specimens were modelled by means of twonode heat transfer links DC1D2.

The results from the nonlinear heat transfer analysis consisted of the temperature-time curves for all the nodes within the three-dimensional model, which were subsequently applied as a thermal loading to the mechanical model.

\subsection{Structural analysis}

A nonlinear stress analysis was afterwards conducted using the same FEM package, accounting for the nodal temperaturetime curves previously calculated in the thermal model. The finite element meshes and the node numbering were exactly the same as those used in the thermal analysis model.

The three-dimensional eight-node solid element C3D8R with reduced integration was used to mesh the concrete infill and the steel tube. The longitudinal steel bars for the reinforced specimens were modelled by means of two-node T3D2 truss elements with both nodes tied to their corresponding concrete nodes.

The choice of the relevant properties of the mechanical model, such as the constitutive laws at elevated temperatures, the values of the thermal expansion coefficient for both concrete and steel, the initial imperfection of the column specimens or the frictional contact at the steel-concrete interface will be discussed in depth in the sensitivity analysis section.

\subsection{Thermal and mechanical contact at the steel-concrete interface}

The thermal resistance at the boundary between the steel tube and the concrete core was modelled by employing a constant value of $200 \mathrm{~W} / \mathrm{m}^{2} \mathrm{~K}$ for the gap conductance. This is one of the aspects that have traditionally been ignored and that will be deeply studied later on in the sensitivity analysis section. Moreover, a radiative heat transfer mechanism was modelled at the steel-concrete interface with emissivities of both steel and concrete surfaces equal to 0.7 and a configuration factor equal to 1 .

The mechanical interaction between the steel tube and concrete infill contacting surfaces was modelled as follows. The normal behaviour employed a "hard point" contact formulation, which allows any pressure value when the surfaces are in contact and transmits no pressure when the surfaces do not contact. The tangent behaviour made use of the Coulomb friction model with a constant friction coefficient of 0.3 , which had previously produced accurate results for the room temperature simulations carried out by the authors.

\section{Validation of the numerical model}

The three-dimensional numerical model was validated by comparing its results with experimental fire resistance tests of circular CFT columns available in the literature. Most of the columns analysed were tested at the National Research Council of Canada [9], [18]. These specimens were filled with 
both siliceous and calcareous aggregate concrete, some of them reinforced and subjected to concentric axial load, apart from test C-16 which was eccentrically loaded. All the columns were tested fixed at both ends, except for three of them, tested as pinned-pinned. The total length of the columns was 3810 $\mathrm{mm}$, although only the central $3048 \mathrm{~mm}$ were directly exposed to fire.

Five column specimens from the CIDECT Research Report 15B [13] were also simulated. These specimens were filled with plain concrete, fixed at both ends and subjected to concentric axial load. The length of the columns was $3600 \mathrm{~mm}$.

Finally, the only circular column available at the CIDECT Research Report $15 \mathrm{C} 1 / \mathrm{C} 2$ [16] was simulated. This was a bar-reinforced column with a length of 4200 $\mathrm{mm}$ subjected to eccentric axial load and with pinned-fixed end conditions.

The columns analysed have been arranged in two tables for the purpose of establishing a limitation in the scope of the numerical model presented in this paper. Table 1 lists those columns with a concrete filling cylindrical compressive strength lower than $40 \mathrm{MPa}$ (NSC), while Table 2 lists those columns with a concrete filling strength over $40 \mathrm{MPa}$ (as from now "medium strength concrete"). The former will be employed for validating the numerical model and discussing EC4 simple calculation model, while the latter will only be used for studying the possibility of the occurrence of spalling in concrete and therefore establishing the limitations of the numerical model.

Table 1. List of CFT columns analysed from the literature [18], $f_{c}<40 \mathrm{MPa}$

\begin{tabular}{|c|c|c|c|c|c|c|c|c|c|c|}
\hline $\begin{array}{c}\text { Column } \\
\text { No. }\end{array}$ & $\begin{array}{c}L \\
(\mathbf{m m})\end{array}$ & $\begin{array}{c}D \\
(\mathbf{m m})\end{array}$ & $\begin{array}{c}t \\
(\mathbf{m m})\end{array}$ & $\begin{array}{c}\boldsymbol{f}_{\boldsymbol{y}} \\
\left(\mathrm{N} / \mathbf{m m}^{2}\right)\end{array}$ & $\begin{array}{c}\boldsymbol{f}_{\boldsymbol{c}} \\
\left(\mathbf{N} / \mathbf{m m}^{2}\right)\end{array}$ & $\begin{array}{c}\text { End } \\
\text { Cond. }\end{array}$ & $\begin{array}{c}e \\
(\mathbf{m m})\end{array}$ & $\begin{array}{c}N \\
(\mathbf{k N})\end{array}$ & $\mu$ & $\begin{array}{l}\text { FRR } \\
\text { (min) }\end{array}$ \\
\hline C-02 & 3810 & 141.3 & 6.55 & 350 & 33.1 (sil) & F-F & 0 & 110 & 0.12 & 55 \\
\hline C-04 & 3810 & 141.3 & 6.55 & 350 & 31.0 (sil) & F-F & 0 & 131 & 0.14 & 57 \\
\hline C-05 & 3810 & 168.3 & 4.78 & 350 & 32.7 (sil) & F-F & 0 & 150 & 0.16 & 76 \\
\hline C-06 & 3810 & 168.3 & 4.78 & 350 & 32.7 (sil) & P-P & 0 & 150 & 0.19 & 60 \\
\hline C-08 & 3810 & 168.3 & 4.78 & 350 & 35.5 (sil) & F-F & 0 & 218 & 0.23 & 56 \\
\hline C-09 & 3810 & 168.3 & 6.35 & 350 & 35.4 (sil) & F-F & 0 & 150 & 0.13 & 81 \\
\hline C-11 & 3810 & 219.1 & 4.78 & 350 & 31.0 (sil) & F-F & 0 & 492 & 0.35 & 80 \\
\hline C-13 & 3810 & 219.1 & 4.78 & 350 & 32.3 (sil) & F-F & 0 & 384 & 0.27 & 102 \\
\hline C-15 & 3810 & 219.1 & 8.18 & 350 & 31.9 (sil) & P-P & 0 & 525 & 0.28 & 73 \\
\hline C-16 & 3810 & 219.1 & 8.18 & 350 & 31.9 (sil) & P-P & 34 & 525 & 0.47 & 33 \\
\hline C-17 & 3810 & 219.1 & 8.18 & 350 & 31.7 (sil) & F-F & 0 & 525 & 0.26 & 82 \\
\hline C-20 & 3810 & 273.1 & 5.56 & 350 & 28.6 (sil) & F-F & 0 & 574 & 0.26 & 112 \\
\hline C-21 & 3810 & 273.1 & 5.56 & 350 & 29.0 (sil) & F-F & 0 & 525 & 0.23 & 133 \\
\hline C-22 & 3810 & 273.1 & 5.56 & 350 & 27.2 (sil) & F-F & 0 & 1000 & 0.45 & 70 \\
\hline C-23 & 3810 & 273.1 & 12.70 & 350 & 27.4 (sil) & F-F & 0 & 525 & 0.13 & 143 \\
\hline C-31 & 3810 & 141.3 & 6.55 & 300 & 30.2 (cal) & F-F & 0 & 80 & 0.09 & 82 \\
\hline C-32 & 3810 & 141.3 & 6.55 & 300 & 34.8 (cal) & F-F & 0 & 143 & 0.17 & 64 \\
\hline C-34 & 3810 & 219.1 & 4.78 & 300 & 35.4 (cal) & F-F & 0 & 500 & 0.36 & 111 \\
\hline C-37 & 3810 & 219.1 & 8.18 & 350 & 28.7 (cal) & F-F & 0 & 560 & 0.25 & 102 \\
\hline C-44 & 3810 & 273.1 & 6.35 & 350 & 38.7 (cal) & F-F & 0 & 715 & 0.27 & 178 \\
\hline
\end{tabular}

Fig. 2 shows the result of one of the numerical simulations, where the temperature field along the column and its deformed shape after failure can be seen, together with the picture of the fire test.

\subsection{Thermal response}

A first validation step consisted of comparing the evolution of temperature along the fire exposure time in the numerical simulations with the temperatures recorded in the tests at those sectional points where thermocouples were installed. The compari- 
son between measured and calculated temperatures is shown in Fig. 3 for one of the column specimens studied.

Table 2. List of CFT columns analysed from the literature [9], [13], [16], [18], $f_{c}>40 \mathrm{MPa}$

\begin{tabular}{cccccccc}
\hline $\begin{array}{c}\text { Column } \\
\text { No. }\end{array}$ & $\begin{array}{c}\boldsymbol{L} \\
(\mathbf{m m})\end{array}$ & $\begin{array}{c}\boldsymbol{D} \\
(\mathbf{m m})\end{array}$ & $\begin{array}{c}\boldsymbol{t} \\
(\mathbf{m m})\end{array}$ & $\begin{array}{c}\text { Rebar } \\
(\mathbf{m m})\end{array}$ & $\begin{array}{c}\boldsymbol{f}_{\boldsymbol{y}} \\
\left(\mathbf{N} / \mathbf{m m}^{2}\right)\end{array}$ & $\begin{array}{c}\boldsymbol{f}_{\boldsymbol{c}} \\
\left(\mathbf{N} / \mathbf{m m}^{2}\right)\end{array}$ & $\begin{array}{c}\boldsymbol{f}_{\boldsymbol{s}} \\
\left(\mathbf{N} / \mathbf{m m}^{2}\right)\end{array}$ \\
\hline C-35 [18] & 3810 & 219.1 & 4.78 & - & 300 & $42.7(\mathrm{cal})$ & - \\
C-40 [18] & 3810 & 273.1 & 6.35 & - & 350 & $46.5(\mathrm{cal})$ & - \\
C-41 [18] & 3810 & 273.1 & 6.35 & - & 350 & $50.7(\mathrm{cal})$ & - \\
C-42 [18] & 3810 & 273.1 & 6.35 & - & 350 & $55.4(\mathrm{cal})$ & - \\
C-48 [9] & 3810 & 273.1 & 6.35 & $4 \phi 19.5$ & 350 & $46.7(\mathrm{cal})$ & 400 \\
C-49 [9] & 3810 & 273.1 & 6.35 & $4 \phi 19.5$ & 350 & $47.0(\mathrm{cal})$ & 400 \\
15C-15 [16] & 4200 & 273 & 5 & $4 \phi 18$ & 348 & $53 *$ & 475 \\
77.12524A [13] & 3600 & 168.3 & 3.6 & - & 323 & 43.9 & - \\
77.12524B [13] & 3600 & 219.1 & 3.6 & - & 395 & 43.7 & - \\
77.12524D [13] & 3600 & 219.1 & 3.6 & - & 385 & 43.9 & - \\
77.12524E [13] & 3600 & 219.1 & 3.6 & - & 400 & 43.7 & - \\
77.12524F [13] & 3600 & 219.1 & 3.6 & - & 400 & 43.7 & - \\
\hline
\end{tabular}

Table 2. (continued)

\begin{tabular}{cccccc}
\hline $\begin{array}{c}\text { Column } \\
\text { No. }\end{array}$ & $\begin{array}{c}\text { End } \\
\text { Cond. }\end{array}$ & $\begin{array}{c}\boldsymbol{e} \\
(\mathbf{m m})\end{array}$ & $\begin{array}{c}\boldsymbol{N} \\
(\mathbf{k N})\end{array}$ & $\boldsymbol{\mu}$ & $\begin{array}{c}\text { FRR } \\
(\mathbf{m i n})\end{array}$ \\
\hline C-35 [18] & F-F & 0 & 560 & 0.36 & 108 \\
C-40 [18] & F-F & 0 & 1050 & 0.37 & 106 \\
C-41 [18] & F-F & 0 & 1050 & 0.37 & 76 \\
C-42 [18] & F-F & 0 & 1050 & 0.35 & 90 \\
C-48 [9] & F-F & 0 & 1050 & 0.37 & 188 \\
C-49 [9] & F-F & 0 & 1900 & 0.67 & 96 \\
15C-15 [16] & P-F & 27 & 692 & 0.70 & 56 \\
77.12524A [13] & F-F & 0 & 300 & 0.23 & 56 \\
77.12524B [13] & F-F & 0 & 600 & 0.26 & 45 \\
77.12524D [13] & F-F & 0 & 600 & 0.26 & 43 \\
77.12524E [13] & F-F & 0 & 300 & 0.13 & 102 \\
77.12524F [13] & F-F & 0 & 900 & 0.39 & 35 \\
\hline \multicolumn{7}{|c}{} & &
\end{tabular}

A constant value of $200 \mathrm{~W} / \mathrm{m}^{2} \mathrm{~K}$ was employed for the gap conductance at the steel-concrete interface and a moisture content of $3 \%$ or $10 \%$ in concrete weight, depending on the case study was considered. It was found that, in general, concrete with calcareous aggregates retained more humidity than concrete with siliceous aggregates, thus in this research a value of $10 \%$ was considered for the specimens filled with calcareous aggregates, whereas a $3 \%$ value was employed for the siliceous ones.

Employing these moisture values, the overall temperature-time response in the selected points followed accurately the test results, with the exception of the range of tem- peratures between 100 and $200{ }^{\circ} \mathrm{C}$ in the concrete layers, where the evaporation of moisture occurs. This phenomenon is treated in a simple manner in this research by introducing a peak point in the concrete specific heat formulation, as recommended in EN 1994-1-2 [8]. Nevertheless, if the realistic moisture movement and evaporation within the concrete core wants to be predicted, a more complex hydro-thermal model would be needed.

As mentioned above, some of the tests did not follow as closely as desired the standard fire curve, which introduced some distortions in the fire response of the columns. Thus, the real furnace temperature-time 
curve reported from the fire tests was applied in the simulations, when available.

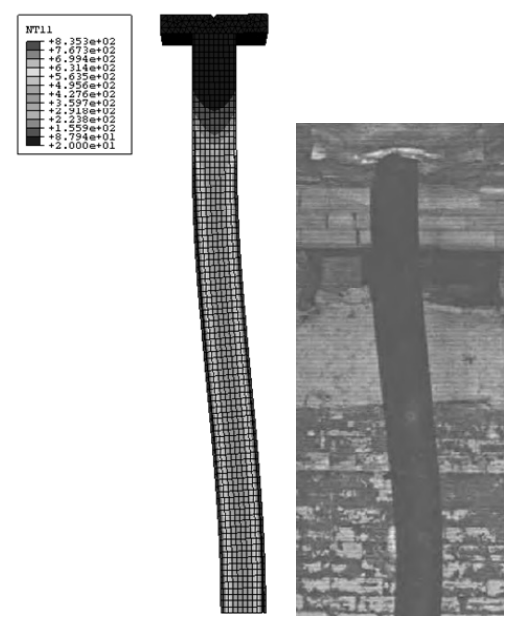

Fig. 2. Deformed shape after exposure to standard fire, for column C-04 [18].

\subsection{Mechanical response}

The structural behaviour of CFT columns under fire was fully captured with the numerical model presented in this paper and can be easily understood through the example at Fig. 4, which shows the axial displacement-time curve together with the axial force ratio versus time curves for both the steel tube and concrete core. The behaviour of CFT columns in fire can be divided into four stages clearly indicated in the graphic, where the load transfer process from the steel tube to the concrete core can be noticed.

During the first minutes of heating, the steel tube heats up more rapidly and expands faster than concrete (stage 1) since it is directly exposed to fire and has a higher thermal conductivity. Because of this faster axial elongation of the steel tube and the occurrence of slip at the steel-concrete interface, the concrete core loses contact with the loading plate, thus progressively increasing the axial load ratio of steel until the whole applied load is sustained by the steel tube. The steel tube remains fully loaded during a significant period of time until the critical temperature of steel is reached. At this point, the local yielding of the steel tube occurs and it starts to shorten (stage 2), allowing the loading plate to contact the concrete core again. As the column shortens, the steel tube progressively transfers the load to the concrete core (stage 3) and an inversion in the axial force ratio takes place, in such a way that the concrete core becomes the main resistant element of the column, since the steel tube has already lost its load-bearing capacity. Because of its low thermal conductivity, the concrete core degrades slowly as temperature advances through the cross-section, until eventually the column fails when concrete loses completely its resistance and stiffness (stage 4).

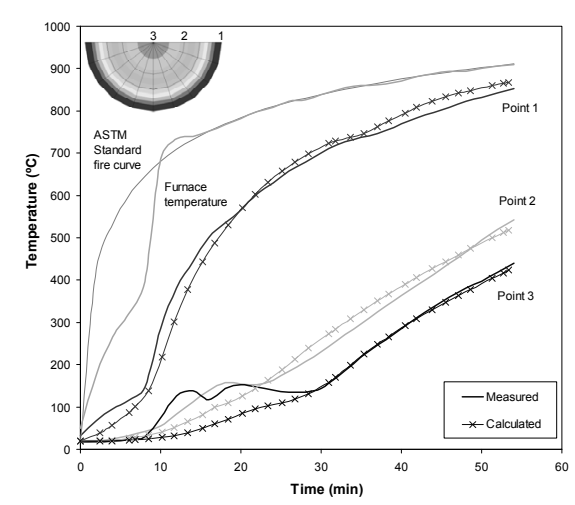

Fig. 3. Comparison between measured and predicted temperatures for column C-02.

For each of the columns listed in Table 1 , the axial displacement at the top of the column versus the fire exposure time was registered during the simulation, comparing this curve with the one obtained in the fire test. Fig. 5 shows the comparison between both curves for two of the column specimens studied. 


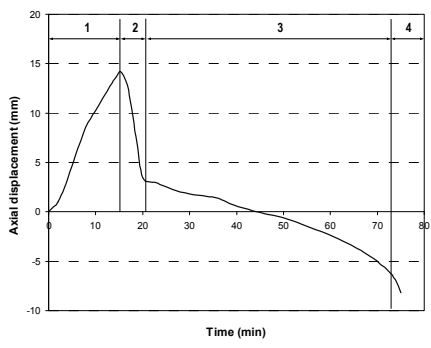

(a) Axial displacement versus time

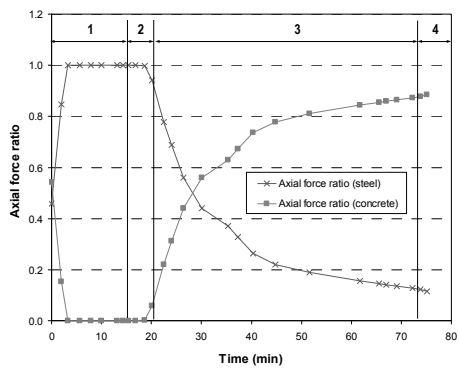

(b) Axial force ratio versus time
1)

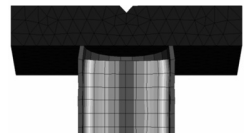

2)

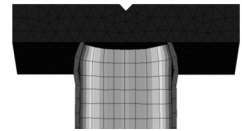

3)

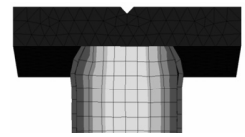

4)

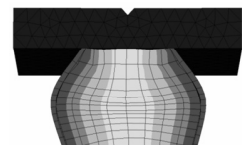

(c) Stages of the fire response of a CFT column

Fig. 4. Axial displacement and axial force ratio versus time, for column C-11.

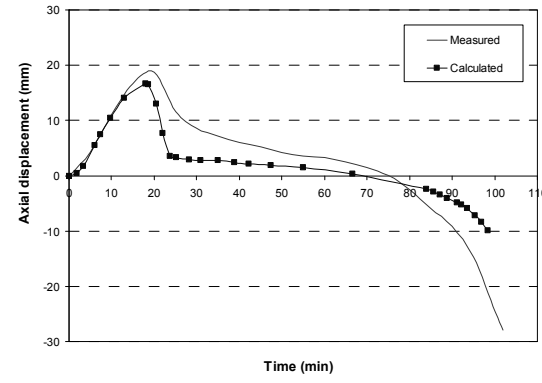

(a) Column C-13

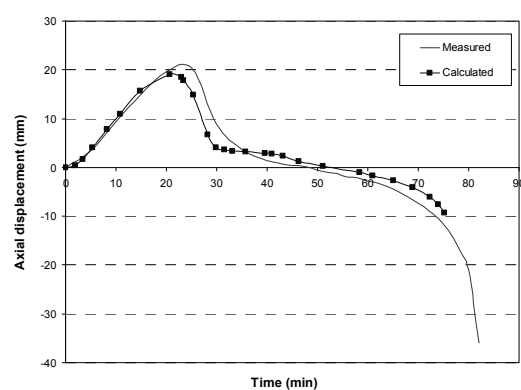

(b) Column C-17

Fig. 5. Comparison of measured and predicted axial displacement. 
At this point a comment regarding the pinned-pinned specimens must be done. Despite being designed as hinged at both ends in the experimental tests, the numerical model showed better agreement when the supporting conditions were considered as pinned-fixed. Three different supporting conditions were studied for simulating the pinned-pinned columns and the results for one of the specimens are shown in Fig. 6. It can be seen that the best prediction was obtained modelling the column as pinnedfixed. As it was already found by Renaud et al. in the CIDECT research project 15Q [22], the reason of this behaviour is that in real fire tests the unexposed ends of the column lying outside the furnace retain more stiffness, therefore introducing some rotational restraints to the column. In fact, the deformed shape of these column specimens after the tests suggests employing pinned-fixed supporting conditions when simulating their fire behaviour.

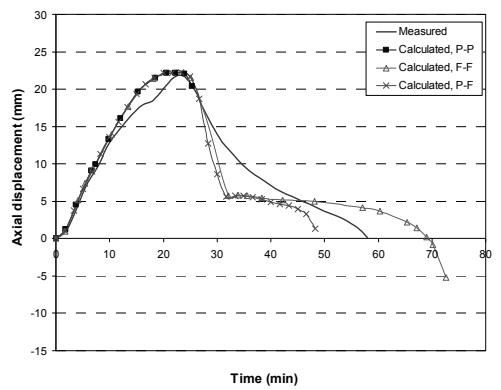

Fig. 6. Comparison of measured and predicted axial displacement with different supporting conditions, for column C-06.

Table 3. Predicted and measured FRR and maximum axial displacement, $f_{c}<40 \mathrm{MPa}$

\begin{tabular}{|c|c|c|c|c|c|c|}
\hline \multirow{2}{*}{ Column No. } & \multicolumn{2}{|c|}{ FRR (min) } & \multirow{2}{*}{$\frac{F R R_{\text {test }}}{F R R_{N S}}$} & \multicolumn{2}{|c|}{$\delta_{\max }(\mathbf{m m})$} & \multirow{2}{*}{$\xi \delta_{\max }=\frac{\delta_{\max , t e s t}}{\delta_{\max , N S}}$} \\
\hline & Test & Simulation & & Test & Simulation & \\
\hline C-02 & 55 & 55 & 1.00 & 24.57 & 25.44 & 0.97 \\
\hline C-04 & 57 & 50 & 1.14 & 24.09 & 24.28 & 0.99 \\
\hline C- 05 & 76 & 72 & 1.06 & 22.77 & 22.17 & 1.03 \\
\hline C-06 & 60 & 48 & 1.25 & 21.66 & 22.26 & 0.97 \\
\hline C- 08 & 56 & 59 & 0.95 & 20.48 & 19.39 & 1.06 \\
\hline C-09 & 81 & 75 & 1.08 & 25.77 & 24.38 & 1.06 \\
\hline C-11 & 80 & 77 & 1.04 & 18.13 & 14.14 & 1.28 \\
\hline $\mathrm{C}-13$ & 102 & 98 & 1.04 & 18.77 & 16.71 & 1.12 \\
\hline C-15 & 73 & 47 & 1.55 & 19.52 & 18.93 & 1.03 \\
\hline C-16 & 33 & 32 & 1.03 & 18.73 & 18.31 & 1.02 \\
\hline C-17 & 82 & 75 & 1.09 & 20.36 & 19.05 & 1.07 \\
\hline C-20 & 112 & 150 & 0.75 & 19.44 & 15.26 & 1.27 \\
\hline C-21 & 133 & 163 & 0.82 & 20.25 & 16.05 & 1.26 \\
\hline C-22 & 70 & 79 & 0.89 & 5.51 & 7.06 & 0.78 \\
\hline C-23 & 143 & 147 & 0.97 & 26.09 & 23.66 & 1.10 \\
\hline C-31 & 82 & 65 & 1.26 & 30.53 & 27.05 & 1.13 \\
\hline C-32 & 64 & 50 & 1.28 & 28.5 & 23.65 & 1.21 \\
\hline C-34 & 111 & 101 & 1.10 & 20.09 & 11.02 & 1.82 \\
\hline C-37 & 102 & 75 & 1.36 & 20.2 & 19.43 & 1.04 \\
\hline \multirow[t]{3}{*}{ C-44 } & 178 & 180 & 0.99 & 20.36 & 16.28 & 1.25 \\
\hline & \multirow{2}{*}{\multicolumn{2}{|c|}{$\begin{array}{c}\text { Average } \\
\text { Standard deviation }\end{array}$}} & 1.08 & & verage & 1.12 \\
\hline & & & 0.19 & \multicolumn{2}{|c|}{ Standard deviation } & 0.21 \\
\hline
\end{tabular}

For modelling these specimens as pinned-fixed, the whole length of the column was used, since there is a loss of symmetry on the end conditions, but because of the sectional symmetry only half the section was modelled. 
From the axial displacement versus time curves, the fire resistance rating was obtained for each one of the specimens under study. These values are summarized in Table 1 for those specimens with concrete filling resistance under $40 \mathrm{MPa}$. As it can be seen in Fig. 7, most of the values calculated lie in the region of the $15 \%$ error.

The maximum axial displacement was also obtained at the simulations of each of the column specimens studied. Table 3 shows the predicted values and the comparison with the values registered at the fire tests.

It can be noticed that there was more agreement with the test results in those columns with smaller diameters and thus more slender, whereas the massive columns produced more error, which may be attributed to the higher contribution of concrete and its more complex failure mechanisms.

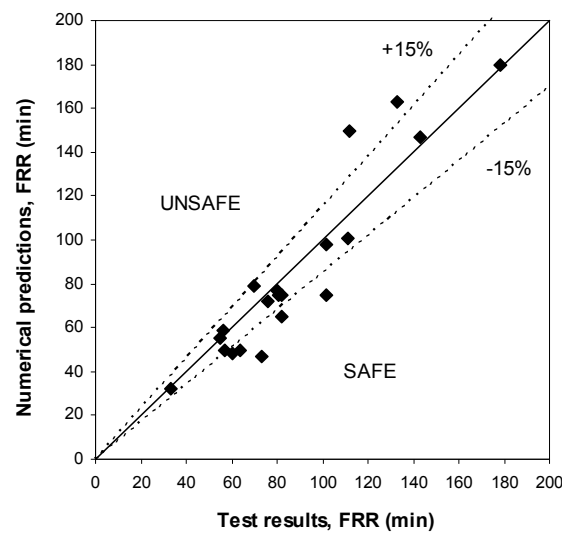

Fig. 7. Comparison of fire resistance rating between calculated and test results, $f_{c}<40 \mathrm{MPa}$.

\subsection{Medium strength concrete}

A series of columns with concrete filling compressive resistances over $40 \mathrm{MPa}$ were also simulated. These columns must be studied with special care since the spalling starts to be noticeable in their fire behaviour. The values of their measured and computed fire resistance ratings are summarized in Table 4 and plotted in Fig. 8. The maximum axial displacement for each of these column specimens is also listed in Table 4. As it was expected, for most of the specimens analysed in this series, the predicted fire resistance rating was higher than the measured value. This result suggests that a different failure mechanism is likely to be occurring at those column tests with higher concrete strength fillings. In fact, failure in columns C-40, C-41 and C-42 from the National Research Council of Canada [18] was reported to be due to compression instead of overall buckling, which suggests the occurrence of brittle cracking in concrete, effect that the numerical model could not accurately capture at this level of development and therefore explains the divergence between computed and measured failure times.

As reported by Schaumann et al. [23], the cracks initiated at the concrete core by the expansion of the steel tube can be considerable in case there is lack of any reinforcement for high strength concrete specimens. Associated with this effect, the steel hollow section experiences an outward local buckling when the steel section yields at reaching critical temperature. This local buckling of the steel hollow section and crushing of the outer concrete cause the failure in these columns. The micro-cracking effect could not be reproduced in the numerical model and thus explains the high difference encountered for the plain concrete filled specimens in this range of strengths. Nevertheless, the simulations of columns C-48 and C-49 from NRCC [9] are in good agreement with the tests, since the failure mode in these cases was overall buckling, micro-cracking being prevented via the reinforcing bars. In the case of CIDECT column 15C-15 [16], despite being bar-reinforced, the loading eccentricity might have magnified the opening of the concrete cracks, leading to the local failure of the column, again not captured by the numerical model proposed here. 
Table 4. Predicted and measured FRR and maximum axial displacement, $f_{c}>40 \mathrm{MPa}$

\begin{tabular}{|c|c|c|c|c|c|c|}
\hline \multirow{2}{*}{ Column No. } & \multicolumn{2}{|c|}{ FRR (min) } & \multirow{2}{*}{$\frac{F R R_{\text {test }}}{F R R_{N S}}$} & \multicolumn{2}{|c|}{$\delta_{\max }(\mathrm{mm})$} & \multirow{2}{*}{$=\frac{\delta_{\max , t e s t}}{\delta_{\max , N S}}$} \\
\hline & Test & Simulation & & Test & Simulation & \\
\hline $\mathrm{C}-35$ & 108 & 104 & 1.04 & 15.59 & 8.2 & 1.90 \\
\hline $\mathrm{C}-40$ & 106 & 157 & 0.68 & 15.22 & 8.73 & 1.74 \\
\hline C-41 & 76 & 165 & 0.46 & 16.05 & 8.63 & 1.86 \\
\hline $\mathrm{C}-42$ & 90 & 173 & 0.52 & 14.16 & 8.47 & 1.67 \\
\hline C- -48 & 188 & 174 & 1.08 & 12.7 & 8.11 & 1.57 \\
\hline C-49 & 96 & 100 & 0.96 & 1.36 & 1.95 & 0.70 \\
\hline $15 \mathrm{C}-15$ & 56 & 87 & 0.64 & 18 & 16.3 & 1.10 \\
\hline $77.12524 \mathrm{~A}$ & 56 & 47 & 1.19 & 13.7 & 13.44 & 1.02 \\
\hline 77.12524B & 45 & 72 & 0.63 & 6.7 & 6.3 & 1.06 \\
\hline 77.12524D & 43 & 72 & 0.60 & 7.7 & 5.15 & 1.50 \\
\hline $77.12524 \mathrm{E}$ & 102 & 115 & 0.89 & 17 & 21.2 & 0.80 \\
\hline \multirow[t]{3}{*}{$77.12524 \mathrm{~F}$} & 35 & 49 & 0.71 & 2 & 2.15 & 0.93 \\
\hline & \multicolumn{2}{|c|}{ Average } & 0.78 & \multicolumn{2}{|c|}{ Average } & 1.32 \\
\hline & \multicolumn{2}{|c|}{ Standard deviation } & 0.24 & \multicolumn{2}{|c|}{ Standard deviation } & 0.43 \\
\hline
\end{tabular}

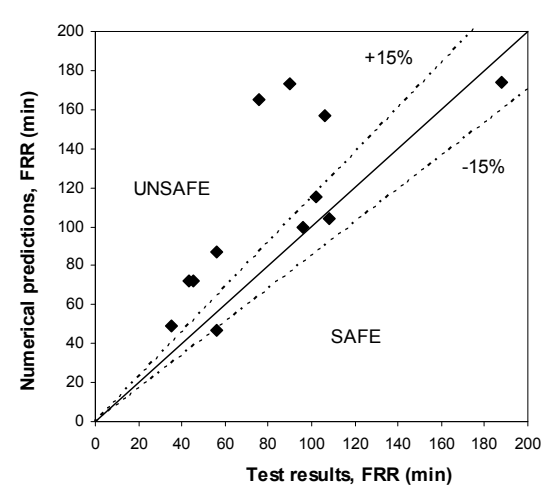

Fig. 8. Comparison of fire resistance rating between calculated and test results, $f_{c}>40 \mathrm{MPa}$.

The mechanism described above can induce spalling in high strength concrete specimens or even in normal strength concrete ones in case the moisture concentration is too large. Whether the vapour pressure developed is sufficient to cause spalling or not depends not only on the amount of moisture but also on the rate of heating, permeability, porosity and pore distribution in concrete. This is therefore a complicated phenomenon that needs a more complex thermohydro-mechanical model for its simulation, which is out of the scope of this paper. This is in fact one of the current research lines of the authors.

\section{Sensitivity analysis}

An extensive sensitivity analysis was carried out in order to study the influence of the main aspects of the model and to find their optimal values. The aspects studied were the friction model and gap conductance value to be used at the steel-concrete interface, the initial geometric imperfection, the mechanical and thermal expansion models of the materials at elevated temperatures, the concrete moisture and density and the rebar element type. For this purpose, two column specimens from those tested at the National Research Council of Canada [18] were selected, with similar material properties, buckling length and load level but very different $D / t$ ratio, so that the study can be valid for CFT columns with both elevated and reduced steel contribution. These column specimens are coded as C-04 and C-05 and their properties collected in Table 1. The influence of the rebar element type was studied by means of column C-48 from NRCC [9]. 


\subsection{Steel-concrete interface friction model}

Three options were studied for the steel-concrete frictional interaction: the first option used the classical Coulomb friction model, the second option assumed a full slip between the steel tube and the concrete core (frictionless contact) and the third option considered the existence of a full bond at the steel-concrete interface (rough contact).

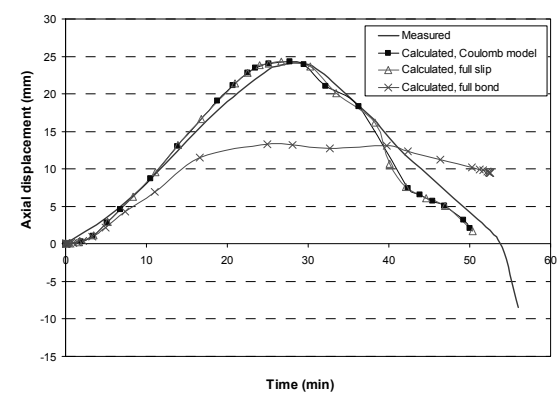

(a) Column C-04
The full bond model deviated excessively from the real behaviour of the column, as it can be seen in Fig. 9. The Coulomb friction model and full slip model produced exactly the same results, therefore it can be confirmed that a full slip occurs at the steelconcrete interface in fire situation, since the different thermal expansions cause the separation of the steel tube from the concrete core at elevated temperatures.

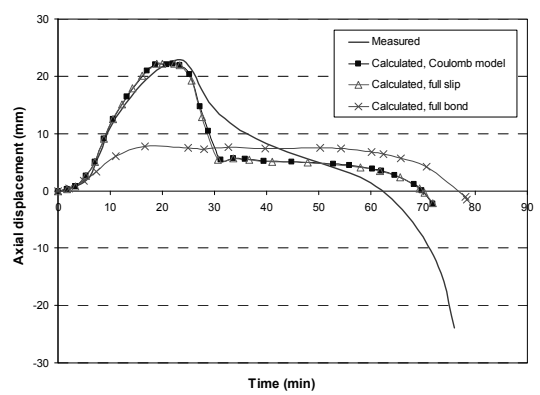

(b) Column C-05

Fig. 9. Comparison of measured and predicted axial displacement with different friction models.

To further confirm this fact, different values of the friction coefficient in the Coulomb model were studied, ranging from 0.2 to 0.8 , no difference being obtained in the overall fire response. It can be therefore inferred that the value of the friction coefficient at the steel-concrete interface does not have any influence to the column fire behaviour, as the steel tube and concrete core slide relative to each other in fire situation, and thus a frictionless model can be adopted.

\subsection{Gap thermal conductance}

Existing mathematical models for the prediction of the temperature field in concrete filled steel tubular columns [19] do not take into account the resistance to heat flow at the steel-concrete interface, resulting in a significant disagreement between measured and predicted temperatures. This resistance to heat flow is known as the contact thermal resistance and is usually expressed in terms of a joint contact conductance $h_{j}$, defined in terms of Newton's law of cooling:

$$
q=h_{j} \cdot \Delta T
$$

As discussed in 2.4, the thermal conductance across the steel-concrete interface can be considered either dependent or independent on the gap clearance. In the first case, a fully coupled thermal-stress analysis is required. That is a more realistic approach but requires excessive computational time. Nevertheless, conducting a sequentially coupled thermal-stress analysis assuming the gap conductance to be uncoupled from the clearance produces accurate enough results in a more permissible level of calculation times.

Another aspect to take into account is the dependence of the gap conductance with temperature. In a first approach, a constant value of $h_{j}=200 \mathrm{~W} / \mathrm{m}^{2} \mathrm{~K}$ for the gap conductance was employed, as recommended by Ding-Wang [10]. In a second approach, the interfacial thermal conductance was expressed as a function of temperature as sug- 
gested by Ghojel [12], adopting the following correlation proposed by the author for loaded circular steel tubes filled with plain or bar-reinforced concrete:

$h_{j}=160.5-63.8 \cdot \exp \left(-339.9 \cdot T^{-1.4}\right) \mathrm{W} / \mathrm{m}^{2} \mathrm{~K}$

where $T$ is the temperature in degrees Celsius.

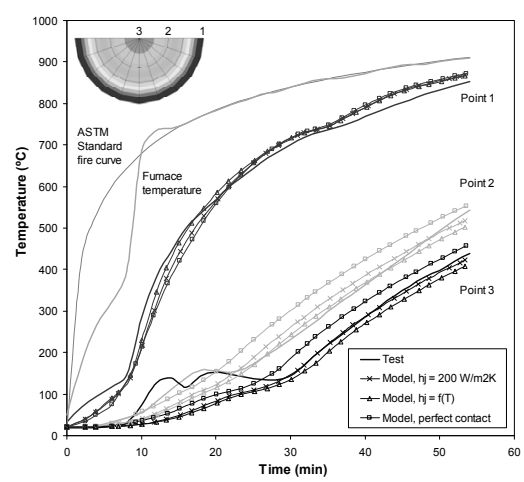

Fig. 10. Comparison between measured and predicted temperatures with different gap conductance values, for column C-02.

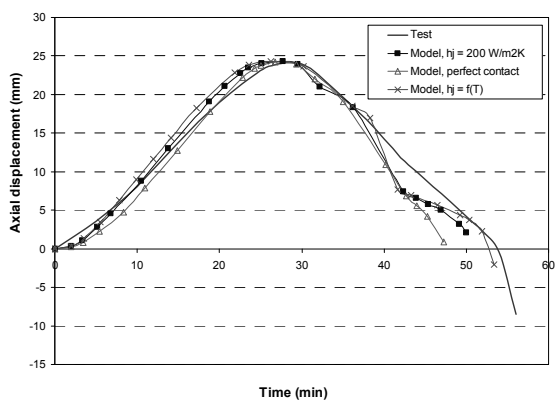

(a) Column C-04
The third approach considered the existence of a perfect thermal contact at the steel-concrete interface, that is, the temperature at the contacting surfaces of steel and concrete is the same.

Fig. 10 shows the comparison for the evolution of temperature at significant points of the cross-section under the three approaches studied, where it can be clearly seen that the perfect contact approach overestimates the temperature field. As it can be appreciated in Fig. 11, the model proposed by Ghojel produced the better estimations in failure time, although adopting a constant value of $h_{j}=200 \mathrm{~W} / \mathrm{m}^{2} \mathrm{~K}$ produced acceptable results as well. Assuming that no thermal resistance occurs at the steel-concrete interface is not so realistic and gives very conservative estimations, since the temperature field is moved forward.

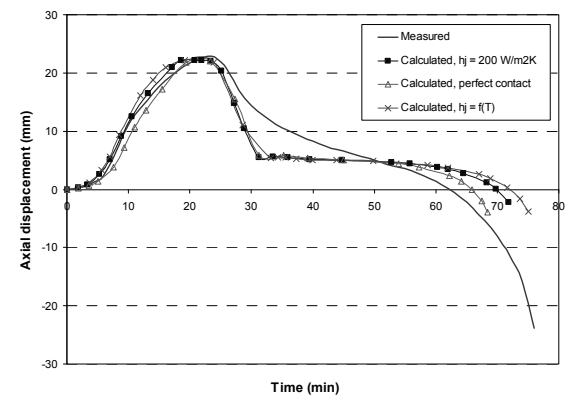

(b) Column C-05

Fig. 11. Comparison of measured and predicted axial displacement with different gap conductance values.

\subsection{Initial geometric imperfection}

In order to represent the initial geometric imperfection of the columns, the deformed shape of the pinned-pinned column first buckling mode was obtained, and afterwards amplified by means of an imperfection factor for each of the geometries under study. 
Different values for the out-ofstraightness of the column ranging from $L / 500$ to $L / 7500$ were studied, producing the results shown in Fig. 12. From this study, it can be recommended that values no higher than $L / 500$ be adopted, being optimum to employ an amplitude of $L / 1000-L / 2000$, as normally assumed by researchers. The $L / 7500$ value suggested by Galambos [11] for CFT columns produced good results for some of the specimens studied, but in some cases gave place to convergence problems not being able to induce the overall buckling of the column.

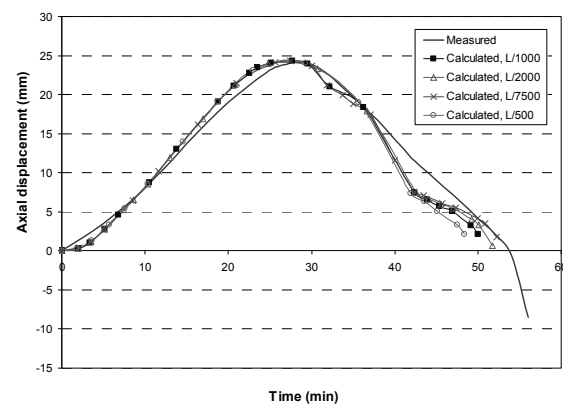

(a) Column C-04

\subsection{Material mechanical models at elevated} temperatures

Several mechanical models at high temperatures were studied for both steel and concrete.

\section{Steel}

For steel, four models were studied and contrasted: EN 1993-1-2 [7], Lie [19], Yin [26] and Poh [20]. The first one produced the optimal results, whereas the model from Lie predicted an excessively resistant behaviour, as it can be seen in Fig. 13. The models from Yin and Poh did not produce a converged solution, which was attributed to the elastic-perfectly plastic shape of the stressstrain curves. The steel model determines the shape and extension of stages 1 and 2 at the axial displacement versus time curve (Fig. $4)$.

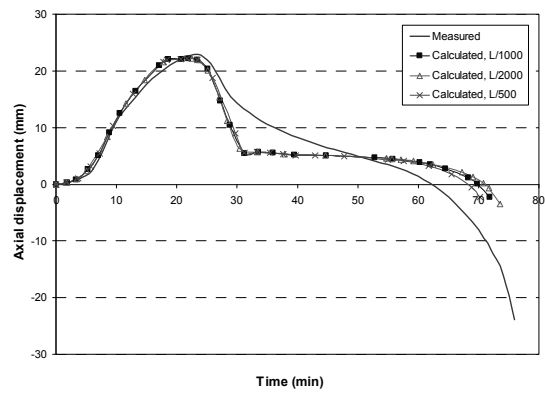

(b) Column C-05

Fig. 12. Comparison of measured and predicted axial displacement with different initial imperfections.

\section{Concrete}

In the case of concrete, a wider variety of mechanical models at elevated temperatures exists in the literature. Five of them were studied in this research: Lie [19], EN 1992-1-2 [6], Anderberg [2], Li-Purkiss [17] and Schneider [24]. The concrete model determines the extension of stage 3 at the axial displacement versus time curve (Fig. 4) and fixes the position of the failure branch (stage 4 at Fig. 4). Among all these models, the model from Lie was the one that best predicted the fire resistance of the columns, as it can be seen in Fig. 14. This model was specifically developed by the author for concrete employed as filling in CFT columns. Regarding EC2, this model produced the most conservative results. 


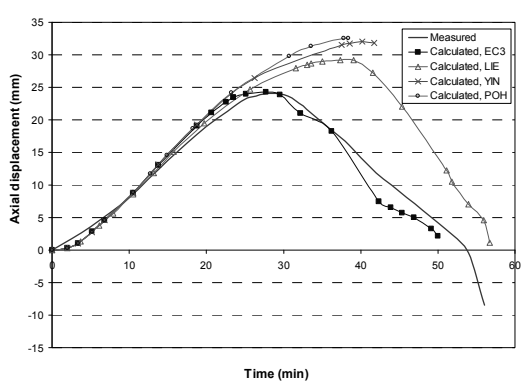

(a) Column C-04

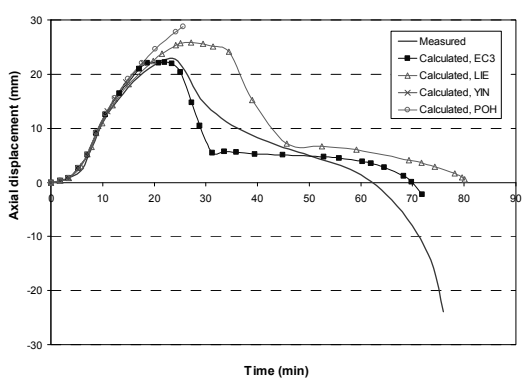

(b) Column C-05

Fig. 13. Comparison of measured and predicted axial displacement with different steel models.

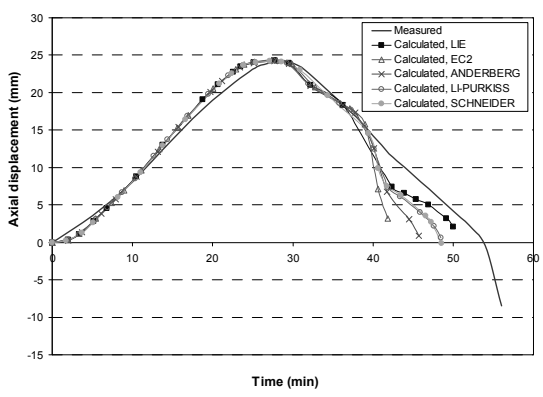

(a) Column C-04

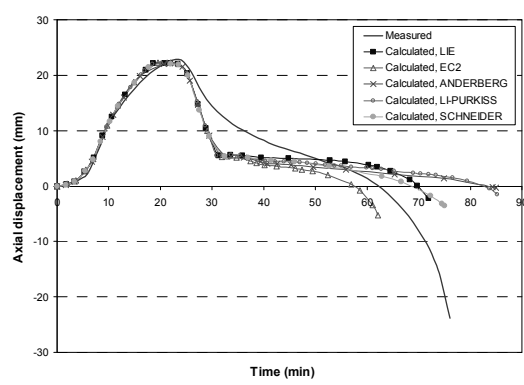

(b) Column C-05

Fig. 14. Comparison of measured and predicted axial displacement with different concrete models.

\subsection{Thermal expansion coefficient}

\section{Steel}

Two options were studied for modelling the thermal expansion of steel at elevated temperatures. On one hand, the temperature dependent values of the thermal expansion coefficient from EN 1993-1-2 [7] were studied. On the other hand, the constant value recommended by Hong-Varma [14], $\alpha_{s}=$ $12 \times 10^{-6}{ }^{\circ} \mathrm{C}^{-1}$, was checked. The EC3 thermal expansion model produced very accurate results, whereas the constant value proposed by Hong-Varma predicted a shorter maximum axial displacement, as shown in Fig. 15.

\section{Concrete}

Two options were studied for modelling the thermal expansion of concrete at elevated temperatures: the temperature dependent formulation from EN 1992-1-2 [6] and the constant value recommended by HongVarma [14], $\alpha_{c}=6 \times 10^{-6}{ }^{\circ} \mathrm{C}^{-1}$. This constant value produced remarkably better results for concrete, as shown in Fig. 16, while the EC2 model resulted in a very unreal response, giving place to excessive axial displacement in the stage when the concrete is sustaining the majority of the applied load (stage 3 at Fig. 4). 


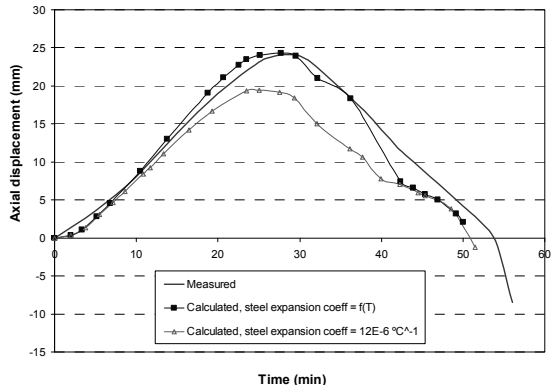

(a) Column C-04

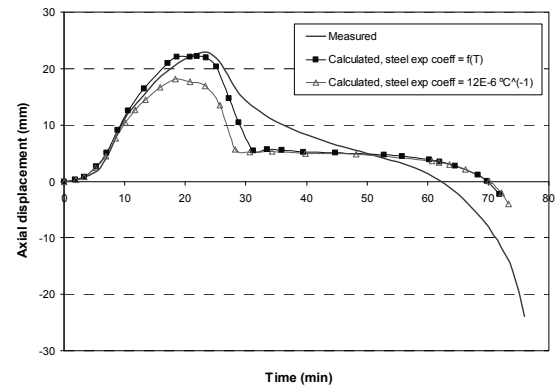

(b) Column C-05

Fig. 15. Comparison of measured and predicted axial displacement with different steel expansion models.

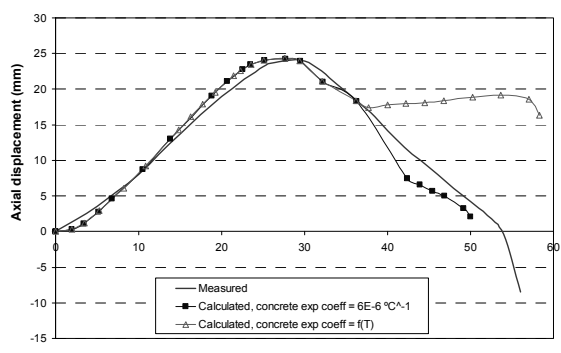

Time (min)

(a) Column C-04

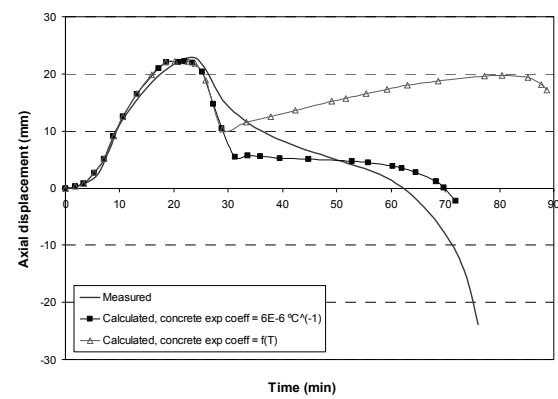

(b) Column C-05

Fig. 16. Comparison of measured and predicted axial displacement with different concrete expansion models.

\subsection{Concrete moisture}

The moisture content at the concrete infill was modelled through a peak value in the specific heat formulation, as recommended by EN 1994-1-2 [8]. A first peak value of $2020 \mathrm{~J} / \mathrm{kgK}$ corresponding to a moisture content of $3 \%$ in concrete weight was implemented, and a second value of 5600 $\mathrm{J} / \mathrm{kgK}$ for a moisture content of $10 \%$ was next studied. For the siliceous concrete filled specimens, the optimal results were obtained both in thermal and mechanical response with a $3 \%$ moisture value. This is shown in Fig. 17 for the temperature field of column C-02 and in Fig. 18 for the axial displacement response of columns C-04 and C-05. Nevertheless, for those specimens filled with calcareous concrete, the optimal moisture value was found to be a $10 \%$. The real moisture content value at test date, which may be different for each column specimen, was not reported in the literature and therefore a global value suitable for the majority of the tests was adopted in this research.

\subsection{Concrete density}

The variation of concrete density with temperature formulated in EN 1992-1-2 [6] was studied in contrast to the constant value of $2300 \mathrm{~kg} / \mathrm{m}^{3}$ adopted by most researchers. This study proved that there is no significant influence of this aspect over the fire behaviour of CFT columns, and therefore the figure is not presented here for simplicity to the 
reader. Thus, the temperature dependence of concrete density can be omitted in the model.

\subsection{Rebar finite element type}

Two different finite element types for modelling the reinforcing steel bars were studied in this research: the two-node truss elements and the three-dimensional solid elements. The truss elements gave a more accurate prediction for the reinforced specimens studied, as it can be seen in Fig. 19, producing an overall more realistic response. Full bond was assumed between the steel reinforcing bars and concrete, tying both rebar nodes to their corresponding concrete nodes.

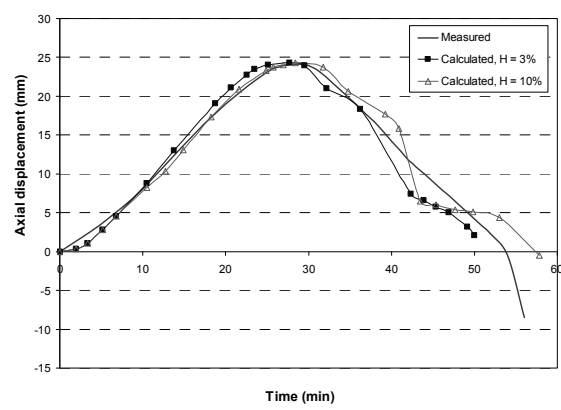

(a) Column C-04

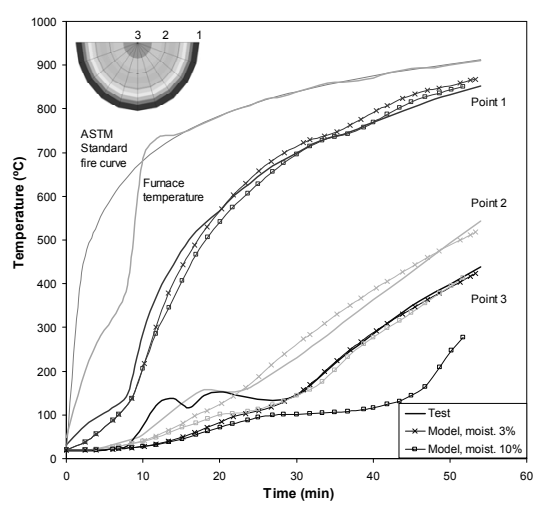

Fig. 17. Comparison between measured and predicted temperatures with different moisture values, for column C-02.

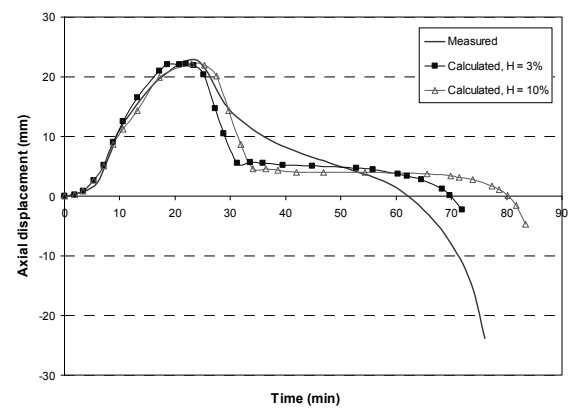

(b) Column C-05

Fig. 18. Comparison of measured and predicted axial displacement with different moisture values.

\subsection{Recommendations}

Based on the results of the sensitivity analysis carried out in this research, several recommendations can be done for the future numerical modelling of CFT columns under fire.

- For modelling the tangent behaviour at the steel-concrete interface, a full slip can be assumed and thus a frictionless contact model adopted, since in fire situation the different thermal expansions cause the transverse separation of the steel tube from the concrete core.
- In case that a Coulomb friction model is selected, the value of the friction coefficient at the steel-concrete interface does not have any influence on the column behaviour under fire.

- Regarding the gap thermal conductance at the steel-concrete interface, the model proposed by Ghojel [12] produces the best estimations in failure time, although adopting a constant value of $h_{j}=200$ $\mathrm{W} / \mathrm{m}^{2} \mathrm{~K}$ is more simplistic and produces acceptable results as well. 
- It is recommended to employ an amplitude value of $L / 1000-L / 2000$ for the initial geometric imperfection of the columns.

- For steel the EC3 [7] mechanical model produces the most accurate response, while for concrete the model developed by Lie [19] is the one that best predicts the overall behaviour in fire situation.

- The EC3 [7] thermal expansion model gives very accurate results for steel, whereas for concrete the constant value $\alpha_{c}=6 \times 10^{-6}{ }^{\circ} \mathrm{C}^{-1}$ recommended by HongVarma [14] produces the best results.

- The optimal results are obtained both in thermal and mechanical response with a moisture content value at the concrete core of $3 \%$ for the siliceous concrete specimens and with a $10 \%$ for the calcareous ones, even though this variable should be reported in the tests for every specimen and its exact value introduced to the model.

- A constant value of $2300 \mathrm{~kg} / \mathrm{m}^{3}$ is sufficient for modelling the concrete density. There is no significant influence of the temperature variation of this parameter over the fire behaviour of the columns.

- It is recommended to employ the twonode truss finite elements for modelling the longitudinal steel bars in the reinforced column specimens.

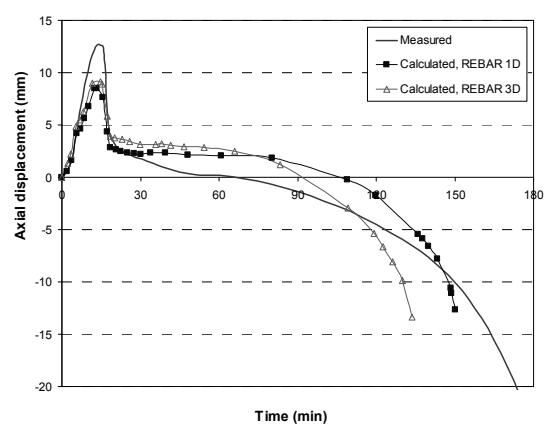

Fig. 19. Comparison of measured and predicted axial displacement with different rebar element types, for column C-48.

\section{Comparison with Eurocode 4 simple calculation model}

In this section, the validated numerical model will be used to study and discuss the EC4 simple calculation model [8]. This standard provides a simple method for calculating the fire resistance of CFT columns subjected to concentric axial loads. For eccentrically loaded columns, an equivalent concentric load is obtained by means of two factors, which are a function of the percentage of reinforcement and the relative eccentricity.

Only those columns with concrete filling resistance under $40 \mathrm{MPa}$ will be used for this study, as the current field of application of EC4 is $\mathrm{C} 20 / 25-\mathrm{C} 40 / 50$.

As already found by Aribert et al. [3], the EC4 simple calculation model does not take into account the effects of selfequilibrated thermal stresses and those of geometrical second-order local behaviour, which are crucial for the stability of the column. As the method is sectional, the strain in all the fibres within the cross-section of the column is assumed to be equal. This approach clearly neglects the effects of the differential longitudinal expansion between the steel tube and concrete core, thus assuming that a full bond occurs. All these factors lead to important deviations from the actual fire response of CFT columns.

\subsection{Concentric axial load}

\section{a) Influence of the thermal expansion}

One of the most important factors affecting the accuracy of EC4 simple calculation model is the differential longitudinal thermal expansion between the steel tube and the concrete core, which cannot be taken into account through a sectional approach as the one in EC4. If the same assumptions adopted by EC4 are applied to the numerical model (no thermal expansion occurs, no thermal resistance exists at the steel-concrete interface, all the column is uniformly exposed to a standard fire), more similar results to those predicted by EC4 are obtained, 
as it can be seen in Table 5 and Fig. 20. These results seem to confirm that EC4 neglects the differential thermal expansion effect. With these assumptions applied to the numerical model, a more conservative trend but still parallel to the real trend is obtained, which could be used to improve the accuracy and extension of the EC4 provisions.

Table 5. Comparison of the numerical simulations (with various assumptions) and EC4 simple calculation model with the tests

\begin{tabular}{|c|c|c|c|c|c|c|c|}
\hline \multirow{2}{*}{$\begin{array}{c}\text { Column } \\
\text { No. }\end{array}$} & \multicolumn{4}{|c|}{ FRR (min) } & \multicolumn{3}{|c|}{$\xi_{\mathrm{FRR}}=\frac{F R R_{\text {test }}}{F R R_{\text {calc }}}$} \\
\hline & Test & Simulation & $\begin{array}{c}\text { Simulation } \\
\text { (no expan- } \\
\text { sion) }\end{array}$ & EC4 & Simulation & $\begin{array}{c}\text { Simulation } \\
\text { (no expan- } \\
\text { sion) }\end{array}$ & EC4 \\
\hline $\mathrm{C}-02$ & 55 & 55 & 46 & 59 & 1.00 & 1.20 & 0.93 \\
\hline C-04 & 57 & 50 & 41 & 49 & 1.14 & 1.39 & 1.16 \\
\hline C- -05 & 76 & 72 & 58 & 67 & 1.06 & 1.31 & 1.14 \\
\hline C-08 & 56 & 59 & 48 & 48 & 1.25 & 1.17 & 1.18 \\
\hline C-09 & 81 & 75 & 61 & 77 & 0.95 & 1.33 & 1.05 \\
\hline C-11 & 80 & 77 & 60 & 47 & 1.08 & 1.33 & 1.71 \\
\hline C-13 & 102 & 98 & 75 & 63 & 1.04 & 1.36 & 1.61 \\
\hline $\mathrm{C}-17$ & 82 & 75 & 59 & 53 & 1.04 & 1.39 & 1.54 \\
\hline $\mathrm{C}-20$ & 112 & 150 & 121 & 86 & 1.55 & 0.93 & 1.30 \\
\hline $\mathrm{C}-21$ & 133 & 163 & 130 & 95 & 1.03 & 1.02 & 1.40 \\
\hline $\mathrm{C}-22$ & 70 & 79 & 55 & 39 & 1.09 & 1.27 & 1.79 \\
\hline $\mathrm{C}-23$ & 143 & 147 & 123 & 109 & 0.75 & 1.16 & 1.32 \\
\hline C-31 & 82 & 65 & 54 & 86 & 0.82 & 1.52 & 0.96 \\
\hline $\mathrm{C}-32$ & 64 & 50 & 42 & 52 & 0.89 & 1.52 & 1.22 \\
\hline C-34 & 111 & 101 & 75 & 58 & 0.97 & 1.48 & 1.93 \\
\hline $\mathrm{C}-37$ & 102 & 75 & 58 & 52 & 1.26 & 1.76 & 1.97 \\
\hline \multirow[t]{3}{*}{ C-44 } & 178 & 180 & 142 & 103 & 1.28 & 1.25 & 1.73 \\
\hline & \multicolumn{4}{|c|}{ Average } & 1.08 & 1.32 & 1.41 \\
\hline & \multicolumn{4}{|c|}{ Standard deviation } & 0.19 & 0.20 & $\mathbf{0 . 3 3}$ \\
\hline
\end{tabular}

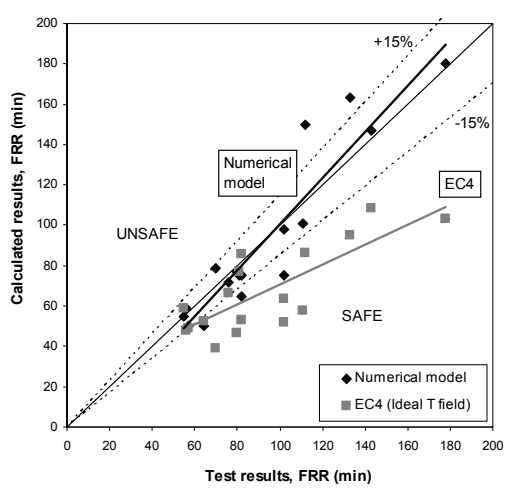

(a) Original numerical model

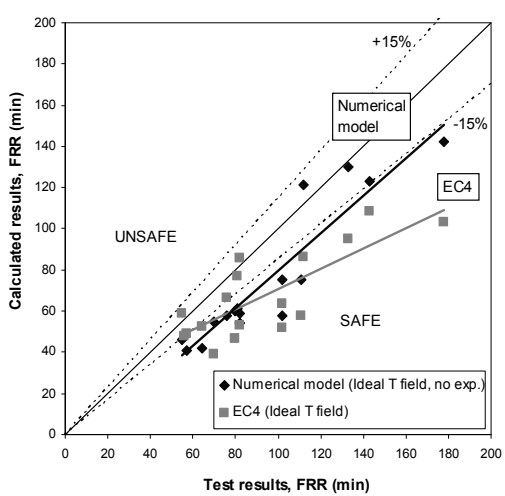

(b) Numerical model with ideal temperature field (perfect contact) and no thermal expansion

Fig. 20. Comparison of the numerical simulations (with various assumptions) and EC4 predictions with the tests. 


\section{b) Influence of the temperature field}

It is known that the EC4 simple calculation model for obtaining the fire resistance of unprotected concrete filled hollow section columns in axial compression requires the cross-sectional temperature field to be previously known and applied as a first step. Therefore, the calculated axial buckling load in fire will be influenced by the level of accuracy of the thermal distribution employed by the designer. This influence is studied hereafter.

\section{b.1) Fixed-fixed end conditions}

On a first level of comparison, the fixed-fixed specimens from the Canadian tests were contrasted with the predictions of the EC4 simple calculation model, employing both an ideal temperature field calculated assuming perfect thermal contact and the real temperature field obtained by means of the validated numerical model. The results are listed in Table 6 and plotted in Fig. 21. It was found that when the real temperature distribution over the cross-section was adopted, the EC4 simple calculation model produced unsafe results for those columns with the highest relative slenderness.

Table 6. Comparison in FRR between fire tests, numerical simulations and EC4 simple calculation model, for fixed-fixed centrally loaded columns

\begin{tabular}{ccccc}
\hline Column No. & Test & $\begin{array}{c}\text { Numerical } \\
\text { model }\end{array}$ & $\begin{array}{c}\text { EC4 } \\
\text { (Ideal T field) }\end{array}$ & $\begin{array}{c}\text { EC4 } \\
\text { (Real T field) }\end{array}$ \\
\hline C-02 & 55 & 55 & 59 & 70 \\
C-04 & 57 & 50 & 49 & 59 \\
C-05 & 76 & 72 & 67 & 80 \\
C-08 & 56 & 59 & 48 & 56 \\
C-09 & 81 & 75 & 77 & 88 \\
C-11 & 80 & 77 & 47 & 54 \\
C-13 & 102 & 98 & 63 & 75 \\
C-17 & 82 & 75 & 53 & 59 \\
C-20 & 112 & 150 & 86 & 100 \\
C-21 & 133 & 163 & 95 & 109 \\
C-22 & 70 & 79 & 39 & 46 \\
C-23 & 143 & 147 & 109 & 114 \\
C-31 & 82 & 65 & 86 & 99 \\
C-32 & 64 & 50 & 52 & 60 \\
C-34 & 111 & 101 & 58 & 78 \\
C-37 & 102 & 75 & 52 & 62 \\
C-44 & 178 & 180 & 103 & 151 \\
\hline
\end{tabular}

Special mention must be done regarding this aspect. EC4 establishes that the thermal resistance between the steel wall and the concrete core may be neglected in the calculation of the cross-sectional temperature field. This is a conservative assumption which leads to safe results, but the structural engineer must be aware that when adopting a more complex temperature field obtained by means of any advanced model the results of EC4 can turn into the unsafe side. The temperature field employed as a previous step for calculating the axial buckling load at elevated temperature with EC4 simple calcula- tion model must be therefore carefully considered, since it can noticeably influence the simple model predictions.

\section{b.2) Pinned-pinned end conditions}

On a second level of comparison, the same specimens were simulated hinged at both ends, and the results compared with the predictions of the EC4 simple calculation model employing both the ideal temperature field and the real temperature field. The results are listed in Table 7 and plotted in Fig. 22. For most of these cases, the EC4 model became unsafe, since the buckling length of 
the columns was higher. Only those cases corresponding to the massive columns remained on the safe side. The influence of the adopted temperature field was noticeable again, in such a way that employing a real temperature field moves the trend of the results series towards the unsafe side.
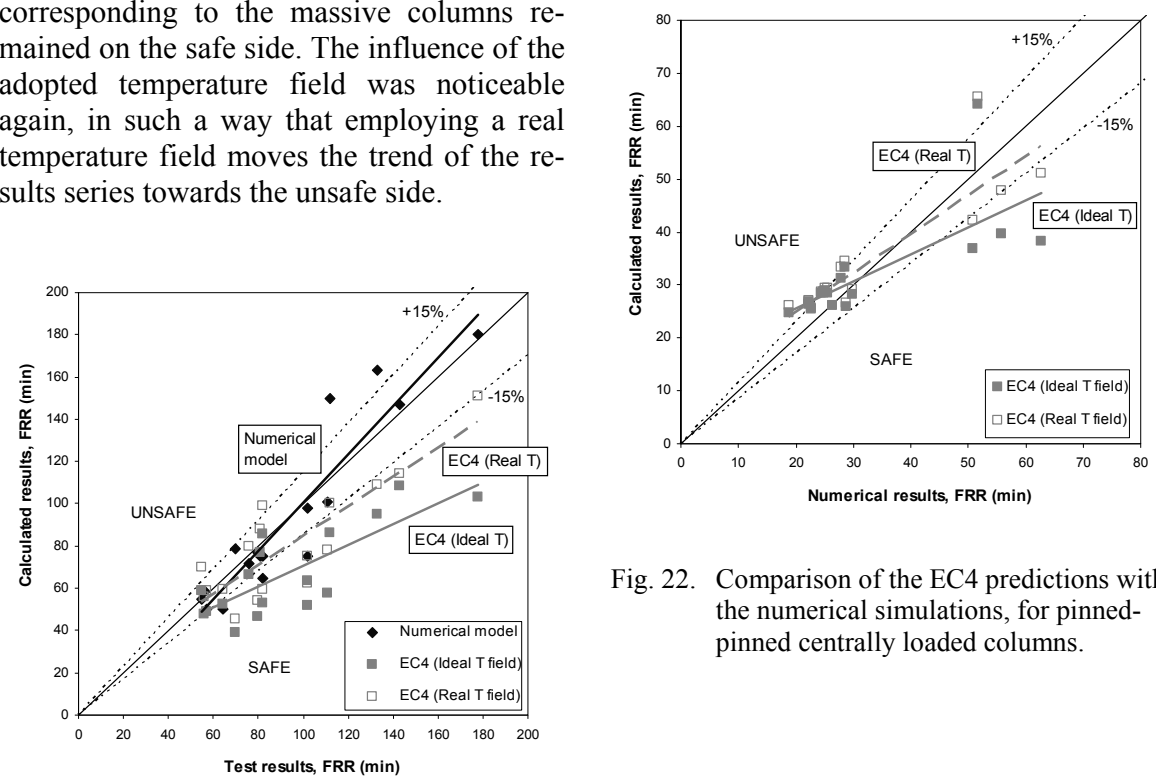

Fig. 22. Comparison of the EC4 predictions with the numerical simulations, for pinnedpinned centrally loaded columns.

Fig. 21. Comparison of the numerical simulations and EC4 predictions with the tests, for fixed-fixed centrally loaded columns.

Table 7. Comparison in FRR between numerical simulations and EC4 simple calculation model, for pinned-pinned centrally loaded columns

\begin{tabular}{cccc}
\hline Column No. & $\begin{array}{c}\text { Numerical } \\
\text { model }\end{array}$ & $\begin{array}{c}\text { EC4 } \\
\text { (Ideal T field) }\end{array}$ & $\begin{array}{c}\text { EC4 } \\
\text { (Real T field) }\end{array}$ \\
\hline C-02 & 24 & 28 & 29 \\
C-04 & 22 & 27 & 27 \\
C-05 & 26 & 28 & 29 \\
C-08 & 19 & 25 & 26 \\
C-09 & 28 & 31 & 33 \\
C-11 & 23 & 25 & 26 \\
C-13 & 30 & 28 & 29 \\
C-17 & 25 & 29 & 29 \\
C-20 & 51 & 37 & 42 \\
C-21 & 56 & 40 & 48 \\
C-22 & 26 & 26 & 26 \\
C-23 & 52 & 64 & 65 \\
C-31 & 29 & 33 & 35 \\
C-32 & 22 & 26 & 26 \\
C-34 & 29 & 26 & 27 \\
C-37 & 25 & 28 & 29 \\
C-44 & 63 & 38 & 51 \\
\hline
\end{tabular}


In general, it can be concluded that for centrally loaded columns, values of the relative slenderness at ambient temperature greater than 0.4 lead to unsafe results, as in can be seen in Fig. 23.

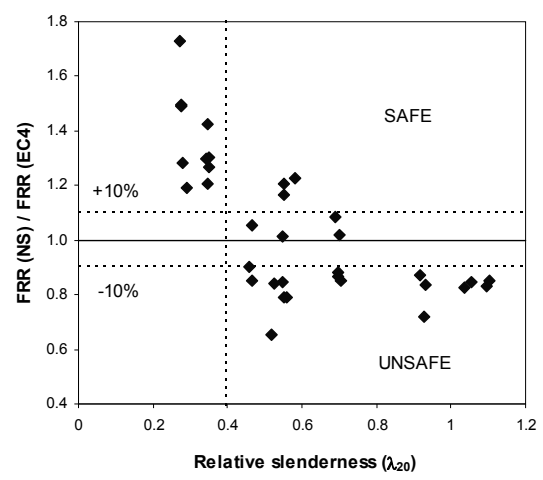

Fig. 23. Relative error of EC4 simple calculation model for different relative slenderness values.
This fact was already confirmed by Aribert et al. [3], who found that EC4 simple calculation model leads to buckling load values that are quite unsafe when the column slenderness increases.

\subsection{Eccentrically loaded columns}

Finally, the same series of pinnedpinned columns were simulated introducing a $20 \mathrm{~mm}$ and $50 \mathrm{~mm}$ eccentricity and afterwards compared with the EC4 simple calculation model predictions employing both the ideal temperature field and the real temperature field. The results are listed in Table 8 and plotted in Fig. 24 for the $20 \mathrm{~mm}$ eccentric specimens. In these cases, the simple calculation model produced results that were on the safe side, due to the application of the corresponding reduction factors. Thus, for eccentrically loaded columns, it can be concluded that EC4 simple calculation model becomes conservative.

Table 8. Comparison in FRR between numerical simulations and EC4 simple calculation model, for pinned-pinned eccentrically loaded columns

\begin{tabular}{ccccccc}
\hline \multirow{3}{C}{$\begin{array}{c}\text { Column } \\
\text { No. }\end{array}$} & $\begin{array}{c}\text { Numerical } \\
\text { model }\end{array}$ & $\begin{array}{c}\text { EC4 } \\
\text { (Ideal T } \\
\text { field) }\end{array}$ & $\begin{array}{c}\text { EC4 } \\
\text { (Real T } \\
\text { field) }\end{array}$ & $\begin{array}{c}\text { Numerical } \\
\text { model }\end{array}$ & $\begin{array}{c}\text { EC4 } \\
\text { (Ideal T } \\
\text { field) }\end{array}$ & $\begin{array}{c}\text { EC4 } \\
\text { (Real T } \\
\text { field) }\end{array}$ \\
\hline C-02 & 22 & 13 & 12 & 19 & 3 & 3 \\
C-04 & 20 & 9 & 8 & 17 & 0 & 0 \\
C-05 & 23 & 12 & 13 & 20 & 1 & 1 \\
C-08 & 16 & 0 & 0 & 14 & 0 & 0 \\
C-09 & 25 & 16 & 16 & 23 & 11 & 10 \\
C-11 & 17 & 0 & 0 & 13 & 0 & 0 \\
C-13 & 20 & 4 & 3 & 18 & 0 & 0 \\
C-17 & 22 & 5 & 4 & 19 & 0 & 0 \\
C-20 & 21 & 14 & 13 & 19 & 0 & 0 \\
C-21 & 22 & 17 & 16 & 20 & 3 & 3 \\
C-22 & 17 & 0 & 0 & 11 & 0 & 0 \\
C-23 & 39 & 28 & 28 & 35 & 25 & 24 \\
C-31 & 27 & 17 & 17 & 23 & 12 & 12 \\
C-32 & 20 & 5 & 4 & 17 & 0 & 0 \\
C-34 & 17 & 0 & 0 & 12 & 0 & 0 \\
C-37 & 22 & 0 & 0 & 19 & 0 & 0 \\
C-44 & 22 & 13 & 14 & 19 & 0 & 0 \\
\hline
\end{tabular}




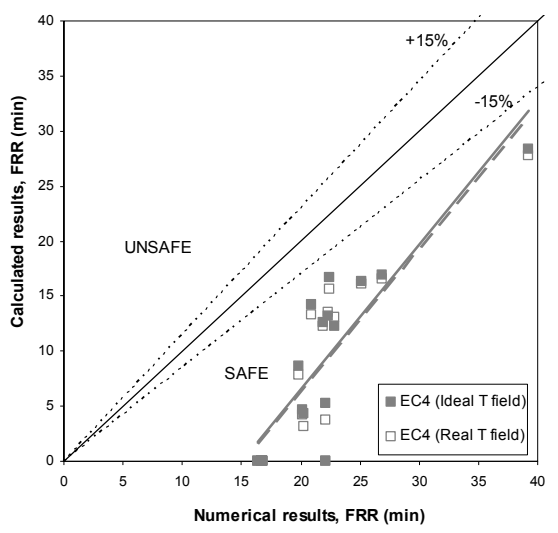

Fig. 24. Comparison of the EC4 predictions with the numerical simulations, for pinnedpinned $20 \mathrm{~mm}$ eccentrically loaded columns.

Regarding the temperature field adopted as the previous step for applying the simple calculation model, it showed not to have a significant influence for eccentrically loaded columns.

Summarizing all the findings exposed above, this extensive study evidences some limitations in the EC4 simple calculation model when predicting the axial buckling load of concrete filled hollow steel sections at elevated temperatures and suggests that the model should be revised in the future on the bases of these findings.

\section{Summary and conclusions}

A realistic three-dimensional numerical model for predicting the fire response of axially loaded CFT columns was presented. By means of this model, the fire behaviour of a series of column specimens previously tested by other researchers was predicted. The numerical model showed good agreement with the tests both quantitative, producing acceptable results in fire resistance rating, and qualitative, capturing the overall axial displacement response along time. There was better agreement for the leaner columns, whereas the massive columns produced more error, which was attributed to the higher contribution of concrete and its more complex failure mechanisms.

The behaviour of CFT columns with concrete fillings in the medium strength range was also explored but could not be so well captured in this initial research work, due to the local effects associated to microcracking that appear in non-reinforced HSC at elevated temperatures. Despite this aspect, the model showed good agreement when contrasted with the fire tests of CFT columns in the range of the normal strength, which was the scope of this paper. The aim of future work will be to extend the model to high strength concrete, including the simulation of the effect of spalling.

By means of the validated numerical model, an extensive sensitivity analysis was carried out, covering the main aspects of the problem. With the results of this sensitivity study a number of modelling recommendations for CFT columns in fire were given in this paper.

This research also proved that the EC4 simple calculation model may lead to unsafe results when working with columns with relative slenderness values over 0.4 and in general for pinned-pinned columns under concentric axial load. Moreover, it was found that applying a realistic predefined temperature field to the model can magnify this effect. However, EC4 simple calculation model becomes highly conservative for eccentric loads.

The simple calculation model should be therefore improved based on the results of this paper. In future work it will be intended to capture the failure mechanism of high strength concrete filled specimens, in order to create a virtual laboratory for simulating a wider range of cases that can be used to extend and improve the current provisions of EC4.

\section{Acknowledgements}

The authors express their sincere gratitude to the Spanish "Ministerio de Ciencia e 
Innovación" for the help provided through the Project BIA2009-9411 and to the European Union through the FEDER funds.

\section{References}

[1] ABAQUS. ABAQUS/Standard Version 6.6 User's Manual: Volumes I-III. Pawtucket, Rhode Island: Hibbit, Karlsson \& Sorenson, Inc.; 2005.

[2] Anderberg Y, Thelandersson S. Stress and deformation characteristics of concrete at high temperatures - Experimental investigation and material behaviour model. Bulletin 54. Lund, Sweden: Lund Institute of Technology; 1976.

[3] Aribert JM, Renaud C, Zhao B. Simple fire design for composite hollow-section columns. Structures \& Buildings 2008; 161:325-336.

[4] ASTM. Standard ASTM E119-88: Standard methods of fire test of building construction and materials. Philadelphia, $\mathrm{Pa}$ : American Society for Testing and Materials; 1990.

[5] CEN. EN 1991-1-2, Eurocode 1: Actions on structures, Part 1.2: General actions Actions on structures exposed to fire. Brussels, Belgium: Comité Européen de Normalisation; 2002.

[6] CEN. EN 1992-1-2, Eurocode 2: Design of concrete structures, Part 1.2: General rules - Structural fire design. Brussels, Belgium: Comité Européen de Normalisation; 2004.

[7] CEN. EN 1993-1-2, Eurocode 3: Design of steel structures, Part 1.2: General rules Structural fire design. Brussels, Belgium: Comité Européen de Normalisation; 2005.

[8] CEN. EN 1994-1-2, Eurocode 4: Design of composite steel and concrete structures, Part 1.2: General rules - Structural fire design. Brussels, Belgium: Comité Européen de Normalisation; 2005.

[9] Chabot M, Lie TT. Experimental studies on the fire resistance of hollow steel columns filled with bar-reinforced concrete. Internal report No. 628. Ottawa, Canada: Institute for Research in Construction, National Research Council of Canada (NRCC); 1992.

[10] Ding J, Wang YC. Realistic modelling of thermal and structural behaviour of unprotected concrete filled tubular columns in fire. Journal of Constructional Steel Research 2008; 64:1086-1102.

[11] Galambos TV. Guide to stability design criteria for metal structures. Fifth edition. New York: John Wiley and Sons Inc.; 1998.

[12] Ghojel J. Experimental and analytical technique for estimating interface thermal conductance in composite structural elements under simulated fire conditions. Experimental Thermal and Fluid Science 2004; 28:347-354.

[13] Grandjean G, Grimault JP, Petit L. Determination de la duree au feu des profils creux remplis de beton. CIDECT Research Project 15B-80/10. Cologne, Germany: Comité International pour le Développement et l'Etude de la Construction Tubulaire; 1980.

[14] Hong S, Varma AH. Analytical modeling of the standard fire behavior of loaded CFT columns. Journal of Constructional Steel Research 2009; 65:54-69.

[15] ISO (International Standards Organization). ISO 834: Fire resistance tests, elements of building construction. Switzerland: International Standards Organisation; 1980.

[16] Kordina K, Klingsch W. Fire resistance of composite columns of concrete filled hollow sections. CIDECT Research Project 15C1/C2-83/27. Cologne, Germany: Comité International pour le Développement et l'Etude de la Construction Tubulaire; 1983.

[17] Li LY, Purkiss J. Stress-strain constitutive equations of concrete material at elevated temperatures. Fire Safety Journal 2005; 40(7):669-686.

[18] Lie TT, Chabot M. Experimental studies on the fire resistance of hollow steel columns filled with plain concrete. Internal report No. 611. Ottawa, Canada: Institute for Research in Construction, National Research Council of Canada (NRCC); 1992.

[19] Lie TT. Fire resistance of circular steel columns filled with bar-reinforced concrete. Journal of Structural EngineeringASCE 1994; 120(5):1489-1509.

[20] Poh KW. Stress-strain-temperature relationships for structural steel. Journal of 
Materials in Civil Engineering 2001; 13(5):371-379.

[21] Renaud C, Aribert JM, Zhao B. Advanced numerical model for the fire behaviour of composite columns with hollow steel section. Steel and Composite Structures 2003; 3(2):75-95.

[22] Renaud C, Joyeux D, Kruppa J. Improvement and extension of the simple calculation method for fire resistance of unprotected concrete filled hollow columns. CIDECT Research Project 15Q-12/03. Saint-Rémy-lès-Chevreuse Cedex, France: Centre Technique Industriel de la Construction Métallique (CTICM); 2004.

[23] Schaumann P, Kodur V, Bahr O. Fire behaviour of hollow structural section steel columns filled with high strength concrete. Journal of Constructional Steel Research 2009; 65:1794-1802.

[24] Schneider U, Haksever A. Bestimmung der aquialenten branddauer vor statisch bestimmt gelagerten stahlbetonbalken bei naturlichen branden. Bericht des Instituts fur Baustoffkunde und Stahlbetonbau der Technischen Universität Braunschweig; 1976.

[25] Twilt L, Hass R, Klingsch W, Edwards M, Dutta D. Design guide for structural hollow section columns exposed to fire. Cologne, Germany: Comité International pour le Développement et l'Etude de la Construction Tubulaire (CIDECT); 1996.

[26] Yin J, Zha XX, Li LY. Fire resistance of axially loaded concrete filled steel tube columns. Journal of Constructional Steel Research 2006; 62(7):723-729.

[27] Zha XX. FE analysis of fire resistance of concrete filled CHS columns. Journal of Constructional Steel Research 2003; 59:769-779. 



\section{ANNEX I. COMPENDIUM OF PUBLICATIONS}

\section{ARTICLE 2}

Published in Thin-Walled Structures 49 (2011) 239-255

For copyright restrictions, the article is presented in its pre-print version. 



\title{
FIRE BEHAVIOUR OF CONCRETE FILLED ELLIPTICAL STEEL COLUMNS
}

\author{
Ana Espinos ${ }^{\mathrm{a}, 1}$, Leroy Gardner ${ }^{\mathrm{b}}$, Manuel L. Romero ${ }^{\mathrm{a}}$, Antonio Hospitaler ${ }^{\mathrm{a}}$ \\ ${ }^{a}$ Instituto de Ciencia y Tecnología del Hormigón (ICITECH), \\ Universidad Politécnica de Valencia, Valencia, Spain \\ ${ }^{b}$ Department of Civil and Environmental Engineering, South Kensington Campus, \\ Imperial College London, London, United Kingdom \\ ${ }^{1}$ Visiting academic at Imperial College London
}

\begin{abstract}
In this work, a non-linear three-dimensional finite element model is presented in order to study the behaviour of axially loaded concrete filled elliptical hollow section (CFEHS) columns exposed to fire. This study builds on previous work carried out by the authors on concrete filled circular hollow section (CFCHS) columns both at room temperature and in fire. The numerical model is first validated at room temperature against a series of experiments on CFEHS stub columns available in the literature and subsequently extended to study the performance of slender columns at elevated temperatures. The aim of this work is to understand and represent the behaviour of axially loaded CFEHS columns in fire situations and to compare their effectiveness with that of the circular concrete filled tubular (CFT) columns. Parametric studies to explore the influence of variation in global member slenderness, load level, cross-section slenderness and section size are presented. Finally, guidance on the fire design of CFEHS columns is proposed: it is recommended to follow the guidelines of Clause 4.3.5.1 in EN 1994-1-2, but employing the flexural stiffness reduction coefficients established in the French National Annex with an equivalent EHS diameter equal to $P / \pi$, where $P$ is the perimeter of the ellipse.
\end{abstract}

Keywords: Fire resistance; Composite columns; Concrete filled steel tubes; Elliptical hollow sections; Finite element analysis; Simple calculation model

\section{Notation}

$\begin{array}{ll}A / V & \text { Section factor } \\ a & \text { Half larger outer dimension of an elliptical section } \\ B & \text { Outer dimension of a square section } \\ b & \text { Half smaller outer dimension of an elliptical section } \\ \text { CFT } & \text { Concrete filled tube } \\ \text { CFCHS } & \text { Concrete filled circular hollow section } \\ \text { CFEHS } & \text { Concrete filled elliptical hollow section } \\ \text { CFRHS } & \text { Concrete filled rectangular hollow section } \\ \text { CHS } & \text { Circular hollow section } \\ D & \text { Outer diameter of a circular section } \\ \text { EC4 } & \text { Eurocode 4 Part 1-2 } \\ \text { EHS } & \text { Elliptical hollow section }\end{array}$




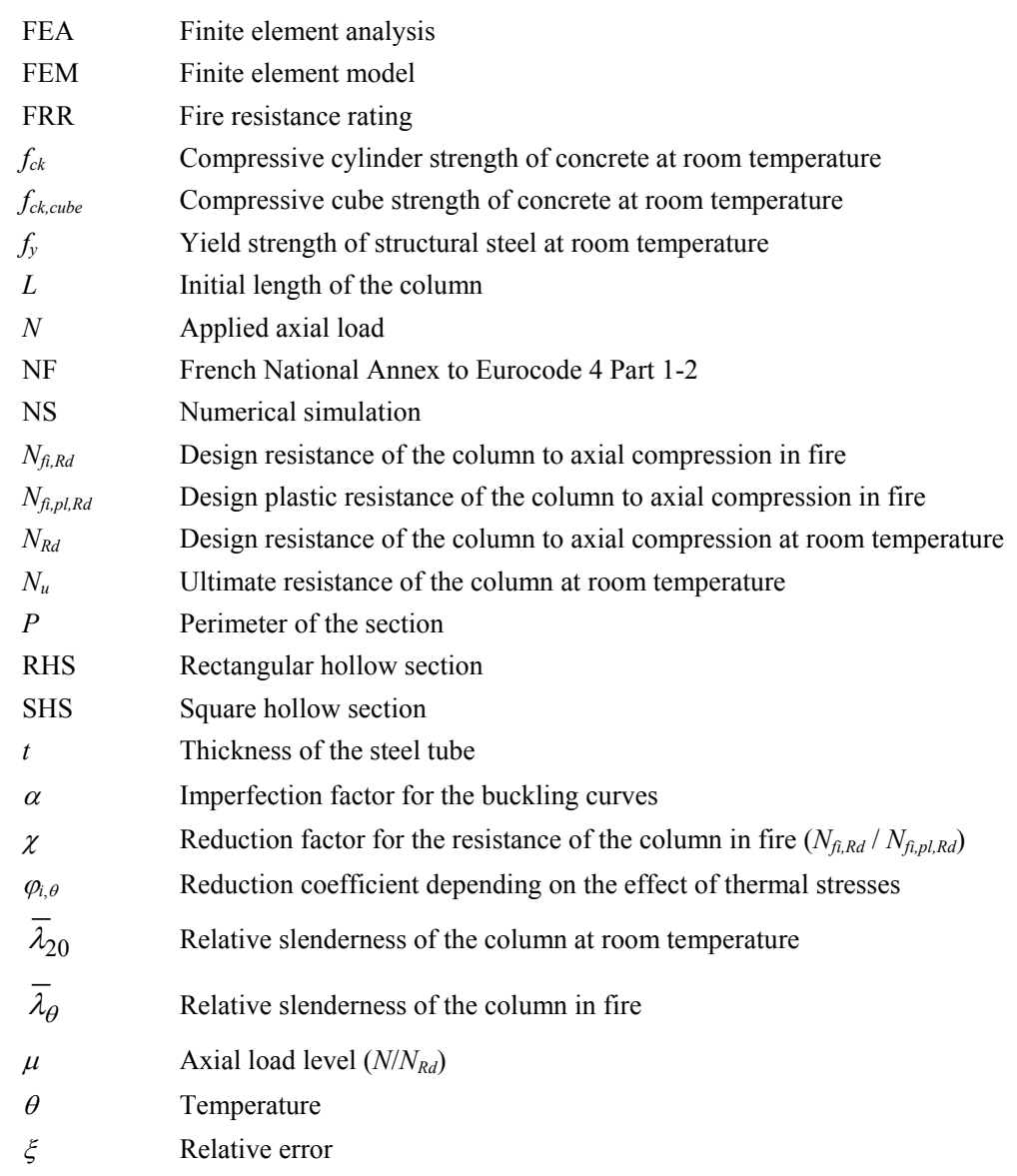

\section{Introduction}

The use of concrete filled tubular columns has increased in recent decades due to their excellent structural performance, which takes advantage of the combined effect of steel and concrete working together - the steel tube provides confinement to the concrete core, resulting in increased compressive strength, while the concrete core restricts inward deformation of the steel tube thus enhancing local buckling resistance and enabling the use of thinner cross-sections. Circular, square and rectangular steel tubes have been traditionally used to form these composite columns. Parallel to this, a new shape of tubular section [1] has now been introduced to the construction industry: the el- liptical hollow section [2]. Their aesthetic appeal and reduced visual intrusion, combined with their structural advantages associated with sections of differing major and minor axis properties, make these sections of great interest for designers [3], [4]. The structural behaviour of the elliptical sections has been deeply studied in recent years by Gardner and Chan [5] [6] [7] [8], covering cross-section classification and the evaluation of compressive, shear and bending resistances. Furthermore, the elastic buckling response of elliptical hollow sections in compression has been studied by Ruiz-Teran and Gardner [9] and Silvestre [10]. The effect of filling these columns with concrete has been examined by Yang et al. [11] and Zhao and 
Packer [12], through testing stub columns under compressive axial load at room temperature.

Yang et al. [11] carried out an experimental programme consisting of 21 test specimens filled with three different concrete grades (C30, C60 and $\mathrm{C} 100), 15$ of which were compositely loaded, the rest being core-loaded. They found out that higher tube thickness improved the load-bearing capacity and ductility of the columns, while higher concrete strength resulted in higher load-bearing capacity but reduced ductility. Concrete shrinkage was found to have little effect on the compressive response of the columns. The confinement provided to the concrete core by the elliptical steel tubes was also assessed, finding that the strength and ductility of the concrete was greatly improved. Through comparing their experimental results with existing code provisions for concrete filled hollow sections, Yang et al. [11] confirmed that the behaviour of CFEHS lies between that of concrete filled circular and square/rectangular hollow sections. According to the authors, the EN 1994-1-1 [13] design expression for SHS and RHS provides an accurate and safe prediction of the compressive response of CFEHS.

Zhao and Packer [12] performed a series of tests on normal and self-consolidating concrete filled elliptical hollow section stub columns with different loading methods (compositely loaded, core-loaded and tubeloaded). The experimental load-carrying capacity of the tested specimens was compared with different code provisions. The authors proposed several design formulae, through three approaches: simple superposition of steel and concrete strengths, CFCHS approach and CFRHS approach, concluding that the existing design rules for circular and rectangular hollow section tubes are applicable to CFEHS stub columns, provided that appropriate equivalent section properties are used.

Dai and Lam [14], [15] recently developed a numerical model to represent the axial compressive behaviour of short concrete filled elliptical steel columns. They studied the differences in concrete confinement between circular and elliptical hollow sections, finding that the circular hollow sections provided higher confinement than the elliptical ones. Unlike the uniform contact stress distribution around the perimeter of circular sections, the contact forces along the perimeter of elliptical sections were non-uniform, with higher stresses at the sharper corners. Based on this study, Dai and Lam [14] developed a stress-strain model for concrete confined by elliptical steel hollow sections.

Despite the room temperature behaviour of CFEHS columns being widely studied in the last few years, the performance of these columns in a fire situation has not yet been investigated, which limits their applicability in the building industry. Since there are no experimental results available in the literature on concrete filled elliptical hollow section columns exposed to elevated temperatures, their fire behaviour will be initially studied through numerical modelling.

The present study builds on previous research performed by the authors on concrete filled circular hollow section columns both at room temperature and in fire.

\section{Validation of the numerical model}

\subsection{Concrete filled circular hollow section columns at room temperature and exposed to fire}

Previous research on the modelling of the behaviour of concrete filled circular hollow section columns at room temperature and exposed to fire has been carried out by the authors. Firstly, the compressive resistance of both stub and slender circular CFT columns filled with different concrete grades (normal and high strength concrete) at room temperature was studied by Lacuesta et al. [16], with the models validated against experimental results obtained by Portoles et al. [17] in the testing facilities of Jaume I University (Castellón). Having established the compressive behaviour of the CFCHS col- 
umns at room temperature, their performance in fire was studied by Espinos et al. [18], where an advanced thermo-mechanical numerical model was developed and validated by comparing its results with a series of fire tests available in the literature. An extensive sensitivity analysis was carried out, in order to investigate the main aspects of the model, which will serve as a basis for future work on the numerical simulation of CFT columns at elevated temperatures.

A validated model for predicting the compressive resistance of CFCHS at room temperature and under fire conditions is therefore available. From this basis, the aim of the present study is to extend the existing model to the recently developed elliptical sections, in order to study their effectiveness in a fire situation when compared with circular sections.

\subsection{Concrete filled elliptical hollow section columns at room temperature}

The compressive behaviour of CFEHS stub columns has now been well established through experimental research and numerical modelling carried out by Yang et al. [11] and Dai and Lam [14]. Nevertheless, in order to demonstrate that the model which will be developed here for studying the behaviour of CFEHS in fire is accurate, initial validation of the model at room temperature is required. For this purpose, the nine compositely loaded specimens tested by Yang et al. [11] will be utilised.

\subsubsection{Description of the finite element model}

By means of the finite element analysis package ABAQUS [19], a three-dimensional numerical model for simulating the room temperature response of CFEHS stub columns under axial compression was developed. The full length and the complete crosssection of the columns was modelled, since the experiments had revealed that in some of the cases the response was dominated by shear failure of the concrete and therefore an unsymmetrical deformed shape was ex- pected to be obtained. Fig. 1 shows the typical finite element model adopted for this numerical investigation.

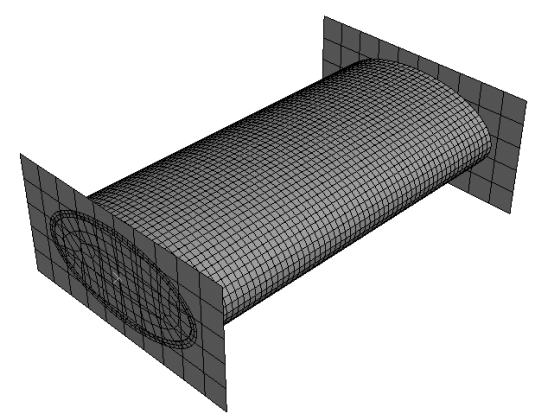

Fig. 1. Three-dimensional finite element model for CFEHS stub columns.

The steel tube and concrete core were meshed using three-dimensional eight-noded solid elements with reduced integration (C3D8R). Based on the results of a mesh sensitivity study, a suitable element size which provided accurate results with practical computational times was found: $5 \mathrm{~mm}$ for the steel tube and $10 \mathrm{~mm}$ for the concrete core, i.e. the concrete element size was twice the size of the steel elements.

As already found by Dai and Lam [14], two layers of elements through the thickness of the steel tube were required to accurately capture the observed experimental response. This finding is reflected in Fig. 2, where it is clear that a mesh arrangement with only one layer of elements through the thickness of the steel tube underestimates the loadcarrying capacity of the column and fails to accurately capture the deformation history exhibited in the test.

The steel end plates were modelled as discrete rigid parts with all nodes coupled to a reference point located at the column axis. The axial load was applied to the upper rigid plate through its reference node as an imposed static displacement, transmitting load to both the concrete core and the steel tube. Following the testing procedure, all six de- 
grees of freedom of the lower rigid plate were fixed, while the upper rigid plate was allowed to move along the column axis but was fixed against the other five degrees of freedom. The rigid plates were meshed using four-noded three-dimensional bilinear rigid quadrilateral elements (R3D4), with a maximum element size of $20 \mathrm{~mm}$.

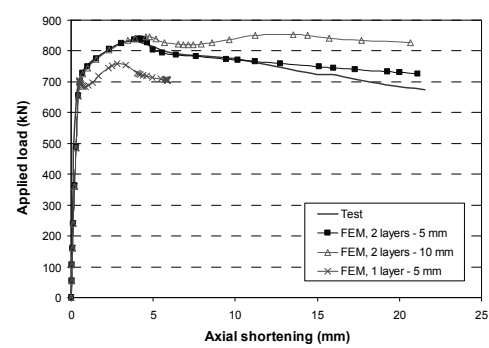

Fig. 2. Comparison of experimental and numerical results with different steel tube meshes, $150 \times 75 \times 4$ _C30.

The mechanical interaction between the contact surfaces of the steel tube and the concrete infill was modelled as follows. In the normal direction, a "hard point" contact formulation was used, which allows any pressure value when the surfaces are in contact and transmits no pressure when the surfaces do not contact. For the tangent interaction at the steel-concrete interface, the Coulomb friction model was used. It was found that values lower than 0.2 for the friction coefficient produced convergence difficulties, while values higher than 0.3 deviated from the observed response of the tested specimens. Thus, a value of 0.25 was adopted for the friction coefficient, as previously employed by Ellobody et al. [20]. Moreover, Dai and Lam [14] had previously shown that the use of different friction factors had little effect on the axial resistance of CFEHS columns, and suggested that a friction factor between 0.2 and 0.3 would provide an accurate reflection of the actual frictional contact and achieve rapid convergence. Fig. 3 shows the effect of the friction coefficient on the compressive behaviour of the columns. The same steel-concrete mechanical interaction was employed to take into account the contact between the concrete core ends and the rigid plates. Relative displacement between the steel tube and the rigid end plates was prevented by means of a "tie" constraint.

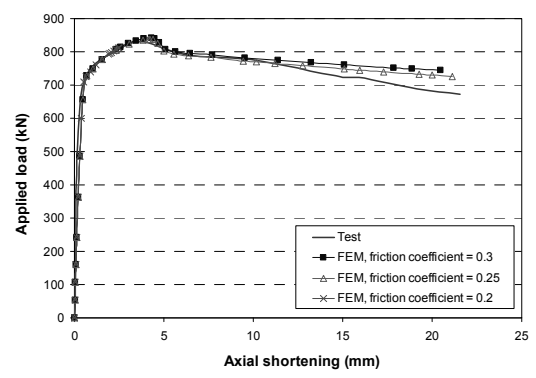

Fig. 3. Comparison of experimental and numerical results with different friction coefficients, $150 \times 75 \times 4$ _C 30 .

\subsubsection{Material models at room temperature}

For the structural steel material model, the experimental data from the coupon tests performed for each of the elliptical hollow sections under study were used. These stress-strain relationships were introduced in an isotropic multiaxial plasticity model with the Von Mises yield surface.

For concrete, the specific model developed by Dai and Lam [14] for taking into account the confinement effect in elliptical steel hollow sections was used. The model was based on that developed by other authors (Ellobody et al. [20], Mander et al. [21], Hu et al. [22] and Saenz [23]) for concrete confined by circular steel tubes. Dai and Lam [14] proposed a modified four-part stress-strain curve, with a "quick softening" section after concrete crushing based on their findings on the differences in concrete confinement between circular and elliptical hollow sections.

The yielding part of the concrete model was considered employing the DruckerPrager yield criterion, with the values of the 
friction angle $(\beta)$ and flow stress ratio in triaxial tension to that in compression $(K)$ recommended by $\mathrm{Hu}$ et al. [22] and adopted by Ellobody et al. [20] in previous research: $\beta=$ $20, K=0.8$. No plastic flow was considered, since the confinement effect was directly introduced to the model by means of the confined compressive stress-strain curve. Thus, a zero dilation angle $(\psi=0)$ was adopted.

\subsubsection{Comparison between numerical and experimental results}

The numerical model at room temperature was validated by comparing its results with a series of tests on concrete filled elliptical stub columns carried out at the University of Leeds [11]. From the 21 stub columns tested, only those 9 which were compositely loaded and non-greased were selected for this research. Those specimens were tested with full contact between the concrete infill and steel tube, and the load was applied simultaneously to the steel tube and concrete core. Three nominal tube thicknesses $(4 \mathrm{~mm}$, $5 \mathrm{~mm}$ and $6.3 \mathrm{~mm}$ ) and three nominal concrete grades (C30, C60 and C100) were employed, with an elliptical section of $150 \times 75$ $\mathrm{mm}$ and a length of $300 \mathrm{~mm}$, common to the nine columns. The columns analysed in this section are listed in Table 1.
For each of the nine columns analysed, the load versus end shortening response was obtained and compared with the one registered in the experimental tests. Fig. 4 shows the comparison between the numerical and experimental results for the series of columns with a $150 \times 75 \times 4 \mathrm{~mm}$ cross-section.

The numerical model showed good agreement with the tests, as can be seen in Table 2. This table compares the maximum axial compressive loads obtained from the tests with the values predicted by means of the numerical model. The error is computed as the experimental result divided by the numerical result. The maximum relative error is lower than a $5 \%$, which shows a good level of accuracy. As can be seen in the load versus end shortening curves of Fig. 4, the agreement in terms of the overall response is also satisfactory, including capturing the softening part of the curve after reaching the maximum load. On the basis of the described comparisons, the numerical model is considered to be validated at room temperature.

Table 1. List of room temperature CFEHS stub columns analysed in this research

\begin{tabular}{|c|c|c|c|c|c|c|}
\hline $\begin{array}{c}\text { Specimen } \\
\text { designation }\end{array}$ & $\begin{array}{c}2 a \\
(\mathrm{~mm})\end{array}$ & $\begin{array}{c}2 b \\
(\mathrm{~mm})\end{array}$ & $\begin{array}{c}t \\
(\mathbf{m m})\end{array}$ & $\begin{array}{c}\boldsymbol{f}_{\boldsymbol{y}} \\
\left(\mathrm{N} / \mathbf{m m}^{2}\right)\end{array}$ & $\begin{array}{c}f_{c k, c u b e} \\
\left(\mathbf{N} / \mathbf{m m}^{2}\right)\end{array}$ & $\begin{array}{l}N_{u, t e s t} \\
(\mathbf{k N})\end{array}$ \\
\hline $150 \times 75 \times 4$ _C 30 & 150 & 75 & 4 & 376.5 & 36.9 & 839 \\
\hline $150 \times 75 \times 4$ _C60 & 150 & 75 & 4 & 376.5 & 59.8 & 974 \\
\hline $150 \times 75 \times 4 \_C 100$ & 150 & 75 & 4 & 376.5 & 98.4 & 1265 \\
\hline $150 \times 75 \times 5$ _C30 & 150 & 75 & 5 & 369 & 36.9 & 981 \\
\hline $150 \times 75 \times 5$ _C60 & 150 & 75 & 5 & 369 & 59.8 & 1084 \\
\hline $150 \times 75 \times 5$ C 100 & 150 & 75 & 5 & 369 & 98.4 & 1296 \\
\hline $150 \times 75 \times 6.3 \_\mathrm{C} 30$ & 150 & 75 & 6.3 & 400.5 & 36.9 & 1193 \\
\hline $150 \times 75 \times 6.3$ _C60 & 150 & 75 & 6.3 & 400.5 & 59.8 & 1280 \\
\hline $150 \times 75 \times 6.3$ C 100 & 150 & 75 & 6.3 & 400.5 & 98.4 & 1483 \\
\hline
\end{tabular}




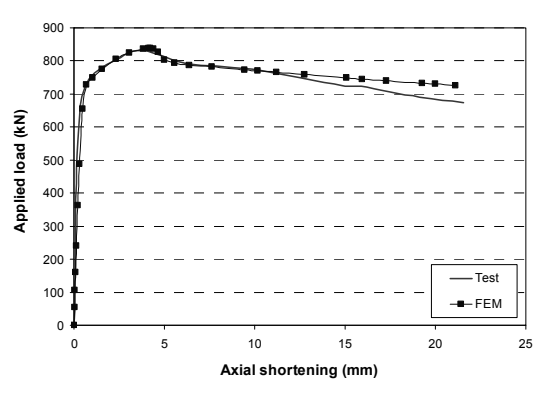

(a) $150 \times 75 \times 4$ C 30

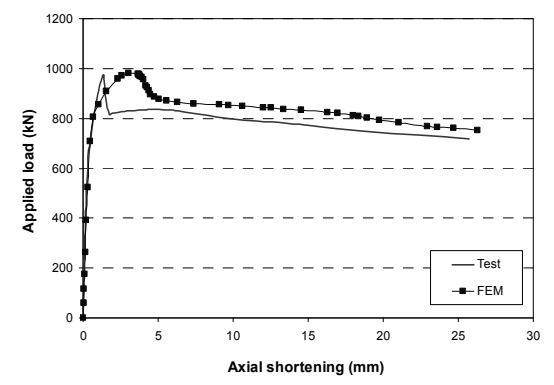

(b) $150 \times 75 \times 4$ C60

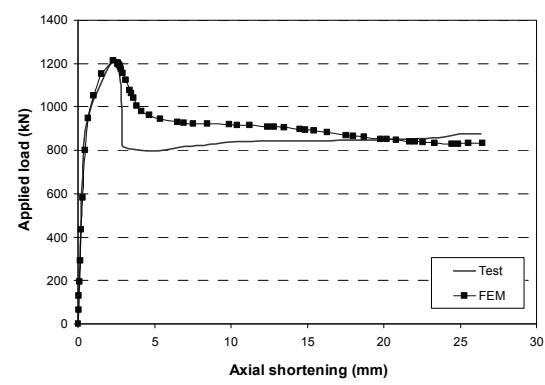

(c) $150 \times 75 \times 4+C 100$

Fig. 4. Comparison of experimental and numerical results, for $150 \times 75 \times 4 \mathrm{~mm}$ columns.

Table 2. Measured and predicted maximum axial loads

\begin{tabular}{|c|c|c|c|}
\hline \multirow{2}{*}{$\begin{array}{c}\text { Specimen } \\
\text { designation }\end{array}$} & \multicolumn{2}{|c|}{ Maximum load (kN) } & \multirow{2}{*}{$\xi=\frac{N_{u, \text { test }}}{N_{u, F E M}}$} \\
\hline & Test, $N_{u, t e s t}$ & Simulation, $N_{u, F E M}$ & \\
\hline $150 \times 75 \times 4 \_C 30$ & 839 & 838 & 1.00 \\
\hline $150 \times 75 \times 4$ C60 & 974 & 982 & 0.99 \\
\hline $150 \times 75 \times 4$ C 100 & 1265 & 1213 & 1.04 \\
\hline $150 \times 75 \times 5$ C 30 & 981 & 963 & 1.02 \\
\hline 150×75×5_C60 & 1084 & 1095 & 0.99 \\
\hline $150 \times 75 \times 5 \_\mathrm{C} 100$ & 1296 & 1316 & 0.98 \\
\hline $150 \times 75 \times 6.3 \_\mathrm{C} 30$ & 1192 & 1178 & 1.01 \\
\hline $150 \times 75 \times 6.3 \_C 60$ & 1280 & 1304 & 0.98 \\
\hline \multirow[t]{3}{*}{ 150×75×6.3_C100 } & 1483 & 1506 & 0.98 \\
\hline & \multicolumn{2}{|l|}{ Average } & 1.00 \\
\hline & \multicolumn{2}{|c|}{ Standard deviation } & 0.02 \\
\hline
\end{tabular}




\subsubsection{Findings from the finite element modelling}

A number of findings have emerged from the modelling of the CFEHS at room temperature. The mesh density study revealed that an element size of $5 \mathrm{~mm}$ for the steel tube and $10 \mathrm{~mm}$ for the concrete core should be adopted to obtain accurate results and that at least two layers of elements through the thickness of the steel tube wall should be employed.

Although the loading and boundary conditions of all the stub column specimens were symmetric, modelling the full crosssection and length of the columns revealed a more realistic response in terms of deformed shape, since it was in some cases unsymmetrical, being dominated by shear failure of the concrete core. Nevertheless, in terms of maximum load, the results obtained from a quarter model with symmetrical boundary conditions were similar to the full model results.
As previously found in the experiments by Yang et al. [11], two different failure patterns were observed. Fig. 5 shows these typical failure modes obtained from the numerical analysis. In some of the specimens, outward local buckling of the tube wall occurred close to the column ends (Fig. 5(a)), accompanied in some cases with a bulge at the centre of the column (Fig. 5(b)). In both cases, inward buckling of the tube wall was prevented by the concrete core. In other cases, primarily those with thinner wall thicknesses, an inclined shear failure of the concrete core was obtained (Fig. 5(c)), which is related to a loss of confinement.

As was expected and confirmed by the experimental research [11], the compressive load-bearing capacity of the columns increased both with an increase in the steel tube wall thickness and with the strength of the concrete core.

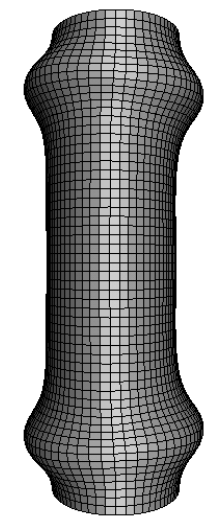

(a) $150 \times 75 \times 5 \_$C30

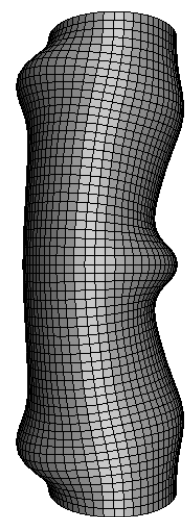

(b) $150 \times 75 \times 5+C 60$

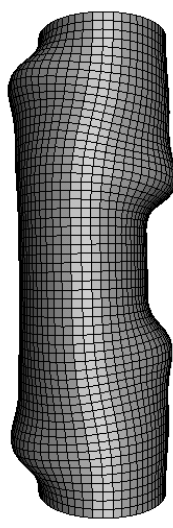

(c) $150 \times 75 \times 5 \_$C100

Fig. 5. Different failure modes obtained from the FEA of the stub columns. 


\section{Behaviour of concrete filled elliptical hollow section columns exposed to fire}

Having demonstrated the ability to capture the observed response of circular CFT columns both at room temperature and in fire situations and that of the elliptical CFT columns at room temperature, it can be assumed that the numerical model will also yield accurate results for CFEHS in fire.

\subsection{Description of the finite element model}

For the analysis of the CFEHS in fire, two finite element models were needed: a thermal model and a mechanical model, since a sequentially coupled thermal-stress analysis was carried out. The steel tube and concrete core were meshed using threedimensional eight-noded heat transfer solid elements with nodal temperature degree of freedom (DC3D8) for the thermal analysis and three-dimensional eight-noded solid elements with reduced integration (C3D8R) in the mechanical analysis. The same mesh density as that employed for modelling the circular specimens was used for the elliptical sections, as this had proved to be sufficient to accurately predict the thermal and mechanical behaviour of CFCHS columns in fire [18]. Therefore, a maximum element size of $20 \mathrm{~mm}$ was employed for meshing both the concrete core and the steel tube. A higher mesh density would lead to unacceptable computational times for a transient thermal-stress analysis. Following the results of the numerical analysis of the stub columns at room temperature, two layers of elements through the thickness of the steel tube were employed.

The steel end plates were modelled in the same way as described in Section 2.2.1, and only used in the mechanical analysis. The columns were therefore fixed ended. The axial load was applied to the upper rigid plate through its reference node and maintained during the fire history. Owing to symmetry of both the geometry and the boundary conditions, only a quarter of the column was modelled. Since the columns analysed in this section were slender, the failure was expected to be due to global buckling, thus it was not necessary to model the entire member to account for a possible shear failure of the concrete core (which was observed in the CFEHS stub columns). Fig. 6 shows the finite element mesh for one of the CFEHS column specimens analysed.

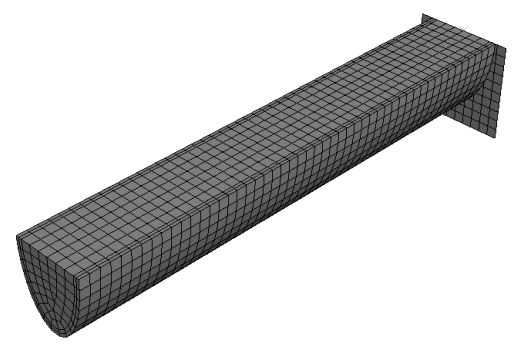

Fig. 6. Three-dimensional finite element model for slender CFEHS columns in fire.

The numerical model contained an initial geometric imperfection generated by means of the first buckling mode shape of an equivalent hinged column multiplied by an amplification factor. For this purpose, a prior eigenvalue buckling analysis was conducted. Once the initial shape of the column was obtained, it was imported to the mechanical model as the starting geometry from which to run the analysis. An amplification factor equal to the maximum imperfection along the length of the column was then applied to the column. Following the results of a sensitivity analysis carried out in previous research [18], a value of $L / 1000$ for the amplification factor was used. This value has also often been employed by other authors when modelling the fire behaviour of CFT columns [24].

\subsection{Material models at elevated temperatures}

The numerical simulations took into account the temperature dependent thermal and mechanical properties of steel and concrete. The adopted material models had been 
shown in previous research [18] to represent accurately the response of these materials in fire.

For concrete, the mechanical model developed by Lie [25] was employed, together with the hyperbolic Drucker-Prager yield surface. The thermal properties for concrete at elevated temperatures were extracted from EN 1992-1-2 [26].

For structural steel, the temperature dependent thermal and mechanical properties recommended in EN 1993-1-2 [27] were adopted. The isotropic multiaxial plasticity model with the Von Mises yield surface was employed.

The value of the thermal expansion coefficient for concrete recommended by Hong and Varma [28] was employed: $\alpha_{c}=6 \times 10^{-6}$ ${ }^{\circ} \mathrm{C}^{-1}$. For steel, the temperature dependent values of the thermal expansion coefficient from EN 1993-1-2 [27] were adopted.

The moisture content of the concrete infill was taken into account through a peak value in the specific heat, representing the latent heat of water vaporisation. A moisture content of $3 \%$ in concrete weight was considered in all cases. Hence, following the recommendations in EN 1994-1-2 [29], a specific heat peak value of $2020 \mathrm{~J} / \mathrm{kgK}$ was introduced.

\subsection{Analysis procedure}

A sequentially coupled thermal-stress analysis was used to conduct the numerical simulations, thus two different models were needed: a heat transfer model and a mechanical model. The analysis was performed by first conducting a pure heat transfer analysis for computing the temperature field and afterwards a stress/deformation analysis for calculating the structural response. Nodal temperatures were stored as a function of time in the heat transfer analysis results and then read into the stress analysis as a predefined field.

\subsubsection{Thermal analysis}

A non-linear heat transfer analysis was first conducted for each of the column specimens under study. The standard ISO834 [30] fire curve was applied to the exposed surface of the CFT column specimens as a thermal load, through the convection and radiation heat transfer mechanisms. The entire length of the columns was exposed to fire, in order to consider the worst case scenario, since protecting the column ends would introduce a higher rotational stiffness at elevated temperatures leading to a delay in the failure time. The values recommended in EN 1991-1-2 [31] were adopted for the governing parameters of the heat transfer problem.

The results from the non-linear heat transfer analysis consisted of the temperature-time curves for all the nodes within the three-dimensional model, which were subsequently applied as a thermal load to the mechanical model.

The thermal resistance at the boundary between the steel tube and the concrete core was considered through a gap conductance value of $200 \mathrm{~W} / \mathrm{m}^{2} \mathrm{~K}$, as was used when modelling the circular specimens [18]. Moreover, the radiative heat transfer mechanism was modelled at the steel-concrete interface with emissivities of both steel and concrete surfaces equal to 0.7 and a configuration factor equal to 1 .

\subsubsection{Structural analysis}

A non-linear stress analysis was subsequently conducted using the same FEA package [19], accounting for the nodal temperature-time curves previously calculated in the thermal model. The finite element meshes and the node numbering were exactly the same as those used in the thermal analysis model.

In the first step, the load was applied at room temperature to the top end of the column through the loading plate. This load was maintained during the second step (the fire step), where the evolution of the tem- 
perature with the fire exposure time was imported from the thermal model.

The mechanical interaction between the steel tube and concrete infill was modelled as follows. In the normal direction, a "hard point" contact formulation was used, which allows any pressure value when the surfaces are in contact and transmits no pressure when the surfaces do not contact. For the tangent interaction, the Coulomb friction model was used, with a friction coefficient of 0.3 , though this factor had been found to have relatively little effect on the fire response of CFT columns in previous research carried out by the authors [18]. The same steel-concrete mechanical interaction was employed to model the contact between the concrete core ends and the rigid end plates. Relative displacement between the steel tube and the rigid end plates was prevented by introducing a "tie" constraint.

\subsection{Parametric studies}

The following parametric studies explore the influence of variation in global member slenderness, load level, crosssection slenderness and section size on the fire behaviour of CFEHS columns.

\subsubsection{Analysis cases}

Parametric studies were performed on the basis of a series of elliptical hollow sections of commercially available dimensions; these sections are listed in Table 3. All the analysed specimens were fixed at both ends and subjected to a concentric axial load, which was maintained during the heating step. All hollow sections had a yield strength of $355 \mathrm{MPa}$ and were filled with C30 grade concrete. The nominal elliptical section sizes employed were $150 \times 75 \mathrm{~mm}$ and $300 \times 150$ $\mathrm{mm}$. The studied thicknesses were 4,5 and $6.3 \mathrm{~mm}$ for the $150 \times 75 \mathrm{~mm}$ sections and 8 , $10,12.5$ and $16 \mathrm{~mm}$ for the $300 \times 150 \mathrm{~mm}$ sections, in order to have a variety of crosssectional slenderness values. The length of the column specimens was varied from 1 to 4 metres in order to cover a wide range of member slenderness values. Three different load levels were applied to each column specimen: $20 \%, 40 \%$ and $60 \%$ of their minor axis buckling resistance at room temperature. This resistance was calculated in accordance with Clause 6.7.3.5 of EN 1994-1-1 [13], employing the buckling curve "a" given in Clause 6.3.1.2 of EN 1993-1-1 [32] for hot finished hollow section columns. The applicability of this buckling curve to EHS was confirmed by Chan and Gardner [33]. The influence of enhanced concrete confinement was not considered in the room temperature resistance calculations. The material factors employed in the calculations were $\gamma_{s}=1.0$ and $\gamma_{c}=1.5$ for steel and concrete respectively.

Fig. 7 shows a typical deformed column shape after fire exposure. It can be seen how overall buckling of the column is accompanied by local buckling near the column ends and a progressive opening of the gap between the steel tube and the concrete core. The temperature field at the moment of the failure of the column is plotted in this figure, where a clear radial temperature gradient can be observed.

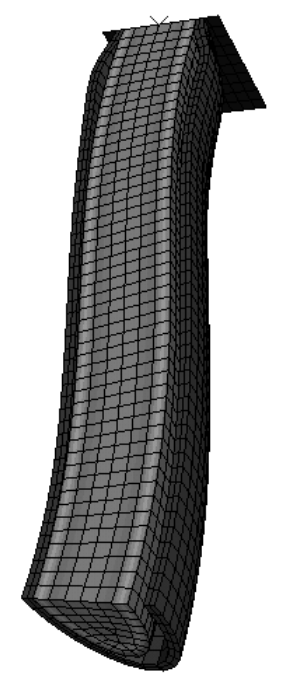

Fig. 7. Deformed shape after fire exposure, $300 \times 150 \times 12.5 \mathrm{~mm}, L=2 \mathrm{~m}, \mu=0.2$. 
Table 3 presents the results of all analysed column specimens. The fire resistance rating (FRR) for each column is expressed as the time measured in minutes that it is capable of sustaining the applied load before collapsing.

The period of time that a column can maintain a certain load was determined ac- cording to EN 1363-1 [34]. This standard establishes that for vertical members in compression, failure occurs when either of the following two criteria is reached:

- Axial displacement limit: $L / 100 \mathrm{~mm}$

- Axial displacement velocity limit: $3 L / 1000 \mathrm{~mm} / \mathrm{min}$

Table 3. List of CFEHS columns exposed to fire analysed in this research

\begin{tabular}{|c|c|c|c|c|c|c|c|c|c|c|}
\hline $\begin{array}{c}\text { Specimen } \\
\text { designation }\end{array}$ & $\begin{array}{c}2 a \\
(\mathrm{~mm})\end{array}$ & $\begin{array}{c}2 b \\
(\mathbf{m m})\end{array}$ & $\begin{array}{c}t \\
(\mathbf{m m})\end{array}$ & $\begin{array}{c}L \\
(\mathbf{m m})\end{array}$ & $\mu$ & $\begin{array}{c}N \\
(\mathbf{k N})\end{array}$ & $\begin{array}{l}\text { FRR } \\
\text { (min) }\end{array}$ & $\mu$ & $\begin{array}{c}N \\
(\mathbf{k N})\end{array}$ & $\begin{array}{l}\text { FRR } \\
(\mathrm{min})\end{array}$ \\
\hline $75 \times 37.5 \times 2 \_0.5$ & 75 & 37.5 & 2 & 500 & 0.20 & 30 & 22 & 0.40 & 60 & 16 \\
\hline $150 \times 75 \times 4 \_1$ & 150 & 75 & 4 & 1000 & 0.20 & 121 & 35 & 0.40 & 241 & 29 \\
\hline $150 \times 75 \times 4 \_2$ & 150 & 75 & 4 & 2000 & 0.20 & 112 & 23 & 0.40 & 224 & 16 \\
\hline $150 \times 75 \times 4 \_3$ & 150 & 75 & 4 & 3000 & 0.20 & 98 & 20 & 0.40 & 197 & 13 \\
\hline $150 \times 75 \times 4 \_4$ & 150 & 75 & 4 & 4000 & 0.20 & 77 & 19 & 0.40 & 155 & 13 \\
\hline $150 \times 75 \times 5 \_1$ & 150 & 75 & 5 & 1000 & 0.20 & 146 & 33 & 0.40 & 293 & 23 \\
\hline $150 \times 75 \times 5 \_2$ & 150 & 75 & 5 & 2000 & 0.20 & 136 & 22 & 0.40 & 272 & 16 \\
\hline $150 \times 75 \times 5 \_3$ & 150 & 75 & 5 & 3000 & 0.20 & 119 & 20 & 0.40 & 237 & 14 \\
\hline $150 \times 75 \times 5 \_4$ & 150 & 75 & 5 & 4000 & 0.20 & 93 & 20 & 0.40 & 185 & 14 \\
\hline $150 \times 75 \times 6.3 \_1$ & 150 & 75 & 6.3 & 1000 & 0.20 & 174 & 32 & 0.40 & 347 & 22 \\
\hline $150 \times 75 \times 6.3 \_2$ & 150 & 75 & 6.3 & 2000 & 0.20 & 161 & 23 & 0.40 & 322 & 16 \\
\hline $150 \times 75 \times 6.3 \_3$ & 150 & 75 & 6.3 & 3000 & 0.20 & 141 & 20 & 0.40 & 281 & 14 \\
\hline $150 \times 75 \times 6.3 \_4$ & 150 & 75 & 6.3 & 4000 & 0.20 & 110 & 19 & 0.40 & 219 & 14 \\
\hline $300 \times 150 \times 8 \_1$ & 300 & 150 & 8 & 1000 & 0.20 & 490 & 87 & 0.40 & 979 & 41 \\
\hline $300 \times 150 \times 8 \_2$ & 300 & 150 & 8 & 2000 & 0.20 & 483 & 65 & 0.40 & 966 & 37 \\
\hline $300 \times 150 \times 8 \_3$ & 300 & 150 & 8 & 3000 & 0.20 & 467 & 48 & 0.40 & 935 & 29 \\
\hline $300 \times 150 \times 8 \_4$ & 300 & 150 & 8 & 4000 & & 449 & 28 & 0.40 & 898 & 19 \\
\hline $300 \times 150 \times 10 \_1$ & 300 & 150 & 10 & 1000 & 0.20 & 594 & 71 & 0.40 & 1188 & 36 \\
\hline $300 \times 150 \times 10 \_2$ & 300 & 150 & 10 & 2000 & 0.20 & 585 & 55 & 0.40 & 1171 & 32 \\
\hline $300 \times 150 \times 10 \_3$ & 300 & 150 & 10 & 3000 & 0.20 & 566 & 41 & 0.40 & 1132 & 25 \\
\hline $300 \times 150 \times 10 \_4$ & 300 & 150 & 10 & 4000 & 0.20 & 543 & 29 & 0.40 & 1086 & 20 \\
\hline $300 \times 150 \times 12.5 \_1$ & 300 & 150 & 12.5 & 1000 & 0.20 & 700 & 61 & 0.40 & 1401 & 34 \\
\hline $300 \times 150 \times 12.5 \_2$ & 300 & 150 & 12.5 & 2000 & 0.20 & 690 & 49 & 0.40 & 1381 & 31 \\
\hline $300 \times 150 \times 12.5 \_3$ & 300 & 150 & 12.5 & 3000 & 0.20 & 668 & 37 & 0.40 & 1335 & 26 \\
\hline $300 \times 150 \times 12.5 \_4$ & 300 & 150 & 12.5 & 4000 & 0.20 & 640 & 31 & 0.40 & 1281 & 22 \\
\hline $300 \times 150 \times 16 \_1$ & 300 & 150 & 16 & 1000 & 0.20 & 845 & 55 & 0.40 & 1690 & 35 \\
\hline $300 \times 150 \times 16 \_2$ & 300 & 150 & 16 & 2000 & 0.20 & 832 & 48 & 0.40 & 1665 & 32 \\
\hline $300 \times 150 \times 16 \_3$ & 300 & 150 & 16 & 3000 & 0.20 & 805 & 36 & 0.40 & 1610 & 27 \\
\hline $300 \times 150 \times 16 \_4$ & 300 & 150 & 16 & 4000 & 0.20 & 772 & 33 & 0.40 & 1543 & 24 \\
\hline $600 \times 300 \times 16 \_4$ & 600 & 300 & 16 & 4000 & 0.20 & 1932 & 133 & 0.40 & 3864 & 67 \\
\hline
\end{tabular}


Table 3. (continued)

\begin{tabular}{|c|c|c|c|c|c|c|c|}
\hline $\begin{array}{c}\text { Specimen } \\
\text { designation }\end{array}$ & $\begin{array}{c}2 a \\
(\mathrm{~mm})\end{array}$ & $\begin{array}{c}2 b \\
(\mathrm{~mm})\end{array}$ & $\begin{array}{c}t \\
(\mathrm{~mm})\end{array}$ & $\begin{array}{c}\begin{array}{l}L \\
(\mathrm{~mm})\end{array} \\
\end{array}$ & $\mu$ & $\begin{array}{c}N \\
(\mathbf{k N})\end{array}$ & $\begin{array}{l}\text { FRR } \\
\text { (min) }\end{array}$ \\
\hline $75 \times 37.5 \times 2 \_0.5$ & 75 & 37.5 & 2 & 500 & 0.60 & 91 & 12 \\
\hline $150 \times 75 \times 4 \_1$ & 150 & 75 & 4 & 1000 & 0.60 & 362 & 19 \\
\hline $150 \times 75 \times 4 \_2$ & 150 & 75 & 4 & 2000 & 0.60 & 337 & 11 \\
\hline $150 \times 75 \times 4 \_3$ & 150 & 75 & 4 & 3000 & 0.60 & 295 & 5 \\
\hline $150 \times 75 \times 4 \_4$ & 150 & 75 & 4 & 4000 & 0.60 & 232 & 7 \\
\hline $150 \times 75 \times 5 \_1$ & 150 & 75 & 5 & 1000 & 0.60 & 439 & 18 \\
\hline $150 \times 75 \times 5 \_2$ & 150 & 75 & 5 & 2000 & 0.60 & 407 & 11 \\
\hline $150 \times 75 \times 5 \_3$ & 150 & 75 & 5 & 3000 & 0.60 & 356 & 5 \\
\hline $150 \times 75 \times 5 \_4$ & 150 & 75 & 5 & 4000 & 0.60 & 278 & 7 \\
\hline $150 \times 75 \times 6.3 \_1$ & 150 & 75 & 6.3 & 1000 & 0.60 & 521 & 20 \\
\hline $150 \times 75 \times 6.3 \_2$ & 150 & 75 & 6.3 & 2000 & 0.60 & 483 & 10 \\
\hline $150 \times 75 \times 6.3 \_3$ & 150 & 75 & 6.3 & 3000 & 0.60 & 422 & 2 \\
\hline $150 \times 75 \times 6.3 \_4$ & 150 & 75 & 6.3 & 4000 & 0.60 & 329 & 1 \\
\hline $300 \times 150 \times 8 \_1$ & 300 & 150 & 8 & 1000 & 0.60 & 1469 & 26 \\
\hline $300 \times 150 \times 8 \_2$ & 300 & 150 & 8 & 2000 & 0.60 & 1449 & 25 \\
\hline $300 \times 150 \times 8 \_3$ & 300 & 150 & 8 & 3000 & 0.60 & 1402 & 21 \\
\hline $300 \times 150 \times 8 \_4$ & 300 & 150 & 8 & 4000 & 0.60 & 1347 & 14 \\
\hline $300 \times 150 \times 10 \_1$ & 300 & 150 & 10 & 1000 & 0.60 & 1782 & 25 \\
\hline $300 \times 150 \times 10 \_2$ & 300 & 150 & 10 & 2000 & 0.60 & 1756 & 24 \\
\hline $300 \times 150 \times 10 \_3$ & 300 & 150 & 10 & 3000 & 0.60 & 1699 & 20 \\
\hline $300 \times 150 \times 10 \_4$ & 300 & 150 & 10 & 4000 & 0.60 & 1630 & 15 \\
\hline $300 \times 150 \times 12.5 \_1$ & 300 & 150 & 12.5 & 1000 & 0.60 & 2101 & 26 \\
\hline $300 \times 150 \times 12.5 \_2$ & 300 & 150 & 12.5 & 2000 & 0.60 & 2071 & 24 \\
\hline $300 \times 150 \times 12.5 \_3$ & 300 & 150 & 12.5 & 3000 & 0.60 & 2003 & 21 \\
\hline $300 \times 150 \times 12.5 \_4$ & 300 & 150 & 12.5 & 4000 & 0.60 & 1921 & 15 \\
\hline $300 \times 150 \times 16 \_1$ & 300 & 150 & 16 & 1000 & 0.60 & 2536 & 27 \\
\hline $300 \times 150 \times 16 \_2$ & 300 & 150 & 16 & 2000 & 0.60 & 2497 & 25 \\
\hline $300 \times 150 \times 16 \_3$ & 300 & 150 & 16 & 3000 & 0.60 & 2415 & 22 \\
\hline $300 \times 150 \times 16 \_4$ & 300 & 150 & 16 & 4000 & 0.60 & 2315 & 16 \\
\hline $600 \times 300 \times 16 \_4$ & 600 & 300 & 16 & 4000 & 0.60 & 5796 & 41 \\
\hline
\end{tabular}

Fig. 8 shows the evolution of the axial displacement at the top end of the column against the fire exposure time, for two of the analysed columns - (a) EHS $300 \times 150 \times 10$ $\mathrm{mm}, L=2 \mathrm{~m}, \mu=0.2$ and (b) EHS $300 \times 150 \times 10 \mathrm{~mm}, L=4 \mathrm{~m}, \mu=0.2-$. The limits given by the two failure criteria are included on the graphs. 


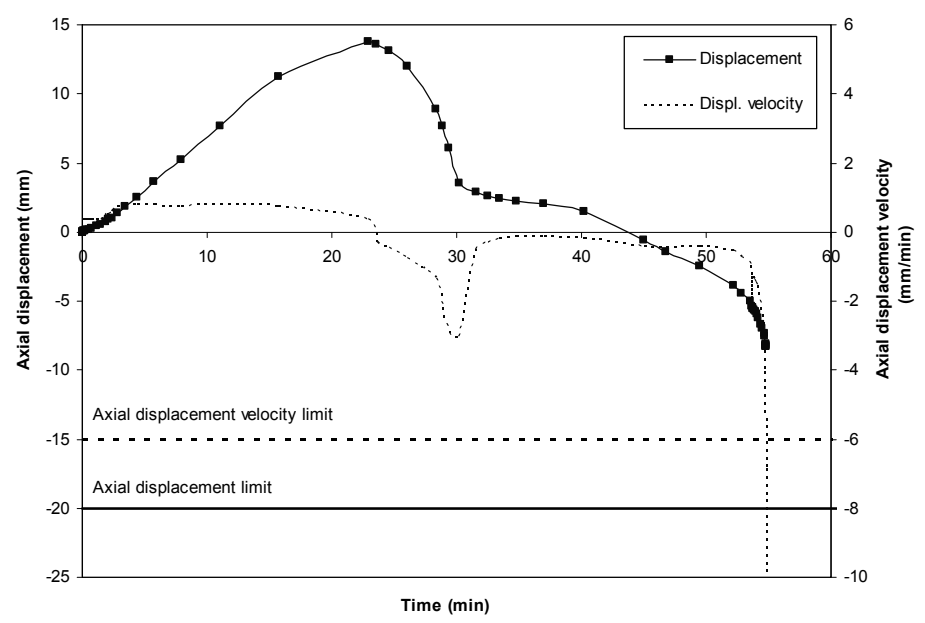

(a) $300 \times 150 \times 10 \mathrm{~mm}, L=2 \mathrm{~m}, \mu=0.2$

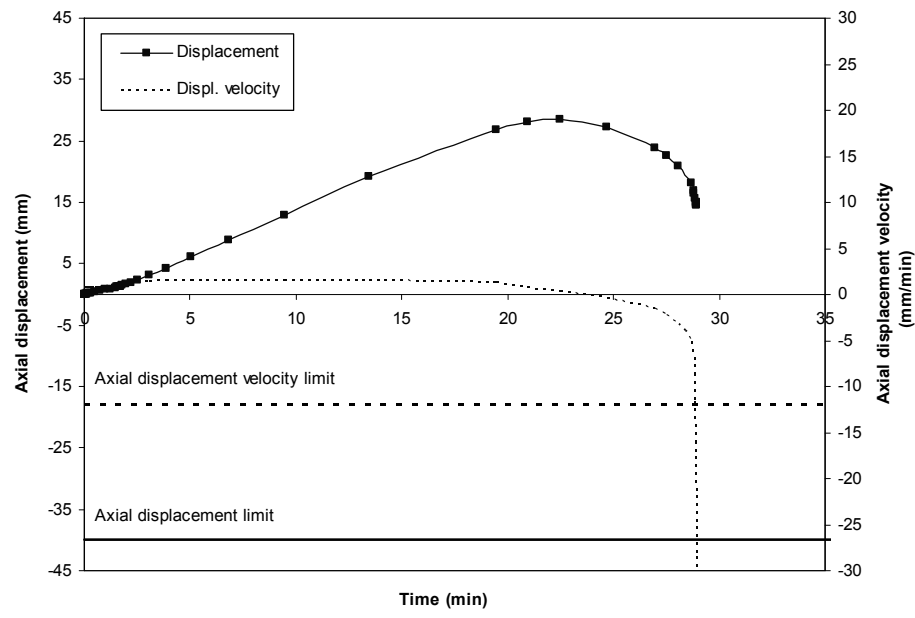

(b) $300 \times 150 \times 10 \mathrm{~mm}, L=4 \mathrm{~m}, \mu=0.2$

Fig. 8. Axial displacement versus time curves.

A clear difference between the overall responses of these two columns can be observed. In Fig. 8(a), the four typical stages of the fire response of a CFT column can be easily identified: expansion of the steel tube, followed by local yielding and subsequent transfer of the applied load to the concrete core, up to the final column failure.
Further explanation of this behaviour can be found in [18]. In Fig. 8(b), on the other hand, only two stages of behaviour can be identified in the fire response (expansion of the steel tube and final failure), since the column buckles before the loading plate has come back into contact with the concrete core. This effect occurs in columns with 
high slenderness, where failure of the column is initiated at an early stage of the fire exposure, when the steel tube is still sustaining the load without the contribution of the concrete core. Therefore, it can be inferred that the contribution of the concrete core to the load bearing capacity of the columns in a fire situation strongly depends on their slenderness.

\subsubsection{Effect of column slenderness}

It is known that the slenderness plays an important role in the buckling resistance

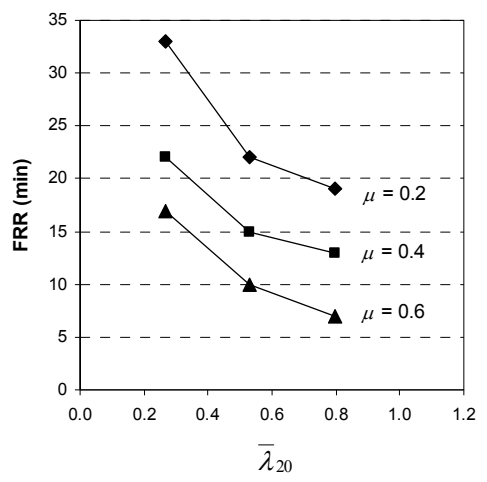

(a) $150 \times 75 \times 5 \mathrm{~mm}$ of a column in compression. In order to illustrate the effect of the column slenderness on the fire resistance of CFEHS columns, a set of columns with fixed cross-sectional dimensions $-150 \times 75 \times 5 \mathrm{~mm}$ and $300 \times 150 \times$ $10 \mathrm{~mm}$ - were chosen. The influence of the non-dimensional slenderness was investigated by varying the column length from 1 to $4 \mathrm{~m}$ with an initial imperfection of $L / 1000$. Three different loading levels were taken into account for this study: $20 \%, 40 \%$ and $60 \%$ of the room temperature buckling resistance of the columns.

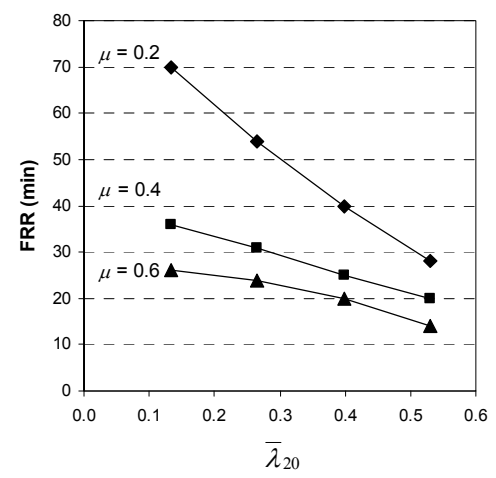

(b) $300 \times 150 \times 10 \mathrm{~mm}$

Fig. 9. Effect of the non-dimensional slenderness on the fire resistance rating of the columns.

The interrelationship between the fire resistance period of a column and its nondimensional slenderness is plotted in Fig. 9. As expected, the FRR of the columns decreased with an increase in non-dimensional slenderness. Higher load levels produced the same trend, but with lower resistance times. The FRR levels shown in Fig. 9(b) are higher than those in Fig. 9(a), since the larger the cross-section, the greater the effect of the concrete filling in delaying the temperature increase.

\subsubsection{Effect of load level}

The effect of load level on the fire resistance of CFEHS columns was studied by fix- ing the cross-section to $150 \times 75 \times 5 \mathrm{~mm}$ or $300 \times 150 \times 10 \mathrm{~mm}$ and the length of the column. Three loading levels were considered: $20 \%, 40 \%$ and $60 \%$ of the room temperature buckling resistance of the columns. The parametric study was repeated for four different lengths (1, 2, 3 and $4 \mathrm{~m})$. The results from this analysis are plotted in Fig. 10. As expected, the fire resistance rating of the column decreased with an increase in the applied load. The drop in the fire resistance period was more abrupt for the larger columns in Fig. 10(b), which attain higher FRR values than those in Fig. 10(a), due to the higher thermal and mechanical contribution of the concrete core. 


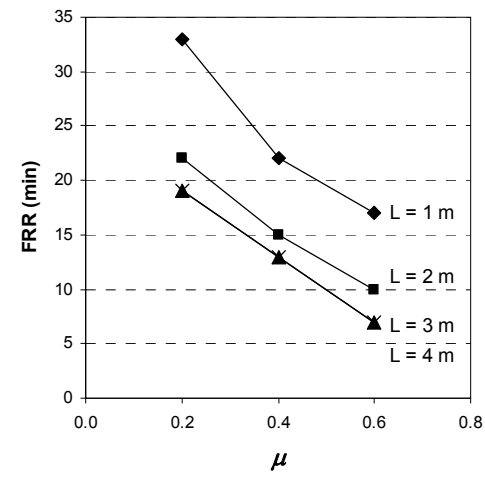

(a) $150 \times 75 \times 5 \mathrm{~mm}$

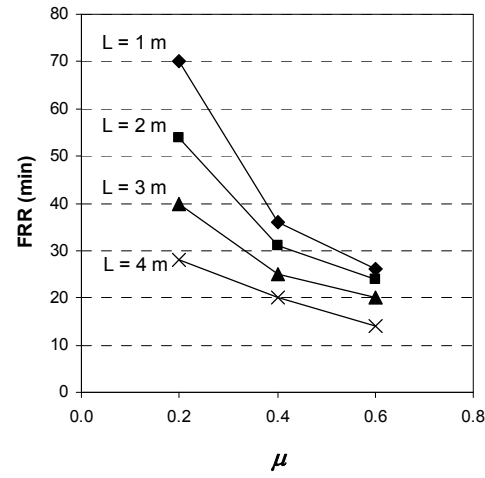

(b) $300 \times 150 \times 10 \mathrm{~mm}$

Fig. 10. Effect of the load level on the fire resistance rating of the columns.

\subsubsection{Effect of cross-section slenderness}

The effect of cross-section slenderness on the fire resistance of CFEHS columns was examined by varying the thickness of the columns, while mantaining fixed external dimensions, length and loading level. The cross-section slenderness was evaluated through the parameter $D_{e} / t \varepsilon^{2}$, where $D_{e}$ is the equivalent diameter and $\varepsilon^{2}=235 / f_{y}$. The equivalent diameter was calculated according to the expression proposed by RuizTeran and Gardner [9] for axial compression.

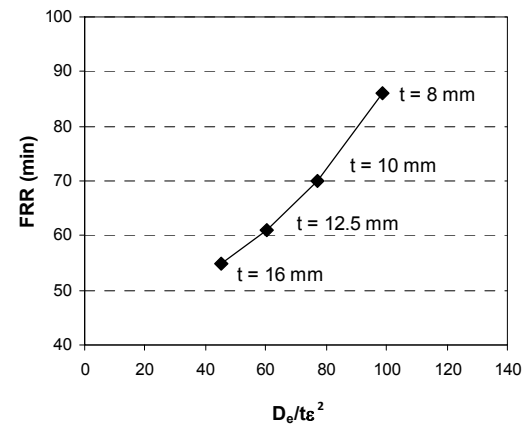

(a) $300 \times 150 \mathrm{~mm}, L=1 \mathrm{~m}, \mu=0.2$
The cross-sectional dimensions $2 a$ and $2 b$ were fixed to $300 \mathrm{~mm}$ and $150 \mathrm{~mm}$ respectively, and the thickness varied in the range of commercial values (i.e. 8, 10, 12.5 and $16 \mathrm{~mm}$ ). The length of the columns was fixed to $1 \mathrm{~m}$ and the load level to $20 \%$ of their room temperature axial compression resistance for buckling about the minor axis. The same procedure was repeated for $4 \mathrm{~m}$ length columns under the same load level. The effect of the cross-section slenderness on the fire resistance rating of the columns is illustrated in Fig. 11.

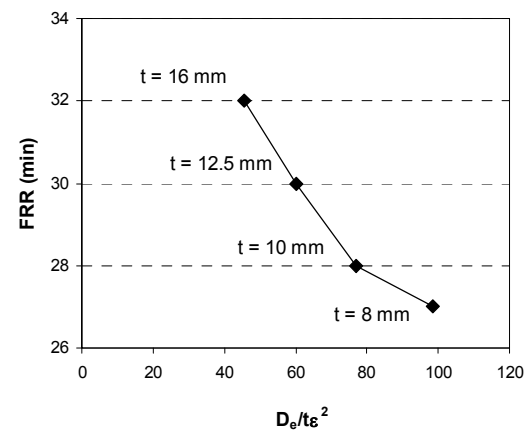

(b) $300 \times 150 \mathrm{~mm}, L=4 \mathrm{~m}, \mu=0.2$

Fig. 11. Effect of the cross-sectional slenderness on the fire resistance rating of the columns. 
For stocky columns loaded at a low percentage of their room temperature capacity, it was found that the higher the slenderness of the steel section, the higher the fire resistance of the column, which is the case in Fig. 11(a). This means that columns with lower steel tube wall thicknesses achieve higher fire resistance for the same external dimensions. The explanation of this may reside in the fact that for a given section size, lower thicknesses of the steel tube wall allow more quantity of concrete to fill the column and thus contributing to delay its heating, which lengthens the fire resistance rating. This behaviour holds true for this particular range of columns, where the fire response is highly influenced by the amount of concrete filling, since after the expansion and subsequent yielding of the steel tube, the loading plate comes back into contact with the concrete core, which will sustain the load until the final failure.

However, the more slender columns show the inverse response: the higher the slenderness of the steel section, the lower the fire resistance of the column, as it can be seen in Fig. 11(b). This is the logical response expected for these columns, since their failure is initiated by the local buckling of the steel tube at an early stage when it is still sustaining the load without the contribution of the concrete core. The slenderness of the unfilled steel tube (and thus its thickness) is therefore a relevant factor in this case, whereas the amount of concrete filling does not influence the response.

\subsubsection{Effect of section size}

The effect of section size was measured by means of the $A / V$ ratio (also known as section factor), where $A$ is the area of the fire exposed surface of the column per unit length and $V$ is the volume of the composite column per unit length.

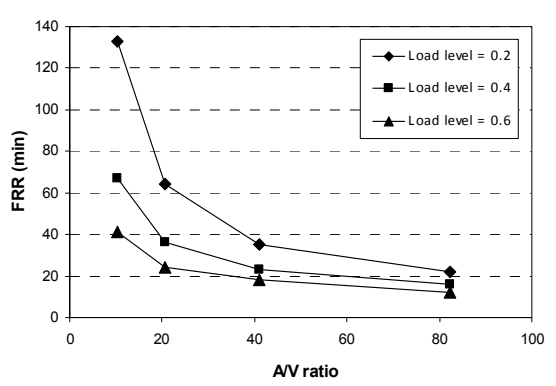

Fig. 12. Effect of the section factor on the fire resistance rating of the columns.

From the series of columns studied, four of them with the same cross-sectional slenderness, member slenderness and loading level were selected: $75 \times 37.5 \times 2 \mathrm{~mm}$ with $0.5 \mathrm{~m}$ length, $150 \times 75 \times 4 \mathrm{~mm}$ with $1 \mathrm{~m}$ length, $300 \times 150 \times 8 \mathrm{~mm}$ with $2 \mathrm{~m}$ length and $600 \times 300 \times 16 \mathrm{~mm}$ with $4 \mathrm{~m}$ length. The procedure was repeated for three loading levels: $20 \%, 40 \%$ and $60 \%$ of their room temperature buckling resistance. The interrelationship between the fire resistance period of a column and its section factor is plotted in Fig. 12.

A column with a high $A / V$ ratio exposes a relatively high surface to the fire, heating up faster, while a column with a low $A / V$ ratio exposes a lower surface to the fire for the same volume, thus delaying its heating. Therefore, as expected, the columns with the higher $A / V$ ratios had a lower fire resistance period than those with low $A / V$ ratios. The same trend was followed for all three load levels, but was steeper for the lower one. From Fig. 12, it can be concluded that for high $A / V$ ratios, the effect of a change in the load level is minor. Conversely, for columns with a low $A / V$ ratio, an important difference in terms of fire resistance can be found under different load levels. 


\section{Discussion and design recommendations}

\subsection{Comparison between elliptical and circular concrete filled columns in fire}

In order to study the differences in fire performance between CFEHS columns and CFCHS columns, a series of circular sections equivalent to the elliptical sections previously analysed were numerically examined.

The circular columns were designed to have the same buckling resistance at room temperature as the corresponding elliptical columns, whilst maintaining the same length. This was selected for practical purposes, in order to serve as a reference to designers when having to choose between circular and elliptical sections for a given interstorey height and design load. The diameters of the circular sections were determined by fixing the thickness of the steel tube to be the same as that of the elliptical sections. The main characteristics of the circular columns analysed in this research are listed in Table 4, together with the fire resistance rating obtained from the numerical model for the three different loading levels under consideration.

Table 4. List of CFCHS columns exposed to fire analysed in this research

\begin{tabular}{|c|c|c|c|c|c|c|c|}
\hline $\begin{array}{c}\text { Specimen } \\
\text { designation }\end{array}$ & $\begin{array}{c}\text { Equivalent } \\
\text { CFEHS column } \\
\end{array}$ & $\begin{array}{c}D \\
(\mathbf{m m}) \\
\end{array}$ & $\begin{array}{c}t \\
(\mathrm{~mm})\end{array}$ & $\begin{array}{c}L \\
(\mathbf{m m})\end{array}$ & $\mu$ & $\begin{array}{c} \\
(\mathbf{k N})\end{array}$ & $\begin{array}{r}\text { FRR } \\
(\mathrm{min}) \\
\end{array}$ \\
\hline $108.74 \times 5 \_1$ & $150 \times 75 \times 5 \_1$ & 108.74 & 5 & 1000 & 0.20 & 146 & 41 \\
\hline $106.38 \times 5 \_2$ & $150 \times 75 \times 5 \_2$ & 106.38 & 5 & 2000 & 0.20 & 136 & 30 \\
\hline $101.64 \times 5 \_3$ & $150 \times 75 \times 5 \_3$ & 101.64 & 5 & 3000 & 0.20 & 119 & 20 \\
\hline $95.29 \times 5 \_4$ & $150 \times 75 \times 5 \_4$ & 95.29 & 5 & 4000 & 0.20 & 93 & 18 \\
\hline $219.95 \times 10 \_1$ & $300 \times 150 \times 10 \_1$ & 219.95 & 10 & 1000 & 0.20 & 594 & 91 \\
\hline $217.48 \times 10 \_2$ & $300 \times 150 \times 10 \_2$ & 217.48 & 10 & 2000 & 0.20 & 585 & 75 \\
\hline $215.39 \times 10 \_3$ & $300 \times 150 \times 10 \_3$ & 215.39 & 10 & 3000 & 0.20 & 566 & 59 \\
\hline $212.77 \times 10 \_4$ & $300 \times 150 \times 10 \_4$ & 212.77 & 10 & 4000 & 0.20 & 543 & 47 \\
\hline
\end{tabular}

Table 4. (continued)

\begin{tabular}{ll|ccc|ccc}
\hline $\begin{array}{c}\text { Specimen } \\
\text { designation }\end{array}$ & \multicolumn{1}{c|}{$\begin{array}{c}\text { Equivalent } \\
\text { CFEHS column }\end{array}$} & $\boldsymbol{\mu}$ & $\begin{array}{c}\boldsymbol{N} \\
(\mathbf{k N})\end{array}$ & $\begin{array}{c}\text { FRR } \\
(\mathbf{m i n})\end{array}$ & $\boldsymbol{\mu}$ & $\begin{array}{c}\boldsymbol{N} \\
(\mathbf{k N})\end{array}$ & $\begin{array}{c}\text { FRR } \\
(\mathbf{m i n})\end{array}$ \\
\hline $108.74 \times 5 \_1$ & $150 \times 75 \times 5 \_1$ & 0.40 & 293 & 26 & 0.60 & 439 & 19 \\
$106.38 \times 5 \_2$ & $150 \times 75 \times 5 \_2$ & 0.40 & 272 & 19 & 0.60 & 407 & 15 \\
$101.64 \times 5 \_3$ & $150 \times 75 \times 5 \_3$ & 0.40 & 237 & 14 & 0.60 & 356 & 7 \\
$95.29 \times 5 \_4$ & $150 \times 75 \times 5 \_4$ & 0.40 & 185 & 12 & 0.60 & 278 & 5 \\
$219.95 \times 10 \_1$ & $300 \times 150 \times 10 \_1$ & 0.40 & 1188 & 38 & 0.60 & 1782 & 25 \\
$217.48 \times 10 \_2$ & $300 \times 150 \times 10 \_2$ & 0.40 & 1171 & 36 & 0.60 & 1756 & 25 \\
$215.39 \times 10 \_3$ & $300 \times 150 \times 10 \_3$ & 0.40 & 1132 & 31 & 0.60 & 1699 & 23 \\
$212.77 \times 10 \_4$ & $300 \times 150 \times 10 \_4$ & 0.40 & 1086 & 28 & 0.60 & 1630 & 21 \\
\hline
\end{tabular}

Through the numerical analysis of the equivalent circular columns and its comparison with the previously calculated elliptical columns it was observed that the CFCHS achieved in general higher fire resistance than the equivalent CFEHS, due to the lower $A / V$ ratio of the circular columns for a same room temperature resistance. This results in a delay in the temperature field evolution and thus an increase in fire resistance rating. Only for the $150 \times 75 \times 5 \mathrm{~mm}$ of $4 \mathrm{~m}$ length did the elliptical column resist longer than the circular column, due to the fact that, for this particular column, the $A / V$ ratio of the 
elliptical column was lower than that of its equivalent circular column.

This effect can easily be noticed if the temperature field of the elliptical and its equivalent circular section are compared for the same fire exposure time. Fig. 13 shows the resulting cross-sectional temperature fields for an elliptical column and its equivalent circular column after 90 minutes of exposure to fire. It can be seen that for the same exposure time, and thus a similar temperature at the steel surface, the temperatures

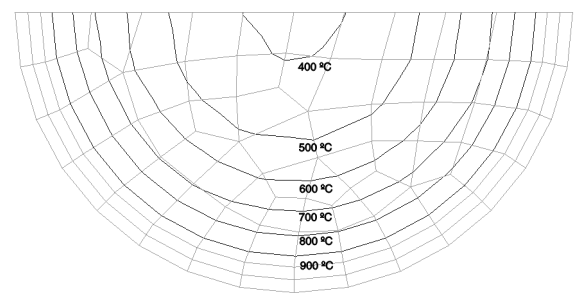

along the concrete core are higher in the elliptical column than in the circular. This is due to the higher $A / V$ ratio of the elliptical column, which exposes more surface to the fire for the same cross-section, and therefore heats up faster. This effect can be clearly seen in Fig. 14, where the temperature evolution along the cross-section is compared for different fire exposure times. The relative distance to the centre of the column is expressed as the distance from a particular point of the cross-section to its centre, divided by the radius.

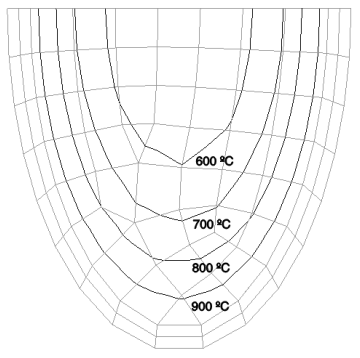

Fig. 13. Comparison of the cross-sectional temperature field between CFCHS $219.95 \times 10 \mathrm{~mm}$ and CFEHS $300 \times 150 \times 10 \mathrm{~mm}$, after 90 minutes of fire exposure.

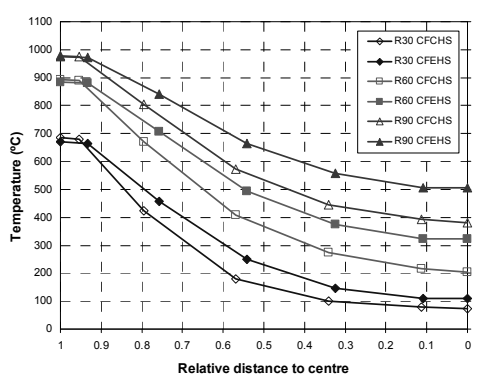

Fig. 14. Comparison of the cross-sectional temperature evolution between circular and elliptical columns for different exposure times.

In terms of fire resistance rating, a comparison is shown in Fig. 15 between circular and elliptical columns with different lengths and load levels. It can be seen that the circular columns attain higher fire resistance ratings than their elliptical counterparts; the difference is more pronounced for the stocky columns and for low loading levels. As the length and therefore the slenderness of the column increases, the difference in fire performance between elliptical and circular shapes is not so clear for the $150 \times 75 \times 5 \mathrm{~mm}$ columns, since the failure is due to yielding of the steel tube wall followed by global buckling before the concrete core comes back into contact with the loading plate, and thus the section shape and its related temperature distribution within the cross-section have less influence over the response of the columns. This aspect can also be appreciated in the larger columns $(300 \times 150 \times 10 \mathrm{~mm})$ for load levels of 0.4 and 0.6 , where the difference is clearly narrower than for a load level of 0.2 . The explanation resides in the fact that for these high load magnitudes the sectional effects are of less 
importance since the severity of the load limits the temperature development within the cross-section and hence the sectional shape and its effect on the thermal distribution is not crucial.

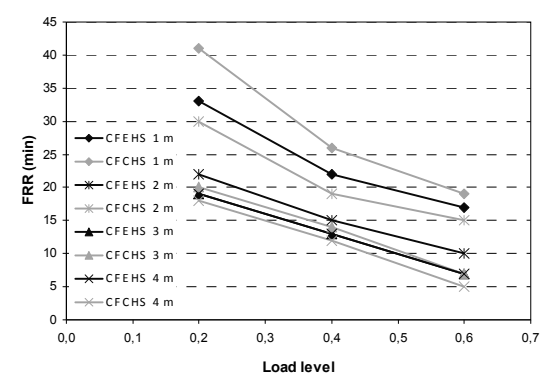

(a) $150 \times 75 \times 5 \mathrm{~mm}$

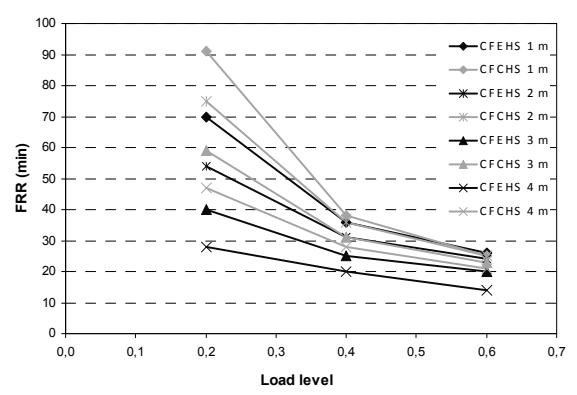

(b) $300 \times 150 \times 10 \mathrm{~mm}$

Fig. 15. Comparison between elliptical and circular columns for different lengths and load levels.

For the set of columns compared in this research, the average improvement in fire resistance achieved by the circular columns over the elliptical columns was about $20 \%$, with less use of steel in all cases ( $6 \%$ less on average) and a similar volume of concrete, except for columns $150 \times 75 \times 5 \mathrm{~mm}$ with 3 and $4 \mathrm{~m}$ length, where the amount of concrete was considerably reduced in the circular columns. It is worth noting that the comparison was carried out by considering buckling of the elliptical columns about their mi- nor axis. Therefore, for the same length and load bearing capacity at room temperature, the slenderness of the elliptical columns was higher than that of the circular ones, which is magnified when exposed to fire (due to the different rate of loss of strength and stiffness with temperature) and explains the high differences encountered in some cases even when the amount of material employed in the circular columns was lower.

\subsection{Simple calculation models for concrete filled elliptical hollow section columns in fire}

\subsubsection{Discussion of existing design guidance}

The fire behaviour of concrete filled elliptical hollow sections is not explicitly covered in existing design codes. EN 1994-1-2 [29] covers concrete encased and partially encased steel columns as well as unprotected concrete filled hollow sections. Clause 4.3.5.1 describes a simple calculation model for composite columns in general, while Annex $\mathrm{G}$ and Annex $\mathrm{H}$ give specific methods for steel sections with partial concrete encasement and unprotected concrete filled hollow sections, respectively.

Despite there being no reference to concrete filled tubes of elliptical shape in the current version of EN 1994-1-2 [29], application of the simple calculation model for concrete filled hollow section columns to the elliptical tubes is considered in this paper. The design procedure of Clause 4.3.5.1 in EN 1994-1-2 [29] is described below.

The design value of the resistance of composite columns in axial compression exposed to fire is calculated as:

$N_{f i, R d}=\chi N_{f i, p l, R d}$

where $\chi$ is the reduction coefficient for buckling curve "c" given in Clause 6.3.1.2 of EN 1993-1-1 [32] (obtained from the value of the relative slenderness at elevated temperature) and $N_{f i, p l, R d}$ is the design value 
of the plastic resistance to axial compression in fire.

The design value of the plastic resistance of the column in fire, considering that it has no reinforcement, is given by:

$$
\begin{aligned}
& N_{f i, p l, R d}=\sum_{j}\left(A_{a, \theta} f_{a y, \theta}\right) / \gamma_{M, f i, a}+ \\
& +\sum_{m}\left(A_{c, \theta} f_{c, \theta}\right) / \gamma_{M, f i, c}
\end{aligned}
$$

where $\mathrm{A}_{i, \theta}$ is the area of each element of the cross-section to which a certain temperature $\theta$ is attributed and subscripts " $a$ " and " $c$ " refer to the steel profile and concrete, respectively.

The effective flexural stiffness of the column can be calculated through:

$$
\begin{aligned}
& (E I)_{f i, e f f}=\sum_{j}\left(\varphi_{a, \theta} E_{a, \theta} I_{a, \theta}\right)+ \\
& +\sum_{m}\left(\varphi_{c, \theta} E_{c, \sec , \theta} I_{c, \theta}\right)
\end{aligned}
$$

where $I_{i, \theta}$ is the second moment of area of each element of the cross-section to which a certain temperature $\theta$ is attributed, $\varphi_{i, \theta}$ is a reduction coefficient depending on the effect of thermal stresses and $E_{c, s e c, \theta}$ is the secant modulus of concrete at a temperature $\theta$. For partially encased steel sections, the reduction coefficients have been defined in Annex G. However, for concrete filled sections these reduction coefficients have yet to be established; in the absence of predefined values a common approach in practice is to take them as equal to unity [35].

The Euler buckling load in a fire situation is calculated as:

$$
N_{f i, c r}=\pi^{2}(E I)_{f i, e f f} / \ell_{\theta}^{2}
$$

where $\ell_{\theta}$ is the buckling length of the column at a certain temperature $\theta$.
The relative slenderness of the column at elevated temperatures is given by:

$$
\bar{\lambda}_{\theta}=\sqrt{N_{f i, p l, R} / N_{f i, c r}}
$$

where $N_{f i, p l, R}$ is the value of $N_{f i, p l, R d}$ when the material factors are taken as 1.0. This value of the relative slenderness is used to enter to the buckling curve "c", from where the reduction coefficient needed for determining the buckling load is obtained.

In addition to the approach described above, Annex H (informative) of EN 19941-2 [29] provides a simple calculation model specifically for concrete filled hollow sections in fire. It establishes that the design axial buckling load can be obtained from the equilibrium equation:

$$
N_{f i, R d}=N_{f i, c r}=N_{f i, p l, R d}
$$

The procedure is based on increasing the strain in steps until $N_{f i, c r}$ and $N_{f i, p l, R d}$ are equal, subjected to the condition that the axial strain of all the components of the crosssection is the same. The instantaneous values of the stress and tangent modulus of each material for a particular temperature are used, varying with the strain level. In this approach, the reduction coefficients to account for the thermal stresses are not used.

Recently, Leskela [36] and Aribert et al. [37] have highlighted several shortcomings of Annex $\mathrm{H}$, which at present is under revision. While a new specific simplified model for concrete filled columns in fire is developed, it seems that following the general principles of Clause 4.3.5.1 is more appropriate. However, as the values of the reduction coefficients to account for the effect of thermal stresses are not given in EN 1994-12 [29] for concrete filled columns, some assumptions must be adopted for their treatment.

These flexural stiffness reduction coefficients were introduced into the simple calculation model to account for the effect of 
the thermal stresses caused by the nonuniform temperature distribution within a composite cross-section and the unequal thermal expansion of steel and concrete [35]. This leads to a non-uniform thermal and thus mechanical strain distribution and since the stress-strain curves of the materials are nonlinear, it results into a redistribution of stiffness across the composite section, different from that based on assuming a uniform strain distribution.

As a first approach (hereafter referred to as EC4(1)), the reduction coefficients were taken as unity, which means neglecting the effect of the thermal stresses. In a second approach (hereafter referred to as EC4(2)), the values proposed by Aribert et al. [37] for the reduction coefficients were adopted. These values are a result of an extensive parametric investigation carried out at the CTICM (Centre Technique Industriel de la Construction Métallique) [38] and are currently normative in France, having been included in the French National Annex to EN 1994-1-2 (NF EN 1994-1-2/NA) [39]. For the concrete core, a reduction coefficient of 0.8 is specified, resulting in $\varphi_{c, \theta}=1.2$, which includes implicitly the use of the initial tangent modulus of concrete (calculated as $3 / 2$ times the secant modulus, therefore $0.8 \times 3 / 2$ $=1.2$ for direct application over the secant modulus), while for the steel hollow section the value of the reduction coefficient $\varphi_{a, \theta}$ depends on the fire duration and the size $(B$ or $D$ ) of the steel section, according to Table 5, taken from Clause 4(2) of NF EN 1994-12/NA. The rest of the procedure used in this second approach followed the general flow chart of Clause 4.3.5.1 in EN 1994-1-2, employing as recommended buckling curve "c".

Table 5. Values of coefficient $\varphi_{a, \theta}$ according to the French National Annex to EN 1994-1-2 [39]

\begin{tabular}{lccccc}
\hline & \multicolumn{5}{c}{$\boldsymbol{B}$ or $\boldsymbol{D}(\mathbf{m m})$} \\
\cline { 2 - 6 } & 100 & 150 & 200 & 250 & 350 to 610 \\
\hline R30 & 0.30 & 0.23 & 0.15 & 0.15 & 0.15 \\
R60 & - & 0.30 & 0.23 & 0.15 & 0.15 \\
R90 & - & - & 0.30 & 0.20 & 0.15 \\
R120 & - & - & 0.30 & 0.20 & 0.20 \\
\hline
\end{tabular}

Finally, the complete method described in NF EN 1994-1-2/NA [39] (hereafter referred to as EC4(NF)) was applied and included in this study. The method included in the French National Annex, apart from accounting for the effect of the differential thermal stresses within the composite column cross-section through the reduction coefficients, establishes specific buckling curves with a discontinuity at a certain value of the relative slenderness, called the "transition relative slenderness". This transition value is dependent on the fire exposure time, and is equal to 1.0 for R30 and 1.35 for R60 in the case of unreinforced columns. Before reaching the transition value, the buckling curve follows the shape of the EN 1993-1-1 [32] curves but with a different imperfection factor for the different fire periods $(\alpha=0.21$ for R30 and $\alpha=0.265$ for R60). For relative slenderness values above the transition slenderness, the method employs a buckling curve of the form:

$\chi\left(\bar{\lambda}_{\theta}\right)=\beta\left(\bar{\lambda}_{\theta}\right)^{-\gamma}$

with non-dimensional coefficients $\beta$ and $\gamma$ as a function of the sectional dimensions.

Since the French proposal is specific to circular and square columns, not considering different dimensions in the two axes, for entering to Table 2 in NF EN 1994-1-2/NA (Table 5 in this paper) an equivalent diameter has to be defined in order to apply the method to the elliptical columns.

It can be thought that the temperature field of a CFEHS lies between that of the CFCHS of diameter equal to $2 a$ and $2 b$. This can be confirmed by comparing the temperature distributions of these columns, which is represented in Fig. 16. It can be seen that the thermal gradient within the elliptical crosssection lies between that of the circular cross-sections of diameter equal to $2 a$ (higher gradient) and $2 b$ (lower gradient) for a particular exposure time. An intermediate equivalent diameter, between $2 a$ and $2 b$ should be therefore adopted for entering to Table 2 in NF EN 1994-1-2/NA. As a first 
approximation, a value of $P / \pi$ (i.e. the diameter of that circle which has the same perimeter than the elliptical section) is adopted.

The three different approaches outlined above were applied to a series of circular and elliptical concrete filled columns listed in Table 6 and Table 7 respectively. In these tables Clause 4.3.5.1 of EN 1994-1-2 with coefficients $\varphi_{i, \theta}$ equal to unity and buckling curve "c" is referred to as EC4(1), the same procedure with coefficients proposed by Aribert et al. [37] is referred to as EC4(2) and NF EN 1994-1-2/NA is referred to as $\mathrm{EC} 4(\mathrm{NF})$.

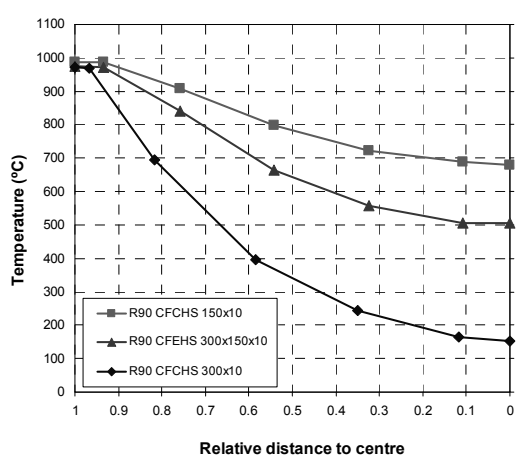

Fig. 16. Comparison of the cross-sectional temperature evolution between an elliptical and its bound circular columns after 90 minutes of fire exposure.

Table 6. Comparison of numerical simulation (NS) results with existing design guidance, for CFCHS columns

\begin{tabular}{|c|c|c|c|c|c|}
\hline \multirow[b]{2}{*}{$\begin{array}{c}\text { Specimen } \\
\text { designation }\end{array}$} & \multirow[b]{2}{*}{$\begin{array}{c}N \\
(\mathbf{k N})\end{array}$} & \multirow[b]{2}{*}{$\begin{array}{l}\text { FRR } \\
(\mathrm{min})\end{array}$} & \multicolumn{3}{|c|}{ Buckling resistance at critical temperature } \\
\hline & & & EC4(1)/NS & EC4(2)/NS & EC4(NF)/NS \\
\hline $108.74 \times 5 \_1(0.2)$ & 146 & 41 & 0.90 & 0.79 & 1.06 \\
\hline $108.74 \times 5 \_1(0.4)$ & 293 & 26 & 0.88 & 0.78 & 0.96 \\
\hline $108.74 \times 5-1(0.6)$ & 439 & 19 & 0.98 & 0.88 & 0.93 \\
\hline $106.38 \times 5 \_2(0.2)$ & 136 & 30 & 1.26 & 0.80 & 0.99 \\
\hline $106.38 \times 5 \_2(0.4)$ & 272 & 19 & 1.27 & 0.90 & 1.19 \\
\hline $106.38 \times 52(0.6)$ & 407 & 15 & 1.23 & 0.88 & 0.96 \\
\hline $101.64 \times 5 \_3(0.2)$ & 119 & 20 & 1.84 & 0.96 & 1.52 \\
\hline $101.64 \times 5 \_3(0.4)$ & 237 & 14 & 1.72 & 0.90 & 1.11 \\
\hline $101.64 \times 5 \_3(0.6)$ & 356 & 7 & 1.48 & 0.89 & 1.01 \\
\hline $95.29 \times 5 \_\overline{4}(0.2)$ & 93 & 18 & 1.71 & 0.74 & 1.21 \\
\hline $95.29 \times 5 \_4(0.4)$ & 185 & 12 & 1.61 & 0.70 & 0.87 \\
\hline $95.29 \times 5 \_4(0.6)$ & 278 & 5 & 1.36 & 0.67 & 0.78 \\
\hline $219.95 \times 10 \_1(0.2)$ & 594 & 91 & 0.80 & 0.74 & - \\
\hline $219.95 \times 10 \_1(0.4)$ & 1188 & 38 & 0.99 & 0.95 & 1.00 \\
\hline $219.95 \times 10 \_1(0.6)$ & 1782 & 25 & 1.04 & 1.02 & 0.94 \\
\hline $217.48 \times 10 \_2(0.2)$ & 585 & 75 & 0.89 & 0.71 & - \\
\hline $217.48 \times 10 \_2(0.4)$ & 1171 & 36 & 0.94 & 0.82 & 0.94 \\
\hline $217.48 \times 10 \_2(0.6)$ & 1756 & 25 & 1.00 & 0.88 & 0.87 \\
\hline $215.39 \times 10 \_3(0.2)$ & 566 & 59 & 1.01 & 0.68 & 0.82 \\
\hline $215.39 \times 10 \_3(0.4)$ & 1132 & 31 & 1.00 & 0.78 & 0.89 \\
\hline $215.39 \times 10 \_3(0.6)$ & 1699 & 23 & 1.06 & 0.84 & 0.83 \\
\hline $212.77 \times 10 \_4(0.2)$ & 543 & 47 & 1.12 & 0.64 & 0.86 \\
\hline $212.77 \times 10 \_4(0.4)$ & 1086 & 28 & 1.09 & 0.71 & 0.72 \\
\hline $212.77 \times 10 \_4(0.6)$ & 1630 & 21 & 1.14 & 0.77 & 0.73 \\
\hline Average & & & 1.18 & 0.81 & 0.96 \\
\hline Standard deviation & & & 0.30 & 0.10 & 0.18 \\
\hline
\end{tabular}


As an initial step, the cross-sectional temperature field of each column was obtained by means of the finite element model previously described in this paper. Once the temperature field had been established, the cross-section was divided into a number of concentric circular or elliptical layers, and each of these layers was assigned a representative temperature. The structural behaviour of the columns was then evaluated through the application of the reduction coefficients of strength and stiffness corresponding to each layer for a particular exposure time, according to the corresponding code provisions.

The errors in terms of buckling load obtained with reference to the numerical results by applying these different design approaches are included in Table 6 for CFCHS columns and Table 7 for CFEHS columns.
The buckling loads were obtained in all cases by taking the temperature field at the time of failure from the numerical analysis and assuming a buckling length equal to 0.5 times the length of the column in the application of the code, corresponding to columns located in an intermediate storey of a building as per Clause 4.3.5.1(10) of EN 1994-12 [29].

Fig. 17 shows the results obtained from the three approaches for CFCHS columns, expressed in terms of difference between code predictions and numerical model against the relative slenderness of the columns at room temperature. Fig. 18 shows the corresponding results for CFEHS columns, having assumed an equivalent diameter of $P / \pi$ for applying the French reduction coefficients.

Table 7. Comparison of numerical simulation (NS) results with existing design guidance, for CFEHS columns

\begin{tabular}{|c|c|c|c|c|c|}
\hline \multirow[b]{2}{*}{$\begin{array}{c}\text { Specimen } \\
\text { designation }\end{array}$} & \multirow[b]{2}{*}{$\begin{array}{c}N \\
(\mathbf{k N})\end{array}$} & \multirow[b]{2}{*}{$\begin{array}{l}\text { FRR } \\
\text { (min) }\end{array}$} & \multicolumn{3}{|c|}{ Buckling resistance at critical temperature } \\
\hline & & & EC4(1)/NS & $\mathrm{EC4}(2) / \mathrm{NS}$ & $\mathrm{EC} 4(\mathrm{NF}) / \mathrm{NS}$ \\
\hline $150 \times 75 \times 5 \quad 1(0.2)$ & 146 & 33 & 1.14 & 0.91 & 1.09 \\
\hline $150 \times 75 \times 5-1(0.4)$ & 293 & 22 & 1.12 & 0.93 & 1.09 \\
\hline $150 \times 75 \times 5 \_1(0.6)$ & 439 & 17 & 1.15 & 0.97 & 0.94 \\
\hline $150 \times 75 \times 5-2(0.2)$ & 136 & 22 & 1.81 & 1.02 & 1.42 \\
\hline $150 \times 75 \times 5 \_2(0.4)$ & 272 & 15 & 1.78 & 1.04 & 1.14 \\
\hline $150 \times 75 \times 5 \_2(0.6)$ & 407 & 10 & 1.50 & 0.96 & 0.97 \\
\hline $150 \times 75 \times 53(0.2)$ & 119 & 19 & 1.90 & 0.84 & 1.17 \\
\hline $150 \times 75 \times 5 \_3(0.4)$ & 237 & 13 & 1.68 & 0.76 & 0.86 \\
\hline $150 \times 75 \times 5 \_3(0.6)$ & 356 & 7 & 1.37 & 0.68 & 0.75 \\
\hline $150 \times 75 \times 5-4(0.2)$ & 93 & 19 & 1.64 & 0.65 & 0.91 \\
\hline $150 \times 75 \times 54(0.4)$ & 185 & 13 & 1.51 & 0.60 & 0.67 \\
\hline $150 \times 75 \times 5+4(0.6)$ & 278 & 7 & 1.26 & 0.54 & 0.59 \\
\hline $300 \times 150 \times 10 \_1(0.2)$ & 594 & 70 & 0.84 & 0.77 & - \\
\hline $300 \times 150 \times 10-1(0.4)$ & 1188 & 36 & 0.95 & 0.87 & 0.98 \\
\hline $300 \times 150 \times 10^{-} 1(0.6)$ & 1782 & 26 & 1.00 & 0.93 & 0.87 \\
\hline $300 \times 150 \times 10 \_2(0.2)$ & 585 & 54 & 1.03 & 0.82 & 0.92 \\
\hline $300 \times 150 \times 10-2(0.4)$ & 1171 & 31 & 1.04 & 0.83 & 0.89 \\
\hline $300 \times 150 \times 10 \_2(0.6)$ & 1756 & 24 & 1.04 & 0.85 & 0.81 \\
\hline $300 \times 150 \times 10 \_3(0.2)$ & 566 & 40 & 1.38 & 0.84 & 0.78 \\
\hline $300 \times 150 \times 10 \_3(0.4)$ & 1132 & 25 & 1.34 & 0.88 & 0.74 \\
\hline $300 \times 150 \times 10 \_3(0.6)$ & 1699 & 20 & 1.26 & 0.87 & 0.68 \\
\hline $300 \times 150 \times 10 \_4(0.2)$ & 543 & 28 & 1.98 & 1.01 & 0.64 \\
\hline $300 \times 150 \times 10 \_4(0.4)$ & 1086 & 20 & 1.75 & 0.98 & 0.71 \\
\hline $300 \times 150 \times 10-4(0.6)$ & 1630 & 14 & 1.50 & 0.89 & 0.67 \\
\hline Average & & & 1.37 & 0.85 & 0.88 \\
\hline Standard deviation & & & 0.33 & 0.13 & 0.20 \\
\hline
\end{tabular}




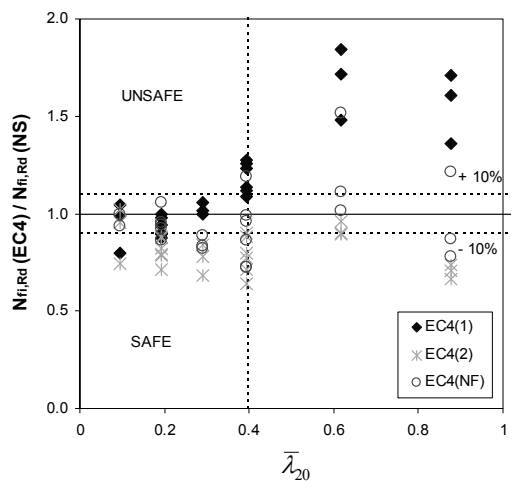

Fig. 17. Comparison between EN 1994-1-2 simple calculation model and numerical model, for CFCHS columns.

The first approach, where the reduction coefficients were taken as equal to unity, clearly produced unsafe results for room temperature relative slenderness values over 0.4, which can be seen in Fig. 17 and Fig. 18. This finding confirms the conclusions obtained in previous research by the authors [18], and proves to be also valid for elliptical columns. The average value of the error in buckling load was higher than unity for both circular (Table 6) and elliptical columns (Table 7), indicating unsafe results. This effect was more noticeable for the elliptical columns. In turn, the second approach, employing the French National Annex coefficients combined with buckling curve "c", generally produced safe results for the full range of slenderness studied (with average values lower than unity in Table 6 and Table 7). The results obtained by means of NF EN 1994-1-2/NA are also included in the tables and in Fig. 17 and Fig. 18. This method also produced conservative results, with an average error closer to unity in Table 6 and Table 7 , although with more scattered predictions. Unsafe values were obtained in a number of cases. The resulting average value was closer to the numerical predictions for the circular columns than for the elliptical columns, where the difference in accuracy between EC4(2) and EC4(NF) approaches is not so clear. It is worth noting that the
French method is limited to a minimum dimension of $100 \mathrm{~mm}$ and a maximum fire resistance of 60 minutes for unreinforced columns, which puts some of the specimens under study outside the limits of applicability.

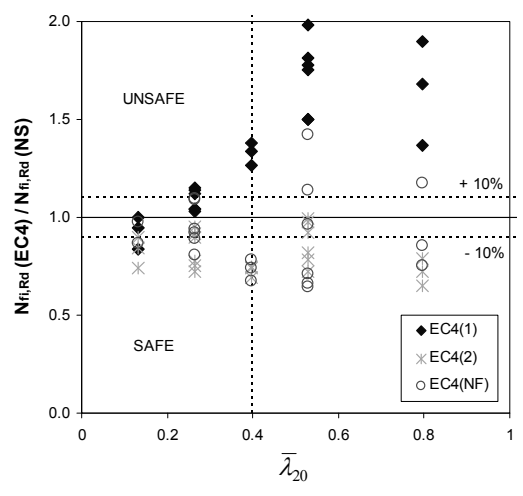

Fig. 18. Comparison between EN 1994-1-2 simple calculation model and numerical model, for CFEHS columns.

In order to investigate further the differences caused by the reduction coefficients to account for the thermal stresses and have a basis to develop future design recommendations for elliptical columns, the numerical results expressed in terms of normalised resistance (relative to the plastic resistance to axial compression in fire) are plotted against the relative slenderness at the time of failure of the columns in Fig. 19 (considering the reduction coefficients equal to unity) and Fig. 20 (adopting the values for the reduction coefficients proposed by Aribert et al. [37]). The EN 1993-1-1 [32] buckling curve "c" has been superimposed onto both graphs for comparison purposes.

Fig. 19 shows that when neglecting the reduction coefficients, the results are generally over-predicted by buckling curve "c" for both circular and elliptical columns, except for the stockier ones, which are underpredicted. This result for stocky columns means that in the numerical simulations these columns showed higher load bearing capacity than their computed plastic resis- 
tance in fire, which is attributed to the confinement effect of the steel tube which increases the load bearing capacity of the composite section and is not accounted for in the plastic resistance calculation. Most of the points, however, lie below the buckling curve "c", which means that when employing this curve with the general flow chart for design, the results obtained would be unsafe.

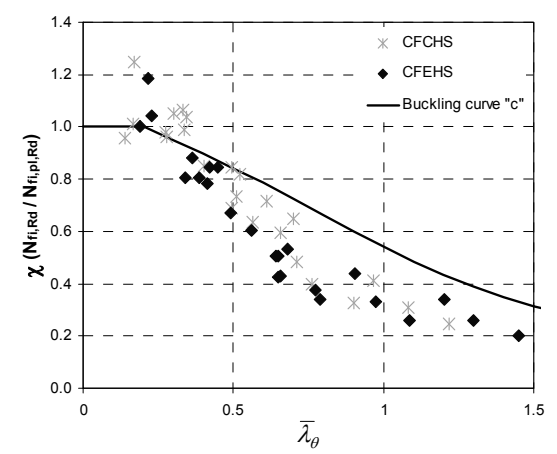

Fig. 19. Comparison of numerical results with EN 1993-1-1 buckling curve "c" (relative slenderness computed with coefficients equal to unity).

It therefore seems that neglecting the effect of the thermal stresses when applying the simple calculation model results in clear deviation from the actual buckling response of the columns. It can be observed in Fig. 19 that this difference with reference to buckling curve "c" is larger for the more slender columns. This can be explained as follows: for both short and long columns, the thermal stresses are the same for a certain restraint level and temperature field (since they are caused by thermal strains which are only a function of temperature). However, in long columns the applied stress levels required to cause buckling are lower than for short columns, so the thermal stresses are a higher proportion of the total stress and therefore have a greater influence in the buckling response at elevated temperatures. To sum up, the effect of the thermal stresses is more noticeable for slender columns and therefore has to be carefully taken into account when calculating their buckling resistance in fire.

When the flexural stiffness reduction coefficients proposed by Aribert et al. [37] are adopted, the majority of the points lie above the buckling curve "c", as can be seen in Fig. 20 for both circular and elliptical columns, which means that it can be safely applied to compute the column buckling resistance in fire. It seems therefore that this approach is the one to follow when one wants to apply the general flow chart of Clause 4.3.5.1 in EN 1994-1-2, although a better fitted curve could be developed in order to obtain more accurate predictions of fire resistance.

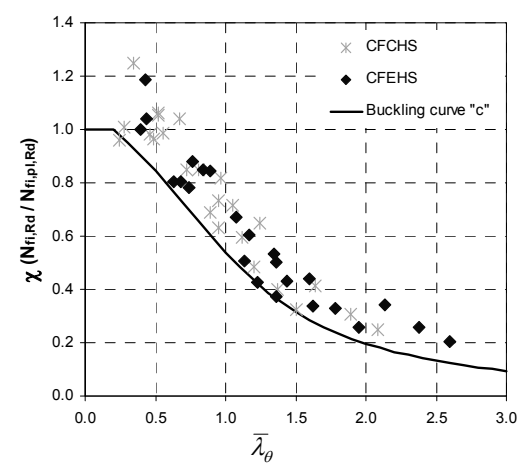

Fig. 20. Comparison of numerical results with EN 1993-1-1 buckling curve "c" (relative slenderness computed with French National Annex coefficients).

\subsubsection{Recommendations for design guidance of elliptical columns}

Following the previous discussion of the existing design guidance, it can be concluded that, in the absence of predefined values for the reduction coefficients to account for the effect of thermal stresses in concrete filled columns, employing the coefficients proposed by Aribert et al. [37] is acceptable, producing conservative results when used in combination with the buckling curve "c". The NF EN 1994-1-2/NA [39] simple calculation model, which uses these 
same coefficients but with revised buckling curves, generally produces conservative results, with a better average prediction, but with a higher dispersion of results.

Hence, for CFEHS columns, it is recommended that the flexural stiffness reduction coefficients are obtained from the French National Annex, using an equivalent diameter $D=P / \pi$ when applying the tabulated data. It is then proposed to follow the guidelines of the simple calculation model of Clause 4.3.5.1 in EN 1994-1-2 [29], employing buckling curve "c", this proposal being valid for both circular and elliptical columns. The NF EN 1994-1-2/NA [39] simple calculation model can be applied as an alternative for calculating the fire resistance of CFT columns, although a wider study should be conducted to confirm its validity for elliptical sections.

\section{Summary and conclusions}

The fire response of concrete filled elliptical hollow section columns has been studied in this paper through finite element modelling. The numerical model had previously been validated for concrete filled circular columns exposed to fire and, in the absence of fire tests on elliptical columns, the values of the modelling parameters previously obtained from the circular column sensitivity analysis were employed. As further validation, the response of concrete filled elliptical stub columns at room temperature was studied by means of the numerical model and compared with test results. The model showed good agreement with the tests, indicating that it is capable of representing the composite behaviour between the steel and concrete in elliptical sections. Having obtained a good representation of the room temperature interaction for elliptical columns, the behaviour at elevated temperatures was studied. Parametric studies were conducted in order to assess the influence of the column slenderness, load level, crosssection slenderness and section size on the fire response of the concrete filled elliptical columns. As expected, the fire resistance of the columns decreases with an increase in member slenderness and load level, as well as with an increase of the section factor $(A / V$ ratio). The influence of cross-section slenderness and section thickness is not so clear, with opposing trends obtained for stocky and slender columns, which is related to their different failure modes.

A comparative study between elliptical and circular concrete filled hollow section columns in fire has also been presented. This study has shown that for a certain column length and load bearing capacity at room temperature, the circular columns attain higher fire resistance than the elliptical columns, with reduced material use. This is due to the lower $A / V$ ratio that the circular sections present, which delays the heating up of the column therefore providing a longer fire resistance period. The difference in performance between elliptical and circular columns is less evident for slender columns, since the sectional effects have a lower influence. These conclusions are only valid for centrally loaded columns under axial compression, since for eccentric loads the elliptical shapes would provide more efficient structural performance than the circular sections if the load is aligned such that it generates a bending moment about the major axis. The differences in fire behaviour under eccentric loads therefore require a wider study, which will be addressed in future work.

Finally, a review of existing design guidance for the calculation of the buckling resistance of concrete filled columns in fire has been carried out. In the absence of guidance on the flexural stiffness reduction coefficients to account for the effect of thermal stresses in concrete filled columns in EN 1994-1-2, a number of alternative values were assumed. This study showed that assuming these coefficients are equal to unity (i.e. neglecting the effect of the differential thermal stresses) gives rise to unsafe results when applying the EN 1994-1-2 simple calculation model for columns with room temperature relative slenderness over 0.4 ; this was observed for both circular and elliptical shapes. However, assuming the reduction coefficients proposed in the French National 
Annex to EN 1994-1-2 in combination with buckling curve "c", safe results are achieved. It is recommended that the general flow chart in Clause 4.3.5.1 of EN 1994-1-2 with the flexural stiffness reduction coefficients taken from the French National Annex using an equivalent diameter of $D=P / \pi$ is adopted for elliptical columns.

\section{Acknowledgements}

The authors would like to express their sincere gratitude to the Spanish "Ministerio de Ciencia e Innovación" for the help provided through the Project BIA2009-9411 and to the European Union through the FEDER funds.

The authors would also like to acknowledge Universidad Politécnica de Valencia for providing fellowship funding for the first author's stay as a visiting academic at Imperial College London.

\section{References}

[1] CEN. EN 10210-2. Hot finished structural hollow sections of non-alloy and fine grain steels. Part 2: Tolerances, dimensions and sectional properties. Brussels, Belgium: Comité Européen de Normalisation; 2006.

[2] Corus. Celsius 355 Ovals - Sizes and Capacities, EC3 Version. Corus Tubes Structural \& conveyance business; 2007.

[3] Gardner L, Ministro A. Structural steel oval hollow sections. Structural Engineer 2005; 83(21):32-36.

[4] Packer JA. Going elliptical. Modern Steel Construction 2008; 48(3):65-67.

[5] Chan TM, Gardner L. Compressive resistance of hot-rolled elliptical hollow sections. Engineering Structures 2008; 30(2):522-532.

[6] Chan TM, Gardner L. Bending strength of hot-rolled elliptical hollow sections. Journal of Constructional Steel Research 2008; 64(9):971-986.

[7] Gardner L, Chan TM, Wadee MA. Shear response of elliptical hollow sections. Proceedings of the Institution of Civil Engineers - Structures and Buildings 2008; 161(6):301-309.
[8] Gardner L, Chan TM. Cross-section classification of elliptical hollow sections. Steel and Composite Structures 2007; 7(3):185200.

[9] Ruiz-Teran AM, Gardner L. Elastic buckling of elliptical tubes. Thin-Walled Structures 2008; 46(11):1304-1318.

[10] Silvestre N. Buckling behaviour of elliptical cylindrical shells and tubes under compression. International Journal of Solids and Structures 2008; 45(16):4427-4447.

[11] Yang H, Lam D, Gardner L. Testing and analysis of concrete-filled elliptical hollow sections. Engineering Structures 2008; 30:3771-3781.

[12] Zhao XL, Packer JA. Tests and design of concrete-filled elliptical hollow section stub columns. Thin-Walled Structures 2009; 47:617-628.

[13] CEN. EN 1994-1-1, Eurocode 4: Design of composite steel and concrete structures. Part 1-1: General rules and rules for buildings. Brussels, Belgium: Comité Européen de Normalisation; 2004.

[14] Dai X, Lam D. Numerical modelling of the axial compressive behaviour of short concrete-filled elliptical steel columns. Journal of Constructional Steel Research 2010; 66:931-942.

[15] Lam D, Dai X. Modelling the confinement effect of composite concrete-filled elliptical steel columns. In: Proceedings of the Sixth International Conference on Advances in Steel Structures, p. 49-62. Hong Kong, China: The Hong Kong Institute of Steel Construction; 2009.

[16] Lacuesta C, Romero ML, Ivorra S, Portoles JM. A three-dimensional numerical model of circular concrete filled columns. In: Proceedings of the Eighth International Conference on Computational Structures Technology. Stirlingshire, UK: B.H.V. Topping, G. Montero, R. Montenegro (Editors); 2006. Paper 22, doi:10.4203/ccp.83.22.

[17] Portoles JM, Romero ML, Bonet JL, Filippou FC. Experimental study of high strength concrete-filled circular tubular columns under eccentric loading. Journal of Constructional Steel Research 2010 (submitted for evaluation).

[18] Espinos A, Romero ML, Hospitaler A. Advanced model for predicting the fire re- 
sponse of concrete filled tubular columns. Journal of Constructional Steel Research 2010; 66:1030-1046.

[19] ABAQUS. ABAQUS/Standard Version 6.6 User's Manual: Volumes I-III. Pawtucket, Rhode Island: Hibbit, Karlsson \& Sorenson, Inc.; 2005.

[20] Ellobody E, Young B, Lam D. Behaviour of normal and high strength concrete-filled compact steel tube circular stub columns. Journal of Constructional Steel Research 2006; 62:706-715.

[21] Mander JB, Priestley MJN, Park R. Theoretical stress-strain model for confined concrete. ASCE Journal of Structural Engineering 1988; 114(8):1804-1826.

[22] Hu HT, Huang CS, Wu MH, Wu YM. Nonlinear analysis of axially loaded concrete-filled tube columns with confinement effect. ASCE Journal of Structural Engineering 2003; 129(10):1322-1329.

[23] Saenz LP. Discussion of 'Equation for the stress-strain curve of concrete' by P. Desayi, and S. Krishnan. Journal of the American Concrete Institute 1964; 61:1229-1235.

[24] Ding J, Wang YC. Realistic modelling of thermal and structural behaviour of unprotected concrete filled tubular columns in fire. Journal of Constructional Steel Research 2008; 64:1086-1102.

[25] Lie TT. Fire resistance of circular steel columns filled with bar-reinforced concrete. ASCE Journal of Structural Engineering 1994; 120(5):1489-1509.

[26] CEN. EN 1992-1-2, Eurocode 2: Design of concrete structures. Part 1-2: General rules - Structural fire design. Brussels, Belgium: Comité Européen de Normalisation; 2004.

[27] CEN. EN 1993-1-2, Eurocode 3: Design of steel structures. Part 1-2: General rules Structural fire design. Brussels, Belgium: Comité Européen de Normalisation; 2005.

[28] Hong S, Varma AH. Analytical modeling of the standard fire behavior of loaded CFT columns. Journal of Constructional Steel Research 2009; 65:54-69.

[29] CEN. EN 1994-1-2, Eurocode 4: Design of composite steel and concrete structures. Part 1-2: General rules - Structural fire de- sign. Brussels, Belgium: Comité Européen de Normalisation; 2005.

[30] ISO (International Standards Organization). ISO 834: Fire resistance tests, elements of building construction. Switzerland: International Standards Organisation; 1980 .

[31] CEN. EN 1991-1-2, Eurocode 1: Actions on structures. Part 1-2: General actions Actions on structures exposed to fire. Brussels, Belgium: Comité Européen de Normalisation; 2002.

[32] CEN. EN 1993-1-1, Eurocode 3: Design of steel structures. Part 1-1: General rules and rules for buildings. Brussels, Belgium: Comité Européen de Normalisation; 2005.

[33] Chan TM, Gardner L. Flexural buckling of elliptical hollow section columns. ASCE Journal of Structural Engineering 2009; 135:546-557.

[34] CEN. EN 1363-1: Fire resistance tests. Part 1: General requirements. Brussels, Belgium: Comité Européen de Normalisation; 1999.

[35] Lennon T, Moore DB, Wang YC, Bailey CG. Designers' guide to EN 1991-1-2, EN 1992-1-2, EN 1993-1-2 and EN 1994-1-2. Thomas Telford Limited; 2007.

[36] Leskela MV. Inconsistencies in the fire design rules of composite columns to $\mathrm{EN}$ 1994-1-2. Steel Concrete Composite and Hybrid Structures, pp. 489-494. Leeds, England; 2009.

[37] Aribert JM, Renaud C, Zhao B. Simplified fire design for composite hollow-section columns. Structures \& Buildings 2008; 161:325-336.

[38] Renaud C, Joyeux D, Kruppa J. Improvement and extension of the simple calculation method for fire resistance of unprotected concrete filled hollow columns. CIDECT Research Project 15Q-12/03 Saint-Rémy-lès-Chevreuse Cedex, France: Centre Technique Industriel de la Construction Métallique (CTICM); 2004.

[39] AFNOR. Calcul simplifié de la résistance au feu des profils creux remplis de béton exposés aux conditions d'incendie normalisé. Annexe PCRB, pp. 9-16, NF-EN 19941-2/NA. Paris, France: Association Française de Normalisation; 2007. 



\section{ANNEX I. COMPENDIUM OF PUBLICATIONS}

\section{ARTICLE 3}

Published in Engineering Structures 42 (2012) 231-244

For copyright restrictions, the article is presented in its pre-print version. 



\title{
SIMPLE CALCULATION MODEL FOR EVALUATING THE FIRE RESISTANCE OF UNREINFORCED CONCRETE FILLED TUBULAR COLUMNS
}

\author{
Ana Espinos ${ }^{\text {a }}$, Manuel L. Romero ${ }^{\text {a }}$, Antonio Hospitaler ${ }^{\text {a }}$ \\ ${ }^{a}$ Instituto de Ciencia y Tecnología del Hormigón (ICITECH), \\ Universitat Politècnica de València, Valencia, Spain
}

\begin{abstract}
This paper presents a method for calculating the fire resistance of unreinforced axially loaded concrete filled circular hollow section columns, based on the guidelines of Eurocode 4 Part 1.2 for the fire design of composite columns. The different design approaches which are currently available worldwide are reviewed in this paper, focusing in particular on the European code, which is discussed and analysed in depth. Several of the aspects which are nowadays missing or thought to be arguable by researchers in the Eurocode 4 method are studied and on the basis of parametric studies a new proposal is developed, so that designers can easily apply the code in the future. The parametric studies investigate the main factors affecting the fire resistance of unreinforced concrete filled tubular (CFT) columns, such as the outer diameter, the thickness of the steel tube wall, the relative slenderness of the column at room temperature and the fire exposure time, widely covering the range of values which can be found in practice. From the results of these parametric studies, equations for obtaining the equivalent temperatures of steel and concrete are developed, and appropriate flexural stiffness reduction coefficients are integrated in the simple calculation model of Eurocode 4. The method presented here is valid for centrally loaded circular CFT columns filled with unreinforced normal strength concrete, and makes possible the calculation of slender columns, extending the current limitations in buckling length of the European code.
\end{abstract}

Keywords: Fire resistance; Concrete filled tubular columns; Eurocode 4; Simple calculation model

\section{Notation}

$\begin{array}{ll}A_{a, \theta} & \text { Cross-sectional area of the steel profile at the temperature } \theta \\ A_{c, \theta} & \text { Cross-sectional area of the concrete at the temperature } \theta \\ A_{m} / V & \text { Section factor } \\ \text { CFT } & \text { Concrete filled tube } \\ D & \text { Outer diameter of the circular section } \\ E_{a, \theta} & \text { Modulus of elasticity of steel at the temperature } \theta \\ E_{c, \theta} & \text { Tangent modulus of concrete at the temperature } \theta \\ E_{c, s e c, \theta} & \text { Secant modulus of concrete at the temperature } \theta \\ (E I)_{f i, e f f} & \text { Effective flexural stiffness in the fire situation } \\ \text { EC4 } & \text { Eurocode } 4 \\ f_{c} & \text { Compressive cylinder strength of concrete at room temperature } \\ f_{y} & \text { Yield strength of structural steel at room temperature }\end{array}$




$\begin{array}{ll}I_{a, \theta} & \text { Second moment of area of the steel profile at the temperature } \theta \\ I_{c, \theta} & \text { Second moment of area of the concrete at the temperature } \theta \\ k_{i, \theta} & \text { Reduction factor for a material property at elevated temperature } \\ L & \text { Length of the column } \\ \ell_{\theta} & \text { Buckling length of the column in the fire situation } \\ N & \text { Applied axial load } \\ \text { NF } & \text { French National Annex to Eurocode } 4 \text { Part } 1-2 \\ N_{f i, c r} & \text { Elastic critical load in the fire situation } \\ N_{f i, p l, R d} & \text { Design cross-sectional plastic resistance to axial compression in fire } \\ N_{f i, R d} & \text { Design axial buckling load of the column in the fire situation } \\ R & \text { Standard fire resistance } \\ t & \text { Thickness of the steel tube } \\ \alpha & \text { Imperfection factor for the buckling curves } \\ \theta & \text { Temperature } \\ \bar{\lambda} & \text { Relative slenderness of the column at room temperature } \\ \bar{\lambda} & \text { Relative slenderness of the column in the fire situation } \\ \xi & \text { Relative error } \\ \chi & \text { Reduction coefficient to make allowance for the effect of thermal stresses } \\ \varphi_{i, \theta} & \text { Member slenderness reduction factor }\left(\chi=N_{f i, R d} / N_{f i, p l, R d}\right)\end{array}$

\section{Introduction}

The fire resistance of the structural elements is one of the factors that must be taken into account during the design process of a building. Depending on several factors related to the future use and characteristics of the building itself, the required fire resistance time will be higher or lower, ranging from 30 to 180 minutes. Therefore, calculation tools are sought by designers in order to obtain an estimation of the fire resistance that the different structural elements within the building can achieve, or conversely to be able to determine the minimum dimensions of the structural member which fulfil the required fire resistance period.

In particular, the interest in the use and development of simple methods for calculating the fire resistance of concrete filled tubular (CFT) columns is growing, due to the increased usage of this structural typology.

Authors as Zhao et al. [1] or Rush et al. [2] have reviewed the current methods that exist for calculating the fire resistance of CFT columns. Several codes are in use nowadays, which are a result of numerical and experimental investigations carried out by the main groups working in this field of research.

The Chinese Code DBJ13-51 [3] establishes an equation to calculate the thickness of the external fire protection required to achieve a certain fire resistance time and is based on a research carried out by Han et al. [4] [5]. Also a method for calculating the ultimate strength of unprotected concrete filled steel tubular columns subjected to standard fire was developed by this research group [4].

Another approach, which is in use in North America, was developed by Kodur and co-workers [6] [7] [8] at the National Research Council of Canada (NRCC) and has been incorporated into the National Building Code of Canada [9], ASCE/SFPE 29-99 [10], ACI 216 [11] and AISC Steel 
Design Guide 19 [12]. This approach consists of a single design equation which includes the main parameters affecting the fire resistance of CFT columns.

Other design equations in use presently include the one in the design guide manual for CFT columns published by the Association of New Urban Housing Technology (ANUHT) in Japan [13] [14].

In Europe, the most extended methods for calculating the fire resistance of CFT columns are those included in EN 1994-1-2 [15], comprising three levels of design: a) tabulated data, b) simple calculation models and c) advanced calculation models. Option a) is available in Clause 4.2.3.4 in the form of a selection table which provides the minimum cross-sectional dimensions and reinforcement that a CFT column must have in order to achieve a rated standard fire resistance time under a certain load level. This approach is the most simplistic and its results are highly conservative as pointed out by Rush et al. [2]. Option b), simple calculation models, are the most widespread, and amongst them a full method is presented for calculating the fire resistance of composite columns in Clause 4.3.5.1 based on the elastic buckling theory. A specific method for columns composed of unprotected concrete filled hollow sections is also given in Annex $\mathrm{H}$ of the same code. Finally, advanced calculation models (option c) allow the use of finite element models capable to simulate the realistic fire behaviour of the element based on the modelling of the actual thermomechanical problem. This last approach can provide a more accurate approximation of the behaviour, but is generally out of reach of practitioners and often due to limited time or resources it is only applied to very specific design situations.

Authors as Wang [16] [17] [18], Leskela [19], Aribert et al. [20], Ribeiro et al. [21] and Espinos et al. [22] [23] have focused on the study of the simple calculation model in EC4 (option b). Because of the complexity of the specific method in Annex $\mathrm{H}$ and after having been proved that it produces unsafe results for slender columns
[16] [20], authors are more inclined to follow the general principles in Clause 4.3.5.1, which cover all types of composite columns. However, in the case of CFT columns, only a few studies have been carried out so far to investigate the applicability of the general method in Clause 4.3.5.1. The work by the CTICM group in France [20] [24] has led to the rules published in the French National Annex to EN 1994-1-2 [25]. The authors of the present paper have also carried out some previous work in this direction [23].

Several design guides have been developed on the calculation of the fire resistance of CFT columns, amongst which one can find the Corus Tubes guide [26] and the CIDECT guide [27]. In the latter of these guides, practitioners can find a number of design charts valid for the more commonly used cross-sectional dimensions, where the load bearing capacity of the column for a certain fire exposure time is given as a function of its buckling length, cross-sectional dimensions and percentage of reinforcement. Nevertheless, the number of charts available in the technical guides is limited and it would be rather desirable to have a unique and robust method which would be easy to use by designers and readily implemented in any design software.

In this paper, the current provisions of the simple calculation model in EN 1994-1-2 [15] and their modifications included in the French National Annex [25] are discussed, and by means of the results of an extensive parametric study a new proposal is presented, which improves the accuracy of the method and extends its current field of application. Appropriate values of the flexural stiffness reduction coefficients, missing in the actual version of EN 1994-1-2 for concrete filled tubular columns, are developed in this paper, as well as expressions for the equivalent temperatures of the steel tube and concrete core at different standard fire periods, which will facilitate the fire design of such columns. The proposed method is applicable to unprotected CFT columns of circular shape and filled with normal strength plain concrete. It covers a wide range of col- 
umn slenderness, with buckling lengths at elevated temperature up to $10 \mathrm{~m}$ (corresponding to relative slenderness values in fire from 0.5 to 4.5 ), diameters from 139.7 $\mathrm{mm}$ to $508 \mathrm{~mm}$ and standard fire classes from R30 to R120.

The new proposal is verified against experimental results and also compared with other methods available in the literature and which are being used worldwide [4] [6] [13], and finally a design example which illustrates the use of the method is presented.

\section{Review of existing design guidance}

\subsection{Simple calculation model in Annex $H$ of EN 1994-1-2 [15]}

Annex H (informative) of EN 1994-1-2 [15] provides a simple calculation model which is specific for concrete filled hollow sections in fire. In this Annex, it is established that the design axial buckling load can be obtained from the following equilibrium equation:

$$
N_{f i, R d}(\varepsilon)=N_{f i, c r}(\varepsilon)=N_{f i, p l, R d}(\varepsilon)
$$

where $N_{f i, R d}(\varepsilon)$ is the design value of the fire resistance of the column in axial compression, $N_{f i, c r}(\varepsilon)$ is the Euler buckling load of the column in the fire situation and $N_{f i, p l, R d}(\varepsilon)$ is the design value of the plastic resistance to axial compression of the cross-section at elevated temperature. In this method, these values correspond to a certain axial strain and therefore to a certain stress distribution within the cross-section, and need to be evaluated through an incremental procedure, until the equilibrium is found.

The procedure is based on increasing the strain in steps until $N_{f i, c r}(\varepsilon)$ and $N_{f i, p l, R d}(\varepsilon)$ are equal, subjected to the condition that the axial strain of all the components of the cross-section is the same. The instantaneous values of the stress and tangent modulus of each material for a particular temperature are used, varying with the strain level.
The CTICM group [24] conducted a numerical investigation which revealed important shortcomings of the tangent method. It was found out that Annex $\mathrm{H}$ produces fire buckling loads which lay on the unsafe side when the relative slenderness of the column at room temperature exceeds 0.4 [20]. These findings have recently led to the inclusion of an amendment to the existing Annex $\mathrm{H}$ which states that the relative slenderness of the columns should be limited to $\bar{\lambda} \leq 0.5$ for the use of the method.

The method in Annex H can only be applied to columns with buckling lengths in the fire situation $\ell_{\theta} \leq 4.5 \mathrm{~m}$, diameter of cross-section $140 \mathrm{~mm} \leq D \leq 400 \mathrm{~mm}$, concrete grades $\mathrm{C} 20 / 25-\mathrm{C} 40 / 50$ and standard fire resistance $R \leq 120 \mathrm{~min}$.

\subsection{General method for composite columns in Clause 4.3.5.1 of EN 1994-1-2 [15]}

While the method in Annex $\mathrm{H}$ has revealed to produce unsafe results for slender columns [20] and has duly been criticised because of its complexity, the general calculation method in Clause 4.3.5.1 can be used instead, as it is done for other type of composite columns. In fact, the method in Annex $G$ of the same code for partially encased steel sections follows the general rules given in Clause 4.3.5.1.

In this method, the design value of the resistance of composite columns in axial compression exposed to fire $\left(N_{f i, R d}\right)$ is calculated as:

$$
N_{f i, R d}=\chi N_{f i, p l, R d}
$$

where $\chi$ is the reduction coefficient for buckling curve "c" given in Clause 6.3.1.2 of EN 1993-1-1 [28] (obtained from the value of the relative slenderness at elevated temperature) and $N_{f i, p l, R d}$ is the design value of the plastic resistance of the cross-section to axial compression in fire.

The design value of the plastic resistance of the cross-section in fire $\left(N_{f i, p l, R d}\right)$, 
considering that the column has no reinforcement, is given by:

$$
\begin{aligned}
& N_{f i, p l, R d}=\sum_{j}\left(A_{a, \theta} f_{y, \theta}\right) / \gamma_{M, f i, a}+ \\
& +\sum_{m}\left(A_{c, \theta} f_{c, \theta}\right) / \gamma_{M, f i, c}
\end{aligned}
$$

where $A_{i, \theta}$ is the area of each element of the cross-section to which a certain temperature $\theta$ is attributed and subscripts " $a$ " and " $c$ " refer to the steel profile and concrete core, respectively. $\gamma_{M, f, i}$ are the partial factors for the materials in the fire situation.

The effective flexural stiffness of the column can be calculated through:

$$
\begin{aligned}
& (E I)_{f i, e f f}=\sum_{j}\left(\varphi_{a, \theta} E_{a, \theta} I_{a, \theta}\right)+ \\
& +\sum_{m}\left(\varphi_{c, \theta} E_{c, \sec , \theta} I_{c, \theta}\right)
\end{aligned}
$$

where $I_{i, \theta}$ is the second moment of area of each element of the cross-section to which a certain temperature $\theta$ is attributed, $\varphi_{i, \theta}$ is a reduction coefficient depending on the effect of thermal stresses and $E_{c, s e c, \theta}$ is the secant modulus of concrete at the temperature $\theta$. For composite columns with partially encased steel sections, the reduction coefficients have been defined in Annex G of EN 1994-1-2 [15]. However, for concrete filled sections, the values of these reduction coefficients still have to be established.

The flexural stiffness reduction coefficients were introduced in this formulation to account for the effect of the self-equilibrated thermal stresses caused by the non-uniform temperature distribution within the composite cross-section and the unequal thermal expansion of steel and concrete [29]. In the absence of predefined values for these coefficients, as it is the case of CFT columns, a common approach in practice is to take them as equal to unity [29]. Only few studies have been carried out so far on the suitable values of the coefficients, those of the CTICM group [20] [24] and that of the authors of this paper [23].

Once the effective flexural stiffness is calculated, the Euler buckling load in the fire situation is obtained:

$$
N_{f i, c r}=\pi^{2}(E I)_{f i, e f f} / \ell_{\theta}^{2}
$$

where $\ell_{\theta}$ is the effective length of the column at a certain temperature $\theta$.

The relative slenderness of the column at elevated temperatures is given by:

$$
\bar{\lambda}_{\theta}=\sqrt{N_{f i, p l, R} / N_{f i, c r}}
$$

where $N_{f i, p l, R}$ is the value of $N_{f i, p l, R d}$ when the material factors are taken as 1.0. This value of the relative slenderness is used to enter to the buckling curve "c", from where the reduction coefficient $\chi$ needed for determining the buckling load is finally obtained.

\subsection{French National Annex to EN 1994-1-2 [25]}

The French National Annex to EN 1994-1-2 (NF EN 1994-1-2/NA) [25] is based on the general method described in Clause 4.3.5.1 of EN 1994-1-2 [15]. In this National Annex, specific values for the flexural stiffness reduction coefficients have been included to account for the effect of the differential thermal stresses within the composite cross-section. These values are a result of an extensive parametric investigation carried out at the CTICM [24]. For the concrete core, a reduction coefficient of 0.8 is specified, resulting in $\varphi_{c, \theta}=1.2$, which includes implicitly the use of the initial tangent modulus of concrete (calculated as 3/2 times the secant modulus, therefore $0.8 \times 3 / 2=1.2$ for direct application over the secant modulus), while for the steel hollow section the value of the reduction coefficient $\varphi_{a, \theta}$ depends on the fire duration and the size $(B$ 
or $D$ ) of the steel section, according to Clause 4(2) of NF EN 1994-1-2/NA.

The method included in the French National Annex establishes also specific buckling curves with a discontinuity at a certain value of the relative slenderness, called the "transition relative slenderness". This transition value is dependent on the fire exposure time, and is equal to 1.0 for R 30 and 1.35 for R60 in the case of unreinforced columns. Before reaching the transition value, the buckling curve follows the shape of the EN 1993-1-1 [28] curves but with a different imperfection factor for the different fire periods $(\alpha=0.21$ for $\mathrm{R} 30$ and $\alpha=0.265$ for R60). For relative slenderness values above the transition slenderness, the method makes use of specific buckling curves.

The French method is limited to buckling lengths in the fire situation $\ell_{\theta} / D \leq 30$, concrete grades $\mathrm{C} 20 / 25$ - C60/75, $D \leq 610$ $\mathrm{mm}$, and for centrally loaded unreinforced CFT columns a minimum dimension is required depending on the fire resistance class: $D>100 \mathrm{~mm}$ for R30 and $D>150 \mathrm{~mm}$ for R60. For unreinforced columns longer fire resistance times cannot be evaluated by this method, since a minimum percentage of reinforcement is required for achieving a R90 or higher fire resistance class.

\subsection{Simplified design equation proposed by Kodur [6] [8]}

Kodur [6] [8] proposed a simplified equation based on the results of parametric studies supported by an experimental program carried out in the Institute for Research in Construction, NRCC (Canada) [30] on circular and square concrete filled tubular columns under fire. This approach is used in the United States and Canada after having been incorporated into several building codes [9], [10], [11] and design guides [12].

Kodur's design equation directly provides the fire resistance time of the column in minutes as a function of different parameters such as the concrete strength, the column diameter and effective length, the type of concrete filling, cross-sectional shape and percentage of steel reinforcement.

The fire resistance time of a column can be evaluated by the following equation as a function of the different parameters:

$$
R=f \frac{f_{c}+20}{\ell_{\theta}-1000} D^{2} \sqrt{\frac{D}{N}}
$$

where $R$ is the fire resistance time in minutes, $f_{c}$ is the concrete strength at the age of 28 days in $\mathrm{MPa}, D$ is the outside diameter of the column in $\mathrm{mm}$ (also applicable to square columns if the width is used instead), $N$ is the applied load in $\mathrm{kN}, \ell_{\theta}$ is the effective buckling length of the column in $\mathrm{mm}$ and $f$ is a coefficient which includes the effect of the rest of the parameters, given in [6]. This coefficient is tabulated as a function of the type of concrete filling (plain, bar-reinforced or fibre-reinforced concrete), the type of aggregate used (carbonate or siliceous), the percentage of reinforcement, the thickness of the concrete cover, and the cross-sectional shape of the column (circular or square).

The applicability of equation (7) is limited to $f_{c}=20-40 \mathrm{MPa}, D=140-410 \mathrm{~mm}$, $R \leq 120 \mathrm{~min}$ and $\ell_{\theta}=2000-4000 \mathrm{~mm}$ for columns without any reinforcement. Therefore, the method cannot be applied to columns with a high slenderness.

\subsection{Strength index formulation proposed by Han [4]}

Han and co-workers [4] proposed a formulation which makes possible to determine the strength index (SI) of CFT columns based on the results of parametric and experimental studies carried out at the Tianjin Fire Research Institute (China). The formulation was obtained by using regression analysis, and is valid for circular hollow steel columns without fire protection, filled with plain concrete. Also columns with external fire protection were investigated, and the design equations developed were incorporated in the Chinese code DBJ13-51 [3]. 
For simplicity, the formulation of the method has not been transcribed here, but it can be found in [4]. The validity limits of Han's design equation are: $t \leq 180 \mathrm{~min}, D=$ $150-2000 \mathrm{~mm}, f_{y}=200-500 \mathrm{MPa}, f_{c}=20-$ $60 \mathrm{MPa}$ and $\lambda=15-80$ (slenderness ratio defined here as $\lambda=4 L / D$ ).

\subsection{Fire resistance design formula used in Japan [13]}

The actual state of the fire design codes in Japan was reviewed by Harada [14]. Regarding concrete-filled steel tubular columns, the Association of New Urban Housing Technology (ANUHT) in Japan published a design guide manual [13] where a simple equation for obtaining the ultimate load of the column under a certain fire period can be found. For circular columns, the expression is as follows:

$$
\frac{N_{f i, R d}}{A_{c} f_{c}}=\left(5.75 \cdot 10^{-5} \cdot f_{c}^{2.63} \cdot t+1\right)^{-0.214}
$$

where $A_{c}$ is the cross-sectional area of concrete in $\mathrm{mm}^{2}, f_{c}$ is the specified 28 day concrete strength in MPa and $t$ is the fire resistance time in minutes.

\section{Numerical model and parametric studies}

\subsection{Description of the numerical model}

A previously validated numerical model developed by the authors with the finite element analysis package ABAQUS [31] is available. This model is capable to simulate with enough accuracy the fire behaviour of slender concrete filled circular hollow section columns. The details of the model and its validation process are described in [22], where the numerical model was validated against fire tests available in the literature [30]. The average value of the error in the predictions of the fire resistance time, evaluated as test/prediction, was 1.08 with a standard deviation equal to 0.19 . The range of diameters analysed is this validation stage varied between $141.3 \mathrm{~mm}$ and $273.1 \mathrm{~mm}$, and the room temperature relative slenderness of the columns ranged from 0.29 to 0.98 . Recently, a second validation stage of the model was carried out against fire tests performed by the own authors [32], where columns with high relative slenderness and different types of concrete infill were analysed. In this second validation stage, for those columns filled with normal strength concrete, an average error in the predictions equal to 1.09 was obtained, with a 0.16 standard deviation. The cross-sectional dimensions of the columns were constant in this case, while the concrete grade, reinforcement type and load level were varied. The room temperature relative slenderness of the columns tested in this experimental research ranged from 0.61 to 0.88 .

By means of the numerical model, a sequentially coupled thermal-stress analysis can be performed. First, a pure heat transfer analysis is conducted for computing the temperature evolution along the column and afterwards a stress/deformation analysis is run for calculating the structural response. Nodal temperatures are stored as a function of time in the heat transfer analysis results and then read into the stress analysis as a predefined field.

The standard ISO-834 [33] fire curve is applied to the exposed surface of the CFT column specimens as a thermal load, through the convection and radiation heat transfer mechanisms. The values recommended in EN 1991-1-2 [34] are used for the main heat transfer parameters. The entire length of the columns is considered to be exposed to the fire. The thermal resistance at the boundary between the steel tube and the concrete core is taken into account through a gap conductance value of $200 \mathrm{~W} / \mathrm{m}^{2} \mathrm{~K}$, as was used in previous investigations [22]. It was proved through a sensitivity analysis that, despite it is known that the gap clearance size and therefore the thermal resistance at the steelconcrete interface vary during the evolution of the fire, a constant value can be assumed obtaining satisfactory results. 
Once the thermal problem is solved, a nonlinear stress analysis is subsequently conducted, accounting for the previously calculated nodal temperature-time curves.

The numerical model takes into account an initial out-of-straightness of the columns equal to $L / 1000$, which is a result of a sensitivity analysis carried out in previous investigations [22]. Pin-ended boundary conditions are considered. Owing to symmetry of both the geometry and the boundary conditions, only a quarter of the column needs to be modelled. Fig. 1 shows the finite element mesh for one of the column specimens analysed.

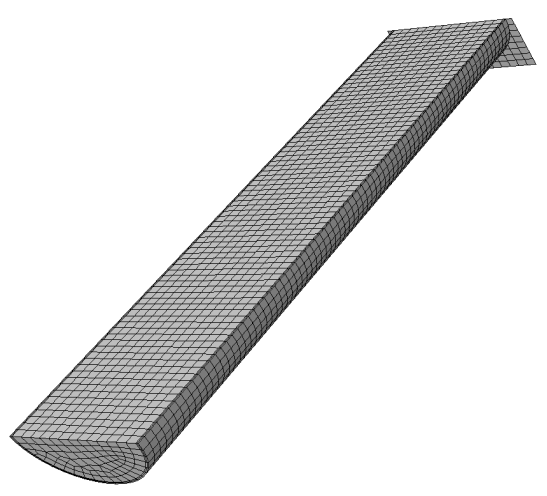

Fig. 1. Finite element mesh of the model for one of the columns analysed.

The steel tube and concrete core are meshed using three-dimensional eight-noded solid elements, with a maximum element size of $20 \mathrm{~mm}$, which had been proved to be sufficient to predict with enough accuracy the fire behaviour of CFT columns [22]. The steel end plate is modelled as a discrete rigid part with all nodes coupled to a reference point, located at the column axis. The axial load is applied to the rigid plate through its reference node and maintained constant during the fire history. The rigid plate is meshed using four-noded three-dimensional bilinear rigid quadrilateral elements, with a maximum element size of $20 \mathrm{~mm}$.

The selected material models are a result of an extensive sensitivity analysis carried out in previous research [22]. For concrete, the stress-strain curves at elevated temperatures proposed by Lie [35] are employed. The high temperature thermal properties for concrete are taken from EN 19921-2 [36], except for the thermal expansion coefficient, which is given a value of $\alpha_{c}=$ $6 \times 10^{-6}{ }^{\circ} \mathrm{C}^{-1}$ as recommended by Hong and Varma [37] and subsequently verified by the authors in the sensitivity analysis [22]. For structural steel, the temperature dependent thermal and mechanical properties recommended in EN 1993-1-2 [38] are adopted. A moisture content of $3 \%$ in concrete weight is considered in this research, which is taken into account through a peak value of 2020 $\mathrm{J} / \mathrm{kgK}$ in the specific heat formulation of concrete.

\subsection{Parametric studies}

Parametric studies were performed by means of the numerical model described in the previous section. The main parameters affecting the buckling resistance of unreinforced CFT columns at elevated temperatures were investigated through these parametric studies. The parameters studied are the outer diameter of the column $(D)$, the thickness of the steel tube wall $(t)$, the relative slenderness of the column at room temperature $(\bar{\lambda})$ and the standard fire period $(R)$, widely covering the range of values which can be found in practice. A summary of the cases analysed in this parametric study is shown in Table 1 . 
Table 1. Summary of the analysis cases in the parametric studies

\begin{tabular}{ccccccc}
\hline Variable & \multicolumn{5}{c}{ Specified values } \\
\hline$D(\mathrm{~mm})$ & 139.7 & 193.7 & 273 & 323.9 & 406.4 & 508 \\
$t(\mathrm{~mm})$ & $3.2 ; 12.5$ & $5 ; 16$ & $5 ; 16$ & $6.3 ; 16$ & $8 ; 16$ & $10 ; 16$ \\
$\bar{\lambda}$ & \multicolumn{5}{c}{$0.3 ; 0.5 ; 1 ; 1.5 ; 2$} \\
$R(\mathrm{~min})$ & $30 ; 60 ; 90 ; 120$ \\
\hline
\end{tabular}

The composite sections analysed in this parametric study considered a steel yield strength of $355 \mathrm{MPa}$ as most commonly used, and concrete compressive strength of $30 \mathrm{MPa}$, since this study is limited to normal strength concrete. Six different circular section sizes of commercially available dimensions were employed: 139.7, 193.7, 273, $323.9,406.4$ and $508 \mathrm{~mm}$. For each diameter, two steel tube wall thicknesses were selected: the minimum and maximum commercially available values, although it is noteworthy that the minimum thickness was chosen as the first value which produced a class 3 section (thin-walled sections were not included in this study). For each crosssection, five different column lengths were used, corresponding to slenderness values at room temperature of $0.3,0.5,1,1.5$ and 2 . The relative slenderness values of the columns at room temperature were calculated in accordance with Clause 6.7.3.3 of EN 19941-1 [39] assuming hinged end conditions. The influence of enhanced concrete confinement was not considered in the room temperature calculations.

The maximum slenderness analysed for each cross-section was selected in such a way that the associated buckling length of the column did not exceed 10 meters, in order to reduce the computational cost of this study. Therefore, the combinations of diameters and member slenderness were as follows: $D=139.7 \mathrm{~mm}(\bar{\lambda}=0.3,0.5,1,1.5$, 2); $D=193.7 \mathrm{~mm}(\bar{\lambda}=0.3,0.5,1,1.5,2) ; D$ $=273 \mathrm{~mm}(\bar{\lambda}=0.3,0.5,1,1.5) ; D=323.9$ $\mathrm{mm}(\bar{\lambda}=0.3,0.5,1) ; D=406.4 \mathrm{~mm}(\bar{\lambda}=$ $0.3,0.5,1) ; 508 \mathrm{~mm}(\bar{\lambda}=0.3,0.5)$.
For each column, four different standard fire resistance classes were considered: $30,60,90$ and 120 minutes (hereafter referred to as R30, R60, R90 and R120), which are the common values prescribed in the design codes. Each column specimen employed a different combination of the specified values of the variables shown in Table 1. In total, the number of specimens analysed in this parametric study was 176 .

The procedure employed in this research to calculate the buckling resistances which correspond to the different fire exposure times analysed (30, 60, 90 and 120 minutes) was as follows. In a first step, the fire resistance time of the column was obtained by means of the numerical model under several values of the applied axial load (in general, 10 different values were used), so as to be able to build up a curve of the evolution of the buckling load versus the fire exposure time. In a second step, the value of the buckling load corresponding to the desired standard time (R30, R60, R90 or R120) was obtained from this curve by using linear interpolation. Special care was taken in the vicinity of the standard fire times, where the curve was refined, so that the error in the interpolation was minimum.

Fig. 2 explains graphically the process followed for obtaining the buckling resistance of a column at the specified standard fire times. As can be seen, this procedure requires an elevated number of calculations to perform for each column specimen, which limits the extension of this parametric analysis. 


\subsection{Analysis of results}

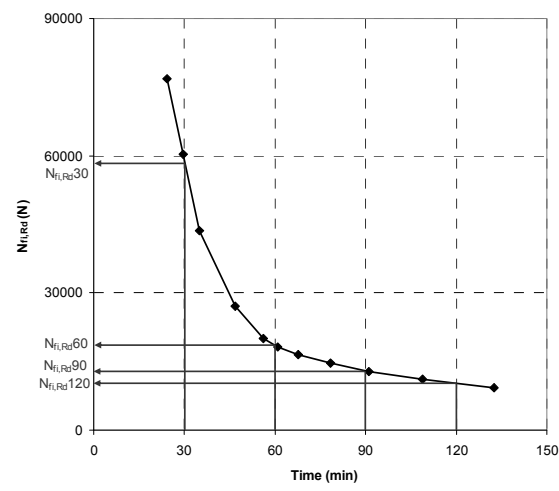

Fig. 2. Process for obtaining the buckling resistance of the columns at the different standard fire periods.
From the results of all the calculations performed in the parametric studies, the numerical buckling coefficient was computed. It was defined as the column axial buckling resistance obtained from the numerical simulation divided by the design value of the cross-sectional plastic resistance, both in the fire situation: $\chi^{N U M}=N_{f i, R d}{ }^{N U M} / N_{f i, p l, R d}$. This value was plotted against the relative slenderness at elevated temperature $\bar{\lambda}_{\theta}$, calculated as described in Section 2.2 and using reduction coefficients equal to unity. Fig. 3 shows the results for all the columns analysed in this research, were buckling curve "c" has been superimposed for comparison purposes.

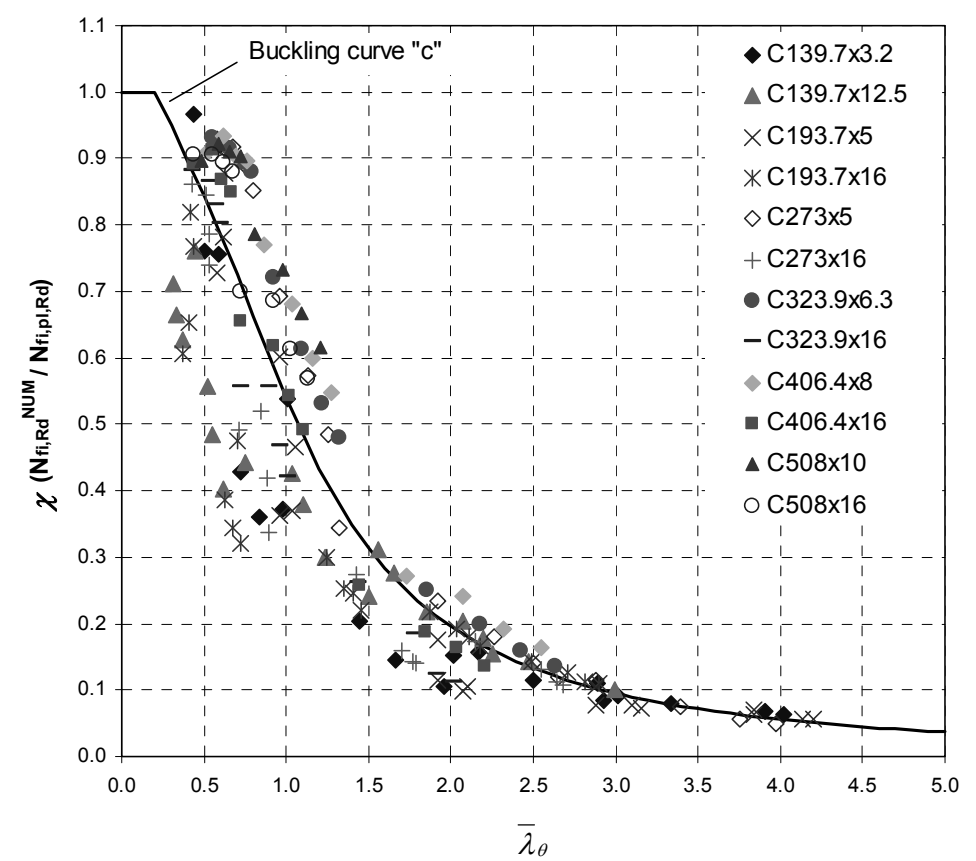

Fig. 3. Evolution of the buckling coefficient with the relative slenderness at elevated temperature (neglecting the flexural stiffness reduction coefficients). 
Another important aspect can be observed from Fig. 3. In the range of low slenderness, for each diameter of the columns analysed, the buckling coefficient $\chi$ of the columns with the maximum wall thickness of the tube (reduced $D / t$ values) appeared to be smaller than the $\chi$ values of the columns with the minimum wall thickness and thus having a higher $D / t$; e.g. the points for columns of $406.4 \times 16 \mathrm{~mm}$ section lie below the points corresponding to columns of $406.4 \times 8$ $\mathrm{mm}$ section). This result was more evident in stocky columns ( $\bar{\lambda} \leq 0.5$ ), while for slender columns the difference was not so clear. It is worth noting that this phenomenon was found when comparing buckling coefficients (where the buckling load is referred to the cross-sectional plastic resistance) and not with the absolute value of the buckling load, which resulted generally in higher values for the columns with a higher steel tube wall thickness.

The explanation of this may reside in the fact that for a given section size, lower thicknesses of the steel tube wall allow more quantity of concrete to fill the column and thus contributing to delay its heating and as a consequence being able to sustain a higher load. This behaviour holds true for this particular range of columns, where the fire response is highly influenced by the amount of concrete filling. However, the more slender columns show the inverse response, since their failure is initiated by the local buckling of the steel tube at an early stage when it is still sustaining the load without the contribution of the concrete core. The slenderness of the unfilled steel tube (and thus its thickness) is therefore a relevant factor in this case, whereas the amount of concrete filling does not play an important role here. This phenomenon was already addressed in previous numerical investigations carried out by the authors [23] and other groups [8], and has also been observed in real fire tests [30].

\section{Study and discussion of Eurocode 4 Part 1.2}

On the basis of the results of the parametric studies presented above, a comparison is done in this section between the current calculation methods available in the Eurocode 4 Part 1.2 [15] for CFT columns. Four different approaches will be studied (see sections 2.1, 2.2, 2.3 from this paper): Clause 4.3.5.1 with flexural stiffness reduction coefficients equal to unity (EC4(1)), Clause 4.3.5.1 with the reduction coefficients proposed by Aribert et al. [20] (EC4(2)), Annex H (EC4(H)), and French National Annex [25] (EC4(NF)). For each method, the numerical temperature field obtained at the standard fire resistance classes (R30, R60, R90 and R120 minutes) was applied, and following the code provisions the buckling load was calculated.

Fig. 4 shows a comparison between the predictions and the numerical simulations in terms of normalised buckling load (divided by the theoretical cross-sectional plastic resistance).

Fig. 5 plots the relative error of the predictions $\xi$ against the relative slenderness of the columns at room temperature, for each of the design approaches studied. The relative error was computed as follows:

$\xi=1-\frac{N_{f i, R d}^{P R E D}-N_{f i, R d}^{N U M}}{N_{f i, R d}^{N U M}}$

where $N_{f i, R d}{ }^{P R E D}$ is the predicted buckling resistance with the calculation method employed and $N_{f i, R d} N U M$ is the numerical simulation result, which here is taken as the reference value. Therefore, values greater than 1 mean safe predictions, while values lower than 1 mean unsafe predictions. 
a)

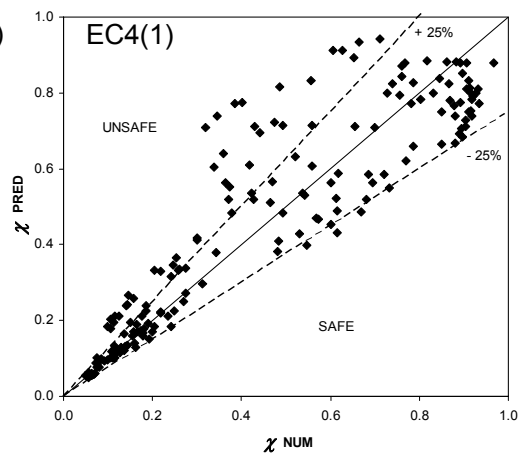

c)

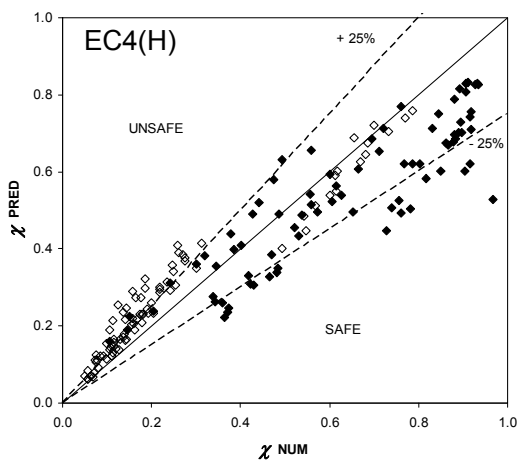

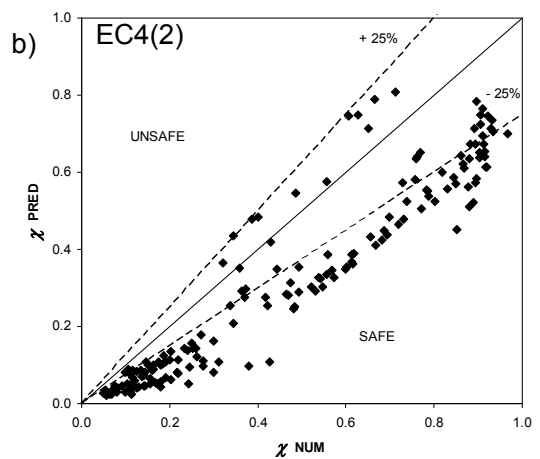

d)

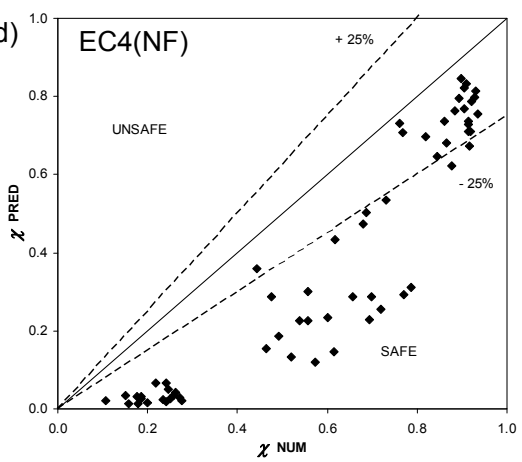

Fig. 4. Comparison between the different approaches studied in terms of the normalised buckling resistance: a) EC4(1), b) EC4(2), c) EC4(H), d) EC4(NF).

As can be seen in Fig. 4a and Fig. 5a, EC4(1) yields unsafe results with a high dispersion of values for all the range of slenderness studied, except for $\bar{\lambda}=2$, when the predictions become safe and the dispersion is much lower. Therefore, to neglect the flexural stiffness reduction coefficients when applying Clause 4.3.5.1 of EC4 to CFT columns produces inadmissible errors. Nevertheless, when the French coefficients are used in combination with Clause 4.3.5.1, Fig. 4b and Fig. 5b (EC4(2)), safe results are obtained in all the range of slenderness studied (except for some cases with $\bar{\lambda} \leq 0.5$ ), but with high errors and an elevated dispersion of results. As the slenderness is increased, the predictions become safer but the errors produced by this method are higher. Annex $\mathrm{H}$ predictions $(\mathrm{EC} 4(\mathrm{H}))$ turn from safe at low slenderness $(\bar{\lambda}=0.3)$ to unsafe for intermediate slenderness $(\bar{\lambda}=0.5-1.5)$ and close to the reference value again at $\bar{\lambda}=$ 2, Fig. $4 \mathrm{c}$ and Fig. 5c. This confirms the results from the CTICM group [20] [24], who found that the method in Annex $\mathrm{H}$ is unsafe for slenderness values over 0.4. Note that in these two figures, those cases which are out of the applicability limits of Annex H (buckling length $>4.5 \mathrm{~m}$ ) have been plotted with an empty mark. The magnitude of the error produced by Annex $\mathrm{H}$ is lower, but still leading to high errors, which in most of the cases are over a $25 \%$. Finally, EC4(NF) produces safe results for all the cases analysed, but 
with a high error which increases with the slenderness, Fig. 4d and Fig. 5d. Note that the number of points plotted in these two last figures is lower, since some column specimens are out of the applicability limits of the

a)

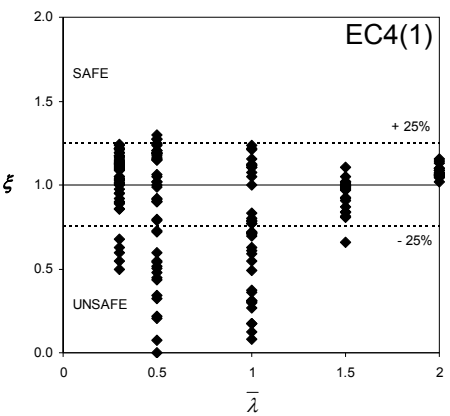

c)

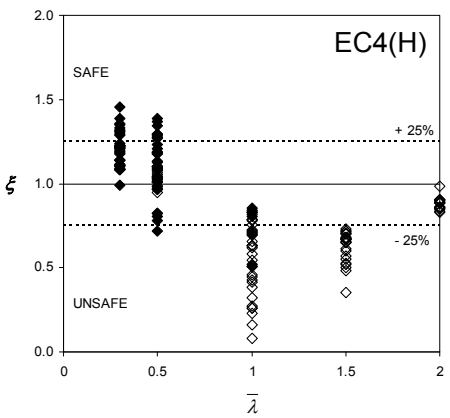

French method (only R30 and R60 are allowed for unreinforced columns).

The results obtained in this section confirm and extend the conclusions drawn by the authors in previous research [23].

b)

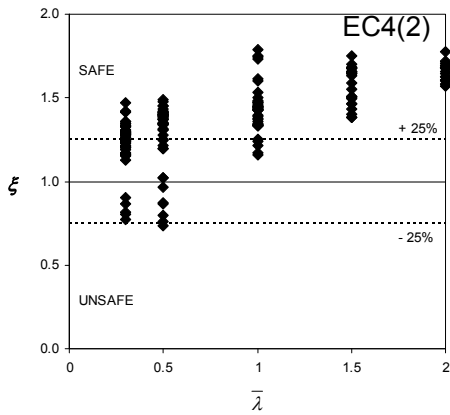

d)

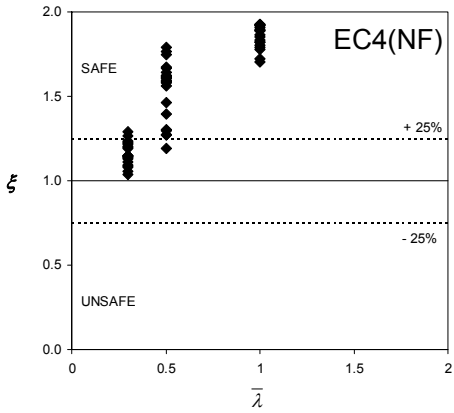

Fig. 5. Evolution of the prediction errors with the relative slenderness of the columns, for the different approaches studied: a) EC4(1), b) EC4(2), c) EC4(H), d) EC4(NF).

\section{Development of a new simple calculation model for axially loaded concrete filled tubular columns}

\subsection{Simplified cross-sectional temperature field}

In both Annex $\mathrm{H}$ and Clause 4.3.5.1 of EN 1994-1-2 [15] it is required that the designer obtains the cross-sectional temperature field in the composite cross-section after a given duration of fire exposure prior to ap- plying the method to calculate the design axial buckling load. Nevertheless, no simplified method for the temperature evaluation is given in the code which helps the designer obtain easily this temperature field. In order to help practitioners in the future, a simple method for evaluating the temperature field within the cross-section of a CFT column of any dimensions is proposed here.

It would be desirable to obtain a uniform equivalent temperature for the whole concrete core $\left(\theta_{c, e q}\right)$ and another one for the steel tube $\left(\theta_{a, e q}\right)$ so as to obtain the same fire 
resistance of the column as by using the real non-uniform temperature distribution. This approach is already used in Annex G of EN 1994-1-2 [15] for composite columns with partially encased steel sections. The benefit of this approach is that the designer can evaluate the fire resistance of the column by using a single strength and stiffness value for each component of the composite crosssection corresponding to its temperature. A calculation procedure was proposed by Leskela [19], whose recommendations are followed hereafter.

\section{Calculation of the equivalent temperature for the concrete core}

The concrete cross-section is subdivided in a number of $n$ layers, being $A_{c, \theta, i}$ the area of a particular layer $i$ at the temperature $\theta$ and $I_{c, \theta, i}$ the second moment of area of that same layer. The equivalent temperature representing the whole concrete core can be found through two different approaches:

a) Plastic resistance approach

The plastic resistance to axial compression of the concrete core in the fire situation is equal to:

$$
\begin{aligned}
& N_{f i, p l, R d, c}=\sum_{i=1}^{n}\left(A_{c, \theta, i} f_{c, \theta, i}\right)= \\
& =\sum_{i=1}^{n}\left(A_{c, \theta, i} k_{c, \theta, i} f_{c}\right)= \\
& =f_{c} \sum_{i=1}^{n}\left(A_{c, \theta, i} k_{c, \theta, i}\right)
\end{aligned}
$$

A single equivalent temperature is needed, which produces the same plastic resistance through its corresponding reduction factor when applied to the whole concrete core:

$$
\begin{aligned}
& N_{f i, p l, R d, c}=f_{c} \sum_{i=1}^{n}\left(A_{c, \theta, i} k_{c, \theta, i}\right)= \\
& =k_{c, \theta}\left(\theta_{c, e q 1}\right) f_{c} A_{c} \rightarrow \\
& \rightarrow k_{c, \theta}\left(\theta_{c, e q 1}\right)=\frac{\sum_{i=1}^{n}\left(A_{c, \theta, i} k_{c, \theta, i}\right)}{A_{c}}
\end{aligned}
$$

Once this reduction coefficient is calculated, the equivalent temperature $\theta_{c, e q I}$ representing the whole concrete core can be found through Table 3.3 in EN 1994-1-2 [15] by using linear interpolation.

b) Flexural stiffness approach

The flexural stiffness of the concrete core in the fire situation is equal to:

$$
\begin{aligned}
& (E I)_{f i, c}=\sum_{i=1}^{n}\left(E_{c, \sec , \theta, i} I_{c, \theta, i}\right)= \\
& =\sum_{i=1}^{n}\left(\frac{f_{c, \theta, i}}{\varepsilon_{c u, \theta, i}} I_{c, \theta, i}\right)= \\
& =\frac{f_{c}}{\varepsilon_{c u}} \sum_{i=1}^{n}\left(\frac{k_{c, \theta, i}}{\frac{\varepsilon_{c u, \theta, i}}{\varepsilon_{c u}}} I_{c, \theta, i}\right)= \\
& =E_{c, \sec } \sum_{i=1}^{n}\left(k_{E c, \theta, i} I_{c, \theta, i}\right)
\end{aligned}
$$

with $k_{E c, \theta, i}=k_{c, \theta, i} \varepsilon_{c u} / \varepsilon_{c u, \theta, i}$.

It is required to obtain an equivalent temperature which produces the same flexural stiffness through its corresponding reduction factor when applied to the whole concrete core: 


$$
\begin{aligned}
& (E I)_{f i, c}=E_{c, \sec } \sum_{i=1}^{n}\left(k_{E c, \theta, i} I_{c, \theta, i}\right)= \\
& =k_{E c, \theta}\left(\theta_{c, e q 2}\right) E_{c, \sec } I_{c} \rightarrow \\
& \rightarrow k_{E c, \theta}\left(\theta_{c, e q 2}\right)=\frac{\sum_{i=1}^{n}\left(k_{E c, \theta, i} I_{c, \theta, i}\right)}{I_{c}}
\end{aligned}
$$

Once this coefficient is calculated, the equivalent temperature $\theta_{c, e q 2}$ representing the whole concrete core can be found through Table 3.3 in EN 1994-1-2 [15] by using linear interpolation and considering $k_{E c, \theta}=k_{c, \theta} \varepsilon_{c u} / \varepsilon_{c u, \theta}$.

Conservatively, the equivalent temperature of the concrete core will be defined as the maximum of the temperatures obtained through the two approaches described above:

$$
\theta_{c, e q}=\max \left\{\theta_{c, e q 1}, \theta_{c, e q 2}\right\}
$$

The previous procedure was applied to the different cross-sections used in the parametric studies, for which the temperature field had been calculated by means of the numerical model. The diameters studied covered a wide range of section factor values (from 7.87 to 28.63). In this research, the number of layers $n$ within the concrete crosssection was chosen in such a way that the width of the individual layers did not exceed $20 \mathrm{~mm}$. Therefore, as the diameter of the column increases, a higher number of layers is required. The equivalent temperature of the concrete core was obtained for four different standard fire resistance classes: R30, R60, R90 and R120. The evolution of the equivalent temperature of the concrete core with the section factor of the columns is plotted in Fig. 6. As expected, as the fire exposure time increases, the equivalent temperatures also increase. The equivalent temperatures are also affected by the section factor of the columns, reaching higher values for those columns with higher section factors (i.e. small diameters), which expose a relatively high surface to the fire for the same volume and thus heat up faster. For each section factor and fire period, two points are plotted, corresponding to the two different steel tube wall thicknesses analysed. It can be observed that no significant influence is obtained with a change in the steel tube wall thickness, and therefore this parameter will not be taken into account in the development of the equivalent temperature proposal.

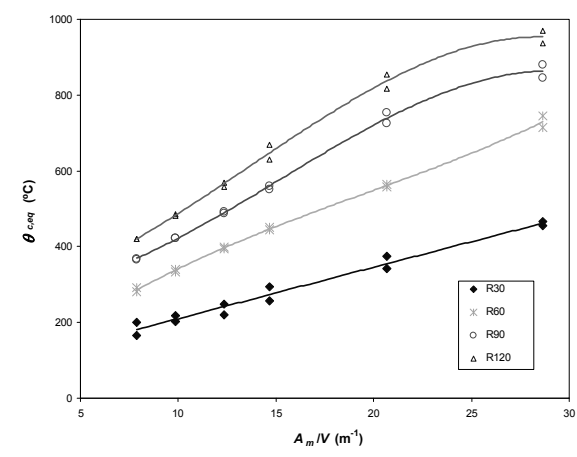

Fig. 6. Evolution of the equivalent temperature of the concrete core with the section factor, for the standard fire resistance classes.

For each of the standard fire resistance classes studied, a regression curve was fitted to the data, as can be seen in Fig. 6. With the aid of the regression equations, a selection chart was built up (Table 2) to facilitate designers obtain the equivalent temperature of the concrete core for a particular fire period directly from the value of the section factor of the column. For intermediate values of the section factor, linear interpolation can be used. Note that the section factor of a circular CFT column is calculated as $4 / D\left(\mathrm{~m}^{-1}\right)$. 
Table 2. Values of the equivalent temperatures for concrete $\left(\theta_{c, e q}\right)$ and steel $\left(\theta_{a, e q}\right)$ in function of the section factor

\begin{tabular}{|c|c|c|c|c|c|c|c|c|c|}
\hline & \multicolumn{2}{|c|}{ R30 } & \multicolumn{2}{|c|}{ R60 } & \multicolumn{2}{|c|}{ R90 } & \multicolumn{2}{|c|}{ R120 } \\
\hline & & $\theta_{c, e q}\left({ }^{\circ} \mathrm{C}\right)$ & $\theta_{a, e q}\left({ }^{\circ} \mathrm{C}\right)$ & $\theta_{c, e q}\left({ }^{\circ} \mathrm{C}\right)$ & $\theta_{a, e q}\left({ }^{\circ} \mathrm{C}\right)$ & $\theta_{c, e q}\left({ }^{\circ} \mathrm{C}\right)$ & $\theta_{a, e q}\left({ }^{\circ} \mathrm{C}\right)$ & $\theta_{c, e q}\left({ }^{\circ} \mathrm{C}\right)$ & $\theta_{a, e q}\left({ }^{\circ} \mathrm{C}\right)$ \\
\hline \multirow{6}{*}{$\begin{array}{l}A_{m} / V \\
\left(\mathrm{~m}^{-1}\right)\end{array}$} & 5 & 141 & 636 & 197 & 857 & 316 & 957 & 344 & 1013 \\
\hline & 10 & 210 & 652 & 342 & 869 & 422 & 964 & 487 & 1018 \\
\hline & 15 & 278 & 669 & 453 & 880 & 571 & 971 & 659 & 1024 \\
\hline & 20 & 346 & 686 & 549 & 891 & 721 & 978 & 819 & 1030 \\
\hline & 25 & 413 & 703 & 647 & 903 & 831 & 985 & 928 & 1035 \\
\hline & 30 & 480 & 719 & 764 & 914 & 860 & 992 & 947 & 1041 \\
\hline
\end{tabular}

It is worth noting that the temperatures close to $1000^{\circ} \mathrm{C}$ which are obtained at $\mathrm{R} 120$ for the smaller diameters (high section factors) are only indicative, nevertheless they cannot be reached in practice, since they would correspond to columns loaded at a very low level.

$\theta_{c, e q}=-186.44+5.764 R-0.026 R^{2}+22.577 A_{m} / V-0.32\left(A_{m} / V\right)^{2}+0.14 R \cdot A_{m} / V$

\section{Calculation of the equivalent temperature for the steel tube}

In the case of the steel tube, the equivalent temperature corresponding to each of the columns for a standard fire time was obtained directly from the numerical analysis without the need of employing the procedure described above, since its temperature remains almost uniform through the wall thickness for each fire period.

The equivalent temperatures for the steel tube $\left(\theta_{a, e q}\right)$ have been included in Table 2 , for the different values of the section fac-
A unique equation for the equivalent temperature of concrete valid for any fire resistance period was also developed by using a multiple nonlinear regression analysis, which includes the effect of $A_{m} / V$ and $R$ :

This equation can be used as an alternative to the selection chart.

$$
\theta_{a, e q}=342.1+10.77 R-0.044 R^{2}+3.922 A_{m} / V-0.025 R \cdot A_{m} / V
$$

\subsection{Flexural stiffness reduction coefficients}

The applicability of the general principles in Clause 4.3.5.1 of EC4 [15] has been studied in Section 4 by comparing the predictions of the method (with some assumptions regarding the reduction coefficients) to the results obtained by means of the numeri- tor and the four standard fire resistance classes. For intermediate values of the section factor, linear interpolation can be used.

An alternative equation for the equivalent temperature of the steel section was developed by using a multiple nonlinear regression analysis, including the effect of $A_{m} / V$ and $R$ and therefore valid for any fire resistance period:

The temperature obtained through this equation can be used instead of the one obtained by means of the selection chart.

cal model. It has been revealed that the predicted buckling loads result in most cases unsafe when the reduction coefficients are assumed to be equal to unity, which confirms the findings of previous work [22] [23]. 
Thus, a set of flexural stiffness reduction coefficients different to unity should be applied. Also the buckling curve should be revised as suggested by other authors [17] [19] [20].

Through the results of the parametric studies presented in this paper, the values of these coefficients will be derived for the standard fire exposure times. The procedure employed to calculate the theoretical values of the coefficients is described next.

In what follows, the value of the concrete flexural stiffness reduction coefficient will be taken as $\varphi_{c, \theta}=0.8$ and the initial tangent stiffness will be used (calculated as $3 / 2$ times the secant modulus), as the researchers from CTICM [20] [24] proposed. In fact, the value of 0.8 is already being used in Annex $\mathrm{G}$ of EN 1994-1-2 for composite columns with partially encased steel sections. If the secant modulus of concrete is used, as it is specified in Clause 4.3.5.1 of EN 1994-1-2, the coefficient $\varphi_{c, \theta}$ should be taken as 1.2. This value accounts for the effect of the differential thermal stresses produced by the unequal temperature field along the width of the concrete cross-section, which other authors have reported in their research [16] [20] [40]. The reduction coefficient for the steel tube will be then derived from the numerical data and assuming the concrete contribution to be known.

By means of the numerical simulations results, the buckling coefficient corresponding to each column is obtained as the computed buckling resistance divided by the theoretical cross-sectional plastic resistance at the time of failure.

$$
\chi^{N U M}=\frac{N_{f i, R d}{ }^{N U M}}{N_{f i, p l, R d}}
$$

Once the buckling coefficient $\chi^{N U M}$ is calculated, the relative slenderness of the column at elevated temperature $\bar{\lambda}_{\theta}{ }^{N U M}$ can be obtained from the corresponding buckling curve (here, buckling curve "a" was used, since it showed to produce a better fit to the data). With this value, the elastic critical load in the fire situation can be derived from equation (6):

$$
N_{f i, c r}{ }^{N U M}=\frac{N_{f i, p l, R}}{\left(\bar{\lambda}_{\theta} N U M\right)^{2}}
$$

where $N_{f i, p l, R}$ can be calculated with equation (3).

Buckling curve "a" was not chosen for the elevated temperature design by chance; in fact this curve was selected as an intend of using the same buckling curve as in the main part of Eurocode 4 for room temperature design (EN 1994-1-1 [39]), which employs buckling curve "a" for CFT columns with a percentage of reinforcement under a $3 \%$. As later on will be demonstrated, this buckling curve provided a better fit to the analysis data. Wang [17] also defended the use of column buckling curve "a" instead of "c" on his work, proving that more accurate results were obtained when using the elevated temperature material models in the main text of Eurocode 4 Part 1.2 [15].

Using now the definition of the Euler buckling load (equation 5), the numerical value of the effective flexural stiffness of the column in the fire situation can be determined:

$$
\begin{aligned}
& (E I)_{f i, e f f}{ }^{N U M}=\frac{N_{f i, c r}{ }^{N U M} \cdot \ell_{\theta}^{2}}{\pi^{2}}= \\
& =\sum_{j}\left(\varphi_{a, \theta} E_{a, \theta} I_{a, \theta}\right)+ \\
& +\sum_{m}\left(\varphi_{c, \theta} E_{c, \theta} I_{c, \theta}\right)
\end{aligned}
$$

which is set equal with the summation of the contribution of the different layers.

Through this value and being known $E_{a, \theta} I_{a, \theta}$ for the steel tube layers and $E_{c, \theta} I_{c, \theta}$ for the different layers within the 
concrete core, the reduction coefficient for steel can be obtained, provided that a fixed value is assigned to the reduction coefficient of concrete, which here was equalled to 0.8 , and considering only one layer in the steel tube wall.

$$
\varphi_{a, \theta}=\frac{(E I)_{f i, e f f}{ }^{N U M}-\sum_{m}\left(\varphi_{c, \theta} E_{c, \theta} I_{c, \theta}\right)}{E_{a, \theta} I_{a, \theta}}
$$

Following this procedure, the numerical value of the steel flexural stiffness reduction coefficient was obtained for each of the columns analysed in the parametric study. Through a statistical study of the values obtained, it became clear that this coefficient is a complex function of the different variables that interact in the problem, such as the member slenderness (trough $\bar{\lambda}$ or $\ell_{\theta} / D$ ), cross-sectional slenderness $(D / t)$ and section factor $\left(A_{m} / V\right)$, and cannot be readily transformed into a unique value of the coefficient or a simple analytical expression. Therefore, an equation depending on the different parameters or alternatively a set of tabulated data must be developed.

A correlation analysis was first performed in order to investigate the strength of the dependency between $\varphi_{a, \theta}$ and the independent variables. The results showed that there was a high correlation with the relative slenderness (an therefore with $\ell_{\theta} / D$ ) and a moderated correlation with $D / t$ and $A / V$. Nevertheless, no correlation was found with the standard fire exposure time, and therefore this variable was not used in the development of the design equation.

\section{Design equation}

On a first instance, the shape of the relationship of $\varphi_{a, \theta}$ with each of the independent variables was studied by means of univariant analysis, and afterwards a more complex equation which used the three independent variables was built up, in the form of a product of three factors:

$$
\begin{aligned}
& \varphi_{a, \theta}=\varphi_{a, \theta 1}(D / t) \times \\
& \times \varphi_{a, \theta 2}\left(A_{m} / V\right) \times \varphi_{a, \theta 3}\left(\ell_{\theta} / D\right)
\end{aligned}
$$

where the first term represents the influence of the cross-sectional slenderness, the second term the effect of the section factor (which determines the temperature field pattern within the cross-section) and the third term measures the influence of the member slenderness.

Based on the results of the previous statistical analysis, the following shape of the functions was proposed:

$$
\begin{aligned}
& \varphi_{a, \theta}=\varphi_{a, \theta 1}(D / t) \times \\
& \times\left(a_{0}+a_{1} \cdot\left(A_{m} / V\right)^{a_{2}}\right) \times \\
& \times\left(b_{0}+b_{1} \cdot\left(\ell_{\theta} / D\right)^{b_{2}}\right)
\end{aligned}
$$

The first factor $\varphi_{a, \theta l}$ was found to have only a moderate effect for the stocky columns $\left(\ell_{\theta} / D \leq 12\right)$, whereas for slender columns it did not show an important influence, therefore it was designed as a correction factor which must only be applied to columns with low slenderness.

A multiple nonlinear regression analysis of the simulated data was conducted in order to obtain the coefficients associated with the proposed equation. The corresponding regression equation results: 
$\varphi_{a, \theta}=\varphi_{a, \theta 1}(D / t) \times\left(2.747-1.48 \cdot\left(A_{m} / V\right)^{0.08}\right) \times\left(0.0813+0.0133 \cdot\left(\ell_{\theta} / D\right)^{1.097}\right) \leq 1$

In this equation, the reduction coefficient $\varphi_{a, \theta}$ is a product of two partial reduction coefficients lower than unity, $\varphi_{a, \theta 2}$ and $\varphi_{a, \theta 3}$, which are corrected by the factor $\varphi_{a, \theta l}$ as a function of $D / t$ only for stocky columns $\left(\ell_{\theta} / D \leq 12\right)$, using the values tabulated in Table 1 . For $\ell_{\theta} / D>12$, the factor $\varphi_{a, \theta l}$ is equal to unity.

Table 3. Values of the partial reduction coefficient for steel $\varphi_{a, \theta 1}$ to include in the design equation for stocky columns $\left(\ell_{\theta} / D \leq 12\right)$

\begin{tabular}{cc}
\hline $\boldsymbol{D} / \boldsymbol{t}$ & $\boldsymbol{\varphi}_{a, \boldsymbol{\theta} \boldsymbol{I}}$ \\
\hline$<15$ & 0.75 \\
$15-35$ & 1 \\
$35-45$ & 1.25 \\
$>45$ & 2.5 \\
\hline
\end{tabular}

For $\ell_{\theta} / D \geq 46$, which corresponds to columns with relative slenderness at room temperature $\bar{\lambda}$ around 2 , the total factor $\varphi_{a, \theta}$ can be taken as equal to unity, which means that the reduction coefficient for the steel tube can be neglected.

Once the reduction coefficients have been calculated through the proposed equation, the general principles in Clause 4.3.5.1 of EN 1994-1-2 [15] can be followed, with the only particularity of using buckling curve "a" instead of "c".

The design equation presented here was applied to all the data available from the parametric studies in order to obtain the predicted values of the buckling resistance, and for each case specimen the error was measured with the expression in (9), obtaining an average value of the error equal to 1.09 (safe) and a standard deviation of 0.11 .

Table 4. Values of the reduction coefficient for steel $\varphi_{a, \theta}$ (tabulated method)

\begin{tabular}{|c|c|cccc|}
\cline { 3 - 6 } \multicolumn{2}{c|}{} & \multicolumn{4}{c|}{$\boldsymbol{A}_{\boldsymbol{m}} \boldsymbol{V}\left(\mathbf{m}^{-1}\right)$} \\
\cline { 3 - 6 }$\ell_{\theta} / D$ & $<\mathbf{1 0}$ & $\mathbf{1 0 - 1 5}$ & $\mathbf{1 5 - 2 0}$ & $>\mathbf{2 0}$ \\
\hline \multirow{4}{*}{$\ell_{\theta}$} & $\leq \mathbf{1 2}$ & 0.4 & 0.35 & 0.3 & 0.25 \\
& $\mathbf{2 4}$ & - & 0.5 & 0.5 & 0.4 \\
& $\mathbf{3 6}$ & - & - & 0.7 & 0.7 \\
& $\geq \mathbf{4 6}$ & - & - & - & 1 \\
\hline
\end{tabular}

\section{Tabulated data}

A more simplistic proposal was also developed, in the form of a selection table where the values of the reduction coefficient $\varphi_{a, \theta}$ can be obtained as a function of the section factor $A_{m} / V$ and the elevated temperature slenderness, measured as $\ell_{\theta} / D$. The values of the reduction coefficient for the steel tube for different combinations of the two parameters can be found in Table 4 . For intermediate values of $\ell_{\theta} / D$, linear inter- polation may be used. To account for the effect of the cross-sectional slenderness of the steel tube, the resulting coefficient must be corrected by the factor $\varphi_{a, \theta l}$ as a function of $D / t$ if $\ell_{\theta} / D \leq 12$, using the values tabulated in Table 1. Again, for higher values of $\ell_{\theta} / D$, no correction is needed.

The reduction coefficient of concrete $\varphi_{c, \theta}$ must be taken as a constant value equal to 0.8 and used with the tangent modulus. 
With these values, the general principles in Clause 4.3.5.1 of EN 1994-1-2 [15] can be followed, using buckling curve "a" as mentioned before. With the tabulated method, a mean error equal to 1.04 with a standard deviation of 0.11 was obtained.

It is worth noting that the resulting coefficients are much lower for steel than for concrete, which means that the flexural stiffness of the steel tube is more highly affected than the concrete core in the fire situation as compared to their theoretical values. The explanation to the low values of the steel reduction coefficient is that it incorporates the effect of the overload of the steel tube during the early stages of the fire exposure. To the authors' point of view, more than representing the possible effect of the thermal stresses, in the case of steel, this coefficient acts as a reduction factor to account for this overload, which is generally not taken into account and reduces significantly the fire resistance of the column. How this overload affects the fire performance of the column is a complex combination of different factors such as the member slenderness, the crosssectional dimensions and the fire exposure time, which are included in the proposed equations. Nevertheless, in the case of concrete, the reduction coefficient represents the effect of the differential thermal stresses developed as a result of the non-uniform temperature distribution within the concrete core, which other authors have explained before [16] [20] [40].

Fig. 7a shows a comparison between the predictions and the numerical simulations in terms of normalised buckling load (divided by the theoretical plastic resistance) and Fig. $7 \mathrm{~b}$ plots the errors of the predictions against the relative slenderness of the columns at room temperature, for the proposed method using the design equation (23) and buckling curve "a".
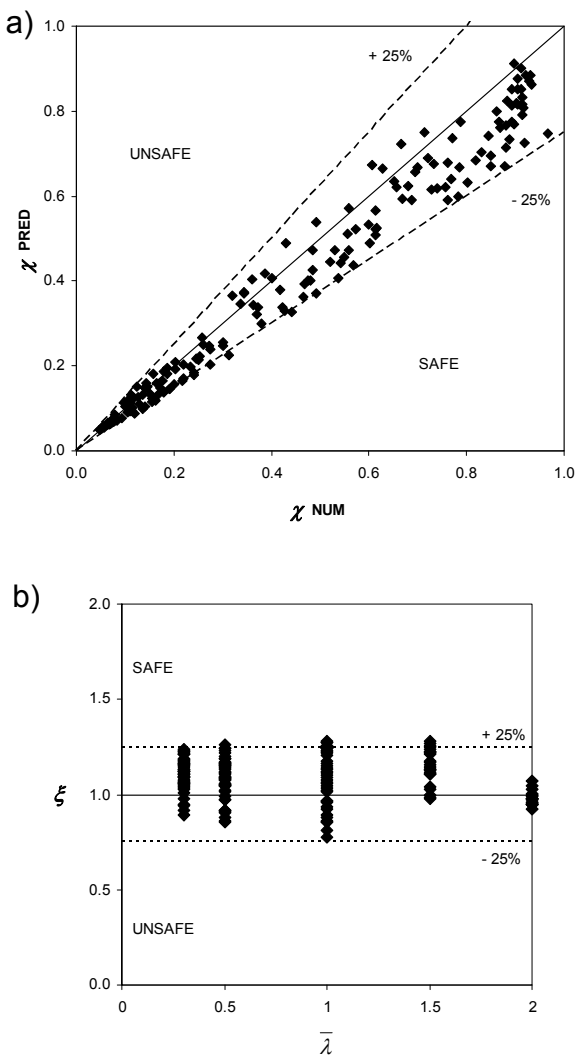

Fig. 7. Comparison between the proposed method and numerical simulations: a) Normalised buckling load, b) Relative error.

Fig. 8 presents the evolution of the buckling coefficient with the relative slenderness at elevated temperature. As can be seen, there is a good agreement between the predicted and reference values, with a maximum relative error of a $25 \%$ (only exceeded in a few number of cases which lay on the safe side) and a reasonably uniform distribution of the prediction errors for all the range of relative slenderness studied. Using the proposed coefficients, obtained by means of the design equation (23), or alternatively through the tables, the data follow closely the reference buckling curve "a", as can be seen in Fig. 8, with an excellent agreement for the higher slenderness and a 
moderated dispersion for intermediate slenderness but still following the shape of the normalised buckling curve and remaining on the safe side for short columns.

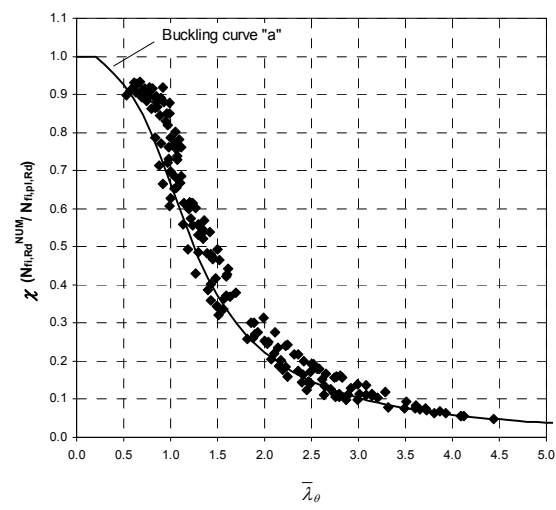

Fig. 8. Evolution of the buckling coefficient with the relative slenderness at elevated temperature, calculated with the proposed method.

The frequency histogram plotted in Fig. 9 shows that the prediction errors follow the shape of a normal distribution, with the mean value located on the safe side (where the most repeated values can be found) and a narrow dispersion.

The proposed calculation method can only be applied in the following conditions:

- Buckling length in the fire situation:

$$
\ell_{\theta} / D<50 \text { and } \ell_{\theta}<10 \mathrm{~m} *
$$

- Diameter of the cross-section: 139.7 $\mathrm{mm} \leq D \leq 508 \mathrm{~mm}$

- Normal strength concrete: C20/25 $\mathrm{C} 40 / 50$

- Standard fire resistance: $R \leq 120 \mathrm{~min}$

* Note that a buckling length equal to 10 meters in the fire situation corresponds to a column with a real length equal to 20 meters placed on an intermediate storey, according to Clause 4.3.5.1(10) in EN 1994-12 [15].

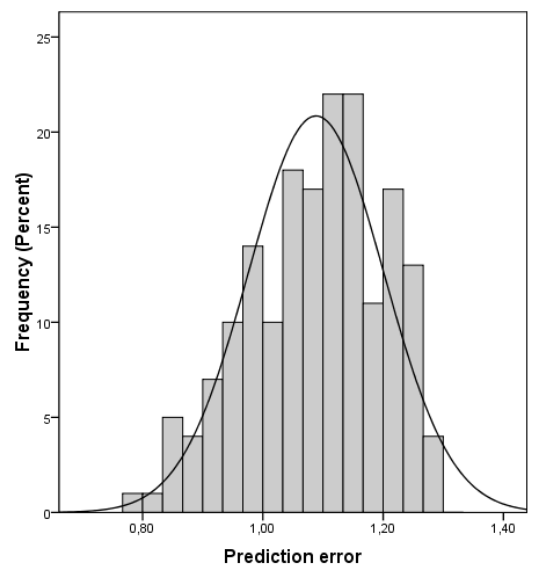

Fig. 9. Frequency histogram for the prediction error obtained with the proposed method.

\section{Comparison of the proposed method with experiments}

The proposed method is compared in this section with real fire tests carried out recently by the authors in the laboratories of AIDICO (Valencia, Spain) [32] and also against the tests available in the literature from the experimental program conducted at the Institute for Research in Construction, National Research Council of Canada (NRCC) [30].

From both sources, only those column specimens within the range of application of the method were selected, i.e. columns of circular cross-section, filled with plain (unreinforced) normal strength concrete (C20C40) and centrally loaded. Fig. 10 compares the results of all the tests against the predictions of the method, in terms of the failure load. For the Canadian tests, the equivalent temperatures for steel and concrete were obtained for the failure time reported at the tests as described in Section 5.1 and afterwards the method in Section 0.0 was applied using the calculated temperatures. It can be seen in Fig. 10 that the accuracy of the method was reasonable given the uncertainties that one can find when using data from 
external tests, and in general the predictions were conservative.

For comparing with the own tests by the authors, two options were considered: using the calculated equivalent temperatures for steel and concrete and using the real temperatures measured at the tests. As can be observed in Fig. 10, a better approximation was obviously obtained under the second option, since the real temperatures were employed; in any case using the simplified equivalent temperatures produced safe results for all the specimens compared, what confirms that the method described in Section 5.1 for obtaining the simplified crosssectional temperature field can be safely applied in combination with the general principles in Clause 4.3.5.1 of EN 1994-1-2 [15], with the flexural stiffness reduction coefficients calculated as described in Section 1.1 and the use of buckling curve "a".

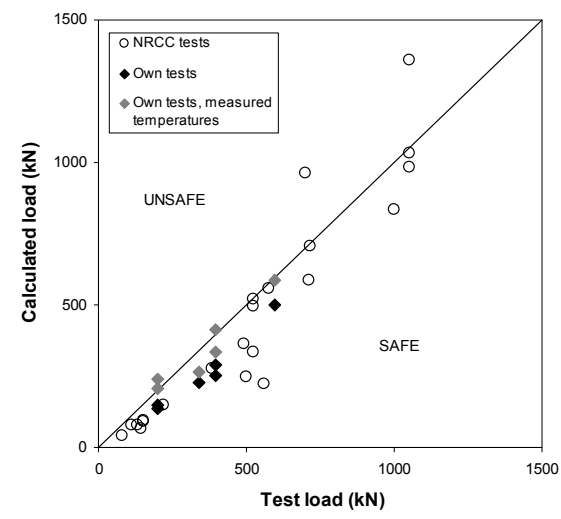

Fig. 10. Comparison of ultimate loads between the proposed method and tests.

Fig. 11 compares the results of the proposed method with the values of the predictions obtained by means of other three methods which are being used worldwide and which were previously described in Section 2: the design equation proposed by Kodur [6] (used in North America), the strength index formulation proposed by Han [4] (used in China) and the method from ANUHT
2004 [13] (used in Japan). As can be seen, the proposed method results generally safer than the rest of the methods. A wide dispersion of results is found under all the methods when comparing with real fire tests, being higher for the formulations from Han and Kodur, while the Japanese method seems to provide a narrower dispersion and more accurate predictions. Compared to the rest of the methods, it can be concluded that the proposed method provides a reasonable accuracy in the predictions and tends to be on the safe side.

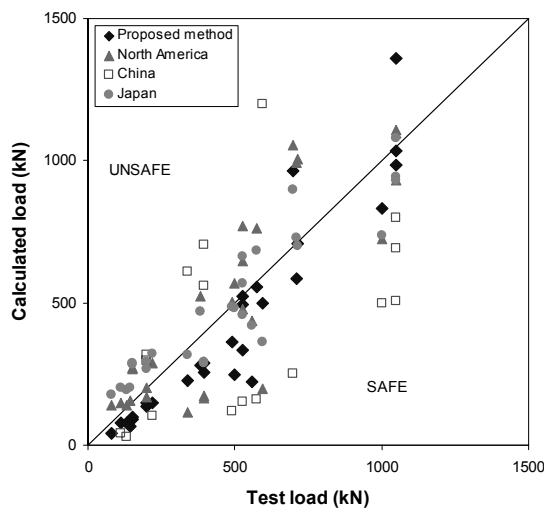

Fig. 11. Comparison of ultimate loads between the proposed method, other methods and tests.

\section{Design example}

The following design example illustrates the application of the proposed simple calculation model for obtaining the buckling resistance of an axially loaded CFT column for a specified standard fire period.

Consider that the designer wants to calculate the maximum axial load that a column placed on the top floor of a building can sustain during a period of 60 minutes of fire exposure. The column has the following characteristics:

- Column length: $L=3000 \mathrm{~mm}$

- Cross-sectional dimensions:

$D \times t=159 \times 6 \mathrm{~mm}$ 
- Steel yield strength: $f_{y}=355 \mathrm{MPa}$

- Compressive strength of concrete: $f_{c}=30 \mathrm{MPa}$

First, the following parameters must be calculated:

- Section factor of the column:

$$
A_{m} / V=4 / D=4 / 159 \times 1000=25.16 \mathrm{~m}^{-1}
$$

- Member slenderness in the fire situation:

$$
\ell_{\theta} / D=(0.7 * \times 3000) / 159=13.21
$$

- Cross-sectional slenderness:

$$
D / t=159 / 6=26.5
$$

*According to Clause 4.3.5.1(10) of EN 1994-1-2, for a column on the top floor of a building, the buckling length in the fire situation is calculated as 0.7 times the column length.
Note that the column in this example is being verified for axial loading conditions, which requires that the loads transferred to the column are balanced and do not introduce any bending effects at the top of the column.

On a first stage, the equivalent temperatures for the steel tube and concrete core must be obtained, by means of the proposed equations, or alternatively using the values in Table 2.

For the section factor of the column and the required standard fire period R60, the proposed equations (15) and (16) produce the following values, for the concrete core:

$$
\begin{aligned}
& \theta_{c, e q}=-186.44+5.764 \times 60-0.026 \times 60^{2}+22.577 \times 25.16-0.32 \times 25.16^{2}+ \\
& +0.14 \times 60 \times 25.16=642.61^{\circ} \mathrm{C}
\end{aligned}
$$

and for the steel tube:

$$
\theta_{a, e q}=342.1+10.77 \times 60-0.044 \times 60^{2}+3.922 \times 25.16-0.025 \times 60 \times 25.16=890.84^{\circ} \mathrm{C}
$$

Alternatively, linear interpolation can be used in Table 2 , obtaining $650.74{ }^{\circ} \mathrm{C}$ for the concrete core and $903.35^{\circ} \mathrm{C}$ for the steel tube. The temperatures obtained through the equations will be used in this case.

Once the equivalent temperatures of steel and concrete are known for the speci- fied fire period, the design values of the cross-sectional plastic resistance and effective flexural stiffness of the column can be calculated, following the rules in Clause 4.3.5.1 of EN 1994-1-2 [15] and considering only one layer for the steel tube and concrete core:

$$
\begin{aligned}
& N_{f i, p l, R d}=A_{a} f_{y}\left(\theta_{a, e q}\right)+A_{c} f_{c}\left(\theta_{c, e q}\right)= \\
& =2883.98 \mathrm{~mm}^{2} \times k_{y}(890.84) \times 355 \mathrm{MPa}+16971.67 \mathrm{~mm}^{2} \times k_{c}(642.61) \times 30 \mathrm{MPa}= \\
& =2883.98 \times 0.0646 \times 355+16971.67 \times 0.3861 \times 30=262721.17 \mathrm{~N}=262.72 \mathrm{kN}
\end{aligned}
$$

The partial factors for the materials in the fire situation, $\gamma_{M, f, i}$ have been taken as unity, as established in Clause 2.3 of EN 1994-1-2 [15].

reduction coefficient of the concrete core is equal to 0.8 , and the reduction coefficient for the steel tube can be obtained from equation (23), resulting:

Prior to obtaining the effective flexural stiffness, the values of the reduction coefficients $\varphi_{a, \theta}$ and $\varphi_{c, \theta}$ must be determined. The 
$\varphi_{a, \theta}=\varphi_{a, \theta 1} \times \varphi_{a, \theta 2} \times \varphi_{a, \theta 3}=$

$=1 \times\left(2.747-1.48 \cdot 25.16^{0.08}\right) \times\left(0.0813+0.0133 \cdot 13.21^{1.097}\right)=1 \times 0.83 \times 0.31=0.26$

Note that in this case the correction factor depending on the cross-sectional slenderness $\varphi_{a, \theta 1}$ is not needed, since $\ell_{\theta} / D>12$, therefore it is equal to unity.

where a value of 0.27 is found by using linear interpolation.

The effective flexural stiffness of the column after 60 minutes of fire exposure is:

The reduction coefficient for the steel tube can also be obtained from Table 4,

$$
\begin{aligned}
& (E I)_{f i, e f f}=\varphi_{a, \theta} E_{a}\left(\theta_{a, e q}\right) I_{a}+\varphi_{c, \theta} E_{c}\left(\theta_{c, e q}\right) I_{c}= \\
& =0.26 \times 210000 \mathrm{MPa} \times k_{E}(890.84) \times 8451869.91 \mathrm{~mm}^{4}+ \\
& +0.8 \times 3 / 2 \times k_{c}(642.61) \times 30 \mathrm{MPa} / \varepsilon_{c u}(642.61) \times 22921299.6 \mathrm{~mm}^{4}= \\
& =0.26 \times 210000 \times 0.0696 \times 8451869.91+0.8 \times 3 / 2 \times 0.3861 \times 30 / 0.025 \times 22921299.6= \\
& =44862333794.1 \mathrm{~N} \cdot \mathrm{mm}^{2}
\end{aligned}
$$

Now, the Euler buckling load in the fire situation can be calculated as:

$$
N_{f i, c r}=\pi^{2}(E I)_{f i, e f f} / \ell_{\theta}^{2}=\pi^{2} \times 44862333794.1 /(0.7 \times 3000)^{2}=100401.98 \mathrm{~N}=100.4 \mathrm{kN}
$$

and the relative slenderness of the column at elevated temperature therefore results:

$$
\bar{\lambda}_{\theta}=\sqrt{N_{f i, p l, R} / N_{f i, c r}}=\sqrt{262.72 / 100.4}=1.62
$$

This value of the relative slenderness is used to enter to the buckling curve "a", from where the reduction coefficient needed for determining the buckling load is obtained, which in this case is $\chi=0.32$.
Finally, the design value of the resistance of the column to axial compression after a period of 60 minutes results:

$$
N_{f i, R d}=\chi N_{f i, p l, R d}=0.32 \times 262.72 \mathrm{kN}=84.07 \mathrm{kN}
$$

\section{Summary and conclusions}

This paper reviewed the current design guidelines which are available worldwide for calculating the fire resistance of CFT columns, specially focusing on the Eurocode 4 Part 1.2 approach. Given the inaccuracy and limitations of the Annex $\mathrm{H}$ on this code, a new proposal based on the general rules for composite columns in Clause 4.3.5.1 was developed.
Parametric studies were carried out by means of a validated numerical model in order to investigate the main parameters affecting the fire behaviour of CFT columns, and through their results, design equations and tables were proposed for defining the appropriate values of the flexural stiffness reduction coefficients for the steel tube and concrete core. 
A flexural stiffness reduction coefficient equal to 0.8 applied over the initial tangent modulus of concrete can be assumed to account for the thermal stresses, while for the steel tube more conservative coefficients are needed, in order to include the overload effect. The equations and tables proposed in this paper can be used in combination with buckling curve "a" to obtain a good estimation of the buckling resistance of CFT columns.

There was a good agreement between the proposed method predictions and the numerical simulations, with a uniform distribution of the error for all the range of relative slenderness studied, which clearly improves the accuracy of the currently available methods in Eurocode 4 Part 1.2.

Expressions and tables for obtaining the equivalent temperatures for the steel tube and concrete core were also developed, in order to facilitate the designer to apply the method without the need of using advanced heat transfer calculation tools.

It was demonstrated that the proposed method provides a good estimation of the buckling resistance of CFT columns at elevated temperatures as compared with real fire tests, producing safe predictions in the majority of the cases.

\section{Acknowledgements}

The authors would like to express their sincere gratitude to the Spanish "Ministerio de Ciencia e Innovación" for the help provided through the Project BIA2009-9411 and to the European Union through the FEDER funds.

\section{References}

[1] Zhao XL, Han LH, Lu H. Concrete-filled tubular members and connections. Spon Press; 2010.

[2] Rush D, Bisby L, Melandinos A, Lane B. Fire resistance design of unprotected concrete filled steel hollow sections: metaanalysis of available furnace test data. International Association of Fire Safety Science; 2011.
[3] DBJ13-51-2003: Technical specification for concrete-filled steel tubular structures (in Chinese). Fuzhou: The Construction Department of Fujian Province; 2003.

[4] Han LH, Zhao XL, Yang YF, Feng JB. Experimental study and calculation of the fire resistance of concrete-filled hollow steel columns. Journal of Structural Engineering, ASCE 2003; 129(3):346-356.

[5] Han LH, Yang YF, Xu L. An experimental study and calculation on the fire resistance of concrete-filled SHS columns. Journal of Constructional Steel Research 2003; 59(4):427-452.

[6] Kodur VKR. Performance-based fire resistance design of concrete-filled steel columns. Journal of Constructional Steel Research 1999; 51:21-36.

[7] Kodur VKR. Guidelines for fire resistant design of concrete-filled steel HSS columns - State-of-the-art and research needs. Steel Structures 2007; 7:173-182.

[8] Kodur VKR, MacKinnon DH. Design of concrete-filled hollow structural steel columns for fire endurance. Engineering Journal-AISC 2000; 37(1):13-24.

[9] Canadian Commission on Building and Fire Codes. NBCC, National Building Code of Canada. Ottawa, Canada: National Research Council of Canada (NRCC); 2005.

[10] ASCE, ASCE/SFPE 29-99: Standard Calculation Method for Structural Fire Protection. Reston, USA: American Society of Civil Engineers; 1999.

[11] ACI, ACI 216.1M-07: Standard Method for Determining Fire Resistance of Concrete and Masonry Construction Assemblies. Detroit, USA: American Concrete Institute; 2007.

[12] Ruddy JL, Marlo JP, Ioannides SA, Alfawakhiri F. Fire Resistance of Structural Steel Framing. Steel Design Guide 19. Chicago, USA: American Institute of Steel Construction; 2003.

[13] Association of New Urban Housing Technology (ANUHT). Fire resistance design of non-insulated CFT columns - Guidelines, technical explanations and design examples (in Japanese); 2004.

[14] Harada K. Actual state of the codes on fire design in Japan. Proceedings of the Work- 
shop "Fire Design of Concrete Structures: What now? What next?". Milan, Italy, December 2-3, 2004. Brescia, Italy: Starrylink Editrice; 2004.

[15] CEN. EN 1994-1-2, Eurocode 4: Design of composite steel and concrete structures. Part 1-2: General rules - Structural fire design. Brussels, Belgium: Comité Européen de Normalisation; 2005.

[16] Wang YC, Orton AH. Fire resistant design of concrete filled tubular steel columns. The Structural Engineer 2008; 7:40-45.

[17] Wang YC. Some considerations in the design of unprotected concrete-filled steel tubular columns under fire conditions. Journal of Constructional Steel Research 1997; 44(3):203-223.

[18] Wang YC. A simple method for calculating the fire resistance of concrete-filled CHS columns. Journal of Constructional Steel Research 2000; 54:365-386.

[19] Leskela MV. Inconsistencies in the fire design rules of composite columns to EN 1994-1-2. Steel Concrete Composite and Hybrid Structures, pp. 489-494. Leeds, England; 2009.

[20] Aribert JM, Renaud C, Zhao B. Simplified fire design for composite hollow-section columns. Structures \& Buildings 2008; 161:325-336.

[21] Ribeiro JCL, Fakury RH, de Las Casas EB. Eurocode structural fire design and its application for composite circular hollow section columns. Journal of the Brazilian Society of Mechanical Science and Engineering 2008; 30(1):39-46.

[22] Espinos A, Romero ML, Hospitaler A. Advanced model for predicting the fire response of concrete filled tubular columns. Journal of Constructional Steel Research 2010; 66:1030-1046.

[23] Espinos A, Gardner L, Romero M, Hospitaler A. Fire behaviour of concrete filled elliptical steel columns. Thin-Walled Structures 2011; 49(2):239-255.

[24] Renaud C, Joyeux D, Kruppa J. Improvement and extension of the simple calculation method for fire resistance of unprotected concrete filled hollow columns. CIDECT Research Project 15Q-12/03. Saint-Rémy-lès-Chevreuse, France: Centre
Technique Industriel de la Construction Métallique (CTICM); 2004.

[25] AFNOR. Calcul simplifié de la résistance au feu des profils creux remplis de béton exposés aux conditions d'incendie normalisé. Annexe PCRB, pp. 9-16, NF-EN 19941-2/NA. Paris, France: Association Française de Normalisation; 2007.

[26] Hicks SJ, Newman GM. Design guide for SHS concrete filled columns. Corus Tubes; 2002.

[27] Twilt L, Hass R, Klingsch W, Edwards M, Dutta D. Design guide for structural hollow section columns exposed to fire. Cologne, Germany: Comité International pour le Développement et l'Etude de la Construction Tubulaire (CIDECT); 1996.

[28] CEN. EN 1993-1-1, Eurocode 3: Design of steel structures. Part 1-1: General rules and rules for buildings. Brussels, Belgium: Comité Européen de Normalisation; 2005.

[29] Lennon T, Moore DB, Wang YC, Bailey CG. Designers' guide to EN 1991-1-2, EN 1992-1-2, EN 1993-1-2 and EN 1994-1-2. Thomas Telford Limited; 2007.

[30] Lie TT, Chabot M. Experimental studies on the fire resistance of hollow steel columns filled with plain concrete. Internal report No. 611. Ottawa, Canada: Institute for Research in Construction, National Research Council of Canada (NRCC); 1992.

[31] ABAQUS. ABAQUS/Standard Version 6.6 User's Manual: Volumes I-III. Pawtucket, Rhode Island: Hibbit, Karlsson \& Sorenson, Inc.; 2005.

[32] Romero ML, Moliner V, Espinos A, Ibañez C, Hospitaler A. Fire behavior of axially loaded slender high strength concrete-filled tubular columns. Journal of Constructional Steel Research 2011; 67(12):1953-1965.

[33] ISO (International Standards Organization). ISO 834: Fire resistance tests, elements of building construction. Switzerland: International Standards Organisation; 1980.

[34] CEN. EN 1991-1-2, Eurocode 1: Actions on structures. Part 1-2: General actions Actions on structures exposed to fire. Brussels, Belgium: Comité Européen de Normalisation; 2002.

[35] Lie TT. Fire resistance of circular steel columns filled with bar-reinforced concrete. 
ASCE Journal of Structural Engineering 1994; 120(5):1489-1509.

[36] CEN. EN 1992-1-2, Eurocode 2: Design of concrete structures. Part 1-2: General rules - Structural fire design. Brussels, Belgium: Comité Européen de Normalisation; 2004.

[37] Hong S, Varma AH. Analytical modeling of the standard fire behavior of loaded CFT columns. Journal of Constructional Steel Research 2009; 65:54-69.

[38] CEN. EN 1993-1-2, Eurocode 3: Design of steel structures. Part 1-2: General rules -
Structural fire design. Brussels, Belgium Comité Européen de Normalisation; 2005.

[39] CEN. EN 1994-1-1, Eurocode 4: Design of composite steel and concrete structures. Part 1-1: General rules and rules for buildings. Brussels, Belgium: Comité Européen de Normalisation; 2004

[40] Bailey C. Effective lengths of concretefilled steel square hollow sections in fire. Proceedings of the ICE - Structures and Buildings 2000; 140(2):169-178. 



\section{ANNEX II.}

\section{MATERIAL CONSTITUTIVE MODELLING}

This Annex includes the formulation of the different material models which have been used throughout this thesis. The thermal properties and constitutive laws of steel and concrete at elevated temperatures proposed by the different authors are presented. 



\section{CONCRETE AT ELEVATED TEMPERATURES}

\subsection{Thermal properties of concrete at elevated temperatures}

\subsubsection{Formulation from Eurocode 2}

Eurocode 2 Part 1.2 (CEN 2004a) describes in its Section 3.3 the thermal properties of concrete at elevated temperatures, for both concrete with siliceous and calcareous aggregates. These formulations of the concrete properties at elevated temperatures have been incorporated in the latest version of Eurocode 4 Part 1.2 (CEN 2005c), with some minor changes which will be addressed next.

The formulation of each of the thermal properties of concrete, according Eurocode 2, is hereafter transcribed.

\section{Thermal elongation}

The thermal elongation of concrete $(\Delta l / l)_{c}$ may be determined from the following equations, which are referred to the length of the member at ambient temperature $\left(20^{\circ} \mathrm{C}\right)$ :

Siliceous aggregates:

$$
\begin{array}{ll}
(\Delta l / l)_{c}=-1.8 \cdot 10^{-4}+9 \cdot 10^{-6} \cdot \theta_{c}+2.3 \cdot 10^{-11} \cdot \theta_{c}{ }^{3} & \text { for } 20^{\circ} \mathrm{C} \leq \theta_{c} \leq 700^{\circ} \mathrm{C} \\
(\Delta l / l)_{c}=14 \cdot 10^{-3} & \text { for } 700^{\circ} \mathrm{C} \leq \theta_{c} \leq 1200^{\circ} \mathrm{C}
\end{array}
$$

Calcareous aggregates:

$$
\begin{array}{ll}
(\Delta l / l)_{c}=-1.2 \cdot 10^{-4}+6 \cdot 10^{-6} \cdot \theta_{c}+1.4 \cdot 10^{-11} \cdot \theta_{c}{ }^{3} & \text { for } 20^{\circ} \mathrm{C} \leq \theta_{c} \leq 805^{\circ} \mathrm{C} \\
(\Delta l / l)_{c}=12 \cdot 10^{-3} & \text { for } 805^{\circ} \mathrm{C} \leq \theta_{c} \leq 1200^{\circ} \mathrm{C}
\end{array}
$$

where $\theta_{c}$ is the temperature of concrete, in ${ }^{\circ} \mathrm{C}$.

In simple calculation models, according to EC4 Part 1-2 Section 3.3.2(3), the relationship between the thermal elongation $(\Delta l / l)_{c}$ and concrete temperature may be considered to be linear, through the following expression:

$$
(\Delta l / l)_{c}=18 \cdot 10^{-6} \cdot\left(\theta_{c}-20\right)
$$




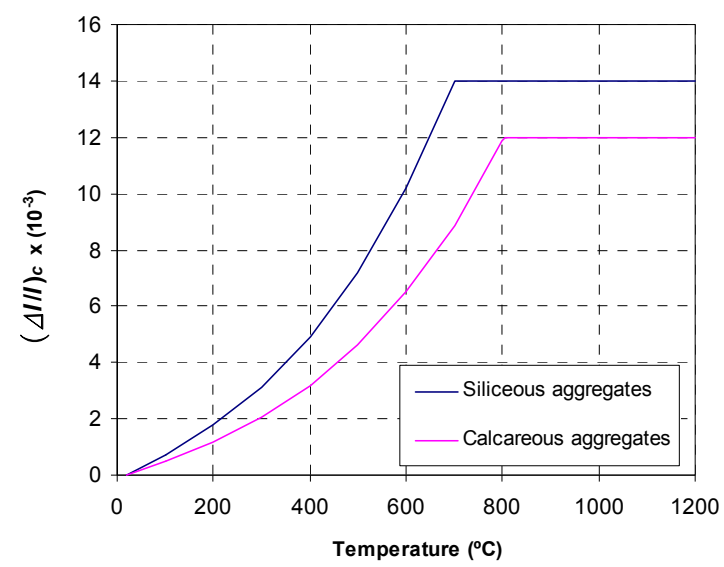

Figure 1. Thermal elongation of concrete at elevated temperatures, according to EC2 (CEN 2004a).

\section{Specific heat}

For dry concrete (moisture content of $0 \%$ ), with calcareous or siliceous aggregates, the specific heat may be determined from the following equations:

$$
\begin{aligned}
& c_{c}=900(\mathrm{~J} / \mathrm{kgK}) \\
& c_{c}=900+\left(\theta_{c}-100\right)(\mathrm{J} / \mathrm{kgK}) \\
& c_{c}=1000+\left(\theta_{c}-200\right) / 2(\mathrm{~J} / \mathrm{kgK}) \\
& c_{c}=1100(\mathrm{~J} / \mathrm{kgK})
\end{aligned}
$$

$$
\begin{aligned}
& \text { for } 20^{\circ} \mathrm{C} \leq \theta_{c} \leq 100^{\circ} \mathrm{C} \\
& \text { for } 100^{\circ} \mathrm{C} \leq \theta_{c} \leq 200^{\circ} \mathrm{C} \\
& \text { for } 200^{\circ} \mathrm{C} \leq \theta_{c} \leq 400^{\circ} \mathrm{C} \\
& \text { for } 400^{\circ} \mathrm{C} \leq \theta_{c} \leq 1200^{\circ} \mathrm{C}
\end{aligned}
$$

where $\theta_{c}$ is the temperature of concrete, in ${ }^{\circ} \mathrm{C}$.

If the moisture content is not considered explicitly in the calculation method, the previous formulae needs to be modified by adding a constant peak value $c_{c \text {,peak }}$ between $100{ }^{\circ} \mathrm{C}$ and $115^{\circ} \mathrm{C}$, with a linear decrease between $115^{\circ} \mathrm{C}$ and $200{ }^{\circ} \mathrm{C}$, which permits to model implicitly the heat consumption which occurs due to water evaporation in this range of temperatures. This peak value is equal to:

$$
\begin{aligned}
& c_{\text {c.peak }}=900 \mathrm{~J} / \mathrm{kgK} \text { for a moisture content of } 0 \% \text { of concrete weight } \\
& c_{\text {c.peak }}=1470 \mathrm{~J} / \mathrm{kgK} \text { for a moisture content of } 1.5 \% \text { of concrete weight } \\
& c_{\text {c.peak }}=2020 \mathrm{~J} / \mathrm{kgK} \text { for a moisture content of } 3 \% \text { of concrete weight }
\end{aligned}
$$


It is worth noting that, according to EC4 Part 1-2 Section 3.3.2(8), in hollow sections filled with concrete, a moisture content of a $10 \%$ may be found, and in that case a value $c_{\text {c.peak }}=5600 \mathrm{~J} / \mathrm{kgK}$ should be used.

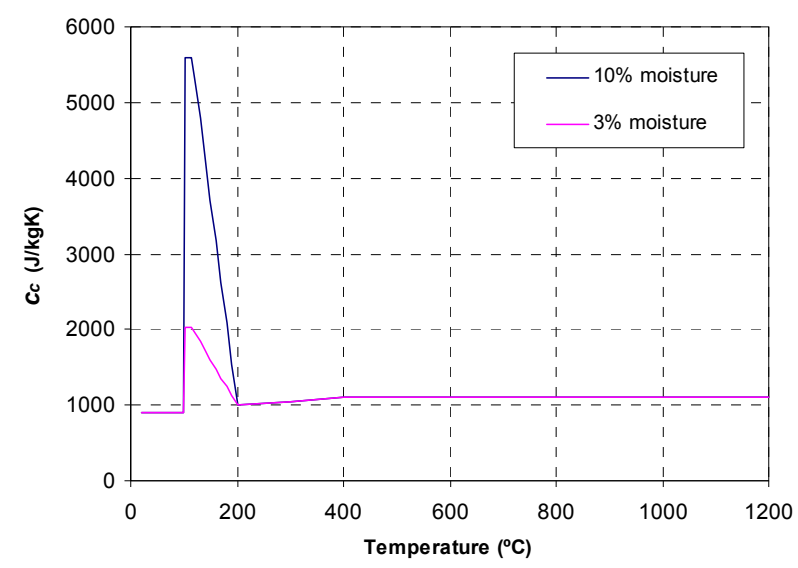

Figure 2. Specific heat of concrete at elevated temperatures, according to EC2 (CEN 2004a).

In simple calculation models, EC4 Part 1-2 3.3.2(6) allows for the use of a constant value for the specific heat equal to $1000 \mathrm{~J} / \mathrm{kgK}$.

\section{Density}

The variation of the density of concrete $\rho_{c}$ with temperature is influenced by water loss, and is defined as follows:

$$
\begin{array}{ll}
\rho_{c}=\rho_{c}\left(20^{\circ} \mathrm{C}\right) & \text { for } 20^{\circ} \mathrm{C} \leq \theta_{c} \leq 115^{\circ} \mathrm{C} \\
\rho_{c}=\rho_{c}\left(20^{\circ} C\right) \cdot\left(1-0.02 \cdot\left(\theta_{c}-115\right) / 85\right) & \text { for } 115^{\circ} \mathrm{C} \leq \theta_{c} \leq 200^{\circ} \mathrm{C} \\
\rho_{c}=\rho_{c}\left(20^{\circ} C\right) \cdot\left(0.98-0.03 \cdot\left(\theta_{c}-200\right) / 200\right) & \text { for } 200^{\circ} \mathrm{C} \leq \theta_{c} \leq 400^{\circ} \mathrm{C} \\
\rho_{c}=\rho_{c}\left(20^{\circ} C\right) \cdot\left(0.95-0.07 \cdot\left(\theta_{c}-400\right) / 800\right) & \text { for } 400^{\circ} \mathrm{C} \leq \theta_{c} \leq 1200^{\circ} \mathrm{C}
\end{array}
$$

where $\theta_{c}$ is the temperature of concrete, in ${ }^{\circ} \mathrm{C}$, and $\rho_{c}\left(20^{\circ} \mathrm{C}\right)=2300 \mathrm{~kg} / \mathrm{m}^{3}$.

The evolution of the concrete density with temperature can also be approximated by means of the following expression, according to EC4 Part 1-2 3.4(2):

$$
\rho_{c}=2354-23.47 \cdot\left(\theta_{c} / 100\right)
$$




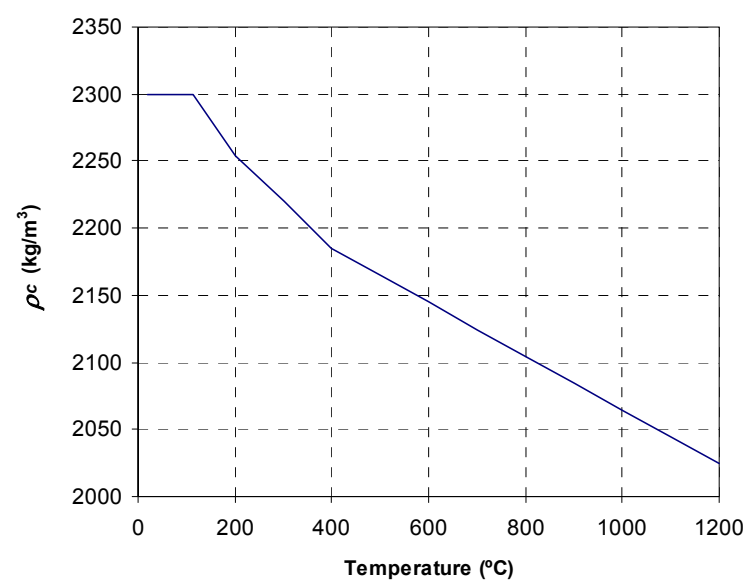

Figure 3. Density of concrete at elevated temperatures, according to EC2 (CEN 2004a).

EC4 Part 1-2 3.4(3) allows for the use of a constant density value for unreinforced normal weight concrete equal to $2300 \mathrm{~kg} / \mathrm{m}^{3}$.

\section{Thermal conductivity}

The thermal conductivity of concrete $\lambda_{c}$ can adopt values comprised between the following lower and upper limits.

Upper limit:

$$
\lambda_{c}=2-0.2451 \cdot\left(\theta_{c} / 100\right)+0.0107 \cdot\left(\theta_{c} / 100\right)^{2}(\mathrm{~W} / \mathrm{mK}) \text { for } 20^{\circ} \mathrm{C} \leq \theta_{c} \leq 1200^{\circ} \mathrm{C}
$$

Lower limit:

$\lambda_{c}=1,36-0.136 \cdot\left(\theta_{c} / 100\right)+0.0057 \cdot\left(\theta_{c} / 100\right)^{2}(\mathrm{~W} / \mathrm{mK})$ for $20^{\circ} \mathrm{C} \leq \theta_{c} \leq 1200^{\circ} \mathrm{C}$ where $\theta_{c}$ is the temperature of concrete, in ${ }^{\circ} \mathrm{C}$.

EC4 Part 1-2 3.3.2(9) recommends the use of the upper limit for steelconcrete composite members.

In simple calculation models, EC4 Part 1-2 3.3.2(12) establishes that a constant value of $1.60 \mathrm{~W} / \mathrm{mK}$ may be adopted for the thermal conductivity of concrete. 


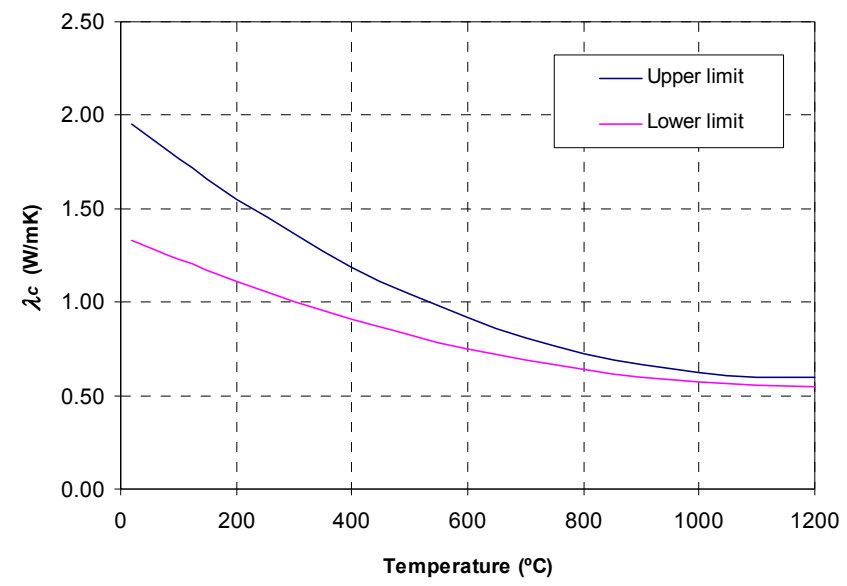

Figure 4. Thermal conductivity of concrete at elevated temperatures, according to EC2 (CEN 2004a).

\subsubsection{Formulation from Lie}

Authors as Lie (1984) have proposed different formulations for the thermal properties of concrete at elevated temperatures. The definition of the concrete thermal properties according to this author is presented next.

\section{Thermal capacity}

The thermal capacity of concrete $\rho_{c} \cdot c_{c}$, may be determined by means of the following expressions:

$$
\begin{aligned}
& \rho_{c} c_{c}=2.566 \cdot 10^{6}\left(\mathrm{~J} / \mathrm{m}^{3 \mathrm{o}} \mathrm{C}\right) \\
& \rho_{c} c_{c}=\left(0.1765 \cdot \theta_{c}-68.034\right) \cdot 10^{6}\left(\mathrm{~J} / \mathrm{m}^{3}{ }^{\mathrm{o}} \mathrm{C}\right) \\
& \text { for } 0^{\circ} \mathrm{C} \leq \theta_{c} \leq 400^{\circ} \mathrm{C} \\
& \rho_{c} c_{c}=\left(-0.05043 \cdot \theta_{c}+25.00671\right) \cdot 10^{6}\left(\mathrm{~J} / \mathrm{m}^{3}{ }^{\mathrm{o}} \mathrm{C}\right) \\
& \text { for } 400^{\circ} \mathrm{C}<\theta_{c} \leq 410^{\circ} \mathrm{C} \\
& \rho_{c} c_{c}=2.566 \cdot 10^{6}\left(\mathrm{~J} / \mathrm{m}^{3 \mathrm{o}} \mathrm{C}\right) \\
& \text { for } 410^{\circ} \mathrm{C}<\theta_{c} \leq 445^{\circ} \mathrm{C} \\
& \rho_{c} c_{c}=\left(0.01603 \cdot \theta_{c}-5.44881\right) \cdot 10^{6}\left(\mathrm{~J} / \mathrm{m}^{3 \mathrm{o}} \mathrm{C}\right) \\
& \text { for } 445^{\circ} \mathrm{C}<\theta_{c} \leq 500^{\circ} \mathrm{C} \\
& \rho_{c} c_{c}=\left(0.16635 \cdot \theta_{c}-100.90225\right) \cdot 10^{6}\left(\mathrm{~J} / \mathrm{m}^{3}{ }^{\mathrm{o}} \mathrm{C}\right) \\
& \text { for } 500^{\circ} \mathrm{C}<\theta_{c} \leq 635^{\circ} \mathrm{C} \\
& \rho_{c} c_{c}=\left(-0.22103 \cdot \theta_{c}+176.07343\right) \cdot 10^{6}\left(\mathrm{~J} / \mathrm{m}^{3 \mathrm{o}} \mathrm{C}\right) \\
& \text { for } 635^{\circ} \mathrm{C}<\theta_{c} \leq 715^{\circ} \mathrm{C} \\
& \rho_{c} c_{c}=2.566 \cdot 10^{6}\left(\mathrm{~J} / \mathrm{m}^{3 \mathrm{o}} \mathrm{C}\right) \\
& \text { for } 715^{\circ} \mathrm{C}<\theta_{c} \leq 785^{\circ} \mathrm{C} \\
& \text { for } \theta_{c}>785^{\circ} \mathrm{C}
\end{aligned}
$$

where $\theta_{c}$ is the temperature of concrete, in ${ }^{\circ} \mathrm{C}$. 


\section{Thermal conductivity}

The thermal conductivity of concrete $\lambda_{c}$, may be obtained from the following equations:

$$
\begin{aligned}
& \lambda_{c}=1.355\left(\mathrm{~W} / \mathrm{m}^{\circ} \mathrm{C}\right) \\
& \lambda_{c}=-0.001241 \cdot \theta_{c}+1.7162\left(\mathrm{~W} / \mathrm{m}^{\circ} \mathrm{C}\right) \quad \text { for } \theta_{c}>293^{\circ} \mathrm{C} \\
& \text { for } 0^{\circ} \mathrm{C} \leq \theta_{c} \leq 293^{\circ} \mathrm{C}
\end{aligned}
$$

where $\theta_{c}$ is the temperature of concrete, in ${ }^{\circ} \mathrm{C}$.

\section{Thermal expansion coefficient}

The thermal expansion coefficient of concrete $\alpha_{c}$, is given by the following equation, as a function of temperature:

$$
\alpha_{c}=\left(0.008 \cdot \theta_{c}+6\right) \cdot 10^{-6}\left(\mathrm{~m} / \mathrm{m}^{\circ} \mathrm{C}\right)
$$

where $\theta_{c}$ is the temperature of concrete, in ${ }^{\circ} \mathrm{C}$.

The formulations of the thermal properties of concrete according EC2 and Lie are compared in Figure 5. For comparison purposes, the specific heat in Lie's model has been obtained by dividing the thermal capacity by a constant value of the density equal to $2300 \mathrm{~kg} / \mathrm{m}^{3}$. Regarding the thermal expansion coefficient, it is obtained in $\mathrm{EC} 2$ model from the thermal elongation as follows:

$$
\alpha_{c}\left(\theta_{c}\right)=\frac{(\Delta l / l)_{c}\left(\theta_{c}\right)}{\left(\theta_{c}-20\right)}
$$

From Figure 5, it can be concluded that a noticeable disagreement exists between the two models. While the thermal conductivity follows the same pattern, the specific heat and thermal expansion models differ notably. It is worth noting that in the EC2 model a peak value corresponding to a $10 \%$ moisture has been included between 100 y $200{ }^{\circ} \mathrm{C}$, while Lie's model does not consider this effect and therefore the water evaporation should be given an explicit treatment. However, in Lie's model some peak values appear at $415{ }^{\circ} \mathrm{C}$ and $715^{\circ} \mathrm{C}$, which can be attributed to possible changes at the micro-structural level. 
a)

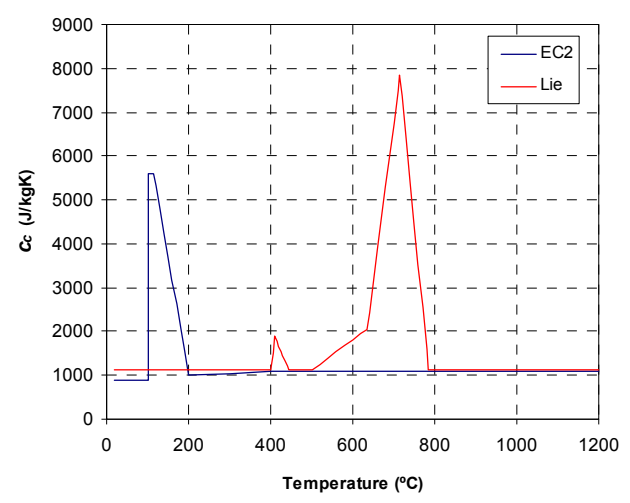

b)

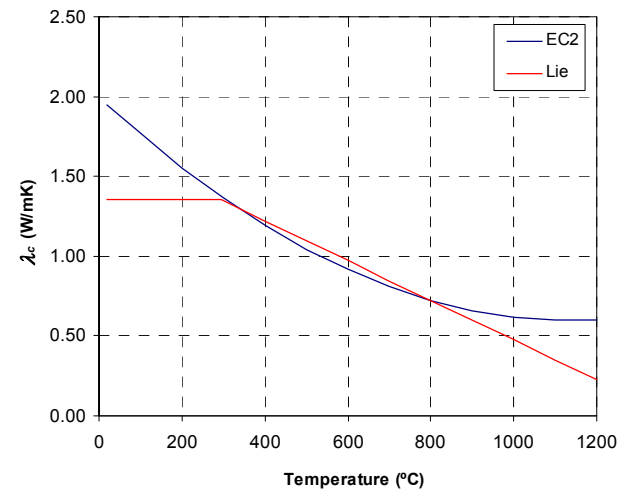

c)

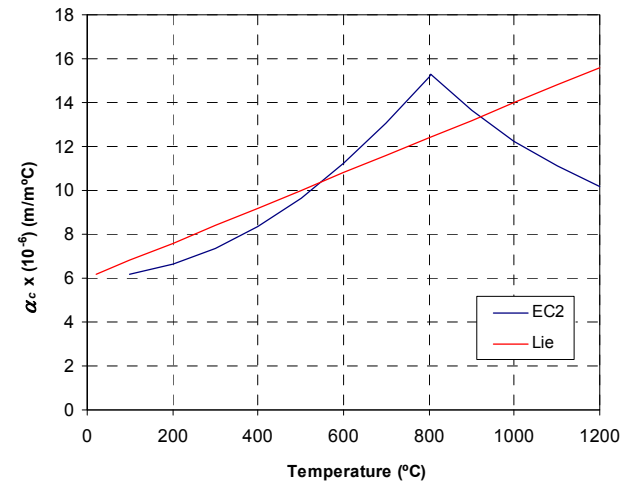

Figure 5. Comparison between EC2 and Lie's formulations for the thermal properties of concrete at elevated temperatures: a) specific heat, b) thermal conductivity, c) thermal expansion coefficient. 


\subsection{Mechanical properties of concrete at elevated temperatures}

The axial deformation in concrete can be expressed as the sum of four components (Li \& Purkiss 2005):

$$
\varepsilon_{c}=\varepsilon_{t h}\left(\theta_{c}\right)+\varepsilon_{\sigma}\left(\sigma_{c}, \theta_{c}\right)+\varepsilon_{c r}\left(\sigma_{c}, \theta_{c}, t\right)+\varepsilon_{t r}\left(\sigma_{c}, \theta_{c}\right)
$$

where:

- $\varepsilon_{c}$ is the total strain

- $\varepsilon_{t h}$ is the free thermal strain (due to the temperature change)

- $\varepsilon_{\sigma}$ is the instantaneous stress-related strain (caused by the externally applied stresses)

- $\varepsilon_{c r}$ is the classical creep strain (caused by the dislocation of microstructures of the material)

- $\varepsilon_{t r}$ is the transient strain (caused by the change of chemical composition)

The free thermal strain $\left(\varepsilon_{t h}\right)$ is traditionally expressed by a linear function of temperature by employing a thermal expansion coefficient:

$$
\varepsilon_{t h}\left(\theta_{c}\right)=\alpha_{c} \cdot\left(\theta_{c}-\theta_{c 0}\right)
$$

where:

- $\alpha_{c}$ is the thermal expansion coefficient, which for normal weight concrete with siliceous aggregates, according to Li \& Purkiss (2005), can be approximated by:

$$
\alpha_{c}=\left(0.008 \cdot \theta_{c}+6\right) \cdot 10^{-6}
$$

- $\theta_{c 0}$ is the initial temperature of concrete

The rest of the components of the total strain, apart from being temperature dependent, are also a function of the stress and time. Some models include the transient and creep strain in the same component.

It is noteworthy that, in general, there is no agreement when accounting for the transient strain, which some models include implicitly in the total strain, while some others treat this component as an additional part and provide specific expressions for its evaluation. 
The main constitutive models which can be found in the literature for representing the mechanical behaviour of concrete at elevated temperatures are subsequently described.

\subsubsection{Anderberg and Thelandersson model}

According to Anderberg \& Thelandersson (1976), the classical creep strain $\left(\varepsilon_{c r}\right)$ can be obtained from the following expression:

$$
\varepsilon_{c r}\left(\sigma_{c}, \theta_{c}, t\right)=-0.00053 \cdot\left(\frac{\sigma_{c}}{\sigma_{u T}}\right) \cdot\left(\frac{t}{180}\right)^{0.5} \cdot e^{0.00304 \cdot\left(\theta_{c}-20\right)}
$$

where:

- $\sigma_{u T}$ is the peak compressive stress at the temperature $\theta_{c}$

- $t$ is the time, expressed in minutes

The classical creep strain is often very small compared to the other three components due to the short period of the fire and, according to the authors, it can be neglected.

The transient strain $\left(\varepsilon_{t r}\right)$ is obtained from the following expression:

For $\theta_{c} \leq 550^{\circ} C \quad \varepsilon_{t r}=-k_{t r} \cdot\left(\frac{\sigma_{c}}{\sigma_{u 0}}\right) \cdot \varepsilon_{t h}$

For $\theta_{c} \geq 550^{\circ} C \frac{\partial \varepsilon_{t r}}{\partial \theta_{c}}=-0.0001 \cdot\left(\frac{\sigma_{c}}{\sigma_{u 0}}\right)$

where:

- $k_{t r}$ is a constant between 1.8 and 2.35

- $\sigma_{u 0}$ is the peak compressive stress at room temperature

The instantaneous stress-related strain $\left(\varepsilon_{\sigma}\right)$ is given by the following expression:

$$
\begin{array}{ll}
\text { For } 0 \leq \varepsilon_{\sigma} \leq \varepsilon_{1}: & \sigma_{c}=E \cdot\left(\varepsilon_{\sigma}-\frac{\varepsilon_{\sigma}^{2}}{2 \cdot \varepsilon_{u T}}\right) \\
\text { For } \varepsilon_{1} \leq \varepsilon_{\sigma} \leq \varepsilon_{u l t}: & \sigma_{c}=\sigma_{1}+E^{-} \cdot\left(\varepsilon_{\sigma}-\varepsilon_{1}\right)
\end{array}
$$

where: 
- $\sigma_{1}=E \cdot\left(\varepsilon_{1}-\frac{\varepsilon_{1}^{2}}{2 \cdot \varepsilon_{u T}}\right) ; \varepsilon_{1}=\varepsilon_{u T} \cdot\left(1-\frac{E^{-}}{E}\right) ; \varepsilon_{u T}=\frac{2 \cdot \sigma_{u T}}{E}$

- $E$ is the initial tangent modulus of the stress-strain curve at the temperature $\theta_{c}$

- $E^{-}$is the initial tangent modulus of the stress-strain curve in the descending branch at the temperature $\theta_{c}$

- $\varepsilon_{u l t}$ is the ultimate compressive strain at the temperature $\theta_{c}$

\subsubsection{Schneider model}

Schneider (1986) used only two components, apart from the thermal strain, for expressing the total strain, combining together the transient and creep strains:

$$
\varepsilon_{c}-\varepsilon_{t h}=\varepsilon_{\sigma}+\left(\varepsilon_{c r}+\varepsilon_{t r}\right)=\frac{1+\beta}{g} \cdot \frac{\sigma_{c}}{E}+\frac{\Phi}{g} \cdot \frac{\sigma_{c}}{E}
$$

with:

$$
\begin{aligned}
& \beta\left(\sigma_{c}, \theta_{c}\right)=\frac{1}{n-1} \cdot\left(\frac{\sigma_{c}}{\sigma_{u T}}\right)^{5} \text { or } \beta\left(\sigma_{c}, \theta_{c}\right)=\frac{1}{n-1} \cdot\left(\frac{\varepsilon_{\sigma}}{\varepsilon_{u T}}\right)^{5} \\
& g\left(\sigma_{F}, \theta_{c}\right)= \begin{cases}1+\frac{\sigma_{F}}{\sigma_{u 0}} \cdot \frac{\theta_{c}-20}{100} & \text { for } \frac{\sigma_{F}}{\sigma_{u 0}} \leq 0.3 \\
1+\frac{0.3 \cdot\left(\theta_{c}-20\right)}{100} & \text { for } \frac{\sigma_{F}}{\sigma_{u 0}}>0.3\end{cases} \\
& \Phi\left(\sigma_{F}, \theta_{c}\right)= \begin{cases}g \cdot \varphi+\frac{\sigma_{c}}{\sigma_{u T}} \cdot \frac{\theta_{c}-20}{100} & \text { for } \frac{\sigma_{c}}{\sigma_{u T}} \leq 0.3 \\
g \cdot \varphi+\frac{0.3 \cdot\left(\theta_{c}-20\right)}{100} & \text { for } \frac{\sigma_{c}}{\sigma_{u T}}>0.3\end{cases} \\
& \varphi=C_{1} \cdot \tanh \left[\gamma_{w} \cdot\left(\theta_{c}-20\right)\right]+C_{2} \cdot \tanh \left[\gamma_{0} \cdot\left(\theta_{c}-\theta_{g}\right)\right]+C_{3}
\end{aligned}
$$

where:

- $\sigma_{F}$ is the compressive stress generated by external forces before the concrete is heated

- $w$ is the moisture content 
- $n, \gamma_{0}, \theta_{g}, C_{1}, C_{2}$ y $C_{3}$ are constants defined by Schneider (1986) for different types of concrete

\subsubsection{Diederichs model}

Diederichs (1987) presented a simple equation using also two components of the strain, with the following expression:

$$
\varepsilon_{c}-\varepsilon_{t h}=\varepsilon_{\sigma}+\left(\varepsilon_{c r}+\varepsilon_{t r}\right)=\frac{\sigma_{c}}{E_{0}} \cdot\left[1-\frac{E_{0}}{\sigma_{u 0}} \cdot f\left(\theta_{c}\right)\right]
$$

with $f\left(\theta_{c}\right)=3.3 \cdot 10^{-7} \cdot\left(\theta_{c}-20\right)^{3}-1.72 \cdot 10^{-4} \cdot\left(\theta_{c}-20\right)^{2}+0.0412 \cdot\left(\theta_{c}-20\right)$

where:

- $E_{0}$ is the initial tangent modulus of concrete at room temperature

- $f\left(\theta_{c}\right)$ is an empirical function obtained by fitting experimental data provided by the author (Diederichs 1987)

\subsubsection{Khoury and Terro model}

Khoury et al. $(1985,1986)$ and Terro (1998) used a three term formulation for the total strain, combining the transient and creep strains in the so-called "Load Induced Thermal Strain" (LITS):

$$
\varepsilon_{c}=\varepsilon_{t h}+\varepsilon_{\sigma}+\left(\varepsilon_{c r}+\varepsilon_{t r}\right)=\varepsilon_{t h}+\varepsilon_{\sigma}+\text { LITS }
$$

with $\operatorname{LITS}\left(\theta_{c}, \sigma_{c}\right)=\left(\varepsilon_{c}-\varepsilon_{t h}-\frac{\sigma_{c}}{E_{0}}\right)$

Terro (1998) developed an empirical formula by data fitting, assuming the LITS to be a linear function of the applied stress.

For a stress level equal to $0.3 \cdot \sigma_{u 0}$ :

$$
\begin{aligned}
& \operatorname{LITS}\left(\theta_{c}, 0.3 \cdot \sigma_{u 0}\right)= \\
& =\left(43.87-2.73 \cdot \theta_{c}-6.35 \cdot 10^{-2} \cdot \theta_{c}^{2}+2.19 \cdot 10^{-4} \cdot \theta_{c}^{3}-2.77 \cdot 10^{-7} \cdot \theta_{c}^{4}\right) \cdot 10^{-6}
\end{aligned}
$$

For siliceous aggregate concrete, this equation needs to be modified:

$$
\begin{aligned}
& \operatorname{LITS}\left(\theta_{c}, 0.3 \cdot \sigma_{u 0}\right)=1.48 \cdot 10^{-6} \cdot\left(1098.5-39.21 \cdot \theta_{c}+0.43 \cdot \theta_{c}{ }^{2}\right)- \\
& -1.48 \cdot 10^{-9} \cdot\left(2.44 \cdot \theta_{c}{ }^{3}-6.27 \cdot 10^{-3} \cdot \theta_{c}{ }^{4}+5.95 \cdot 10^{-6} \cdot \theta_{c}{ }^{5}\right)
\end{aligned}
$$


For other stress levels:

$$
\operatorname{LITS}\left(\theta_{c}, \sigma_{c}\right)=\operatorname{LITS}\left(\theta_{c}, 0.3 \cdot \sigma_{u 0}\right) \cdot\left(0.032+3.226 \cdot \frac{\sigma_{c}}{\sigma_{u 0}}\right)
$$

These curves are valid for concrete containing $65 \%$ aggregate by volume. For any other volume fraction of aggregate $V_{a}$, the load induced thermal strain is given by:

$$
\left.\operatorname{LITS}\left(\theta_{c}, \sigma_{c}\right)\right|_{V_{a}}=\left.\operatorname{LITS}\left(\theta_{c}, \sigma_{c}\right)\right|_{65 \%} \cdot \frac{V_{a}}{0.65}
$$

where $V_{a}$ is the volume fraction of aggregate in concrete.

The equations in this model are only valid for temperatures up to $590{ }^{\circ} \mathrm{C}$.

\subsubsection{Li and Purkiss model}

Li \& Purkiss (2005) proposed reduction functions for the initial tangent modulus and the peak compressive strength of concrete, according to the following expressions:

$$
\begin{aligned}
& E\left(\theta_{c}\right)= \begin{cases}E_{0} & \text { for } \theta_{c} \leq 60{ }^{\circ} \mathrm{C} \\
\frac{800-\theta_{c}}{740} E_{0} & \text { for } 60^{\circ} \mathrm{C} \leq \theta_{c} \leq 800^{\circ} \mathrm{C}\end{cases} \\
& \sigma_{u T}\left(\theta_{c}\right)=\sigma_{u 0}\left[0.00165 \cdot\left(\frac{\theta_{c}}{100}\right)^{3}-0.03 \cdot\left(\frac{\theta_{c}}{100}\right)^{2}+0.025 \cdot\left(\frac{\theta_{c}}{100}\right)+1.002\right]
\end{aligned}
$$

Li \& Purkiss also developed an empirical formula for determining the peak strain corresponding to the maximum stress, based on Anderberg \& Thelanderson model for temperatures under $350{ }^{\circ} \mathrm{C}$, and on a combination of the models from Schneider, Diederichs and Khoury \& Terro for the rest of temperatures:

$$
\varepsilon_{u T}^{*}\left(\theta_{c}\right)=\frac{2 \sigma_{u 0}}{E_{0}}+0.21 \cdot 10^{-4} \cdot\left(\theta_{c}-20\right)-0.9 \cdot 10^{-8} \cdot\left(\theta_{c}-20\right)^{2}
$$

Based on the stress and strain values at the peak point, one can calculate the secant modulus $E_{a v}^{*}=\sigma_{u T} / \varepsilon_{u T}^{*}$, or the initial tangent modulus if the nonlinear stressstrain equation given in EN 1992-1-2 is used, $E^{*}=1.5 \cdot \sigma_{u T} / \varepsilon_{u T}^{*}$.

For the tangent modulus in the descending branch of the stress-strain curve at elevated temperatures, Li \& Purkiss proposed the following equation: 


$$
E_{p}^{*}\left(\theta_{c}\right)=E_{0}^{-} \cdot \exp \left\lfloor k_{p} \cdot\left(\theta_{c}-20\right)^{2.15}\right\rfloor
$$

where:

- $E_{0}^{-}=E^{-}=-880 \mathrm{MPa}$ is the tangent modulus in the descending branch at room temperature

- $k_{p}=10^{-6}$ is a constant obtained by fitting the previous equation to the stress-strain curves from Anderberg \& Thelanderson (1976) at different temperatures

\subsubsection{Yin et al. model}

The total axial strain in Yin et al. (2006) model incorporates the four components described previously:

$$
\varepsilon_{c}=\varepsilon_{\sigma}+\varepsilon_{c r}+\varepsilon_{t r}+\varepsilon_{t h}
$$

According to these authors, the classical creep strain $\left(\varepsilon_{c r}\right)$ developed during a fire is not very important and therefore it can generally be ignored.

The thermal strain $\left(\varepsilon_{t h}\right)$ can be expressed in terms of temperature as follows:

$$
\varepsilon_{t h}\left(\theta_{c}\right)=\left(6+0.008 \cdot \theta_{c}\right) \cdot 10^{-6} \cdot\left(\theta_{c}-20\right)
$$

This component of the total strain is considered separately in this model.

The following relationship between the stress and strain for concrete at elevated temperatures is proposed by the authors:

$$
\frac{\sigma_{c}}{\sigma_{u}}= \begin{cases}\alpha \cdot\left(\frac{\varepsilon_{c}}{\varepsilon_{u}}\right)+(1-\alpha) \cdot\left(\frac{\varepsilon_{c}}{\varepsilon_{u}}\right)^{2} & \text { for } \varepsilon_{c} \leq \varepsilon_{u} \\ 1+\frac{E^{-}}{\sigma_{u}} \cdot\left(\varepsilon_{c}-\varepsilon_{u}\right) & \text { for } \varepsilon_{c}>\varepsilon_{u}\end{cases}
$$

with $\varepsilon_{c}=\varepsilon_{\sigma}+\varepsilon_{t r}$

where:

- $\sigma_{u}$ is the maximum compressive stress of the concrete at elevated temperature, which can be taken as given by Li \& Purkiss (2005):

$$
\frac{\sigma_{u}}{\sigma_{u 0}}=1+0.132 \cdot\left(\frac{\theta_{c}-20}{1000}\right)-2.901 \cdot\left(\frac{\theta_{c}-20}{1000}\right)^{2}+1.650 \cdot\left(\frac{\theta_{c}-20}{1000}\right)^{3}
$$

where $\sigma_{u 0}$ is the compressive strength of concrete at room temperature. 
- $\varepsilon_{u}$ is the corresponding strain at the peak point, which can be calculated based on Anderberg \& Thelandersson (1976) model through the following expression:

$$
\varepsilon_{u}=\frac{2 \cdot \sigma_{u 0}}{E_{0}}+0.021 \cdot\left(\frac{\theta_{c}-20}{1000}\right)-0.009 \cdot\left(\frac{\theta_{c}-20}{1000}\right)^{2}
$$

where $E_{0}$ is the initial tangent modulus of concrete at room temperature.

The parameters $\alpha$ and $E^{-}$are dependent of temperature and can be taken as follows:

$$
\begin{aligned}
& \alpha=1+\exp \left[-k_{1} \cdot\left(\theta_{c}-20\right)\right] \\
& E^{-}=-0.045 \cdot E_{0} \cdot \exp \cdot\left[k_{2} \cdot\left(\theta_{c}-20\right)^{2.15}\right]
\end{aligned}
$$

where $k_{1}=0.0025$ and $k_{2}=10^{-6}$ are constants describing the influence of the temperature on the ascending and descending parts of the stress-strain curves.

\subsubsection{Lie's model}

The stress-strain relations proposed by Lie (1984) were based on the previous work of Ritter (1899) and Hognestad (1951), although the relations were slightly modified to take into account the creep of concrete at elevated temperatures. The modifications were based on results of work by Schneider \& Haksever (1976) and consisted of a movement of the maxima in the stress-strain curves to higher strains with higher temperatures. The formulation of the stress-strain relations at elevated temperatures proposed by Lie is as follows:

$$
\begin{aligned}
& \text { For } \varepsilon_{c} \leq \varepsilon_{\max }: f_{c}=f_{c}^{\prime} \cdot\left[1-\left(\frac{\varepsilon_{\max }-\varepsilon_{c}}{\varepsilon_{\max }}\right)^{2}\right] \\
& \text { For } \varepsilon_{c}>\varepsilon_{\max }: f_{c}=f_{c}^{\prime} \cdot\left[1-\left(\frac{\varepsilon_{c}-\varepsilon_{\max }}{\varepsilon_{\max }}\right)^{2}\right]
\end{aligned}
$$

where:

$$
\begin{array}{ll}
-\varepsilon_{\max }=0.0025+\left(6.0 \cdot \theta_{c}+0.04 \cdot \theta_{c}^{2}\right) \cdot 10^{-6} \\
-f_{c}^{\prime}=f_{c 0}^{\prime} & \text { for } 0^{\circ} C \leq \theta_{c} \leq 450^{\circ} C \\
f_{c}^{\prime}=f_{c 0}^{\prime} \cdot\left[2.011-2.353 \cdot\left(\frac{\theta_{c}-20}{1000}\right)\right] & \text { for } 450^{\circ} C \leq \theta_{c} \leq 874^{\circ} C
\end{array}
$$




$$
f_{c}^{\prime}=0 \quad \text { for } \theta_{c}>874^{\circ} \mathrm{C}
$$

\subsubsection{Eurocode 2 model}

The mechanical properties of concrete at elevated temperatures are given in Section 3.2.2 of Eurocode 2 Part 1.2 (CEN 2004a). For uniaxially stressed concrete under compression, the general stress-strain curve in Figure 6 is used, which can be obtained from the following expressions:

\begin{tabular}{cc}
\hline Strain range & Stress \\
\hline$\varepsilon_{c, \theta} \leq \varepsilon_{c 1, \theta}$ & $\sigma_{c, \theta}=\frac{3 \cdot \varepsilon_{c, \theta} \cdot f_{c, \theta}}{\varepsilon_{c 1, \theta}\left[2+\left(\frac{\varepsilon_{c, \theta}}{\varepsilon_{c 1, \theta}}\right)^{3}\right]}$ \\
$\varepsilon_{c 1, \theta} \leq \varepsilon_{c, \theta} \leq \varepsilon_{c u 1, \theta}$ & $\begin{array}{c}\text { For numerical purposes, a descending branch } \\
\text { should be adopted. Linear or non-linear } \\
\text { models are permitted. }\end{array}$ \\
\hline
\end{tabular}

This mathematical model is defined by means of two parameters: the compressive strength $\left(f_{c, \theta}\right)$ for a given temperature, and the strain corresponding to the peak stress $\left(\varepsilon_{c 1, \theta}\right)$. The values of these parameters are obtained for each temperature by means of applying the reduction factors in Table 3.1 of EC2 Part 1-2 Section 3.2.2.1 (Figure 7), where the value of the ultimate strain $\varepsilon_{c u 1, \theta}$ which defines the extension of the descending branch is also included. 


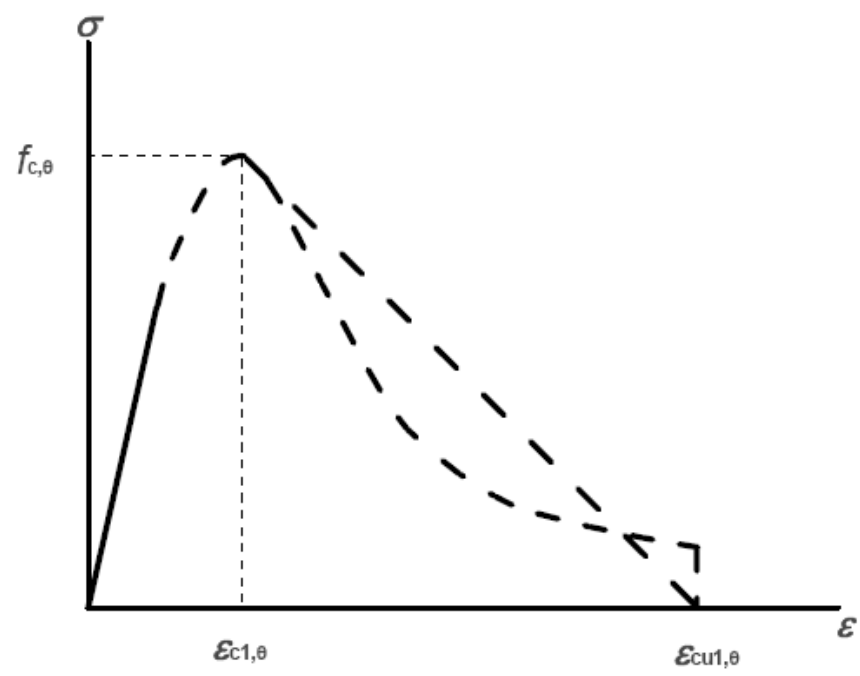

Figure 6. Mathematical model for the stress-strain relationships of concrete under compression at elevated temperatures, according to EC2 (CEN 2004a).

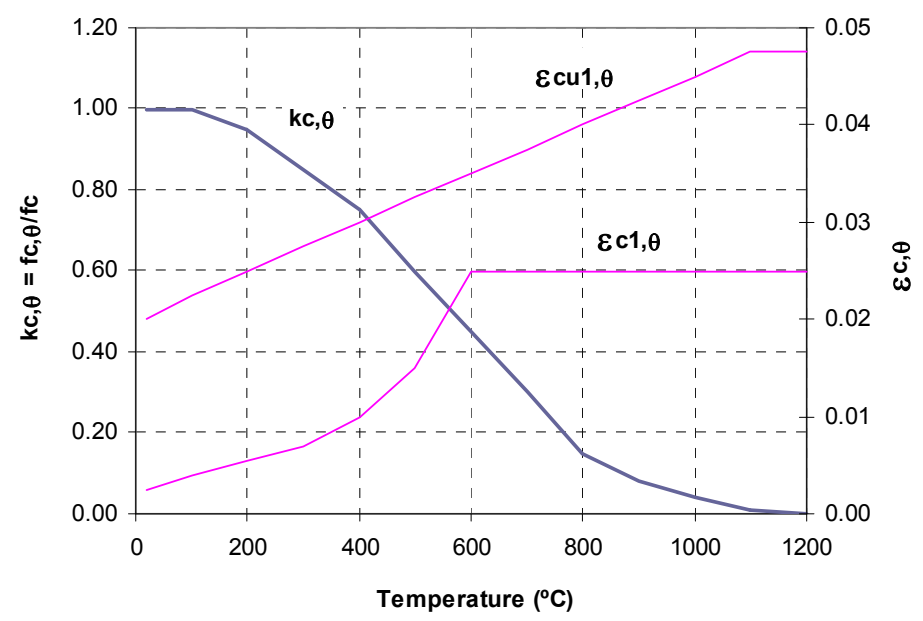

Figure 7. Reduction factors for the stress-strain relationships of concrete at elevated temperatures, according to EC2 (CEN 2004a). 
A graphical analysis is presented in Figure 8, where the main constitutive models available in the literature for concrete under compression at elevated temperatures are compared, representing for each temperature the corresponding normalized stress-strain curve (strain considered as $\varepsilon_{\sigma}+\varepsilon_{t r}$ ). The represented strain does not include the thermal strain.

In this figure, the influence of temperature over the mechanical behaviour of concrete can be clearly observed, with a progressive reduction of the compressive strength and an increase in ductility.

When the different constitutive models are compared, it can be seen that the loading branch is generally similar in shape, whereas for the descending branch, less agreement can be found.

A great similarity can be observed between Li \& Purkiss and Anderberg \& Thelandersson models. Nevertheless, the stress-strain curves from EC2 result dissimilar from these two models, with a noticeable difference in the peak strain values and in the slope of the descending branch.

At high temperatures (above $500{ }^{\circ} \mathrm{C}$ ), the stress-strain curves from EC2 predict a higher ductility as compared to the rest of the models. At low temperatures, where the transient strain is not important, the difference between EC2 and the rest of the models is moderated. Nevertheless, as the temperature increases, EC2 model predicts higher deformations for a certain stress level and a higher peak strain, which implies higher ductility. It is no clear if EC2 model includes implicitly the transient strain, which can be the cause of the difference with the rest of the models in this range of temperatures.

Schneider model also differentiates from the rest, predicting lower strain values, therefore being more conservative. This model assumes a non-linear descending branch of concave shape, while the rest of the models approximate the descending branch with a straight line.

It is additionally necessary to mention Lie's model. This model presents important differences with the rest of the models, predicting a higher compressive strength and ductility, which is noticeable for temperatures above $200{ }^{\circ} \mathrm{C}$. 
a)

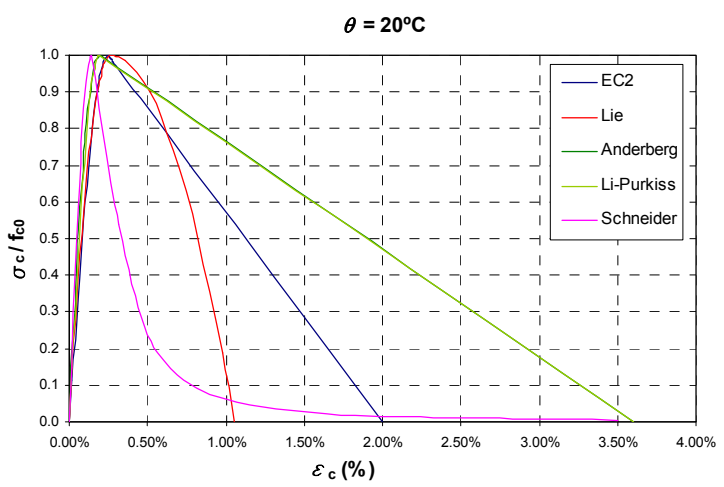

b)

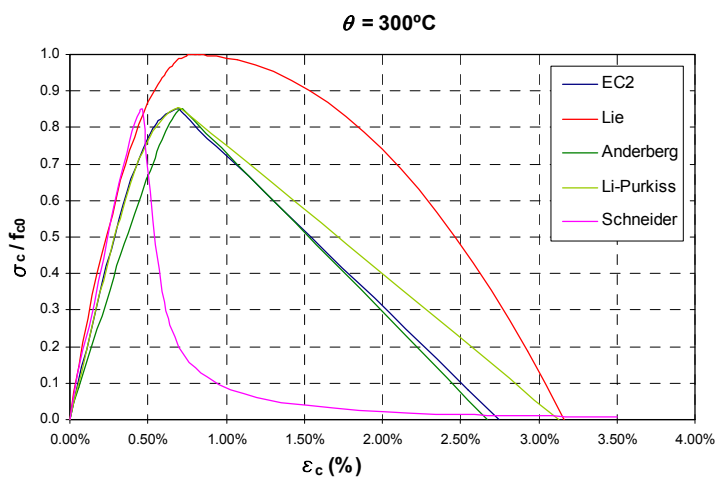

c)

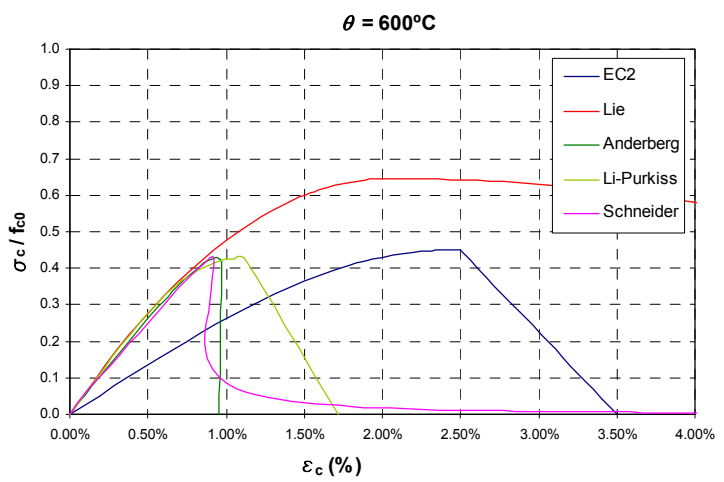

Figure 8. Comparison between the different constitutive models for concrete at elevated temperatures: a) $20^{\circ} \mathrm{C}$, b) $300^{\circ} \mathrm{C}$, c) $600^{\circ} \mathrm{C}$. 
In Figure 9 the stress-strain curves from EC2, Anderberg \& Thelandersson and Schneider are compared, for temperatures of 20,300 and $600{ }^{\circ} \mathrm{C}$.

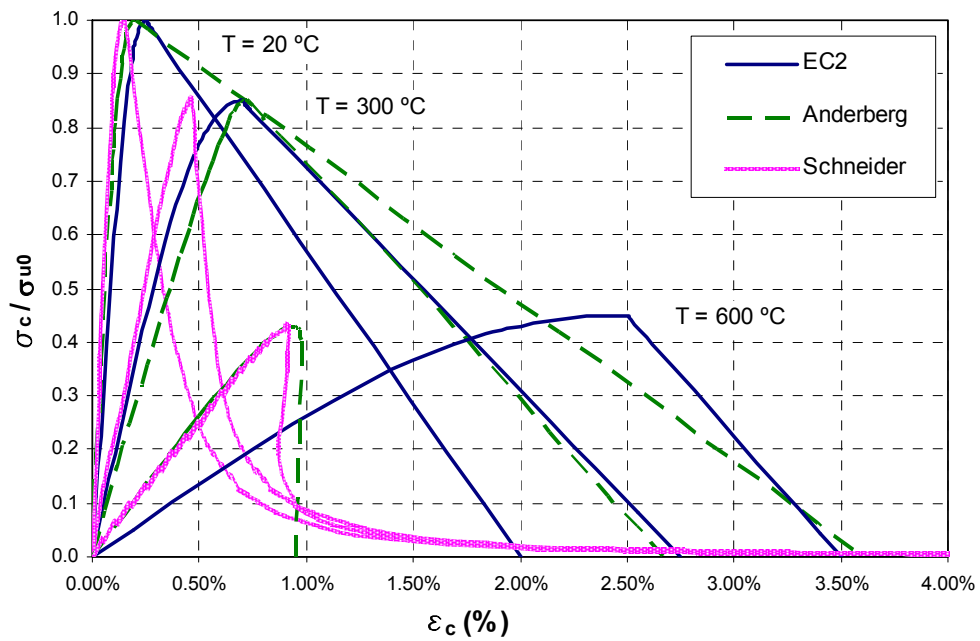

Figure 9. Comparison between EC2, Anderberg \& Thelandersson and Schneider model at different temperatures.

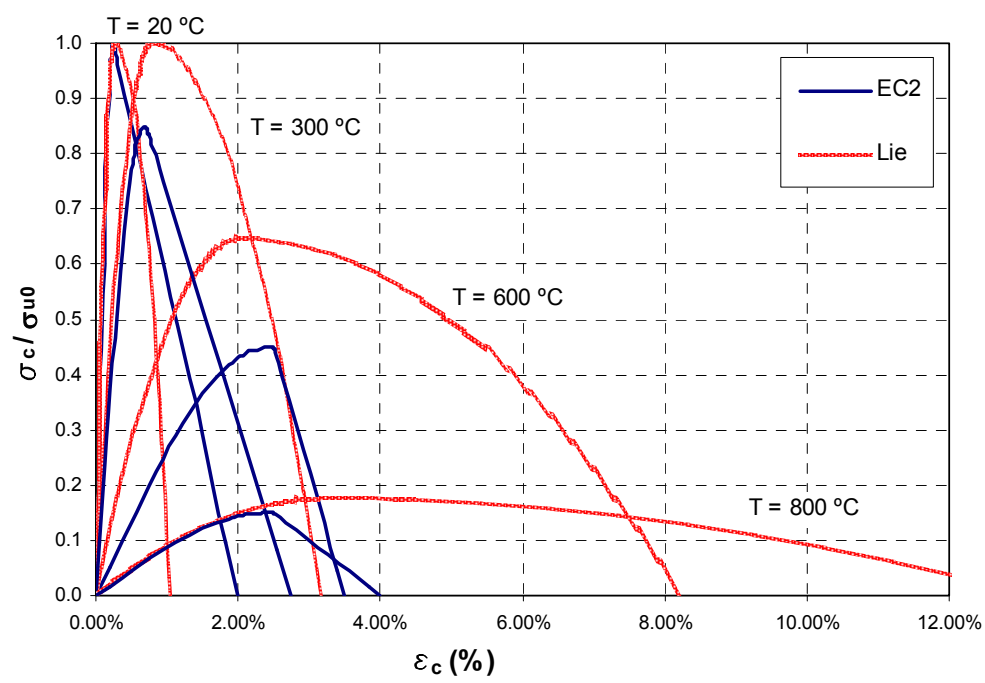

Figure 10. Comparison between EC2 and Lie's model at different temperatures. 
In Figure 10, Lie's model is compared with EC2 model, where it can be observed that Lie's model reaches higher strains as the temperature increases. This is due to the fact that Lie's model accounts for the creep of concrete at elevated temperatures, therefore predicting a more ductile behaviour. The compressive strength in Lie's model reduces with temperature at a slower rate, remaining equal to the ambient temperature value up to $400{ }^{\circ} \mathrm{C}$, when it starts to decrease.

In Figure 11 and Figure 12, the normalized stress-strain curves from Anderberg \& Thelandersson and Schneider are analyzed separately, for 20, 300 and $600{ }^{\circ} \mathrm{C}$.

Two important aspects concerning the mechanical behaviour of concrete at elevated temperatures can be observed through Anderberg \& Thelandersson (Figure 11) and Schneider (Figure 12) models: the curvature of the ascending branch and the slope of the descending branch. It can be observed how the non-linearity of the ascending branch decreases with the temperature, while the slope of the descending branch increases, which is due to the contribution of the transient strain. It can be explained through the fact that, at elevated temperatures, the dominant component of the total strain is the transient strain, which is a linear function of the stress, thus the loading ram becomes nearly linear.

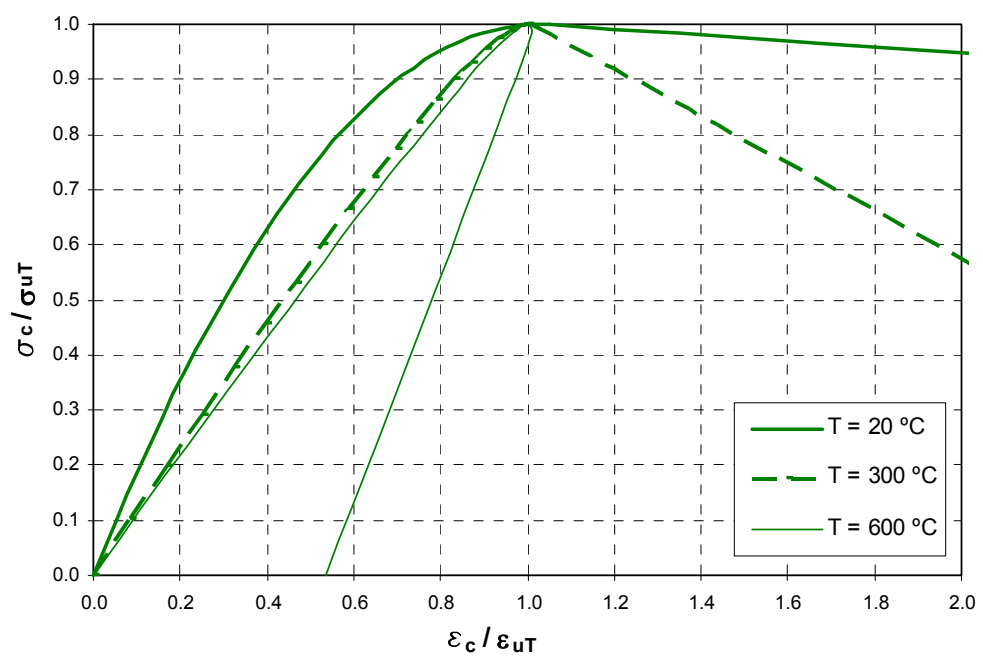

Figure 11. Normalized stress-strain curves from Anderberg \& Thelandersson model at elevated temperatures. 


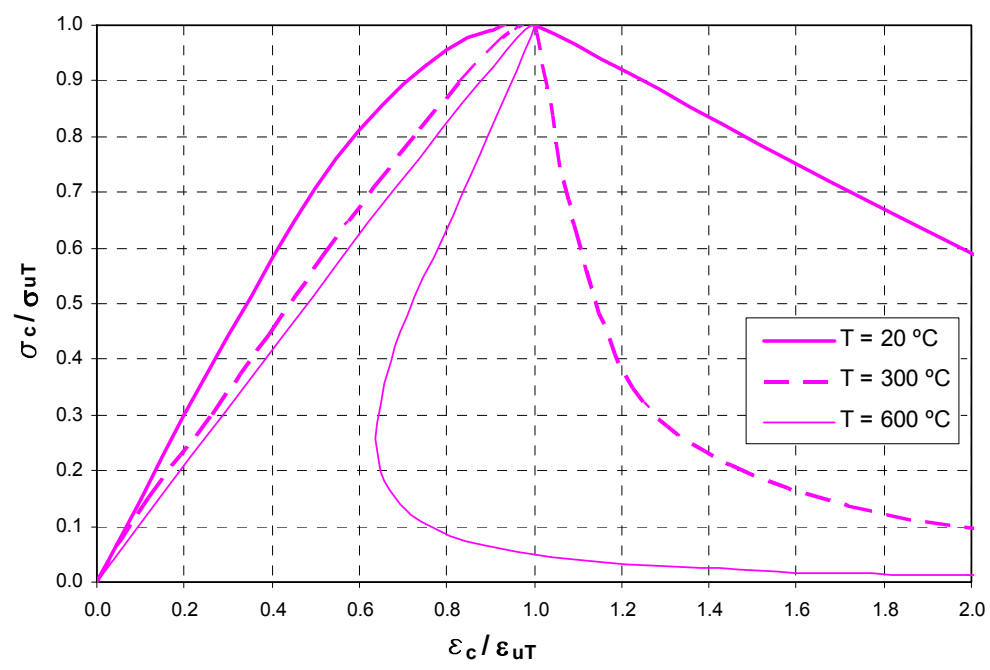

Figure 12. Normalized stress-strain curves from Schneider model at elevated temperatures.

\section{Tensile strength of concrete at elevated temperatures}

The tensile strength of concrete may normally be ignored, which is a safe assumption. In the case that it is necessary to take account of the tensile strength (i.e. in advanced models), the equations in Section 3.2.2.2 of EC2 Part 1-2 (CEN 2004a) should be used.

At elevated temperatures, the characteristic tensile strength of concrete $\left(f_{c k, t}\right)$ is reduced by a coefficient $k_{c, t}$, which is given by the following expression:

$$
\begin{array}{ll}
k_{c, t}=1 & \text { for } 20^{\circ} \mathrm{C} \leq \theta_{c} \leq 100^{\circ} \mathrm{C} \\
k_{c, t}=1-\left(\theta_{c}-100\right) / 500 & \text { for } 100^{\circ} \mathrm{C} \leq \theta_{c} \leq 600^{\circ} \mathrm{C}
\end{array}
$$

being $f_{c k, t}\left(\theta_{c}\right)=k_{c, t}\left(\theta_{c}\right) \cdot f_{c k, t}$. 


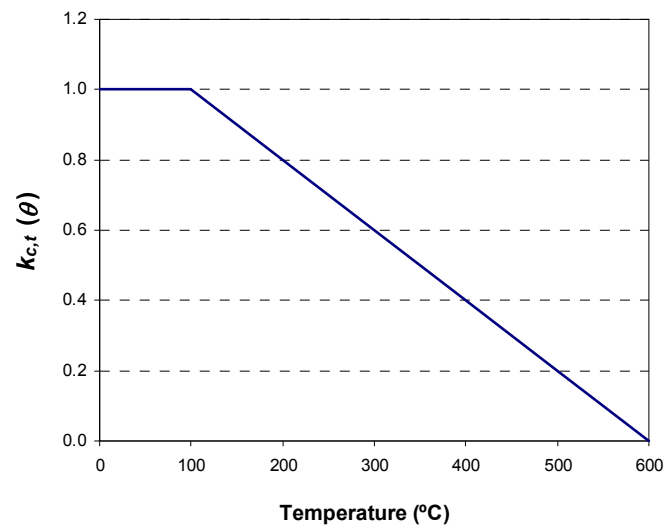

Figure 13. Evolution of the tensile strength reduction coefficient for concrete, according to EC2 (CEN 2004a).

\section{STEEL AT ELEVATED TEMPERATURES}

\subsection{Thermal properties of steel at elevated temperatures}

\subsubsection{Formulation from Eurocode 3}

Eurocode 3 Part 1.2 (CEN 2005b) describes in its Section 3.4, the thermal properties of steel at elevated temperatures. The same definition of the thermal properties has been included in the last version of EC4 Part 1.2 (CEN 2005c), with some minor changes which will be highlighted along this section.

The formulation of the thermal properties of steel, according to Eurocode 3 Part 1.2 is presented next.

\section{Thermal elongation}

The thermal elongation of steel $(\Delta l / l)_{a}$ may be determined from the following equations, referred to the length of the member at room temperature $\left(20^{\circ} \mathrm{C}\right)$ :

$$
\begin{array}{llrl}
(\Delta l / l)_{a}=1.2 \cdot 10^{-5} \cdot \theta_{a}+0.4 \cdot 10^{-8} \cdot \theta_{a}{ }^{2}-2.416 \cdot 10^{-4} & & \text { for } 20^{\circ} \mathrm{C} \leq \theta_{a} \leq 750^{\circ} \mathrm{C} \\
(\Delta l / l)_{a}=1.1 \cdot 10^{-2} & & \text { for } 750^{\circ} \mathrm{C} \leq \theta_{a} \leq 860^{\circ} \mathrm{C} \\
(\Delta l / l)_{a}=2 \cdot 10^{-5} \cdot \theta_{a}-6.2 \cdot 10^{-3} & & \text { for } 860^{\circ} \mathrm{C} \leq \theta_{a} \leq 1200^{\circ} \mathrm{C}
\end{array}
$$

where $\theta_{a}$ is the temperature of steel, in ${ }^{\circ} \mathrm{C}$. 


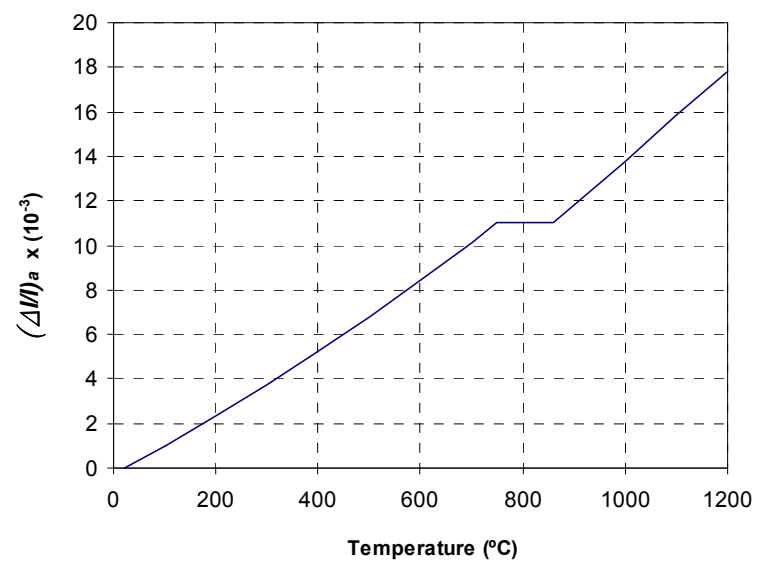

Figure 14. Thermal elongation of steel at elevated temperatures, according to EC3 (CEN 2005b).

In simple calculation models, the variation of the thermal elongation of steel $(\Delta l / l)_{a}$ with the temperature may be considered to be linear, according to EC4 Part12 Section 3.3.1(3), through the following equation:

$$
(\Delta l / l)_{a}=14 \cdot 10^{-6} \cdot\left(\theta_{a}-20\right)
$$

\section{Specific heat}

The specific heat of steel, $c_{a}$, is given by the following expressions:

$c_{a}=425+7.73 \cdot 10^{-1} \cdot \theta_{a}-1.69 \cdot 10^{-3} \cdot \theta_{a}{ }^{2}+2.22 \cdot 10^{-6} \cdot \theta_{a}{ }^{3}(\mathrm{~J} / \mathrm{kgK})$ for $20^{\circ} \mathrm{C} \leq \theta_{a} \leq 600^{\circ} \mathrm{C}$ $c_{a}=666+\frac{13002}{738-\theta_{a}}(\mathrm{~J} / \mathrm{kgK}) \quad$ for $600^{\circ} \mathrm{C} \leq \theta_{a} \leq 735^{\circ} \mathrm{C}$ $c_{a}=545+\frac{17820}{\theta_{a}-731}(\mathrm{~J} / \mathrm{kgK}) \quad$ for $735^{\circ} \mathrm{C} \leq \theta_{a} \leq 900^{\circ} \mathrm{C}$ $c_{a}=650(\mathrm{~J} / \mathrm{kgK})$ for $900^{\circ} \mathrm{C} \leq \theta_{a} \leq 1200^{\circ} \mathrm{C}$

where $\theta_{a}$ is the temperature of steel, in ${ }^{\circ} \mathrm{C}$.

According to EC4 Part 1-2 Section 3.3.1(6), in simple calculation models the specific heat of steel may be considered to be independent of the temperature, adopting a value of $600 \mathrm{~J} / \mathrm{kgK}$. 


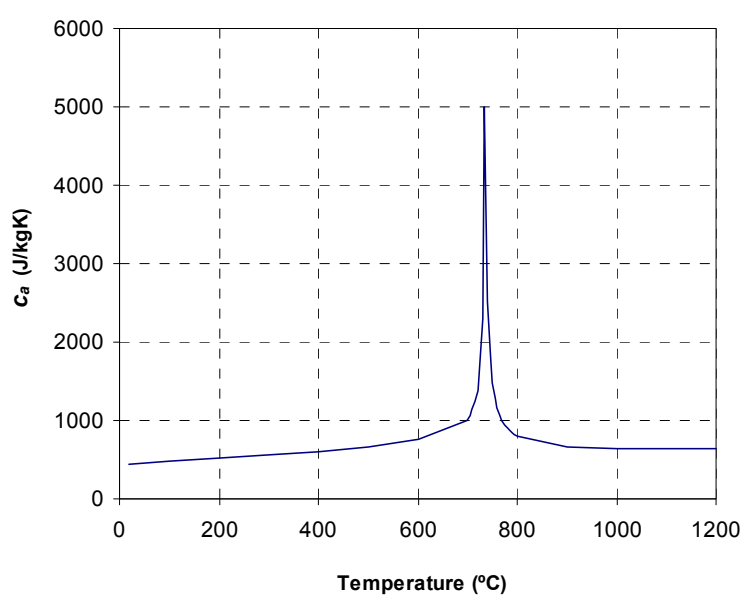

Figure 15. Specific heat of steel at elevated temperatures, according to EC3 (CEN 2005b).

\section{Thermal conductivity}

The thermal conductivity of steel, $\lambda_{a}$, should be determined from the following equations:

$$
\begin{aligned}
& \lambda_{a}=54-3.33 \cdot 10^{-2} \cdot \theta_{a}(\mathrm{~W} / \mathrm{mK}) \quad \text { for } 20^{\circ} \mathrm{C} \leq \theta_{a} \leq 800^{\circ} \mathrm{C} \\
& \lambda_{a}=27.3(\mathrm{~W} / \mathrm{mK}) \quad \text { for } 800^{\circ} \mathrm{C} \leq \theta_{a} \leq 1200^{\circ} \mathrm{C}
\end{aligned}
$$

where $\theta_{a}$ is the temperature of steel, in ${ }^{\circ} \mathrm{C}$.

According to EC4 Part 1-2 Section 3.3.1(9), in simple calculation models the thermal conductivity of steel may be considered to be independent of the temperature, adopting a value of $45 \mathrm{~W} / \mathrm{mK}$.

\section{Density}

The density of steel $\rho_{a}$ shall be considered to be independent of the temperature, according to EC4 Part 1-2 Section 3.4(1), with a value $\rho_{a}=7850 \mathrm{~kg} / \mathrm{m}^{3}$. 


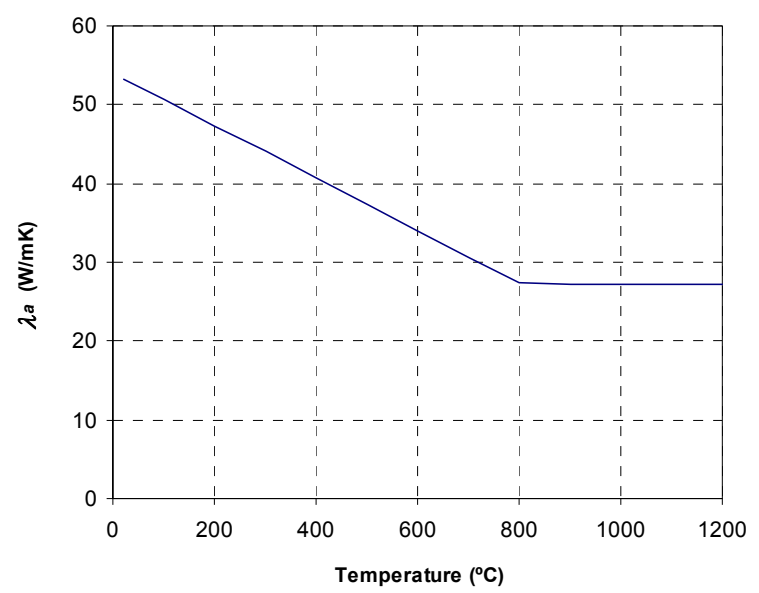

Figure 16. Thermal conductivity of steel at elevated temperatures, according to EC3 (CEN 2005b).

\subsubsection{Formulation from Lie}

Authors as Lie (1984) have proposed different formulations for the thermal properties of steel at elevated temperatures. The definition of the steel thermal properties according to this author is presented next.

\section{Thermal capacity}

The thermal capacity of steel, $\rho_{a} \cdot c_{a}$, is given by the following equations:

$$
\begin{aligned}
& \rho_{a} c_{a}=\left(0.004 \cdot \theta_{a}+3.3\right) \cdot 10^{6}\left(\mathrm{~J} / \mathrm{m}^{3}{ }^{\mathrm{o}} \mathrm{C}\right) \quad \text { for } 0^{\circ} \mathrm{C} \leq \theta_{a} \leq 650^{\circ} \mathrm{C} \\
& \rho_{a} c_{a}=\left(0.068 \cdot \theta_{a}-38.3\right) \cdot 10^{6}\left(\mathrm{~J} / \mathrm{m}^{3}{ }^{\mathrm{o}} \mathrm{C}\right) \quad \text { for } 650^{\circ} \mathrm{C}<\theta_{a} \leq 725^{\circ} \mathrm{C} \\
& \rho_{a} c_{a}=\left(-0.086 \cdot \theta_{a}+73.35\right) \cdot 10^{6}\left(\mathrm{~J} / \mathrm{m}^{3}{ }^{\mathrm{o}} \mathrm{C}\right) \quad \text { for } 725^{\circ} \mathrm{C}<\theta_{a} \leq 800^{\circ} \mathrm{C} \\
& \rho_{a} c_{a}=4.55 \cdot 10^{6}\left(\mathrm{~J} / \mathrm{m}^{3 \mathrm{o}} \mathrm{C}\right) \quad \text { for } \theta_{a}>800^{\circ} \mathrm{C}
\end{aligned}
$$

where $\theta_{a}$ is the temperature of steel, in ${ }^{\circ} \mathrm{C}$.

\section{Thermal conductivity}

The thermal conductivity of steel, $\lambda_{a}$, may be obtained from the following equations:

$$
\begin{array}{ll}
\lambda_{a}=-0.022 \cdot \theta_{a}+48\left(\mathrm{~W} / \mathrm{m}^{\circ} \mathrm{C}\right) & \text { for } 0^{\circ} \mathrm{C} \leq \theta_{a} \leq 900^{\circ} \mathrm{C} \\
\lambda_{a}=28.2\left(\mathrm{~W} / \mathrm{m}^{\circ} \mathrm{C}\right) & \text { for } \theta_{a}>900^{\circ} \mathrm{C}
\end{array}
$$


where $\theta_{a}$ is the temperature of steel, in ${ }^{\circ} \mathrm{C}$.

\section{Thermal expansion coefficient}

The steel thermal expansion coefficient $\alpha_{a}$, is given by the following equation:

$$
\begin{array}{ll}
\alpha_{a}=\left(0.004 \cdot \theta_{a}+12\right) \cdot 10^{-6}\left(\mathrm{~m} / \mathrm{m}^{\circ} \mathrm{C}\right) & \text { for } 0^{\circ} \mathrm{C} \leq \theta_{a} \leq 1000^{\circ} \mathrm{C} \\
\alpha_{a}=16 \cdot 10^{-6}\left(\mathrm{~m} / \mathrm{m}^{\circ} \mathrm{C}\right) & \text { for } \theta_{a}>1000^{\circ} \mathrm{C}
\end{array}
$$

where $\theta_{a}$ is the temperature of steel, in ${ }^{\circ} \mathrm{C}$.

The formulations of the thermal properties of steel from Lie and EC3 are compared in Figure 17. For comparison purposes, the specific heat in Lie's model has been obtained by dividing the thermal capacity $\rho_{a} \cdot c_{a}$ by the density of steel, $\rho_{a}=$ $7850 \mathrm{~kg} / \mathrm{m}^{3}$. Regarding the thermal expansion coefficient in EC3 model, it is obtained from the thermal elongation as:

$$
\alpha_{a}\left(\theta_{a}\right)=\frac{(\Delta l / l)_{a}\left(\theta_{a}\right)}{\left(\theta_{a}-20\right)}
$$

It can be observed that, in general, there is more agreement when predicting the thermal properties of steel than in the case of concrete. Both models predict a peak value in the specific heat due to a change at the micro-structural level which occurs in steel around $735^{\circ} \mathrm{C}\left(725^{\circ} \mathrm{C}\right.$ according to Lie). This energy consumption due to the change is more pronounced in EC3 model. In what concerns the rest of thermal properties, both models show similar trends. 
a)

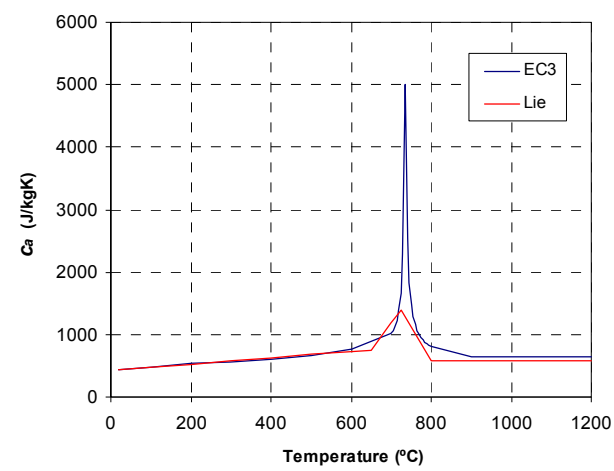

b)

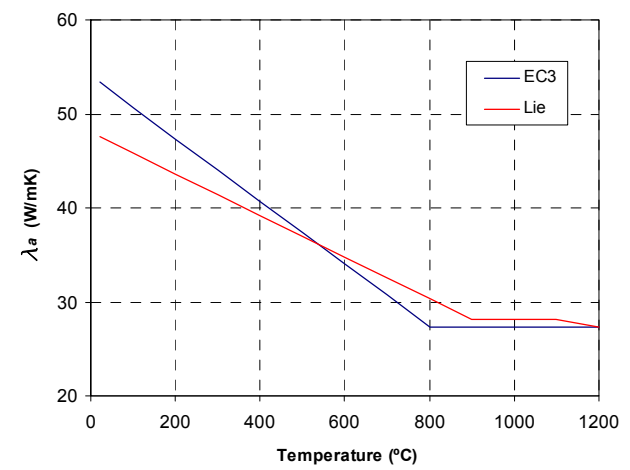

c)

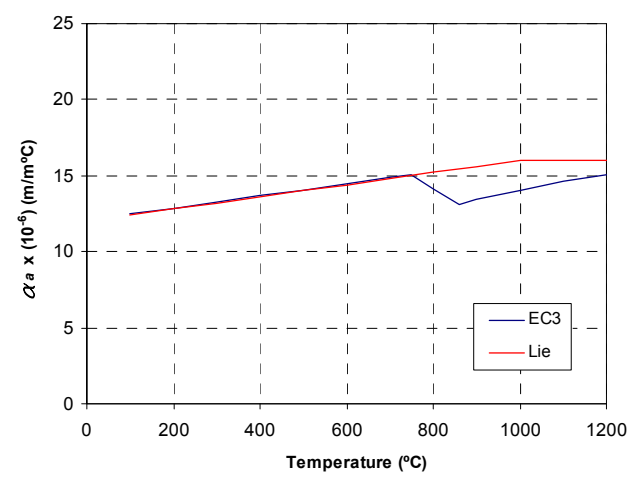

Figure 17. Comparison between EC3 and Lie's formulations for the thermal properties of steel at elevated temperatures: a) specific heat, b) thermal conductivity, c) thermal expansion coefficient. 


\subsection{Mechanical properties of steel at elevated temperatures}

The total strain of steel $\left(\varepsilon_{a}\right)$ can be expressed as the sum of three components:

$$
\varepsilon_{a}=\varepsilon_{\sigma}+\varepsilon_{c r}+\varepsilon_{t h}
$$

where:

- $\varepsilon_{\sigma}$ is the instantaneous stress-related strain (caused by the externally applied stresses)

- $\varepsilon_{c r}$ is the classical creep strain (caused by the dislocation of microstructures of the material)

- $\varepsilon_{t h}$ is the free thermal strain (due to the temperature change)

The main constitutive models which can be found in the literature for representing the mechanical behaviour of steel at elevated temperatures are subsequently described.

\subsubsection{Yin et al. model}

Yin et al. (2006) proposed an elasto-plastic model for steel, where the relationship between the stress and the stress-induced strain $\left(\varepsilon_{\sigma}\right)$ at elevated temperatures can be obtained from the following expression:

$$
\frac{\sigma_{a}}{\sigma_{y}}= \begin{cases}\frac{E \cdot \varepsilon_{\sigma}}{\sigma_{y}} & \text { for } \varepsilon_{\sigma} \leq \frac{\sigma_{y}}{E} \\ 1 & \text { for } \frac{\sigma_{y}}{E} \leq \varepsilon_{\sigma}\end{cases}
$$

where:

- $E$ is the Young's modulus, which is expressed in terms of temperature as follows (Lie 1994):

$$
\frac{E}{E_{0}}= \begin{cases}1+\frac{0.0005 \cdot \theta_{a}}{\ln \left(\theta_{a} / 1100\right)} & \text { for } \theta_{a} \leq 600^{\circ} \mathrm{C} \\ \frac{690-0.69 \cdot \theta_{a}}{\theta_{a}-53.5} & \text { for } 600^{\circ} \mathrm{C} \leq \theta_{a} \leq 1000^{\circ} \mathrm{C}\end{cases}
$$

with $E_{0}$ the Young's modulus at room temperature. 
- $\sigma_{y}$ is the yield stress of steel, which is expressed in terms of temperature as follows (Lie 1994):

$$
\frac{\sigma_{a}}{\sigma_{y 0}}= \begin{cases}1+\frac{\theta_{a}}{900 \cdot \ln \left(\theta_{a} / 1750\right)} & \text { for } \theta_{a} \leq 600^{\circ} \mathrm{C} \\ \frac{340-0.34 \cdot \theta_{a}}{\theta_{a}-240} & \text { for } 600^{\circ} \mathrm{C} \leq \theta_{a} \leq 1000^{\circ} \mathrm{C}\end{cases}
$$

where $\sigma_{y 0}$ is the yield stress of steel at room temperature.

According to these authors, the classical creep strain $\left(\varepsilon_{c r}\right)$ developed during a fire is not very important and therefore it can generally be ignored.

The thermal strain $\left(\varepsilon_{t h}\right)$ can be expressed in terms of temperature as follows:

$$
\varepsilon_{t h}\left(\theta_{a}\right)= \begin{cases}\left(0.4 \cdot 10^{-3} \cdot \theta_{a}+1.2\right) \cdot 10^{-5} \cdot\left(\theta_{a}-20\right) & \text { for } \theta_{a} \leq 1000^{\circ} \mathrm{C} \\ 1.6 \cdot 10^{-5} \cdot\left(\theta_{a}-20\right) & \text { for } \theta_{a}>1000^{\circ} \mathrm{C}\end{cases}
$$

\subsubsection{Lie's model}

The stress-strain relations for steel at elevated temperatures proposed by Lie (1984) were derived from data provided by Ingberg \& Sale (1926) and by Witteveen et al. (1977). These relations include the effect of creep at elevated temperatures, and were obtained at heating rates that approximate real fire situations. The relations were generalized for other structural steels by assuming that, for a given temperature, the curves are the same for all steels, but the stress below which the stress-strain relation is linear is proportional to the yield strength of the steel. The formulation of Lie's stress-strain curves for steel at elevated temperatures is as follows:

$$
\text { For } \varepsilon_{a} \leq \varepsilon_{p}: f_{y}=\frac{f\left(\theta_{a}, 0.001\right)}{0.001} \cdot \varepsilon_{a}
$$

where:

- $\varepsilon_{p}=4 \cdot 10^{-6} \cdot f_{y 0}$

- $f\left(\theta_{a}, 0.001\right)=\left(50-0.04 \cdot \theta_{a}\right) \cdot\left[1-\exp \left(\left(-30+0.03 \cdot \theta_{a}\right) \cdot \sqrt{0.001}\right)\right] 6.9$

For $\varepsilon_{a}>\varepsilon_{p}: f_{y}=\frac{f\left(\theta_{a}, 0.001\right)}{0.001} \cdot \varepsilon_{p}+f\left(\theta_{a},\left(\varepsilon_{a}-\varepsilon_{p}+0.001\right)\right)-f\left(\theta_{a}, 0.001\right)$ 
with: $\begin{aligned} & f\left(\theta_{a},\left(\varepsilon_{a}-\varepsilon_{p}+0.001\right)\right)= \\ = & \left(50-0.04 \cdot \theta_{a}\right) \cdot\left[1-\exp \left(\left(-30+0.03 \cdot \theta_{a}\right) \cdot \sqrt{\left(\varepsilon_{a}-\varepsilon_{p}+0.001\right)}\right)\right] 6.9\end{aligned}$

\subsubsection{Eurocode 3 model}

The mechanical behaviour of structural steel at elevated temperatures is defined by means of the general stress-strain curve in Figure 18, which can be reproduced by the following mathematical model:

\begin{tabular}{ccc}
\hline Strain range & Stress & Tangent modulus \\
\hline$\varepsilon_{a, \theta} \leq \varepsilon_{p, \theta}$ & $\sigma_{a, \theta}=E_{a, \theta} \cdot \varepsilon_{a, \theta}$ & $E_{a, \theta}$ \\
& $\sigma_{a, \theta}=f_{p, \theta}-c+\frac{b}{a} \cdot \sqrt{a^{2}-\left(\varepsilon_{y, \theta}-\varepsilon_{a, \theta}\right)^{2}}$ & \\
with: & $\frac{b \cdot\left(\varepsilon_{y, \theta}-\varepsilon_{a, \theta}\right)}{a \cdot \sqrt{a^{2}-\left(\varepsilon_{y, \theta}-\varepsilon_{a, \theta}\right)^{2}}}$ \\
$\varepsilon_{p, \theta} \leq \varepsilon_{a, \theta} \leq \varepsilon_{y, \theta}$ & $a^{2}=\left(\varepsilon_{y, \theta}-\varepsilon_{p, \theta}\right) \cdot \frac{\varepsilon_{y, \theta}-\varepsilon_{p, \theta}+c}{E_{a, \theta}}$ & \\
$\varepsilon_{y, \theta} \leq \varepsilon_{a, \theta} \leq \varepsilon_{t, \theta}$ & $c=\frac{\left(f_{y, \theta}-f_{p, \theta}\right)^{2}}{E_{a, \theta} \cdot\left(\varepsilon_{y, \theta}-\varepsilon_{p, \theta}\right)-2 \cdot\left(f_{y, \theta}-f_{p, \theta}\right)}$ & \\
$\varepsilon_{t, \theta} \leq \varepsilon_{a, \theta} \leq \varepsilon_{u, \theta}$ & $\left.\sigma_{a, \theta}=\varepsilon_{p, \theta}\right) \cdot c+c^{2}$ & \\
\hline
\end{tabular}

where:

- $\varepsilon_{p, \theta}=f_{p, \theta} / E_{a, \theta}$ is the strain at the proportional limit

- $\varepsilon_{y, \theta}$ is the yield strain

- $\varepsilon_{t, \theta}$ is the limiting strain for yield strength

- $\varepsilon_{u, \theta}$ is the ultimate strain

The parameters $f_{y, \theta}$ (effective yield strength), $f_{p, \theta}$ (proportional limit) and $E_{a, \theta}$ (elastic modulus) for a certain temperature $\theta_{a}$ are obtained by applying the reduction factors $k_{y, \theta}, k_{p, \theta}, k_{E, \theta}$ in Table 3.1 of EC3 Part 1-2 3.2.1 (Figure 19) to the corresponding values at room temperature $f_{y}, E_{a}$. 


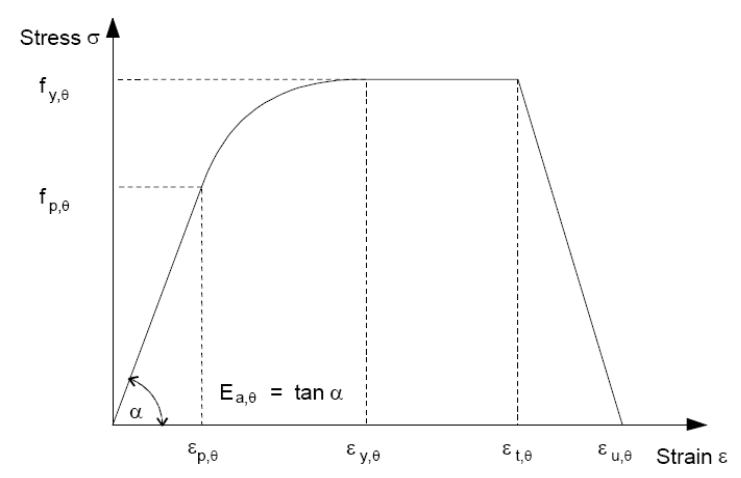

Figure 18. Stress-strain relationship for structural steel at elevated temperatures, according to EC3 (CEN 2005b).

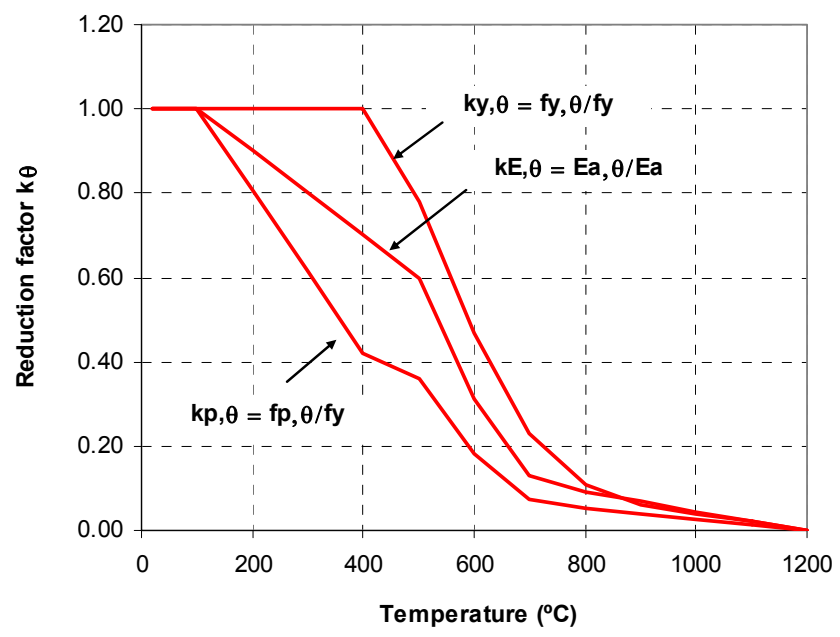

Figure 19. Reduction factors for the stress-strain relationships of structural steel at elevated temperatures, according to EC3 (CEN 2005b).

A graphical analysis is presented in Figure 20, where the different steel constitutive models at elevated temperatures are compared. For each temperature, the normalized stress-strain curve is represented. The thermal strain is not included in the total strain. 
a)

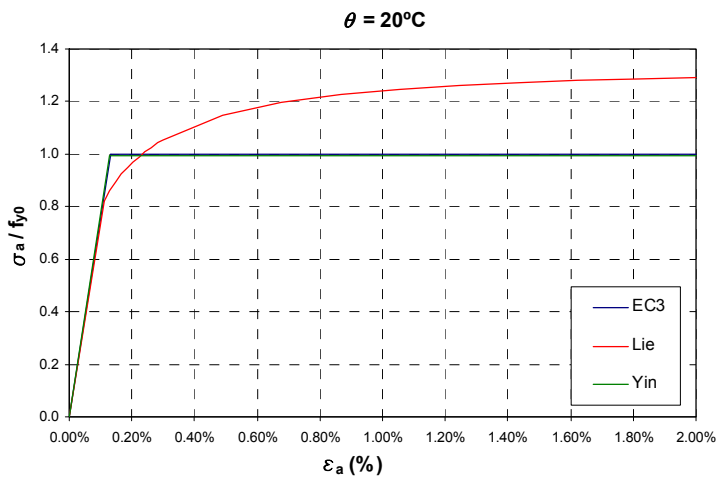

b)

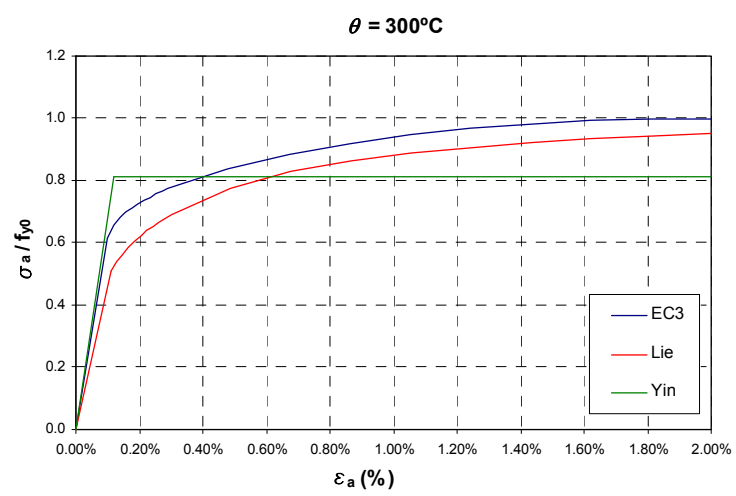

c)

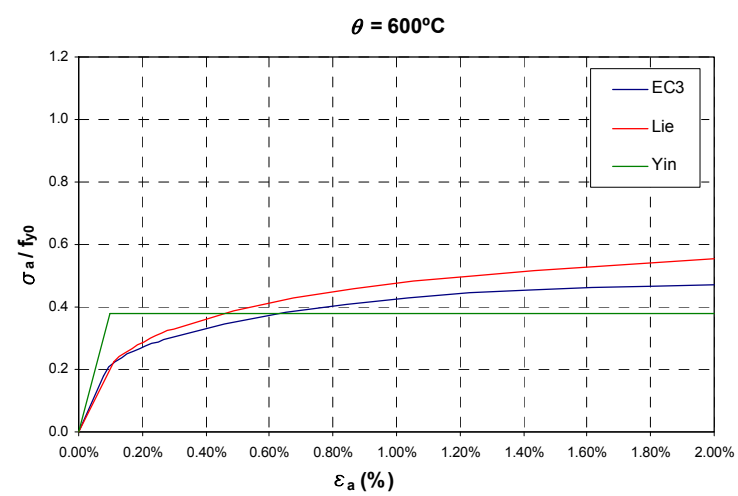

Figure 20. Comparison between the different constitutive models for steel at elevated temperatures: a) $20^{\circ} \mathrm{C}$, b) $300{ }^{\circ} \mathrm{C}$, c) $600{ }^{\circ} \mathrm{C}$. 
In the previous figure, it can be observed how the model from Yin proposes an elasto-plastic curve for the different temperatures, while EC3 only uses the elasto-plastic shape for temperatures up to $100^{\circ} \mathrm{C}$, while for higher temperatures this model uses a transition curve between the elastic and plastic regions. Lie's model takes into account the effect of strain hardening, as can be observed in the stressstrain curve at room temperature. The model from Yin predicts a faster deterioration of the strength of steel with temperature, and therefore its corresponding curves lay below those from Lie or EC3 model. At elevated temperatures, the shape of the curves from Lie and EC3 are similar, although with differences in the evolution of strength and rigidity. 
